DOC.20041103.0003

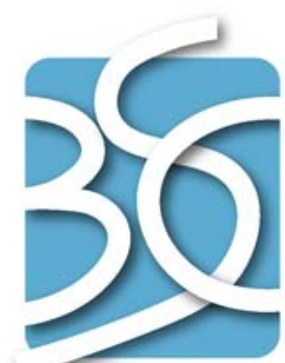

BECHTEL SAIC COMPANYLC

QA: QA

MDL-NBS-HS-000019 REV 01

November 2004

\title{
Abstraction of Drift Seepage
}

Prepared for:

U.S. Department of Energy

Office of Civilian Radioactive Waste Management

Office of Repository Development

1551 Hillshire Drive

Las Vegas, Nevada 89134-6321

Prepared by:

Bechtel SAIC Company, LLC

1180 Town Center Drive

Las Vegas, Nevada 89144

Under Contract Number

DE-AC28-01RW12101 


\section{DISCLAIMER}

This report was prepared as an account of work sponsored by an agency of the United States Government. Neither the United States Government nor any agency thereof, nor any of their employees, nor any of their contractors, subcontractors or their employees, makes any warranty, express or implied, or assumes any legal liability or responsibility for the accuracy, completeness, or any third party's use or the results of such use of any information, apparatus, product, or process disclosed, or represents that its use would not infringe privately owned rights. Reference herein to any specific commercial product, process, or service by trade name, trademark, manufacturer, or otherwise, does not necessarily constitute or imply its endorsement, recommendation, or favoring by the United States Government or any agency thereof or its contractors or subcontractors. The views and opinions of authors expressed herein do not necessarily state or reflect those of the United States Government or any agency thereof. 
Abstraction of Drift Seepage

MDL-NBS-HS-000019 REV 01

November 2004 


\begin{tabular}{|l|l|l|}
\hline OCRWh & Model signature Page/Chanoe History & Page iii \\
\cline { 3 - 4 } & 1. Total Pages: 302 \\
\hline
\end{tabular}

\section{Type of Methematical Model \\ [1 Process Nodel}

Describe Intended Use of Model

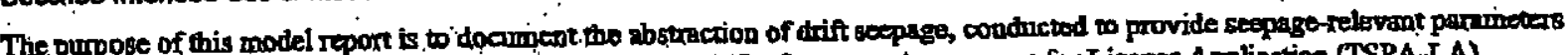
and their probability distributions for the use in Toml Systein Performance Assessment for License Application (TSPA-LA).

3. Thle

Abstraction of Drift Seepage

4. Dl (inctuding Rov. No., if applkable);

MDLNDS-HS-000019 REV D1

5. Tollal Appendices

Eight (8)

\begin{tabular}{|c|c|c|c|}
\hline Eight (8) & : & $C-8, D-8,5$ & \\
\hline . & Privited Nams & Signahure & Date \\
\hline 7. Origlnator & J:T: Bikktolzer & & \\
\hline $\begin{array}{l}\text { 8. Independent Technical } \\
\text { Reviewer }\end{array}$ & P. Vaughn & & \\
\hline 9. Cheiker & Q. Lia & & \\
\hline 10. QER & K.T. McFall & & \\
\hline 11. Responalble Menagarhasud & HYH. Liu/S. Finsterlo & & \\
\hline 12. Responsible Manager & M.Zhu. & & \\
\hline
\end{tabular}

13. Remariks

Change Mistory

14. Revlstori No.

REV 00
This toport is a revision of an Analysis/Model Reproxt by the same tide-Document Identifier following min changes: New data analyses and modeling results bave become avanlable. As a teisult the abstraction model has been substantially revised Major revisions include the Seepage Model for Performance Assessmant, improved treatment of secpage duping the period of theimally pertarbed flow cooditions, disposition of mechanical and chemical alturations based on process models, new probability distribartions for variability and uncertainty, and a revised conciept for flow focusing.

In this: new model report, the entire documentation was revised. Side bars are not used becanise thio changes wete too extensive to use Step 5.9d)1) per AP-SIII.100 Rev. 1/fCN 2. ANL-NBS-MD-0000OS (CRWMS M*O 2001 [DRS 154291]). The revision inchudes the a 


\begin{tabular}{|c|c|}
\hline REV 00 ICN 01 & 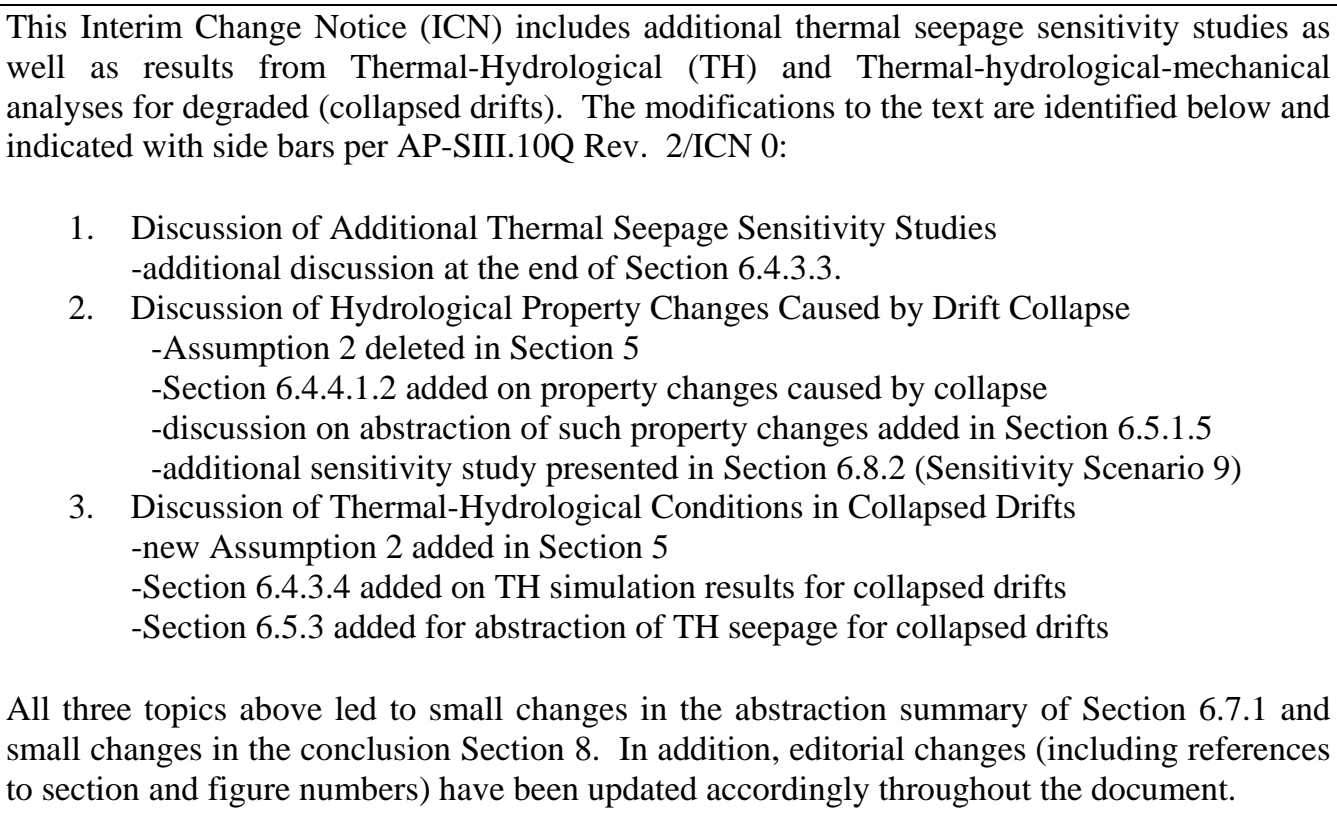 \\
\hline REV 00 ICN 01 Errata 001 & Response to CR-1100 \\
\hline REV 01 & $\begin{array}{l}\text { Increased transparency in response to the regulatory-focused evaluation performed by the } \\
\text { Regulatory Integration Team. Entire model documentation was revised. Side bars are not } \\
\text { used because the changes were too extensive to use Step 5.8f)1) per AP-SIII.10Q, REV 02, } \\
\text { ICN } 07 .\end{array}$ \\
\hline
\end{tabular}




\section{CONTENTS}

Page

ACRONYMS . $\mathrm{XV}$

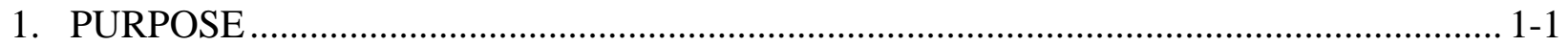

2. QUALITY ASSURANCE ............................................................................. 2-1

3. USE OF SOFTWARE ....................................................................................... $3-1$

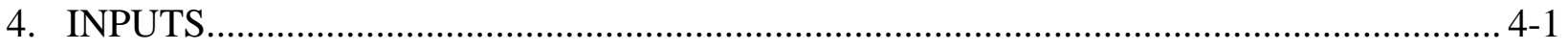

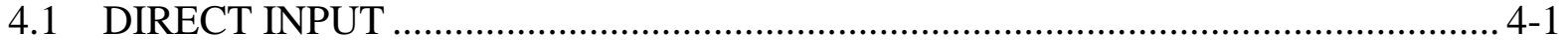

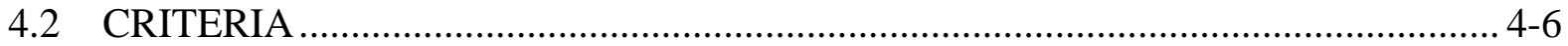

4.3 CODES, STANDARDS, AND REGULATIONS.............................................. 4-12

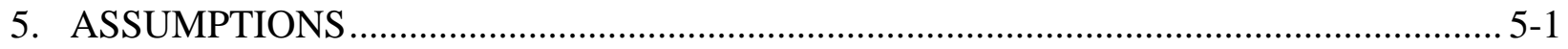

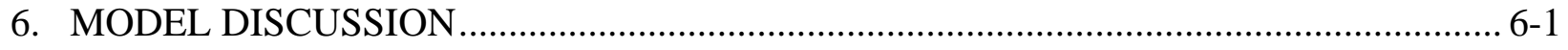

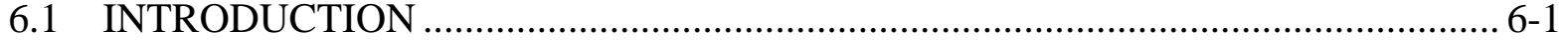

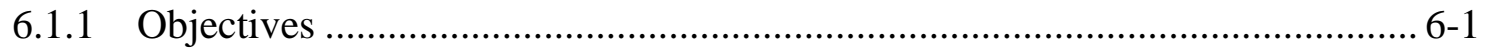

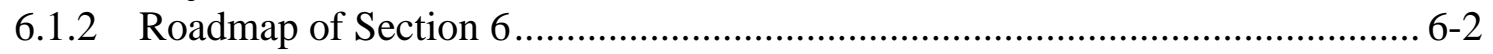

6.1.3 Definition of Seepage Properties ............................................................. 6-3

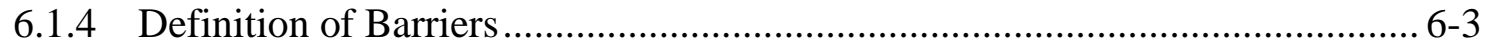

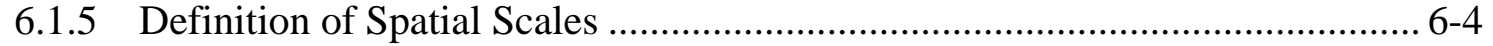

6.1.6 Definition of Uncertainty and Spatial Variability............................................ 6-4

6.1.7 Scientific Notebooks ............................................................................... 6-5

6.2 FEATURES, EVENTS, AND PROCESSES .................................................... 6-6

6.3 SEEPAGE PHENOMENA AND IMPORTANT FACTORS FOR SEEPAGE .......... 6-8

6.3.1 Seepage under Ambient Conditions................................................................ 6-8

6.3.2 Thermal Seepage................................................................................... 6-12

6.4 PROCESS MODELS PROVIDING INPUT TO SEEPAGE ABSTRACTION ........ 6-15

6.4.1 Seepage Calibration Model.................................................................. 6-15

6.4.1.1 Model Description ................................................................ 6-15

6.4.1.2 Model Validation .......................................................................... 6-17

6.4.1.3 Model Results ....................................................................... 6-19

6.4.2 Seepage Model for Performance Assessment............................................. 6-19

6.4.2.1 Model Description .................................................................. 6-19

6.4.2.2 Model Validation ......................................................................... 6-22

6.4.2.3 Model Results: Systematic Study of Ambient Seepage................ 6-23

6.4.2.4 Model Results: Impact of Drift Degradation ............................... 6-28

6.4.2.4.1 Drift Degradation Analysis ...................................... 6-28

6.4.2.4.2 Seepage Analysis for Degraded Drifts ...................... 6-30

6.4.2.5 Model Results: Impact of Rock Bolts ....................................... 6-36

6.4.3 TH Seepage Model ............................................................................. 6-36

6.4.3.1 Model Description ............................................................. 6-37 


\section{CONTENTS (Continued)}

Page

6.4.3.2 Model Validation .................................................................. 6-43

6.4.3.3 Model Results ........................................................................... 6-44

6.4.3.4 TH Conditions in Collapsed Drifts ................................................ 6-50

6.4.4 Supporting THM and THC Models ............................................................. 6-68

6.4.4.1 Drift-Scale THM Model ............................................................. 6-68

6.4.4.1.1 Hydrological Property Changes Caused by

Thermal Effects............................................................ 6-68

6.4.4.1.2 Hydrological Property Changes Caused by Drift

Collapse in the Tptpll Unit........................................... 6-71

6.4.4.2 THC Seepage Model................................................................... 6-74

6.5 SEEPAGE ABSTRACTION METHODOLOGY ……………………………..... 6-76

6.5.1 Abstraction of Ambient Seepage ........................................................... 6-78

6.5.1.1 Random Sampling Methodology .................................................. 6-80

6.5.1.2 Seepage Interpolation...................................................................... 6-83

6.5.1.3 Ambient Seepage Uncertainty ........................................................ 6-84

6.5.1.4 Abstraction of THM and THC Parameter Alterations .................... 6-86

6.5.1.5 Abstraction of Drift Degradation .................................................... 6-88

6.5.1.6 Abstraction of Rock-Bolt Effects............................................... 6-90

6.5.1.7 Abstraction for Igneous Events.................................................... 6-90

6.5.2 Abstraction of Thermal Seepage for Intact Drifts............................................. 6-91

6.5.2.1 Alternative Thermal-Seepage-Abstraction Approaches ................. 6-93

6.5.2.2 Uncertainty and Recommended Abstraction Method for Intact

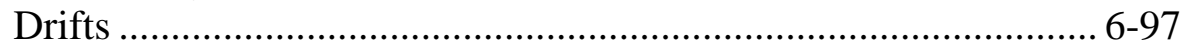

6.5.3 Abstraction of Thermal Seepage for Collapsed Drifts.................................... 6-99

6.6 PARAMETER DISTRIBUTIONS FOR SEEPAGE-RELEVANT

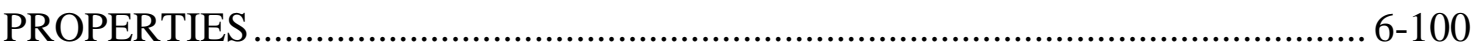

6.6.1 Geologic Characteristics of Repository Rock Units ..................................... 6-101

6.6.1.1 Lithostratigraphy ....................................................................... 6-101

6.6.1.2 Fracturing ................................................................................. 6-102

6.6.1.3 Lithophysal Characteristics........................................................... 6-104

6.6.1.4 Implications for Seepage Analyses ............................................. 6-105

6.6.2 Capillary-Strength Parameter...................................................................... 6-106

6.6.2.1 Supporting Information............................................................ 6-106

6.6.2.2 Spatial Variability ...................................................................... 6-108

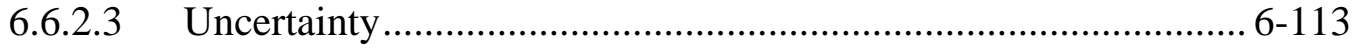

6.6.3 Fracture Permeability ............................................................................. 6-116

6.6.3.1 Supporting Information....................................................... 6-119

6.6.3.2 Spatial Variability .................................................................... 6-122

6.6.3.2.1 Middle Nonlithophysal Unit ...................................... 6-123

6.6.3.2.2 Lower Lithophysal Unit ........................................... 6-130

6.6.3.3 Uncertainty ............................................................................ 6-132

6.6.4 Capillary Strength and Permeability Distributions for the Tptpul and Tptpln Units ........................................................................................ 6-137

6.6.5 Percolation Flux and Flow Focusing …………........................................ 6-139 


\section{CONTENTS (Continued)}

Page

6.6.5.1 Percolation Flux from the Site-Scale Model................................. 6-139

6.6.5.2 Flow Focusing......................................................................... 6-148

6.6.5.2.1 Flow Focusing Model and Results............................. 6-148

6.6.5.2.2 Alternative Flow Focusing Model and Results......... 6-152

6.6.5.2.3 Choice of Flow Focusing Distribution for Use in

Seepage Abstraction................................................... 6-153

6.6.5.3 Resulting Distribution of Percolation Fluxes................................ 6-155

6.7 SUMMARY OF SEEPAGE ABSTRACTION .................................................... 6-157

6.7.1 TSPA Seepage Calculation Methodology and Relevant Abstraction

Results.................................................................................................... 6-157

6.7.1.1 Step 1: Ambient Seepage ……………………………………... 6-157

6.7.1.2 Step 2: Adjustments for Other Relevant Factors ......................... 6-162

6.7.1.3 Step 3: Analysis of Seepage Results............................................. 6-163

6.7.2 Propagation of Uncertainty through the Abstraction.................................... 6-164

6.8 SEEPAGE CALCULATION AND SENSITIVITIES ............................................... 6-165

6.8.1 Base-Case Seepage Evaluation ................................................................... 6-166

6.8.2 Sensitivity Analysis ................................................................................... 6-174

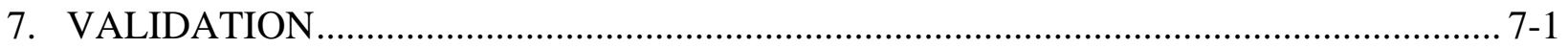

7.1 CONFIDENCE BUILDING DURING MODEL DEVELOPMENT TO ESTABLISH SCIENTIFIC BASIS AND ACCURACY FOR INTENDED USE....... 7-2

7.2 POST-DEVELOPMENT VALIDATION TO SUPPORT THE SCIENTIFIC

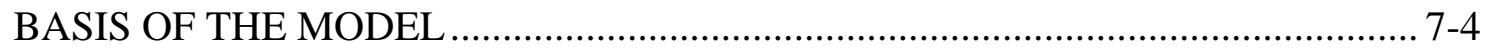

7.3 MULTIPLE LINES OF EVIDENCE …………................................................

7.3.1 ECRB Moisture Monitoring Study ……………........................................... 7-7

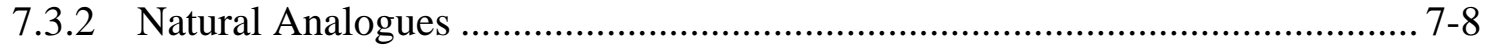

7.4 SUMMARY OF VALIDATION ACTIVITIES ..................................................... 7-8

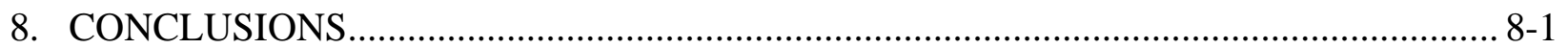

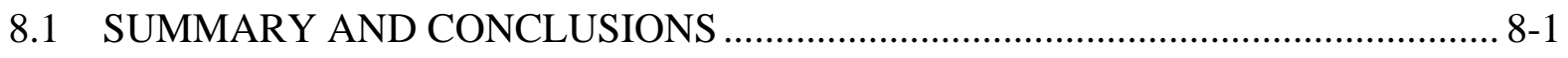

8.2 MODEL OUTPUT TO TSPA ……………………........................................... 8-4

8.3 SATISFACTION OF YMRP ACCEPTANCE CRITERIA ....................................... 8-5

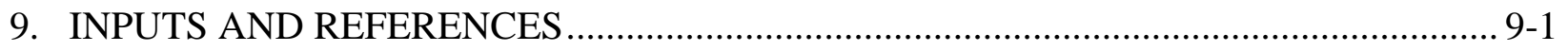

9.1 DOCUMENTS CITED ........................................................................................... 9-1

9.2 CODES, STANDARDS, REGULATIONS, AND PROCEDURES............................ 9-8

9.3 SOURCE DATA, LISTED BY DATA TRACKING NUMBER …………….............. 9-8

9.4 OUTPUT DATA, LISTED BY DATA TRACKING NUMBER ……………........... 9-10

APPENDIX A - HISTOGRAM OF SMPA REALIZATION RESULTS ................................ A-1

APPENDIX B - STATISTICAL ANALYSIS OF CAPILLARY-STRENGTH PARAMETER VALUES. 


\section{CONTENTS (Continued)}

Page

APPENDIX C - STATISTICAL ANALYSIS OF PERMEABILITY VALUES ..........................-1

APPENDIX D - ANALYSIS OF PERCOLATION FLUX FIELDS ......................................... D-1

APPENDIX E - PROBABILISTIX SEEPAGE CALCULATION ...............................................

APPENDIX F - INTERPOLATION OF SMPA RESULTS IN SEEPAGE

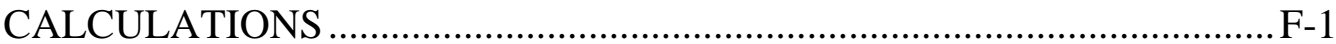

APPENDIX G - COMPARISON OF FLUX DISTRIBUTIONS FROM UZ FLOW

MODEL AND FROM SEEPAGE CALCULATIONS …………………….... G-1

APPENDIX H - TABLES AND FIGURES DESCRIBING FRACTURE

GEOMETRY CHARACTERISTICS .......................................................... H-1 


\section{FIGURES}

1-1. Relationship and Information Flow between Primary Process Models and the Seepage Abstraction Model............................................................................................ 1-4

6.3-1. Schematic of Phenomena and Processes Affecting Drift Seepage............................... 6-11

6.3-2. Schematic of TH Processes Occurring in the Drift Vicinity as a Result of Repository Heating (not to scale) ............................................................................. 6-14

6.4-1. Example of Numerical Grid and Permeability Distribution Used for the SCM Simulation of Liquid-Release Tests Conducted in Niche 1620, Showing One Injection Interval in Borehole \#4 .............................................................................. 6-16

6.4-2. Model Domain and Mesh Design of the SMPA.................................................... 6-21

6.4-3. Mean Seepage Percentage as a Function of Capillary-Strength Parameter and Mean Permeability for a Percolation Flux of $5 \mathrm{~mm} /$ year.....

6.4-4. Mean Seepage Percentage as a Function of Capillary-Strength Parameter and Mean Permeability for a Percolation Flux of $50 \mathrm{~mm} /$ year...

6.4-5. Mean Seepage Percentage as a Function of Capillary-Strength Parameter and Mean Permeability for a Percolation Flux of $200 \mathrm{~mm} /$ year...

6.4-6. Mean Seepage Percentage as a Function of Capillary-Strength Parameter and Mean Permeability for a Percolation Flux of $500 \mathrm{~mm} /$ year.....

6.4-7. Example Histograms of Seepage Percentage from 20 Realizations for Two Selected Parameter Cases.....

6.4-8. Mean Seepage Percentage for the Collapsed Drift Scenario as a Function of Capillary-Strength Parameter and Mean Permeability for a Percolation Flux of 5 $\mathrm{mm} /$ year.....

6.4-9. Mean Seepage Percentage for the Collapsed Drift Scenario as a Function of Capillary-Strength Parameter and Mean Permeability for a Percolation Flux of $50 \mathrm{~mm} /$ year.

6.4-10. Mean Seepage Percentage for the Collapsed Drift Scenario as a Function of Capillary-Strength Parameter and Mean Permeability for a Percolation Flux of $200 \mathrm{~mm} /$ year.

6.4-11. Mean Seepage Percentage for the Collapsed Drift Scenario as a Function of Capillary-Strength Parameter and Mean Permeability for a Percolation Flux of $500 \mathrm{~mm} /$ year.

6.4-12. Example of Numerical Grid for the TH Seepage Model.

6.4-13. Rock Temperature Evolution at the Drift Wall for Tptpmn Submodel Showing

(a) Different Percolation Flux Scenarios for Reference Thermal Mode, and (b) Different Thermal Modes for Percolation Flux Scenario with a Multiplication

Factor of 10

6.4-14. Fracture Saturation in Different Gridblocks along Drift Perimeter for Tptpmn

Submodel with Reference Thermal Mode Using Percolation Flux Scenario with a Multiplication Factor of 10.

6.4-15. Seepage Percentage for Tptpmn Submodel with Reference Thermal Mode Using

Percolation Flux Scenario with a Multiplication Factor of 10 $6-48$ 


\section{FIGURES (Continued)}

Page

6.4-16. Schematic of TH Differences between an Open Nondegraded Drift and a Rubble-filled Collapsed Drift.

6.4-17. Close-up View of the Collapsed Drift Discretization and Properties Assignment ...... 6-52

6.4-18. Rock Temperature Evolution for Base Case with Full Contact Area (Solid Lines) and 50-Percent Contact-Area Case (Dashed Lines) at Three Representative Locations within and Close to Collapsed Drift

6.4-19. Saturation and Temperature (in ${ }^{\circ} \mathrm{C}$ ) at 100 Years after Emplacement, for Fragmented Rock Blocks (within Collapsed Drift) and Matrix Rock (Outside of Collapsed Drift). 6-56

6.4-20. Saturation and Liquid Flux Vectors at 100 Years after Emplacement, for Void Space (within Collapsed Drift) and Fractures (Outside of Collapsed Drift)

6.4-21. Saturation and Temperature (in ${ }^{\circ} \mathrm{C}$ ) at 1,000 Years after Emplacement, for Fragmented Rock Blocks (within Collapsed Drift) and Matrix Rock (Outside of Collapsed Drift)

6.4-22. Saturation and Liquid Flux Vectors at 1,000 Years after Emplacement, for Void Space (within Collapsed Drift) and Fractures (Outside of Collapsed Drift).

6.4-23. Saturation and Temperature (in ${ }^{\circ} \mathrm{C}$ ) at 2,000 Years after Emplacement, for Fragmented Rock Blocks (within Collapsed Drift) and Matrix Rock (Outside of Collapsed Drift)

6.4-24. Saturation and Liquid Flux Vectors at 2,000 Years after Emplacement, for Void Space (within Collapsed Drift) and Fractures (Outside of Collapsed Drift)

6.4-25. Saturation and Temperature (in ${ }^{\circ} \mathrm{C}$ ) at 10,000 Years after Emplacement, for Fragmented Rock Blocks (within Collapsed Drift) and Matrix Rock (Outside of Collapsed Drift)

6.4-26. Saturation and Liquid Flux Vectors at 10,000 Years after Emplacement, for Void Space (within Collapsed Drift) and Fractures (Outside of Collapsed Drift)

6.4-27. Downward Flux in the Fractures/Voids along a Vertical Line through the Center of the Collapsed Drift for Base Case Simulation

6.4-28. Downward Flux in the Fractures/Voids along a Vertical Line through the Center of the Collapsed Drift for Simulation with Limited Contact Area

6.4-29. Evolution of Relative Humidity in the Rubble Material Immediately above the Drip Shield, for Base Case (Solid Line) and 50-Percent Contact-Area Case (Dashed Line)

6.4-30. Rock Temperature Evolution for Percolation Flux Scenario with a Multiplication Factor of 10 (Solid Lines) Compared to Base Case (Dashed Lines) at Three Representative Locations within and Close to Collapsed Drift

6.4-31. Downward Flux in the Fractures/Voids along a Vertical Line through the Center of the Collapsed Drift, for Percolation Flux Scenario with a Multiplication Factor of 10 ...

6.4-32. Example Result Illustrating the Difference in Vertical Percolation Flux $\left(\mathrm{Q}_{z}\right)$ in Fractures at 10,000 Years for (a) Fully Coupled THM Simulation, and (b) TH Simulation (Tptpmn Unit Model Domain). 


\section{FIGURES (Continued)}

Page

6.4-33. Seepage Percentage as a Function of Percolation Flux Simulated Using the Initial Post-Excavation Permeability Field without THM Changes (HM Excavation Effects) and the Permeability Field at 10,000 years after Emplacement Including THM Changes (THM 10,000 Years)

6.4-34. Changes in Hydrological Properties Expected for a Completely Collapsed Drift in Scenario 12 (100 percent cohesion loss), Showing (a) the Ratio of PostCollapse Fracture Permeability Relative to the Undisturbed Values, and (b) the Ratio of Post-Collapse Fracture Capillary Strength Relative to the Undisturbed Values.

6.4-35. Example of Effects of Mineral Alteration as Predicted by the THC Seepage Model: Contour Plot of Modeled (a) Permeability Change, and (b) Liquid Saturation and Temperature Contours $\left({ }^{\circ} \mathrm{C}\right)$ at 2,400 Years

6.5-1. Schematic of Probabilistic TSPA Procedure for Calculating Seepage 6-79

6.5-2. Schematic Illustration of Random Sampling Procedure for Capillary-Strength Parameter 1/ $\alpha$, Using Cumulative Probability Distributions for Spatial Variability (Uniform Probability Distribution) and Uncertainty (Triangular Probability Distribution). Subscripts $\mathrm{n}$ and $\mathrm{m}$ denote random sampling values between 0 and 1 .

6.5-3. Illustration of Seepage Abstraction Models 1 and 2 for Simulation Case with Tptpmn Submodel, Reference Thermal Mode, Percolation Flux Multiplication Factor 10, and Capillary-Strength Parameter $1 / \alpha=589$ Pa: (a) Temperature Evolution of Fracture Continuum at the Drift Wall, and (b) Abstracted Seepage Percentage as a Function of Time 6-95

6.5-4. Illustration of Seepage Abstraction Models 1 and 2 for Simulation Case with Tptpmn Submodel, Reference Thermal Mode, Percolation Flux Multiplication Factor 10, and Capillary-Strength Parameter 1/ $\alpha=400$ Pa: (a) Temperature Evolution of Fracture Continuum at the Drift Wall, and (b) Abstracted Seepage Percentage as a Function of Time 6-96

6.6-1. Schematic Geological Map Showing Approximate Location and Schematic Setup of Niches and Systematic Testing Boreholes SYBT-ECRB-LA\#1-3 (Formations Depicted at the Elevation of the ESF)

6.6-2. Histogram and Related Probability Distribution for Spatial Variability of Capillary-Strength Parameter 1/a, Using Statistical Parameters Based on Method A .....

6.6-3. Schematic Showing the Triangular Probability Distribution (Blue Line) for Covering Uncertainty of the Capillary-Strength Parameter by Varying the Mean of the Spatial Probability Distribution, Using Statistical Parameters Based on Method A

6.6-4. Schematic Showing the Relation between Statistics of Small-Scale Measurements (Mean Permeability $\mu_{S}$ ) and the Intermediate-Scale Variability Distribution of the Repository Units (Mean $\mu$ and Standard Deviation $\sigma$ )

6.6-5. Map Showing Approximate Location of Surface-Based Boreholes NRG-7a, NRG-6, SD-12, and UZ\#16 and SHT/DST Heater Test Area (Alcove 5), together with the 2002 Repository Layout. 


\section{FIGURES (Continued)}

Page

6.6-6. Mean Fracture Permeabilities for Different Locations in the Tptpmn Unit. $6-126$

6.6-7. Schematic Showing Triangular Probability Distribution (Blue Line) for Covering Uncertainty of Permeability in the Tptpmn Unit by Varying the Mean of the Spatial Probability Distribution.

6.6-8. Schematic Showing Triangular Probability Distribution (Blue Line) for Covering Uncertainty of Permeability in the Tptpll Unit by Varying the Mean of the Spatial Probability Distribution.

6.6-9. Contour Map of Vertical Fluxes at the PTn/TSw Interface for the Glacial Transition Climate (Mean Infiltration scenario)

6.6-10. Extracted Vertical Fluxes at the PTn/TSw Interface for the Glacial Transition Climate (Mean Infiltration scenario)

6.6-11. Histograms of Vertical Fluxes at the PTn/TSw Interface for the Mean Infiltration scenario.

6.6-12. Histograms of Vertical Fluxes at the PTn/TSw Interface for the Mean Infiltration Scenario Using the Alternative Flow Concept in the PTn

6.6-13. Distribution of Flow Focusing Factors within the 2-D Model Domain, for Two Different Realizations of Random Permeability Fields and a $5 \mathrm{~mm} /$ year Uniform Infiltration on the Top Boundary...

6.6-14. Flow Focusing Results for a Selected Simulation Case, Showing (a) Spatial Variability of Flow Focusing Factors (FFF) at the Bottom of the Model Domain, and (b) Frequency and Cumulative Frequency Distributions at the Bottom of the Model Domain and for the Entire Model Domain

6.6-15. Data Points from 15 Different Sensitivity Cases (Symbols) and Generalized Cumulative Frequency Curves of Flow Focusing Factors

6.6-16. Cumulative Frequency Distributions of Flow Focusing Factors, Averaged over 5meter Horizontal Sections along the Bottom Boundary for 15 Sensitivity Cases Obtained for the Most Recent Calibrated Fracture Property Set..

6.8-1. Histograms of Seepage Rates for Tptpll Unit

6.8-2. Histograms of Seepage Percentages for Tptpll Unit 6-170

6.8-3. Mean Seepage Rate as a Function of Time after Emplacement for Tptpll Unit and Different Infiltration Scenarios

6.8-4. Mean Seepage Percentage as a Function of Time after Emplacement for Tptpll Unit and Different Infiltration Scenarios.

6.8-5. Seepage Fraction as a Function of Time after Emplacement for Tptpll Unit and Different Infiltration Scenarios

H-1. Fracture Frequency Measured in the ESF H-3

H-2. Fracture Frequency and Lithophysal Abundance Measured in the ECRB CrossDrift from Stations $0+00$ to $27+00$........................................................................... H-4

H-3. Fractures in the Wall of the ECRB Cross-Drift in the Tptpmn Unit............................. H-4

H-4. $\quad$ Comparison of Lithophysae and Fracturing in the Tptpul and Tptpll Units .................. H-5 


\section{TABLES}

Page

4.1-1. Input Data and Parameters Used in This Model Report.................................................. 4-1

4.2-1. Project Requirements and YMRP Acceptance Criteria Applicable to This Model

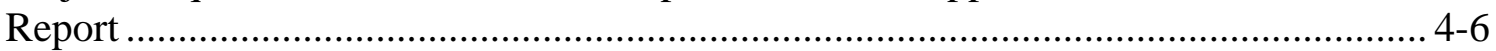

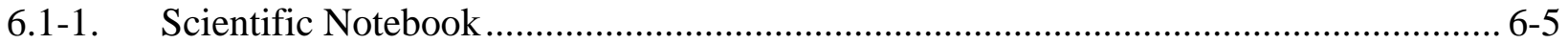

6.2-1. Included FEPs Addressed in This Model Report ....................................................... 6-6

6.2-2. Excluded FEPs Addressed in This Model Report ............................................................ 6-8

6.6-1. Summary Statistics of Estimated Capillary-Strength Parameter for Lower Lithophysal Zone and Middle Nonlithophysal Zone ................................................... 6-108

6.6-2. Intermediate-Scale Variability Statistics of Estimated Capillary-Strength Parameter over Repository Rock Block, Using Different Calculation Methods

6.6-3. Summary Statistics of Air Permeabilities Derived from Small-Scale Air-Injection Tests for Undisturbed and Excavation-Disturbed Conditions in the Middle Nonlithophysal Zone and the Lower Lithophysal Zone.

6.6-4. Intermediate-Scale Variability Statistics (Mean $\mu$ and Standard Deviation $\sigma$ ) of Permeability over Repository Rock Block, for Pre- and Post-Excavation Data in the Tptpmn Unit, Based on Air permeability Measurements in Niches

6.6-5. Mean Permeabilities of Undisturbed Rock from Tptpmn Unit Measured in Surface-Based Boreholes and Intermediate-Scale Variability Statistics over the Repository Rock Block

6.6-6. Upscaling Factors for Air Permeabilities in the Tptpmn Unit Derived Using Two Different Upscaling Approaches

6.6-7. Intermediate-Scale Variability Statistics (Mean $\mu$ and Standard Deviation $\sigma$ ) of Permeability over the Repository Rock Block, for Pre- and Post-Excavation Data in the Tptpll Unit, Based on Air Permeability Measurements in Niche 1620 and in ECRB

6.6-8. Mean Permeabilities of Undisturbed Rock from Tptpll and Tptpul Units

Measured in Vertical Boreholes and Intermediate-Scale Variability Statistics over Repository Rock Block

6.6-9. Upscaling Factors for Air permeability Measurements in the Tptpll Unit Derived Using Two Different Upscaling Approaches

6.6-10. Mean Permeabilities of Undisturbed Rock from Tptpln Unit Measured in Surface-Based Boreholes and Intermediate-Scale Variability Statistics over the Repository Rock Block

6.6-11. Statistics of Percolation Flux Distributions at the PTn/TSw Interface 6-145

6.8-1. Summary Statistics for Probabilistic Seepage Evaluation (Tptpll Unit)

6.8-2. Summary Statistics for Probabilistic Seepage Evaluation (Tptpmn Unit)

6.8-3. Summary Statistics for Seepage Sensitivity Cases (Tptpll Unit) 6-179 


\section{TABLES (Continued)}

Page

D-1. Mathcad Spreadsheets for Percolation Flux Analysis Using the Base Case Flow Fields from DTN: LB0302PTNTSW9I.001 [DIRS 162277]. Calculation is Conducted for All Repository Elements D-3

D-2. Mathcad Spreadsheets for Percolation Flux Analysis Using the Base Case Flow Fields from DTN: LB0302PTNTSW9I.001 [DIRS 162277]. Calculation is Conducted for No-Fault Repository Elements

D-3. Mathcad Spreadsheets for Percolation Flux Analysis Using the Alternative Flow Fields from DTN: LB0305PTNTSW9I.001 [DIRS 163690]. Calculation is Conducted for All Repository Elements

D-4. Mathcad Spreadsheets for Percolation Flux Analysis Using the Alternative Flow Fields from DTN: LB0305PTNTSW9I.001 [DIRS 163690]. Calculation is Conducted for No-Fault Repository Elements

E-1. Mathcad Spreadsheets for Probabilistic Seepage Calculation for the Tptpll Unit (Base Case Seepage Evaluation)

E-2. Mathcad Spreadsheets for Probabilistic Seepage Calculation for the Tptpmn Unit (Base Case Seepage Evaluation)

E-3. Mathcad Spreadsheets for Probabilistic Seepage Calculation for the Tptpll Unit (Sensitivity Cases)

E-4. $\quad$ Mathcad Spreadsheets for Seepage Interpolation Check in Appendix F ..........................-4

G-1. Comparison of Flux Statistics between UZ Flow Model and Probabilistic Seepage Calculation G-1

H-1. Joint Set Spacing Summary Data from ESF and ECRB ............................................ H-1

H-2. Joint Set Trace Length Summary Data from ESF and ECRB...................................... H-2 


\section{ACRONYMS}

2-D two-dimensional

3-D three-dimensional

AFM active fracture model

AP

BSC

CRWMS

DFNM

DIRS

DOE

DST

DTN

ECRB

ESF

FEPs

LA

LBNL

$\mathrm{M} \& \mathrm{O}$

NRC

OCRWM

PA

Q

QA

SCM

SD

SE

SHT

SMPA
Administrative Procedure (DOE)

Bechtel SAIC Company, LLC

Civilian Radioactive Waste Management System

discrete fracture network model

Document Input Reference System

Department of Energy

Drift Scale Test

Data Tracking Number

Enhanced Characterization of Repository Block

Exploratory Studies Facility

Features, Events, and Processes

License Application

Lawrence Berkeley National Laboratory

Management and Operating Contractor

Nuclear Regulatory Commission

Office of Civilian Radioactive Waste Management

Performance Assessment

Qualified

Quality Assurance

Seepage Calibration Model

standard deviation

standard error of mean

Single Heater Test

Seepage Model for Performance Assessment 


\section{ACRONYMS (Continued)}

TDMS Technical Data Management System

$\mathrm{TH} \quad$ thermal-hydrological

TM thermal-mechanical

THC thermal-hydrological-chemical

THM thermal-hydrological-mechanical

Tptpul Topopah Spring Tuff Upper Lithophysal

Tptpmn Topopah Spring Tuff Middle Nonlithophysal

Tptpll Topopah Spring Tuff Lower Lithophysal

Tptpln Topopah Spring Tuff Lower Nonlithophysal

TSPA-LA Total System Performance Assessment for License Application

TWP Technical Work Plan

UZ unsaturated zone

YMP Yucca Mountain Project

YMRP Yucca Mountain Review Plan, Final Report 


\section{PURPOSE}

This model report documents the abstraction of drift seepage, conducted to provide seepage-relevant parameters and their probability distributions for use in Total System Performance Assessment for License Application (TSPA-LA). Drift seepage refers to the flow of liquid water into waste emplacement drifts. Water that seeps into drifts may contact waste packages and potentially mobilize radionuclides, and may result in advective transport of radionuclides through breached waste packages [Risk Information to Support Prioritization of Performance Assessment Models (BSC 2003 [DIRS 168796], Section 3.3.2)]. The unsaturated rock layers overlying and hosting the repository form a natural barrier that reduces the amount of water entering emplacement drifts by natural subsurface processes. For example, drift seepage is limited by the capillary barrier forming at the drift crown, which decreases or even eliminates water flow from the unsaturated fractured rock into the drift. During the first few hundred years after waste emplacement, when above-boiling rock temperatures will develop as a result of heat generated by the decay of the radioactive waste, vaporization of percolation water is an additional factor limiting seepage. Estimating the effectiveness of these natural barrier capabilities and predicting the amount of seepage into drifts is an important aspect of assessing the performance of the repository. The TSPA-LA therefore includes a seepage component that calculates the amount of seepage into drifts [Total System Performance Assessment (TSPA) Model/Analysis for the License Application (BSC 2004 [DIRS 168504], Section 6.3.3.1)]. The TSPA-LA calculation is performed with a probabilistic approach that accounts for the spatial and temporal variability and inherent uncertainty of seepage-relevant properties and processes. Results are used for subsequent TSPA-LA components that may handle, for example, waste package corrosion or radionuclide transport.

Abstraction is defined as the process of purposely simplifying a mathematical model (component, barrier, or subsystem process model) for incorporation into an overall system model of the geological repository [Guidelines for Developing and Documenting Alternative Conceptual Models, Model Abstractions, and Parameter Uncertainty in the Total System Performance Assessment for the License Application (BSC 2002 [DIRS 158794], Section 3.1.1)]. The purpose of this model report on seepage abstraction is to modify the information generated by various seepage process models into a form that can be used in the TSPA-LA seepage calculation. The simplifications and assumptions made in this abstraction process must be realistic and appropriate. In particular, uncertainties and spatial variabilities of the primary process models for seepage must be represented in the abstraction and must be propagated to TSPA-LA. The seepage abstraction methodology developed in this model report is referred to as the seepage abstraction model. Note that this model report deals with the magnitude of seepage into drifts, not with the chemistry of seeping water. This latter information is provided to TSPA-LA by the Post-Processing Analysis of THC Seepage (BSC 2004 [DIRS 169858]).

A suite of primary process models provides seepage model results used as input to the abstraction performed in this report. The following three models-compatible and consistent in 
their conceptual treatment of flow diversion and capillary barrier behavior-provide the basis for the seepage abstraction model:

1. The Seepage Calibration Model (SCM)

This process model provides the conceptual basis for seepage modeling and derives seepage-relevant parameters through calibration of the model against seepage-rate data from liquid-release tests [Seepage Calibration Model and Seepage Testing Data (BSC 2004 [DIRS 171764])].

2. The Seepage Model for Performance Assessment (SMPA)

This process model predicts drift seepage rates for long-term ambient conditions at Yucca Mountain, for a wide range of seepage-relevant parameters and for potentially important perturbing effects [Seepage Model for PA Including Drift Collapse (BSC 2004 [DIRS 167652])]. The latter include the effect of rock bolts on flow paths and the impact of drift shape changes caused by degradation. Information on drift shape changes caused by, for example, seismic and thermal stresses, is provided to the SMPA by the drift degradation analysis in BSC (2004 [DIRS 166107]).

3. The Thermal-Hydrological Seepage Model (TH Seepage Model)

This process model predicts drift seepage during the period when water-flow processes in the drift vicinity are perturbed by heating of the rock [Drift-Scale Coupled Processes (DST and TH Seepage) Models (BSC 2004 [DIRS 170338])].

Additional input from scientific analyses or from process models is required to define probability distributions that appropriately cover uncertainty and spatial variability of seepage-affecting parameters. In addition to the capillary strength in the fractures close to the drift-calibrated with the SCM - the most important parameters affecting seepage are the local percolation flux and the formation's permeability close to the drifts (BSC 2004 [DIRS 171764]). Information on these parameters is mainly derived from the following sources:

1. Site-scale Unsaturated Zone (UZ) Flow Simulations

The UZ Flow Model provides three-dimensional (3-D) site-scale flow fields to derive the local percolation flux $[U Z$ Flow Models and Submodels (BSC 2004 [DIRS 169861])].

2. Intermediate-scale Flow Simulations

An intermediate-scale flow focusing model provides a distribution of flow focusing factors (BSC 2004 [DIRS 167652], Section 6.8). These factors account for intermediate-scale heterogeneity that is not represented in the layer-averaged UZ Flow Model.

3. In situ Testing at Yucca Mountain

Air-injection tests performed at different scales and locations provide estimates of local fracture permeability [In Situ Field Testing of Processes (BSC 2004 [DIRS 170004])].

Finally, results from the coupled thermal-hydrological-mechanical (THM) and thermal-hydrological-chemical (THC) models are utilized to assess whether seepage-relevant 
parameters may be affected by mechanical and/or chemical processes. These processes occur in response to the heat generated in the repository [Drift-Scale THC Seepage Model (BSC 2004 [DIRS 169856]) and Drift Scale THM Model (BSC 2004 [DIRS 169864])]. The relationship and the information flow between the suite of primary process models important for seepage and the seepage abstraction model are schematically illustrated in Figure 1-1. A more detailed description is given in Section 6.4.

The seepage abstraction model developed in this model report synthesizes and simplifies the relevant input from the above sources, and provides a realistic and appropriate abstraction model for TSPA-LA. The scope of this work is to (1) develop an appropriate abstraction methodology for drift seepage, considering both the nominal scenario and disruptive scenarios such as seismic and igneous events, (2) determine the uncertainty and spatial variability of seepage relevant parameters, (3) provide look-up tables for seepage into nondegraded and collapsed drifts as a function of these parameters, (4) evaluate and discuss the impact of additional factors affecting seepage, such as THM, THC processes, rock bolts, and disruptive events, (5) validate the seepage abstraction methodology, and (6) evaluate and discuss seepage-related features, events, and processes (FEPs).

The analyses documented in this report were initially conducted under the Technical Work Plan for: Performance Assessment Unsaturated Zone (BSC 2004 [DIRS 167969]). The relevant technical work plan (TWP) sections for this work were Section 1.13.5 (entitled "Update Seepage Abstraction Model”) and Section I-4-3 of Attachment I (entitled "Model Validation Plans"). Recently, the model report has been further modified according to the activities described in the recent Technical Work Plan for: Unsaturated Zone Flow Analysis and Model Report Integration (BSC 2004 [DIRS 169654]). The modifications include editing, partial rewriting, and reformatting to incorporate Regulatory Integration Team evaluation comments. The primary tasks associated with these modifications are given in Section 1.2 of the recent TWP (BSC 2004 [DIRS 169654]), with specifics to this model report given in Section 1.2.11 of the recent TWP.

The output from this model report is primarily used by TSPA-LA (BSC 2004 [DIRS 168504]); it is also used to evaluate the water flow characteristics after magma intrusion into waste emplacement drifts [in model report Igneous Intrusion Impacts on Waste Packages and Waste Forms].

The primary limitations of this model report and its results are as follows:

- The results of the seepage abstraction model are based on the available data and the available analyses/models, as listed above and in Sections 4.1 and 6.4. Limitations reported in analyses or model reports that directly support this model report are implicit limitations of the seepage abstraction model. The limitations of predictive models (process models), for example, are defined by the conceptual model, as described in the pertinent sections of the respective model reports.

- The predictive seepage models and the seepage abstraction model are probabilistic models that provide estimates of seepage fluxes averaged over drift segments. These models are not expected to predict individual seepage events or to provide the precise 
spatial seepage distribution along the drifts and within the repository. This is consistent with the probabilistic seepage calculation conducted in the TSPA-LA simulation.

\section{TSPA}

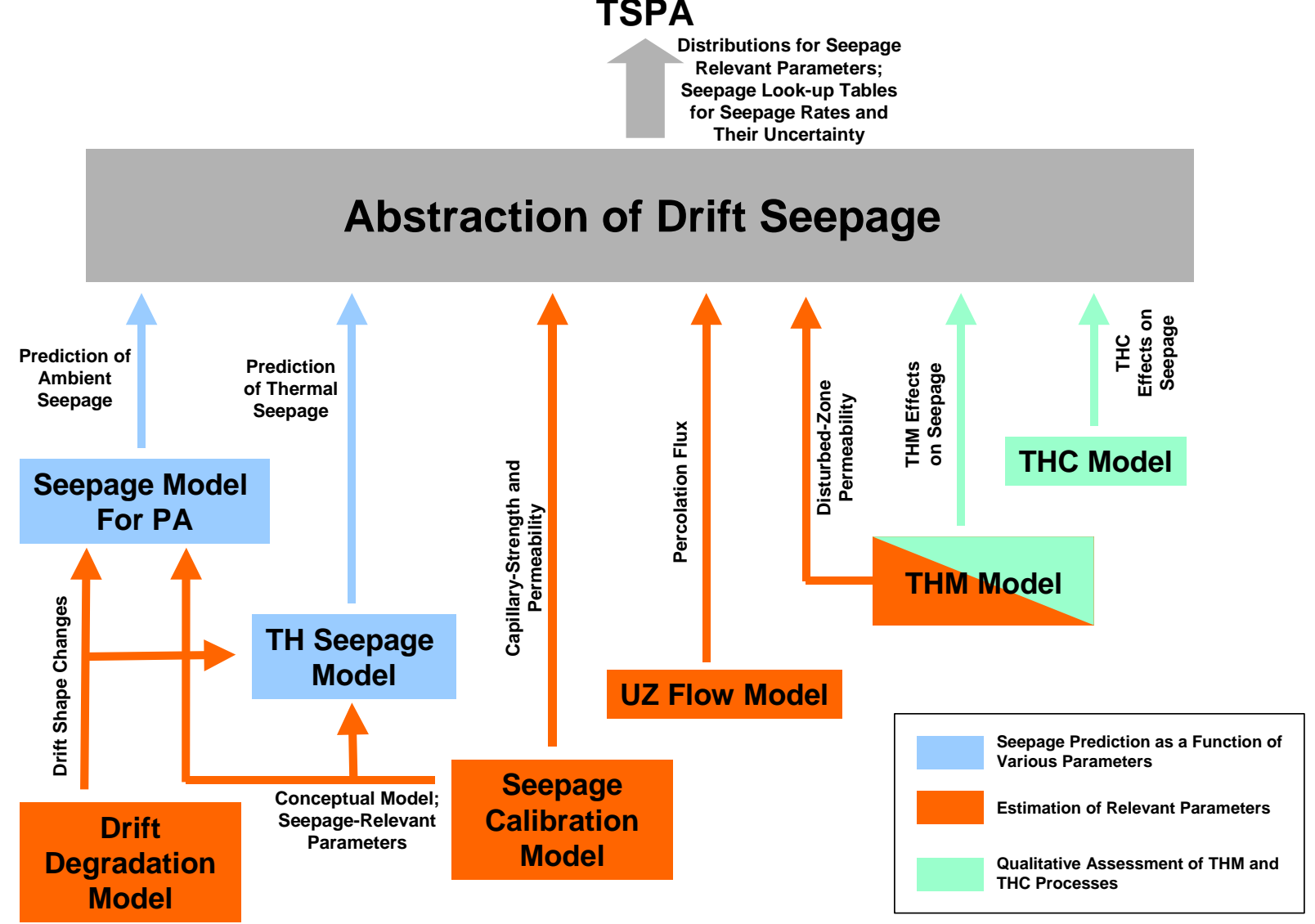

Figure 1-1. Relationship and Information Flow between Primary Process Models and the Seepage Abstraction Model 


\section{QUALITY ASSURANCE}

Development of this model report and the supporting modeling activities have been determined to be subject to the Yucca Mountain Project's quality assurance (QA) program as indicated in Technical Work Plan for: Unsaturated Zone Flow Analysis and Model Report Integration, TWP-MGR-HS-000001 REV 00 (BSC 2004 [DIRS 169654], Section 8.1). Approved QA procedures identified in the TWP (BSC 2004 [DIRS 169654], Section 4) have been used to conduct and document the activities described in this model report. The TWP also identifies the methods used to control the electronic management of data (BSC 2004 [DIRS 169654], Section 8.4) during the modeling and documentation activities.

This model report examines the properties of the upper natural barrier above the repository (see Section 6.1.4) that is classified in the Q-List (BSC 2004 [DIRS 168361]) as "Safety Category" because it is important to waste isolation, as defined in AP-2.22Q, Classification Analyses and Maintenance of the Q-List. It contributes to the analysis and modeling data used to support TSPA-LA. The conclusions of this model report do not affect the proposed repository design or engineered features important to safety, as defined in AP-2.22Q. 


\section{INTENTIONALLY LEFT BLANK}




\section{USE OF SOFTWARE}

Only standard off-the-shelf commercially available software was used for this model report. These are not subject to software quality assurance requirements. The software used was Microsoft Excel 97 SR-2 for calculations and graphical display, Mathcad 11 for calculations, and Tecplot V9.0 for graphical display. All information needed to reproduce the calculations using these standard software programs, including the input, computation, and output, as required by AP-SIII.10Q, is included in this report, with references specified (see Appendices A through G). 


\section{INTENTIONALLY LEFT BLANK}




\section{INPUTS}

\subsection{DIRECT INPUT}

Table 4.1-1 summarizes the input data and parameters used in this model report. All input data and parameters needed for the seepage abstraction model are obtained from the Technical Data Management System (TDMS). These data are considered appropriate as input for the seepage abstraction model (see Section 6). The parameter values used for abstraction, as well as the spatial variability and uncertainty associated with these values, are presented and discussed in detail in Section 6.

Table 4.1-1. Input Data and Parameters Used in This Model Report

\begin{tabular}{|c|c|c|c|}
\hline Item & Data Name & $\begin{array}{c}\text { Data Source/Data Tracking } \\
\text { Number (DTN) } \\
\text { Roadmap (if applicable) }\end{array}$ & $\begin{array}{l}\text { Parameters } \\
\text { Comments }\end{array}$ \\
\hline 1 & $\begin{array}{l}\text { Ambient Seepage } \\
\text { Prediction Results } \\
\text { For Nondegraded } \\
\text { Drifts }\end{array}$ & $\begin{array}{l}\text { DTN: LB0304SMDCREV2.002 } \\
\text { [DIRS 163687] } \\
\text { The data file from the } \\
\text { DTN: LB0304SMDCREV2.002.zip } \\
\text { must be unzipped. File Fig 6-3 to } \\
\text { Fig6-8.dat contains a seepage } \\
\text { look-up table for nondegraded drifts. } \\
\text { Another file Fig 6-3 to Fig 6-8.xls } \\
\text { contains seepage results for all } \\
20 \text { individual realizations. This file } \\
\text { opens in a subdirectory "Supporting } \\
\text { data for tecplot input". }\end{array}$ & $\begin{array}{l}\text { Predicted ambient seepage rates and } \\
\text { uncertainty for suite of simulation cases for the } \\
\text { nondegraded drift scenario } \\
\text { Ambient seepage was predicted by the SMPA. } \\
\text { Seepage results are given as a function of } \\
\text { permeability, capillary-strength parameter, and } \\
\text { percolation flux. Simulation cases cover } \\
\text { parameter distributions required for TSPA. The } \\
\text { SMPA is documented in BSC (2004 } \\
\text { [DIRS 167652]). }\end{array}$ \\
\hline 2 & $\begin{array}{l}\text { Ambient Seepage } \\
\text { Prediction Results } \\
\text { for THM Effects }\end{array}$ & $\begin{array}{l}\text { DTN: LB0304SMDCREV2.004 } \\
\text { [DIRS 163691] } \\
\text { The data file from the } \\
\text { DTN: LB0304SMDCREV02.004.zip } \\
\text { must be unzipped. File Fig6-22.wmf } \\
\text { contains a figure comparing } \\
\text { seepage results for ambient } \\
\text { conditions versus THM altered } \\
\text { conditions. }\end{array}$ & $\begin{array}{l}\text { Predicted seepage rates from ambient model } \\
\text { compared to model including THM permeability } \\
\text { changes } \\
\text { Seepage results were obtained using the Drift- } \\
\text { Scale THM Model. Two cases are studied and } \\
\text { compared. The first one calculates seepage } \\
\text { using the initial permeability field, the second } \\
\text { one calculates seepage using the altered } \\
\text { permeability at 10,000 years after } \\
\text { emplacement. The two cases are compared. } \\
\text { The THM simulation model is documented in } \\
\text { BSC (2004 [DIRS 169864]); the specific results } \\
\text { of this DTN are presented in BSC (2004 } \\
\text { [DIRS 167652]). }\end{array}$ \\
\hline 3 & $\begin{array}{l}\text { Ambient Seepage } \\
\text { Prediction Results } \\
\text { for Collapsed } \\
\text { Drifts }\end{array}$ & $\begin{array}{l}\text { DTN: LB0307SEEPDRCL.002 } \\
\text { [DIRS 164337] } \\
\text { The data file from the } \\
\text { DTN: LBO307SEEPDRCL.002.zip } \\
\text { must be unzipped. File Response } \\
\text { Surface SMPA-CollapsedDrift.dat } \\
\text { contains a seepage look-up table for } \\
\text { a collapsed drift. }\end{array}$ & $\begin{array}{l}\text { Predicted ambient seepage rates and } \\
\text { uncertainty for suite of simulation cases for the } \\
\text { collapsed drift scenario } \\
\text { Ambient seepage was predicted by the SMPA. } \\
\text { Seepage results are given as a function of } \\
\text { permeability, capillary-strength parameter, and } \\
\text { percolation flux. Simulation cases cover } \\
\text { parameter distributions required for TSPA. The } \\
\text { ambient seepage model for collapsed drifts and } \\
\text { results are documented in BSC (2004 } \\
\text { [DIRS 167652]). }\end{array}$ \\
\hline
\end{tabular}


Table 4.1-1. Input Data and Parameters Used in This Model Report (Continued)

\begin{tabular}{|c|c|c|c|}
\hline Item & Data Name & $\begin{array}{c}\text { Data Source/DTN } \\
\text { Roadmap (if applicable) }\end{array}$ & $\begin{array}{l}\text { Parameters } \\
\text { Comments }\end{array}$ \\
\hline 4 & $\begin{array}{l}\text { Thermal Seepage } \\
\text { Prediction Results } \\
\text { for Nongraded Drifts } \\
\text { (TOUGH2 } \\
\text { Simulation Files) }\end{array}$ & $\begin{array}{l}\text { DTN: LB0303DSCPTHSM.001 } \\
\text { [DIRS 163688] } \\
\text { File Readme.doc explains the } \\
\text { different simulation cases } \\
\text { included in the DTN. There are } \\
\text { five compressed data files that } \\
\text { need to be unzipped onto a } \\
\text { large enough disc. A directory } \\
\text { structure with different result } \\
\text { data files opens, as explained in } \\
\text { the Readme document. The } \\
\text { temporal evolution of relevant } \\
\text { TH parameters is given in } \\
\text { simulation files named } \\
\text { si_heat.obs. Use the Readme } \\
\text { document to relate simulation } \\
\text { cases and subdirectories. }\end{array}$ & $\begin{array}{l}\text { Thermal seepage modeling results for } \\
\text { nondegraded drifts } \\
\text { The future drift-scale TH conditions were } \\
\text { predicted for selected simulation cases, using the } \\
\text { TH Seepage Model. The DTN gives the entire } \\
\text { suite of simulation input and output files. The } \\
\text { thermal seepage model and results are } \\
\text { documented in BSC (2004 [DIRS 170338]). }\end{array}$ \\
\hline 5 & $\begin{array}{l}\text { Thermal Seepage } \\
\text { Prediction Results } \\
\text { for Nondegraded } \\
\text { Drifts } \\
\text { (Developed Data) }\end{array}$ & $\begin{array}{l}\text { DTN: LB0301DSCPTHSM.002 } \\
\text { [DIRS 163689] } \\
\text { File Readme.doc explains the } \\
\text { different simulation cases } \\
\text { included in the DTN. The data } \\
\text { file TH_Seepage_Model.data_ } \\
\text { summary.tar.gz must be } \\
\text { unzipped. A directory structure } \\
\text { with different result data files } \\
\text { opens, as explained in the } \\
\text { Readme document. The } \\
\text { thermal seepage results are } \\
\text { given in developed data files } \\
\text { named seep_relrate.tec. Use } \\
\text { the Readme document to relate } \\
\text { simulation cases and } \\
\text { subdirectories. }\end{array}$ & $\begin{array}{l}\text { Thermal seepage percentage for nondegraded } \\
\text { drifts } \\
\text { Thermal seepage was predicted for selected } \\
\text { simulation cases, using the TH Seepage Model. } \\
\text { Evolution of seepage with time is given for } \\
\text { different rock properties and two geological units. } \\
\text { The thermal seepage model and results are } \\
\text { documented in BSC (2004 [DIRS 170338]). }\end{array}$ \\
\hline 6 & $\begin{array}{l}\text { Additional Thermal } \\
\text { Seepage Prediction } \\
\text { Results for } \\
\text { Nondegraded Drifts } \\
\text { (TOUGH2 } \\
\text { Simulation Files) }\end{array}$ & $\begin{array}{l}\text { DTN: LB0309DSCPTHSM.001 } \\
\text { [DIRS 165538] } \\
\text { File Readme.doc explains the } \\
\text { different simulation cases } \\
\text { included in the DTN. The data } \\
\text { file TH_Seepage_Model.tough } \\
\text { data. tar.gz must be unzipped. } \\
\text { A directory structure with } \\
\text { different result data files opens, } \\
\text { as explained in the Readme } \\
\text { document. The temporal } \\
\text { evolution of relevant TH } \\
\text { parameters is given in } \\
\text { simulation files named } \\
\text { si_heat.obs. Use the Readme } \\
\text { document to relate simulation } \\
\text { cases and subdirectories. }\end{array}$ & $\begin{array}{l}\text { Additional thermal seepage modeling results for } \\
\text { nondegraded drifts } \\
\text { The future drift-scale TH conditions were } \\
\text { predicted for additional simulation cases, using } \\
\text { the TH Seepage Model. The DTN gives the entire } \\
\text { suite of simulation input and output files. The } \\
\text { thermal seepage model and results are } \\
\text { documented in BSC (2004 [DIRS 170338]). }\end{array}$ \\
\hline
\end{tabular}


Table 4.1-1. Input Data and Parameters Used in This Model Report (Continued)

\begin{tabular}{|c|c|c|c|}
\hline Item & Data Name & $\begin{array}{c}\text { Data Source/DTN } \\
\text { Roadmap (if applicable) }\end{array}$ & $\begin{array}{l}\text { Parameters } \\
\text { Comments }\end{array}$ \\
\hline 7 & $\begin{array}{l}\text { Additional Thermal } \\
\text { Seepage Prediction } \\
\text { Results for } \\
\text { Nondegraded Drifts } \\
\text { (Developed Data) }\end{array}$ & $\begin{array}{l}\text { DTN: LB0309DSCPTHSM.002 } \\
\text { [DIRS 165539] } \\
\text { File Readme.doc explains the } \\
\text { different simulation cases } \\
\text { included in the DTN. The data } \\
\text { file TH_Seepage_Model.data_ } \\
\text { summary.tar.gz must be } \\
\text { unzipped. A directory structure } \\
\text { with different result data files } \\
\text { opens, as explained in the } \\
\text { Readme document. The } \\
\text { thermal seepage results are } \\
\text { given in developed data files } \\
\text { named seep_relrate.tec. Use } \\
\text { the Readme document to relate } \\
\text { simulation cases and } \\
\text { subdirectories. }\end{array}$ & $\begin{array}{l}\text { Thermal seepage percentage for nondegraded } \\
\text { drifts (additional cases) } \\
\text { Thermal seepage was predicted for additional } \\
\text { simulation cases, using the TH Seepage Model. } \\
\text { Evolution of seepage with time is given for } \\
\text { different rock properties and two geological units. } \\
\text { The thermal seepage model and results are } \\
\text { documented in BSC (2004 [DIRS 170338]). }\end{array}$ \\
\hline 8 & $\begin{array}{l}\text { Thermal Seepage } \\
\text { Prediction Results } \\
\text { for Collapsed Drifts } \\
\text { (TOUGH2 } \\
\text { Simulation Files) }\end{array}$ & $\begin{array}{l}\text { DTN: LB0310DSCPTHSM.001 } \\
\text { [DIRS 165943] } \\
\text { File Readme.doc explains the } \\
\text { different simulation cases } \\
\text { included in the DTN. The data } \\
\text { fileTH_Seepage_Model.tough } \\
\text { data. tar.gz must be unzipped. } \\
\text { A directory structure with } \\
\text { different result data files opens, } \\
\text { as explained in the Readme } \\
\text { document. Use the Readme } \\
\text { document to relate simulation } \\
\text { cases and subdirectories. }\end{array}$ & $\begin{array}{l}\text { TH modeling results for collapsed drifts in the } \\
\text { Tptpll Unit } \\
\text { The future drift-scale TH conditions were } \\
\text { predicted for collapsed drifts, using the TH } \\
\text { Seepage Model. The DTN gives the entire suite } \\
\text { of simulation input and output files. The thermal } \\
\text { seepage model and results are documented in } \\
\text { BSC (2004 [DIRS 170338]).). }\end{array}$ \\
\hline 9 & $\begin{array}{l}\text { Thermal Seepage } \\
\text { Prediction Results } \\
\text { for Collapsed Drifts } \\
\text { (Developed Data) }\end{array}$ & $\begin{array}{l}\text { DTN: LB0310DSCPTHSM.002 } \\
\text { [DIRS 165944] } \\
\text { File Readme.doc explains the } \\
\text { different simulation cases } \\
\text { included in the DTN. The data } \\
\text { file TH_Seepage_Model.data_- } \\
\text { summary.tar.gz must be } \\
\text { unzipped. A directory structure } \\
\text { with different result plot files } \\
\text { opens, as explained in the } \\
\text { Readme document. Use the } \\
\text { Readme document to relate } \\
\text { simulation cases and } \\
\text { subdirectories. The plotfiles } \\
\text { can be readily used as input to } \\
\text { graphic utilities such as Tecplot. } \\
\text { In addition, the DTN contains a } \\
\text { word document "TH Conditions } \\
\text { in Collapsed Drifts.doc" that } \\
\text { includes selected figures } \\
\text { showing representative } \\
\text { simulation results for further } \\
\text { use. }\end{array}$ & $\begin{array}{l}\text { Plots of TH results for collapsed drifts } \\
\text { The future drift-scale TH conditions were } \\
\text { predicted for collapsed drifts, using the TH } \\
\text { Seepage Model. Figures of TH conditions are } \\
\text { provided in this DTN. The thermal seepage } \\
\text { model and results are documented in BSC (2004 } \\
\text { [DIRS 170338]). }\end{array}$ \\
\hline
\end{tabular}


Table 4.1-1. Input Data and Parameters Used in This Model Report (Continued)

\begin{tabular}{|c|c|c|c|}
\hline Item & Data Name & $\begin{array}{c}\text { Data Source/DTN } \\
\text { Roadmap (if applicable) }\end{array}$ & $\begin{array}{l}\text { Parameters } \\
\text { Comments }\end{array}$ \\
\hline 10 & $\begin{array}{l}\text { Seepage Calibration } \\
\text { Results }\end{array}$ & $\begin{array}{l}\text { DTN: LB0302SCMREV02.002 } \\
\text { [DIRS 162273] } \\
\text { File LB0302SCMREV02.002.zip } \\
\text { must be unzipped. Zip-file } \\
\text { contains one informational } \\
\text { README file and one word } \\
\text { document that contains } \\
\text { permeability data in Tables } 1 \\
\text { and 2, and calibrated } \\
\text { capillary-strength parameters in } \\
\text { Table 3. }\end{array}$ & $\begin{array}{l}\text { Post-excavation air-permeability statistics and } \\
\text { calibrated capillary-strength parameters for niches } \\
\text { and systematic testing boreholes } \\
\text { Calibration was conducted by the SCM. The SCM } \\
\text { and model results are documented in BSC ( } 2004 \\
\text { [DIRS 171764]). }\end{array}$ \\
\hline 11 & $\begin{array}{l}\text { Drift Design and } \\
\text { Waste-Package }\end{array}$ & $\begin{array}{l}\text { 800-IED-MGR0-00201-000-00B } \\
\text { (BSC } 2004 \text { [DIRS 168489]) }\end{array}$ & $\begin{array}{l}\text { Drift diameter, waste-package spacing, average } \\
\text { thermal load, ground support }\end{array}$ \\
\hline & & $\begin{array}{l}\text { 800-IED-WISO-00202-000-00C } \\
\text { (BSC } 2004 \text { [DIRS 169472]) }\end{array}$ & $\begin{array}{l}\text { Waste-package length } \\
\text { Length used in this report is } 5.0 \mathrm{~m} \text {. This is the } \\
\text { rounded length for the 44-BWR and 21-PWR } \\
\text { waste packages. }\end{array}$ \\
\hline & & $\begin{array}{l}\text { 800-IED-WISO-00302-000-00B } \\
\text { (BSC } 2004 \text { [DIRS 169058] }\end{array}$ & Ground support \\
\hline 12 & \multirow{5}{*}{$\begin{array}{l}\text { Air Permeability } \\
\text { Data }\end{array}$} & $\begin{array}{l}\text { DTN: GS960908312232.013 } \\
\text { [DIRS 105574] } \\
\text { Data are in Table S01163_001. }\end{array}$ & Air-permeability data from vertical boreholes \\
\hline 13 & & $\begin{array}{l}\text { DTN: LB990901233124.004 } \\
\text { [DIRS 123273] } \\
\text { Data are in Table S00017_o02. }\end{array}$ & $\begin{array}{l}\text { Pre-excavation air-permeability summary statistics } \\
\text { from niches } \\
\text { Analysis is documented in BSC (2004 } \\
\text { [DIRS 170004], Table 6.1.2-5). }\end{array}$ \\
\hline 14 & & $\begin{array}{l}\text { DTN: LB0012AIRKTEST.001 } \\
\text { [DIRS 154586] } \\
\text { Data are in Table S01048_001. }\end{array}$ & $\begin{array}{l}\text { Pre-excavation air-permeability data from Niche } \\
1620 \text { (also referred to as Niche 5) }\end{array}$ \\
\hline 15 & & $\begin{array}{l}\text { DTN: LB980901233124.101 } \\
\text { [DIRS 136593] } \\
\text { Data for Niche } 3107 \text { are in } \\
\text { Table S99469_001. } \\
\text { Data for Niche } 4788 \text { are in } \\
\text { Table S99469_002. }\end{array}$ & $\begin{array}{l}\text { Pre-excavation air-permeability data from Niches } \\
3107 \text { (Niche 3) and } 4788 \text { (Niche 4) }\end{array}$ \\
\hline 16 & & $\begin{array}{l}\text { DTN: LB0011AIRKTEST.001 } \\
\text { [DIRS 153155] } \\
\text { Data for Niche } 3650 \text { are in } \\
\text { Tables S00434_006 through } \\
\text { S00434_009, S00434_011, } \\
\text { S00434_013, and S00434_015 } \\
\text { (each borehole in separate } \\
\text { table). } \\
\text { Data for Niche } 3566 \text { are in } \\
\text { Tables S00434_001, } \\
\text { S00434_002, and S00434_005 } \\
\text { (each borehole in separate } \\
\text { table). }\end{array}$ & $\begin{array}{l}\text { Pre-excavation air-permeability data from Niches } \\
3650 \text { (Niche 2) and } 3566 \text { (Niche 1) }\end{array}$ \\
\hline
\end{tabular}


Table 4.1-1. Input Data and Parameters Used in This Model Report (Continued)

\begin{tabular}{|c|c|c|c|}
\hline Item & Data Name & $\begin{array}{c}\text { Data Source/DTN } \\
\text { Roadmap (if applicable) }\end{array}$ & $\begin{array}{l}\text { Parameters } \\
\text { Comments }\end{array}$ \\
\hline 17 & $\begin{array}{l}\text { Flow Field } \\
\text { Simulations for } \\
\text { Different Infiltration } \\
\text { scenarios }\end{array}$ & $\begin{array}{l}\text { DTN: LB0302PTNTSW9I.001 } \\
\text { [DIRS 162277] } \\
\text { File LB0302PTNTSW9I.001.zip } \\
\text { must be unzipped. Zip-file } \\
\text { contains one informational } \\
\text { README file and nine } \\
\text { percolation flux data files, each } \\
\text { representing one climate stage } \\
\text { and one infiltration scenario. }\end{array}$ & $\begin{array}{l}\text { Percolation fluxes at the PTn/TSw interface } \\
\text { Fluxes have been predicted by the UZ Flow } \\
\text { Model. Results are given for three climate states } \\
\text { (present-day, monsoon, and glacial transition) and } \\
\text { three infiltration scenarios (mean, upper, lower). } \\
\text { The simulation model and results are documented } \\
\text { in BSC (2004 [DIRS 169861]). }\end{array}$ \\
\hline 18 & $\begin{array}{l}\text { Alternative Flow } \\
\text { Field Simulations for } \\
\text { Infiltration scenarios }\end{array}$ & $\begin{array}{l}\text { DTN: LB0305PTNTSW9I.001 } \\
\text { [DIRS 163690] } \\
\text { File LB0305PTNTSW9I.001.zip } \\
\text { must be unzipped. Zip-file } \\
\text { contains one informational } \\
\text { README file and nine } \\
\text { percolation flux data files, each } \\
\text { representing one climate stage } \\
\text { and one infiltration scenario. }\end{array}$ & $\begin{array}{l}\text { Percolation fluxes at the PTn/TSw interface for } \\
\text { alternative conceptualization of flow in the PTn } \\
\text { Fluxes have been predicted by the UZ Flow } \\
\text { Model. Results are given for three climate states } \\
\text { (present-day, monsoon, and glacial transition) and } \\
\text { three infiltration scenarios (mean, upper, lower). } \\
\text { The simulation model and results are documented } \\
\text { in BSC (2004 [DIRS 169861]). }\end{array}$ \\
\hline 19 & $\begin{array}{l}\text { UZ Model Columns } \\
\text { Representative of } \\
\text { Repository Area }\end{array}$ & $\begin{array}{l}\text { DTN: LB03033DSSFF9I.001 } \\
\text { [DIRS 163047] } \\
\text { File xcheckutil.tar.gz must be } \\
\text { unzipped. One of the extracted } \\
\text { files is REPO_ZONE.cell. This } \\
\text { file provides a list of repository } \\
\text { zone elements. }\end{array}$ & $\begin{array}{l}\text { Repository Element Names } \\
\text { The repository element names are used to extract } \\
\text { the fluxes over the repository area from } \\
\text { DTN: LB0302PTNTSW9I.001 [DIRS 162277]. } \\
\text { Only the repository fluxes are needed for seepage } \\
\text { abstraction. }\end{array}$ \\
\hline 20 & $\begin{array}{l}\text { Flow Focusing } \\
\text { Factor Distribution }\end{array}$ & $\begin{array}{l}\text { DTN: LB0406U0075FCS.002 } \\
\text { [DIRS 170712] } \\
\text { File LB0406U0075FCS.002 } \\
\text { must be unzipped. One of the } \\
\text { files opening in folder } \\
\text { DTNSubmision is the Excel } \\
\text { spreadsheet } \\
\text { Summary_CFC_2000Rocks.xIs. } \\
\text { The text section in cell A1 gives } \\
\text { the polynomial regression } \\
\text { curve. }\end{array}$ & $\begin{array}{l}\text { Flow Focusing Factor } \\
\text { Cumulative probability distribution of flow focusing } \\
\text { factors is given as a regression curve, derived } \\
\text { from a stochastic modeling analysis of a vertical } \\
\text { cross-section of Yucca Mountain. Derivation of } \\
\text { this probability distribution is explained in BSC } \\
\text { (2004 [DIRS 167652]). }\end{array}$ \\
\hline 21 & $\begin{array}{l}\text { Degraded Drift } \\
\text { Profiles }\end{array}$ & $\begin{array}{l}\text { DTN: MO0306MWDDPPDR.000 } \\
\text { [DIRS 164736] } \\
\text { Depending on which scenario } \\
\text { number is considered, a file } \\
\text { named scenarioNN.zip must be } \\
\text { unzipped (NN is the number). A } \\
\text { directory opens containing an } \\
\text { eps plot file with a figure of the } \\
\text { drift profile. }\end{array}$ & $\begin{array}{l}\text { Degraded Profiles for Several Scenarios } \\
\text { Drift profiles have been calculated for several } \\
\text { scenarios, such as from thermal stresses, seismic } \\
\text { events, and reduction in rock strength. The drift } \\
\text { degradation analysis is documented in BSC (2004 } \\
\text { [166107]). }\end{array}$ \\
\hline
\end{tabular}




\subsection{CRITERIA}

The licensing criteria for postclosure performance assessment are stated in 10 CFR 63 [DIRS 156605] (Requirements for Performance Assessment). The requirements to be satisfied by TSPA are identified in the Yucca Mountain Project Requirements Document (Canori and Leitner 2003 [DIRS 166275], Section 3). The acceptance criteria that will be used by the Nuclear Regulatory Commission (NRC) to determine whether the technical requirements have been met are identified in the Yucca Mountain Review Plan, Final Report (YMRP) (NRC 2003 [DIRS 163274]). Seepage abstraction is based on the current understanding of flow paths in the unsaturated zone (UZ) at Yucca Mountain to provide information about the quantity of water seeping into drifts and potentially contacting waste packages. Thus, the abstraction must meet acceptance criteria in Section 2.2.1.3.6.3, Flow Paths in the UZ, and in Section 2.2.1.3.3.3, Quantity and Chemistry of Water Contacting Engineered Barriers and Waste Forms, of the YMRP (NRC 2003 [DIRS 163274]). Each of these criteria has several subsidiary criteria, not all of which are applicable to seepage abstractions. The pertinent requirements and acceptance criteria (including subcriteria) for this model report are summarized in Table 4.2-1. Section 8.3 provides cross-references to demonstrate how this model report has addressed the acceptance criteria.

Table 4.2-1. Project Requirements and YMRP Acceptance Criteria Applicable to This Model Report

\begin{tabular}{|c|c|c|c|}
\hline $\begin{array}{c}\text { Requirement } \\
\text { Number }^{\mathrm{a}}\end{array}$ & Requirement Title $^{a}$ & 10 CFR 63 Link & YMRP Acceptance Criteria \\
\hline PRD-002/T-015 & $\begin{array}{l}\text { Requirements for } \\
\text { Performance Assessment }\end{array}$ & $\begin{array}{l}10 \text { CFR } 63.114 \\
(a-c, e, g)\end{array}$ & $\begin{array}{l}\text { Criteria } 1 \text { to } 5 \text { for Quantity and Chemistry of } \\
\text { Water Contacting Engineered Barriers and } \\
\text { Waste Forms }{ }^{\mathrm{b}} \\
\text { Criteria } 1 \text { to } 5 \text { for Flow Paths in the } \\
\text { Unsaturated Zone }{ }^{\mathrm{c}} \text {. }\end{array}$ \\
\hline
\end{tabular}

${ }^{a}$ from Canori and Leitner (2003 [DIRS 166275], Section 3)

${ }^{\mathrm{b}}$ from NRC (2003 [DIRS 163274], Section 2.2.1.3.3.3)

${ }^{\mathrm{c}}$ from NRC (2003 [DIRS 163274], Section 2.2.1.3.6.3)

The acceptance criteria identified in Sections 2.2.1.3.3.3 and 2.2.1.3.6.3 of the YMRP (NRC 2003 [DIRS 163274]) are listed below (text extracted from YMRP without changes). In cases where subsidiary criteria are provided in the YMRP for a given criterion, only the subsidiary criteria addressed by this model report are listed below. Explanation of how this report meets the acceptance criteria below is given in Section 8.3.

\section{Acceptance Criteria from Section 2.2.1.3.3.3, Quantity and Chemistry of Water Contacting} Engineered Barriers and Waste Forms.

Acceptance Criterion 1: System Description and Model Integration Are Adequate.

(1) Total system performance assessment adequately incorporates important design features, physical phenomena, and couplings, and uses consistent and appropriate assumptions throughout the quantity and chemistry of water contacting engineered barriers and waste forms abstraction process;

(2) The abstraction of the quantity and chemistry of water contacting engineered barriers and waste forms uses assumptions, technical bases, data, and models that are 
appropriate and consistent with other related U.S. Department of Energy abstractions. For example, the assumptions used for the quantity and chemistry of water contacting engineered barriers and waste forms are consistent with the abstractions of “Degradation of Engineered Barriers” (Section 2.2.1.3.1); “Mechanical Disruption of Engineered Barriers” (Section 2.2.1.3.2); "Radionuclide Release Rates and Solubility Limits" (Section 2.2.1.3.4); "Climate and Infiltration" (Section 2.2.1.3.5); and "Flow Paths in the Unsaturated Zone” (Section 2.2.1.3.6). The descriptions and technical bases provide transparent and traceable support for the abstraction of quantity and chemistry of water contacting engineered barriers and waste forms;

(4) Spatial and temporal abstractions appropriately address physical couplings (thermal-hydrologic-mechanical-chemical). For example, the U.S. Department of Energy evaluates the potential for focusing of water flow into drifts, caused by coupled thermal-hydrologic-mechanical-chemical processes;

(5) Sufficient technical bases and justification are provided for total system performance assessment assumptions and approximations for modeling coupled thermal-hydrologic-mechanical-chemical effects on seepage and flow, the waste package chemical environment, and the chemical environment for radionuclide release. The effects of distribution of flow on the amount of water contacting the engineered barriers and waste forms are consistently addressed, in all relevant abstractions;

(8) Adequate technical bases are provided, including activities such as independent modeling, laboratory or field data, or sensitivity studies, for inclusion of any thermal-hydrologic-mechanical-chemical couplings and features, events, and processes;

(9) Performance-affecting processes that have been observed in thermal-hydrologic tests and experiments are included into the performance assessment. For example, the U.S. Department of Energy either demonstrates that liquid water will not reflux into the underground facility or incorporates refluxing water into the performance assessment calculation, and bounds the potential adverse effects of alteration of the hydraulic pathway that result from refluxing water; and

(12) Guidance in NUREG-1297 (Altman et al. 1988 [DIRS 103597]) and NUREG-1298 (Altman et al. 1988 [DIRS 103750]), or other acceptable approaches for peer review and data qualification is followed.

Acceptance Criterion 2: Data are Sufficient for Model Justification.

(1) Geological, hydrological, and geochemical values used in the license application are adequately justified. Adequate description of how the data were used, interpreted, and appropriately synthesized into the parameters is provided;

(2) Sufficient data were collected on the characteristics of the natural system and engineered materials to establish initial and boundary conditions for conceptual 
models of thermal-hydrologic-mechanical-chemical coupled processes, that affect seepage and flow and the engineered barrier chemical environment; and

(3) Thermo-hydrologic tests were designed and conducted with the explicit objectives of observing thermal-hydrologic processes for the temperature ranges expected for repository conditions and making measurements for mathematical models. Data are sufficient to verify that thermal-hydrologic conceptual models address important thermal-hydrologic phenomena.

Acceptance Criterion 3: Data Uncertainty is Characterized and Propagated Through the Model Abstraction.

(1) Models use parameter values, assumed ranges, probability distributions, and bounding assumptions that are technically defensible, reasonably account for uncertainties and variabilities, and do not result in an under-representation of the risk estimate;

(2) Parameter values, assumed ranges, probability distributions, and bounding assumptions used in the total system performance assessment calculations of quantity and chemistry of water contacting engineered barriers and waste forms are technically defensible and reasonable, based on data from the Yucca Mountain region (e.g., results from large block and drift-scale heater and niche tests), and a combination of techniques that may include laboratory experiments, field measurements, natural analog research, and process-level modeling studies;

(3) Input values used in the total system performance assessment calculations of quantity and chemistry of water contacting engineered barriers (e.g., drip shield and waste package) are consistent with the initial and boundary conditions and the assumptions of the conceptual models and design concepts for the Yucca Mountain site. Correlations between input values are appropriately established in the U.S. Department of Energy total system performance assessment. Parameters used to define initial conditions, boundary conditions, and computational domain in sensitivity analyses involving coupled thermal-hydrologic-mechanical-chemical effects on seepage and flow, the waste package chemical environment, and the chemical environment for radionuclide release, are consistent with available data. Reasonable or conservative ranges of parameters or functional relations are established; and

(4) Adequate representation of uncertainties in the characteristics of the natural system and engineered materials is provided in parameter development for conceptual models, process-level models, and alternative conceptual models. The U.S. Department of Energy may constrain these uncertainties using sensitivity analyses or conservative limits. For example, the U.S. Department of Energy demonstrates how parameters used to describe flow through the engineered barrier system bound the effects of backfill and excavation-induced changes. 
Acceptance Criterion 4, Model Uncertainty is Characterized and Propagated Through the Model Abstraction.

(1) Alternative modeling approaches of features, events, and processes are considered and are consistent with available data and current scientific understanding, and the results and limitations are appropriately considered in the abstraction;

(2) Alternative modeling approaches are considered and the selected modeling approach is consistent with available data and current scientific understanding. A description that includes a discussion of alternative modeling approaches not considered in the final analysis and the limitations and uncertainties of the chosen model is provided;

(3) Consideration of conceptual model uncertainty is consistent with available site characterization data, laboratory experiments, field measurements, natural analog information and process-level modeling studies; and the treatment of conceptual model uncertainty does not result in an under-representation of the risk estimate;

(4) Adequate consideration is given to effects of thermal-hydrologic-mechanical-chemical coupled processes in the assessment of alternative conceptual models. These effects may include: (i) thermal-hydrologic effects on gas, water, and mineral chemistry; (ii) effects of microbial processes on the engineered barrier chemical environment and the chemical environment for radionuclide release; (iii) changes in water chemistry that may result from the release of corrosion products from the engineered barriers and interactions between engineered materials and ground water; and (iv) changes in boundary conditions (e.g., drift shape and size) and hydrologic properties, relating to the response of the geomechanical system to thermal loading; and

(5) If the U.S. Department of Energy uses an equivalent continuum model for the total system performance assessment abstraction, the models produce conservative estimates of coupled thermal-hydrologic-mechanical-chemical processes on calculated compliance with the postclosure public health and environmental standards.

\section{Acceptance Criterion 5: Model Abstraction Output is Supported by Objective Comparisons.}

(1) The models implemented in this total system performance assessment abstraction provide results consistent with output from detailed process-level models and/or empirical observations (laboratory and field testings and/or natural analogs);

(2) Abstracted models for coupled thermal-hydrologic-mechanical-chemical effects on seepage and flow and the engineered barrier chemical environment, as well as on the chemical environment for radionuclide release, are based on the same assumptions and approximations demonstrated to be appropriate for process-level models or closely analogous natural or experimental systems. For example, abstractions of processes, such as thermally induced changes in hydrological properties, or estimated diversion of percolation away from the drifts, are adequately justified by comparison to results of process-level modeling, that are consistent with direct observations and field studies; and 
(3) Accepted and well-documented procedures are used to construct and test the numerical models that simulate coupled thermal-hydrologic-mechanical-chemical effects on seepage and flow, engineered barrier chemical environment, and the chemical environment for radionuclide release. Analytical and numerical models are appropriately supported. Abstracted model results are compared with different mathematical models, to judge robustness of results.

\section{Acceptance Criteria from Section 2.2.1.3.6.3, Flow Paths in the Unsaturated Zone}

Acceptance Criterion 1: System Description and Model Integration Are Adequate.

(1) The total system performance assessment adequately incorporates, or bounds, important design features, physical phenomena, and couplings, and uses consistent and appropriate assumptions throughout the flow paths in the unsaturated zone abstraction process. Couplings include thermal-hydrologic-mechanical-chemical effects, as appropriate;

(2) The aspects of geology, hydrology, geochemistry, physical phenomena, and couplings that may affect flow paths in the unsaturated zone are adequately considered. Conditions and assumptions in the abstraction of flow paths in the unsaturated zone are readily identified and consistent with the body of data presented in the description;

(3) The abstraction of flow paths in the unsaturated zone uses assumptions, technical bases, data, and models that are appropriate and consistent with other related U.S. Department of Energy abstractions. For example, the assumptions used for flow paths in the unsaturated zone are consistent with the abstractions of quantity and chemistry of water contacting waste packages and waste forms, climate and infiltration, and flow paths in the saturated zone (Sections 2.2.1.3.3, 2.2.1.3.5, and 2.2.1.3.8 of the Yucca Mountain Review Plan, respectively). The descriptions and technical bases are transparent and traceable to site and design data;

(5) Sufficient data and technical bases to assess the degree to which features, events, and processes have been included in this abstraction are provided;

(6) Adequate spatial and temporal variability of model parameters and boundary conditions are employed in process-level models to estimate flow paths in the unsaturated zone, percolation flux, and seepage flux;

(7) Average parameter estimates used in process-level models are representative of the temporal and spatial discretizations considered in the model; and

(9) Guidance in NUREG-1297 (Altman et al. 1988 [DIRS 103597]) and NUREG-1298 (Altman et al. 1988 [DIRS 103750]), or other acceptable approaches for peer review and data qualification is followed. 


\section{Acceptance Criterion 2: Data Are Sufficient for Model Justification.}

(1) Hydrological and thermal-hydrological-mechanical-chemical values used in the license application are adequately justified. Adequate descriptions of how the data were used, interpreted, and appropriately synthesized into the parameters are provided;

(2) The data on the geology, hydrology, and geochemistry of the unsaturated zone, are collected using acceptable techniques;

(3) Estimates of deep-percolation flux rates constitute an upper bound, or are based on a technically defensible unsaturated zone flow model that reasonably represents the physical system. The flow model is calibrated, using site-specific hydrologic, geologic, and geochemical data. Deep-percolation flux is estimated, using the appropriate spatial and temporal variability of model parameters, and boundary conditions that consider climate-induced change in soil depths and vegetation;

(4) Appropriate thermal-hydrologic tests are designed and conducted, so that critical thermal-hydrologic processes can be observed, and values for relevant parameters estimated;

(5) Sensitivity or uncertainty analyses are performed to assess data sufficiency, and verify the possible need for additional data;

(6) Accepted and well-documented procedures are used to construct and calibrate numerical models; and

(7) Reasonably complete process-level conceptual and mathematical models are used in the analyses. In particular: (i) mathematical models are provided that are consistent with conceptual models and site characteristics; and (ii) the robustness of results from different mathematical models is compared;

Acceptance Criterion 3: Data Uncertainty is Characterized and Propagated Through the Model Abstraction.

(1) Models use parameter values, assumed ranges, probability distributions, and bounding assumptions that are technically defensible, reasonably account for uncertainties and variabilities, and do not result in an under-representation of the risk estimate;

(2) The technical bases for the parameter values used in this abstraction are provided;

(3) Possible statistical correlations are established between parameters in this abstraction. An adequate technical basis or bounding argument is provided for neglected correlations;

(4) The initial conditions, boundary conditions, and computational domain used in sensitivity analyses and/or similar analyses are consistent with available data. Parameter values are consistent with the initial and boundary conditions and the assumptions of the conceptual models for the Yucca Mountain site; 
(5) Coupled processes are adequately represented; and

(6) Uncertainties in the characteristics of the natural system and engineered materials are considered.

Acceptance Criterion 4: Model Uncertainty is Characterized and Propagated Through the Model Abstraction.

(1) Alternative modeling approaches of features, events, and processes, consistent with available data and current scientific understanding, are investigated. The results and limitations are appropriately considered in the abstraction;

(2) The bounds of uncertainty created by the process-level models are considered in this abstraction; and

(3) Consideration of conceptual model uncertainty is consistent with available site characterization data, laboratory experiments, field measurements, natural analog information and process-level modeling studies; and the treatment of conceptual model uncertainty does not result in an under-representation of the risk estimate;

Acceptance Criterion 5: Model Abstraction Output Is Supported by Objective Comparisons.

(1) The models implemented in this total system performance assessment abstraction provide results consistent with output from detailed process-level models and/or empirical observations (laboratory and field testing and/or natural analogs);

(2) Abstractions of process-level models conservatively bound process-level predictions; and

(3) Comparisons are provided of output of abstracted model of flow paths in the unsaturated zone with outputs of sensitivity studies, detailed process-level models, natural analogs, and empirical observations, as appropriate.

\subsection{CODES, STANDARDS, AND REGULATIONS}

No codes, standards, and regulations, other than those identified in Project Requirements Documents (Canori and Leitner 2003 [DIRS 166275]) and determined to be applicable in Table 4.2-1, were used in this model report. 


\section{ASSUMPTIONS}

No assumptions pertain directly to this seepage abstraction model. However, several assumptions pertain to the upstream analyses that provide input information to the seepage abstraction model. These assumptions are explained and justified in the following model reports:

- Seepage Calibration Model and Seepage Testing Data (BSC 2004 [DIRS 171764], Section 5)

- Seepage Model for PA Including Drift Collapse (BSC 2004 [DIRS 167652], Section 5)

- Drift-Scale Coupled Processes (DST and TH Seepage) Models (BSC 2004 [DIRS 170338], Section 5)

- Drift-Scale THM Model (BSC 2004 [DIRS 169864], Section 5)

- Drift-Scale THC Seepage Model (BSC 2004 [DIRS 169856], Section 5). 


\section{INTENTIONALLY LEFT BLANK}




\section{MODEL DISCUSSION}

\subsection{INTRODUCTION}

\subsubsection{Objectives}

Drift seepage refers to the flow of liquid water into waste emplacement drifts. Water that seeps into drifts may contact waste packages and potentially mobilize radionuclides, and may result in advective transport of radionuclides through breached waste packages (BSC 2003 [DIRS 168796], Section 3.3.2). Therefore, a calculation of the amount and distribution of seepage is included in the TSPA-LA. The objective of this model report is to synthesize and simplify the relevant input for the seepage calculations to be conducted in the TSPA-LA. This input stems from several different sources, such as drift- and site-scale simulation models, as well as from in situ testing conducted in the unsaturated zone (UZ) at Yucca Mountain.

Seepage is treated as a stochastic process in the TSPA-LA simulations (Total System Performance Assessment (TSPA) Model/Analysis for the License Application, BSC 2004 [DIRS 168504], Section 6.3.3.1). It is recognized that the amount of seepage is sensitive to key hydrological parameters that are both spatially variable and uncertain. One of the main tasks of this model report is therefore to define appropriate probability distributions that represent this spatial variability and uncertainty in a cautiously realistic manner. Using these distributions in the Monte Carlo analysis, the probability of seepage will be calculated in the TSPA-LA simulations under explicit consideration of spatial variability and uncertainty. Note that some of the probabilities needed for the TSPA-LA seepage calculation are defined in other documents that feed directly into the TSPA-LA. These include, for example, the occurrence probabilities of seismic events or the likelihood of alternative infiltration scenarios. The seepage abstraction model developed in this model report provides the necessary input so that these cases can be included in the TSPA seepage calculations, but it does not provide the associated probabilities of these cases.

The TSPA calculations use seepage look-up tables that provide the seepage rate (and related estimation uncertainty) as a function of key hydrological properties (capillary strength, permeability, and percolation flux). These look-up tables have been developed from modeling results of the predictive Seepage Model for Performance Assessment (SMPA), as described in BSC (2004 [DIRS 167652]), for both nondegraded and for collapsed drifts (a possible result of seismic events). Since the SMPA accounts for seepage at ambient and somewhat idealized conditions, the SMPA results may need to be adjusted for the impact of additional factors. These factors include thermal perturbation in response to the heat emitted from the radioactive waste, transient changes in rock properties as a result of mechanical and chemical processes, and impact of rock bolts providing potential pathways for seepage. Based on scientific analyses from several sources, the seepage abstraction model considers the relative importance of these factors and develops appropriate and realistic methods for incorporating them into the TSPA-LA simulations.

It is the nature of each probabilistic approach that it includes events, processes, and parameters that have a small probability and may even be considered as "extreme" cases compared to the "reasonable” average. Independent of their small probability, such cases must be accounted for 
in the seepage abstraction model in case they have been considered relevant for and included in the TSPA calculations. For example, even though the occurrence probability of a seismic event is as small as $10^{-7}$ measured in annual probability of exceedance, it is addressed in this seepage abstraction because it is one of the seismic scenarios considered in TSPA. Another example is the probability distribution of percolation fluxes arriving at the repository horizon. The average percolation flux at Yucca Mountain is less than $10 \mathrm{~mm} /$ year, a flux value that would typically not give rise to seepage because it is below the seepage threshold value (see definition of seepage threshold in Section 6.1.3). However, the maximum percolation fluxes may be much higher at certain emplacement locations (as a result of spatial variability over the repository horizon and/or future climate changes), which is reflected in the fact that the respective probability distribution allows for fluxes up to $1,000 \mathrm{~mm} /$ year. Since the potential for seepage increases with percolation flux, the high end of the distribution may be most relevant for TSPA, although the probability of such high fluxes is small. As a result, the seepage abstraction model and its supporting process models need to make sure that such high-end parameter ranges are adequately covered. This means that not just the reasonable mean cases need to be addressed, but also some rather "extreme" choices that are associated with very small probabilities.

The abstraction model is an extension of the previous seepage abstraction model (CRWMS M\&O 2001 [DIRS 154291]) that was developed for earlier performance assessments of the Yucca Mountain site. Since then, new data analyses and modeling results have become available. As a result, the abstraction model has been substantially revised. Major revisions include the incorporation of new seepage calibration data and new predictive modeling results from the SMPA (Sections 6.4.1 and 6.4.2), improved treatment of seepage during the period of thermally perturbed flow conditions (Section 6.4.3), disposition of mechanical and chemical alterations based on process models (Section 6.4.4), new probability distributions for variability and uncertainty (Sections 6.6.2, 6.6.3, and 6.6.4), and a revised concept for flow focusing (Section 6.6.5.2).

\subsubsection{Roadmap of Section 6}

The following sections describe the development of the abstraction model for seepage of water into emplacement drifts. Sections 6.1.3 through 6.1.6 below provide definitions of seepage properties, barriers, relevant scales, and uncertainties. Section 6.1.7 lists the scientific notebooks that provide additional details supporting the abstraction model. In Section 6.2, seepage-related features, events, and processes (FEPs) are evaluated, and relevant sections of this AMR are identified. Section 6.3 describes basic processes and factors that can be important for seepage. In Section 6.4, several drift-scale process models used in the abstraction are introduced and main results are presented. The seepage abstraction methodology, developed mainly from these model results, is explained in detail in Section 6.5. Probability distributions covering spatial variability and uncertainty in relevant parameters for seepage are generated in Section 6.6. A summary of the proposed seepage abstraction methodology is provided in Section 6.7. Finally, using the proposed abstraction methodology and the probability distributions for seepage-relevant parameters, a stochastic Monte Carlo analysis is conducted to illustrate the probability for seepage into the waste emplacement drifts at Yucca Mountain, in Section 6.8. 


\subsubsection{Definition of Seepage Properties}

Seepage is defined as flow of liquid water from the surrounding porous or fractured medium into an underground opening such as a niche or a waste emplacement drift. According to this definition, seepage does not include advective or diffusive vapor flow into the opening or condensation of water vapor on surfaces, which may lead to drop formation and drop detachment. Issues related to in-drift flux of vapor and related condensation processes are analyzed and abstracted in the In-Drift Natural Convection and Condensation Model report (BSC 2004 [DIRS 164327]). In collapsed drifts, where the initial drift opening is filled with rubble, seepage is defined as the flow of water from the fractured formation into the rubble-filled drift.

Thermal seepage refers to the seepage of water during the time period when water flow processes in the drift vicinity are perturbed from heating of the rock.

Seepage flux is the amount of water seeping into the opening per unit of time per unit area.

Seepage rate is the amount of water seeping into the opening per unit of time. A 5.1-meter long drift section (the approximate length of a waste package plus the 0.1-meter spacing between waste packages (BSC 2004 [DIRS 169472] and BSC 2004 [DIRS 168489])) is used as the reference scale for calculating the seepage rate. Thus, the seepage rate refers to seepage per time and waste package.

Seepage percentage is defined as the ratio of seepage rate divided by percolation rate across the reference area multiplied by 100 . The reference area is given by the footprint area of a 5.1-meter long drift section.

Seepage threshold is defined here as the critical percolation flux below which no seepage occurs, i.e., all percolating water is diverted around the opening, evaporates, or flows along the drift surface as a thin water film.

Seepage fraction is defined as the fraction of waste packages affected by seepage. This is equivalent to the fraction of 5.1-meter long drift sections that exhibit a nonzero seepage percentage.

\subsubsection{Definition of Barriers}

The surficial soils and topography, the volcanic units overlying the repository, and the volcanic units below the repository are natural barriers to flow and transport in the UZ. The work described in this model report analyzes one of the barrier functions associated with the upper natural barrier, i.e., to reduce the amount of water entering emplacement drifts (seepage). This barrier function is considered to be brought about by two natural processes, which are (1) capillary forces holding water in the fractured rock around drifts, and (2) reduction of flow towards drifts as a result of vaporization. While these two processes are not barriers in the terminology of LA, they are referred to in this abstraction report as (1) capillary barrier and (2) vaporization barrier, respectively. 


\subsubsection{Definition of Spatial Scales}

The seepage abstraction model utilizes simulation results from UZ process models that represent different spatial model scales. These relevant model scales for seepage abstraction are defined as follows:

\section{Drift-Scale Model:}

Model that focuses on the processes occurring in the vicinity of waste emplacement drifts. A typical model domain includes appropriate rock portions covering a few drift diameters. The discretization in the drift vicinity is relatively fine (having model elements considerably smaller than the drift diameter), while the geometry of the drift is explicitly accounted for in the model discretization.

Site-Scale Model:

Model that represents the entire UZ at Yucca Mountain extending from the ground surface to the water table, including relevant stratigraphic units and major faults. Due to the size of the model domain, explicit consideration of individual drifts is not taken into account in site-scale models.

Abstraction needs to consider spatial variability in properties and processes that occur on different spatial scales. The relevant heterogeneity scales for seepage abstraction are defined as follows:

\section{Small-Scale Heterogeneity:}

Heterogeneity on a resolution much smaller than the drift diameter. An example is the small-scale variability of fracture permeability (resolution of about $0.3 \mathrm{~m}$ ) considered in the seepage process models.

Intermediate-Scale Heterogeneity:

Heterogeneity on a resolution similar to the drift diameter. An example is the spatial distribution of the calibrated capillary-strength parameter used in the drift-scale seepage models throughout different sections of the repository.

\section{Large-Scale Heterogeneity:}

Heterogeneity on a resolution much larger than the drift diameter. In this model report, large-scale variability refers to the variability between the different stratigraphic units at Yucca Mountain, which is explicitly accounted for by considering separate rock property sets for each unit. (Intermediate-scale heterogeneity, on the other hand, is heterogeneity within stratigraphic units, on a drift-scale model resolution.)

\subsubsection{Definition of Uncertainty and Spatial Variability}

Seepage is treated by probabilistic methods in this model abstraction. Probabilistic methods need to account for the variability and uncertainty of parameters (BSC 2002 [DIRS 158794], Section 4.1):

- Variability, also referred to as aleatory uncertainty, arises because of natural randomness or heterogeneity. This type of uncertainty cannot be reduced through further testing and 
data collection; it can only be better characterized. Thus, this type of uncertainty is also referred to as irreducible uncertainty. It is typically accounted for using geostatistical approaches, e.g., using appropriate probability distribution functions.

- Uncertainty, also referred to as epistemic uncertainty, arises from lack of knowledge about a parameter, because the data are limited or there are alternative interpretations of the available data. This type of uncertainty can be reduced because the state of knowledge can be improved by further analysis, testing, or data collection. As a consequence, this type of uncertainty is also referred to as reducible uncertainty.

In this model report, the term variability is used for aleatory uncertainty, and the term uncertainty is used for epistemic uncertainty.

Uncertainty may have different sources as follows, depending on the respective method of deriving the parameter in question (e.g., derived from measurements, analyses, or models):

- Measurement uncertainty refers to the exactness of the actual measurement method and related data processing.

- Spatial variability uncertainty refers to the uncertainty in parameters describing the spatial variability of data, typically arising from the limited number of samples.

- Conceptual model uncertainty arises when the most appropriate conceptual model for a system is uncertain.

- Estimation uncertainty arises if the resulting parameter is estimated from a random process (e.g., from noisy data or from a Monte Carlo analysis), giving a range of possible results.

\subsubsection{Scientific Notebooks}

The scientific notebooks listed in Table 6.1-1 provide details supporting the abstraction model developed in this model report.

Table 6.1-1. Scientific Notebook

\begin{tabular}{|l|l|l|l|}
\hline $\begin{array}{c}\text { Lawrence Berkeley National } \\
\text { Laboratory (LBNL) Scientific } \\
\text { Notebook ID }\end{array}$ & \multicolumn{1}{|c|}{$\begin{array}{c}\text { M\&O Scientific } \\
\text { Notebook ID }\end{array}$} & \multicolumn{1}{c|}{ Relevant Pages } & \multicolumn{1}{c|}{ Citation } \\
\hline YMP-LBNL-JTB-2 & SN-LBNL-SCI-231-V1 & $1-146$ & Birkholzer 2003 [DIRS 164526] \\
\hline YMP-LBNL-JTB-3 & SN-LBNL-SCI-231-V2 & $1-142$ & Birkholzer 2003 [DIRS 164525] \\
\hline YMP-LBNL-JTB-4 & SN-LBNL-SCI-231-V3 & $1-48$ & Wang 2003 [DIRS 163702] \\
\hline YMP-LBNL-JTB-4 & SN-LBNL-SCI-231-V3 & $54-93$ & Wang 2003 [DIRS 165552] \\
\hline YMP-LBNL-JTB-4 & SN-LBNL-SCI-231-V3 & $98-118$ & Wang 2004 [DIRS 170994] \\
\hline
\end{tabular}




\subsection{FEATURES, EVENTS, AND PROCESSES}

The following Table 6.2-1 provides a list of relevant FEPs taken from the LA FEP List (DTN: MO0407SEPFEPLA.000 [DIRS 170760]. The selected FEPs are those taken from the LA FEP list that are associated with the subject matter of this report. Table 6.2-1 also gives the cross-reference for each FEP to the relevant sections of this report. With the exception of FEP 2.2.10.03.0B, the FEPs listed in Table 6.2-1 are consistent with the FEPs listed in Table 2.1.5-1 of the technical work plan TWP-MGR-HS-000001 REV 00 (BSC 2004 [DIRS 169654], Section 2.1.5, Table 2.1.5-1).

The results of this and other model reports are used to provide or document the technical basis for the include/exclude status of these FEPs for TSPA-LA. In addition to the included FEPs in Table 6.2-1, Table 6.2-2 lists the excluded FEPs 1.1.01.01.0B, 2.1.09.12.0A, 2.2.01.02.0A, and 2.2.10.04.0A that are addressed in this report. All seepage-related FEPs are documented in the UZ FEP report (BSC 2004 [DIRS 170012]). The results of this model report, as given in the DTNs listed in Sections 8.2 and 9.4, also support the analysis of post-seismic changes in the in-drift environment (BSC 2004 [DIRS 169183]), which is part of the basis for treatment of FEP 1.2.03.02.0D (Seismic-induced drift collapse alters in-drift thermohydrology) in Features, Events, and Processes: Disruptive Events (BSC 2004 [DIRS 170017]) as well as in Engineered Barrier System Features, Events, and Processes (BSC 2004 [DIRS 169898]).

Table 6.2-1. Included FEPs Addressed in This Model Report

\begin{tabular}{|c|c|c|}
\hline FEP No. & FEP Name & Relevant Section of this AMR \\
\hline 1.1.02.02.0A & Pre-closure ventilation & $\begin{array}{l}\text { Effect of preclosure ventilation on the thermal load provided to the rock - } \\
\text { Section 6.4.3.1. } \\
\text { Early dryout of near-field rock from ventilation - Section } 6.5 .2\end{array}$ \\
\hline 1.2.02.01.0A & Fractures & $\begin{array}{l}\text { Importance of fracture flow for seepage - Section } 6.3 .1 \\
\text { Fracture flow in upstream process models - Section } 6.4 \\
\text { Fracture characteristics - Section } 6.6 .1 \\
\text { Probability distributions of fracture characteristics important for seepage - } \\
\text { Sections } 6.6 .2 \text { and } 6.6 .3 \\
\text { THM and THC effects on fracture flow - Section } 6.4 .4\end{array}$ \\
\hline 1.3.01.00.0A & Climate change & Section 6.6 .5 \\
\hline 1.4.01.01.0A & $\begin{array}{l}\text { Climate modification } \\
\text { increases recharge }\end{array}$ & Section 6.6 .5 \\
\hline 2.1.08.01.0A & $\begin{array}{l}\text { Water influx at the } \\
\text { repository }\end{array}$ & Section 6.6 .5 \\
\hline 2.1.08.02.0A & $\begin{array}{l}\text { Enhanced influx at the } \\
\text { repository }\end{array}$ & $\begin{array}{l}\text { Ambient flow effects around an underground opening - Sections } 6.4 .1 \text { and } \\
6.4 .2 \\
\text { Thermal flow effects around an underground opening - Section 6.4.3 }\end{array}$ \\
\hline 2.2.01.01.0A & $\begin{array}{l}\text { Mechanical effects of } \\
\text { excavation/construc- } \\
\text { tion in the near field }\end{array}$ & $\begin{array}{l}\text { Excavation effects on air permeability data and estimated capillary-strength } \\
\text { parameter - Sections } 6.6 .2 \text { and 6.6.3 } \\
\text { THM modeling results - Sections } 6.4 .4 .1 \text { and 6.6.3.1 }\end{array}$ \\
\hline 2.2.03.01.0A & Stratigraphy & $\begin{array}{l}\text { Effects of stratigraphy on flow - Sections } 6.4 .1 .1 \text { and 6.6.5.1 } \\
\text { Discussion of lithostratigraphy of repository units }-6.6 .1 \\
\text { Statigraphy in upstream models - Sections 6.4.3.1, 6.4.4.1.1, 6.4.4.2, and } \\
\text { 6.6.5.1 }\end{array}$ \\
\hline
\end{tabular}


Table 6.2-1. FEPs Addressed in This Model Report (Continued)

\begin{tabular}{|c|c|c|}
\hline FEP No. & FEP Name & Relevant Section of this AMR \\
\hline 2.2.03.02.0A & $\begin{array}{l}\text { Rock properties of } \\
\text { host rock and other } \\
\text { units }\end{array}$ & $\begin{array}{l}\text { Physical properties of rock in upstream models - Sections } 6.4 \text { and 6.6.5.1 } \\
\text { Small-scale heterogeneity of properties - Section 6.4.1, 6.4.2, and 6.4.3 } \\
\text { Discussion of geology of repository units - 6.6.1 } \\
\text { Intermediate-scale heterogeneity of properties - Sections 6.6.2 and 6.6.3 } \\
\text { Large-scale heterogeneity of properties - Section 6.6.5.1 } \\
\text { THM and THC effects on properties - Section 6.4.4 }\end{array}$ \\
\hline 2.2.07.02.0A & $\begin{array}{l}\text { Unsaturated } \\
\text { groundwater flow in } \\
\text { the geosphere }\end{array}$ & $\begin{array}{l}\text { Groundwater flow in upstream process models - Section } 6.4 \text {. } \\
\text { Groundwater flow and ambient seepage - Section } 6.4 .2 \\
\text { Groundwater flow and thermal seepage - Section } 6.4 .3 \\
\text { Groundwater flow processes affected by THM and THC parameter alterations } \\
\text { - Sections 6.4.4.1.1 and 6.4.4.2 } \\
\text { Large-scale groundwater flow predicted by the UZ Flow Model - } \\
\text { Section 6.6.5.1 }\end{array}$ \\
\hline 2.2.07.04.0A & $\begin{array}{l}\text { Focusing of } \\
\text { unsaturated flow } \\
\text { (fingers, weeps) }\end{array}$ & $\begin{array}{l}\text { Intermediate-scale focusing of flow }- \text { Section } 6.6 .5 .2 \\
\text { Small-scale preferential flow }- \text { Sections 6.4.1.1, 6.4.2.1, and 6.4.3.1 } \\
\text { Episodic finger flow - Section 6.4.3.2 }\end{array}$ \\
\hline 2.2.07.08.0A & $\begin{array}{l}\text { Fracture flow in the } \\
\text { UZ }\end{array}$ & $\begin{array}{l}\text { Importance of fracture flow for seepage - Section } 6.3 .1 \\
\text { Fracture flow in upstream process models - Section } 6.4 \\
\text { Probability distributions of fracture characteristics important for seepage - } \\
\text { Section } 6.6 \\
\text { THM and THC effects on fracture flow - Section } 6.4 .4 \\
\text { Large-scale fracture flow - Section } 6.6 .5 .2\end{array}$ \\
\hline 2.2.07.09.0A & $\begin{array}{l}\text { Matrix imbibition in the } \\
\text { UZ }\end{array}$ & $\begin{array}{l}\text { Matrix imbibition in the drift-scale process models addressing TH, THM, and } \\
\text { THC processes - Sections 6.4.3.1, 6.4.4.1.1, and 6.4.4.2 } \\
\text { Matrix imbibition in the UZ Flow Model - Section 6.6.5.1 }\end{array}$ \\
\hline 2.2.07.10.0A & $\begin{array}{l}\text { Condensation zone } \\
\text { forms around drifts }\end{array}$ & $\begin{array}{l}\text { Impact of condensation zone on seepage - Section } 6.3 .2 \\
\text { Modeling the condensation cap with the TH Seepage Model - Section 6.4.3.3 } \\
\text { Abstraction of these processes - Section 6.5.2 }\end{array}$ \\
\hline 2.2.07.11.0A & $\begin{array}{l}\text { Resaturation of } \\
\text { geosphere dryout } \\
\text { zone }\end{array}$ & $\begin{array}{l}\text { Simulation of resaturation with TH Seepage Model - Section 6.4.3.3 } \\
\text { Abstraction of these processes - Section 6.5.2 }\end{array}$ \\
\hline 2.2.07.18.0A & $\begin{array}{l}\text { Film flow into the } \\
\text { repository }\end{array}$ & Sect \\
\hline 2.2.07.20.0A & $\begin{array}{l}\text { Flow diversion around } \\
\text { repository drifts }\end{array}$ & Sections 6.4.1, 6.4.2, and 6.4.3 \\
\hline 2.2.10.03.0B & $\begin{array}{l}\text { Natural geothermal } \\
\text { effects on flow in the } \\
\text { UZ }\end{array}$ & $\begin{array}{l}\text { Natural geothermal effects considered in TH, THM, and THC models - } \\
\text { Sections 6.4.3 and 6.4.4 } \\
\text { Natural geothermal effects not considered in ambient process models - } \\
\text { Sections 6.4.1, 6.4.2, and 6.6.5.1 }\end{array}$ \\
\hline 2.2.10.10.0A & $\begin{array}{l}\text { Two-phase buoyant } \\
\text { flow /heat pipes }\end{array}$ & $\begin{array}{l}\text { Discussion of coupled processes causing heat-pipe behavior - Section 6.3.2 } \\
\text { Simulation of heat pipe processes with TH Seepage Model - Section 6.4.3.3 } \\
\text { Abstraction of these processes - Section 6.5.2 }\end{array}$ \\
\hline $2.2 .10 .12 .0 \mathrm{~A}$ & $\begin{array}{l}\text { Geosphere dry-out } \\
\text { due to waste heat }\end{array}$ & $\begin{array}{l}\text { Simulation of dryout and resaturation with the TH Seepage Model - } \\
\text { Section 6.4.3.3 } \\
\text { Abstraction of these processes - Section 6.5.2 }\end{array}$ \\
\hline
\end{tabular}


Table 6.2-2. Excluded FEPs Addressed in This Model Report

\begin{tabular}{|c|l|l|}
\hline FEP No. & \multicolumn{1}{|c|}{ FEP Name } & \multicolumn{1}{c|}{ Relevant Section of this AMR } \\
\hline 1.1.01.01.0B & $\begin{array}{l}\text { Influx through holes } \\
\text { drilled in drift wall or } \\
\text { crown }\end{array}$ & $\begin{array}{l}\text { Impact of the presence of rock bolts - Section 6.4.2.5 } \\
\text { Abstraction of rock bolt impact - Section 6.5.1.6 }\end{array}$ \\
\hline 2.1.09.12.0A & $\begin{array}{l}\text { Rind (chemically } \\
\text { altered zone) forms in } \\
\text { the near-field }\end{array}$ & $\begin{array}{l}\text { Simulation of THC processes such as the precipitation and dissolution of } \\
\text { minerals - Section 6.4.4.2 } \\
\text { Abstraction of these THC processes - Section 6.5.1.4 }\end{array}$ \\
\hline 2.2.01.02.0A & $\begin{array}{l}\text { Thermally-induced } \\
\text { stress changes in the } \\
\text { near-field }\end{array}$ & $\begin{array}{l}\text { Simulation of impact of thermal stresses in the drift vicinity - Section 6.4.4.1. } \\
\text { Abstraction of THM processes - Section 6.5.1.4 }\end{array}$ \\
\hline $\begin{array}{l}\text { Thermo-mechanical } \\
\text { stresses alter } \\
\text { characteristics of } \\
\text { fractures near } \\
\text { repository }\end{array}$ & $\begin{array}{l}\text { Simulation of impact of thermal stresses on fracture characteristics in the drift } \\
\text { vicinity - Section 6.4.4.1. } \\
\text { Abstraction of THM processes - Section 6.5.1.4 }\end{array}$ \\
\hline
\end{tabular}

\subsection{SEEPAGE PHENOMENA AND IMPORTANT FACTORS FOR SEEPAGE}

This section explains the basic processes involved in seepage phenomena in unsaturated fractured tuff and identifies the main factors affecting seepage. The description is based on and consistent with the related discussion found in the scientific literature (see, for example, Philip et al. (1989 [DIRS 105743]); Finsterle (2000 [DIRS 151875]) and the references therein for the capillary barrier effect; Pruess et al. (1990 [DIRS 100819]) and Birkholzer and Tsang (2000 [DIRS 154608]) for TH processes). The sections below distinguish between seepage at ambient conditions (Section 6.3.1) and seepage at thermal conditions (Section 6.3.2). In the framework of seepage modeling, "ambient" conditions refer to the time period when the flow and seepage processes in the drift vicinity are not significantly influenced by thermal effects; i.e., the period that rock temperature is above boiling has ended and the local flow and saturation perturbations have mostly equilibrated. "Thermal" conditions, on the other hand, are defined as conditions where the flow and seepage processes are strongly perturbed in the drift vicinity, because boiling of water either occurs or has just recently occurred (BSC 2004 [DIRS 170338], Section 6.1.2). "Thermal" seepage refers to seepage during the time period that thermal conditions prevail. Typically, the time period with "thermal conditions" may cover the first 1,000 to 2,000 years after waste emplacement. Afterwards, rock temperatures are still higher than ambient as a result of the slow heat-transfer processes and the slow decay of the radioactive waste, but the local flow conditions are essentially back to ambient (as defined above); i.e., the fractures and the rock matrix at the drift wall have mostly resaturated to their ambient "preheating" saturation levels (see TH predictions in Section 6.4.3). These conditions can be treated as "ambient" in the seepage evaluation, as pointed out in Section 6.5.1. Additional factors for seepage (e.g., stemming from drift degradation and ground support) are briefly discussed in Section 6.3.1 below.

\subsubsection{Seepage under Ambient Conditions}

Underground openings in unsaturated rock have a tendency to divert water around them because of the capillary barrier effect at the interface between the rock and the opening. Since this effect retains the wetting fluid in the pore space, a significant fraction of the water that percolates down 
the Yucca Mountain UZ can be expected not to seep into the emplacement drifts. As a result of the capillary barrier, a boundary layer of increased saturation is expected to develop in the formation immediately adjacent to the drift (BSC 2004 [DIRS 171764], Section 6.3.1). If capillary strength and tangential permeability (i.e., permeability measured parallel to the drift wall) of the fracture network within this boundary layer are sufficiently high, all or a portion of the water is diverted around the drift under partially saturated conditions. Locally, however, the water potential in the formation may be higher than that in the drift, and then water exits the formation and enters the drift. At the drift surface, the water either evaporates, or follows the inclined, rough wall in a thin film, or forms a drop that grows and eventually detaches (Or and Ghezzehei 2000 [DIRS 144773]). Only this last mechanism-drop detachment-is considered drift seepage according to the definition in Section 6.1.3.

For an emplacement drift of given shape, the seepage threshold-and the amount of seepage once this threshold is exceeded-depend on the local flow conditions in the drift vicinity (Figure 6.3-1). These are mainly influenced by the local percolation flux reaching the drift and by the rock properties in the immediate vicinity of the opening. The capillary barrier effect occurs in a relatively thin boundary layer around the opening, with the thickness of this boundary layer approximately given by the height to which the water rises on account of capillarity. (This height can be estimated by dividing the capillary-strength parameter $1 / \alpha$ by water density and gravitational acceleration.) The key rock properties for seepage are (1) the capillary strength and (2) the tangential conductivity in the boundary layer near the drift wall. Geological formations with large capillary strength and high tangential conductivity generally exhibit zero or low seepage, whereas higher seepage is expected if the capillary strength in the formation is small or if the tangential permeability is insufficient to promote flow diversion. Thus, evaluation and description of these local rock properties are essential for seepage calculations. Because the matrix permeability is small, the tangential conductivity is governed by the properties of the fracture network. For flow diversion to occur, the fracture system must have sufficient connectivity and permeability to provide the necessary effective conductivity in the tangential direction around the drift. Small-scale heterogeneity increases the probability of locally breaching the capillary barrier, because it promotes the existence of flow channeling and local ponding (Birkholzer et al. 1999 [DIRS 105170]).

In addition to the considerable heterogeneity of seepage-relevant properties that needs to be described in appropriate spatial detail, alterations of these properties may occur with time. Initially, the undisturbed rock properties around the openings are likely to be altered as a result of stress redistribution during drift excavation, which typically leads to local opening of fractures and potentially the creation of new microfractures in the drift vicinity (BSC 2004 [DIRS 170004], Section 6.1.2.2.1; Wang and Elsworth 1999 [DIRS 104366], pp. 752-756). These changes affect porosity, permeability, and capillary strength of the fracture system in the vicinity of emplacement drifts. Later, the heat emanating from the radioactive material will induce thermal-hydrological-mechanical (THM) and thermal-hydrological-chemical (THC) property changes (see Section 6.3.2 below). For example, thermal expansion of the rock matrix induces changes in fracture apertures. Also, thermal effects lead to dissolution and precipitation of minerals, again affecting the porosity, permeability, and capillary strength of the fracture system as well as fracture-matrix interaction. The impact of these alterations needs to be assessed in the seepage abstraction model. 
Another key factor for seepage is the percolation flux arriving at the drifts. Seepage is initiated if the local percolation fluxes in individual flow channels and their accumulation near the drift ceiling exceed the diversion capacity of the capillary barrier. The fate of water percolating through the Yucca Mountain UZ and eventually encountering the immediate vicinity of a waste emplacement drift is influenced by various factors. The ultimate source of percolation flux at Yucca Mountain is net infiltration at the ground surface, stemming from precipitation events. Net infiltration is the fraction of precipitation that moves through the ground surface to a depth where the liquid water can no longer be removed by evaporation or transpiration. Net infiltration varies in space (as a result of several factors such as vegetation, morphology, and soil and bedrock conditions) and in time. Time variations are short-term as a result of daily or seasonal fluctuations and long-term as a result of climate changes. As infiltrating water percolates through the UZ, driven by gravity and capillary forces, the initial infiltration and flow patterns will change depending on the hydrogeologic properties in the UZ and their related heterogeneities. On a large scale, several stratigraphic units of volcanic rock can be distinguished at Yucca Mountain, with significant differences in fracture frequency, matrix porosity, and lithophysal characteristics. Variations between units reflect the type of volcanic eruption, the rate of cooling, and the intensity of postdepositional processes. Tilted contacts between hydrogeologic units (especially between welded and nonwelded tuffs) can divert flow laterally. Welded units typically have lower matrix porosities and high fracture densities, whereas the nonwelded and bedded tuffs have relatively high matrix porosities and lower fracture densities (Bodvarsson et al. 1999 [DIRS 120055], Section 2). These nonwelded units can dampen short-term infiltration patterns, homogenizing the unsaturated flow below them.

The repository will be located about 300 meters below the surface in the Topopah Spring welded unit (TSw). Unsaturated flow in the TSw is primarily in the fractures, because the small matrix permeability in many of the TSw subunits can support flows of only a few millimeters per year. Several subunits are defined in the TSw based on the different degrees of lithophysal content (see Section 6.6.1). According to BSC (2004 [DIRS 170040], Appendix H), where the current repository design was analyzed, the Topopah Spring Tuff lower lithophysal unit (Tptpll unit) is by far the most important unit with respect to the part of the repository located in geological units (about 80.5 percent), followed by the Topopah Spring middle nonlithophysal unit (Tptpmn unit) (about 12.4 percent). Less important are two additional geological units, the Topopah Spring Tuff upper lithophysal unit (Tptpul unit) (about 4.5 percent), and Topopah Spring Tuff lower nonlithophysal unit (Tptpln unit) (about 2.6 percent).

On an intermediate scale, there is also considerable heterogeneity within stratigraphic units. This kind of heterogeneity can focus water towards one drift location while diverting it away from another. Flow focusing and diversion of flow paths also happens within a rough-walled fracture, where asperity contacts and locally larger fracture openings lead to small-scale redistribution of water within the fracture. In addition, asperity-induced flow instabilities may cause small-scale episodic flow within fractures, as channels drain and refill repeatedly. All the above factors determining the spatial and temporal variation of local percolation flux need to be considered in seepage calculations. 


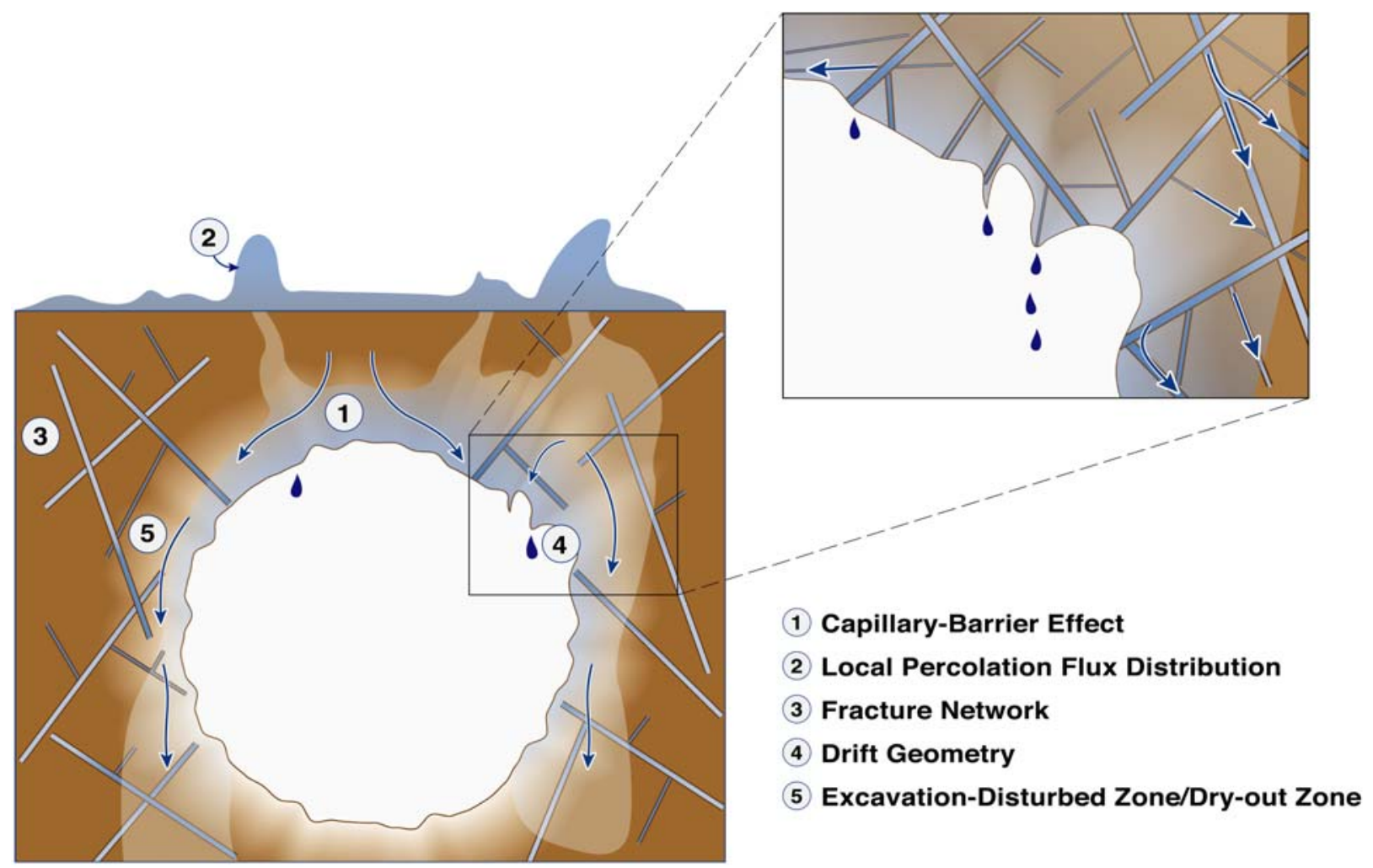

Figure 6.3-1. Schematic of Phenomena and Processes Affecting Drift Seepage

The overall drift size and geometry may also impact the seepage threshold and the seepage amount in the unsaturated fractured rock. As demonstrated by Philip et al. (1989 [DIRS 105743]) for homogeneous media, a large drift exhibits a lower seepage threshold because more water accumulates in the boundary layer as it migrates over a longer diversion distance around the wide opening. Also shown was that the effectiveness of a capillary barrier is highest if the shape of the cavity follows an equipotential surface. Parabolic cavities are more efficient in preventing seepage than circular or flat-roofed openings. Small-scale surface roughness on the drift wall tends to increase seepage because it may encourage drop detachment.

It is possible that the initially circular-shaped open emplacement drifts degrade with time as a result of thermal stress, seismic ground motion, and time-dependent degradation of rock strength. Thermal stresses are caused by the heat generated from the decaying nuclear waste. Significant stresses can also be caused by seismically related ground motion. Time-dependent degradation of rock strength (joint mechanical properties) may be a result of over-stressing from thermal heating and of static fatigue of the rock resulting from stress corrosion mechanisms. All these effects may lead to rock mass damage and rock fall in emplacement drifts, changing the drift shape and size. Depending on the type of rock, the stress conditions, and the time-dependent rock mechanical properties, damage to the drifts may be rather small, with local rock fall at the ceiling of otherwise intact drift openings, or, in extreme cases, may result in partial or complete drift collapse, with rubble rock material filling the enlarged drifts. These changes affect the potential for drift seepage. Local breakouts in the drift ceiling may lead to geometry changes (e.g., topographic lows), which can reduce or prevent flow diversion around the opening. The larger size and potentially different shape of collapsed drifts can also reduce the potential for 
flow diversion; furthermore, the larger footprint of the collapsed drift leads to an increase in the total amount of percolation flux arriving at the drifts, which in turn increases the total amount of seepage. In addition, the capillary-barrier behavior at the drift wall may be affected by the rubble rock blocks filling the opening, as the capillary strength inside the opening will be different from the zero capillary strength condition in the initially open drift. Finally, drift degradation may lead to fracture dilation or the generation of new fractures in the vicinity of emplacement drifts. Fracture dilation would increase the permeability, thereby promoting flow diversion around the drift, but at the same time decrease the fracture capillary strength, which could lead to less flow diversion around the drift. The generation of new fractures in the drift vicinity - with apertures comparable to the existing fractures - would promote flow diversion around the drift opening because of the related increase in fracture permeability, but would not affect the fracture capillary strength.

Another factor potentially affecting seepage is the ground support in the emplacement drifts. In previous repository designs, the main method of ground support for emplacement drifts at Yucca Mountain was grouted rock bolts (BSC 2001 [DIRS 155187]). Rock bolts are steel rods emplaced into a borehole normal to the drift wall (BSC 2001 [DIRS 155187], Section 6.5.1.2.2). The drift ground support system will consist of about 3-meter long rock bolts without grout (BSC 2004 [DIRS 169058]). Both main repository units, the Tptpll and Tptpmn units, will need ground support. There may be up to 10 such bolts in a drift cross section, at a spacing of about 1 meter along the drifts. Rock bolts pose a concern with respect to seepage because they may provide a direct flow conduit to the drift wall and may increase the likelihood of seepage into drifts.

\subsubsection{Thermal Seepage}

The heat generated by the decay of the radioactive waste results in rock temperatures elevated from ambient for thousands of years after emplacement. For the current repository design, these temperatures will be high enough to cause boiling conditions in the drift vicinity, giving rise to local water redistribution and altered flow paths. Key TH processes occurring around a drift are shown schematically in Figure 6.3-2, for an idealized circular-shaped drift. The figure indicates that heating of the rock causes pore water in the rock matrix to boil and vaporize. The vapor moves away from the boiling location through the permeable fracture network, driven primarily by pressure increase caused by boiling. Vapor will either flow into the open drifts, subject to in-drift convective flows along the drift axis, or will flow away from the drifts, further into the near-field rock. (Note that the fate of in-drift vapor flow is not subject of this model report. Issues related to in-drift convective processes are analyzed in the In-Drift Natural Convection and Condensation Model report (BSC 2004 [DIRS 164327]). Vapor that remains in the near-field rock will condense in the rock fractures once it reaches cooler regions away from the drift. The condensate can then drain either toward the heat source from above or away from the drift into the zone below the heat source. Condensed water can also imbibe from fractures into the matrix, leading to increased liquid saturation in the rock matrix.

With continuous heating, a superheated dryout zone may develop in the fractured rock closest to the heat source, separated from the condensation zone by a nearly isothermal zone maintained at about the boiling temperature. This nearly isothermal zone is characterized by a continuous process of boiling on the hot end (close to the heat source), vapor transport from the hot to the 
cool end, condensation at the cool end, and migration of water back towards the hot end (either by capillary forces or gravity drainage), and is often referred to as a heat pipe (Pruess et al. 1990 [DIRS 100819]). The longer the nearly isothermal temperature zone, the more intense are these two-phase circulation processes. Thus, analysis of such heat pipe signatures in temperature data can help to evaluate the intensity of heat-driven reflux processes.

For the current repository design at Yucca Mountain and average infiltration, the dryout zone around drifts will extend to a maximum distance of approximately 5 to 10 meters from the drift wall, and boiling conditions in the rock are expected to exist for hundreds to more than a thousand years after emplacement (BSC 2004 [DIRS 170338], Section 6.2; BSC 2004 [DIRS 169565], Tables 6.3-6 and 6.3-7). While these values reflect average conditions, there may be significant heterogeneity of the TH conditions within the repository. One factor causing heterogeneity is the spatial and temporal variability of the thermal load in different drift sections, stemming from heat output variation between individual waste packages and emplacement-time differences. Another factor is the variability of the formation properties and the local percolation fluxes. Thermal rock properties such as thermal conductivity directly affect the conductive transport of heat. Hydrological properties and local percolation fluxes, on the other hand, affect the significance of TH coupling as they determine the effectiveness of convective heat transport. While heat conduction is the major component of energy transport in Yucca Mountain tuff, the impact of $\mathrm{TH}$ coupling can be quite large. For example, a large percolation flux above a drift segment may cause strong heat-pipe effects that give rise to rock temperatures much lower and boiling periods much shorter than at average conditions (BSC 2004 [DIRS 170338], Section 6.2.2.1.2).

Heating of the rock in the drift vicinity can affect seepage in two different ways:

1. Boiling of rock water will directly affect the seepage-relevant flow processes close to the drift wall. For above-boiling conditions, vaporization of percolating water in the fractured rock overlying the repository provides an additional barrier to seepage. Percolating water is expected to boil off in the superheated rock zone before reaching the drift crown. Therefore, thermal seepage is unlikely as long as boiling conditions exist. On the other hand, condensed water forms a zone of elevated water saturation above the rock dryout zone. Water from this zone may be mobilized to flow rapidly down towards the drift, in particular during later heating stages when the effect of vaporization has already diminished. This flow mobilization may promote seepage.

2. Rock properties relevant for seepage may be affected by reversible and irreversible THM and THC effects. Stress-induced THM changes tend to close existing fractures, leading to a general decrease in fracture permeability and porosity, combined with an increase in fracture capillary strength. Aperture changes that occur during the thermal period could be fully reversible, meaning that these properties would recover to pre-emplacement conditions after the temperature has declined to ambient. Thermal stresses could also induce permeability enhancement through fracture shear slip with accompanying shear dilation opening. Such permeability changes would be irreversible and remain after the temperature has declined to ambient. THC processes such as mineral precipitation and dissolution in fractures and matrix also have the potential for modifying permeability, porosity, and capillary strength of the system. 
Because the molar volumes of minerals created by hydrolysis reactions (i.e., anhydrous phases, such as feldspars, reacting with aqueous fluids to form hydrous minerals, such as zeolites or clays) are commonly larger than the molar volumes of the primary reactant minerals, dissolution-precipitation reactions commonly lead to porosity (and permeability) reductions. The extent of mineral-water reaction is controlled by the surface areas of the mineral phases in contact with the aqueous fluid, as well as heterogeneity in the initial distribution of minerals in the fractures. Therefore, changes in porosity and permeability caused by these processes may also be heterogeneously distributed. Typically, THC effects on hydrological properties are irreversible.

Note that the repository drifts will be ventilated during the first 50 years after emplacement. Ventilation in the drifts will cause initial rock drying in the drift vicinity and will also remove a significant amount of heat during this preclosure period.

As mentioned in Section 6.3.1, emplacement drifts may collapse in extreme cases as a result of mechanical degradation. The thermal conditions in a collapsed drift will be different from those in an open drift, mainly because the thermal-hydrological processes in a drift filled with rubbly rock fragments are different from those in an open, gas-filled drift. The extent to which these differences can be important for thermal seepage is governed by the time at which the drift collapse occurs. Significant differences should only be expected when drift collapse occurs during the time period of strongly elevated temperatures.

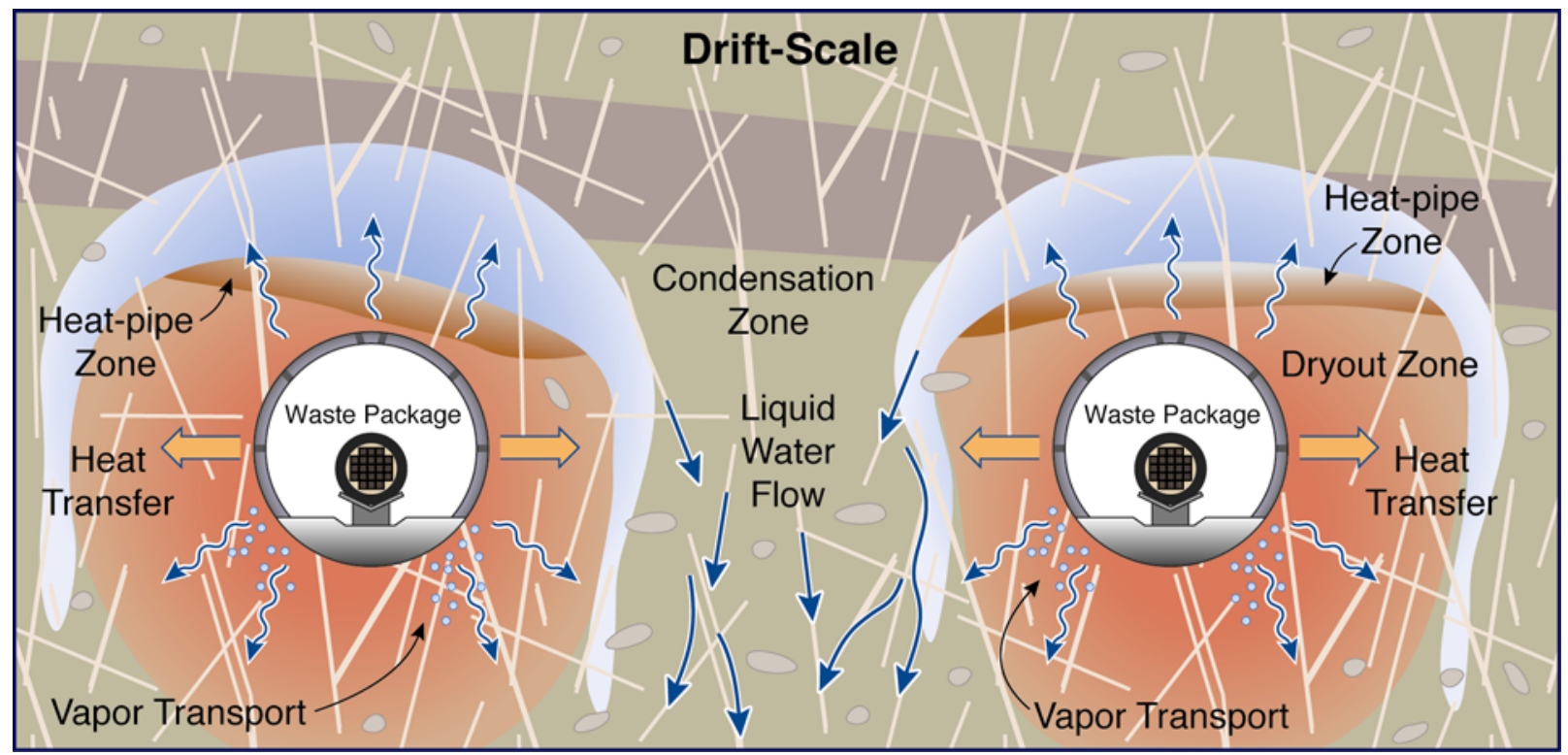

Source: Revised from BSC (2004 [DIRS 170338], Figure 6.1-1).

Figure 6.3-2. Schematic of TH Processes Occurring in the Drift Vicinity as a Result of Repository Heating (not to scale) 


\subsection{PROCESS MODELS PROVIDING INPUT TO SEEPAGE ABSTRACTION}

The seepage abstraction model uses modeling results from several upstream drift-scale process models. These process models can be categorized into (1) models that directly calculate seepage rates for a given set of seepage-relevant properties and boundary conditions, and (2) supporting models that provide information about the potential alteration of relevant properties as a result of THM and THC processes. These upstream models are introduced in the following Sections 6.4.1 through 6.4.3 (seepage process models) and 6.4 .4 (supporting models), and relevant model results are provided. Note that, if not otherwise mentioned, the modeling studies below have been conducted assuming open drifts that have not been affected by drift degradation or collapse (nondegraded drifts).

\subsubsection{Seepage Calibration Model}

The Seepage Calibration Model (SCM) provides the conceptual basis for modeling of ambient seepage processes (BSC 2004 [DIRS 171764], Section 6.3). It also provides estimates of the seepage-relevant capillary-strength parameter through calibration of the model against seepage data obtained from in situ liquid-release tests. The following sections provide a discussion on the model concept, the validation work, and results of the SCM, summarized from the more detailed description in BSC (2004 [DIRS 171764]).

\subsubsection{Model Description}

The key element of the approach chosen to simulate seepage and determine seepage-relevant parameters is to treat seepage as a stochastic process while relying on inverse modeling for the estimation of relevant parameters. Given the complexity of the seepage process in a fractured porous medium, it was recognized that (1) a detailed deterministic simulation of individual seeps is not necessary to estimate average seepage rates into waste emplacement drifts, (2) the impact of certain second-order factors affecting seepage-such as film flow along the drift surface, impact of drift wall roughness, and small-scale effects of discrete fractures terminating at the drift wall - can be lumped into an effective parameter, making explicit consideration of such factors in the model unnecessary, and (3) calibrating and validating the model against data from seepage experiments ensures that the model captures the relevant processes for ambient seepage (BSC 2004 [DIRS 171764], Section 6.3.4). Based on these considerations, the SCM was developed as a three-dimensional (3-D) drift-scale calibration model that describes the smallscale heterogeneity of the fractured rock using a stochastic continuum representation.

As explained in BSC (2004 [DIRS 171764], Section 6), the SCM model domain includes appropriate rock portions (a few meters of rock from the niche walls, see Figure 6.4-1) above and sideways of the tunnel locations where liquid-release tests have been conducted. Section 6.6.2.1 provides information on the location of these tests and briefly explain the testing procedure. Different meshes have been generated representing the different test locations and their respective shapes and test geometries in the Tptpmn and the Tptpll units. The small-scale fracture permeability variation in each test location was described using spatially correlated 


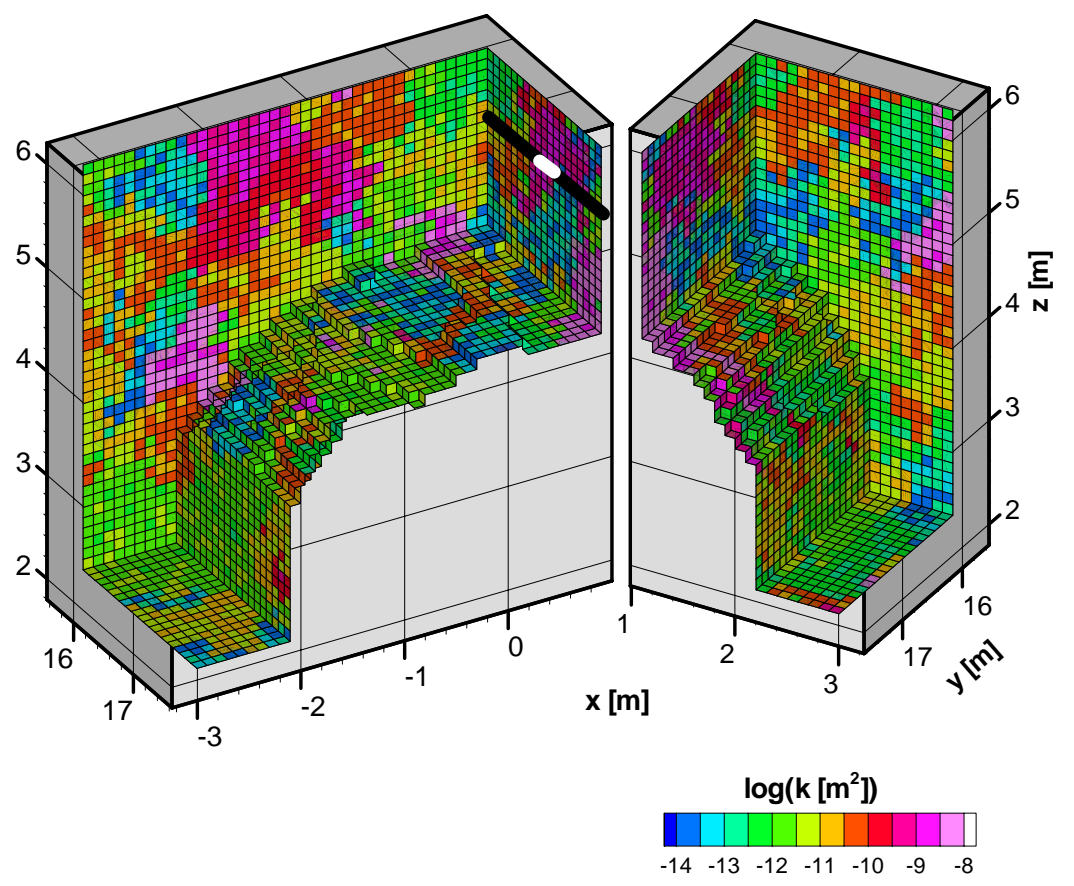

Source: BSC (2004 [DIRS 171764], Figure 6-15a).

NOTE: In this visualization, the mesh is split into two parts to expose the boreholes (indicated by thick black lines) and the injection interval (thick white line).

Figure 6.4-1. Example of Numerical Grid and Permeability Distribution Used for the SCM Simulation of Liquid-Release Tests Conducted in Niche 1620, Showing One Injection Interval in Borehole \#4

stochastic fields based on analysis of air permeability data measured at that location. These measurements were taken in close proximity to the drifts after drift excavation; thus the generated stochastic fields represent the impact of stress redistribution on permeability. The resolution of the stochastic fields is 0.1 meter, uniform in a plane orthogonal to the injection boreholes. Along the injection boreholes, the resolution is 0.3 meter, which is approximately consistent with the measurement resolution of the air-injection tests (1-foot intervals).

No attempt was made in the SCM to describe the excavation-induced alterations of rock properties in spatial detail. In general, the impact of excavation is largest immediately at the opening, and decreases with increasing distance into the rock. However, the extent of the zone affected by alterations (e.g., approximately one drift diameter) is larger than the rock portion affected by the liquid release above the niches, which approximately corresponds to the extent of the model domain. This zone is also much larger than the rather small boundary layer at the drift wall that is important for seepage-related flow processes. It is therefore appropriate for seepage models to represent the impact of excavation within the model domain with averaged excavation-disturbed properties. Thus, the stochastic permeability fields used in the SCM have a uniform mean permeability, independent of the distance to the opening.

Applying the imposed liquid-release rates of each test, inverse modeling runs were conducted with the SCM to calibrate the effective capillary-strength parameter of the fractured rock in the niche vicinity. Note that this calibrated parameter is uniform in the entire model domain; 
i.e., there is no local correlation between this parameter and the stochastically varied permeability values (BSC 2004 [DIRS 171764], Section 6.3.2). Seepage data from multiple test events in one borehole, using different liquid-release rates, were calibrated simultaneously in the inverse modeling approach. Only long-term seepage experiments were considered, where near-steady seepage rates are no longer affected by storage effects. Therefore, and because seepage processes are mainly determined by the properties of the fracture system, the SCM is a single continuum model that does not explicitly account for imbibition and flow in the rock matrix. Note that evaporation effects, stemming from forced ventilation in the Enhanced Characterization of Repository Block (ECRB) Cross Drift, were explicitly accounted for in the model (BSC 2004 [DIRS 171764], Section 6.6.1.3).

The calibrated capillary-strength parameter $1 / \alpha$ provided by the SCM is an effective process parameter for seepage that is specifically determined for its intended use in drift seepage models. This effective parameter not only represents the average capillary characteristics of the fracture network, but also accounts for seepage factors that are not explicitly implemented in the conceptual model of the SCM (BSC 2004 [DIRS 171764], Section 6.3.3). Such factors include effects from (1) small-scale roughness within individual fractures, potentially leading to preferential flow and/or high-episodicity flow, (2) individual fractures cutting into the opening, (3) small-scale surface roughness at the drift ceiling, (4) film flow within fractures and along the drift surface, (5) drop formation and detachment, and (6) fracture-aperture changes as a result of excavation effects. For the Tptpll unit, the effect of lithophysal cavities is also captured in the effective capillary-strength parameter, making the explicit representation of lithophysal cavities into the process model unnecessary. While modeling these factors is theoretically possible, the necessary characterization data needed to warrant such a detailed simulation are not available.

\subsubsection{Model Validation}

The SCM model was validated in comparison with measured data from liquid-release tests (BSC 2004 [DIRS 171764], Section 7). Observed and predicted seepage data were compared for various tests that had not been used for the calibration of the model. It was demonstrated that the calibrated model was capable of reproducing the measured seepage data. As summarized in BSC (2004 [DIRS 171764], Section 7.4), the seepage observations fell within the range of pre-test predictions of seepage rates in all test cases for the lower lithophysal zone, and in almost all test cases for the middle nonlithophysal zone. In the remaining few cases, the seepage observations were lower than the predicted seepage rates, i.e., the model prediction was providing upper bounds to the measured seepage rates. In addition, alternative conceptual models for seepage prediction at Yucca Mountain were qualitatively evaluated. The most important alternative conceptual model is a model that simulates flow through discrete fractures rather than through a stochastic continuum. This alternative, referred to as the discrete fracture network model (DFNM), is discussed in great detail in Finsterle (2000 [DIRS 151875]), and in lesser detail in BSC (2004 [DIRS 171764], Section 6.4) and BSC (2004 [DIRS 170338], Section 6.3.5). It has been concluded that the full development of a DFNM as a potential alternative to the stochastic continuum model is not feasible and not necessary, for the following reasons:

1. A continuum representation of unsaturated fracture flow is appropriate when the fracture density is high and a well-connected fracture network forms at the scale of 
interest. As evidenced in fracture mapping data from the Exploratory Studies Facility (ESF) and the ECRB, the main repository units at Yucca Mountain have a high fracture density, and these fractures form a well-connected 3-D system at the relevant scale (Section 6.6.1).

2. The development of a defensible DFNM requires collecting a very large amount of geometric and hydrological data. The databases required to develop a defensible DFNM are generally difficult or even impossible to obtain for site-specific simulations. To reduce prediction uncertainties, the DFNM must be calibrated against hydrogeologic data — an approach very similar to that used in the SCM. As a result, the cumulative effect of the input uncertainties is likely to outweigh the apparent advantage of a detailed representation of the fracture network.

3. Seepage calculations with a calibrated DFNM are likely to corroborate the results of a calibrated stochastic continuum model. For example, Finsterle (2000 [DIRS 151875]) used synthetically generated data from a model that exhibits discrete flow and seepage behavior to calibrate a simplified fracture continuum model. The calibrated continuum model was used to predict seepage rates. The extrapolated seepage predictions performed with the continuum model were consistent with the synthetically generated data from the discrete-feature model.

Three other possible alternative approaches for seepage estimation are discussed in BSC (2004 [DIRS 171764], Section 6.4): estimating seepage from the local ponding probability (Birkholzer et al. 1999 [DIRS 105170]), estimating seepage from deposition rates of calcite and opal in lithophysal cavities, and estimating the seepage threshold directly from the liquid-release tests. These approaches are not carried further for the reasons presented in BSC (2004 [DIRS 171764], Section 6.4). Nevertheless, they corroborate the general concept and the findings of the SCM.

It was concluded that the SCM provides a solid conceptual basis and sufficient characterization data for predicting seepage into waste emplacement drifts in the repository host rock (BSC 2004 [DIRS 171764], Section 8). Specific recommendations were provided concerning the use of the conceptual model in predictive seepage models such as the SMPA and the TH Seepage Model. These recommendations are as follows (BSC 2004 [DIRS 171764], Section 8.4):

1. Seepage predictions should be conducted with a process model similar to the SCM, capable of simulating unsaturated flow under viscous, capillary pressure, and gravitational forces.

2. A stochastic continuum model should be employed that captures the small-scale heterogeneity of permeability on a spatial resolution similar to the SCM.

3. The permeability values should capture the impact of excavation effects in the vicinity of the emplacement drifts.

4. The calibrated capillary-strength parameters derived from the SCM should be used for the fractured tuff in the vicinity of emplacement drifts. 
5. Several second-order factors are lumped into the effective capillary-strength parameter. These factors should not be explicitly considered in the model. (For example, small-scale roughness of the drift wall or lithophysal cavities should not be explicitly discretized.)

6. A specific boundary condition should be employed at the rock-drift interface, similar to the one chosen in the SCM.

7. Multiple prediction runs with different realizations of the underlying heterogeneous permeability field should be performed.

\subsubsection{Model Results}

The calibrated values of the effective capillary-strength parameter provided by the SCM are directly used in the seepage abstraction model. A total of 22 liquid-release tests conducted in ten test intervals at different locations along the ESF and the ECRB were used in the SCM model calibration (13 tests conducted in the Tptpll unit and 9 in the Tptpmn unit). The resulting capillary-strength parameter values and their associated estimation uncertainty, provided in DTN: LB0302SCMREV02.002 [DIRS 162273], are presented and discussed in Section 6.6.4 of BSC (2004 [DIRS 171764]). Parameter values range roughly between 400 and $800 \mathrm{~Pa}$.

Appropriate probability distributions developed in Section 6.6 of this model report cover the potential spatial variability and uncertainty of the capillary-strength parameter. A detailed discussion of the calibrated parameter values and the derived parameter distributions is presented in Section 6.6.2.

\subsubsection{Seepage Model for Performance Assessment}

The Seepage Model for Performance Assessment (SMPA) adopts the conceptual framework from the SCM to conduct systematic predictions of ambient seepage fluxes into waste emplacement drifts (BSC 2004 [DIRS 167652]). Isothermal flow simulations are performed for selected key parameters that vary over wide ranges. Results are provided in the form of a look-up table (DTN: LB0304SMDCREV2.002 [DIRS 163687]), giving seepage rates and related seepage estimation uncertainty as a function of these key parameters. Note that appropriate distributions describing the spatial variability and uncertainty of these key parameters are developed in Section 6.6 of this model report. The simulation cases studied with the SMPA sufficiently cover the parameter range defined by these distributions. The following sections provide a discussion on the model concept, the validation work, and results of the SMPA, summarized from the more detailed description in BSC (2004 [DIRS 167652]).

\subsubsection{Model Description}

Consistent with the SCM, the predictive SMPA is a 3-D drift-scale model applying a stochastic continuum representation of the small-scale heterogeneity of fractured rock in the drift vicinity. The modeling framework and the processes studied are identical to the SCM; the recommendations for predictive seepage modeling as listed in Section 6.4.1.2 are strictly followed in the SMPA. The major difference between the two models is their scope. The SCM 
is applied to simulate field test data for calibration and validation purposes, while the SMPA is employed to conduct predictive simulations of ambient seepage into waste emplacement drifts.

The 3-D model domain of the SMPA is shown in Figure 6.4-2, representing the fractured rock adjacent to the upper left half of a circular-shaped, 2.44-meter (8 feet) long drift segment with a diameter of 5.5 meters (BSC 2004 [DIRS 168489]). (Potential changes in the drift shape as a result of drift degradation are considered with adjusted SMPA grids, as discussed in Section 6.4.2.4.2.) Based on symmetry considerations, the numerical mesh was reduced to a half-drift model, increasing the computational efficiency of the simulation. (More than 50,000 simulation runs had to be conducted to fully cover the required parameter space for TSPA.) The size of the model domain and the discretization were selected according to the following criteria (BSC 2004 [DIRS 167652], Section 6.3.1): (1) the lateral boundary should cover the region where lateral flow diversion is important, (2) the mesh resolution should be similar to the SCM, and (3) the simulation runs must be computationally efficient. Satisfying these criteria, the lateral boundary was chosen at 4 meters from the drift axis. Grid resolution is identical to the SCM in the plane normal to the drift axis, where flow diversion is most important (i.e., 0.1 meters). Along the drift axis, grid cells are slightly larger at 0.3-meter length (consistent with the SCM grid design of the ECRB). The upper boundary of the model domain is at 10 meters above the drift axis, which is large enough to allow for flow channeling independent of boundary effects. While the side boundaries have no-flow conditions assigned to them, a constant flux boundary is imposed at the top of the domain. This flux boundary represents the local percolation flux arriving at the considered drift segment.

The key parameters affecting ambient seepage are the effective capillary-strength parameter $1 / \alpha$, the statistical parameters defining the small-scale stochastic permeability field, and the local percolation flux $q_{\text {perc,ff }}$ imposed at the upper model boundary. Only these relevant parameters are varied in the predictive SMPA simulation runs, while other model parameters are kept constant, with their values similar to the parameter choices made in the SCM (BSC 2004 [DIRS 167652], Section 6.3). Note that the SCM modeling framework calls for the use of a uniform effective capillary-strength parameter not correlated to the local permeability. Thus, this parameter is taken to be uniform within the model domain.

Similar to the SCM, no attempt was made in the SMPA to describe the excavation-induced alterations of rock properties in spatial detail, despite the fact that the extent of the zone affected by alterations (e.g., approximately one drift diameter) is smaller than the vertical extent of the model area above the drift. Thus, in theory, hydrogeological parameters representing the excavation-disturbed zone should be used within the first diameter from the drift, while undisturbed rock properties should be applied outside of this region. For simplification, however, the SMPA assumes a uniform mean permeability in the entire model domain, representative of the excavation-disturbed zone, and also applies a uniform capillary-strength parameter as calibrated from the SCM. The simplification is appropriate since it is most important for seepage simulations to appropriately represent the conditions in the close vicinity of the drifts. Changes in the hydrogeological properties further away from the drifts do not significantly affect the seepage results. In fact, the seepage rates would most likely be reduced if the undisturbed rock properties were explicitly accounted for outside of the 1-diameter region around drifts. For example, the capillary-strength parameters representative of the undisturbed 


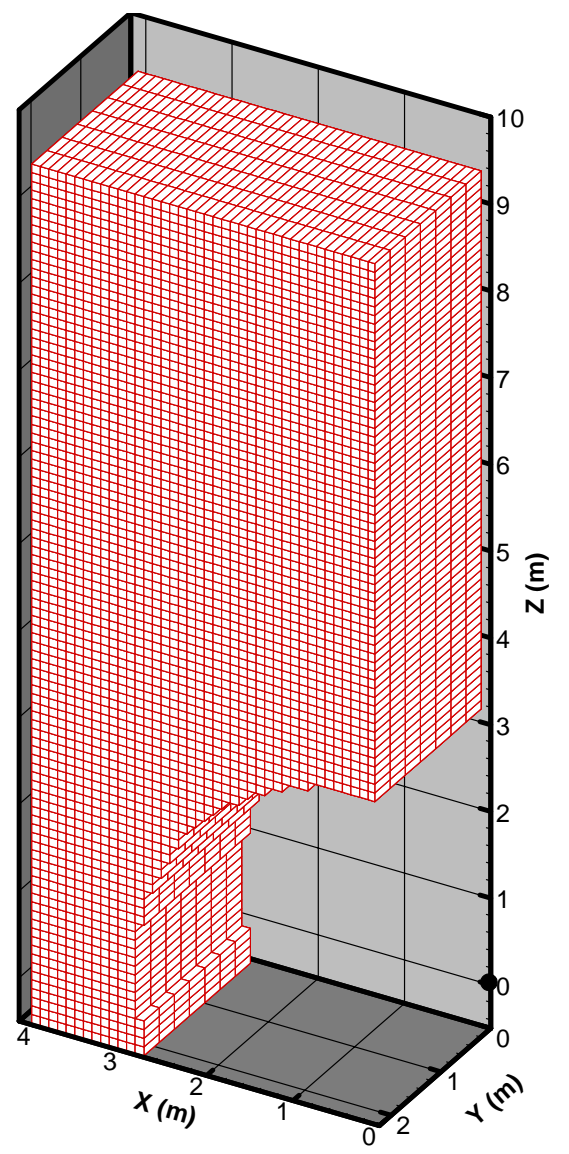

Source: BSC (2004 [DIRS 167652], Figure 6-1).

NOTE: The plot shows the nodes of gridblocks and the gridblock connections. The point shown at $(z=0$ and $x=0$ ) indicates the drift axis.

Figure 6.4-2. Model Domain and Mesh Design of the SMPA

fracture continuum in the Tptpmn and the Tptpll units, determined in BSC (2004 [DIRS 169857], Table 6-8), are much larger than the effective capillary-strength parameters

calibrated with the SCM (by a factor of 10 or more). (Note that tsw34 in BSC (2004 [DIRS 169857], Table 6-8) corresponds to the Tptpmn unit when using the nomenclature of the Geological Framework Model (BSC 2004 [DIRS 170029]). Similarly, the tsw35 corresponds to the Tptpll unit.) Thus, as a result of capillarity effects in the transition zone between undisturbed rock and the excavation-disturbed zone, the percolation flux would partially be diverted before reaching the vicinity of the drifts.

The parameters defining the stochastic permeability fields are the mean permeability $\mu_{S}$, for simplification hereafter referred to as $k$ (in log10), the standard deviation $\sigma_{S}$ (in log10) and the correlation length $\lambda_{s}$. While the mean permeability varies over a wide range in the SMPA simulation runs, corresponding to the significant variability of this parameter over the repository area, the standard deviation and the correlation length of the small-scale permeability fields are kept at constant values of $\sigma_{S}=1.0$ and $\lambda_{S}=0.3 \mathrm{~m}$, respectively. These parameter choices are 
based on post-excavation air permeability data measured using 1-foot-injection intervals that are appropriate to derive small-scale variability. Standard deviations derived from these data range from 0.72 to 1.31, while the correlation structure is described as essentially random (BSC 2004 [DIRS 171764], Table 6-7 and Section 6.6.2.1). Sensitivity analyses were conducted to estimate the impact of varying the standard deviation and correlation length of the random fields (BSC 2004 [DIRS 167652], Section 6.6.2, Figures 6-12 and 6-13). It was demonstrated that even significant parameter variation produced seepage rates comparable to (i.e., for a standard deviation of 2.0 in log10) or smaller than the base case (i.e., correlation length of 1.0 and $2.0 \mathrm{~m}$ ). This indicates that the selected constant values of standard deviation and correlation length are appropriate, and that seepage can be treated as a function of three rather than five key parameters. Note that the SCM modeling framework requires the permeability distribution to be representative of the excavation-disturbed zone in the drift vicinity.

The range of percolation flux $q_{p e r c, f f}$ imposed at the top boundary needs to cover the potential flux variability at Yucca Mountain for present and future infiltration scenarios. Since small-scale flow channeling is explicitly modeled within the SMPA, only the spatial variability on a resolution equal to or larger than the model domain needs to be considered. As explained in Section 6.6.5, appropriate spatial distributions of percolation fluxes as input to the SMPA can be developed using results of the UZ Flow Model (BSC 2004 [DIRS 169861]) under additional consideration of flow focusing effects. These percolation fluxes are considered constant during three distinct long-term climate states, based mainly on daily or seasonal fluctuations in net infiltration being effectively dampened in the overlying PTn nonwelded tuff unit (Section 6.6.5.1). Therefore, the SMPA model runs are conducted for steady-state flow conditions, applying a constant flux condition at the top boundary.

As was already mentioned in Section 6.3, the local flow conditions will be strongly altered by thermal effects during the first 1,000 to 2,000 years after waste emplacement. In a strict interpretation, the derived seepage results from the isothermal SMPA should only be applied for late time periods when both the rock temperatures and saturations have returned to "ambient" state. However, results from the TH Seepage Model presented in Section 6.4.3 demonstrate that ambient seepage rates from the SMPA are reasonably accurate (slightly over-predictive), provided that the rock temperatures have decreased below boiling and that the fractured rock close to the drift wall has resaturated. This means that the SMPA results can be used to abstract seepage during most of the 10,000-year compliance period. The potential impact of THM and THC effects on the applicability of the SMPA is discussed in Section 6.4.4.

\subsubsection{Model Validation}

Since the SMPA and the SCM are similar models that differ only in their scope, validation of the SMPA has been mainly achieved by comparison with results from the SCM. In other words, confidence in the model results was gained by comparison with another model that is validated against field data and other observations (BSC 2004 [DIRS 167652], Section 7.3). The discussion and conclusions regarding alternative conceptual approaches in Section 6.4.1.2 apply similarly to the SCM and the SMPA. 


\subsubsection{Model Results: Systematic Study of Ambient Seepage}

The systematic simulations performed by the SMPA cover a wide range of capillary-strength values $1 / \alpha(100 \mathrm{~Pa}$ to $1,000 \mathrm{~Pa}$ in steps of $100 \mathrm{~Pa})$, mean permeability values $k(-14$ to -10 in steps of 0.25 , given in $\log 10$ with permeability in the unit $\mathrm{m}^{2}$ ), and percolation flux values $q_{\text {perc,ff }}$ $(1,5,10,20,50,100$ through 1,000 mm/year in steps of $100 \mathrm{~mm} /$ year). Since these simulations provide a look-up table for the seepage interpolation in the TSPA-LA, the range of cases simulated must adequately cover the range of parameter combinations relevant for performance, i.e., covering the range of spatial variability and uncertainty of each parameter. The parameter distributions developed in Section 6.6 (for capillary strength, permeability, and percolation flux) demonstrate that the SMPA parameter range is sufficient, though there is a very small probability that sampled values may fall outside the SMPA range and have to be truncated (see discussion in Section 6.5.1.2). The probability distribution for permeability, for example, is infinite and thus, by definition, cannot be bounded by a finite parameter range. Also, as pointed out in Section 6.6.5.3, percolation fluxes larger than the maximum SMPA value of 1,000 mm/year are theoretically possible (as a result of climate changes, spatial variability, and flow focusing), but extremely unlikely.

For each combination of the above values of capillary strength, permeability, and percolation flux, a total of 20 realizations of the heterogeneous permeability fields were simulated. It was demonstrated that the number of 20 realizations was more than sufficient to ensure sufficiently stable estimates of the simulation outputs (BSC 2004 [DIRS 167652], Section 7.3). Comparison of selected simulation cases conducted with 10 vs. 20 realizations indicated differences of 2 percent or less in the mean seepage rates (BSC 2004 [DIRS 167652], Table 7-1).

The resulting seepage values, provided in DTN: LB0304SMDCREV2.002 [DIRS 163687] in the form of a look-up table, are presented and discussed in detail in BSC (2004 [DIRS 167652], Section 6.6.1). Seepage rates and seepage percentages are given for a reference drift section of 5.1-meter length, corresponding to the length of a waste canister plus the 0.1-meter spacing between canisters (see definitions of seepage rate and percentage in Section 6.1.3). The SMPA results used in abstraction are the seepage mean and the standard deviation calculated over the 20 realizations, but values from individual realizations are provided as well. To derive a seepage rate for a particular set of key parameters $1 / \alpha, k_{s}$, and $q_{\text {perc,ff }}$ analyzed in TSPA, the corresponding seepage results need to be interpolated from the seepage values given in the look-up table (DTN: LB0304SMDCREV2.002 [DIRS 163687]).

Example results from the SMPA are illustrated in Figures 6.4-3 through 6.4-6. The figures give contours of the simulated seepage percentage as a function of the capillary-strength parameter and the mean fracture permeability (in log10), for selected percolation fluxes of 5, 50, 200, and $500 \mathrm{~mm} /$ year. Presenting results in the form of seepage percentages (absolute seepage into a drift section relative to the amount of percolation over this drift section) is useful because the effectiveness of flow diversion is immediately evident. As expected, the seepage percentage is large for small capillary strength, small permeability, and large percolation flux. In these cases, seepage may be as high as 100 percent; i.e., there is no flow diversion at the drift wall, and the entire percolation flux seeps into the drift. In contrast, the seepage percentage is small for cases with large capillary strength, large permeability, and small percolation flux. In many of these cases, there is no seepage at all; i.e., the entire percolation flux is diverted around the drift by 
capillary forces, because the percolation flux is below the seepage threshold for the parameters given.

Note that the resulting seepage percentages in the look-up table are identical for simulation cases that have the same ratio of percolation flux $q_{\text {perc,ff }}$ over permeability given in $\mathrm{m}^{2}$ (e.g., the seepage percentages for cases with a permeability of $10^{-13} \mathrm{~m}^{2}$ and $q_{\text {perc,ff }}=5 \mathrm{~mm}$ /year are identical to cases with a permeability of $10^{-12} \mathrm{~m}^{2}$ and $q_{\text {perc,ff }}=50 \mathrm{~mm} /$ year and cases with a permeability of $10^{-11} \mathrm{~m}^{2}$ and $q_{\text {perc,ff }}=500 \mathrm{~mm} /$ year; see Figures $6.4-3$ through 6.4-6). The steady-state capillary pressure and saturation conditions are determined by the ratio of percolation flux over permeability. As a result, it would be possible to reduce the number of key parameters for ambient seepage, and thus the size of the look-up table. However, such a reduction in the number of key parameters is not necessary for technical adequacy, and, to be consistent with previous abstractions, the look-up table is not changed for the TSPA-LA.

It should be recognized that identical seepage percentages for different percolation flux scenarios may correspond to vastly different seepage rates. For example, a seepage percentage of 50 percent at $1 \mathrm{~mm} /$ year percolation relates to a seepage rate of approximately $14 \mathrm{~kg} / \mathrm{year}$ per waste package. At $500 \mathrm{~mm} /$ year, the same percentage relates to a seepage rate of 7,013 kg/year per waste package.

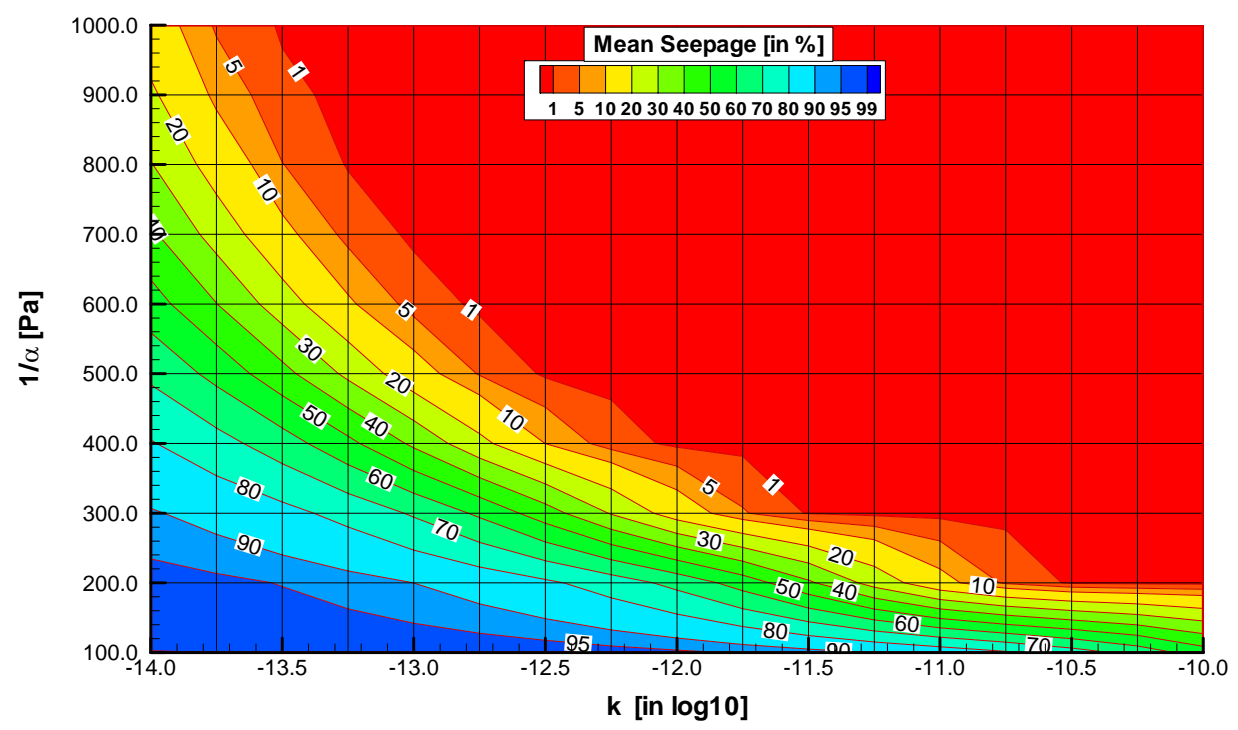

Source: LB0304SMDCREV2.002 [DIRS 163687] (using file Fig6-3toFig6-8.dat).

NOTE: Horizontal and vertical lines indicate simulated parameter cases. Permeability values in $\log 10$ of unit $\mathrm{m}^{2}$.

Figure 6.4-3. Mean Seepage Percentage as a Function of Capillary-Strength Parameter and Mean Permeability for a Percolation Flux of $5 \mathrm{~mm} / \mathrm{year}$ 


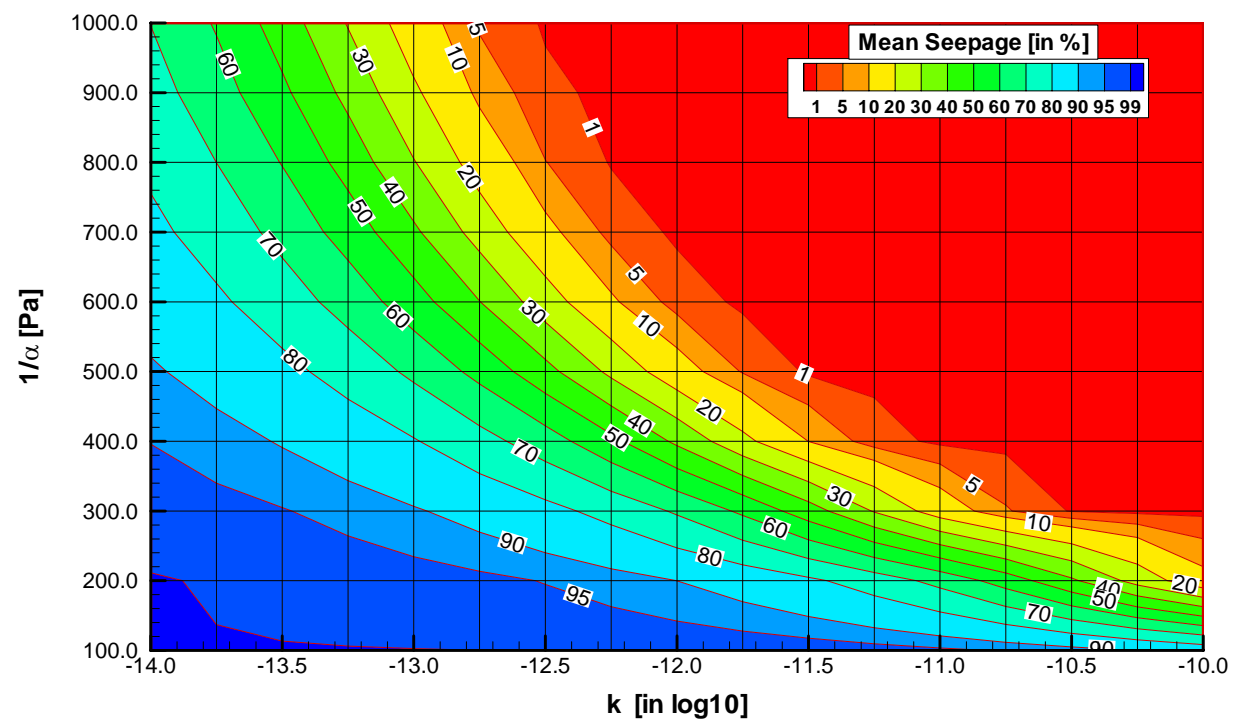

Source: LB0304SMDCREV2.002 [DIRS 163687] (using file Fig6-3toFig6-8.dat).

NOTE: Horizontal and vertical lines indicate simulated parameter cases. Permeability values in $\log 10$ of unit $\mathrm{m}^{2}$.

Figure 6.4-4. Mean Seepage Percentage as a Function of Capillary-Strength Parameter and Mean Permeability for a Percolation Flux of $50 \mathrm{~mm} / \mathrm{year}$

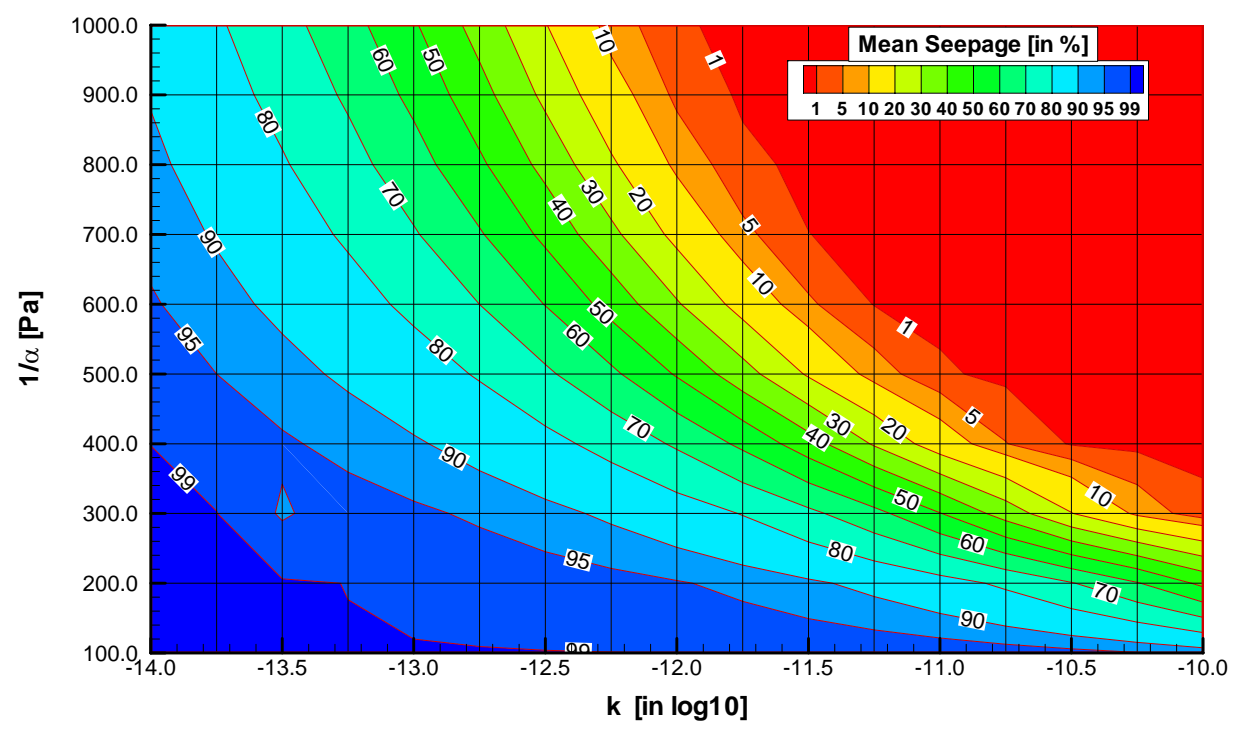

Source: LB0304SMDCREV2.002 [DIRS 163687] (using file Fig6-3toFig6-8.dat).

NOTE: Horizontal and vertical lines indicate simulated parameter cases. Permeability values in $\log 10$ of unit $\mathrm{m}^{2}$.

Figure 6.4-5. Mean Seepage Percentage as a Function of Capillary-Strength Parameter and Mean Permeability for a Percolation Flux of $200 \mathrm{~mm} / \mathrm{year}$ 


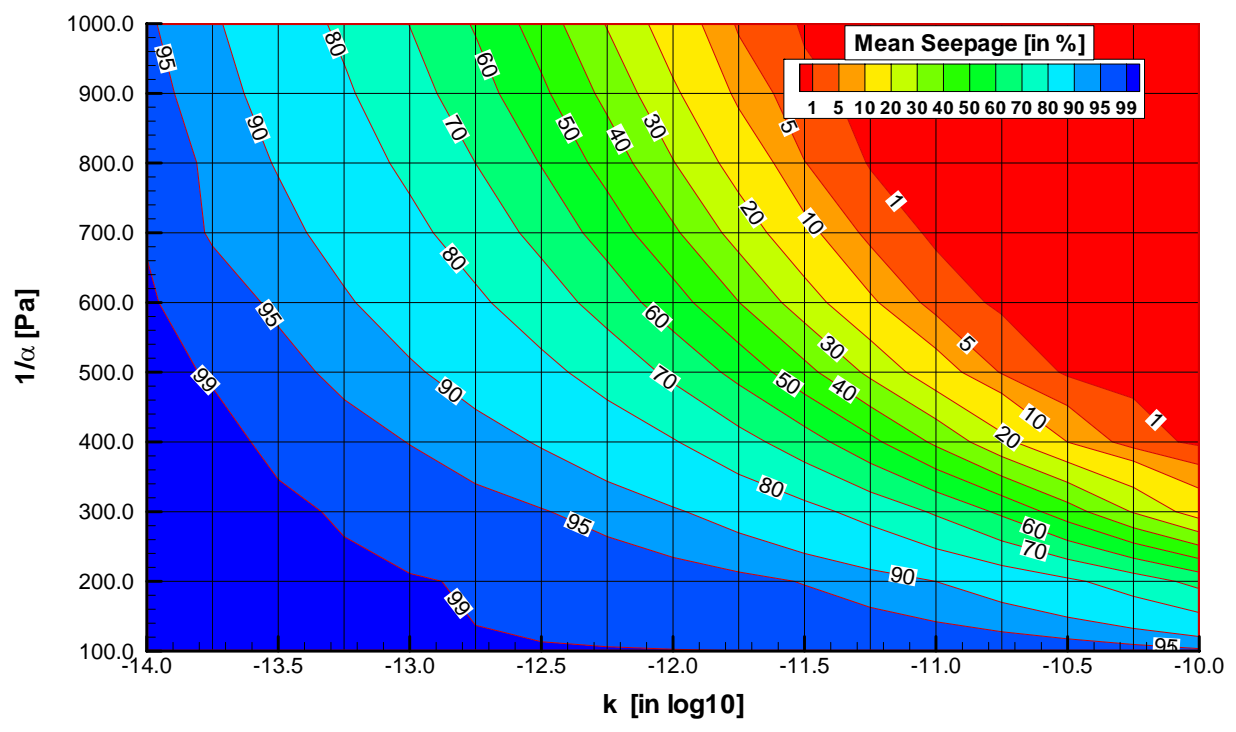

Source: LB0304SMDCREV2.002 [DIRS 163687] (using file Fig6-3toFig6-8.dat).

NOTE: Horizontal and vertical lines indicate simulated parameter cases. Permeability values in $\log 10$ of unit $\mathrm{m}^{2}$.

Figure 6.4-6. Mean Seepage Percentage as a Function of Capillary-Strength Parameter and Mean Permeability for a Percolation Flux of $500 \mathrm{~mm} /$ year

The range of results observed from the 20 realizations provides information about the estimation uncertainty in the predicted seepage rates, on account of uncertainty in the stochastic small-scale heterogeneity. As shown in Figures 6-9, 6-10, and 6-11 of BSC (2004 [DIRS 167652]), the differences obtained between realizations of the random permeability field can be quite large. Thus, this estimation uncertainty should be included in and propagated through seepage abstraction. This can be done using appropriate uncertainty distributions defined on the basis of the standard deviations provided in DTN: LB0304SMDCREV2.002 [DIRS 163687]. Note that these standard deviations can be different for each simulated parameter combination; typically, the larger the derived seepage rate, the larger the associated standard deviation of the seepage rate. It is not evident from the discussion in BSC (2004 [DIRS 167652], Section 6.6.1) which type of uncertainty distribution is best suited to represent the observed statistical spread. Therefore, histograms of the distribution of seepage percentage over the 20 realizations have been calculated for selected parameter cases, chosen to represent cases with small, average, and large seepage (see Appendix A). However, evaluation of these histograms did not reveal a consistent trend (see examples of histograms in Figure 6.4-7). It is therefore recommended for TSPA to use a simple uniform probability distribution to account for the estimation uncertainty of the SMPA results. The impact of using alternative (normal) distribution for the seepage uncertainty is examined in Section 6.8.2, where seepage rates are calculated in a Monte Carlo analysis. It is demonstrated that the resulting seepage rates are hardly affected, indicating a small sensitivity to the shape of the uncertainty distribution. 
Simulation Case: $1 / \alpha=500$ Pa, $k=-12$ in $\log 10\left(\mathrm{~m}^{2}\right), q_{\text {perc,ff }}=50 \mathrm{~mm} / \mathrm{year}$

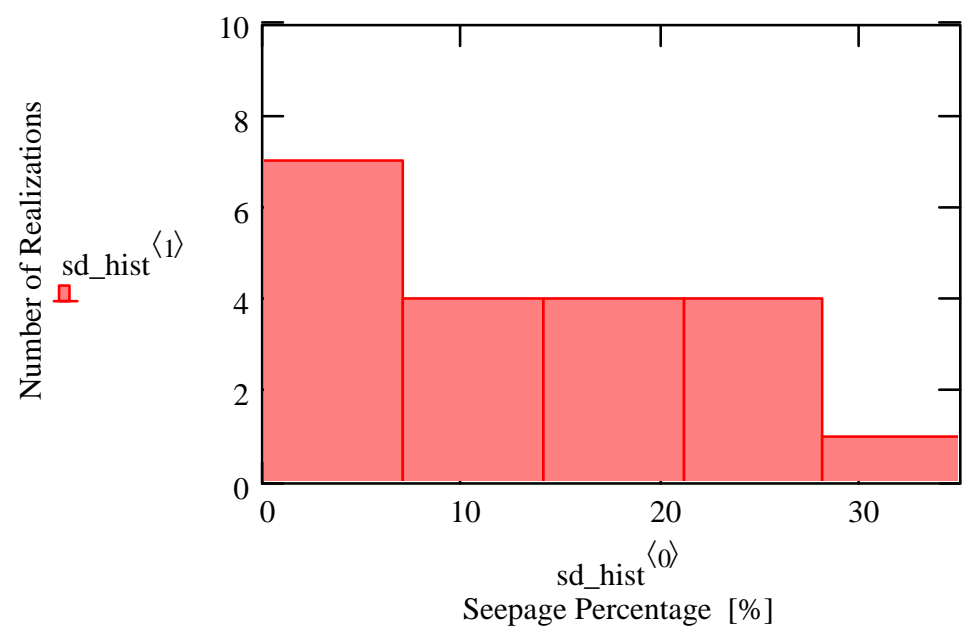

Simulation Case: $1 / \alpha=500 \mathrm{~Pa}, k=-12$ in $\log 10\left(\mathrm{~m}^{2}\right), q_{\text {perc }, f f}=500 \mathrm{~mm} / \mathrm{year}$

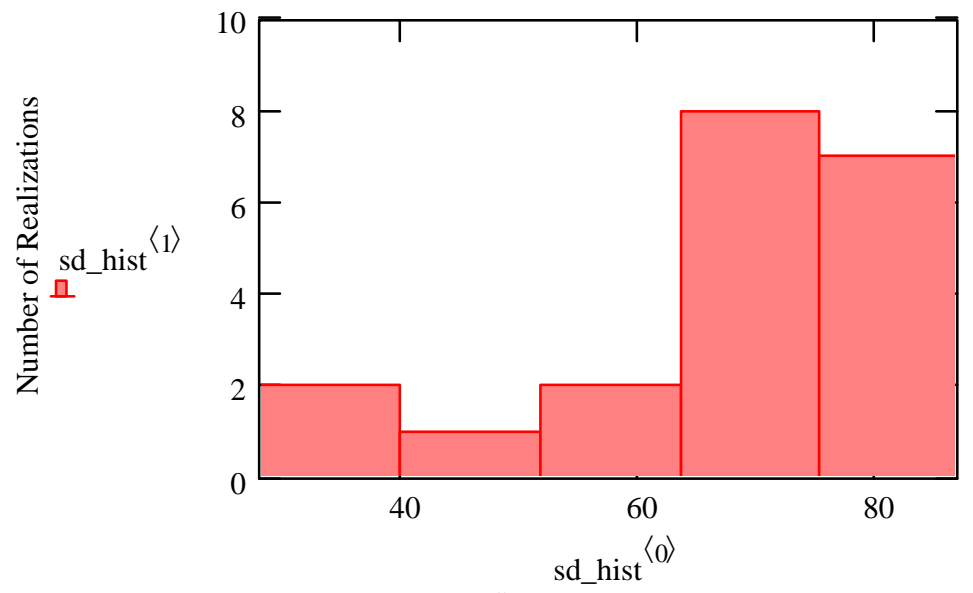

Seepage Percentage

Source: LB0304SMDCREV2.002 [DIRS 163687] (using file Fig6-3toFig6-8.xIs, see Appendix A).

NOTE: The symbols in the histograms (i.e., sd_hist ${ }^{<0>}$ and sd_hist ${ }^{<1>}$ ) denote the variable names given in the Mathcad 11 spreadsheet used for the calculation. The histogram ranges are derived using the largest and the smallest seepage percentage of the 20 realizations of each simulation case, and dividing the difference by the bin number of 5 . For $q_{\text {perc,ff }}=50 \mathrm{~mm} / \mathrm{year}$, the largest value is 34.8 percent, the smallest value is 0.4 . For $q_{\text {perc,ff }}=500 \mathrm{~mm} / \mathrm{year}$, the largest value is 86.9 percent, the smallest value is 28.3 percent.

Figure 6.4-7. Example Histograms of Seepage Percentage from 20 Realizations for Two Selected Parameter Cases 


\subsubsection{Model Results: Impact of Drift Degradation}

Whereas the systematic seepage study of the previous section assumed an idealized circular drift design, additional simulation cases were conducted with the SMPA to analyze the potential impact of changes in the drift shape on seepage. Such shape changes, a possible result of drift degradation caused by seismic motion, thermal stress, and time-dependent reduction in rock strength, have been predicted in the report Drift Degradation Analysis (BSC 2004 [DIRS 166107]). Section 6.4.2.4.1 below briefly introduces the methodology and main results of the drift degradation analyses. Section 6.4.2.4.2 documents the seepage simulation studies that have been conducted for degraded drifts.

\subsection{Drift Degradation Analysis}

The drift degradation analysis, as reported in Revision 03 of the report Drift Degradation Analysis (BSC 2004 [DIRS 166107]), analyzes the mechanical response and potential degradation of the near-field fractured rock mass to seismic events, thermal stresses, and time-dependent degradation in rock strength. Lithophysal (Tptpll and Tptpul units) and nonlithophysal (Tptpmn and Tptpln units) repository units were evaluated with different simulation approaches because the two types of rocks have fundamentally different failure modes under dynamic loading. The nonlithophysal units comprise hard, strong, jointed rock masses, while the lithophysal rocks are relatively deformable with lower compressive strength (BSC 2004 [DIRS 166107]).

Two- and three-dimensional discontinuum simulations were conducted to predict the degradation of the repository units. The nominal cases in the TSPA-LA calculation (i.e., cases without disruptive events such as seismic ground motion or igneous intrusion) included thermal stress analysis and time-dependent rock-strength degradation. The seismic cases included five main simulation scenarios, based on CRWMS M\&O (1998 [DIRS 103731]). The seismic events were defined by their probabilistic seismic hazard level, giving the annual probability that certain levels of ground motion would be exceeded. The annual hazard levels considered were a $5 \times 10^{-4}$, a $1 \times 10^{-4}$, a $1 \times 10^{-5}$, a $1 \times 10^{-6}$, and a $1 \times 10^{-7}$ annual probability of exceedance (BSC 2004 [DIRS 166107], Section 6.3.1.2.1 and Table 6-5). A total of 15 different sets of peak ground motion velocities were selected for each postclosure seismic hazard level, representing a wide range of potential ground motions (BSC 2004 [DIRS 166107], Appendix X). In lithophysal units, five different rock categories were studied, ranging from Category 1 (poor quality) to Category 5 (good quality), with the mechanical properties of the rock mass mainly determined by the volume fraction of the lithophysae (BSC 2004 [DIRS 166107], Appendix S4, Figure S-50).

As pointed out in the Seismic Consequence Abstraction (BSC 2004 [DIRS 169183], Section 4.1), the mean peak ground motion velocities associated with the five main seismic scenarios are $0.19 \mathrm{~m} / \mathrm{s}\left(5 \times 10^{-4}\right.$ annual probability of exceedance), $0.384 \mathrm{~m} / \mathrm{s}\left(1 \times 10^{-4}\right), 1.05 \mathrm{~m} / \mathrm{s}\left(1 \times 10^{-5}\right)$, $2.44 \mathrm{~m} / \mathrm{s}\left(1 \times 10^{-6}\right)$, and $5.35 \mathrm{~m} / \mathrm{s}\left(1 \times 10^{-7}\right)$. BSC (2004 [DIRS 169183], Section 6.4.4) cautions that ground motion velocities above $5 \mathrm{~m} / \mathrm{s}$ are extremely large and may not be realizable for the seismic sources and conditions in and around Yucca Mountain. It is pointed out that extreme ground motions with velocities of $5 \mathrm{~m} / \mathrm{s}$ or above would have damaged the lithophysal strata by generating fractures between adjacent lithophysae or ultimately by crushing the lithophysae. 
Geologic evidence indicates that lithophysal strata have remained intact over the 11-million-years lifetime of Yucca Mountain, indicating that such extreme ground motions have not occurred over the past 11 million years. The Seismic Consequence Abstraction (BSC 2004 [DIRS 169183], Section 6.4.4) has therefore defined an upper bound of $5 \mathrm{~m} / \mathrm{s}$ for the ground motion velocities to be considered in the TSPA. Thus, the drift degradation predictions for conducted ground motion velocities larger than $5 \mathrm{~m} / \mathrm{s}$ (i.e., some ground motion sets of the $1 \times 10^{-6}$ hazard level and all ground motion sets of the $1 \times 10^{-7}$ hazard levels) can be considered worst-case scenarios.

In the Drift Degradation Analysis (BSC 2004 [DIRS 166107]), the impact of rock strength reduction was analyzed as a function of time after emplacement, giving the evolution of drift profiles as a function of time (BSC 2004 [DIRS 166107], Sections 6.3.1, 6.4.2 and Appendix S). In some cases, time-dependent degradation was combined with thermal stresses or seismic loading conditions expected during the regulatory period. The time-dependent degradation analysis was complemented by quasistatic analysis, where the rockfall and damage to the rock mass were calculated as functions of the level of joint cohesive strength reduction. The quasistatic analysis covered the entire range of possible strength reduction, with the two extreme scenarios being the 0 percent reduction case (i.e., present-day rock strength) and the 100 percent reduction case (complete loss of cohesion strength). Results from these quasistatic simulations are given in BSC (2004 [DIRS 166107], Appendix R).

Results from the drift degradation analysis demonstrate fundamental differences between the nonlithophysal and the lithophysal rocks. Drift degradation in the hard, strong, jointed rock of the nonlithophysal units is mostly limited to local gravitational drop of rock blocks (wedge-type rockfall) at the drift ceiling. As summarized in BSC (2004 [DIRS 166107], Section 8.1), minor damage due wedge-type rock fall (i.e., controlled by the geological structure) is expected in nonlithophysal units from (1) all seismic events (BSC 2004 [DIRS 166107], Section 6.3.1.2), (2) thermal stress (BSC 2004 [DIRS 166107], Section 6.3.1.3), and (3) time-dependent strength degradation (BSC 2004 [DIRS 166107], Section 6.3.1.5). Except for local wedge-type rockfall, the drifts in nonlithophysal units remain intact openings with the horizontal extent essentially unchanged (BSC 2004 [DIRS 166107], Figures 6-108 through 6-114), similar to the results obtained in the earlier Revision 01 of the report Drift Degradation Analysis (BSC 2001 [DIRS 156304], compare with profiles in Figures 39 and 40). It was also evaluated whether the extreme seismic cases would possibly lead to very high stresses exceeding the compressive strength of the intact rock mass in the nonlithophysal units (BSC 2004 [DIRS 166107], Section 6.3.1.6.4). In such cases, severe fracturing of the intact rock blocks would occur, which in turn could lead to severe drift damage. The impact of fracturing of solid rock blocks in response to extreme seismic events was examined via a sensitivity study of the shear and tensile strength of solid rock bridges (BSC 2004 [DIRS 166107], Section 6.3.1.6.4). This sensitivity study showed that the expected rock bridge failure of between 5 and 20 percent (for the $1 \times 10^{-6}$ and $1 \times 10^{-7}$ hazard levels, respectively) would increase local wedge-type rockfall, but would not lead to drift collapse (BSC 2004 [DIRS 166107], Figures 6-89 and 6-90). The effect of such wedge-type rockfall in nonlithophysal units is implicitly accounted for in TSPA-LA. As discussed in Section 6.4.2.4.2 below, changes in the drift profile caused by wedge-type rockfall (local breakouts along the wall or the crown) do not significantly affect seepage. 
More significant drift degradation than in the nonlithophysal units is predicted for the relatively deformable lithophysal rock. In lithophysal units, seismic events with peak ground motions greater than about $2 \mathrm{~m} / \mathrm{s}$ lead to complete collapse of emplacement drifts, as discussed in BSC (2004 [DIRS 166107], Sections 6.4.2.2). Peak ground motions larger than $2 \mathrm{~m} / \mathrm{s}$ occur, for example, in some of the $1 \times 10^{-5}$ seismic hazard levels and in all $1 \times 10^{-6}$ and the $1 \times 10^{-7}$ seismic hazard levels. As discussed in Section 6.4.2.4.2, complete collapse of emplacement drifts leads to a significant increase in seepage compared to nondegraded or slightly degraded drifts. For other seismic events with smaller peak ground motions, the extent of drift damage in lithophysal rocks is less significant. For example, according to Figure 6-125 in BSC (2004 [DIRS 166107]), partial drift collapse will occur for a peak ground motion of $1.04 \mathrm{~m} / \mathrm{s}$ for low-strength rock of Category 1, while only minor damage is expected for all other rock strength categories at the same peak ground motion. Independent of the rock category, no (or very minor) rock damage from local rockfall is predicted for the seismic cases with annual occurrence of $5 \times 10^{-4}$ and the $1 \times 10^{-4}$, with the drifts remaining essentially intact. Based on these results (and additional results discussed below where seismic events have been combined with time-dependent rock strength degradation), the Seismic Consequence Abstraction (BSC 2004 [DIRS 169183], Section 6.8.1) recommends for the TSPA-LA that peak ground motions equal or greater than $0.384 \mathrm{~m} / \mathrm{s}$ should be considered large enough to collapse the drift in the lithophysal zones. This threshold value for collapse includes all seismic events with annual occurrence probability equal to or lower than $1 \times 10^{-4}$.

In contrast to the impact of seismic events, thermal effects and time-dependent rock strength degradation result in minor drift damage in the lithophysal units, limited to small breakouts in the wall and the crown (BSC 2004 [DIRS 166107], Sections 6.4.2.3, 8.1 and Appendix S3.4.2, Figures S-42 through S-44). Over a 20,000-year time span, the reduction in rock strength is estimated on the order of 40 percent from the initial cohesive strength. This reduction is not significant enough to allow for major damage or even complete collapse (see also profiles predicted from quasistatic simulations for 40 percent cohesion reduction in Appendix R of BSC (2004 [DIRS 166107])). More damage is expected from a combination of seismic, thermal, and time-dependent effects. As shown for the $1 \times 10^{-4}$ seismic hazard level in Appendix S3.4.3 of BSC (2004 [DIRS 166107]), the extent of rockfall is affected by the timing of the seismic event (effects are stronger at later stages when cohesive strength has reduced) and by the rock category (effects are stronger for low-quality rock). The most significant damage for these cases is predicted for rock of Categories 1 and 2 (about 10 percent of the rock mass in the Tptpll unit) and the seismic event occurring after 10,000 years (BSC 2004 [DIRS 166107], Figures 6-161 and S-47), with partial wall breakouts and a 50 percent diameter increase.

\subsection{Seepage Analysis for Degraded Drifts}

Seepage calculations for degraded drifts have been conducted in BSC (2004 [DIRS 167652], Section 6.6.3). Two profile scenarios have been considered that cover most of the degradation results discussed in Section 6.4.2.4.1. The first profile scenario is for drifts with local wedge-type rockfall along the crown or the wall, as seen in the nonlithophysal rocks. Otherwise, the drifts remain intact openings with the horizontal extent essentially unchanged. Note that this profile scenario is also representative for the seepage conditions in lithophysal units with minor drift damage from rockfall, as predicted for all non-seismic cases and the moderate seismic 
events. The second scenario considers seepage into completely collapsed drifts, as expected in lithophysal rocks as a result of severe seismic events.

For Scenario 1 (seepage into intact drifts with local rockfall), the SMPA seepage calculations were conducted for two selected drift profiles representative of the degradation conditions in the nonlithophysal rocks. These profiles were based on model results from the earlier Revision 01 of the Drift Degradation Analysis (BSC 2001 [DIRS 156304]), which, as pointed out in BSC (2004 [DIRS 167652], Section 6.6.3), are similar to those in the recent revision of this report (BSC 2004 [DIRS 166107]). The selected profiles were the 75 percentile profile and the worst-case profile of the seismic Level 3 case for both geological units, as presented in BSC (2001 [DIRS 156304], Figures 39 and 40, Table 43). The 75 percentile profile for a particular unit and seismic event indicates that 75 percent of the drift length within that unit will have less (or no) drift profile deterioration. The worst-case profile represents the most severely degraded profile of the probabilistic analysis.

The SMPA seepage simulations used the selected drift profiles and the fall-off rock volumes to construct 3-D numerical grids that explicitly represent the predicted changes in drift shape (BSC 2004 [DIRS 167652], Section 6.4). On these discretized drift profiles, seepage was calculated with 10 realizations of the heterogeneous permeability field, using the same methodology as employed for nondegraded drifts. (Note that the seepage calculations for nondegraded drifts were carried out with 20 realizations. The degraded drift analysis was conducted with fewer realizations to limit the computational load of the predictive simulations. The results are expected to be close to the ones obtained from 20 realizations. This assessment is based on the comparison of selected simulation cases conducted with 10 versus 20 realizations, which indicated differences of 2 percent or less in the mean seepage rates (BSC 2004 [DIRS 167652], Table 7-1).) Seepage simulations were conducted for selected parameter cases, using a capillary strength of $600 \mathrm{~Pa}$ and a percolation flux of $200 \mathrm{~mm} /$ year. No-degradation results with the same parameter values were also calculated for comparison, to study the impact of drift degradation on seepage.

The simulation results obtained from the SMPA analysis indicate that the effects of local wedge-type drift shape changes on seepage are not significant. It was demonstrated that, for both considered drift profiles, the average seepage rates as well as the average seepage threshold calculated over the 10 realizations were almost identical to the no-degradation cases (BSC 2004 [DIRS 167652], Section 6.6.3). This result indicates that the impact of geometry changes at the drift ceiling as a result of local breakout of rock blocks can be neglected, as long as the drifts stay essentially intact (i.e., no collapse). Thus, the seepage look-up table derived for the initially circular drift design is also applicable for moderately degraded drifts as expected for Scenario 1 (seepage into intact drifts with local rockfall). However, note that the statistical spread among the 10 realizations was considerably stronger than in the no-degradation case.

Scenario 2 involves seepage into completely collapsed drifts in the lithophysal rocks. During collapse, either sudden or gradual, the rock mass above an underground opening disintegrates into a number of fragments that fall down and begin to fill the open space. Because there are large voids between the rock fragments, the bulk porosity of the fragmented rubble is much larger than the intact rock. As a result, the open space of the original excavation plus the collapsed portion of rock above are completely filled with rubble at a certain stage. When this occurs, the broken rock provides backpressure, which prevents further collapse of the rock mass 
(BSC 2004 [DIRS 166107], Section 6.4.2.5). The final situation after complete drift collapse can be categorized as follows: The original opening has increased in size, but is filled with fragmented rubble with large voids. The solid wall rock surrounding the rubble-filled opening is intact, but may have increased permeability and reduced capillary strength because of the dynamic motion and the stress redistribution (see Section 6.4.4.1.2). For convenience, the rubble-filled opening is referred to as a "collapsed drift," although technically there is no drift after collapse. The size and the shape of a collapsed drift mainly depend on the porosity of the rubble material and on the type of caving mechanism as collapse occurs. The collapsed drift profiles provided in DTN: MO0306MWDDPPDR.000 [DIRS 164736] are all similar, independent of the event leading to collapse. (Note that these profiles are also depicted in Appendix R of BSC (2004 [DIRS 166107]). In this reference, collapsed drifts are shown for Scenarios 2 through 5, 11, 12, 17, 18, 23, 24, 28, 29, and 30.) All drifts remain approximately circular after complete collapse. However, the size of the collapsed drifts increases considerably, with the largest drifts having a diameter of approximately $11 \mathrm{~m}$ after collapse.

For collapsed drifts, seepage is defined as the flow of liquid water from the fractured formation into the rubble-filled opening. It was already discussed in Section 6.3.1 that drift collapse may lead to significantly different seepage behavior. However, even though the collapsed drifts are filled with rubble material, capillary barrier effects still give rise to considerable flow diversion at the interface between the solid rock and the rubble-filled drift opening. This is because of the large scattered voids between the rock fragments (block sizes on the order of centimeters and decimeters (BSC 2004 [DIRS 166107], Section 8.1)), suggesting that the capillary strength parameter in the rubble filled drift is very small, most likely close to the zero capillary strength of an air-filled opening. Also, a small gap can be expected between the solid rock at the ceiling and the collapsed rubble material as a result of consolidation. Therefore, capillary-driven flow diversion remains an important mechanism reducing seepage in collapsed drifts, which should be included in the seepage abstraction model. Additional simulation cases were conducted with the SMPA to study seepage into collapsed drifts. A worst-case drift profile for seepage was selected representative of the complete drift collapse scenarios depicted in MO0306MWDDPPDR.000 [DIRS 164736] (see also Appendix R of BSC (2004 [DIRS 166107])). The chosen profile has a circular shape with a diameter of $11 \mathrm{~m}$, which is the largest diameter predicted. The larger the drift size, the more seepage can be expected because (1) the total amount of percolation flux arriving at the drift increases with the horizontal size, and (2) flow diversion is less effective for a larger drift. A capillary strength parameter of $100 \mathrm{~Pa}$ was used for the fragmented rock material within the collapsed drift (BSC 2004 [DIRS 167652], Section 5). This value is considered a conservative choice for seepage calculations, because the capillary strength of the rubble material is most likely smaller. Otherwise, the conceptual model of the seepage simulations remains identical to the SMPA analysis for nondegraded drifts (see Section 6.4.2.1).

Systematic seepage simulations for the collapsed drift case were conducted for the full set of parameter combinations, with capillary strength values ranging from $100 \mathrm{~Pa}$ to $1,000 \mathrm{~Pa}$, mean permeability values ranging from -14 to -10 (in $\log 10 \mathrm{~m}^{2}$ ), and percolation flux values ranging from $1 \mathrm{~mm} /$ year to 1,000 mm/year. (These are the same parameter cases as simulated for the nondegraded drift in Section 6.4.2.3.) The resulting seepage values are provided in a seepage look-up table for the collapsed drift scenario (DTN: LB0307SEEPDRCL.002 [DIRS 164337]). The format of this look-up table is identical to the nondegraded drift case in Section 6.4.2.3. Thus, to account for collapsed drifts, the seepage abstraction model would simply sample from 
this second look-up table, without changing the basic abstraction methodology (see Section 6.5.1.5). The collapsed drift look-up table in DTN: LB0307SEEPDRCL.002 [DIRS 164337] is based on results from 10 realizations. (As mentioned before, the seepage calculations for nondegraded drifts were carried out with 20 realizations. The collapsed drift analysis was conducted with fewer realizations in order to limit the computational load. The results are expected to be close to the ones obtained from 20 realizations. This assessment is based on the comparison of selected simulation cases conducted with 10 versus 20 realizations, which indicated differences of 2 percent or less in the mean seepage rates (BSC 2004 [DIRS 167652], Table 7-1).)

Example seepage results for the collapsed drift scenario are illustrated in Figures 6.4-8 through 6.4-11, showing contours of simulated seepage percentage. Comparison with results from the nondegraded drift scenario (Figures 6.4-3 through 6.4-6) indicates a considerable increase in seepage percentage, caused by the larger size of the collapsed drift (reducing the effectiveness of flow diversion around the drift) and by the nonzero capillary strength in the drift (reducing the effectiveness of the capillary barrier). Nevertheless, the simulation results demonstrate that most of the percolation flux is still diverted around the collapsed drift for most of the considered parameter range. Note that the related seepage rates for the collapsed drift scenario are much larger than for nondegraded drifts because the footprint of the drifts has doubled in size, thereby doubling the amount of percolation flux arriving at the collapsed drift. (As defined in Section 6.1.3, seepage denotes the flow of liquid water into a drift. Whether the seeping water can actually contact waste packages is not considered in this definition. Obviously, the larger the horizontal extent of a drift, the higher the possibility that seeped water would not drip on the waste package but rather hit the invert or the lower drift wall. The possibility that only a fraction of the seepage water may actually come into contact with the waste packages in the center of the drifts is not considered in the TSPA-LA. The TSPA-LA assumes an upper-bounding case for seepage; it is assumed that the entire volume of seepage water can contact waste packages and possibly pick up contaminants from breached canisters.) Further comparison between seepage results for nondegraded and collapsed drifts is provided in the probabilistic seepage calculations in Section 6.8.2.

As discussed in Section 6.4.2.4.1, a combination of seismic events together with time-dependent rock strength degradation may lead to drift profiles in the lithophysal rocks that are somewhere between Scenario 1 (seepage into intact drifts with local rockfall) and Scenario 2 (complete drift collapse). These are the cases where partial wall breakout occurs, which can lead to a lateral diameter increase of about 1.5 times the original size, but not to a complete collapse of the rock mass above the drift (for example, after a seismic event with $1 \times 10^{-4}$ hazard level combined with rock strength degradation for rock mass of Category 2). As pointed out before, the seismic consequence abstraction and TSPA-LA assume that such seismic events will lead to complete collapse of drifts in the lithophysal rocks. Thus the cases with partial wall breakout and lateral diameter increase will be associated with the increased seepage rates for a much wider, completely collapsed drift. These provide upper bounds to the seepage rates expected for partial breakout cases. 


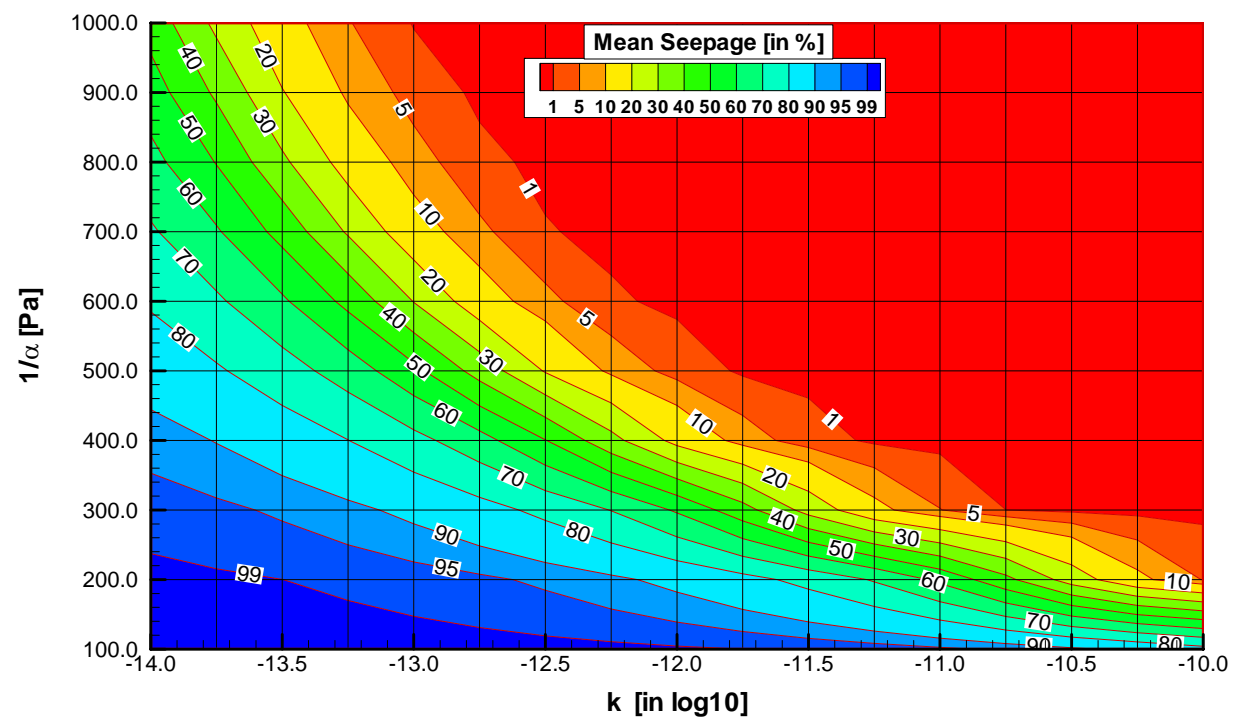

Source: LB0307SEEPDRCL.002 [DIRS 164337].

NOTE: Horizontal and vertical lines indicate simulated parameter cases. Permeability values in $\log 10$ of unit $\mathrm{m}^{2}$.

Figure 6.4-8. Mean Seepage Percentage for the Collapsed Drift Scenario as a Function of Capillary-Strength Parameter and Mean Permeability for a Percolation Flux of $5 \mathrm{~mm} / \mathrm{year}$

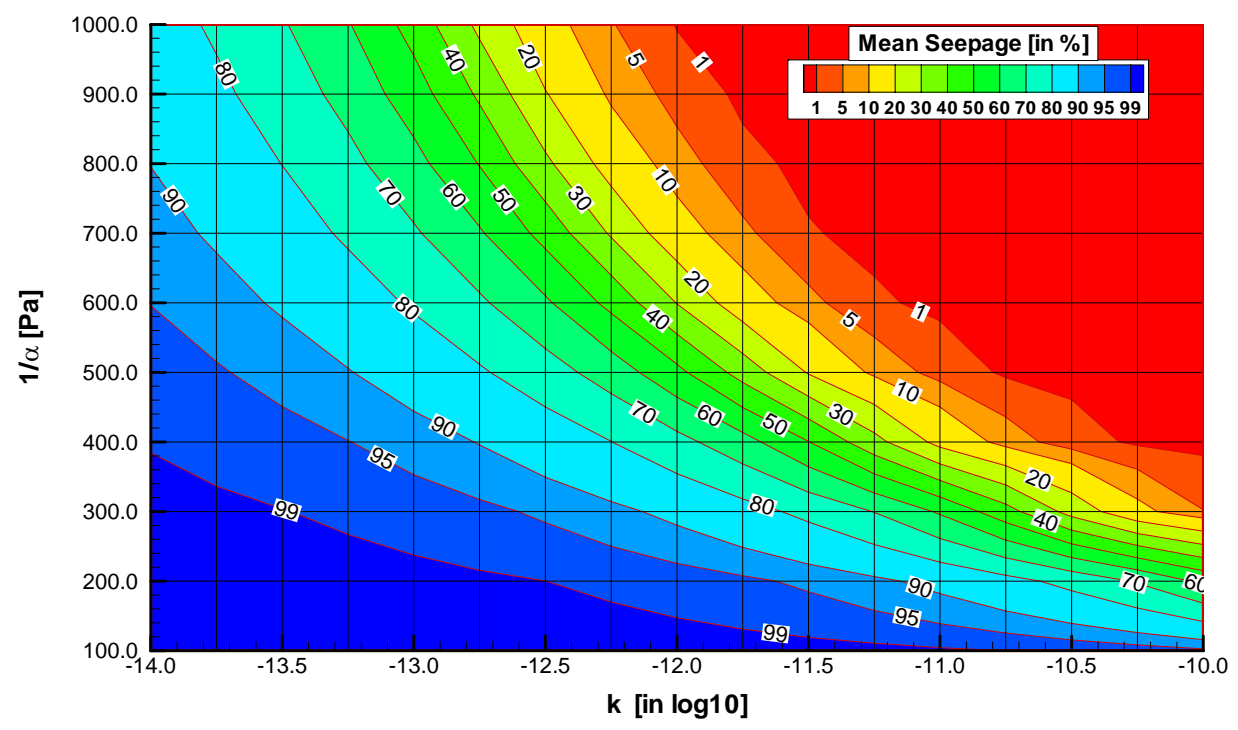

Source: LB0307SEEPDRCL.002 [DIRS 164337].

NOTE: Horizontal and vertical lines indicate simulated parameter cases. Permeability values in $\log 10$ of unit $\mathrm{m}^{2}$.

Figure 6.4-9. Mean Seepage Percentage for the Collapsed Drift Scenario as a Function of Capillary-Strength Parameter and Mean Permeability for a Percolation Flux of 50 $\mathrm{mm} / \mathrm{year}$ 


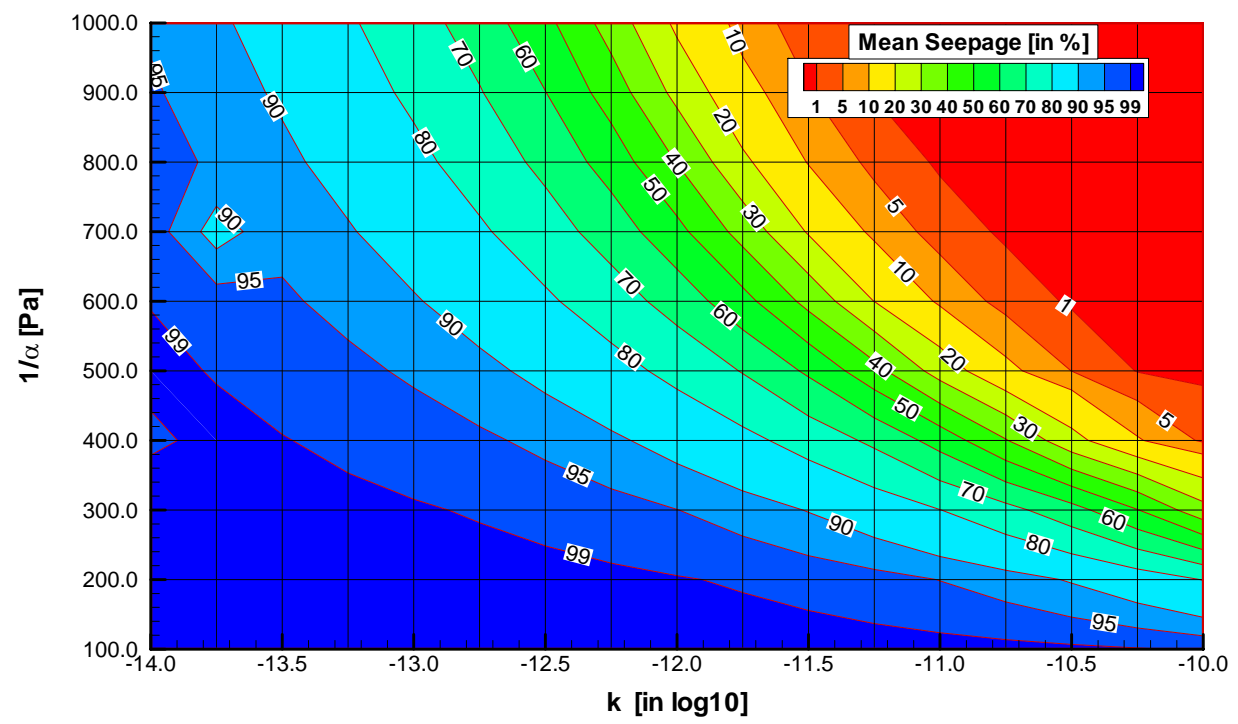

Source: LB0307SEEPDRCL.002 [DIRS 164337].

NOTE: Horizontal and vertical lines indicate simulated parameter cases. Permeability values in $\log 10$ of unit $\mathrm{m}^{2}$.

Figure 6.4-10. Mean Seepage Percentage for the Collapsed Drift Scenario as a Function of Capillary-Strength Parameter and Mean Permeability for a Percolation Flux of 200 $\mathrm{mm} /$ year

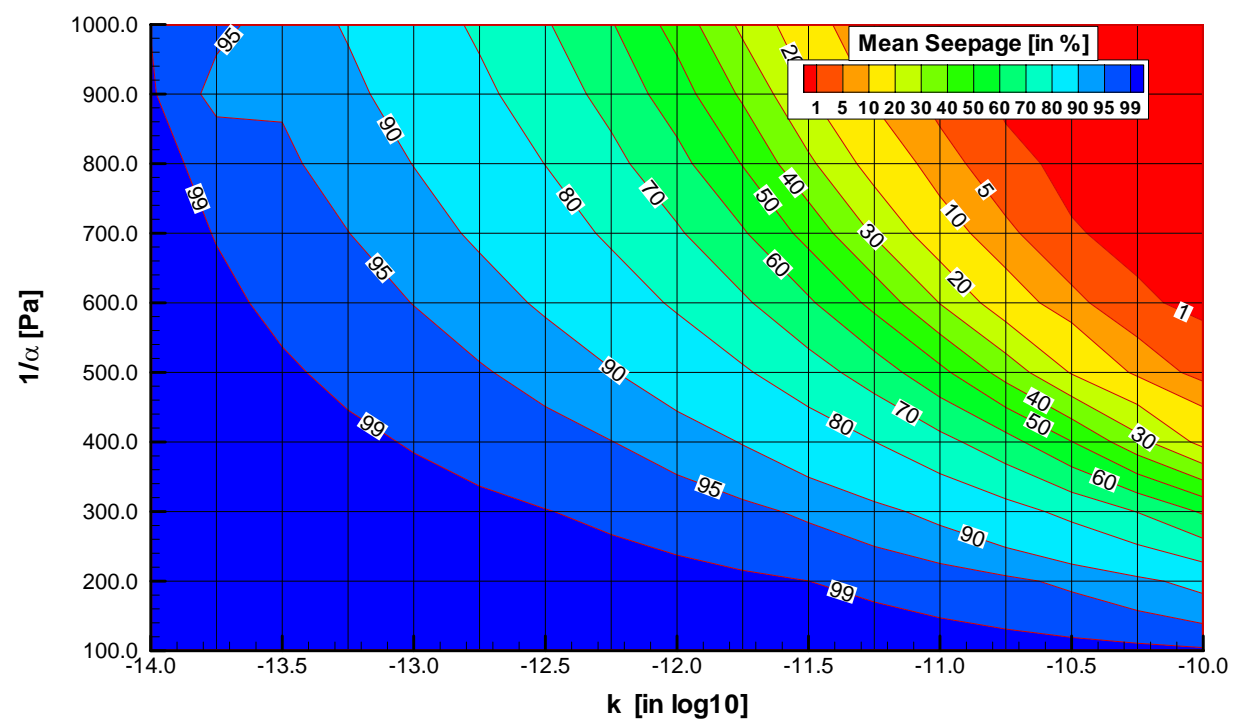

Source: LB0307SEEPDRCL.002 [DIRS 164337].

NOTE: Horizontal and vertical lines indicate simulated parameter cases. Permeability values in $\log 10$ of unit $\mathrm{m}^{2}$.

Figure 6.4-11. Mean Seepage Percentage for the Collapsed Drift Scenario as a Function of Capillary-Strength Parameter and Mean Permeability for a Percolation Flux of 500 mm/year 


\subsubsection{Model Results: Impact of Rock Bolts}

To evaluate the potential impact of rock-bolt ground support on seepage, a refined seepage model including rock bolts was developed (BSC 2004 [DIRS 167652], Section 6.5). The model features a 3-meter long rock-bolt borehole extending vertically upward from the crown of a drift, consistent with the current repository ground support design (BSC 2004 [DIRS 169058]). A fine discretization was chosen at the interface between the rock and the borehole, using grid elements as small as $0.1 \mathrm{~mm}$. The model was applied to several selected simulation cases, using a representative range of formation properties and percolation fluxes.

As pointed out in Section 6.3.1, the current repository design uses rock bolts without grout. In contrast, the base-case simulation model in BSC (2004 [DIRS 167652], Section 6.5) considered grouted boreholes, which is consistent with previous repository designs. A wide range of grout properties was simulated to account for the fact that the grout would most likely not retain its designed hydraulic properties over many thousands of years. In particular, one sensitivity case, designated to represent completely disintegrated grout in the borehole, used a large grout permeability of $10^{-10} \mathrm{~m}^{2}$ and a small capillary strength of $10 \mathrm{~Pa}$, which corresponds essentially to an open rock-bolt borehole (BSC 2004 [DIRS 167652], Section 6.5, Figure 6-3, Case G2). This is the simulation case relevant for seepage abstraction.

Results of the SMPA simulations with explicit consideration of rock bolts are described in BSC (2004 [DIRS 167652], Section 6.6.4). Essentially, no seepage enhancement was found for the simulation case representing an open rock-bolt borehole without grout (BSC 2004 [DIRS 167652], Table 6-4, Case G2). This result is understandable, considering that the open rock-bolt borehole acts as a capillary barrier to flow in the fractured rock, similar to the barrier that exists at the rock-drift interface. Also, the cross-sectional area between the open rock-bolt borehole and the rock is rather small. Thus, the presence of open rock-bolt boreholes is not considered a major factor for seepage into drifts.

\subsubsection{TH Seepage Model}

The TH Seepage Model is employed to evaluate the coupled TH processes-and their impact on seepage processes - in the vicinity of waste emplacement drifts during the heating phase of the repository (BSC 2004 [DIRS 170338]). This drift-scale process model is designed to analyze the combined effect of the two barriers that may prevent seepage into drifts at elevated temperatures: (1) the capillary barrier, which is independent of the thermal conditions, and (2) the vaporization barrier, which is in effect only if boiling temperatures prevail. While incorporating the conceptual framework for ambient seepage from the SCM, the TH Seepage Model accounts for all important flow and energy transport processes in response to the heat emplacement. Transient simulations were performed to explicitly calculate fluid flow down to the drift during the heating phase of the repository, and to directly calculate transient seepage rates into the drift. Results of this model are used in the seepage abstraction model to develop an appropriate methodology of adjusting the SMPA results to account for thermally perturbed conditions. The main thermal analyses with the $\mathrm{TH}$ Seepage Model are conducted for nondegraded drifts. Complementary modeling analyses on the impact of drift collapse on the TH behavior are presented in Section 6.4.3.4. The following sections provide a discussion on the 
model concept, the validation work, and results of the TH Seepage Model, summarized from the more detailed description in BSC (2004 [DIRS 170338]).

\subsubsection{Model Description}

Simulation of the coupled $\mathrm{TH}$ processes in fractured rock requires a modeling framework of considerable complexity. The processes described by the TH Seepage Model include the movement of both gaseous and liquid phases, transport of latent and sensible heat, phase transition between liquid and vapor, and vapor pressure lowering (BSC 2004 [DIRS 170338], Section 6.2.1.1.3). While fluid flow is described with a multiphase extension of Darcy's law, heat flow occurs by conduction (with heat conductivity a function of saturation) and convection. The thermodynamic conditions are based on a local equilibrium model of the three phases (liquid, gas, and solid rock). In contrast to the SCM and the SMPA, where only the fracture continuum is represented, the contribution of the rock matrix cannot be neglected in $\mathrm{TH}$ simulations. The fractured rock is therefore treated as a dual-permeability domain, accounting for the fractures and the rock matrix as two separate, overlapping continua (Doughty 1999 [DIRS 135997]). The active fracture model (AFM) is employed to account for the fact that unsaturated flow may be restricted to a limited number of (active) fractures and that flow within a fracture is likely to be channelized (Liu et al. 1998 [DIRS 105729], p. 2636). Both effects may effectively reduce fracture-matrix interaction, and thus have to be considered in $\mathrm{TH}$ simulations where strong transfer of vapor and condensate is expected between the fractures and the matrix. For further details on the conceptual framework of the TH Seepage Model, see BSC (2004 [DIRS 170338], Section 6.2.1). Rock-property changes as a result of THM and THC effects are not considered in the TH Seepage Model. These are evaluated with separate models as discussed in Section 6.4.4.

Based on the recommendations listed in Section 6.4.1.2 of this report, the conceptual framework for seepage in the TH Seepage Model is similar to the SCM and SMPA conceptualization. A stochastic continuum model is implemented for fractures near the drift that considers the small-scale variability of permeability to account for flow channeling. The capillary-strength parameter close to the drift wall is derived from the properties provided by the SCM calibration (BSC 2004 [DIRS 170338], Section 6.2.1.1.2). Also, the specific seepage boundary condition used in the SCM is implemented for fracture continuum gridblocks immediately at the rock-drift interface. Seepage from the rock matrix into the drift is unlikely because of the large capillary strength of the matrix and the overall small matrix flow; thus, seepage from the matrix into the drift is neglected in the TH Seepage Model.

In contrast to ambient seepage, the thermal seepage behavior of the fractured rock is simulated with a two-dimensional (2-D) model, in a vertical model domain perpendicular to the drift axis. Considering that several simulation cases must be studied to account for the variability in rock properties and boundary conditions important for thermal seepage, a full 3-D simulation of the coupled processes is not feasible because of computational limitations. Similar to the SCM and the SMPA, the TH Seepage Model needs to focus on near-drift conditions, using a refined discretization in the drift vicinity. However, at the same time, the TH simulation requires a large vertical model domain because the thermally disturbed zone extends far into the overlying and underlying geological units. As a result, a 3-D simulation model would be too time-consuming to allow for a large number of simulation runs, which was needed in the thermal seepage study to 
cover a wide range of parameters and conditions relevant for seepage. The main consequences of using a 2-D representation of the drift-scale $\mathrm{TH}$ processes and the impact on the thermal seepage model are discussed in BSC (2004 [DIRS 170338], Section 6.2.1.2). It was concluded that the 2-D representation used in the TH Seepage Model is adequate for the intended application of predicting thermal seepage.

To account for the two main host-rock units of the repository, two submodels with slightly different numerical gridding and different stratigraphy were studied with the TH Seepage Model. The first one, the Tptpmn Submodel, considers a drift located in the Topopah Spring tuff middle nonlithophysal unit (Tptpmn unit). The second one is the Tptpll Submodel, which considers a drift located in the Topopah Spring tuff lower lithophysal unit (Tptpll unit). In both submodels, the discretization in close vicinity to the drift is identical; the differences occur only at some distance from the drifts where geological contacts to other rock units are encountered. As an example, Figure 6.4-12 shows the discretization chosen for the Tptpmn Submodel, illustrating the entire vertical mesh and a close-up view of the drift vicinity. The model extends from the ground surface at the top-with an open atmosphere boundary condition- to the water table at the bottom-represented as a flat, stable surface. Symmetry considerations were applied to reduce the model domain in the lateral direction, perpendicular to the drift axis, to increase the computational efficiency of the simulation runs. The current repository design of parallel drifts spaced at 81 meters can be represented as a series of symmetrical, identical half-drift models with vertical no-flow boundaries between them. Accordingly, the numerical mesh was reduced to a half-drift model with a width of 40.5 meters, extending from the drift center to the midpoint between drifts.

Note that the grid design of the TH Seepage Model is different from the ambient seepage studies, in that it uses radial symmetry and small gridblocks in the drift vicinity with gradual conversion into larger cartesian gridblocks at increasing distance from the drift. This is important for $\mathrm{TH}$ models because sufficient resolution is provided at key locations where steep gradients of $\mathrm{TH}$ properties occur, while maintaining computational efficiency. At the drift wall, gridblocks are about $20 \mathrm{~cm}$ in the radial direction, which is twice the size of the uniform gridblocks used in ambient seepage models. To account for spatial variability in the drift vicinity, stochastic permeability values with random correlation structure and a standard deviation of $\sigma_{s}=0.84$ (in log10 space) are mapped to the gridblocks. The same random structure is used for both the Tptpmn and the Tptpll Submodels. The selected standard deviation is slightly smaller than the value of 1.0 used in the current revisions of SMPA modeling analysis (BSC 2004 [DIRS 167652], Section 6.3.3). It was taken from BSC (2004 [DIRS 171764], Table 6-4, Niches 3107, 3650, and 4788), representing the maximum standard deviation from small-scale disturbed-zone air permeability tests conducted in Tptpmn unit niches (see Table 6.6-3). Note that the respective standard deviations for measurements in the Tptpll unit range from 0.51 (the scale-adjusted value for testing in borehole SYBT-ECRB-LA\#2) to 1.31 (the value for Niche 1620), as discussed in Section 6.6.3.1. Thus, the chosen standard deviation of $\sigma_{s}=0.84$ is similar to the average standard deviation measured in the Tptpll unit. The differences in the grid design and the stochastic parameter representation will bring out differences in the model results between the ambient and thermal seepage models, which are analyzed in Section 6.2.2.2.2 of BSC (2004 [DIRS 170338]). The relevance of these differences for seepage abstraction is discussed in Section 6.5.2 of this model report. 


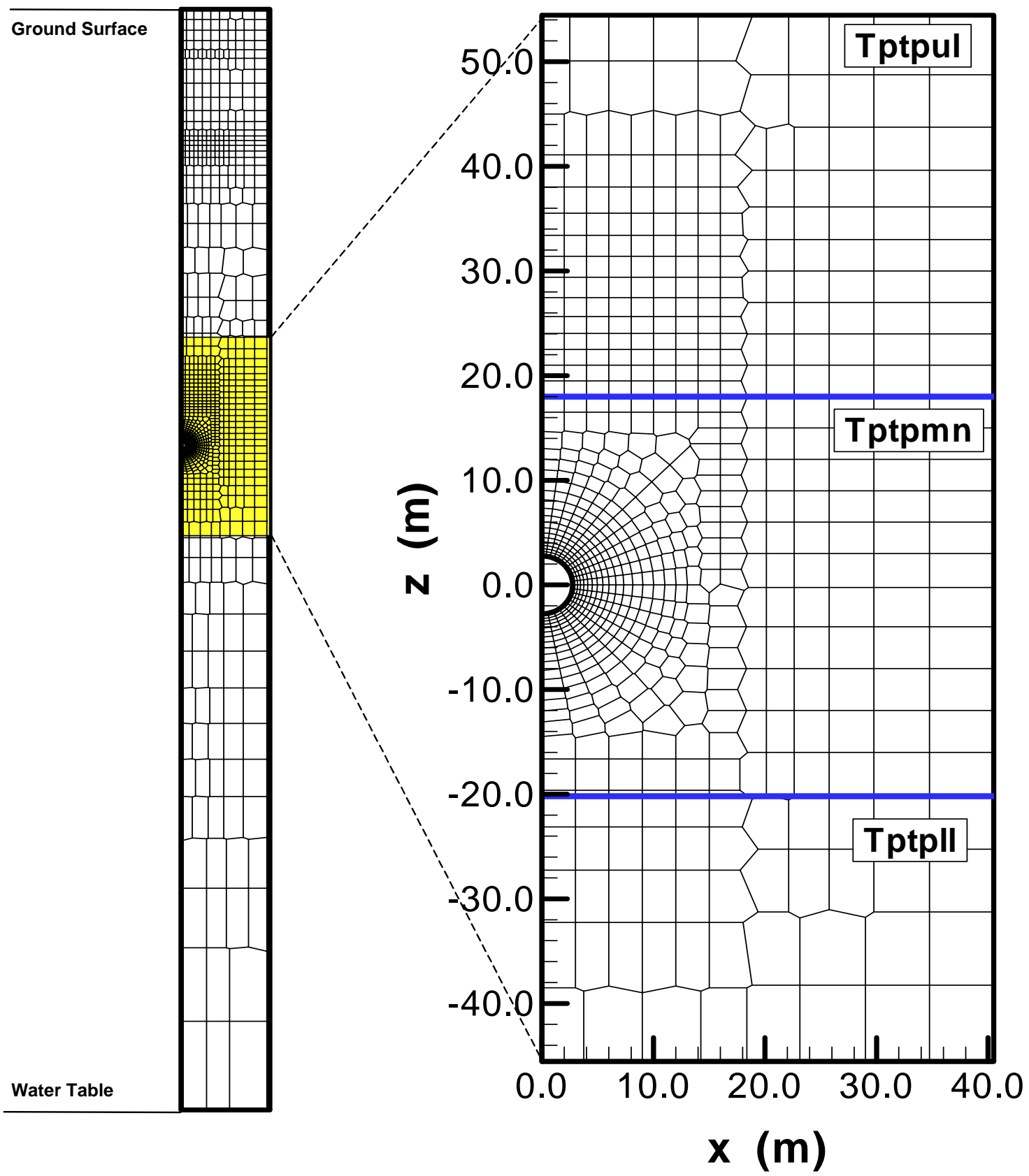

Source: BSC (2004 [DIRS 170338], Figure 6.2.1.2-1).

NOTE: In this example, the emplacement drift is located in the Tptpmn unit (Tptpmn Submodel).

Figure 6.4-12. Example of Numerical Grid for the TH Seepage Model 
Predictive simulations with the TH Seepage Model were performed for two main suites of simulation cases. The first suite of cases addresses the relevant $\mathrm{TH}$ conditions in the drift vicinity, mainly for informative purposes. The second suite of cases focuses specifically on the potential of thermal seepage for further use in seepage abstraction and TSPA, applying the specific modeling framework for seepage that was outlined in Section 6.4.1. Because modeling of coupled processes is so computationally intensive, it was not feasible to conduct a systematic study with thousands of parameter combinations as done with the SMPA. Thus, it was not possible to arrive at similar look-up tables that would provide the rate of thermal seepage as a function of various parameters. Instead, sensitivity analyses were performed with selected simulation cases, varying a small number of parameters that are important for thermal seepage. The scope of this study was to demonstrate that thermal seepage can be described by a simple abstraction method that uses the ambient seepage rates as a base estimate. Thus, modeling results from the TH Seepage Model are not expected to provide the exact quantitative amount of seepage for all possible parameter combinations. Rather, the model is expected to qualitatively describe the evolution of seepage in comparison to the ambient seepage rates. Enough sensitivity cases must be considered to demonstrate that the proposed simple abstraction method for thermal seepage holds for the relevant ranges of parameters (see Section 6.4.3.3).

The relevant parameters varied in the evaluation of thermal seepage were the thermal operating mode, the local percolation flux, and selected rock properties such as permeability, capillary strength, and thermal conductivity. The parameter ranges studied were chosen to cover the expected variability and uncertainty in these relevant factors. The temperature conditions, for example, will vary considerably in the repository, arising from heat-output variation among individual waste packages, emplacement-time differences among repository sections, and threedimensional (3-D) edge effects (e.g., BSC 2004 [DIRS 169565]). Therefore, four different thermal operating modes were analyzed with the TH Seepage Model (BSC 2004 [DIRS 170338], Table 6.2.1.3-1). The "reference mode" denotes a thermal load representative of the average thermal conditions for the current repository design, resulting in maximum rock temperatures above the boiling point of water for several hundred years close to the emplacement drifts. The other thermal-operating modes are studied as sensitivity cases, resulting in rock temperature conditions that can be as high as $143^{\circ} \mathrm{C}$ ("high-temp" mode), that will barely exceed boiling temperature ("additional heat mode"), and that will never even reach boiling conditions ("low-temp mode"). In each case, the thermal load is reduced by a large percentage during the preclosure period-as the forced ventilation effectively removes heat from the emplacement drifts - and decreases with time as a result of the radioactive decay (BSC 2004 [DIRS 170338], Section 6.2.1.3.3).

As explained in Section 6.6.5.1, the local percolation fluxes arriving at emplacement drifts can vary considerably in space and will be affected by future climate changes. The TH Seepage Model accounts for this spatial and temporal variation by using appropriate flux boundary conditions at the top of the model domain. Consistent with the future climate analyses for the Yucca Mountain (BSC 2004 [DIRS 170002]; BSC 2004 [DIRS 170007]), the model considers three long-term climate states with constant net infiltration: the present-day climate (up to 600 years from now), the monsoon climate (600-2,000 years from now), and the glacial transition climate (more than 2,000 years from now). The base-case simulation (the most likely percolation flux scenario) has assigned percolation fluxes of 6, 16, and $25 \mathrm{~mm} /$ year, respectively, for these three periods (BSC 2004 [DIRS 170338], Table 6.2.1.4-1), slightly larger than the 
average fluxes over the repository area for the mean infiltration scenario (see Table 6.6-11). These average fluxes may vary because of spatial variability in surface infiltration, heterogeneity in rock properties, flow diversion at stratigraphic contacts, and flow focusing, giving maximum fluxes much larger than the average values (see Section 6.6.5). Five other flux scenarios have been studied with the TH Seepage Model to cover the expected range of percolation fluxes within the repository units. These scenarios have fluxes larger than the base case flux because the relevant cases for seepage to occur are cases where the percolation flux is comparably high. The five scenarios are defined by multiplying the boundary fluxes of the base case using factors of $5,10,20,40$, and 100 . For the three climate states, the resulting fluxes are: (1) 30, 80, and $125 \mathrm{~mm} /$ year for a multiplication factor of 5; (2) 60, 160, $250 \mathrm{~mm} /$ year for a multiplication factor of 10; (3) 120, 320, and $500 \mathrm{~mm} /$ year for a multiplication factor of 20, (4) 240, 640, and $1,000 \mathrm{~mm} /$ year for a multiplication factor of 40 , and $600,1,600$, and 2,500 mm/year for a multiplication factor of 100 . Together, the five cases more than adequately cover the possible range of percolation fluxes at any location and future time period at Yucca Mountain. As pointed out in Section 6.6.5.3, the maximum possible flux that can be expected at the repository horizon is about $1,400 \mathrm{~mm} /$ year during the glacial transition climate stage (using the upperbound infiltration scenario). However, while this maximum flux is theoretically possible (as a result of climate changes, spatial variability, and flow focusing), all fluxes above 1,000 mm/year are extremely unlikely (i.e., they have very small probabilities in the TSPA-LA calculation, see footnote in Section 6.6.5.3). Thus, the percolation flux scenario with a multiplication factor of 40 is an upper bounding case for the conditions at Yucca Mountain. The percolation flux scenario with a multiplication factor of 100 is an extreme parameter case that is not realistic. It was only chosen to test the general concept of the vaporization barrier for extreme flow events, but is a zero-probability scenario for TSPA.

As mentioned above, the percolation flux boundary condition is applied at the top of the model domain, which represents the ground surface. The ground surface was selected as the top boundary because appropriate boundary conditions for temperature, pressure, and saturation can be easily defined. It is important to note, however, that the definition of boundary fluxes at this location faces a conceptual difficulty for a drift-scale model such as the TH Seepage Model. This is because the percolation flux distribution below the Paintbrush nonwelded hydrogeological unit (PTn), which defines the $\mathrm{TH}$ conditions in the repository units, is considerably different from the distribution of net infiltration at the ground surface, mainly a result of lateral diversion in the PTn. Since the TH Seepage Model is essentially a vertical column model, it cannot account for lateral flow diversion in the PTn. Therefore, instead of using the net infiltration rates at the top boundary, the TH Seepage Model needs to use boundary fluxes representative of the fluxes within the repository units. Thus, the flux boundary conditions at the top of the model domain are designated to represent the range of percolation fluxes below the PTn rather than the range of net infiltration at the ground surface. (Note that this approach is appropriate because the PTn fluxes are hardly affected by TH processes.) As discussed in Section 6.6.5.1, the distribution of percolation fluxes below the PTn is provided by simulation results from the three-dimensional UZ Flow Model (BSC 2004 [DIRS 169861]).

The rock properties assigned to the various stratigraphic units in the TH Seepage Model have been mainly derived from site-scale calibration runs (most hydrological properties) and supplemental data analyses (thermal properties). Since these properties are different for the Tptpmn and the Tptpll units, some effect of parameter variation is already accounted for by 
analyzing the Tptpmn and the Tptpll Submodels. The rock properties that have the strongest impact on the TH conditions in the fractured tuff are the thermal properties, most importantly the bulk thermal conductivity (important for conductive heat transport) and the fracture permeability (important for moisture redistribution). In the TH Seepage Model, the bulk thermal conductivity varies by about 10 percent between the Tptpmn and the Tptpll units, while fracture permeability varies by about one-half order of magnitude (BSC 2004 [DIRS 170338], Table 4.1-2). These parameter ranges are smaller than the estimated variability of these properties over the repository area, as discussed below. Therefore, additional simulation cases were conducted with the $\mathrm{TH}$ Seepage Model varying the thermal conductivity and the mean fracture permeability of the host rock (BSC 2004 [DIRS 170338], Section 6.2.4.2.2). The variation of thermal conductivity is based on the spatial variability reported in Table 6-6 of BSC (2004 [DIRS 169854]), with standard deviations of about $0.25 \mathrm{~W} / \mathrm{m} / \mathrm{K}$ for both dry and wet thermal conductivities in the repository units. Sensitivities are studied for a large-conductivity case, where the base case values are increased by $0.25 \mathrm{~W} / \mathrm{m} / \mathrm{K}$, as well as a small-conductivity case, with the base case values decreased by $0.25 \mathrm{~W} / \mathrm{m} / \mathrm{K}$. The variation of mean fracture permeability is based on the estimated spatial variability of this property over the repository area, as derived in Section 6.6.3. The impact of fracture permeability variation is studied using sensitivity cases with three standard deviations above and below the base case value. Analyses are conducted for the Tptpmn unit, where the standard deviation is 0.34 in log10 permeability (see Section 6.7.1.1). Thus, a three-standard-deviation change refers to roughly a one-order-of-magnitude variation above and below the mean.

For consistency with the ambient seepage models, the capillary-strength parameters close to the drift wall must be based on the effective properties provided by the SCM calibration. In the TH Seepage Model, these calibrated parameters were applied to the entire unit hosting the emplacement drifts, for reasons explained in BSC (2004 [DIRS 170338], Section 6.2.2.1.4). A base-case value of $1 / \alpha=589 \mathrm{~Pa}$ was assigned to both the Tptpmn and the Tptpll units, similar to the mean value of the respective probability distribution developed in Section 6.4.1 of this report (591 $\mathrm{Pa})$. As a sensitivity case, the capillary-strength parameter was set to a smaller value of $400 \mathrm{~Pa}$ (i.e., a parameter choice promoting seepage), similar to the lower bound of the respective probability distribution that describes the spatial variability of this parameter (402 $\mathrm{Pa}$ ), as derived in Section 6.6.2. Additional sensitivity analyses were conducted to evaluate the impact of different conceptual models for fracture-matrix interaction. The AFM, used for the base-case simulations, was compared to a standard dual-permeability method in which all fractures are considered "actively" flowing. It was demonstrated that the seepage rates calculated with the AFM are slightly higher than the DKM results. Note that the AFM is not needed for the drift-scale seepage models considering ambient conditions, such as the SCM and the SMPA, because (1) fracture-matrix interaction is not relevant for the steady-state simulations employed in these ambient seepage predictions, and (2) the effect of flow channeling on ambient seepage is already accounted for through explicit modeling of small-scale heterogeneity in the SCM and the SMPA. Also, the potential impact of all AFM effects on ambient seepage are automatically reflected in the observed seepage-rate data from liquid release tests and thus represented in the effective capillary-strength parameters calibrated by the SCM (BSC 2004 [DIRS 171764], Section 6.3.2). Other conceptual model choices were also tested in the sensitivity analyses (e.g., fracture-matrix interface thermal conductivity, in-drift model parameters), but effects on thermal seepage were shown to be negligible. 


\subsubsection{Model Validation}

The TH Seepage Model was validated in comparison with the measured TH response from a large-scale in situ heater test conducted at Yucca Mountain (BSC 2004 [DIRS 170338], Section 7). This test, the so-called Drift Scale Test (DST), is well-suited for validation of the local $\mathrm{TH}$ processes because its geometry and dimensions are similar to the design of waste emplacement drifts. The model validation included quantitative evaluation of continuously measured temperature data-with a detailed analysis of subtle temperature signals indicative of TH coupling-as well as qualitative evaluation of periodic measurements that monitored moisture redistribution processes, using geophysical methods, air-injection data, and withdrawal of liquid water in packed-off boreholes. It was concluded from the good overall agreement between model and data that the uncertainty of predicted temperature, saturation, and water flux data was within acceptable ranges, demonstrating that the model is valid.

As pointed out in BSC (2004 [DIRS 170338], Section 8.3), there are limitations related to the validation of the TH Seepage Model. While the DST results-as well as results from the other in situ tests-allow model validation with respect to the strongly perturbed near-field $\mathrm{TH}$ conditions in the rock mass, they offer no seepage data (observed seepage rates) that could be used directly for thermal seepage validation purposes. Direct validation of thermal seepage would require a heater test operated at artificially enhanced percolation fluxes, to observe the seepage potential for extreme percolation conditions. Also, there was concern that the setup of the DST was allowing vapor (and heat) to escape from the heated drift through the bulkhead (BSC 2004 [DIRS 170338], Section 7.3.4). A detailed evaluation of this issue is presented in the informal thermal test progress report \#7 (Williams 2001 [DIRS 160809], Sections 3.2 and 3.3) and in Mukhopadhyay and Tsang (2003 [DIRS 160790], Sections 2 and 3). It was concluded that the objectives of the DST-acquiring a more in-depth understanding of the coupled $\mathrm{TH}$ processes and validating the conceptual models in comparison with data-were being met despite these heat and mass losses. However, it was also understood that the measurements in the DST should not be directly used to evaluate the potential of seepage into drifts during the thermal period, because the potential of seepage in the DST might be reduced as a result of the vapor losses. As a result of these limitations, validation of the seepage part of the TH Seepage Model is an indirect one, based on a separate assessment of the two relevant barriers. Validation of the coupled TH processes (using the DST data and data from other in situ tests) provides confidence regarding the predicted effectiveness of the vaporization barrier, while validation of the ambient-seepage conceptual model (using liquid-release data) provides confidence regarding the predicted effectiveness of the capillary barrier. (The conceptual framework for the capillary barrier treatment in the TH Seepage Model can already be considered validated, because the conceptual model is identical to the one validated and successfully applied in the SCM [see Section 6.4.1.1].) However, some uncertainty remains, since no direct test data on thermal seepage at extreme flux conditions are available. Another limitation stems from the fact that no heater testing has been performed in the lower lithophysal unit. Thus, validation of the $\mathrm{TH}$ Seepage Model does not include direct comparison with measured data from the Tptpll unit. While application of the validated model to the Tptpll unit is appropriate, since similar $\mathrm{TH}$ processes need to be described, some uncertainty remains about the rock properties in this unit and the influence of lithophysal cavities. This uncertainty is accounted for by choosing an upper-bound abstraction method for thermal seepage (see Section 6.5.2). 
The TH Seepage Model predictions regarding the effectiveness of the vaporization barrier were also tested in comparison with an alternative conceptual model of water flow in the superheated rock environment (BSC 2004 [DIRS 170338], Section 6.3). In this model, the thermally perturbed downward flux from the condensation zone towards the superheated rock zone is conceptualized to form in episodic preferential-flow patterns. The effectiveness of the vaporization barrier was then tested for these extreme conditions where downward flux is fast and large in magnitude compared to average flow. A semi-analytical solution (Birkholzer 2003 [DIRS 163686]) was employed to simulate the complex flow processes of episodic finger flow in a superheated fracture. With this solution, the maximum penetration distance into the superheated rock was determined for specific episodic flow events and thermal conditions, and the amount of water arriving at the drift crown was calculated.

It was demonstrated in BSC (2004 [DIRS 170338], Section 6.3) that results of the alternative conceptual model are fairly consistent with the process-model results obtained with the TH Seepage Model. Most importantly, it was shown that finger flow is not likely to penetrate through the superheated rock during the first several hundred years of heating, when rock temperature is high and boiling conditions exist in a sufficiently large region above the drifts. These are the conditions when the largest thermal perturbation occurs, or, in other words, when the potential for episodic finger flow is highest. Only later, when the boiling zone is small and the impact of vaporization is limited, can finger flow arrive at the drift crown. The fact that water can reach the drift during the period of above-boiling temperatures makes the alternative conceptual model distinct from the TH Seepage Model. However, the strong thermal perturbation observed at early heating stages has already diminished during this time period, and the net result of water arrival at the drift-considering the combined impact of water buildup in the condensation zone and vaporization in the superheated zone-is similar to ambient percolation. It was pointed out (BSC 2004 [DIRS 170338], Section 6.3) that seepage of water into the drift is not expected from this limited water arrival, because the flow should be effectively diverted around the drift by the capillary barrier capability of the cavity. Note that these findings were consistent over a wide range of finger flow characteristics studied in a sensitivity analysis, covering the potential uncertainty in finger flow patterns (BSC 2004 [DIRS 170338], Section 6.3.2). Thus, the alternative conceptual model results clearly supports the main findings of the TH Seepage Model, adding confidence into the model and reducing the conceptual model uncertainty.

\subsubsection{Model Results}

The TH Seepage Model was applied to simulate the TH coupled processes for a period of 4,000 years after waste emplacement. This is the period when the main flow perturbations are expected to occur as a result of heating. A series of selected simulation cases was conducted for both the Tptpmn and Tptpll Submodels, comprising different thermal loads, various percolation flux scenarios, different fracture permeability values, thermal conductivity values, as well as capillary-strength parameters, and different conceptual models choices (see overview of simulation cases in BSC 2004 [DIRS 170338], Section 6.2.1.6). The resulting simulation data sets are provided in DTNs: LB0303DSCPTHSM.001 [DIRS 163688] and LB0309DSCPTHSM.001 [DIRS 165538]. Transient seepage rates that were developed from these data sets are given in DTNs: LB0301DSCPTHSM.002 [DIRS 163689] and 
LB0309DSCPTHSM.002 [DIRS 165539]. The simulation results relevant for seepage abstraction are briefly discussed below.

For a given rock-property set, the predicted TH conditions are strongly driven by the thermal load placed into the drifts and by the local percolation flux. Example results are provided in Figure 6.4-13 in the form of rock temperature evolution along the perimeter of the drift for simulation cases with elevated percolation (flux multiplication factors of 5, 10, and 20) and different thermal modes. For the reference thermal mode, the heat generated from the waste canisters results in maximum rock temperatures at the drift wall between about $120^{\circ} \mathrm{C}$ and $130^{\circ} \mathrm{C}$, depending on the amount of percolation considered (see Figure 6.4-13a). Elevated percolation leads to cooler temperatures and a shorter boiling period. (For comparison, see Figure 6.2.2.2-2 of BSC (2004 [DIRS 170338]) using base-case percolation fluxes of 6, 16, and $25 \mathrm{~mm} /$ year for the three climate states. The period of above-boiling temperature is about 1,000 years for this base case, and rock temperature at the end of the simulation period is much higher at about $65^{\circ} \mathrm{C}$.)

All simulation cases in Figure 6.4-13a show a temperature plateau near the $96^{\circ} \mathrm{C}$-isotherm, with the temperature staying constant for some time before further decreasing. These plateaus are indicative of thermally driven two-phase circulation processes of vapor, water, and heat, referred to as heat pipes (see Section 6.3.2). The longest heat pipe duration corresponds to the simulation case with the highest percolation flux. In comparison, there is almost no heat pipe for the basecase percolation flux shown in Figure 6.2.2.2-2 of BSC (2004 [DIRS 170338]). This indicates that the intensity of the two-phase circulation flow is largely driven by the amount of percolation flux arriving at the heated drifts. Note also that the intensity of heat pipes varies locally as a result of heterogeneity, giving rise to considerable differences along the drift wall in the duration of the boiling period.

The three thermal modes depicted in Figure 6.4-13b result in boiling conditions in the drift vicinity, with the maximum temperature and the duration of the boiling period strongly dependant on the respective heat load. One other thermal mode discussed in BSC (2004 [DIRS 170338], Figure 6.2.2.1-12), the low-temp mode, results in rock temperatures that never reach boiling conditions. Thermal effects on flow and seepage are negligible in this case, so that the potential for thermal seepage can be estimated from ambient seepage results.

As a first assessment of the potential for thermal seepage, the moisture redistribution processes in response to boiling of rock water have been analyzed in BSC (2004 [DIRS 170338], Section 6.2) for all simulation cases. In general, thermal seepage is possible only when (a) water arrives at the drift crown, which can only happen when the vaporization barrier has failed, and (b) the saturation at the drift wall exceeds a given threshold value, defined by the capillary barrier effect at the rock-drift interface. The modeling results consistently demonstrate that the thermal perturbation of the flow field - causing increased downward flux from the condensation zone towards the drifts - is strongest during the first few hundred years after closure, corresponding to the time period when rock temperature is highest and the vaporization barrier is most effective. Even for high percolation fluxes into the model domain, and strong flow channeling as a result of fracture heterogeneity, water cannot penetrate far into the superheated rock during the time that rock temperature is above boiling. Thus, the potential for seepage is small. The majority of the vaporized (and subsequently condensed) matrix water is diverted 
around the dryout zone and drains away from the drift. At the time when temperature has returned to below-boiling conditions, fractures start rewetting at the drift wall. However, while the vaporization barrier has become ineffective, the capillary barrier at the drift wall may continue to reduce (or prevent) water seepage into the drift, as long as the seepage threshold saturation at the drift wall has not been exceeded. These transient processes are illustrated in Figure 6.4-14, giving the evolution of fracture saturation at all gridblocks adjacent to the drift wall. To illustrate the transient seepage behavior, a simulation case with large percolation flux has been selected so that seepage is eventually observed (BSC 2004 [DIRS 170338], Section 6.2.2.2.4, Simulation Case MN-HET-03). The saturation curves show that no water arrives at the drift during the boiling period of approximately 500 years duration. As rock temperature decreases to and below the boiling point, and the first stepwise change in the percolation boundary condition occurs at 600 years, the saturation values build up strongly, while significant variability in saturation becomes evident. Water starts seeping into the drift at about 1,400 years after emplacement when the seepage threshold saturation is exceeded.

Transient seepage rates were explicitly calculated by the TH Seepage Model to directly quantify the potential for seepage during the thermally perturbed time period. These transient seepage rates were compared with results from ambient (steady-state) simulations conducted to provide reference values for evaluating the vaporization barrier. This allows for comparison of seepage results considering the combined effectiveness of the vaporization and the capillary barrier with seepage results considering only the capillary barrier contribution. Ambient seepage rates were derived by running the thermal seepage model without thermal load until a steady state was achieved (BSC 2004 [DIRS 170338], Sections 6.2.2.2.2 and 6.2.3.2.2). This was done separately for each climate stage using the respective percolation-flux boundary condition.

Example results illustrating the evolution of thermal seepage are given in Figure 6.4-15, for the same simulation case as selected in Figure 6.4-14. The magnitude of seepage is provided in percent, relative to the total liquid flux percolating with constant boundary flux through an area corresponding to the footprint of the drift. There is no seepage until about 1,400 years after waste emplacement. Seepage starts to occur several hundred years after the rock temperatures have dropped below boiling conditions, the delay caused by the retarded saturation buildup in the fractures. Initially, thermal seepage is considerably smaller than the respective ambient seepage value. With the stepwise increase of percolation flux at 2,000 years, the thermal seepage percentage increases, but still remains smaller than ambient seepage. There is no enhanced seepage as a result of reflux of water (because most of the condensate has long before drained down away from the drift). At the end of the simulation period, the thermal seepage percentage is at 17 percent, slightly less than the ambient value of 20 percent.

Note that the ambient seepage percentage for the present-day infiltration rate with multiplication factor 10-i.e., $60 \mathrm{~mm} / \mathrm{year}$ - is zero in this case. In other words, even without heating of the repository, the capillary barrier at the drift wall is predicted to be fully effective during the first 600 years after waste emplacement. This provides additional confidence, as two barriers prevent seepage simultaneously and independently. It also suggests that incorporating the effect of vaporization into the seepage abstraction model may be less important than expected. This is because the period when vaporization processes are most effective coincides with the period of present-day climate, where percolation flux is comparably small and ambient seepage is much less likely than during the monsoon and the glacial transition climate. 


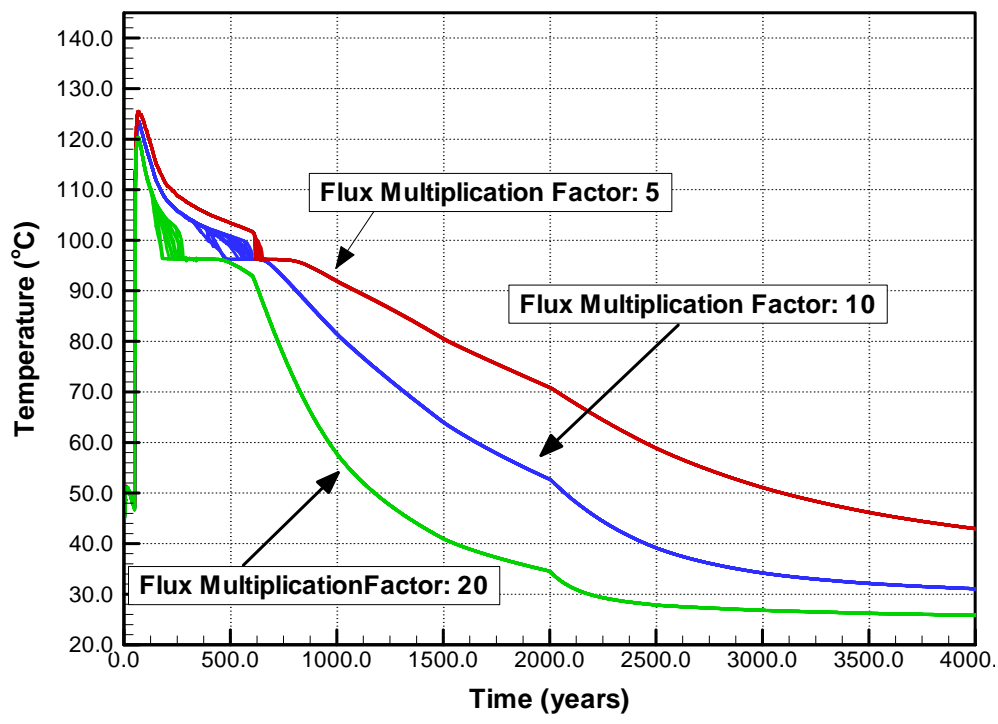

(a)

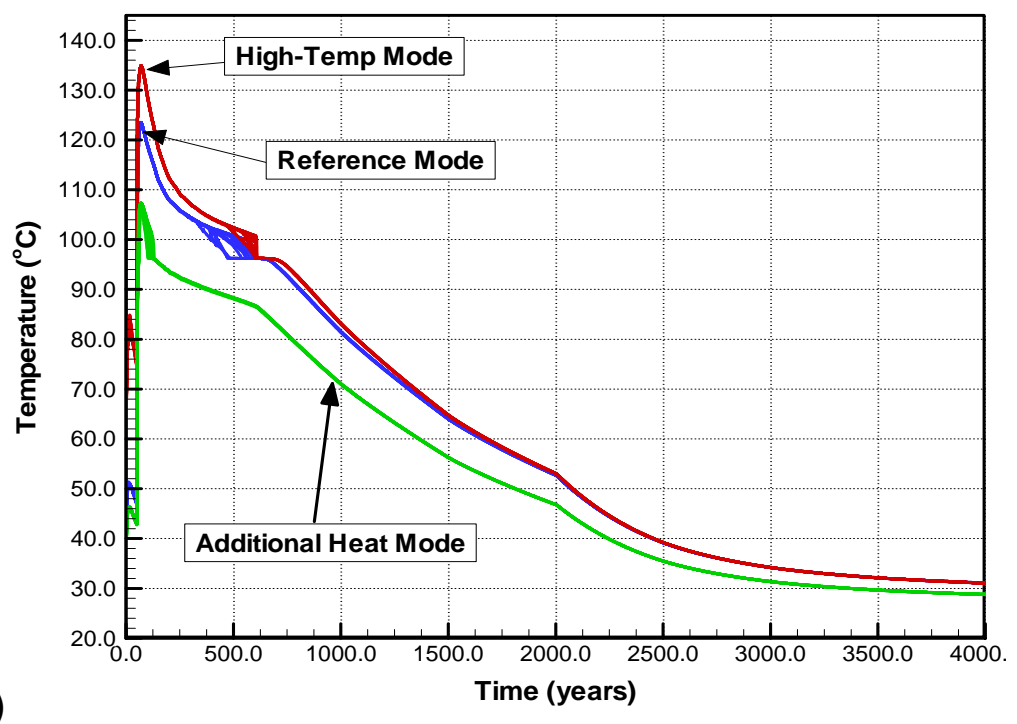

(b)

Source: (a) BSC (2004 [DIRS 170338], Figure 6.2.4.2-1).

(b) BSC (2004 [DIRS 170338], Figure 6.2.4.2-2).

NOTE: For each scenario, the temperature histories in all gridblocks along the drift perimeter are depicted in the same color.

Figure 6.4-13. Rock Temperature Evolution at the Drift Wall for Tptpmn Submodel Showing (a) Different Percolation Flux Scenarios for Reference Thermal Mode, and (b) Different Thermal Modes for Percolation Flux Scenario with a Multiplication Factor of 10 


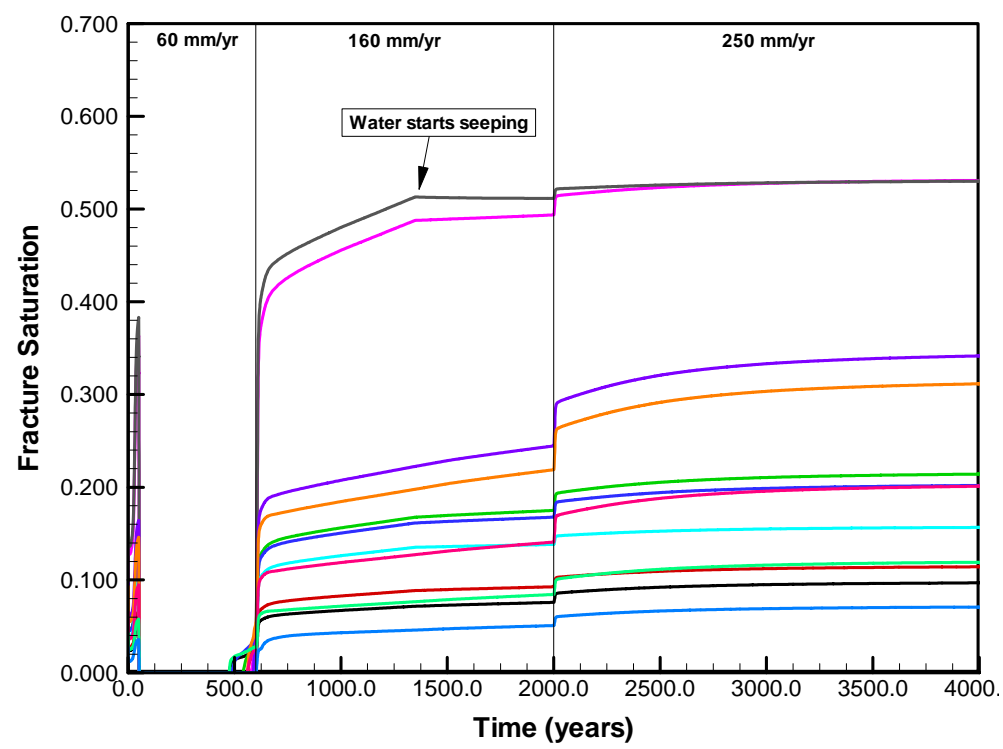

Source: BSC (2004 [DIRS 170338], Figure 6.2.2.2-7a).

Figure 6.4-14. Fracture Saturation in Different Gridblocks along Drift Perimeter for Tptpmn Submodel with Reference Thermal Mode Using Percolation Flux Scenario with a Multiplication Factor of 10

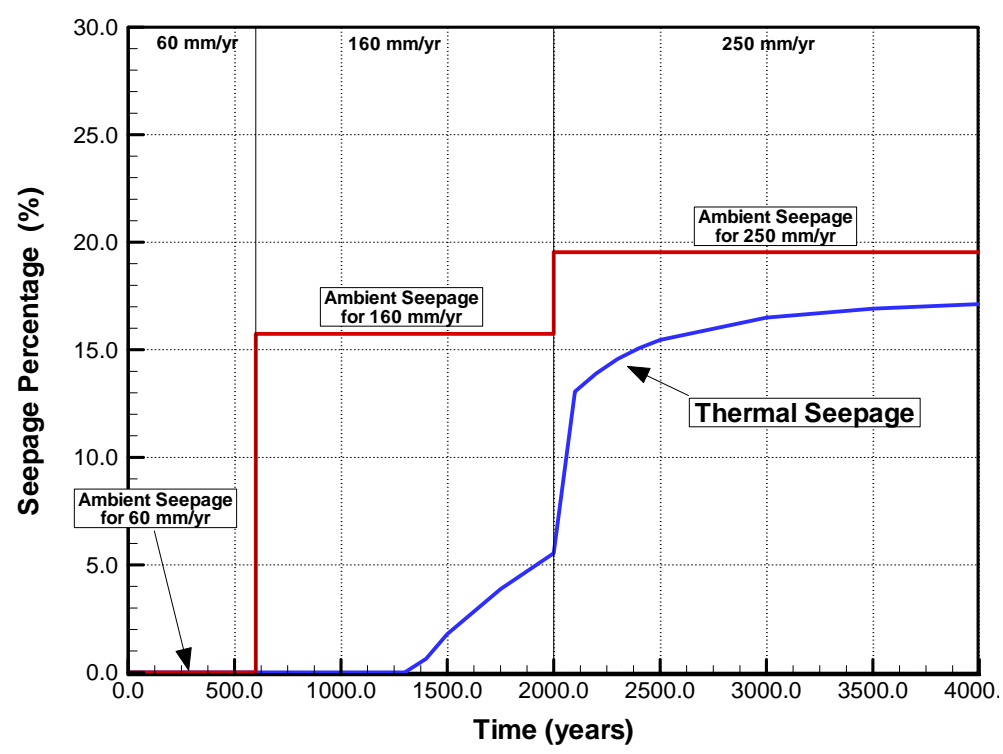

Source: BSC (2004 [DIRS 170338], Figure 6.2.2.2-7b).

Figure 6.4-15. Seepage Percentage for Tptpmn Submodel with Reference Thermal Mode Using Percolation Flux Scenario with a Multiplication Factor of 10 
As mentioned above, the different simulation cases studied with the TH Seepage Model show considerable variability with respect to the TH conditions in the rock. Thermal seepage results for these cases - including variation in percolation flux, thermal load, fracture capillary strength, fracture permeability, matrix thermal conductivity, and host rock unit as well as different realizations of random fields and conceptual model choices-are given in Figures 6.2.2.2-6 through 6.2.2.2-11, 6.2.3.2-1, 6.2.3.2-2, and 6.2.4.2-2 through 6.2.4.2-23 of BSC (2004 [DIRS 170338]). Despite the variability in thermal conditions between these cases, there were important observations with respect to thermal seepage that are common to all these figures (BSC 2004 [DIRS 170338], Sections 6.2.4):

- Conclusion (1): Thermal seepage was never observed in simulation runs where the respective ambient seepage was zero.

- Conclusion (2): Thermal seepage never occurred during the period of above-boiling temperatures in the rock close to the emplacement drifts.

- Conclusion (3): In simulation cases where ambient seepage was obtained, thermal seepage was initiated a few hundred to a few thousand years after rock temperature has returned to and below boiling.

- Conclusion (4): Thermal-seepage rates were always smaller than the respective ambient reference values. The ambient seepage values provide an asymptotic upper limit for thermal seepage.

While these main conclusions hold for all simulation cases, considerable variability exists among simulation runs with respect to the thermal-seepage initiation time, the evolution of seepage with time, and the long-term rate of thermal seepage.

From the quantitative and qualitative results presented in BSC (2004 [DIRS 170338], Sections 6.2.2.2.4, 6.2.3.2.3, and 6.2.4.2), the key parameters affecting thermal seepage can be categorized as follows: (1) parameters mainly affecting the TH conditions, (2) parameters mainly affecting the capillary barrier behavior, and (3) parameters with impact on both the $\mathrm{TH}$ conditions and the capillary barrier behavior.

The thermal load and thermal conductivity, for example, belong to the first category. Varying these parameters results in considerable differences in the duration of the boiling period and the predicted maximum temperature in the rock. These conditions are important for the initiation time and the evolution of thermal seepage, but do not change the ambient seepage rate (which defines the asymptotic upper limit for thermal seepage at later stages). Results showing the sensitivity of thermal seepage to the thermal load are given in Figures 6.2.4.2-3 and 6.2.4.2-4 of BSC (2004 [DIRS 170338]); the sensitivity to thermal conductivity is illustrated in Figures 6.2.4.2-10 and 6.2.4.2-11 of BSC (2004 [DIRS 170338]).

Fracture capillary strength belongs to the second category. This parameter has minor impact on the TH behavior in the fractured rock, as shown in Section 6.2.2.1.4 of BSC (2004 [DIRS 170338]), but significantly affects the asymptotic upper limit for thermal seepage at later stages. As a result of the different seepage threshold saturation, the initiation time and evolution 
of thermal seepage can also be affected. Results for a small capillary-strength parameter of $1 / \alpha=400 \mathrm{~Pa}$ are presented in BSC (2004 [DIRS 170338], Figure 6.2.4.2-7), to be compared with the respective simulation case using $1 / \alpha=589 \mathrm{~Pa}$ (BSC 2004 [DIRS 170338], Figure 6.2.2.2-7b, which is also Figure 6.4-15 in this model report).

The third category comprises parameters that are important for ambient seepage and also affect the intensity of TH coupling. Large percolation fluxes, for example, are typically related to large ambient seepage rates (see Section 6.4.1.2). At the same time, increased percolation flux gives rise to a reduction of temperature and a shorter duration of the boiling period. Thus, for large percolation fluxes, thermal seepage may start earlier and approach larger asymptotic values at later stages of heating. Example results illustrating the impact of percolation flux changes are given in Figures 6.2.4.2-3 through 6.2.4.2-6 of BSC (2004 [DIRS 170338]).

Changes in fracture permeability can also affect both the vaporization and the capillary barriers, but are expected to have counteracting effects on these barriers. Large permeabilities are generally beneficial for the performance of the capillary barrier, because they allow for more flow diversion around the drifts. The vaporization barrier, on the other hand, may be less effective because large permeabilities may cause strong heat-pipe processes that would result in lower rock temperatures and a shorter boiling period. This discussion indicates that the relationship between the relevant parameters and the seepage results can become very complicated when coupled TH processes are considered. Example results illustrating the sensitivity to fracture permeability are given in Figures 6.2.4.2-8 through 6.2.4.2-9 of BSC (2004 [DIRS 170338]).

\subsubsection{TH Conditions in Collapsed Drifts}

Emplacement drifts in the lower lithophysal unit may collapse in extreme cases as a result of seismic stresses. The collapsed drifts are expected to have about double the diameter and to be filled with fragmented rubble rock blocks separated by large voids (see Section 6.4.2.4.2). The thermal conditions in a collapsed drift will be different from those in an open drift, as discussed in BSC (2004 [DIRS 170338], Section 6.2.5) and schematically indicated in Figure 6.4-16. In an open, gas-filled drift, thermal radiation is strong enough to effectively transport heat to the drift walls, creating a $\mathrm{TH}$ environment in the rock above the drifts that combines capillary and vaporization barrier effects. Above a collapsed drift, a capillary barrier is still expected to form at the interface between the solid rock and the rubble material. Vaporization, on the other hand, may not be effective in the solid rock above the drift, because the rock temperatures at this location may never reach boiling. This is because (1) the drift size above the heat-producing waste canisters has increased after the collapse and (2) thermal conduction within the rubble material is less effective than thermal radiation within an open drift, giving rise to a much stronger in-drift temperature gradient. A vaporization barrier is not expected to develop at the crown of the collapsed drift, whereas significant vaporization will occur in the rubble material within the drift. This will give rise to in-drift TH processes that may or may not be beneficial for the integrity of waste canisters. Such processes may be particularly important when the drift collapse occurs early after waste emplacement. In this case, the falling rock blocks are still at ambient saturation, holding significant amounts of water that will boil off, condense, and possibly flow back towards the waste packages. Technically, from the definition given in 

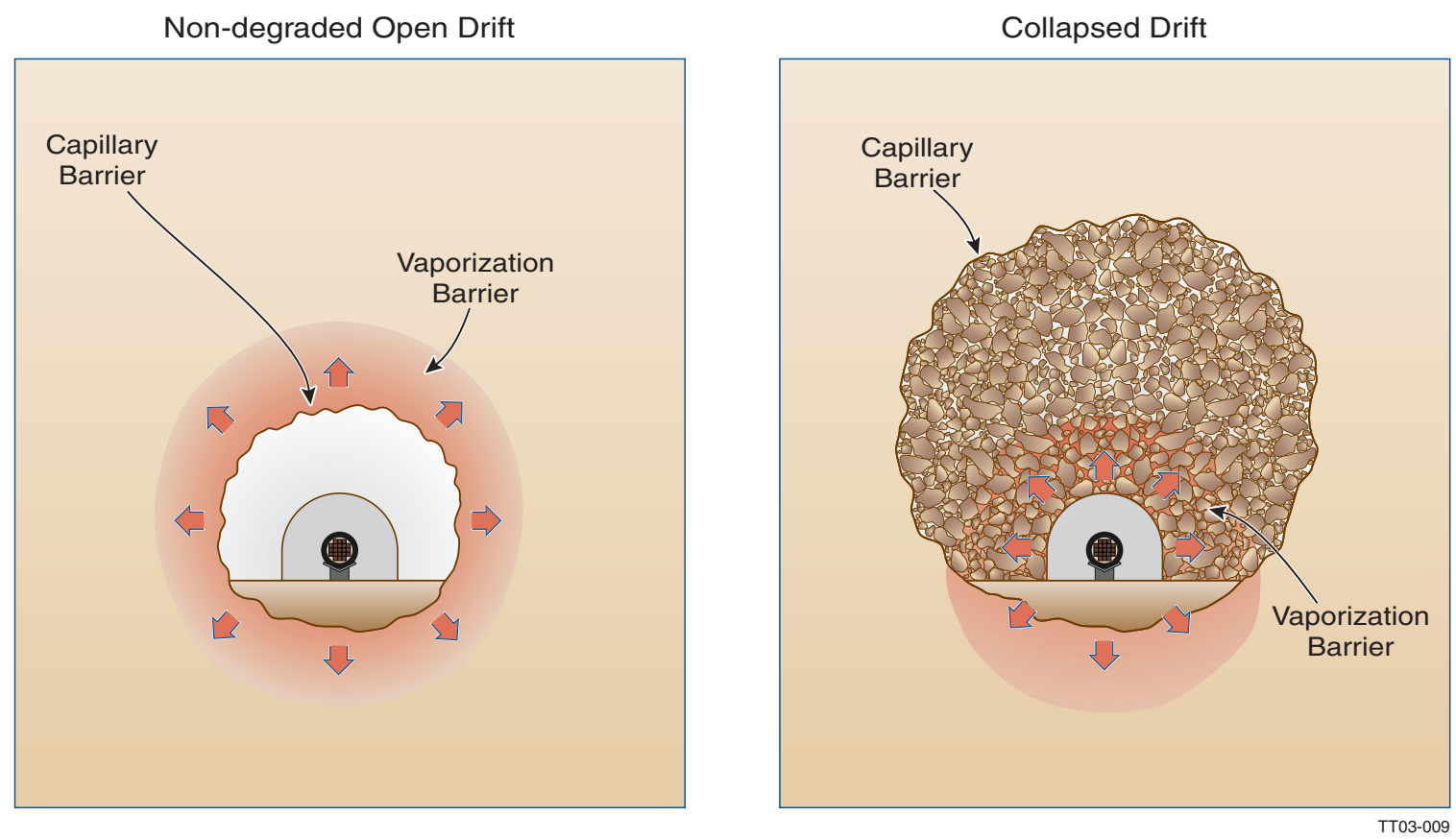

Source: BSC (2004 [DIRS 170338], Figure 6.2.5-1).

Figure 6.4-16. Schematic of TH Differences between an Open Nondegraded Drift and a Rubble-filled Collapsed Drift

Section 6.1.3, these in-drift processes are not considered seepage. However, they may lead to the presence of liquid water close to the waste packages and should therefore be investigated in the context of seepage abstraction.

Additional TH simulations were conducted with the TH Seepage Model to analyze the TH conditions within and around collapsed drifts and to determine the impact on seepage abstraction (BSC 2004 [DIRS 170338], Section 6.2.5). Results from these simulations are provided in DTNs: LB0310DSCPTHSM.001 [DIRS 165943] and LB0310DSCPTHSM.002 [DIRS 165944]. As a worst-case scenario, the drift collapse was assumed to occur immediately after emplacement of the radioactive waste. To account for drift collapse, the Tptpll Submodel was adjusted as indicated in Figure 6.4-17. All grid elements of the original Tptpll Submodel grid with their center nodes located in the collapsed drift (with the assumed 11-meter diameter) were converted into rubble material elements, with the exception of the waste package elements, the invert elements, and the air-filled space between the waste package and the drip shield. The main mechanisms of heat transfer within the rubble and between the rubble and the intact rock are conduction and convection; radiative heat transfer is expected to be negligible. Even if a small gap would form at the ceiling of the drift as a result of consolidation of the rubble material (which is not considered in the model), the open space would be too small to allow for significant radiative heat transfer. 


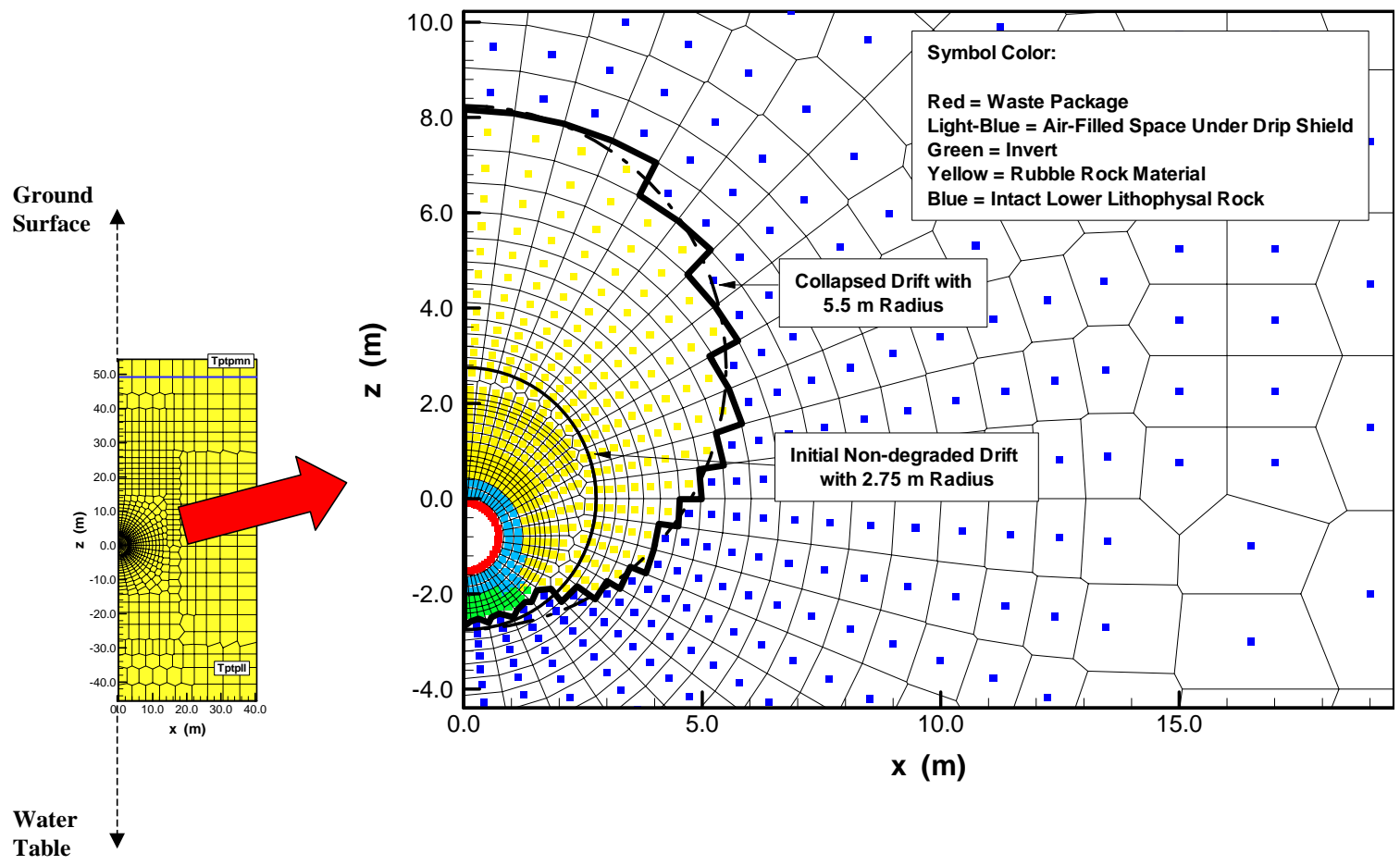

Source: Figure 1 in word file "TH Conditions in Collapsed Drifts.doc" from DTN LB0310DSCPTHSM.002 [DIRS 165944].

NOTE: The heavy line shows the model representation of the collapsed drift in the Tptpll Submodel. The entire model domain extends from the ground surface at the top down to the water table at the bottom. (In the vertical direction, $\mathrm{z}=0 \mathrm{~m}$ refers to the springline of the nondegraded drift).

Figure 6.4-17. Close-up View of the Collapsed Drift Discretization and Properties Assignment

The specific seepage modeling methodology from the TH Seepage Model-including fracture heterogeneity in the drift vicinity and using the SCM calibrated capillary strength values-was not implemented in the collapsed drift runs. As a result, the interface between the intact rock and the rubble-filled drift is an almost perfect capillary barrier, which allows seepage into the drift only for extreme parameter cases. Since the differences in capillary barrier behavior of collapsed drifts have already been addressed in the ambient seepage study presented in Section 6.4.2.4.2, the focus of the TH analysis was mainly on the changes in the TH conditions and the potential for in-drift flux perturbations, which can be evaluated with a less complex numerical model. Besides, since the basic grid design of the numerical mesh was not changed in the collapsed drift simulations, the gridblock size at the crown of the collapsed drift would be too coarse for accurately simulating the capillary barrier behavior. The condition that the grid resolution should be consistent with the SCM would not be met at this key location for ambient seepage. Thus, in contrast to the thermal seepage analyses for nondegraded drifts, the collapsed drift TH simulations are conducted using homogeneous rock properties in the drift vicinity.

An important task in BSC (2004 [DIRS 170338]) was to define reasonable TH properties for the rubble rock material after collapse. From BSC (2004 [DIRS 166107], Section 8.1), the rubble material consists of fragmented rock blocks with sizes on the order of centimeters to decimeters 
with large voids between them. The volume fraction of the voids was estimated in the $\mathrm{TH}$ Seepage Model from the selected bulking factors in Section 6.4.2.5 of BSC (2004 [DIRS 166107]). The bulking factor defines the volume increase of the rubble rock material after caving (volume $V_{B}$ ), compared to the initial intact volume $V$ of the collapsed rock. As to the $\mathrm{TH}$ properties of the rubble rock, the fragmented rock blocks have been assigned property values identical to the matrix properties of the intact rock, e.g., having the same small permeability and large capillary strength that are typically associated with the lithophysal tuff. Also the thermal conductivity and the heat capacity are similar to that of the lithophysal rock matrix.

While the above properties are based on measurements and related calibration effort, the properties of the open void space are unknown and had to be estimated in BSC (2004 [DIRS 170338], Section 5, Assumptions 6 and 7, and Section 6.2.5). Knowing that the open voids form a low capillary strength, high-permeability medium-comparable to a well-connected fracture network with very large apertures - the capillary strength of the void space was set to $100 \mathrm{~Pa}$ (similar to the ambient seepage studies for collapsed drifts) and the corresponding continuum permeability was chosen to be $10^{-10} \mathrm{~m}^{2}$ (about two orders of magnitude larger than the fracture continuum permeability of the Tptpll unit). Again, while these property values provide reasonable estimates, they remain uncertain because no direct measurements exist. This uncertainty is accounted for in the thermal seepage abstraction method for collapsed drifts (see Section 6.5.3). Another uncertain parameter is the interface area between the individual rock blocks of the rubble material. Depending on the degree of settling after collapse, individual rock blocks in the rubble material may only have a limited contact area with other rock blocks. This limited contact area would reduce direct flow of gas, liquid, and heat between the fragmented rock pieces. Two alternative cases were analyzed in BSC (2004 [DIRS 170338], Section 6.2.5) since the resulting contact area is hard to quantify. The base case assumes that the geometric interface area between grid elements should be reduced by the volume fraction of the void space. This is the maximum possible interface for a medium with a given porosity (void volume fraction); therefore, this case is also referred to as full contact area case. The alternative case assumes smaller contact areas half as large as these base case values. The thermal-hydrological properties of the intact rock surrounding the collapsed drift, as well as the properties of all other geologic units, remain unchanged from the TH Seepage Model, as provided in Section 4.1.1 of BSC (2004 [DIRS 170338]).

To account for the vast property differences between rock blocks and voids, the rubble material was conceptualized as a dual-permeability medium, with one continuum representing the fragmented rock fraction and the other continuum representing the scattered connected voids. Collapsed drift simulations were conducted for selected cases, using the reference mode thermal load and applying multiplication factors of 1 and 10 for the local percolation flux arriving at the drift (see Section 6.4.3.1 for the definition of these thermal and flux boundary conditions). The initial conditions at the onset of heating are identical to those of the Tptpll Submodel for nondegraded drifts. Note that the fragmented rock pieces within the collapsed drift have saturation values representing the ambient water content of the lithophysal rocks (about 85 percent water saturation). This means that a significant volume of stagnant water is present in the rock blocks close to the waste package at the onset of heating. Water saturation in the void space is set to a very small value at initial state, consistent with the small capillary strength assigned to this medium. 
The discussion of simulation results from the collapsed drift scenarios is given in BSC (2004 [DIRS 170338], Section 6.2.5). For convenience, part of this discussion and some selected figures are repeated below, starting with the average percolation flux scenario (i.e., using a flux multiplication factor of 1). Figure 6.4-18 shows the temperature evolution at three selected locations within and close to the collapsed drift, for the cases with full and with reduced contact area between fragmented rock blocks. The first location is immediately at the waste package, the second is in the center of the collapsed drift (equivalent to the crown of the originally nondegraded drift), and the third is at the crown of the collapsed drift. The temperature variation between the three locations is significant. The waste package may become as hot as $260^{\circ} \mathrm{C}$ for the reduced contact case, whereas the rock in the center of the collapsed drift has maximum temperatures of about $148^{\circ} \mathrm{C}$ (reduced contact area) and $135^{\circ} \mathrm{C}$ (base case). The latter value is a few degrees centigrade cooler than the maximum crown temperature of the nondegraded drift of the Tptpll Submodel (BSC 2004 [DIRS 170338], Figure 6.2.3.1-1). In contrast, the crown of the collapsed drift approaches, but never exceeds, the boiling temperature of water at prevailing pressures. This means that a vaporization barrier is not expected to form in the intact rock above the collapsed drifts, but rather within the collapsed drifts. Compared to the full-contact-area case, the simulation with the 50-percent contact-area results in higher temperatures close to the heat source (at the waste package and also the center location), but slightly cooler temperatures at the drift crown. This is mainly a result of the less effective heat conduction between the fragmented rock pieces, resulting in hotter conditions at the waste package and cooler conditions further away. Thus, the contact area between rock blocks in the rubble material is an important uncertainty factor determining the TH environment close to the waste package, in particular the waste package temperature.

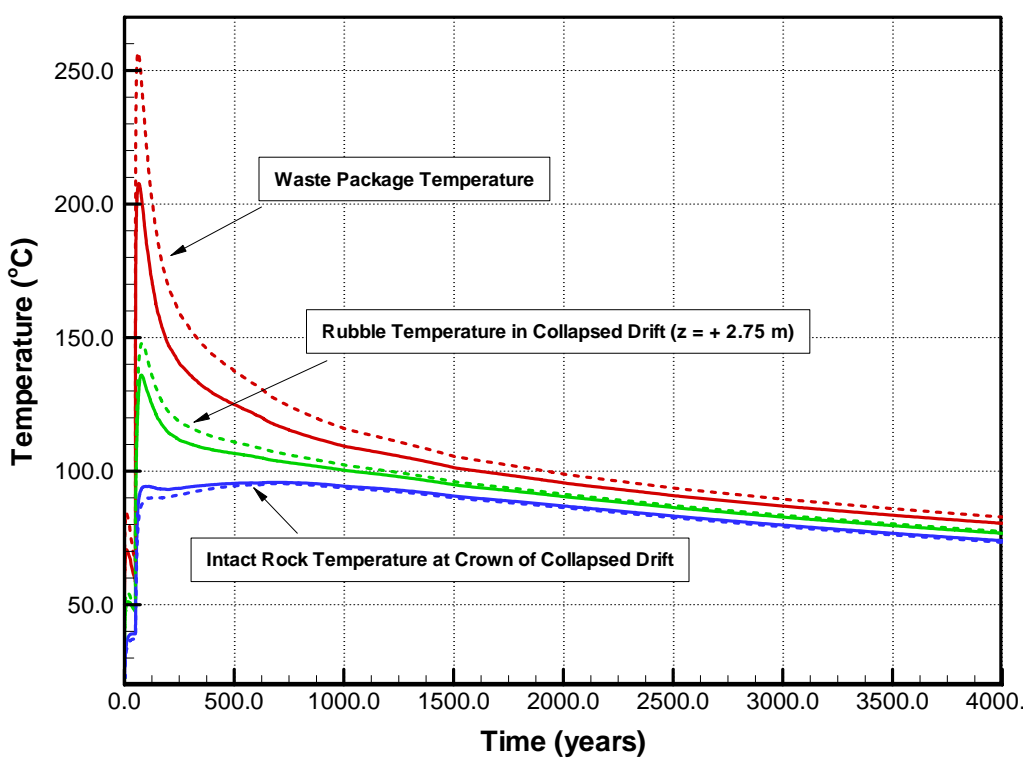

Source: Figure 2 in word file "TH Conditions in Collapsed Drifts.doc" from DTN LB0310DSCPTHSM.002 [DIRS 165944].

Figure 6.4-18. Rock Temperature Evolution for Base Case with Full Contact Area (Solid Lines) and 50-Percent Contact-Area Case (Dashed Lines) at Three Representative Locations within and Close to Collapsed Drift 
In both contact-area cases, the boiling of rock water close to the waste packages and the potential condensation leads to flux perturbations that may be important for performance assessment. These flux perturbations are visualized in a sequence of contour plots given in Figures 6.4-19 through 6.4-26, showing water saturation, temperature, and liquid flux vectors at 100, 1,000, 2,000, and 10,000 years after emplacement, using the full contact area case as an example. Temperatures are only shown for the matrix (fragmented rock blocks) continuum; these are almost identical to the fracture (void space) temperatures. Liquid fluxes are only shown for the fracture (void space) continuum. The matrix fluxes are much smaller; they can be neglected in the seepage abstraction model. For comparison, the reader is referred to the contour plots for nondegraded drifts depicted in Figures 6.2.2.1-3 through 6.2.2.1-6 in BSC (2004 [DIRS 170338]).

The temperature and saturation contours in Figure 6.4-19 indicate that almost the entire collapsed drift is heated to and above the boiling point of water at 100 years after emplacement. As a result, most of the ambient water content in the fragmented rock blocks has vaporized. Most of the vapor is driven away by the pressure gradient and condenses in the cooler rock surrounding the collapsed drift. Above the drift, the boiling-point isotherm follows roughly the interface between the intact rock and the rubble material. Thus, the water shedding that can be seen at the drift crown (Figure 6.4-20) is a result of both condensate and percolation water being diverted sideways, mainly by capillary forces at the rock-rubble interface. The voids within the collapsed drift are essentially dry. Note that the impact of heating extends far into the underlying fractured rock, because the heat source is located close to the bottom of the collapsed drift.

At 1,000 years after waste emplacement, the temperatures in the rubble material have decreased, but are still above boiling in most of the drift except for the crown (Figure 6.4-21). In the upper half of the drift, the matrix saturations have slightly increased compared to the situation at 100 years, indicating rewetting of the fragmented rock blocks. This is mainly a result of condensation in the small below-boiling zone at the drift crown. A small degree of rewetting may also stem from direct flow between the water-bearing rock matrix outside of the drift and the fragmented rock blocks of the rubble material. This flux is limited by (1) the small permeability of the rock matrix, and (2) the limited contact area between the matrix and the rubble. Condensation also leads to moderate rewetting in the void space immediately at the drift crown (Figure 6.4-22). However, downward drainage of water is prevented by the strong vaporization processes below this condensation zone. In contrast to nondegraded open drifts, the vaporization barrier is not effective in the intact rock above the drift, but in the rubble material closer to the waste package. Note that there is no liquid flow from the intact fractured rock directly into the void space, as capillary forces effectively drive water sideways and around the collapsed drift. At 1,000 years, most of the water shedding around the drift is percolation flux. Compared to the conditions at 100 years, the amount of percolation has substantially increased with the change from present-day to monsoon climate, while the amount of condensation has decreased in the area above the drift crown. 


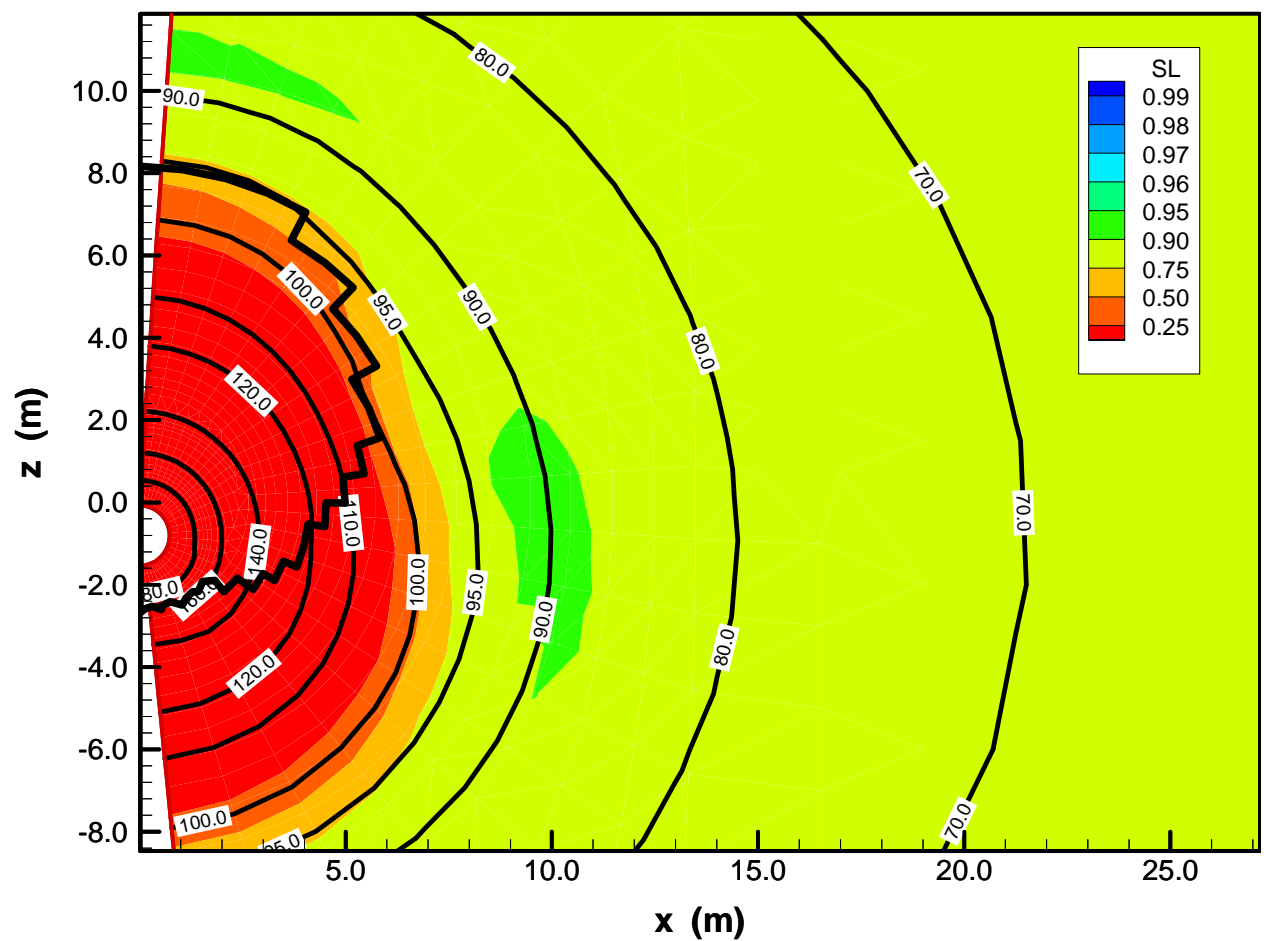

Source: Figure 3 in word file "TH Conditions in Collapsed Drifts.doc" from DTN LB0310DSCPTHSM.002 [DIRS 165944].

Figure 6.4-19. Saturation and Temperature (in ${ }^{\circ} \mathrm{C}$ ) at 100 Years after Emplacement, for Fragmented Rock Blocks (within Collapsed Drift) and Matrix Rock (Outside of Collapsed Drift) 


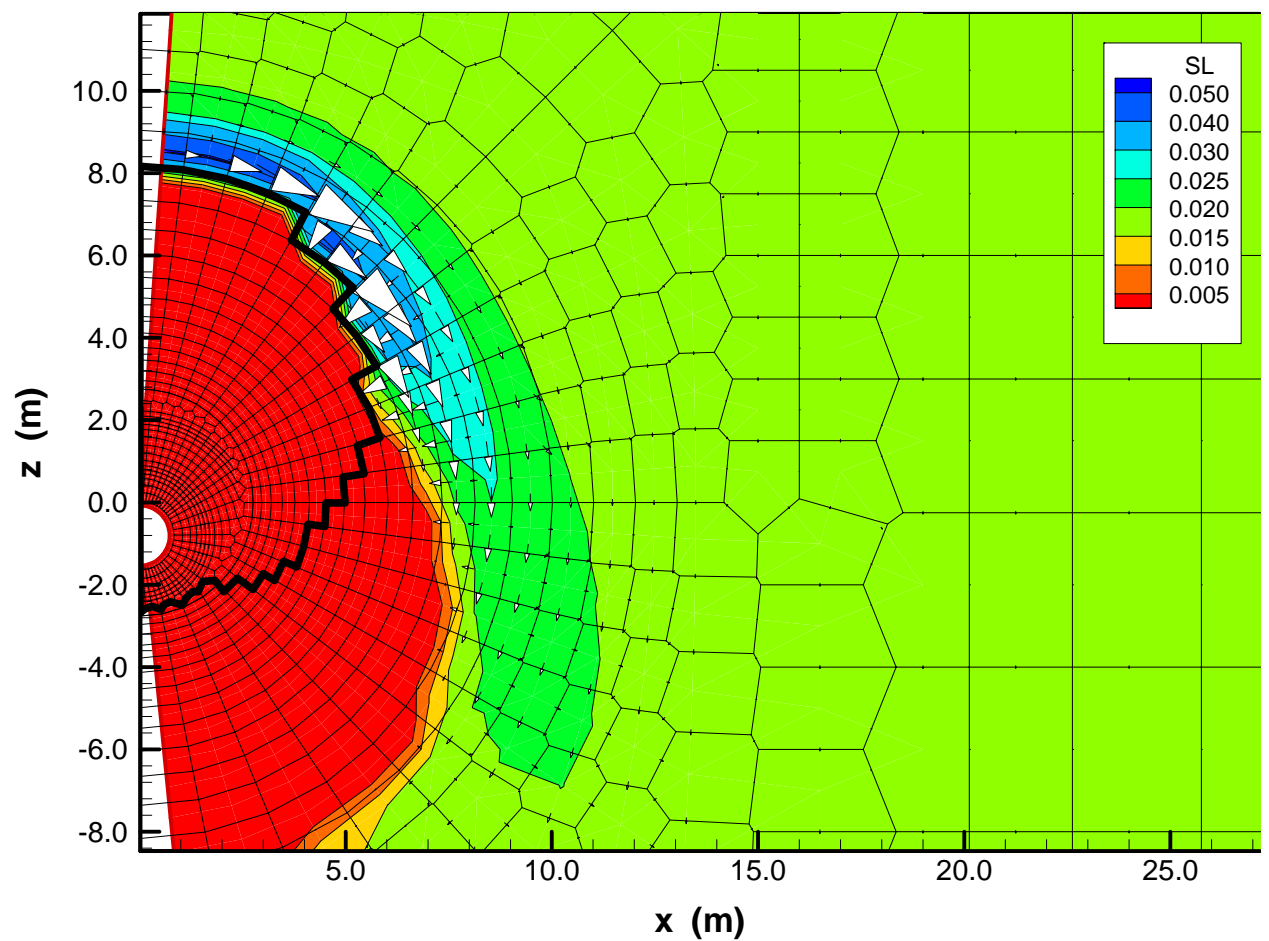

Source: Figure 4 in word file "TH Conditions in Collapsed Drifts.doc" from DTN LB0310DSCPTHSM.002 [DIRS 165944]. Vectors show direction of liquid flux at grid block interfaces; the arrowhead size gives the relative magnitude of liquid flux.

Figure 6.4-20. Saturation and Liquid Flux Vectors at 100 Years after Emplacement, for Void Space (within Collapsed Drift) and Fractures (Outside of Collapsed Drift) 


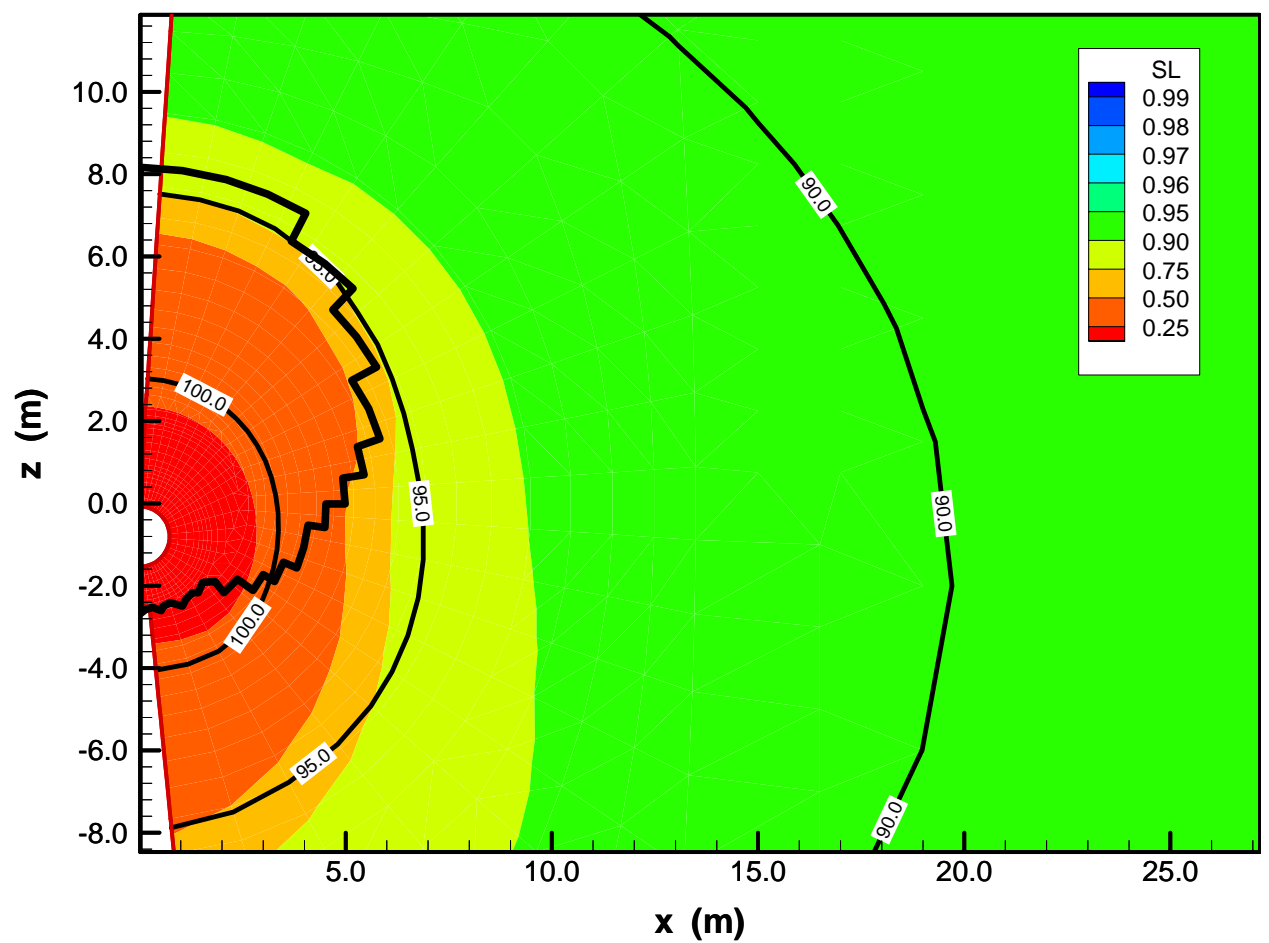

Source: Figure 5 in word file "TH Conditions in Collapsed Drifts.doc" from DTN LB0310DSCPTHSM.002 [DIRS 165944].

Figure 6.4-21. Saturation and Temperature (in ${ }^{\circ} \mathrm{C}$ ) at 1,000 Years after Emplacement, for Fragmented Rock Blocks (within Collapsed Drift) and Matrix Rock (Outside of Collapsed Drift) 


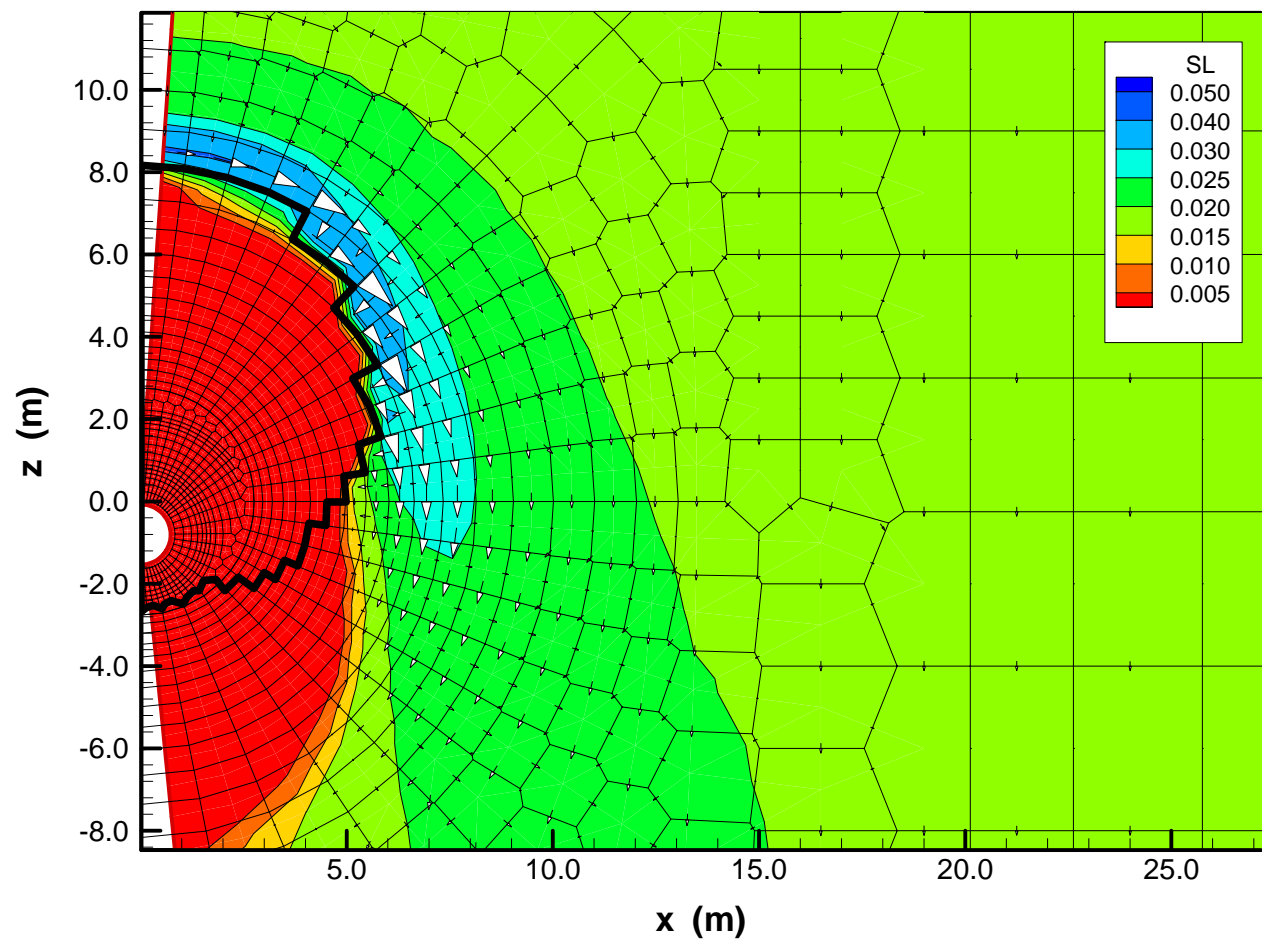

Source: Figure 6 in word file "TH Conditions in Collapsed Drifts.doc" from DTN LB0310DSCPTHSM.002 [DIRS 165944]. Vectors show direction of liquid flux at grid block interfaces; the arrowhead size gives the relative magnitude of liquid flux.

Figure 6.4-22. Saturation and Liquid Flux Vectors at 1,000 Years after Emplacement, for Void Space (within Collapsed Drift) and Fractures (Outside of Collapsed Drift)

At 2,000 years (Figures 6.4-23 and 6.4-24), with the heat output of the waste further reduced by decay, only the lower half of the rubble material is still above boiling and remains dry. In contrast, both the fragmented rock blocks and voids show increased saturations in the upper part of the drift. As discussed earlier, this is mainly caused by in-drift condensation, since the amount of water influx from the surrounding rock into the drift is limited by the small matrix permeability and contact area. As a result, two almost independent water flow systems have developed. In the intact fractured rock, water percolating down towards the collapsed drift is diverted sideways by capillary forces, as evident by the saturation increase at the crown and the sideways oriented flux vectors. Within the collapsed drift, small amounts of water boil and condense, with possible reflux occurring from these coupled processes. The magnitude of this in-drift reflux is discussed later in this section.

Figures 6.4-25 and 6.4-26 show the TH conditions after 10,000 years, the end of the compliance period. The temperatures in the drift are below boiling at around $55^{\circ} \mathrm{C}$, and most of the fragmented rock blocks have rewetted to saturation values similar to the surrounding rock, with the exception of the area closest to the waste package. The voids are dry in the lower half of the collapsed drift, but show slightly elevated saturation (just above residual saturation) in the upper half. The situation at 10,000 years is not yet at steady-state, but already gives some indication of the final steady-state conditions. Under final steady-state conditions, the capillary barrier at the rock-rubble interface limits flow of percolation water from the fractures into the collapsed drift. 
Flow within the collapsed drift is essentially zero, because the boiling, condensation, and reflux processes have ceased due to the close-to-ambient temperature conditions. The voids are in equilibrium with the rubble rock blocks, which means they are essentially dry (at residual saturation) because of their very small capillary strength. The fragmented rock blocks are expected to have saturation values similar to the surrounding rock matrix, because direct flux of water may be possible between the surrounding matrix rock and the fragmented rock pieces. These matrix fluxes are very small and can be neglected for the performance of the repository.

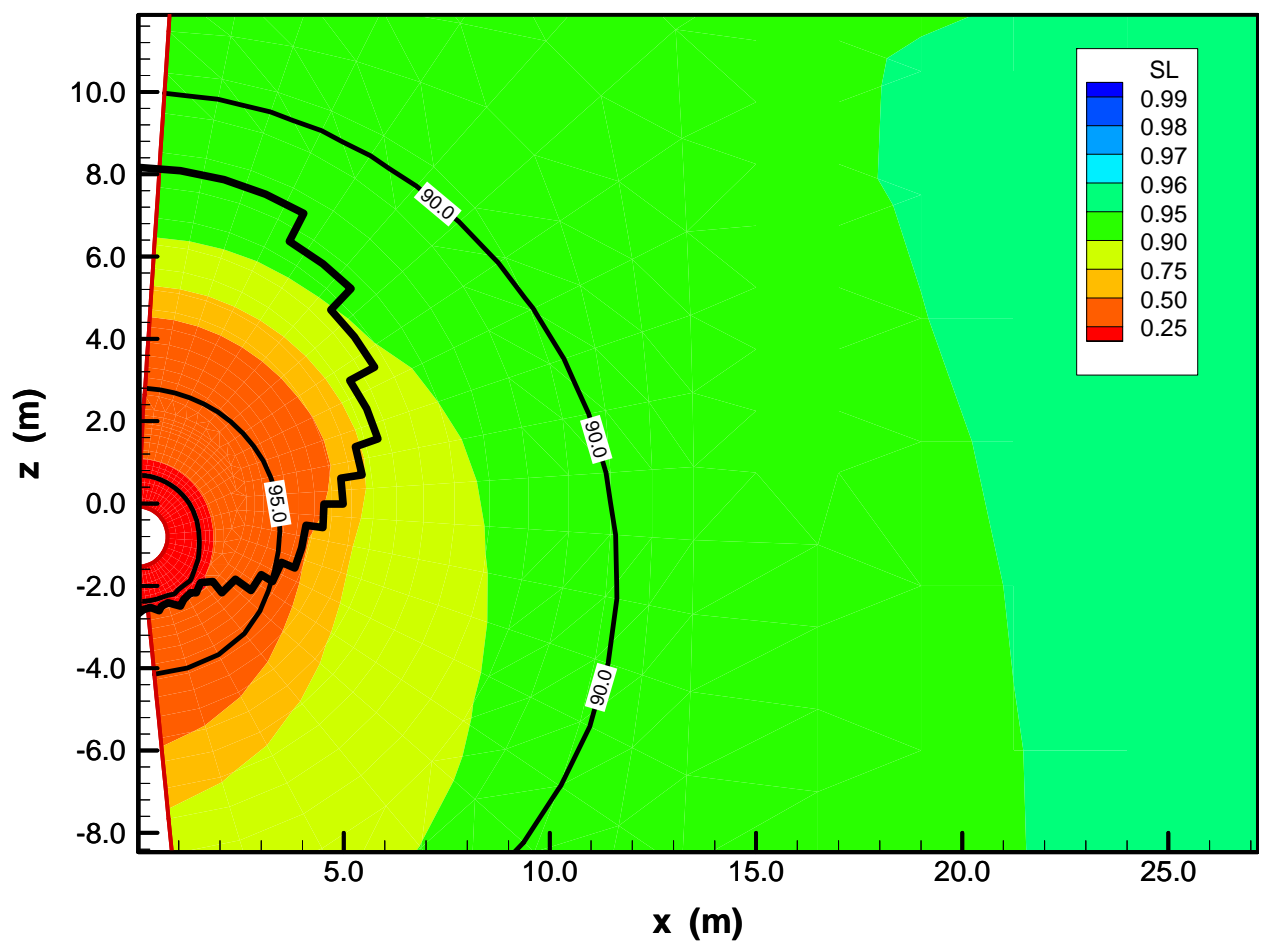

Source: Figure 7 in word file "TH Conditions in Collapsed Drifts.doc" from DTN LB0310DSCPTHSM.002 [DIRS 165944].

Figure 6.4-23. Saturation and Temperature (in ${ }^{\circ} \mathrm{C}$ ) at 2,000 Years after Emplacement, for Fragmented Rock Blocks (within Collapsed Drift) and Matrix Rock (Outside of Collapsed Drift) 


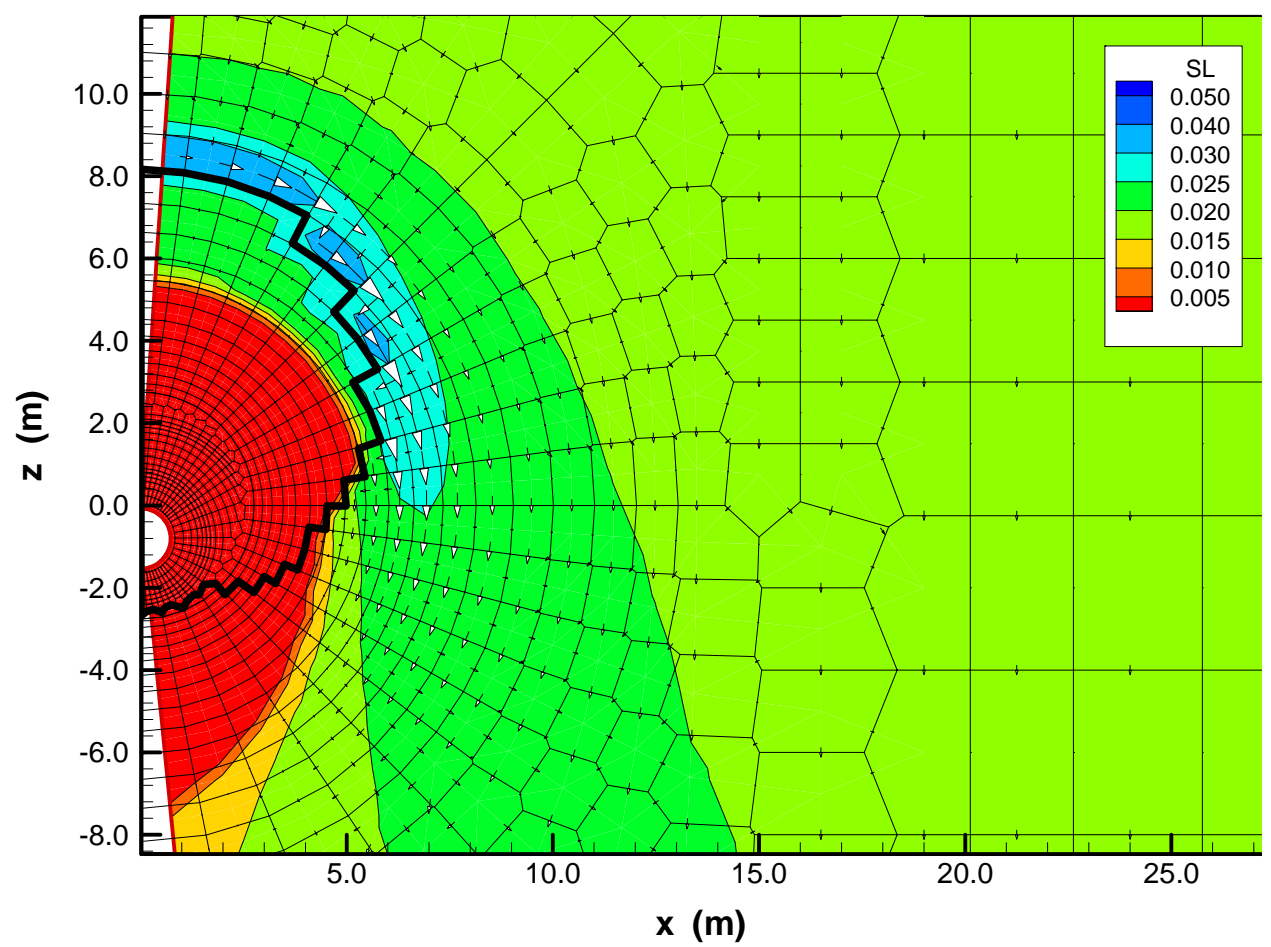

Source: Figure 8 in word file "TH Conditions in Collapsed Drifts.doc" from DTN LB0310DSCPTHSM.002 [DIRS 165944]. Vectors show direction of liquid flux at grid block interfaces; the arrowhead size gives the relative magnitude of liquid flux.

Figure 6.4-24. Saturation and Liquid Flux Vectors at 2,000 Years after Emplacement, for Void Space (within Collapsed Drift) and Fractures (Outside of Collapsed Drift) 


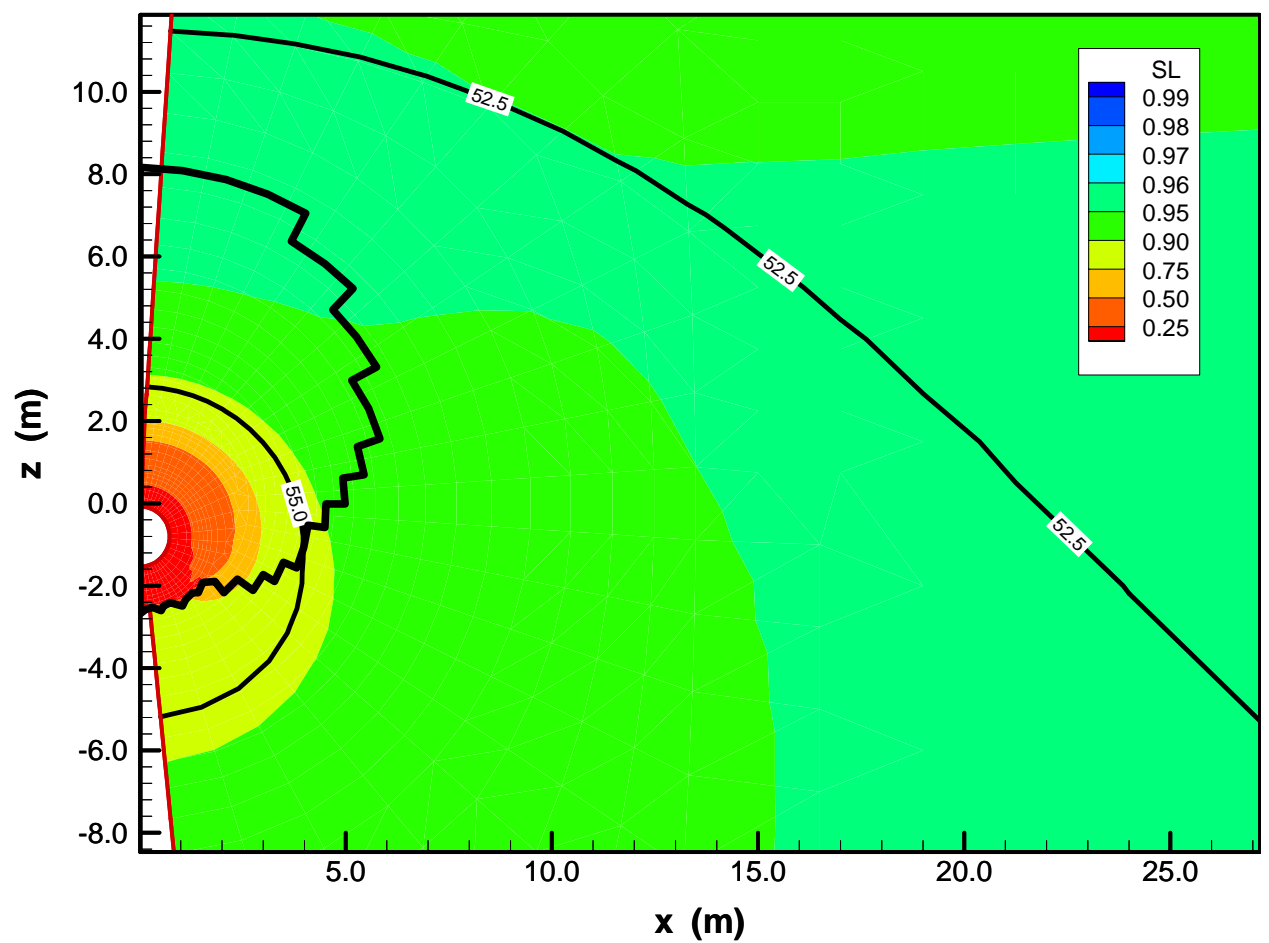

Source: Figure 9 in word file "TH Conditions in Collapsed Drifts.doc" from DTN LB0310DSCPTHSM.002 [DIRS 165944].

Figure 6.4-25. Saturation and Temperature (in ${ }^{\circ} \mathrm{C}$ ) at 10,000 Years after Emplacement, for Fragmented Rock Blocks (within Collapsed Drift) and Matrix Rock (Outside of Collapsed Drift) 


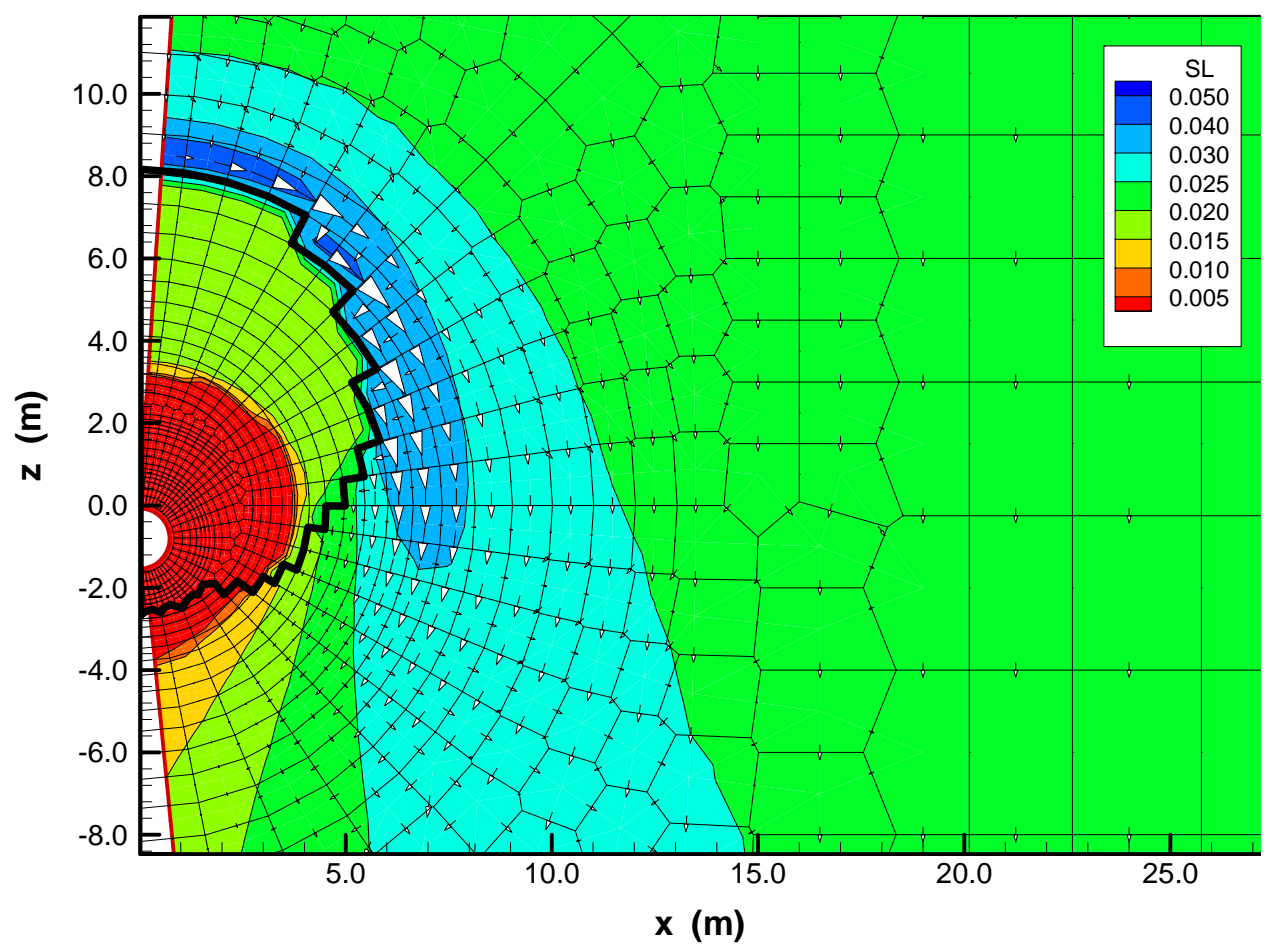

Source: Figure 10 in word file "TH Conditions in Collapsed Drifts.doc" from DTN LB0310DSCPTHSM.002 [DIRS 165944]. Vectors show direction of liquid flux at grid block interfaces; the arrowhead size gives the relative magnitude of liquid flux.

Figure 6.4-26. Saturation and Liquid Flux Vectors at 10,000 Years after Emplacement, for Void Space (within Collapsed Drift) and Fractures (Outside of Collapsed Drift)

The above discussion has indicated the possibility of in-drift flux perturbations in the rubble material, mainly because ambient water-present in the collapsed rock blocks at the onset of heating-boils off, condenses, and may flow back towards the waste package. Figure 6.4-27 analyzes the magnitude of this reflux, showing the downward fluxes at different times along a vertical line that runs through the center of the collapsed drift. The vertical coordinate $\mathrm{z}=0$ meter refers to the springline of the nondegraded drift; the crown of the collapsed drift is at approximately $\mathrm{z}=8.25$ meters. The vertical location of the drip shield is at about $\mathrm{z}=0.43$ meters (in the model grid), with the top of the waste package in close proximity below it.

The figure shows in-drift fluxes of a few millimetes per year in the upper half of the collapsed drift. The maximum vertical flux occurs at 1,500 years after emplacement, when boiling is still effective in the waste package vicinity. At later stages, when the flow systems approach steady-state conditions, the flux values return to zero. No downward flow occurs in the lower half of the collapsed drift at any time. Thus, it can be safely concluded that water will not contact the waste package or the drip shield as a result of in-drift flux perturbation in the rubble material. (This is supported by the evolution of relative humidity in the rubble rock immediately above the drip shield, shown in Figure 6.4-29.) Notice that water flux at the interface between the intact rock and the crown of the collapsed drift is always zero, a result of the capillary barrier (Figure 6.4-27). Fluxes in the rock outside of the drift reflect the percolation flux conditions at 
the respective times; i.e., 6, 16, and $25 \mathrm{~mm} /$ year for the present-day, monsoon, and glacial transition climates (i.e., using a flux multiplication factor of 1). The flux peaks that can be seen close to the crown during the early heating phase (100 and 500 years) stem from the additional effect of condensation in this zone.

Essentially similar results were obtained for the simulation case with the reduced contact area between rock pieces in the collapsed drift. As shown in Figure 6.4-28, the vertical fluxes in the lower half of the collapsed drift are zero at all times. Also, the relative humidity above the drip shield is smaller than 70 percent for the first 2,000 years after emplacement and remains below 90 percent for the rest of the 10,000-year compliance period (Figure 6.4-29). The main difference from the base case is that a maximum flux of about $25 \mathrm{~mm}$ /year occurs after 100 years near the crown of the collapsed drift in Figure 6.4-28, comparable in magnitude to the percolation flux. This is a result of condensation; the boiling zone in the collapsed drift is less extended in this simulation case and allows in-drift condensation close to the crown. Thus, the $\mathrm{TH}$ conditions close to the crown of the collapsed drift are sensitive to the rubble area contact factor. However, this early-time difference is not relevant for the integrity of the waste canister, because (1) the distance between the crown and the waste package comprises several meters of above-boiling rubble material and (2) the considered time coincides with the period of most effective vaporization in the lower part of the drift.

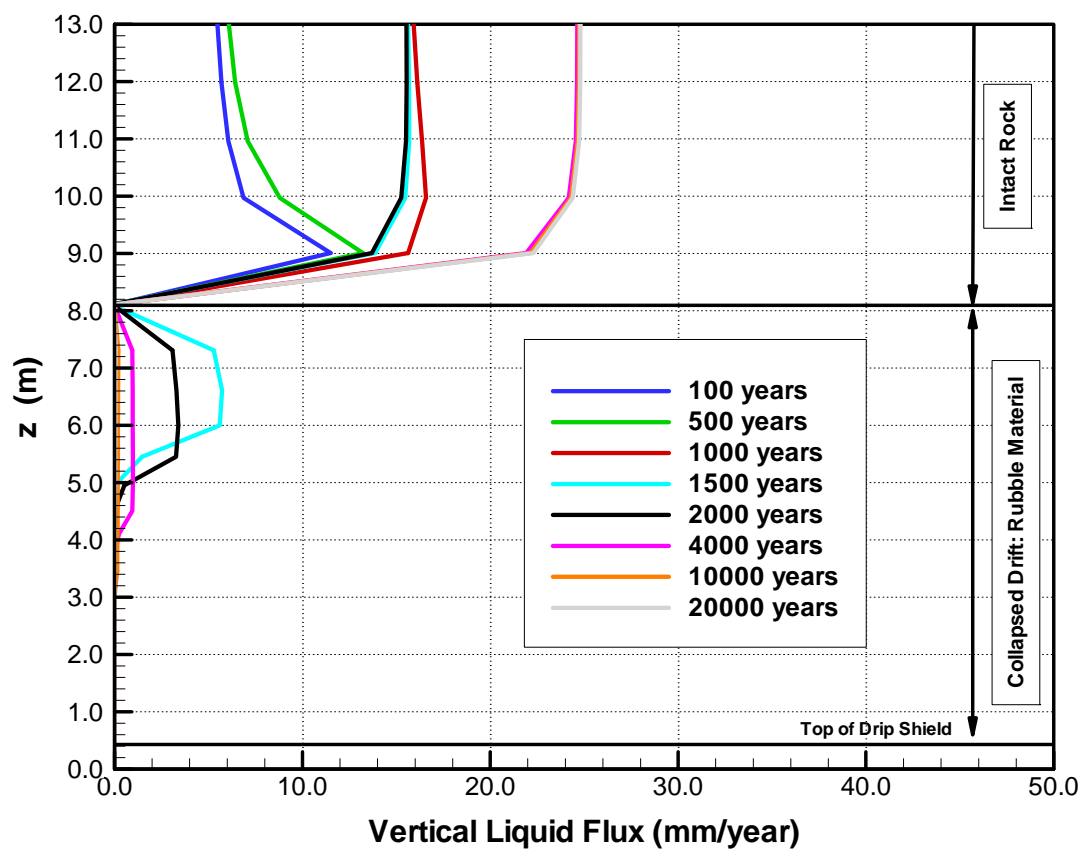

Source: Figure 11 in word file "TH Conditions in Collapsed Drifts.doc" from DTN LB0310DSCPTHSM.002 [DIRS 165944].

NOTE: The vertical coordinate $z=0 \mathrm{~m}$ refers to the springline of the nondegraded drift.

Figure 6.4-27. Downward Flux in the Fractures/Voids along a Vertical Line through the Center of the Collapsed Drift for Base Case Simulation 


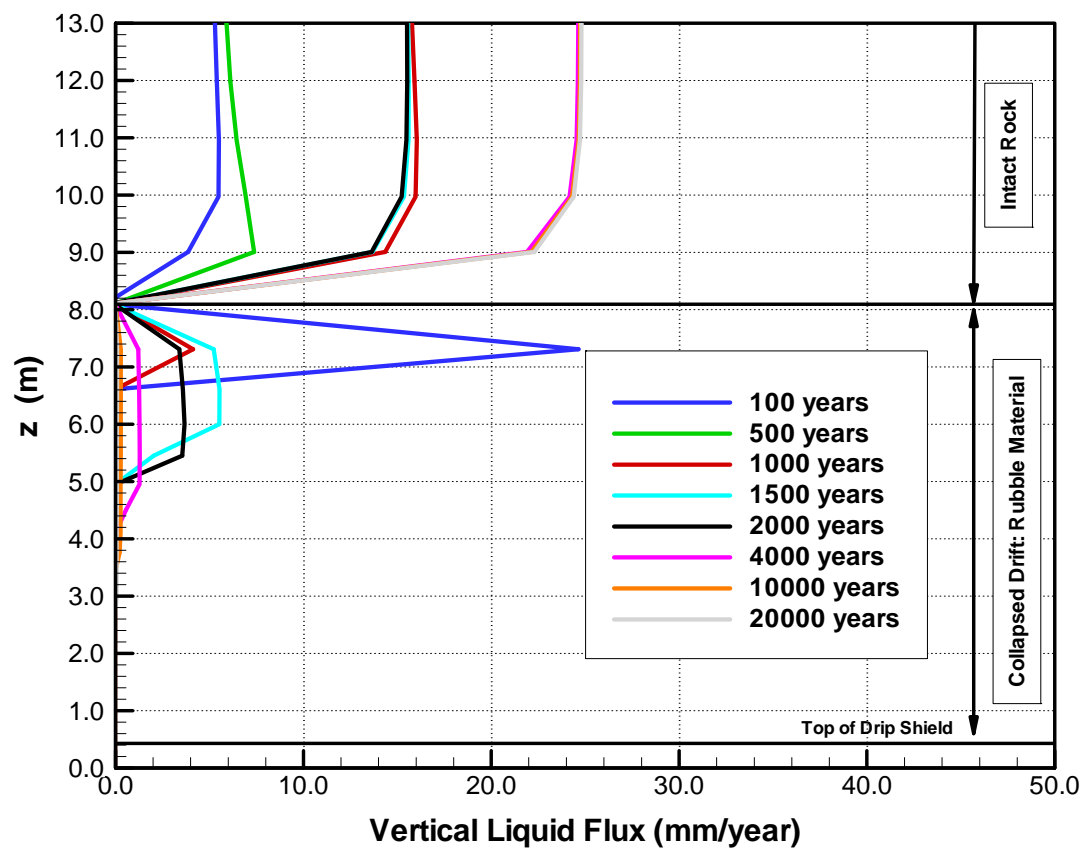

Source: Figure 12 in word file "TH Conditions in Collapsed Drifts.doc" from DTN LB0310DSCPTHSM.002 [DIRS 165944].

NOTE: The vertical coordinate $z=0 \mathrm{~m}$ refers to the springline of the nondegraded drift.

Figure 6.4-28. Downward Flux in the Fractures/Voids along a Vertical Line through the Center of the Collapsed Drift for Simulation with Limited Contact Area

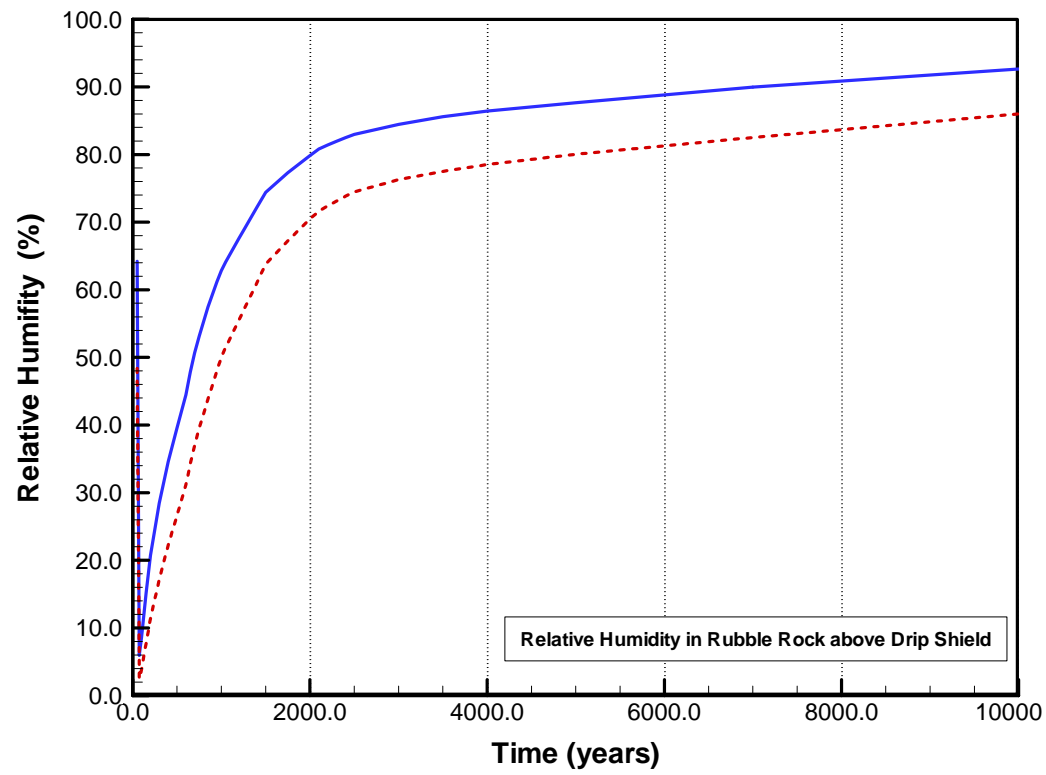

Source: Figure 13 in word file "TH Conditions in Collapsed Drifts.doc" from DTN LB0310DSCPTHSM.002 [DIRS 165944].

Figure 6.4-29. Evolution of Relative Humidity in the Rubble Material Immediately above the Drip Shield, for Base Case (Solid Line) and 50-Percent Contact-Area Case (Dashed Line) 
As mentioned above, collapsed-drift simulation runs were also conducted for enhanced percolation fluxes, using a multiplication factor of 10 . Example results are given in Figures 6.4-30 and 6.4-31 for the case with a full contact area between the fragmented rock blocks. With respect to in-drift fluxes and seepage abstraction, results from the 50-percent contact-area case are quite similar. In general, the effect of increasing the local percolation flux is comparable to the nondegraded case discussed in Section 6.4.3.3, with elevated percolation leading to cooler temperatures and a shorter boiling period (Figure 6.4-30). However, the in-drift flux conditions are hardly affected by these differences, as shown in Figure 6.4-31. (Note the different horizontal scale as compared to Figures 6.4-27 and 6.4-28.) The maximum downward fluxes within the collapsed drift are rather small (up to about $20 \mathrm{~mm} / \mathrm{year}$ ) and concentrated in the upper half of the rubble material, away from the waste package. The maximum flux in the lower half of the collapsed drift has an almost negligible magnitude of $0.3 \mathrm{~mm} /$ year, occurring close to the center of the collapsed drift. Just above the drip shield, the downward fluxes are always zero. Outside of the collapsed drift, the vertical fluxes reflect the percolation flux boundary conditions imposed at the top of the model area, with fluxes of 60, 160, and $250 \mathrm{~mm} /$ year during the three climate stages. It is because these increased fluxes cannot enter the collapsed drift-as a result of capillary forces - that the in-drift conditions are hardly affected by the change in percolation. This gives confidence that the observed results hold for the relevant percolation flux scenarios in TSPA-LA. Note that additional sensitivity cases are provided in DTNs: LB0310DSCPTHSM.001 [DIRS 165943] and LB0310DSCPTHSM.002 [DIRS 165944], varying the void permeability of the in-drift rubble material. Results from these simulations show similar in-drift flux behavior to the cases previously discussed.

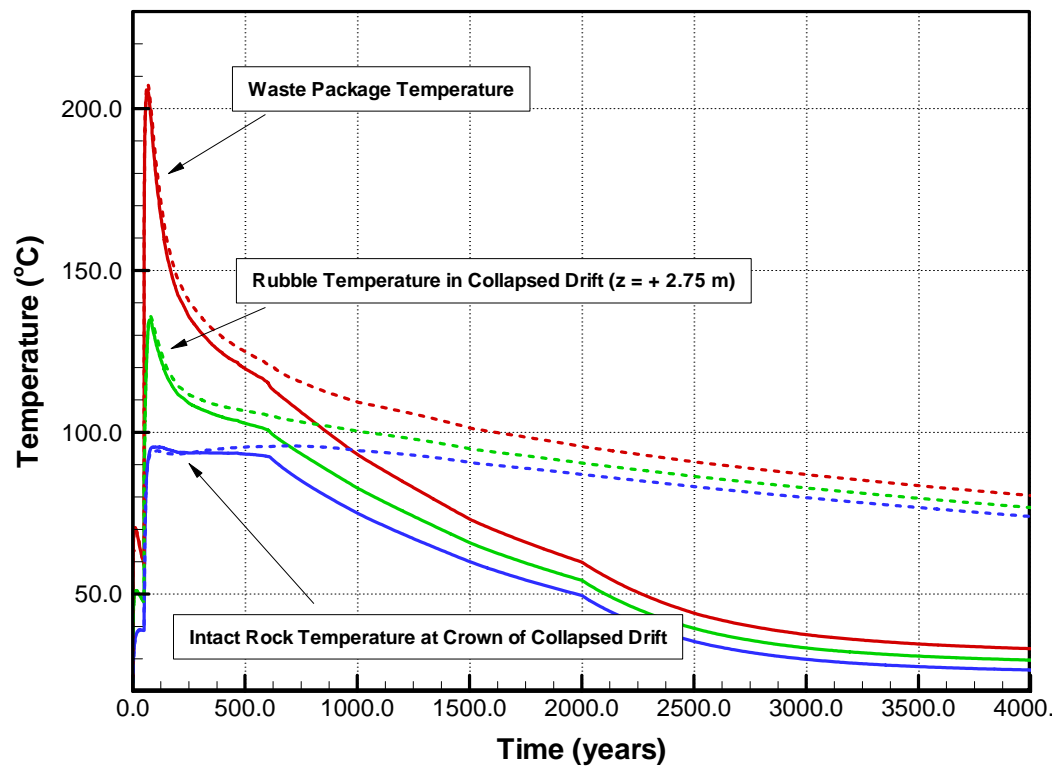


Source: Figure 14 in word file "TH Conditions in Collapsed Drifts.doc" from DTN LB0310DSCPTHSM.002 [DIRS 165944].

Figure 6.4-30. Rock Temperature Evolution for Percolation Flux Scenario with a Multiplication Factor of 10 (Solid Lines) Compared to Base Case (Dashed Lines) at Three Representative Locations within and Close to Collapsed Drift

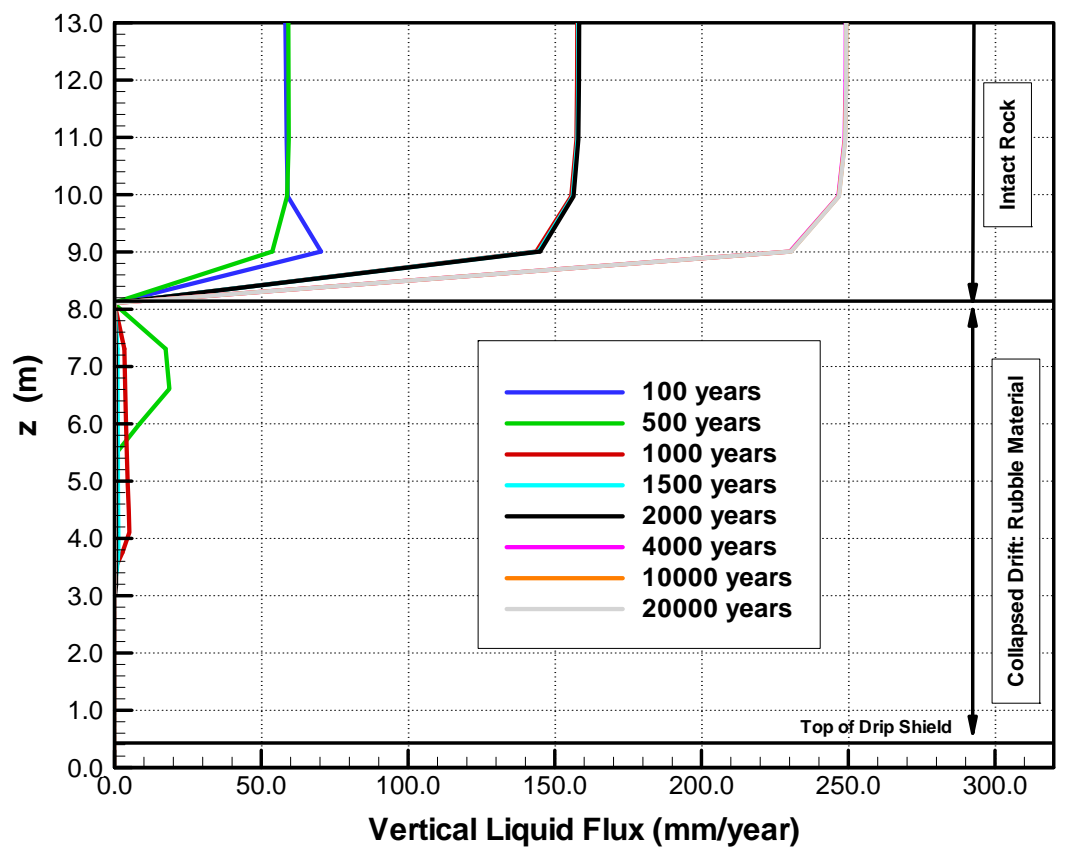

Source: Figure 15 in word file "TH Conditions in Collapsed Drifts.doc" from DTN LB0310DSCPTHSM.002 [DIRS 165944].

NOTE: The vertical coordinate $z=0 \mathrm{~m}$ refers to the springline of the nondegraded drift.

Figure 6.4-31. Downward Flux in the Fractures/Voids along a Vertical Line through the Center of the Collapsed Drift, for Percolation Flux Scenario with a Multiplication Factor of 10

It was already mentioned that the modeling framework for collapsed drifts does not use the specific SCM modeling methodology for simulating the capillary barrier at the interface between the intact rock and the rubble-filled drift. This makes this interface an almost perfect capillary barrier; i.e., in the collapsed-drift simulation cases considered above, flux from the fractured rock into the rubble zone was zero. Thus, the in-drift flow processes modeled above were driven by the vaporization of rock water that was initially present in the matrix. The question arises whether the in-drift TH properties would significantly change if some fraction of the percolation water would seep from the fractured rock into the rubble material. Additional simulations have been conducted in BSC (2004 [DIRS 169565], Section 6.3.7.3) to address this question. The simulations were conducted by explicitly specifying a seep (water source) at the top of the rubble, using a wide range of seep magnitudes from 100 to 10,000 liter/year/WP. The seeps were initiated at 65 years after emplacement (15 years after closure), which is shortly before the maximum waste package temperatures are reached. The simulation results indicate the effect of vaporization is strong enough to prevent water contact with the waste packages for long periods of time (between about 1,400 and 10,000 years after initiation of the seep). While this supports the above findings of "dry" waste packages even when seepage occurs from the fractured 
formation into the rubble-filled opening, the simulations are associated with uncertainty, mainly because of our limited knowledge on the hydrological behavior and the rock properties of the rubble material (no testing in rubble rock material).

\subsubsection{Supporting THM and THC Models}

This section briefly describes the conceptual framework and modeling results from the coupled THM and THC simulation models. The information provided by these models is utilized in the seepage abstraction model to assess the magnitude and impact of mechanical and chemical parameter alterations of relevant rock properties during the heating phase of the repository. In addition to analyzing thermally induced alterations of hydrological properties, results from the THM model are also used to understand the potential rock property changes caused by drift degradation, including complete drift collapse. Note that these models do not directly calculate seepage rates. Having coupled THM or THC models directly provide seepage rates is desirable, but not feasible because of the computational burden involved in such simulations - in particular because seepage calculations have to be available for a large number of parameter sets to cover spatial variability and uncertainty of relevant properties. The following sections provide discussions on the supporting THM and THC models, summarized from the more detailed descriptions in BSC (2004 [DIRS 169864]) and BSC (2004 [DIRS 169856]), respectively.

\subsubsection{Drift-Scale THM Model}

\subsection{Hydrological Property Changes Caused by Thermal Effects}

The Drift-Scale THM Model is applied to assess the magnitude and distribution of stress-induced changes in hydrological properties and to analyze the impact of such changes on the percolation flux in the rock mass around a repository drift (BSC 2004 [DIRS 169864]). Heating will cause thermal expansion of the rock, which in turn will change the stress field around emplacement drifts. Thermally induced changes in the stress field will act upon pre-existing fractures, with the result of changing the hydrological properties of the rock mass. Note that this section focuses on such thermal expansion effects; the impact of drift collapse on the hydrological properties of the remaining rock above the rubble-filled cave-a potential result of seismic events-is discussed in Section 6.4.4.1.2.

The Drift-Scale THM Model uses a simulation tool for thermal-hydrological-mechanical processes based on joining a multiphase flow and transport simulator with a rock and soil mechanics industry-standard simulator (BSC 2004 [DIRS 169864], Section 6.2). The modeling framework for the TH processes-boundary conditions and rock properties - is similar to the $\mathrm{TH}$ Seepage Model as described in Section 6.4.3. However, while the TH Seepage Model focuses on the TH conditions to evaluate seepage rates for various seepage-relevant parameter cases, the THM simulations concentrate on the heat-induced stress changes and resulting impact on the flow field. Predictive simulations were conducted with the Drift-Scale THM Model for 10,000 years after waste emplacement. Careful model validation was performed in comparison with rock-mass displacement data (for TM processes) and air permeability data (for THM processes) measured during the heating phase of the DST (BSC 2004 [DIRS 169864], Section 7). Generally, the model captured the THM behavior in the heated DST rock mass reasonably well. In particular, the THM Model was capable of representing the transient changes in air 
permeability data, stemming from two simultaneous processes: fracture aperture changes in response to stress changes and relative permeability changes in response to water saturation changes (BSC 2004 [DIRS 169864], Section 7.4.3). Note that the air-injection results from the DST were also used to calibrate the stress-permeability relationship that is needed for coupled THM simulations. Calibration of this relationship was conducted against the strongest observed changes in air permeability in the DST, in order to evaluate the maximum possible THM impact on the near-field flow (BSC 2004 [DIRS 169864], Section 7.4.3). The predictive model results are thus likely to overestimate the impact of stress on the flow processes compared to a more moderate relationship. In addition to model corroboration with DST data, the Drift-Scale THM model was also validated using niche test data and observations of sidewall fracturing in the ECRB (BSC 2004 [DIRS 169864], Sections 7.5 and 7.6).

Results from the THM predictive simulations are given in Sections 6.5 (for a drift located in the Tptpmn unit) and 6.6 (for a drift located in the Tptpll unit) of BSC (2004 [DIRS 169864]). The simulation runs start by modeling the impact of excavation on the stress field. (Information from these simulations is used in Section 6.6.3.1 to complement the analysis of measured excavationrelated permeability changes.) In a second simulation step, the waste canisters are emplaced into the excavated drifts and the THM behavior is modeled, assuming average thermal loads and percolation boundary conditions. Finally, the temperature-induced permeability changes are compared to the post-excavation conditions. Comparison with post-excavation conditions is relevant for seepage abstraction because the probability distributions for the seepage-relevant properties defined in Section 6.6 are representative of the excavation-disturbed zone in the drift vicinity. At the drift ceiling (i.e., the region important for seepage), the calculations show generally a decrease in vertical permeability as a result of temperature-induced stresses, while the horizontal permeabilities remain essentially unchanged from the initial post-excavation values (BSC 2004 [DIRS 169864], Figures 6.5.4-3, 6.5.4-4, 6.6.1-4 and 6.6.1-5). The vertical permeability changes are more pronounced in the Tptpmn unit compared to the Tptpll unit. In both units, the transient permeability changes are strongest at around 100 to 500 years after emplacement. At later stages, the declining temperatures allow the stresses and the vertical permeability values to recover somewhat, but not to their initial values because the rock temperatures are still higher than ambient. For example, in the Tptpmn unit, the vertical permeability immediately above the drift crown at 10,000 years after emplacement still remains one order of magnitude below its initial value.

The impact of these permeability changes on the flow field was investigated in BSC (2004 [DIRS 169864], Sections 6.5.5 and 6.6.2) by comparison of the fully coupled THM simulations with $\mathrm{TH}$ simulations where the stress-induced property changes were neglected. This analysis indicated that the flow field differences are small to moderate, but that the reduction in vertical permeability, combined with the basically unchanged horizontal permeability, appeared to give rise to less water reaching the drift crown (Figure 6.4-32). It was suggested in BSC (2004 [DIRS 167652], Section 6.7) that these anisotropic THM property changes would increase the likelihood of flow being diverted around the drift and thus decrease the potential for seepage. 


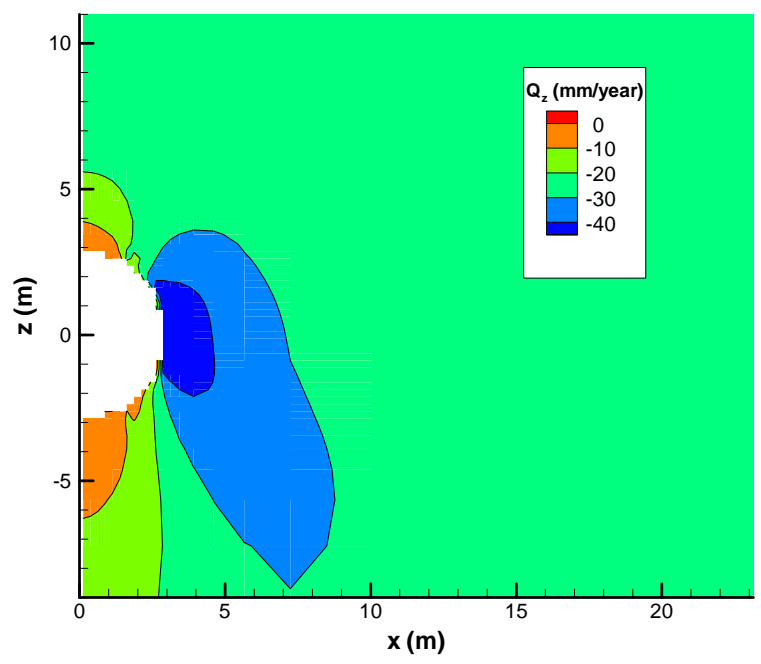

(a) THM

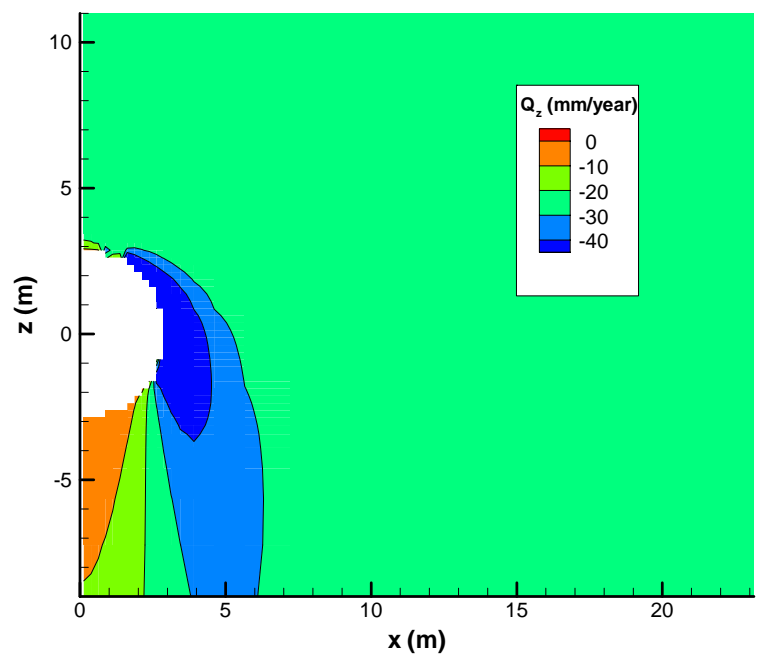

(b) TH

Source: BSC (2004 [DIRS 169864], Figure 6.5.5-5).

NOTE: Negative percolation fluxes indicate downward flow.

Figure 6.4-32. Example Result Illustrating the Difference in Vertical Percolation Flux $\left(\mathrm{Q}_{z}\right)$ in Fractures at 10,000 Years for (a) Fully Coupled THM Simulation, and (b) TH Simulation (Tptpmn Unit Model Domain)

To confirm this point, ambient seepage calculations were conducted with the THM model using the initial post-excavation permeability field without THM changes (BSC 2004 [DIRS 169864], Figure 6.5.1-1) and the permeability field at 10,000 years after emplacement including THM changes (BSC 2004 [DIRS 169864], Figures 6.5.4-3(d) and 6.5.4-4(d)). The conceptual framework applied for these seepage calculations was similar to that of the SMPA, except that the small-scale heterogeneity in the permeability field was neglected. Results from these simulations are shown in Figure 6.4-33. The calculated seepage rates for the THM permeability field are reduced by about 10 percent from the values calculated for the initial permeability field, over the entire range of percolation fluxes analyzed ( $0 \mathrm{~mm} /$ year to 3,000 mm/year) (BSC 2004 [DIRS 167652], Section 6.7). It was concluded that an ambient seepage model without consideration of anisotropic THM property changes is capable of predicting seepage rates with sufficient accuracy. Thus, the SMPA results are representative over most of the 10,000-year compliance period, with the possible exception of the first 1,000 to 2,000 years, in which the TH processes are strongly perturbed from boiling. 


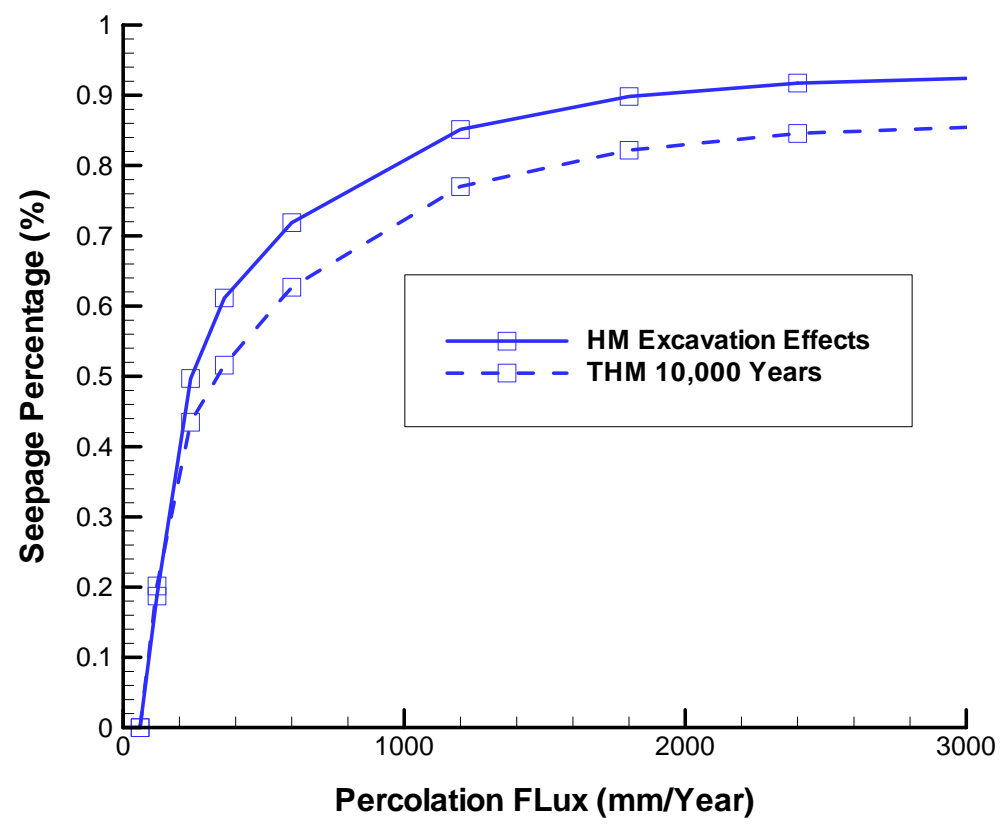

Source: DTN: LB0304SMDCREV2.004 [DIRS 163691] (File Fig 6-22.wmf).

Figure 6.4-33. Seepage Percentage as a Function of Percolation Flux Simulated Using the Initial Post-Excavation Permeability Field without THM Changes (HM Excavation Effects) and the Permeability Field at 10,000 years after Emplacement Including THM Changes (THM 10,000 Years)

\subsection{Hydrological Property Changes Caused by Drift Collapse in the Tptpll Unit}

The potential impact of changes in seepage-relevant parameters (permeability and capillary strength) as a result of severe drift degradation (including complete collapse of emplacement drifts) was estimated in Section 6.8 of BSC (2004 [DIRS 169864]). As pointed out in Section 6.3.1, drift degradation can lead to the dilation of existing fractures or the generation of new fractures in the vicinity of the (collapsed) emplacement drifts. Fracture dilation would increase the permeability, thereby promoting flow diversion around the drift, but at the same time decrease the fracture capillary strength, which could lead to less flow diversion around the drift. The generation of new fractures in the drift vicinity-with apertures comparable to the existing fractures - would promote flow diversion around the drift opening because of the related increase in fracture permeability, but would not affect the fracture capillary strength.

The analysis of hydrological parameter changes was conducted using results from the Drift Degradation Analysis (BSC 2004 [DIRS 166107]) and focuses on the lithophysal rocks, where significant drift degradation is predicted. From the scenarios provided in DTN: MO0306MWDDPPDR.000 [DIRS 164736], changes in hydrological properties were evaluated for three representative cases as follows: Scenario 1 considering the $5 \times 10^{-4}$ seismic hazard case, Scenario 2 considering the $1 \times 10^{-6}$ seismic hazard case, and Scenario 12 with a 100 percent reduction in joint cohesion (see list of scenarios in Appendix R of BSC 2004 [DIRS 166107]). Also note that, according to Section 6.4.2.4.1, the 100 percent joint cohesion 
case is not a realistic scenario, because the reduction in rock strength over 20,000 years is estimated on the order of 40 percent. Scenario 1 is representative of degradation cases that lead to minor damage to otherwise intact drifts; the other two scenarios are representative for cases that result in partial or complete drift collapse (Section 6.4.2.4.1). Another scenario (Scenario 7), which includes only the impact of drift excavation, is also analyzed for comparison.

The changes in fractured rock permeability were calculated using the stress distributions for the respective cases given in DTN: MO0306MWDDPPDR.000 [DIRS 164736], applying the stress-permeability relationship derived from calibration of the THM model to air-injection data from the DST (BSC 2004 [DIRS 169864], Section 6.8). As an alternative approach, the changes in permeability were calculated from changes in the volumetric strains given in DTN: MO0306MWDDPPDR.000 [DIRS 164736]. The latter method is arguably less reliable than the former, because additional calibration is involved to derive a strain-versus-permeability relationship (BSC 2004 [DIRS 169864], Section 6.8). The related changes in fracture capillary strength were evaluated for both alternative approaches, based on the assumption that the permeability changes are only caused by fracture aperture changes, not by the generation of new fractures (i.e., applying the Leverett function given in Equation 6.2-6 of BSC 2004 [DIRS 169864]). Thus, the resulting changes in fracture capillary strength are most likely on the high side, because drift degradation is expected to cause both dilation of existing fractures and generation of new fractures in the drift vicinity. The generation of new fractures, however, would not lead to a change in fracture capillary strength, provided that the new fractures have apertures similar to the existing ones. Evaluating the impact of these capillary-strength changes on seepage abstraction, one must also consider that the physically based capillary strength derived from the Leverett function does not necessarily suggest similar changes in the effective capillary-strength parameter calibrated for and used in the seepage prediction models. This effective parameter implicitly accounts for a number of additional factors affecting seepage, as listed in Section 6.4.1.1, and is thus less influenced by stress redistributions than a capillary-strength parameter that is purely defined by changes in fracture aperture.

The resulting permeability and capillary strength changes for the chosen degraded drift scenarios are described in BSC (2004 [DIRS 169864], Sections 6.8.1 through 6.8.4), with a brief summary given in BSC (2004 [DIRS 169864], Section 6.8.5). It is important to note that the magnitude of these changes is based on comparison with the properties of undisturbed lithophysal rock. Relevant for seepage abstraction purposes, however, is a comparison with the properties of lithophysal rock in the vicinity of excavated drifts, which are influenced by the stress redistribution following excavation. Appropriate probability distributions for these excavation-disturbed properties around nondegraded drifts are developed in Section 6.6 of this model report, based on field measurements and associated modeling/calibration work. Thus, for seepage abstraction, the seepage-relevant rock properties around degraded drifts need to be compared to the properties of the excavation-disturbed zone around nondegraded drifts. In other words, results from the degraded drift scenarios (Scenarios 1, 2, and 12) need to be compared to results from the excavation-only scenario (Scenario 7).

As described in Section 6.8.4 of BSC (2004 [DIRS 169864]), the $5 \times 10^{-4}$ seismic hazard case is not expected to induce relevant changes in hydrological properties. The drifts remain essentially intact, and the predicted conditions after the seismic event are similar to the excavation-disturbed conditions. Compared to the undisturbed rock properties, the fracture permeability above the 
drift crown increases by less than one order of magnitude and the fracture capillary strength is expected to decrease by less than 50 percent, for both the seismic hazard conditions and the excavation-disturbed conditions.

The other scenarios, the $1 \times 10^{-6}$ seismic hazard case and the 100 percent cohesion loss case, result in complete drift collapse. For collapsed drifts, the drift diameter is expected to almost double, and the properties of the intact rock surrounding the rubble-filled cave are subject to stronger and radially more extended changes in the hydrological properties compared to the above scenarios. Example results are given in Figure 6.4-34 for Scenario 12 (100 percent cohesion loss). As reported in BSC (2004 [DIRS 169864], Section 6.8.5), the strongest changes occur on the sides of the collapsed drifts, where loose blocks partly detach and create large fracture openings. In general, these zones may have permeability increases by up to two to three orders of magnitude, and a reduction in fracture capillary strength by up to one order of magnitude, relative to the undisturbed values. (Note that the largest values - up to three orders of magnitude in permeability-are specific to the less reliable approach estimating permeability changes from the strain versus permeability relationship. Permeabilities estimated from the stress versus permeability relationship indicate a one to two orders of magnitude increase.) However, the sides of the drift are not relevant for seepage, as long as downward flow of water along the drift sides is not blocked by low-permeability regions.

Most important are the predicted changes in hydrological properties above the crown of the collapsed drift. Here, the expected conditions are permeability increases by one to two orders of magnitude and a fracture capillary strength decrease by about 50 percent relative to the undisturbed values. Compared to the excavation-disturbed conditions, these changes are rather moderate. The increase in permeability above the drift crown will enhance diversion of percolation water sideways and around the collapsed drift. While most of the presented results in BSC (2004 [DIRS 169864], Section 6.8) show permeability changes averaged over the horizontal and the vertical directions, it is indicated that typically the horizontal increase at the drift crown is larger than the vertical increase. As discussed earlier, such anisotropic behavior would tend to increase the likelihood of flow diversion compared to isotropic conditions. On the other hand, the slight decrease in capillary strength will weaken the capillary barrier, and would thus reduce the likelihood of flow diversion. The net effect of an increased permeability and a reduced capillary strength on the resulting amount of seepage can be estimated using the contour plots of ambient seepage into collapsed drifts given in Figures 6.4-8 through 6.4-11. Estimation of reasonable values for the maximum changes in hydrological properties at the crown of collapsed drifts (represented by Scenarios 2 and 12) compared to the post-excavation conditions (represented by Scenario 7) can be based on the results given in BSC (2004 [DIRS 169864], Section 6.8.5) and the above discussion of the respective scenarios. Reasonable maximum values are a one-order-of-magnitude increase in permeability and a 30 percent decrease in capillary strength. Such changes would generally have minor impact on the ambient seepage percentage, as demonstrated by the sensitivity analysis given in Section 6.8.2. Considering that (1) the horizontal permeability increase is most likely larger than the isotropic value used above and (2) the effective capillary strength decrease that should be used for seepage estimates is most likely smaller than the value estimated from the Leverett function, it can be concluded that the hydrological properties above collapsed drifts are certainly not adverse to the diversion of 

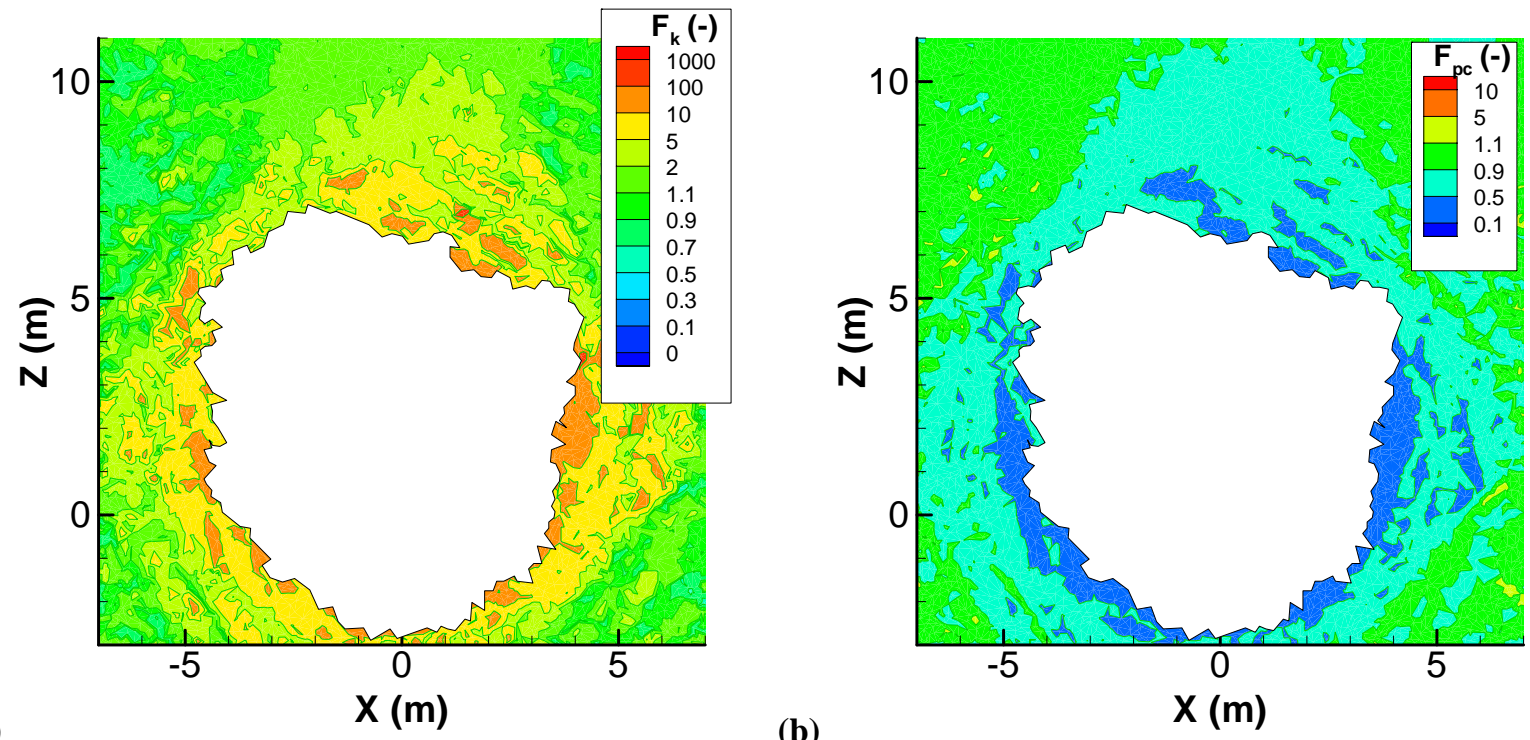

(a)

(b)

Source: BSC (2004 [DIRS 169864], Figures 6.8.2-2a and 6.8.2-3a).

NOTE: The permeability changes were estimated from the stress versus permeability relationship. Capillary strength changes were estimated from the Leverett function.

Figure 6.4-34. Changes in Hydrological Properties Expected for a Completely Collapsed Drift in Scenario 12 (100 percent cohesion loss), Showing (a) the Ratio of Post-Collapse Fracture Permeability Relative to the Undisturbed Values, and (b) the Ratio of Post-Collapse Fracture Capillary Strength Relative to the Undisturbed Values

percolation water around drifts. This indicates that reasonable (somewhat over-predictive) estimates of seepage into collapsed drifts can be derived when the seepage calculation uses the initial properties of the excavation-disturbed zone around drifts; i.e., when the calculation neglects changes to these properties caused by the drift collapse.

\subsubsection{THC Seepage Model}

The THC Seepage Model is a drift-scale process model for predicting (1) the composition (not the rate) of gas and water that could enter waste emplacement drifts and (2) the effects of mineral alteration on flow in rocks surrounding drifts (BSC 2004 [DIRS 169856]). The latter effect can be important for seepage abstraction: Mineral precipitation is predicted to form "precipitation" caps of calcite, silica, and other minerals above emplacement drifts, leading to changes in fracture porosity, permeability, and local percolation.

The THC Seepage Model is based on the thermal-hydrological model for nondegraded drifts introduced in Section 6.4.3. As a result, the modeling framework for the thermal-hydrological simulations-including grid design, boundary conditions, and rock properties-is similar in these models. However, whereas the TH Seepage Model focuses on the TH conditions to evaluate seepage rates for various seepage-relevant parameter cases, the THC simulations concentrate on the chemical processes and their related sensitivities. Predictive simulations are conducted with the THC Seepage Model for a time period of 100,000 years after waste emplacement. The model includes a wide range of major and minor aqueous species and minerals. Sensitivity studies were performed to evaluate the impact of, for example, alternative 
geochemical systems, initial water compositions, and reaction rates. Careful model validation was conducted mainly in comparison with measured gas compositions, water chemistry, and analyses of mineral composition in the DST (BSC 2004 [DIRS 169856], Section 7). Model results were also compared with measured water compositions from a laboratory plug-flow dissolution experiment. In addition, a fracture-sealing laboratory experiment was simulated to compare precipitation data. In general, the model captured the trends in gas composition, water chemistry, and mineral precipitation reasonably well.

The effects of mineral precipitation and dissolution of flow processes in the drift vicinity are discussed in Section 6.5.5.3 of BSC (2004 [DIRS 169856]). The simulation results suggest that a thin region of significantly decreased fracture permeability will form several meters above the drift crown, created by mineral deposition at the boiling front (mainly silica, to a lesser extent calcite). Mineral precipitation is particularly strong in this region because the boiling front remains at this location for several hundred years. Note that there is no indication that significant precipitation may occur immediately at the drift wall. This means that the local permeability and porosity in the boundary layer above the drift wall, important for the capillary barrier behavior, are not affected by THC alterations. Figure 6.4-35 illustrates the spatial distributions of permeability changes and demonstrates its impact on the flow conditions at 2,400 years after emplacement. While the permeability values directly at the drift wall remain unchanged, permeability decreases by a factor of 10 in an area 7-8 meters above the drift. As a result, percolating water is partially deflected sideways at this low-permeability zone, so that less water arrives at the drift crown (BSC 2004 [DIRS 169856], Figure 6.5-39). Since the amount of seepage is correlated to the local percolation flux, this kind of "umbrella effect" would give rise to less seepage compared to a simulation without permeability changes. Note that the permeabilities shown at 2,400 years remain essentially unchanged for the rest of the simulation period of 100,000 years, mainly because the silica solubility decreases with declining temperature. 
(a)

Tptpll Fractures - 2,400 Years (W0)

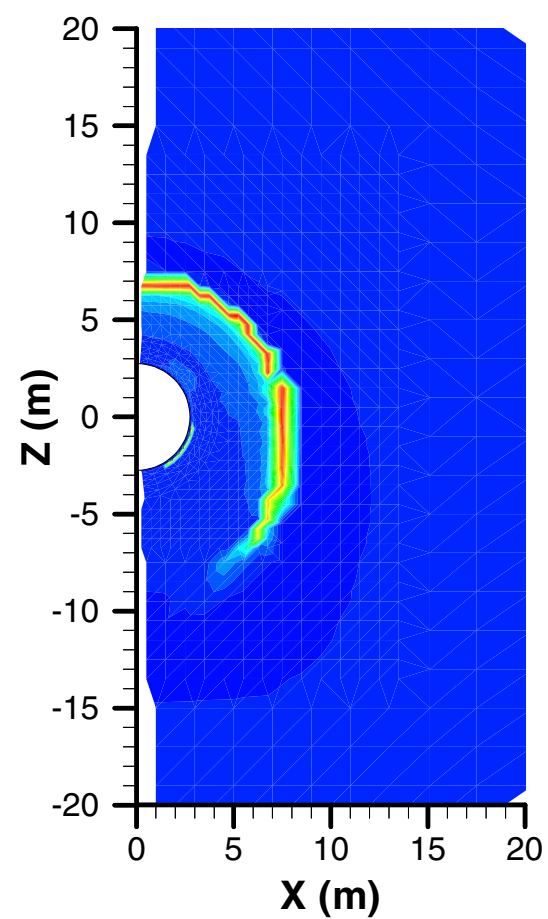

(b)

Tptpll Fractures - 2,400 Years (W0)

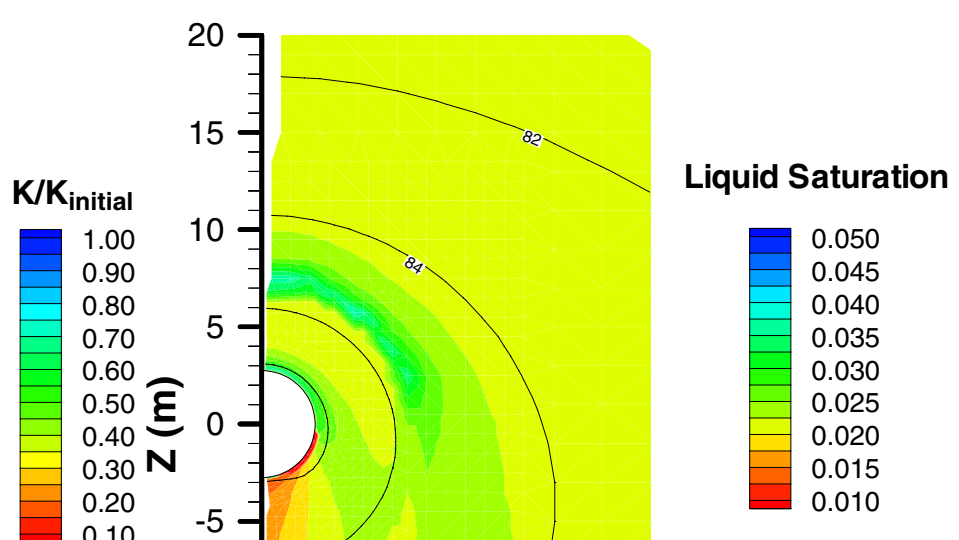

Source: BSC (2004 [DIRS 169856], Figure 6.5-39).

Figure 6.4-35. Example of Effects of Mineral Alteration as Predicted by the THC Seepage Model: Contour Plot of Modeled (a) Permeability Change, and (b) Liquid Saturation and Temperature Contours $\left({ }^{\circ} \mathrm{C}\right)$ at 2,400 Years

BSC (2004 [DIRS 169856], Section 6.5.5.3) presents several sensitivity cases for mineral alteration results using different initial water compositions, showing significantly different permeability changes using these waters. Fracture porosity changes also depend strongly on the initial porosity estimate for the fracture continuum, which is hard to quantify. It is also expected that variability in the $\mathrm{TH}$ conditions (e.g., stemming from thermal-load differences, percolation-flux variability) will bring out strong differences in the precipitation patterns. This variability was not addressed in the THC simulation runs.

\subsection{SEEPAGE ABSTRACTION METHODOLOGY}

The purpose of the seepage component in TSPA-LA is to calculate the seepage rate (amount of seepage per time) and the seepage fraction (the fraction of waste packages affected by seepage) as a function of time and location in the repository (Total System Performance Assessment (TSPA) Model/Analysis for the License Application, BSC 2004 [DIRS 168504], Section 6.3.3.1). The calculation is performed using a probabilistic approach that accounts for the spatial and temporal variability and inherent uncertainty of seepage-relevant properties and processes. The resulting information takes the form of probability distributions for seepage events. As pointed out before, seepage is defined as the flow of liquid water from the fractured formation into the open drift or, in case of drift collapse, the rubble-filled opening. The seepage distributions are used for subsequent TSPA calculations that may handle, for example, the fate of seepage water 
inside the drifts and the impact of seepage on waste form degradation or radionuclide transport. Depending on the downstream modules, the resulting distributions may be directly used or propagated in simplified form (histograms, sorting in bins).

The purpose of this model report is to provide the necessary methodology, tools, parameter distributions, look-up tables, and simplifications to the TSPA-LA, so that the seepage calculations can be performed by the respective TSPA module. The abstraction does not provide TSPA-LA with the resulting distributions of seepage rate and seepage fraction over the repository area. However, Section 6.8 of this model report does include a stochastic evaluation of seepage, where the probabilistic seepage calculation of the TSPA module is adopted in a simplified manner. The purpose of this stochastic evaluation is (1) to demonstrate the barrier capability of the UZ above the repository, and (2) to derive the sensitivity of seepage results to various parameters. The latter helps to justify some of the choices made in the abstraction process (e.g., the choice of particular shapes of probability distribution functions for spatial variability and uncertainty). While the results of Section 6.8 are not directly utilized in the TSPA-LA, they may be useful as corroborative information for comparison with results from the TSPA seepage module.

Seepage is variable in space because of variability in percolation flux and heterogeneity in key hydrological properties. In addition, seepage may be affected by heat generated by the decaying radioactive waste, from changes in hydrological properties as a result of mechanical and chemical effects, from changes in the drift shape due to drift degradation, and from the presence of rock bolts used for ground support. Several of these factors are also time-dependent, such as percolation flux and thermal effects. The methodology of incorporating each of these factors in the seepage abstraction model is directly based on the process-model results as described in Section 6.4. The general procedure has two main steps, as follows:

1. The ambient seepage results derived from the SMPA provide the basis for the quantitative evaluation of seepage as a function of key hydrological properties. The key hydrological parameters defining ambient seepage-capillary strength $1 / \alpha$, permeability $k$, and local percolation flux $q_{\text {perc,ff }}$ are described by appropriate probability distributions, as defined in Section 6.6. For a particular set of these key parameters, sampled from the respective distributions, the ambient seepage rate and its inherent estimation uncertainty are interpolated from the seepage look-up tables provided by the SMPA. The sampling and interpolation procedure is further explained in Section 6.5.1 below. Depending on the considered TSPA event, the sampling will be either conducted from the look-up table for nondegraded drifts (presented in Section 6.4.2.3) or from the look-up table for collapsed drifts (presented in Section 6.4.2.4.2). Specifics to the abstraction of drift degradation effects are provided in Section 6.5.1.5.

2. The ambient seepage rates are then adjusted to account for potentially important factors such as thermal effects on seepage, drift degradation, and rock bolts, if necessary. Thermal effects on seepage include potential changes in key properties (Section 6.5.1.4) as well as potential changes in the resulting seepage rates for nondegraded drifts (Section 6.5.2) and collapsed drifts (Section 6.5.3). These 
adjustments involve simplifications of complex model results. The simplification approaches and their scientific bases are explained in detail in the sections below.

The TSPA procedure of calculating seepage is schematically illustrated in Figure 6.5-1. The TSPA calculations run over several time steps to account for the temporal variability of relevant processes (Total System Performance Assessment (TSPA) Model/Analysis for the License Application, BSC 2004 [DIRS 168504], Section 6.3.3.1). Spatial variability and uncertainty are accounted for by separate probability distributions that are defined later in this document. First, random sampling of the uncertainty distributions is conducted for a sufficiently large number of realizations $\mathrm{R}$. This is done once, outside of the time step loop. Then, at each time step and for each realization $\mathrm{R}$, the seepage rate is evaluated at a sufficiently large number of spatial locations $\mathrm{r}$ in the repository area, using the spatial variability distributions. As pointed out in the Total System Performance Assessment (TSPA) Model/Analysis for the License Application report (BSC 2004 [DIRS 168504], Section 6.3.3.1), the total number of locations is 2,874. Over all locations, the resulting number of locations with seepage, relative to the total number of locations, defines the seepage fraction $f_{\text {seep }}$ for the realization and the time considered. Details are provided in the following sections.

Note that abstraction as outlined above attempts to extract the salient features of the expected seepage behavior by compiling and reviewing field data and by simplifying the results previously obtained with complex process models (such as the SMPA and Thermal Seepage Model). No new mathematical model was developed for the seepage abstraction model, and consequently there are no related equations, algorithms, numerical methods, or other software/computational methods that need to be discussed in this model report. Statistical concepts and methods are used to develop parameter distributions; the related computations are fully documented in this model report, specifically in Appendices A through G.

\subsubsection{Abstraction of Ambient Seepage}

The seepage component in TSPA directly uses the seepage look-up tables provided by the SMPA model results to calculate ambient seepage rates. There is no simplification or other processing of these results involved that would need to be developed within the abstraction process. Thus, the relevant small-scale processes simulated with the ambient-seepage process models are inherently included in TSPA without loss of information. One important role of seepage abstraction is to derive the appropriate probability distributions for seepage-relevant parameters that feed into the look-up tables for seepage. The probability distributions developed within the abstraction need to account for the spatial variability and the uncertainty of these seepage-relevant parameters. The impact of additional factors, such as THC and THM parameter changes, drift degradation, and rock bolts, needs to be assessed and appropriately accounted for. 


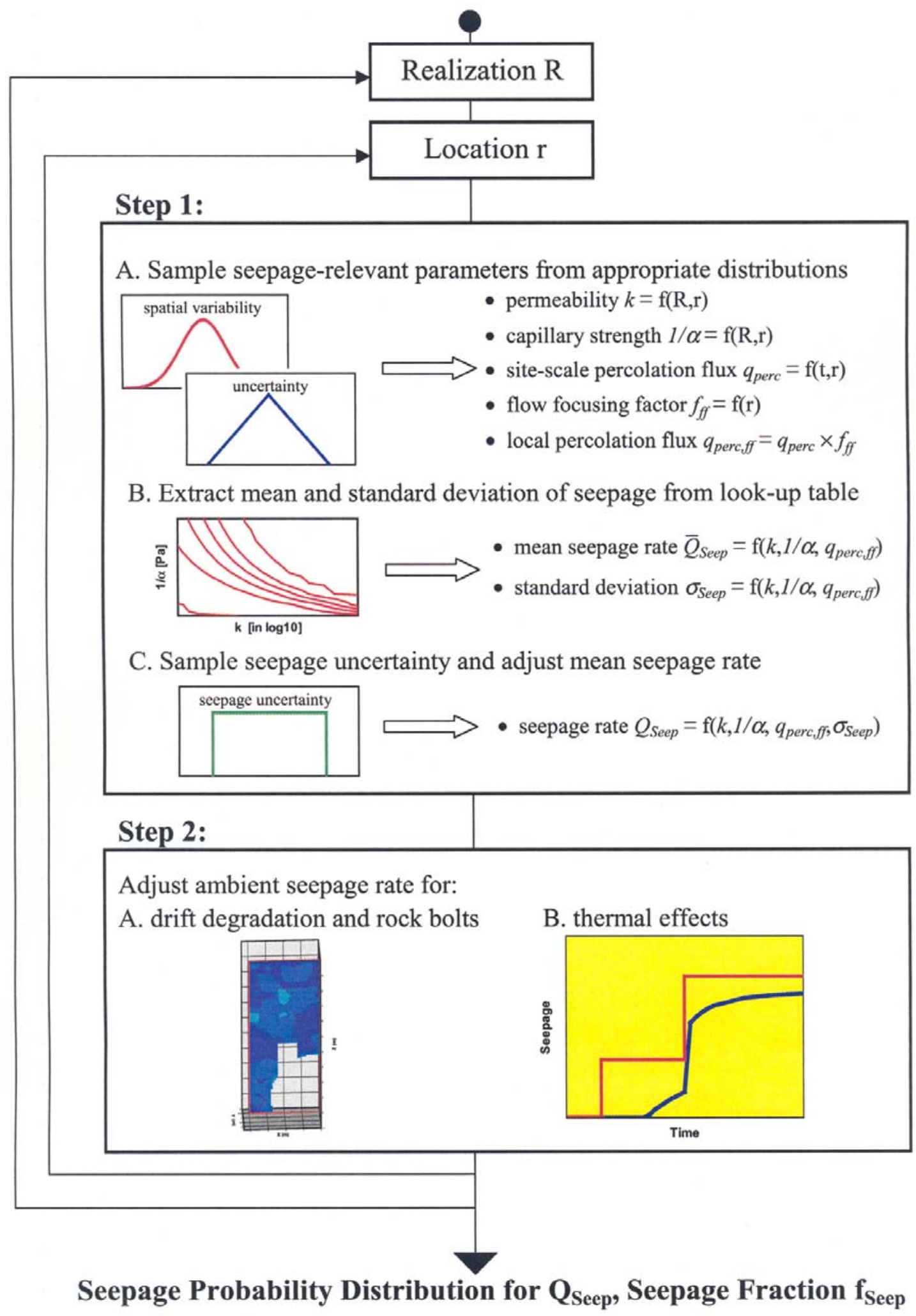

Figure 6.5-1. Schematic of Probabilistic TSPA Procedure for Calculating Seepage 


\subsubsection{Random Sampling Methodology}

The key hydrological parameters for ambient seepage are the capillary strength $1 / \alpha$, permeability $k$, and local percolation flux $q_{\text {perc,ff. }}$ According to the conceptual model of the seepage process models (SCM and SMPA, see Sections 6.4.1 and 6.4.2), the following guidelines apply for defining the respective parameter distributions (considering nondegraded drifts):

1. Since small-scale heterogeneity (on the order of 0.3 meters or less) is explicitly accounted for in the SMPA, the spatial variability to be described by probability distributions is the variability over the repository area that occurs on the spatial resolution of a few drift diameters or more (intermediate-scale heterogeneity).

2. The capillary-strength parameter distribution must be representative of the effective parameter values calibrated from the SCM.

3. The permeability parameter distribution provided to the TSPA must represent the mean values of the small-scale permeability fields used in the SMPA. The standard deviation and the correlation structure of these small-scale fields are not varied in the TSPA, because the "best" parameter estimates produced seepage rates that were either comparable to or larger than seepage rates calculated from selected sensitivity cases (Section 6.4.2).

4. The permeability distribution must be representative of the excavation-disturbed zone in the vicinity of the drifts.

5. The distribution of percolation fluxes needs to cover the potential flux variability for present and future climate stages. Since small-scale flow channeling is explicitly modeled with the SMPA, only the spatial variability on a resolution equal to or larger than a few drift diameters needs to be considered.

Following this guidance, and based on evaluation of available measurements and model data, appropriate probability distributions are developed in Section 6.6 of this report. For permeability and capillary strength, the resulting distributions are representative of the ambient conditions in the vicinity of nondegraded drifts prior to heating of the rock. The abstraction methodology for incorporating time-dependent changes in these properties, e.g., stemming from THM or THC effects or from drift degradation including drift collapse, will be discussed in Sections 6.5.1.4 and 6.5.1.5. It will be demonstrated that these changes can be neglected in the seepage abstraction model, so that the derived parameter distributions are valid for the entire 10,000-year compliance period. The percolation flux, on the other hand, is time-dependent, as a result of future climate changes. Three different spatial distributions representative of three future climate stages are used to account for the temporal evolution of percolation flux (Section 6.6.5).

As mentioned before, the probabilities assigned to the relevant parameters distinguish explicitly between spatial variability and uncertainty, using separate distributions. Distinguishing between aleatory and epistemic uncertainty is not important for estimates of mean risk, but helps to better understand the respective contributions of variability and uncertainty (BSC 2002 [DIRS 158794], Section 4.1.2). As explained in Section 6.6, spatial variability of permeability is described by a 
log-normal probability distribution, whereas spatial variability of the capillary-strength parameter is expressed by a uniform distribution. The statistical properties (mean, standard deviations, range) defining these spatial variability distributions describe the most probable case, i.e., they are determined using the best data at hand without accounting for uncertainty. The uncertainty of both parameters is represented by symmetrical triangular distributions, which are used to adjust the spatial variability sampling on account of various sources of uncertainty. This adjustment can shift the original value in both positive and negative directions. The uncertainty distributions have a mean of zero to ensure that the chosen spatial variability distributions are indeed the most probable cases. The range of the distributions (i.e., the width of the triangle) defines the degree of uncertainty in the parameter (Mishra 2002 [DIRS 163603], Section 2.3). Potential sources of uncertainty included in the triangular distributions are (1) measurement uncertainty, (2) spatial variability uncertainty, (3) conceptual model uncertainty, and (4) estimation uncertainty (Section 6.6).

A schematic illustration of the random sampling procedure is given in Figure 6.5-2. In the outer calculation loop over realizations $\mathrm{R}$, the spatial variability distributions for permeability and capillary strength are adjusted to account for uncertainty, using random samples of the triangular uncertainty distribution (shown here as cumulative probability distribution). The inner calculation loop of the TSPA seepage component conducts random sampling of the adjusted spatial variability distributions at each of the several thousand locations $r$ in the repository area, to derive values of permeability and capillary strength. The schematic illustration in Figure 6.5-2 depicts the uniform spatial variability distribution chosen for the capillary-strength parameter, here shown as cumulative probability distribution. Separate distributions of $r$ are used for each realization $\mathrm{R}$, accounting for the uncertainty in the generated random fields. Note that the two main host-rock units, the Tptpll and the Tptpmn units, may have separate distributions to account for differences in the hydrological properties.

The procedure for sampling of local percolation fluxes $q_{\text {perc.ff }}$ is slightly different from sampling of the other parameters. As explained in Section 6.6.5, the flux variability is provided by model results from the UZ Flow Model (BSC 2004 [DIRS 169861], Section 6.6). These fluxes are provided for three different climate stages (present-day climate from current conditions to approximately 600 years into the future, monsoon climate from 600 to approximately 2,000 years from now, and glacial transition climate starting at approximately 2,000 years from present day), during which the UZ model flow fields are considered steady state. Which one of these flow fields is to be used for sampling depends on the time step considered in the TSPA calculation. For each time step, the local fluxes at the several thousand locations $r$ in the repository area are interpolated from the simulated flux distributions. 

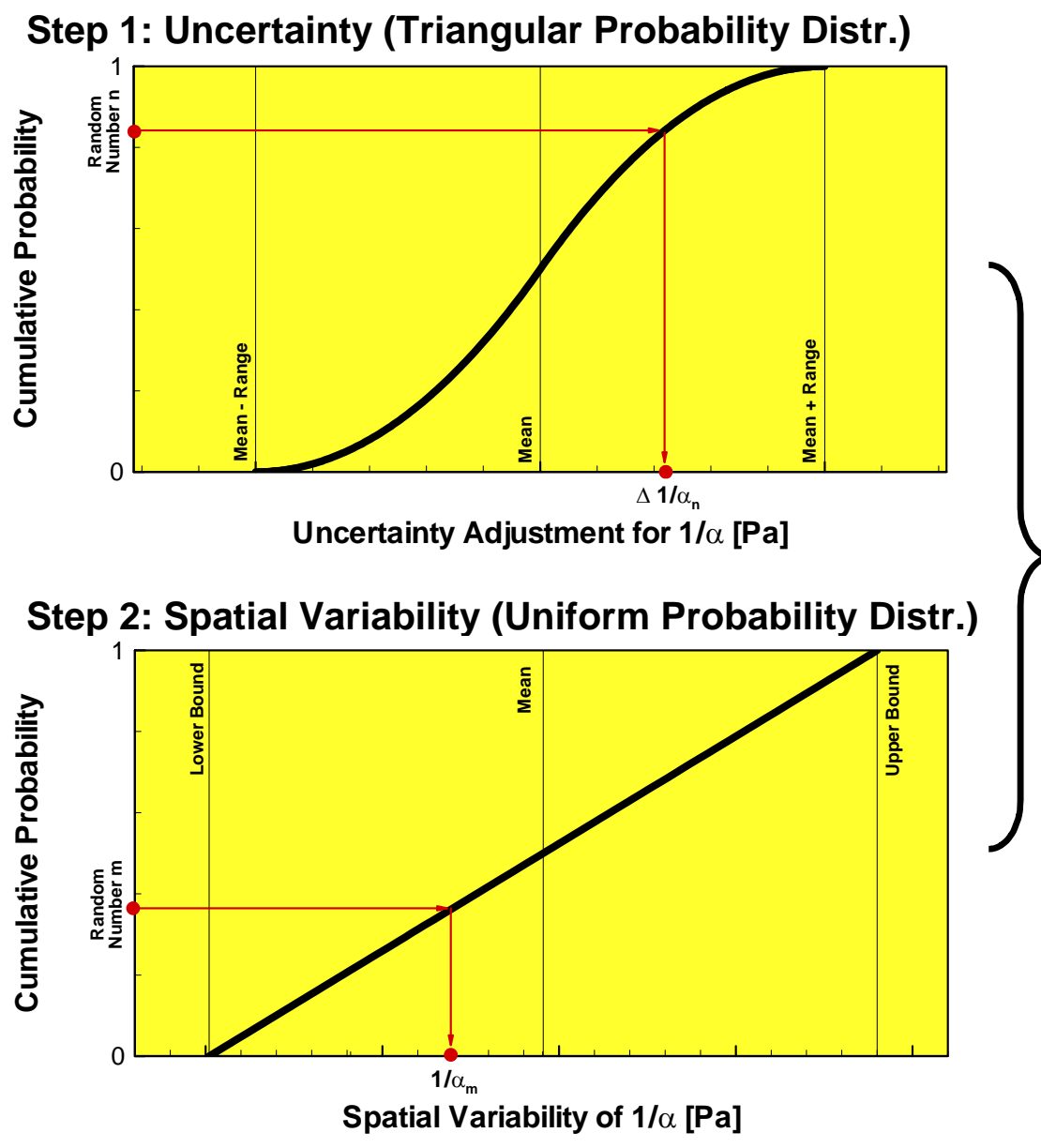

Resulting Value:

$1 / \alpha=1 / \alpha_{m}(R, r)+\Delta 1 / \alpha_{n}(R)$

Figure 6.5-2. Schematic Illustration of Random Sampling Procedure for Capillary-Strength Parameter $1 / \alpha$, Using Cumulative Probability Distributions for Spatial Variability (Uniform Probability Distribution) and Uncertainty (Triangular Probability Distribution). Subscripts $n$ and $m$ denote random sampling values between 0 and 1

Uncertainty inherent in the percolation flux distributions is expressed by using alternative flux scenarios, each of them associated with a certain occurrence probability. These are the mean, the upper-bound, and the lower-bound scenarios, available for two different conceptualizations of flow in the PTn unit. Each scenario comprises three simulated flux distributions for the three climate states defined above; thus, there are 18 different flux distributions altogether. (As shown in Sections 6.6.5.1 and 6.8.2, only nine of them are relevant for TSPA-LA, because one of the flow conceptualizations for flow in the PTn unit can be neglected.) The steps for sampling local percolation fluxes in the TSPA-LA are as follows: First, in a loop over the R uncertainty realizations, the TSPA-LA calculation randomly selects one of the different infiltration scenarios (mean, upper-bound, and lower-bound scenarios), depending on their respective occurrence probability. In the second step, the local percolation flux values are interpolated at all spatial locations $\mathrm{r}$ in the repository, using the simulated flux distributions that are associated with the selected infiltration scenario. Depending on the time step considered in the TSPA-LA calculation, the interpolation procedure is done with the present-day, the monsoon, or the glacial transition flux distribution. For reasons discussed in Section 6.6.5, the local flux values need to be multiplied with flow focusing factors $f_{f f}$ that lead to increased fluxes in some areas, while 
reducing them in others. These factors, also spatially variable and thus randomly sampled in $\mathrm{r}$, account for intermediate-scale heterogeneity not represented in the above-mentioned flux distributions. Multiplication of the local fluxes $q_{\text {perc }}$ from the site-scale model with the flow focusing factors $f_{f f}$ gives the local percolation flux $q_{\text {perc,ff }}$ to be used in the TSPA calculation.

Note that the respective probability distributions for capillary strength, permeability, and percolation flux are not correlated. This means that the random variables used to sample from the respective distributions should be generated independently in the TSPA. There are theoretical reasons to expect that the permeability and the capillary strength in a single fracture should be negatively correlated, since both are related to the fracture aperture. Overall, such negative correlation would give rise to smaller seepage estimates compared to a no-correlation assumption (see Sensitivity Case 9 in Section 6.8.2). This is because, for the chosen probability distributions, seepage rates are largest for "extreme" parameter cases where (1) permeability is comparably small, (2) fracture capillary strength is comparably small, and (3) percolation flux is comparably large. With a negative correlation between permeability and capillary strength, such "extreme" cases are less likely. A parameter value promoting seepage (e.g., small capillary strength $1 / \alpha$ ) would coincide with a parameter value reducing seepage (e.g., large permeability $k$ ), and vice versa. These opposite effects would partially cancel out, so that there would be fewer "extreme" seepage cases, leading to an overall reduction in seepage. However, the calibrated capillary-strength parameter derived from the SCM is not just related to fracture aperture; it is an effective continuum process parameter that implicitly accounts for many additional factors affecting seepage (see Section 6.4.1.1). Thus, no predictable correlation exists between permeability and the effective capillary-strength parameter, and the no-correlation model should be used in TSPA.

Similarly, a no-correlation model should be used for the distributions of permeability and percolation flux, although this kind of correlation would reduce the overall amount of seepage (see Sensitivity Case 10 in Section 6.8.2). While it is reasonable to assume positive correlation between permeability and flux in fully saturated conditions, the flow patterns in the unsaturated rock at Yucca Mountain are determined by various other factors (e.g., boundary conditions, geological structure) that are more important than local permeability. For a given overall infiltration, changes in absolute permeability are simply compensated by changes in saturation (as long as unsaturated conditions prevail). Therefore, TSPA should sample independently from the distributions of permeability and percolation flux.

\subsubsection{Seepage Interpolation}

Seepage rates are calculated for each set of seepage-relevant parameters derived in the random sampling procedure over $\mathrm{R}$ realizations and $\mathrm{r}$ locations, using the seepage look-up tables provided by the SMPA. The sampling and interpolation procedure is identical for the two look-up tables provided for nondegraded and collapsed drifts. Seepage results should be derived from a linear interpolation between the seepage values in the SMPA look-up tables. The tabulated value resolution provided by the systematic SMPA simulation runs is fine enough to justify linear interpolation, even though the functional relation between seepage results and input parameters may be nonlinear overall. The look-up tables generated by the SMPA contain the mean seepage value $\bar{Q}_{\text {seep }}$ and the standard deviation $\sigma_{\text {seep }}$ over the number of simulated realizations, given either as seepage rate per waste package or as seepage percentage. The 
standard deviation $\sigma_{\text {seep }}$ represents the uncertainty of the mean seepage value. As explained in Section 6.5.1.3, the standard deviation is used to adjust the mean seepage value in order to account for uncertainty in the predictions.

Two of the alternative probability distributions chosen for the capillary-strength parameter (i.e., Methods A and B, see Section 6.6.2) are sufficiently bracketed by the parameter range covered in the SMPA results (i.e., $100 \mathrm{~Pa}$ to 1,000 Pa; see Section 6.4.2.3). The other two distributions may arrive at capillary-strength values that are larger than 1,000 $\mathrm{Pa}$, thus exceeding the parameter range simulated with the SMPA. The probability of such cases is rather small, as shown in Section 6.8.1. In the unlikely case that a sampled capillary-strength value is larger than 1,000 $\mathrm{Pa}$ it should be set to 1,000 Pa prior to the seepage interpolation. Truncating at the upper capillary-strength value leads to higher overall seepage, because reducing capillary strength tends to increase the probability of seepage. Thus, the suggested truncation is justified. The infinite distribution for permeability can also exceed the range simulated with the SMPA (i.e., -14 to -10 in $\log 10$; see Section 6.4.2.3). Again, the probability that sampled permeability values fall outside of the SMPA range is very small, as demonstrated in Section 6.8.1. (For comparison, the 99 percent confidence interval for the spatial variability distributions developed in Section 6.6.3 ranges approximately from -13.2 to -11.2 for the Tptpmn unit and from -12.9 to -10.1 for the Tptpll unit.) In the unlikely case that a sampled log-permeability value is smaller than -14 , it should be set to -14 . Similarly, log-permeability values exceeding the upper bound of -10 should be set to -10 . The impact of this truncation on seepage results is insignificant, as discussed in Section 6.8.1.

A similar methodology is recommended for truncating the local percolation-flux distributions $\mathrm{q}_{\text {perc,ff }}$. Flux values smaller than $1 \mathrm{~mm} /$ year should be set to $1 \mathrm{~mm} /$ year, the smallest percolation flux simulated with the SMPA. At such small fluxes, seepage is only expected for extreme parameter combinations, so that this flux adjustment has almost no effect on the seepage results. Percolation fluxes larger than 1,000 mm/year should be set to $1,000 \mathrm{~mm} /$ year. As pointed out in Section 6.6.5.3, local percolation fluxes larger than 1,000 mm/year are theoretically possible (as a result of climate changes, spatial variability, and flow focusing), but extremely unlikely (see footnote in Section 6.6.5.3). This is supported by the probabilistic seepage analysis in Section 6.8.1, where the number of sampled flux values larger than 1,000 mm/year from a sample size of 10,000 values is zero for all climate stages and scenarios (see footnote in Section 6.6.5.3). Therefore, the impact on the seepage results is negligible.

\subsubsection{Ambient Seepage Uncertainty}

The uncertainty inherent in the ambient seepage results is a result of uncertainty in the key input parameters to the model, as well as uncertainty that arises from the modeling methodology independent of the model input. As mentioned above, uncertainty in the input parameters is accounted for in the TSPA by feeding appropriate probability distributions into the seepage look-up tables derived from the SMPA. These distributions are developed in Section 6.6. Uncertainty inherent in the modeling methodology can stem from uncertainty in the conceptual model used for the seepage simulations (conceptual model uncertainty) and from uncertainty 
about the local heterogeneity considered in the SMPA (estimation uncertainty). These are accounted for in the abstraction as follows:

1. The conceptual model used in the SMPA is adopted from the conceptual framework of the seepage calibration analyses, conducted with the SCM. As pointed out in Section 6.4.1, the SMPA and the SCM are in fact similar models that are used for different purposes. Both are sophisticated seepage-process models considering the scale and the conditions of interest. The modeling framework is consistent with the conceptual and numerical models used for calculating flow and transport in the UZ at Yucca Mountain. The calibrated SCM with the appropriate effective parameters is capable of reproducing and predicting observed seepage data from liquid-release tests conducted above and below the seepage threshold. The SMPA predictions are thus likely to yield reasonable estimates of seepage into waste emplacement drifts. Alternative conceptual models that corroborate the findings of the SCM have been qualitatively discussed in BSC (2004 [DIRS 171764], Section 6.4). Altogether, the conceptual model uncertainty should be small compared to other sources of uncertainty that are explicitly accounted for using cautiously realistic uncertainty estimates. Therefore, the contribution of conceptual model uncertainty is neglected in the abstraction of ambient seepage.

2. Because the exact structure of local heterogeneity in the drift vicinity is unknown, multiple realizations of stochastic permeability fields were studied with the SMPA (see Section 6.4.2). The spread of seepage results stemming from these realizations defines the estimation uncertainty of seepage. This uncertainty contribution, as described by the standard deviation values given above, must be accounted for in the TSPA calculations. As recommended in Section 6.4.2, a uniform probability distribution should be used to describe the estimation uncertainty. Uncertainty values are randomly sampled from the uniform uncertainty distribution and then used to adjust the mean seepage values. Since the mean seepage rates provided in the look-up tables are the most probable values, the uniform uncertainty distribution should have a mean of zero. The range of the distribution, which is different for each parameter set, is defined by the interpolated value of the seepage standard deviation. It can be easily shown that the upper bound of a uniform distribution with mean zero and standard deviation $\sigma_{\text {seep }}$ is $+1.7321 \times \sigma_{\text {seep }}$, the lower bound is $-1.7321 \times \sigma_{\text {seep }}$ (derived from Mishra 2002 [DIRS 163603], Section 2.3; see Scientific Notebook Birkholzer 2003 [DIRS 164526], p. 123). The mean seepage rates are adjusted by adding the sampled uncertainty value, which can be positive or negative, to the mean (i.e., the adjusted seepage rate can be higher or lower than the mean, depending on the sign of the sampled uncertainty value). After adjusting the mean seepage rates, the results must be checked for consistency with physical limits. Seepage rates smaller than zero are set to zero. Seepage rates that correspond to a seepage percentage of more than 100 percent (i.e., the resulting seepage is larger than the percolation flux over the drift segment) are set to a seepage rate corresponding to a seepage percentage of 100 percent. Note that a seepage percentage of 100 percent corresponds to a situation in which the entire percolation flux over the footprint of the drift segment seeps into the drift; i.e., there is no flow diversion. Thus, a seepage percentage higher than 100 percent would correspond to a situation where there is no flow diversion and 
where additional water from outside the footprint of the segment is channeled into the drift. Such a situation is extremely unlikely.

\subsubsection{Abstraction of THM and THC Parameter Alterations}

The section below explains why the expected time-dependent alterations of seepage-relevant properties, stemming from THM and THC effects in response to the elevated temperatures in the repository, can be (or should be) neglected in the seepage simulations conducted in the TSPA. In other words, the ambient SMPA results can be directly applied for most of the 10,000-year compliance period (except for the time period of strongly perturbed thermal conditions, see Sections 6.5.2 and 6.5.3). Also, the parameter distributions for capillary strength and permeability can be considered constant in the seepage abstraction model. In other words, the ambient seepage calculations remain unchanged when considering THM and THC effects.

\section{$\underline{\text { THM Parameter Alterations }}$}

The THM simulations discussed in Section 6.4.4.1.1 suggest that temperature-induced stress changes give rise to changes in the vertical fracture permeability in the vicinity of waste emplacement drifts, in particular in the Tptpmn unit. It was demonstrated, however, that these permeability changes do not result in significant changes in the flow fields. In particular, the seepage rates calculated for a permeability field including THM permeability changes were similar to, but slightly smaller than those calculated for a permeability field representative of the initial post-excavation conditions. The SMPA simulation results provide reasonably accurate (slightly over-predictive) estimates of the expected seepage rates at long-term conditions with coupled THM property changes. Therefore, the impact of THM property changes is neglected in the seepage abstraction model. The seepage abstraction model uses the ambient seepage rates without accounting for the transient THM changes in seepage-relevant properties. The rationale for neglecting THM effects is listed below:

- Including the impact of THM property changes would result in slightly smaller seepage rates in the TSPA analyses. However, the limited benefit of including THM effects does not justify the complexity of implementing these processes in the TSPA analyses.

- The THM simulation results were conducted for selected TH conditions using a limited set of THM property estimates. Because of computational limitations, the potential variability in these conditions and properties could not be fully addressed in the THM simulation beyond the determination that the ambient seepage predictions bound the seepage under conditions when THM effects are considered. Thus, there is no sufficient modeling basis to explicitly incorporate THM effects and their uncertainties into the TSPA-LA analysis.

- The stress-permeability relationship used in the predictive THM simulations is a bounding case with maximum THM impact on hydrological properties; i.e., permeability changes predicted by the model are likely to be overestimated.

- The predictive THM simulation is based on model calibration to displacement data from the heating phase of the DST, which indicate predominantly elastic reversible mechanical behavior. Cooling-phase data (that are generally better suited to evaluate the 
potential for nonelastic behavior) had not been available at the time of conducting the THM analysis to support this assessment, resulting in some model uncertainty. There is additional uncertainty regarding the predicted THM behavior in the Tptpll unit, because of the lack of in situ heater tests in this unit (BSC 2004 [DIRS 169864], Section 8.2). These uncertainties are not relevant for the suggested simple THM abstraction model, but would need to be considered for a more complex abstraction using a time-dependent representation of the THM property changes.

Note that the THM model analysis is restricted to thermal expansion effects on seepage-relevant properties. An abstraction method to incorporate the impact of drift collapse on the hydrological properties of the remaining rock above the rubble-filled cave- a potential result of joint cohesion loss or seismic events-is developed in the following section (Section 6.5.1.5). It is proposed that alteration of these hydrological properties can be neglected in the abstraction; i.e., that these properties are unchanged from the properties of the initial excavation-disturbed zone around nondegraded drifts.

\section{THC Parameter Alterations}

The THC simulations discussed in Section 6.4.4.2 suggest formation of a precipitation cap about 7-8 meters above the drift crown. The zone of decreased fracture permeability acts as an "umbrella" that partially deflects percolating water sideways, limits the amount of flux at the drift crown, and reduces seepage. The seepage abstraction model does not incorporate this effect, considering the considerable uncertainty and potential variability in these simulated results. As pointed out in BSC (2004 [DIRS 169856], Section 8.1), both natural variability and process uncertainties exist in modeling the coupled THC processes, because of the large amount of input data needed and the complexity of the natural system. Studies conducted with different initial water compositions have demonstrated the significant sensitivity of the predicted permeability changes. Other relevant sources of uncertainty are the initial fracture porosity and the relation between porosity and permeability changes. In addition, the THC simulations were conducted using average $\mathrm{TH}$ conditions. The location and magnitude of the precipitation "umbrella" can change considerably if the boiling front or the duration of boiling is different from these average conditions. A final note on the DST measurements used for the model validation: While the predicted locations and relative abundances of secondary minerals were consistent with in situ sidewall core samples retrieved from zones that had undergone boiling in the DST, the total amount of mineral precipitation was small and did not create measurable permeability changes. The DST heating phase of 4 years was too short to allow for mineral alteration strong enough to affect permeability.

Because of the uncertainties inherent in the THC results, the seepage abstraction model uses the ambient seepage rates from the SMPA without accounting for the "umbrella" effect. It should be recognized, however, that the simulated trend of a precipitation cap forming at some distance above the drift crown appears to be reliable in a qualitative sense. This adds confidence in the seepage abstraction results, in that the amount of seepage is likely to be smaller than the abstracted seepage because of THC effects. Note that the general conceptual model for seepage simulations of the SMPA is still valid independent of THC alterations, as pointed out in BSC (2004 [DIRS 167652], Section 6.7). The seepage-relevant flow diversion occurs within less than 1 meter from the drift wall and is not affected by the THC porosity and permeability changes. 


\subsubsection{Abstraction of Drift Degradation}

Drift degradation can occur as a result of thermal stresses, seismic ground motion, and rock-strength decrease (Section 6.4.2.4.1). The impact of drift degradation on seepage has been analyzed in Section 6.4.2.4.2, where SMPA seepage predictions for slightly degraded and collapsed drifts are discussed and compared to the nondegraded scenario, and in Section 6.4.4.1.2, where the possibility of degradation-induced changes in seepage-relevant properties is evaluated. First, an abstraction methodology is developed using the SMPA seepage predictions for degraded drifts; second, an abstraction approach is proposed for inclusion of degradation-induced property changes.

The degree to which drift degradation occurs is different between drifts located in nonlithophysal and lithophysal rocks (Section 6.4.2.4.1). Moderate drift degradation, limited to local rockfall at the drift ceiling and wall, is predicted for nonlithophysal rocks, regardless of the considered event leading to degradation. The SMPA seepage simulations discussed in Section 6.4.2.4.2 suggest that local breakout at the drift ceiling is not likely to increase seepage, as long as the drifts stay essentially intact and the horizontal extent remains mostly unchanged. In lithophysal units, the degree of drift degradation depends on the considered stress scenario. Moderate drift degradation similar to the nonlithophysal results is predicted as a result of thermal stress, time-dependent rock strength degradation, and minor to moderate seismic events. More severe seismic events, among them all the $1 \times 10^{-6}$ and the $1 \times 10^{-7}$ seismic hazard levels as well as some of the $1 \times 10^{-7}$ seismic hazard levels, result in complete drift collapse, leading to enlarged openings filled with fragmented rock material. Drift collapse increases the seepage percentage (relative rate of seepage) and the seepage rate compared to nondegraded drifts (absolute rate of seepage), as shown in Section 6.4.2.4.2. Under certain conditions, partial collapse with wall breakout and increase in the lateral drift extension may occur for a scenario combining a $1 \times 10^{-4}$ seismic event with time-dependent rock strength degradation. While the SMPA has not explicitly studied this case, seepage results can be estimated from the complete-collapse seepage results, which provide an upper-bound solution.

Based on Section 6.4.2.4 and consistent with the recommendations given in the Seismic Consequence Abstraction (BSC 2004 [DIRS 169183], Sections 6.4 .4 and 6.8.1), the different degrees of drift degradation are categorized for seepage abstraction as follows: The first category comprises degraded drifts that may show local rock breakout but stay essentially intact. In this category, seepage is interpolated from the look-up table for nondegraded drifts in DTN: LB0304SMDCREV2.002 [DIRS 163687]. Drifts located in nonlithophysal rock are included in Category 1, regardless of the considered nominal or seismic scenario. For drifts located in lithophysal rock, all nominal cases (including thermal stress and rock strength degradation) and seismic events less severe than the $1 \times 10^{-4}$ seismic hazard level (peak ground motion velocity smaller than $0.384 \mathrm{~m} / \mathrm{s}$ ) are included in Category 1 . The second category comprises the cases with partial and complete drift collapse. These include all other seismic events occurring in lithophysal rock units, i.e., all seismic events with annual occurrence probability equal to or lower than $10^{-4}$ (peak ground motions equal or greater than $0.384 \mathrm{~m} / \mathrm{s}$ ), analyzed separately or in combination with thermal stress and rock strength degradation. Systematic seepage simulations have been conducted for a selected (worst-case) drift collapse scenario, modeling seepage into a rubble-filled drift of a 11-meter diameter. Results from these simulations are available in a seepage look-up table similar in structure to the one developed for 
nondegraded drifts (DTN: LB0307SEEPDRCL.002 [DIRS 164337]). Based on the above categorization, the TSPA seepage simulation will sample seepage rates and percentages from either the nondegraded drift or the collapsed drift look-up tables, depending on the considered geologic unit and the selected nominal or disruptive scenarios. If the time of a seismic event leading to drift collapse is not explicitly considered in TSPA, the collapsed drift scenario should be used for the entire postclosure period when one of the strength-induced collapsed drift scenarios is considered in TSPA. On the other hand, if the time of a seismic event leading to drift collapse is considered in TSPA, the collapsed drift scenario should be used starting with the assumed time of the seismic event.

Quantitative assessment of uncertainties involved in the assessment of seepage into degraded drifts is not easy. There may be uncertainty in the drift degradation analysis (degradation profiles) as well as uncertainty in the seepage simulation results for these scenarios. However, it should be recognized that most cases leading to complete drift collapse are based on bounding-case conservative assumptions and represent worst-case scenarios. Therefore, the following procedure is suggested to incorporate the impact of uncertainty in the seepage predictions for degraded drifts. For all cases in Category 2 (uses the seepage look-up table for collapsed drifts), uncertainty is fully accounted for by the conservatism involved in the worst-case analysis (e.g., worst-case profiles). For all cases in Category 1 (uses the seepage look-up table for nondegraded drifts), the interpolated seepage rates are increased by 20 percent, to account for uncertainty associated with the seepage evaluation for these cases. This uncertainty stems in part from the limited number of simulation cases studied for moderately degraded drifts, but is also related to the large estimation differences between the stochastic realizations conducted for these cases (see Section 6.4.2.4.2). The maximum standard deviation of seepage percentage for degraded drifts was found to be above 30 percent, compared to about 16 percent for nondegraded cases. The proposed increase of seepage by 20 percent accounts for the impact of large estimation differences between realizations. (Note that the 20 percent increase is based on a probabilistic seepage sensitivity calculation similar to those conducted in Section 6.8. In this calculation, the sampled seepage standard deviations were all increased by a factor of 2 to mimic the large estimation differences in the simulation cases for moderately degraded drifts. The increase in the standard deviations lead to an increase in the mean seepage rates of about 10 percent for the present-day climate stage, about 7 percent for the monsoon climate stage, and about 6 percent for the glacial transition climate stage, all compared to the base case seepage results given in Table 6.8.1 (mean infiltration scenario). Thus, the impact of having a larger estimation uncertainty is safely bounded by the 20 percent increase in the interpolated seepage rates (see Scientific Notebook, Wang 2004 [DIRS 170994], pp. 116-118).)

Section 6.4.4.1.2 demonstrates that drift degradation may impact the hydrological properties of the rock in the drift vicinity. While simulation scenarios with minor degradation are not expected to result in relevant rock-property changes compared to the initial excavation-disturbed conditions, the hydrological properties around collapsed drifts will be moderately affected, with fracture permeability increases and fracture capillary strength decreases in the relevant area above the drift crown. Local permeability increase would result in less seepage because of enhanced flow diversion around the collapsed drift, whereas local capillary-strength decrease would result in more seepage, since the capillary barrier is weakened. However, it is pointed out in Section 6.4.4.1.2 that the net result of these counteracting property alterations is relatively small; i.e., the interpolated seepage rates using the adjusted properties for collapsed drifts are 
similar to the interpolated seepage rates using the initial excavation-disturbed properties. This assessment is based on estimated rock property changes that (1) neglect the anisotropic nature of fracture permeability alterations above the drift crown and (2) use the Leverett function to derive the fracture capillary-strength parameter (BSC 2004 [DIRS 169864], Section 6.8). The horizontal permeability increase above collapsed drifts is most likely larger than the isotropic value (i.e., promoting flow diversion), whereas the effective capillary strength decrease, to be used for seepage predictions, is most likely smaller than the value resulting from Leverett's function (i.e., enhancing the capillary barrier effectiveness). Based on these considerations (documented in Section 6.4.4.1.2), it can be stated with confidence that the collapsed-drift properties would not give rise to more seepage compared to the initial properties of the excavation-disturbed zone above nondegraded drifts. Thus, a simple bounding-case abstraction model is achieved by setting the seepage-relevant properties around collapsed drifts-local fracture permeability and capillary strength-identical to the properties of the initial excavation-disturbed zone around nondegraded drifts. This model accounts for potential uncertainty in the drift degradation analysis and in the evaluation of degradation-induced parameter changes. As pointed out above, the excavation-disturbed properties also provide reasonable estimates for drifts with minor degradation, since changes in seepage-relevant properties are expected to be negligible. This means that the respective parameter distributions for these properties, developed in Sections 6.6.2 and 6.6.3 based on in situ measurements and related calibration results, are applicable to cases with small degradation as well as cases with complete drift collapse. (However, as indicated earlier, the respective seepage look-up tables are different for these cases.)

\subsubsection{Abstraction of Rock-Bolt Effects}

The simulated rock-bolt cases in Section 6.4.2.5 indicated that there is essentially no seepage enhancement for nongrouted boreholes housing rock bolts. The impact of rock bolts is therefore neglected in the seepage abstraction model.

\subsubsection{Abstraction for Igneous Events}

Igneous intrusions (BSC 2004 [DIRS 170028]) are likely to introduce large thermal, mechanical, and chemical perturbations, both within the intersected emplacement drifts and in the surrounding rock. These perturbations may greatly affect the integrity of the natural and engineered barriers in the vicinity of and within the waste emplacement drifts.

Several different configurations are possible after an igneous intrusion event, when magma has filled emplacement drifts and eventually cooled off. One possible scenario is that thermal contraction gives rise to numerous fractures or joints in the cooling magma, such that the drift would be filled with fractured magma of relatively high permeability and small capillary strength. In case this capillary strength is much smaller than the capillary strength of the surrounding rock (or if a small gap opens at the magma-rock interface as a result of cooling), the capillary barrier and flow diversion potential at the interface between the magma and the rock would be maintained. The magma may also drain out of the drift interior, leaving an air space that would also maintain the capillary barrier capability. Such processes are evident, for example, in the formation of lava tubes present in basaltic lavas (Williams and McBirney 1979 [DIRS 164334], pp. 106-108). To determine the water inflow into magma-filled drifts with the 
capillary barrier potential still in place, the use of the seepage table for a nondegraded drift would provide a reasonable seepage estimate for the abstraction (DTN: LB0304SMDCREV2.002 [DIRS 163687]). However, in view of the considerable uncertainty about the in-drift conditions after an igneous event, it may be reasonable to use an alternative abstraction method providing higher seepage estimates. This alternative abstraction method would use the look-up table for collapsed rubble-filled drifts (DTN: LB0307SEEPDRCL.002 [DIRS 164337]). Both look-up tables account for the effects of site-scale flow focusing and small-scale flow channeling, as caused by drift-scale heterogeneity. This abstraction recommendation should be an acceptable simplification for implementation of these low-probability and localized disruptive events into TSPA.

Another possible in-drift configuration after an igneous event is that the waste may be encapsulated by solidified magma with few cooling joints. In this case, there will be no capillary barrier at the interface between the magma and the fractured tuff. However, water contact with the waste would be limited by the small permeability of the solidified magma. A possible abstraction method for such cases is to set the seepage percentage in intersected drifts to 100 percent; i.e., the seepage flux potentially contacting the waste is equal to the local percolation flux arriving at the drifts. This is equivalent to assuming that the cooled magma and the surrounding tuff have the same hydrological properties, leading to an undistorted flow field in the vicinity and through the drifts. This third method is easily implemented into TSPA by setting seepage flux equal to percolation flux.

Information on which one of the different in-drift conditions after an igneous event is to be expected at Yucca Mountain is not available. It is therefore recommended that TSPA conduct sensitivity analyses with the three abstraction methods described above. The method that provides the maximum seepage estimates should be chosen and propagated to the downstream TSPA modules. If the time of an igneous intrusion event is considered in TSPA, the selected abstraction method for igneous intrusion should be used, starting with the assumed time of the event.

\subsubsection{Abstraction of Thermal Seepage for Intact Drifts}

Thermal seepage into nondegraded or moderately degraded drifts is accounted for in TSPA using results from the TH Seepage Model as introduced in Section 6.4.3. This seepage process model simulates the coupled $\mathrm{TH}$ processes occurring as a result of the heat generated by the radioactive waste and explicitly calculates seepage rates during the time period of significant flux perturbation. Having a sophisticated thermal-seepage-process model available for seepage abstraction is a significant improvement on previous TSPA approaches for seepage.

As pointed out in Section 6.4.3.1, the TH Seepage Model was applied to selected simulation cases by varying parameters that are important for thermal seepage (e.g., thermal-operating mode, local percolation flux, and seepage-relevant rock properties). Because of computational limitations, the number of thermal-seepage-simulation cases was much smaller than in the systematic SMPA analysis of ambient seepage. It was not practical to derive thermal seepage look-up tables that would allow direct interpolation of thermal seepage for any given combination of key properties. Therefore, the seepage abstraction approach developed in this model report uses the thermal seepage results to qualitatively describe the evolution of seepage 
in comparison to the ambient seepage rates. The first step of this approach is to interpolate the ambient seepage rates for the respective parameter case, as described in Section 6.5.1. Depending on the time step considered in the TSPA calculation, the ambient rate is then adjusted to account for the transient impact of thermal seepage, based on the qualitative results of the $\mathrm{TH}$ Seepage Model. For time steps that fall into the period of above-boiling rock temperatures, the ambient seepage rates may be set to zero as seepage is effectively suppressed. For late periods, on the other hand, there is no need to distinguish between thermal and ambient seepage, because the thermal perturbation has become insignificant. The abstraction approach for thermal seepage implicitly defines (and justifies) the time period when seepage can be treated with ambient seepage estimates.

Another advantage of this approach is that results from the TH Seepage Model are not required to provide the exact quantitative amount of seepage. It was already pointed out in Section 6.4.3.1 that the TH Seepage Model and the SMPA are not expected to arrive at identical simulation results of ambient seepage because of unavoidable differences in the model setups. From the two models, the SMPA results are considered quantitatively more reliable than the results from the TH Seepage Model. This is because (1) the SMPA is a 3-D model similar to the SCM, (2) the grid orientation and resolution of the SMPA, as well as the stochastic parameter representation, are identical to the SCM, and (3) the SMPA considers a much larger number of stochastic realizations. The TH Seepage Model, on the other hand, has a radially oriented 2-D and slightly different grid resolution in the drift vicinity. Also, the standard deviation of the stochastic permeability field is slightly smaller than the one used in the SMPA. Because the scope of the thermal seepage abstraction is to derive qualitative seepage rates, these model-setup differences between the SMPA and the TH Seepage Model are not relevant for the abstraction results. Using the SMPA results as the quantitative basis for ambient and thermal seepage ensures consistency in the time-dependent seepage rate.

The abstraction methodology for thermal seepage, relative to the ambient seepage results, is based on the consistent trends that were observed in the thermal seepage results (see Section 6.4.3.3). Despite different thermal loads, percolation conditions, rock properties, and host rock units studied in various simulation cases, the modeling results from the TH Seepage Model demonstrated that thermal seepage did not occur at above-boiling temperatures and that the ambient seepage values provide an asymptotic upper limit for thermal seepage. It was concluded in BSC (2004 [DIRS 170338], Sections 6.2.4 and 8.1) that these qualitative trends hold for all relevant TSPA parameter cases, i.e., cases that cover the expected variability and uncertainty of seepage-relevant properties at Yucca Mountain. This assessment was based on the wide range of simulation cases explicitly addressed with the TH Seepage Model.

While these consistent trends are helpful in developing a simplified abstraction methodology using ambient seepage rates as base estimates, the complex transient nature of the TH coupled processes makes a detailed time-dependent seepage abstraction unnecessarily complicated. The modeling results presented in BSC (2004 [DIRS 170338], Section 6.2) demonstrate considerable variability among simulation runs with respect to the duration of the boiling period, the transient rewetting processes, the initiation time of thermal seepage, and the evolution of thermal seepage in comparison with the ambient seepage rates. As pointed out in Section 6.4.3.3, the key parameters affecting these processes are not only those important for ambient seepagepercolation flux, capillary strength, and permeability - but also the thermal load generated by the 
waste and the thermal conductivity of the rock. In addition, the TH coupling occurring in the superheated rock results in nonlinear relationships between these key parameters and the observed TH conditions in the rock. For example, a large percolation flux may not only promote ambient seepage, but also suppress the temperature build-up in the rock, giving rise to a less extended boiling period and faster rewetting at the drift wall. Thus, implementation of a detailed time-dependent seepage abstraction in TSPA would involve prediction of the transient local TH conditions throughout the repository, depending on a number of spatially varying key parameters. Since such predictions are not available, the two abstraction methods developed in Section 6.5.2.1 make use of simplified models for the time-dependence of thermal seepage.

\subsubsection{Alternative Thermal-Seepage-Abstraction Approaches}

Two alternative abstraction approaches for thermal seepage are proposed below, based on the recommendations made in BSC (2004 [DIRS 170338], Sections 6.2.4.1 and 8.2) and considering the discussion in the previous section. Both approaches define thermal seepage relative to the ambient seepage rates for the respective climate stages-one using a very simple model, one using more complexity and realism. Both models can be fairly easily incorporated into the TSPA-LA seepage calculation. It will be discussed in later sections that the more realistic Abstraction Model 2 should be used for intact drifts (Section 6.5.2.2), whereas the simple Abstraction Model 1 should be applied for collapsed drifts (Section 6.5.3). The two abstraction methods are defined as follows:

\section{Abstraction Model 1:}

This simplified abstraction model sets thermal seepage equal to the respective ambient seepage throughout the entire compliance period of 10,000 years. The abstraction is based on the model finding that ambient seepage provides an asymptotic upper limit for thermal seepage (i.e., there is no enhanced seepage as a result of thermal perturbation). The approach does not incorporate the vaporization barrier that prevents seepage during the period of above-boiling temperatures. Implementation in TSPA is straightforward, since the time-dependent evolution of thermal seepage is not accounted for in this abstraction model.

\section{Abstraction Model 2:}

This abstraction model sets thermal seepage to zero for the period of above-boiling temperatures in the drift vicinity. For the remaining time period, thermal seepage is set equal to the respective ambient seepage. The abstraction is based on model findings that thermal seepage never occurs at above-boiling temperatures and that the ambient seepage values provide an asymptotic upper limit for thermal seepage. The transient seepage result obtained from this abstraction model is more realistic, since the model does incorporate the vaporization barrier limiting water flux towards the drifts. For implementation of this model, detailed information is required about the duration of the boiling period for a large number of parameter cases. This information is provided to TSPA by the Multiscale Thermohydrologic Model, which is described in BSC (2004 [DIRS 169565]). The Multiscale Thermohydrologic Model predicts the near-field and in-drift TH conditions for a large number of locations in the repository. It captures the influence of the key engineering-design variables and natural system factors affecting the 
TH conditions in the emplacement drifts and the adjoining host rock listed in Section 8.1 of BSC (2004 [DIRS 169565]), including their relevant variabilities and uncertainties. (Based on sensitivity simulations conducted with the Multiscale Thermohydrologic Model in Sections 6.3.2.1 through 6.3.2.3 of BSC (2004 [DIRS 169565]), the most important uncertainties in natural systems parameters affecting the TH conditions are the uncertainties in host-rock thermal conductivity and local percolation flux (BSC 2004 [DIRS 169565], Table 6.3-15 and Section 8.2). As pointed out in Section 8.2 of BSC (2004 [DIRS 169565]), the propagation of these parametric uncertainties is captured in the output of the Multiscale Thermohydrologic Model with five sensitivity cases having assigned different percolation fluxes and host-rock thermal conductivities. The resulting variability in the boiling period should be considered in the TSPA-LA.)

Figures 6.5-3 and 6.5-4 give examples of the proposed abstraction models for two simulation cases where seepage occurs. The first figure shows the simulation case that was already presented in Section 6.4.3.3 of this model report (see Figures 6.4-9, 6.4-10, and 6.4-11). The second figure gives the same simulation case, except that a smaller capillary-strength parameter was used. In both figures, the assumed percolation fluxes are relatively large compared to the average flux conditions expected for present-day and future climate stages, totaling $60 \mathrm{~mm} /$ year during the present-day climate, $160 \mathrm{~mm} /$ year during the monsoon climate, and $250 \mathrm{~mm} /$ year during the glacial transition climate. In both cases, the period of above-boiling rock temperature covers only the first 500 years after emplacement. This means that the boiling period is shorter than the present-day climate stage (up to 600 years from emplacement), where percolation fluxes (and seepage rates) are typically smaller than at later times. In Figure 6.5-3, for example, ambient seepage does not occur during the present-day climate, because the capillary barrier is fully effective at a percolation flux of $60 \mathrm{~mm} /$ year. This explains why both abstraction models arrive at the same abstraction result in this simulation case.

On the other hand, in Figure 6.5-4, the capillary-strength parameter is small enough to allow for ambient seepage even during the present-day climate stage. In this case, there are distinct differences between the two approaches. While Abstraction Model 1 results in seepage at all times, Abstraction Model 2 does not allow seepage during the above-boiling period. Note that the $100^{\circ} \mathrm{C}$ isotherm of the fracture continuum is used as the threshold temperature to define the duration of the boiling period for abstraction (to be measured at the drift wall). This temperature is a few degrees centigrade higher than the nominal boiling point of water at prevailing pressures. This guarantees that no heat-pipe conditions occur in the fractures close to the drift (because temperature would be at boiling) and also accounts for some uncertainty in the modeling results (see Section 6.5.2.2). Furthermore, because of potential variability in the TH conditions, the boiling period should be evaluated locally for the grid elements along the drift wall, and the shortest period should be used for abstraction. In the selected simulation case, the resulting time period associated with fracture temperature above $100^{\circ} \mathrm{C}$ is about 420 years.

Note that the simulated thermal seepage rates in Figure 6.5-4 are equal to the ambient ones at the onset of the simulation runs. However, they drop to zero shortly after the 50-year ventilation period, as soon as the rock temperatures approach boiling conditions. This early seepage is merely an artifact of the TH Seepage Model that neglects the impact of reduced relative humidity as a result of forced ventilation with dry air during the 50-year preclosure period (BSC 2004 [DIRS 170338], Section 6.2.1.3.3). The reduced relative humidity in the emplacement drifts 
leads to evaporation of water at the drift wall and the development of a dryout zone in the drift vicinity. For the range of present-day percolation fluxes expected at Yucca Mountain, seepage in ventilated drifts is highly unlikely. As stated in Wang et al. (1996 [DIRS 101309], Section 5), forced ventilation in drifts is expected to evaporate the equivalent of $100 \mathrm{~mm} /$ year to more than $200 \mathrm{~mm} /$ year percolation flux from the rock surfaces of the drifts. Since the predicted percolation fluxes during this time period are smaller than these evaporation estimates of 100 to $200 \mathrm{~mm} /$ year (see Section 6.6.5.1), seepage during the preclosure period can be neglected in both abstraction models.
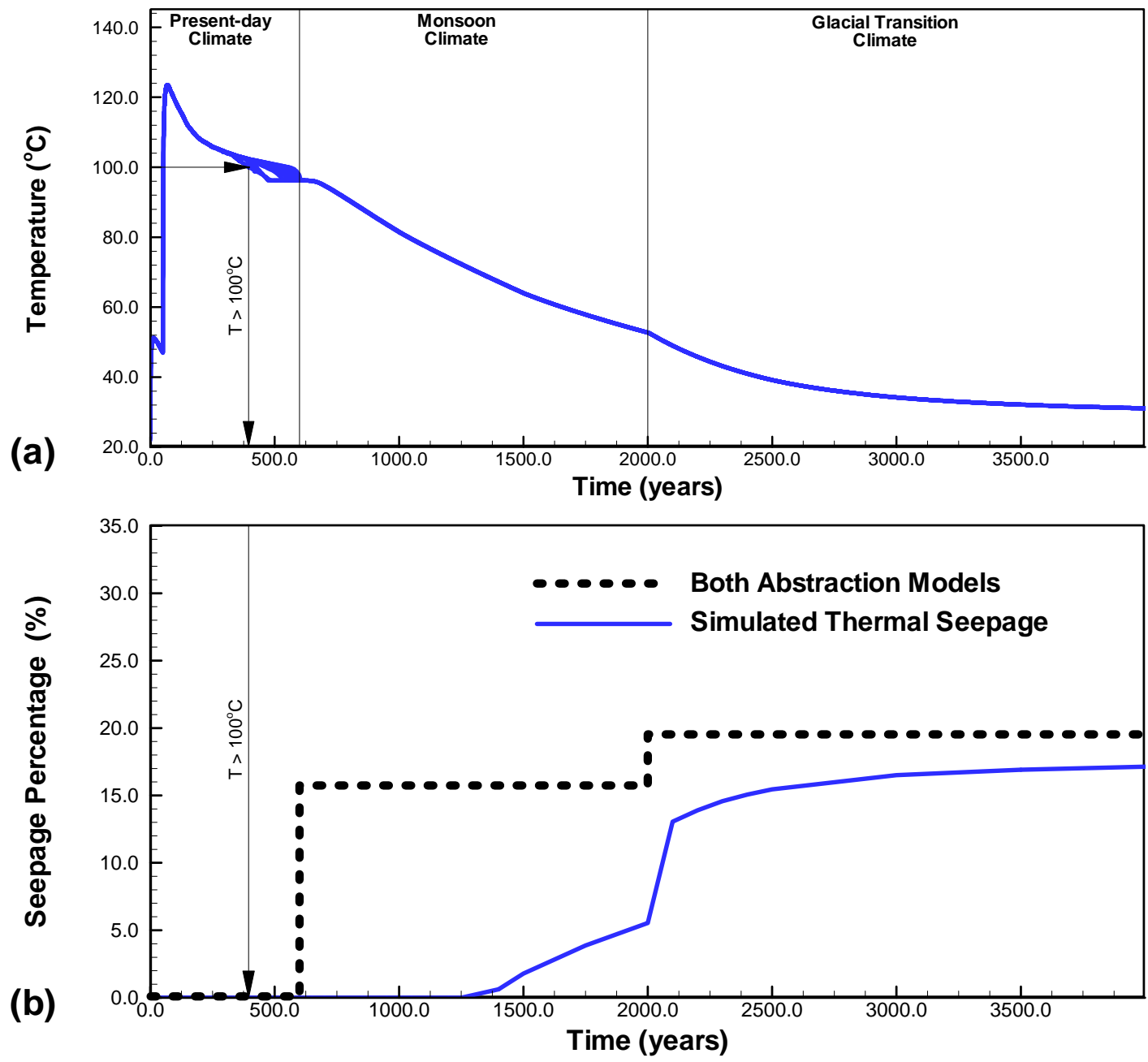

Source: Temperature Evolution from DTN: LB0303DSCPTHSM.001 [DIRS 163688], Simulation Case MN-HET-03, Realization 1. Seepage Percentage from DTN: LB0301DSCPTHSM.002 [DIRS 163689], Simulation Case MN-HET-03, Realization 1.

Figure 6.5-3. Illustration of Seepage Abstraction Models 1 and 2 for Simulation Case with Tptpmn Submodel, Reference Thermal Mode, Percolation Flux Multiplication Factor 10, and Capillary-Strength Parameter $1 / \alpha=589 \mathrm{~Pa}$ : (a) Temperature Evolution of Fracture Continuum at the Drift Wall, and (b) Abstracted Seepage Percentage as a Function of Time 

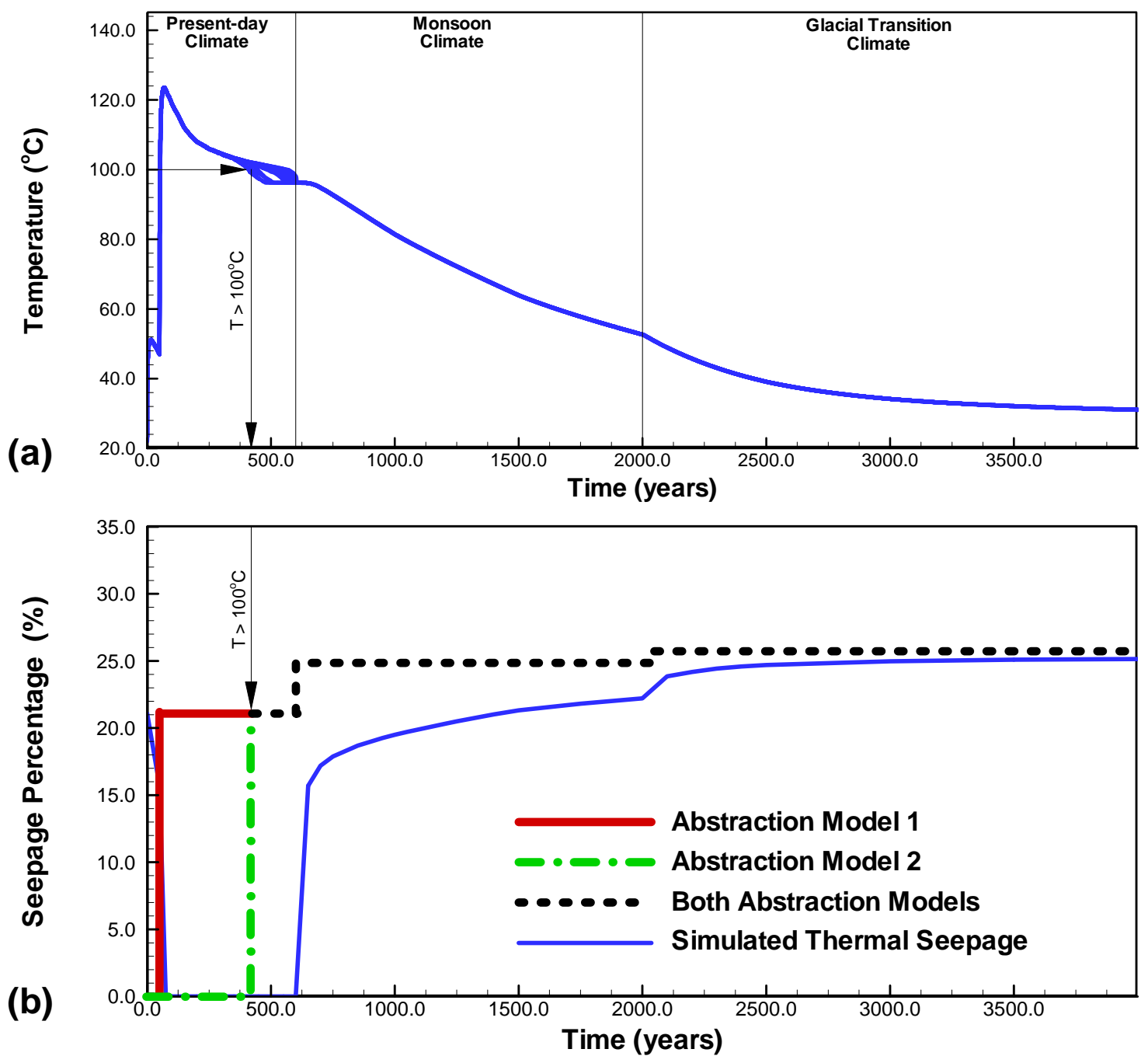

Source: Temperature Evolution from DTN: LB0303DSCPTHSM.001 [DIRS 163688], Simulation Case MN-HET-09, Realization 1. Seepage Percentage from DTN: LB0301DSCPTHSM.002 [DIRS 163689], Simulation Case MN-HET-09, Realization 1.

Figure 6.5-4. Illustration of Seepage Abstraction Models 1 and 2 for Simulation Case with Tptpmn Submodel, Reference Thermal Mode, Percolation Flux Multiplication Factor 10, and Capillary-Strength Parameter $1 / \alpha=400 \mathrm{~Pa}$ : (a) Temperature Evolution of Fracture Continuum at the Drift Wall, and (b) Abstracted Seepage Percentage as a Function of Time

Neither of the proposed abstraction models for thermal seepage incorporates the time-dependent saturation buildup at the drift wall after boiling conditions have ended. As demonstrated in Figures 6.5-3 and 6.5-4 (and in additional simulation cases presented in BSC (2004 [DIRS 170338], Section 6.2), thermal seepage is usually initiated at a few hundred to a few thousand years into the post-boiling period, the delay caused by the retarded rewetting of the dryout zone. These rewetting processes and their temporal evolution depend on many of the key properties for thermal seepage that were mentioned in the previous section-as well as on matrix capillary strength, permeability, and fracture-matrix interface area. With so many key properties 
involved, prediction of the time-dependent buildup of saturation is a formidable task, and the related variabilities and uncertainties are hard to quantify. The seepage abstraction model therefore assumes immediate increase in saturation to the respective ambient value at the end of the boiling period.

Both abstraction models are implicitly valid for repository drifts where the local rock temperatures never reach boiling (e.g., as a result of 3-D edge effects or heat-load variability among waste packages). As pointed out in Section 6.4.3.3, thermal effects on flow and seepage are negligible in such cases, so that the potential for thermal seepage is similar to ambient seepage results. For nonboiling temperatures, both abstraction models per definition use the ambient seepage rates at all times.

\subsubsection{Uncertainty and Recommended Abstraction Method for Intact Drifts}

Uncertainty in the abstracted thermal seepage results is a result of (1) uncertainty in the ambient seepage estimates used as the quantitative basis of the abstraction, and (2) uncertainty in the evolution of thermal seepage compared to the ambient seepage estimates. The first contribution to thermal seepage uncertainty is automatically included in the thermal abstraction, because the abstracted ambient seepage rates explicitly account for the conceptual model uncertainty and the uncertainty in seepage-relevant parameters (see Section 6.5.1.3). The second contribution to thermal seepage uncertainty needs further discussion.

As pointed out in Section 6.4.3.2, conceptual model uncertainty related to the thermal seepage model results for intact drifts has been addressed in BSC (2004 [DIRS 170338], Sections 7 and 8.3) by careful validation of the coupled TH processes in comparison with an in situ heater test. This validation provides confidence regarding the thermally induced flux processes and the predicted effectiveness of the vaporization barrier. In addition, validation of the ambient seepage conceptual model (in comparison with liquid-release tests) provides confidence in the predicted effectiveness of the capillary barrier. Results of an alternative conceptual model, considering the potential penetration of episodic preferential flow into the superheated zone above emplacement drifts, corroborate the main findings of the thermal-seepage process model. Based on these models and studies, the conceptual model uncertainty of the TH Seepage Model is expected to be small. It is recognized, however, that some conceptual model uncertainty remains because the in situ heater test used for model validation was operated at natural percolation, which is comparably small, and heater tests were conducted only in the Tptpmn unit. Thus, these heater tests do not provide seepage data for extreme percolation conditions and cannot account for the potential effect of lithophysal cavities on the TH conditions (Section 6.4.3.2). The two abstraction models account for conceptual model uncertainty as follows:

\section{Abstraction Model 1:}

This bounding-case abstraction model does not incorporate the vaporization barrier formed as a result of heating. The abstraction merely requires that no enhanced seepage occurs during the thermal period compared to ambient seepage estimates. Enhanced seepage could only occur when strong reflux of condensate coincides with late heating periods when vaporization is not effective. However, model results clearly demonstrate that this potential can be neglected in the abstraction, since the thermal perturbation is strongest early in the heating period when vaporization is most intense (see 
Section 6.4.3.3). The model validation of the Thermal Seepage Model, corroborated by the alternative conceptual model for thermal seepage, provides sufficient confidence to support this abstraction model without explicit consideration of conceptual model uncertainty (see discussion in Section 6.4.3.2).

\section{Abstraction Model 2:}

This abstraction model assumes that no thermal seepage occurs during the period of above-boiling temperatures in the drift vicinity. Here, the remaining uncertainty related to the predictive effectiveness of the vaporization barrier needs to be accounted for in the abstraction. This is done by using a threshold temperature higher than the nominal boiling temperature to define the duration of the boiling period for abstraction. As explained above, it is recommended to use the $100^{\circ} \mathrm{C}$ isotherm of the fracture continuum as the threshold temperature. This ensures that the boiling isotherm is at some distance from the drift (and there is a small dryout zone around the wall) when the zero seepage is switched back to ambient seepage in the abstraction. Additional confidence is provided because the abstraction model does not incorporate the delayed seepage initiation caused by the time-dependent saturation buildup at the drift. Thus, Abstraction Model 2, despite assuming no seepage for rock temperature above $100^{\circ} \mathrm{C}$, still provides an upper bound of seepage estimates compared to the predicted thermal seepage results.

Both abstraction methods adequately account for the impact of model uncertainty related to thermal seepage into an intact drift. It is therefore recommended that TSPA-LA uses the more realistic Abstraction Method 2 for the seepage calculations. Abstraction Model 1 is overly conservative with respect to thermal seepage in intact drifts, since it does not incorporate the vaporization barrier capabilities of the superheated rock, and should not be used in the TSPA-LA seepage model. Note that in many parameter cases, the two abstraction models are in fact identical, because the capillary barrier may be fully effective on its own. Even without consideration of the vaporization barrier, there are many parameter cases giving no seepage at any time (see Section 6.4.2). There are also cases where seepage is possible during future climate states with higher net infiltration, but does not occur at the present-day climate stage with comparably small net infiltration. The vaporization processes are most intense during the first several hundred years after emplacement, falling into the present-day climate stage.

Another source of uncertainty in the thermal-seepage modeling results is uncertainty in the relevant input parameters to the TH Seepage Model. However, the selected sensitivity cases analyzed in BSC (2004 [DIRS 170338], Section 6.2), and the additional results provided in DTNs LB0309DSCPTHSM.001 [DIRS 165538] and LB0309DSCPTHSM.002 [DIRS 165539], provide enough confidence that the recommended abstraction procedures are valid over the required range of conditions and values used in TSPA. In other words, it can be stated that the general conclusions about the qualitative magnitude and evolution of thermal seepage-i.e., no seepage during boiling and thermal seepage bounded by ambient seepage estimates-remain consistent for all parameter combinations of capillary strength, permeability, percolation flux, thermal load, and/or thermal conductivity studied in the TSPA calculations. They also remain consistent for the three different realizations analyzed in BSC (2004 [DIRS 170338], Section 6.2); consequently, there is no estimation uncertainty regarding these conclusions. 


\subsubsection{Abstraction of Thermal Seepage for Collapsed Drifts}

The TH conditions in and next to collapsed drifts can be significantly different from the $\mathrm{TH}$ conditions in the vicinity of intact open drifts. As described in Section 6.4.3.4, TH simulations runs have been conducted for collapsed drifts, assuming that the event leading to collapse occurs very early after waste emplacement. This scenario leads to the most significant changes in the $\mathrm{TH}$ conditions, because the strongest thermal perturbations are expected during the first few hundred years. Simulations were performed for two percolation scenarios (flux multiplication factors of 1 and 10) to analyze the TH response at average and strongly increased percolation fluxes. Since the properties of the in-drift rubble material-consisting of fragmented rock blocks and large scattered voids-are uncertain, some of the key parameters were varied in sensitivity analyses. These are (1) the contact area between individual rock blocks, mostly important for the effective thermal conductivity in the rubble filling and (2) the permeability of the void space, mostly important for the intensity of in-drift gas and liquid flow processes.

Results from these simulations, provided in DTNs LB0310DSCPTHSM.001 [DIRS 165943] and LB0310DSCPTHSM.002 [DIRS 165944], can be summarized as follows: (1) In contrast to open drifts, where a combined capillary and vaporization barrier at the drift crown prevents water seepage during the period of above-boiling temperatures, vaporization is not effective at the crown of collapsed drifts. (2) With ambient rock water boiling off in the rubble material, in-drift flux perturbation gives rise to moderate reflux of condensate in the upper half of collapsed drifts. However, water drainage down to the waste packages is not possible, as a result of the vaporization barrier forming in the vicinity of the waste package. (3) The vaporization and reflux processes cease after a few hundred to more than a thousand years and the TH conditions slowly approach steady-state (ambient) behavior. During this transition phase, the fluxes in the lower half of the collapsed drift remain zero at all times. Later, when steady-state conditions have been reached, the entire collapsed drift is characterized by zero fluxes, because the void spaces are essentially dry (at residual saturation). (4) The above in-drift flow processes are largely unaffected by changes in the percolation flux because the capillary barrier at the drift crown limits water flux from the intact rock into the rubble material.

The proposed abstraction model for thermal seepage in collapsed drifts is based on the above simulation results. The general abstraction approach is similar to the one outlined in Section 6.5.2 for intact drifts; i.e., the TH simulation results are used to qualitatively describe the evolution of thermal seepage relative to the quantitative seepage estimates from ambient predictions, using one of the two proposed Abstraction Models 1 and 2. For collapsed drifts, the simple Abstraction Model 1 is recommended. This abstraction model provides the higher seepage rates of the two approaches; thermal seepage is set to be equal to the respective ambient seepage throughout the TSPA period. The choice of this abstraction model is based on the model findings (see Section 6.4.3.4) that there is no vaporization barrier in the intact rock that prevents water flow into the rubble-filled drift. Thus, water seepage from the fractured formation into the rubble-filled collapsed drift is limited only by capillarity-induced flow diversion, as described and accounted for in the ambient seepage predictions.

Note that the seepage abstraction deals with the flow of water from the formation into the rubblefilled opening, not with the fate of this water inside the rubble-filled opening. This information is provided to TSPA-LA in Section 6.8.1 of the Seismic Consequence Abstraction (BSC 2004 
[169183]). Based on studies conducted in BSC (2004 [DIRS 169565], Section 6.3.7.3), the Seismic Consequence Abstraction (BSC 2004 [169183], Section 6.8.1) suggests an abstraction model that assumes zero water arrival at the waste canisters during the time period that the waste package (or its close vicinity) remain safely at above-boiling temperatures. The definition is that seepage water will not be able to contact waste packages as long as the waste package surface temperature is above a $100^{\circ} \mathrm{C}$ threshold value. This constraint implies that seepage entering the rubble-filled will be diverted through the rubble to the invert beneath the waste package. The threshold temperature is based on a sensitivity study of seepage arrival times at the drip shield crown for a collapsed drift that is filled with rubble (BSC 2004 [DIRS 169565], Section 6.3.7.3 and Table 6.3-44).

\subsection{PARAMETER DISTRIBUTIONS FOR SEEPAGE-RELEVANT PROPERTIES}

This section explains the background, methodology, and results of a data analysis intended to derive probability distribution functions for the seepage-relevant properties varied within the TSPA calculations. Separate probability distributions are developed for spatial variability and for uncertainty of these properties. As explained in Section 6.5, the seepage component in TSPA-LA will sample from these distributions at spatial locations $r$ and uncertainty realizations $\mathrm{R}$, and will use the sampled values as input for the interpolation of seepage results from the seepage look-up tables.

The relevant parameters to be described are the capillary-strength parameter $1 / \alpha$, the permeability $k$, and the percolation flux $q_{\text {perc,ff. }}$ These parameters are defined according to the conceptual framework of the ambient-seepage process models; thus, the parameter distributions developed must correspond to the designated use of these parameters within the SMPA simulation model (see Section 6.4.2). This means that (1) the capillary strength is the calibrated effective parameter as estimated from the SCM, (2) the permeability represents the mean value of the small-scale stochastic permeability fields in the SMPA domain, and (3) the percolation flux is the local flux arriving at the upper boundary of the SMPA model (Section 6.5.1.1). It also means that these parameters are representative of properties or processes derived for a typical drift-scale model domain. The spatial variability distributions need to cover the intermediatescale distribution of these drift-scale parameters within the repository units. According to the definition given in Section 6.1.3, intermediate-scale heterogeneity defines heterogeneity on a resolution similar to the typical drift-scale model domain.

Sections 6.6.2 and 6.6.3 below explain the development of the parameter distributions for the capillary-strength parameter and the permeability, respectively. The discussion of parameter distributions focuses on the two main repository units, the Tptpll and the Tptpmn units. Both these units have been characterized by active underground testing (seepage and air-permeability testing) in the ESF and the ECRB, to provide sufficient basis for predictive modeling and seepage abstraction. How the less important (and less extensively tested) Tptpul and Tptpln units are treated in the seepage abstraction is briefly explained in Section 6.6.4. Finally, the magnitude and distribution of percolation fluxes is provided in Section 6.6.5.

As pointed out in Sections 6.6.2.1 and 6.6.3.1, results from seepage testing and air permeability measurements are available at different locations along the ESF and the ECRB. These results provide the basis for defining the spatial variability of the seepage-relevant parameters 
capillary-strength parameter and permeability within the repository rock. It is important that the test locations are representative of the overall conditions in the lithophysal and the nonlithophysal units. Therefore, as a basis for a respective discussion, Section 6.6.1 summarizes briefly the lithostratigraphy at Yucca Mountain, with focus on the similarities and differences between the repository units regarding their fracture and lithophysal characteristics (which are most relevant for near-field flow processes and seepage).

As mentioned before in Section 6.5.1.1, the chosen probability approach distinguishes explicitly between spatial variability and uncertainty, using separate distributions with separate random sampling. The spatial variability distributions describe the most probable scenario of parameter variability within the repository area, i.e., the distributions are determined using the best data at hand without accounting for uncertainty. Spatial variability distributions are provided in Sections 6.6.2.2 (for the capillary-strength parameter) and 6.6.3.2 (for permeability). The uncertainty about these two parameters is accounted for by adjusting these distributions in a separate step, using values that are sampled from symmetrical triangular distributions. The range of the triangular distributions, which is based on the estimated degree of uncertainty in the parameter, defines the degree of adjustment. Note that the uncertainty distributions have a mean of zero, so that the chosen spatial variability distributions are indeed the most probable cases. Uncertainty distributions are provided in Sections 6.6.2.3 (for the capillary-strength parameter) and 6.6.3.3 (for permeability).

\subsubsection{Geologic Characteristics of Repository Rock Units}

All the rocks of the repository rock horizon lie within the crystal-poor member of the Topopah Spring welded tuff. The repository rock horizon includes rocks from the lower part of the upper lithophysal zone (Tptpul unit), the middle nonlithophysal unit (Tptpmn unit), the lower lithophysal unit (Tptpll unit), and the lower nonlithophysal unit (Tptpln unit). As pointed out in Section 6.3.1, the Tptpll unit comprises about 80.5 percent of the repository area, followed by the Tptpmn unit with about 12.4 percent, the Tptpul unit with about 4.5 percent, and the Tptpln unit with about 2.6 percent. These units are described below, mainly based on information presented in Geology of the ECRB Cross Drift - Exploratory Studies Facility, Yucca Mountain Project, Yucca Mountain, Nevada (Mongano et al. 1999 [DIRS 149850]), as summarized in Section 6.1 of the Drift Degradation Analysis report (BSC 2004 [DIRS 166107]), in the Yucca Mountain Site Description (CRWMS M\&O 2000 [DIRS 151945], Section 4.6.6.2.3), and in Fracture Geometry Analysis for the Stratigraphic Units of the Repository Host Horizon (CRWMS M\&O 2000 [DIRS 152286]). The information was mostly gathered from fracture analysis in the ESF and in the ECRB. The upper lithophysal zone (Tptpul unit) and the middle nonlithophysal zone (Tptpmn unit) are mostly exposed in the ESF, with short sections also exposed in the ECRB. The lower lithophysal zone (Tptpll unit) is mainly exposed in the ECRB Cross-Drift, with a shorter section exposed in the ESF main loop. The lower nonlithophysal zone (Tptpln unit) is not exposed in the ESF main loop. A short section of the Tptpln unit is exposed in the ECRB Cross-Drift.

\subsubsection{Lithostratigraphy}

At Yucca Mountain, welded units such as the Topopah Spring welded tuff have low matrix porosities and high fracture densities, as opposed to the nonwelded bedded tuffs. In the densely 
welded and crystallized rocks of the Topopah Spring welded unit, the various subunits are identified on the basis of the abundance, size, and distribution (or lack) of lithophysae. Lithophysae are cavities in the rock that have formed during welding from the accumulation of the vapor phase. Compositionally and mineralogically, the rocks in the lithophysal and nonlithophysal zones are similar. The main difference is in the abundance of lithophysae and, to a lesser degree, in the fracture characteristics.

Tptpul Unit: The crystal-poor upper lithophysal zone (Tptpul unit) is densely welded, crystallized, strongly lithophysal (3 to 60 percent), and has various amounts of vapor-phase corrosion and mineralization. The matrix groundmass contains 3 to 50 percent of spots, veinlets, streaks, rims on fractures, stringers, and vapor-phase partings of crystallized materials.

Tptpmn Unit: The crystal-poor middle nonlithophysal zone (Tptpmn unit) is densely welded, crystallized, and has various amounts of vapor-phase corrosion and mineralization. The lithophysal content is very small. The matrix groundmass contains 0 to 25 percent of spots, veinlets, streaks, rims on fractures, stringers, and vapor-phase partings of crystallized materials.

Tptpll Unit: The crystal-poor lower lithophysal zone (Tptpll unit) is densely welded, crystallized, lithophysal (5 to 30 percent), and has various amounts of vapor-phase corrosion and mineralization. The matrix groundmass contains 3 to 20 percent of spots, veinlets, streaks, rims on fractures, stringers, and vapor-phase partings of crystallized materials.

Tptpln Unit: The crystal-poor lower nonlithophysal zone (Tptpln unit) is densely welded, crystallized pyearoclastic-flow material and contains 0 to 5 percent of lithophysae. Veinlets, streaks and stringers form a minor component of the rock in some portions of the unit. In proximity of the Solitario Canyon fault zone, the unit is brecciated and altered.

As pointed out in Mongano et al. (1999 [DIRS 149850], p. 43, "Comparison of the Cross-Drift and the ESF"), the lithologic character of the same unit exposed in the ESF and the ECRB is similar in terms of the welding, devitrification, and vapor-phase alterations.

\subsubsection{Fracturing}

The fracture inventory of the repository units has been extensively characterized from geological mapping and scanline surveys along the ESF and the ECRB Cross-Drift as well as from borehole cores and video logs. In general, the distribution of fractures in the units exposed is similar in the Cross-Drift and the ESF in terms of frequency, character, and orientation (Mongano et al. 1999 [DIRS 149850], p. 44 "Comparison of the Cross-Drift and the ESF"). The information gathered in the scanline surveys includes location, orientation, trace length, width, and roughness for fractures with a trace length greater than $1 \mathrm{~m}$. The database consists of over 35,000 entries and is recorded in CAD drawings as well as spreadsheets.

Fracture characteristics in the welded units at Yucca Mountain are primarily controlled by variations in the degree of welding and secondarily by lithophysal development, alteration, and pumice content (BSC 2004 [DIRS 169734], Section 3.5.8). Such controls affect fracture spacing, fracture type, number of fracture sets, continuity of fractures within each lithostratigraphic unit, and the connectivity of fractures within the network as a whole. The fracture frequency in various zones of the formation is displayed in Figure $\mathrm{H}-1$ ( $a$ and $b$ ) in 
Appendix $\mathrm{H}$ for a scanline survey conducted in the ESF main tunnel. Figure $\mathrm{H}-2$ in Appendix $\mathrm{H}$ illustrates the fracture frequency and the approximate percentage of lithophysae in the ECRB Cross-Drift between Stations $0+00$ and 27+00. Both figures are based on analysis of fractures with trace length greater than $1 \mathrm{~m}$, which can introduce a bias if the formation has abundant short-length fractures. According to the figures, the density of fractures with trace length greater than 1 meter is larger in the two nonlithophysal units (Tptpmn and Tptpln units) than in the lithophysal units (Tptpul and Tptpll units). As shown in Figure H-2, the occurrence of lithophysae is roughly inversely proportional to the degree of fracturing. Table $\mathrm{H}-1$ in Appendix $\mathrm{H}$ provides summary data extracted from the line surveys in the ESF and the ECRB, showing average/median spacings for fractures with a trace length greater than $1 \mathrm{~m}$. The summary data support the visual information impression given in Figures $\mathrm{H}-1$ and $\mathrm{H}-2$. For fractures longer than $1 \mathrm{~m}$, the average spacing of fractures in the nonlithophysal units is smaller than in the lithophysal units. Table $\mathrm{H}-2$ in Appendix $\mathrm{H}$ provides a summary of fracture trace lengths (average, median trace lengths) for line survey fractures with trace lengths greater than $1 \mathrm{~m}$. Below, fracture characteristics are discussed separately for nonlithophysal and lithophysal repository units.

Nonlithophysal Rock (Tptpmn and Tptpln Units): A network of long, relatively closely spaced joints generally characterizes the Tptpmn unit (CRWMS M\&O 2000 [DIRS 151945], Section 4.6.6.2.3). The highest degree of fracturing is associated with the steeply dipping striking joint set (JS-1 in Table H-1) and the subhorizontal joint set (JS-Subhorizontal in Table H-1), as discussed in Section 6.4.2.1 of CRWMS M\&O (2000 [DIRS 152286]). JS-1 has an average spacing of 0.60 meters (median 0.22 meters), while the subhorizontal joint set has a similar average spacing of 0.56 meters (median 0.29 meters). An intensely fractured zone is present from Stations $42+00$ to $51+50$, in which the overall fracture frequency is more than twice the frequency observed in other areas. This portion of the main drift contains a zone of very closely spaced JS-1 fractures, which commonly exhibit spacings less than 0.3 meters (CRWMS M\&O 2000 [DIRS 152286], Section 6.4.2.1). Average trace lengths in the Tptpmn unit are between 2.54 meters and 3.23 meters for the different joint sets. These trace lengths are relatively long compared to the fracture spacing, suggesting that the Tptpmn unit features a wellconnected fracture system, with numerous large fractures longer than $1 \mathrm{~m}$. In addition, there are shorter fractures that have not been included in the line surveys and fracture analyses, but would increase fracture connectivity. The Tptpln unit is similar in fracture characteristics (joint sets, spacing, trace lengths) to the Tptpmn unit. Also visually, the Tptpln unit appears similar to the Tptpmn unit depicted in Figure H-3 in Appendix H. In both units occurs a zone of intense fracturing associated to a fault. In the Tptpmn unit, this zone occurs close to the Ghost Dance Fault in the ESF (Albin et al. 1997 [DIRS 101367]); in the Tptpln unit, it is the Solitario Canyon Fault in the ECRB. Fracture intensity is about two times larger in the Tptpmn unit, as evident in Figure $\mathrm{H}-2$ and Table $\mathrm{H}-1$. The JS-1 set in the Tptpln unit has an average spacing of 1.44 meters (median 0.74 meters), which is about $2 \frac{1}{2}$ times larger than in the Tptpmn unit. This difference is mostly a result of the intensely fractured zone in the Tptpmn unit, which has very closely spaced JS-1 fractures (CRWMS M\&O 2000 [DIRS 152286], Section 6.4.2.1). Fracture trace lengths are slightly larger than in the Tptpmn unit, except for the subhorizontal joint set. Altogether, the Tptpln unit has a well-connected fracture system that is not much different from the Tptpmn unit. 
Lithophysal Rock (Tptpll and Tptpul Units): The apparent fracture intensity in the lithophysal units is approximately five times smaller than in the Tptpmn unit, and about 2 times smaller than in the Tptpln unit (CRWMS M\&O 2000 [DIRS 152286], Section 6.4.2.1). JS-1 in the Tptpll unit for example has an average spacing of 3.47 meters (median 1.57 meters in Table $\mathrm{H}-1$ ), which is considerably larger than in the nonlithophysal units. Trace lengths are slightly larger in the lithophysal units than in the nonlithophysal units (Table H-2 and CRWMS M\&O 2000 [DIRS 152286], Section 6.4.2.1). Again, these values are derived from line surveys that are limited to fractures with trace lengths greater than $1 \mathrm{~m}$. As shown in Figure $\mathrm{H}-4 \mathrm{~b}$ in Appendix H, the Tptpll unit has abundant short-length, interlithophysal fractures, which have a predominant vertical orientation with spacing on the order of inches. BSC (2004 [DIRS 166107], Section 6.1.4.1) refers to analysis of small-scale fracture traverses, which was conducted in addition to the detailed line surveys. These traverses confirm the close spacing and short trace lengths of the smaller fractures in the Tptpll unit. The average spacing, from a combined 18-meter traverse, is 0.05 meters; the average trace length is 0.29 meters. This discussion indicates that the Tptpll unit has fracture characteristics different from the nonlithophysal units, but nevertheless features a well-connected fracture system, which comprises less intense fracturing with longer fractures, but very intense fracturing with short fractures. In contrast, the Tptpul unit has little small-scale interlithophysal fracturing (Figure H-4a in Appendix H). Otherwise, the statistics of longer fractures are not much different from those of the Tptpll unit (Tables $\mathrm{H}-1$ and $\mathrm{H}-2$ ). In fact, the Tptpul unit has similar fracture spacing and trace length values for the JS-1, JS-2, and JS-Subhorizontal sets, and features a few additional fracture sets (JS-3, JS-4, JS-Med in Table H-1). Yet, without the intense small-scale fracturing that is present in the Tptptll unit, it is uncertain whether the Tptpul unit has a well-connected fracture system on the scale of interest for seepage studies, i.e., the fractured rock in the immediate vicinity of emplacement drifts. That the fractures in the Tptpul unit are well-connected on a larger scale (the scale of the testing interval, about 4 meters) is confirmed by results from air permeability testing in surface-based boreholes (see Table 6.6-8). These tests indicate relatively high permeability of the fractured rock to air, consistent with a well-connected fracture network, and demonstrate that the measured air permeabilities in the Tptpul unit are almost identical to those in the Tptpll unit.

\subsubsection{Lithophysal Characteristics}

While the rocks in the repository units are compositionally and mineralogically similar, there is a considerable difference in the abundance of lithophysae between lithophysal and nonlithophysal zones. The nonlithophysal rocks have very little to no lithophysae. The lithophysal units have abundant lithophysae, but their characteristics vary between the Tptpul and the Tptpll units (BSC 2004 [DIRS 166107], Section 6.1.4.2). The lithophysae in the Tptpul unit tend to be smaller (roughly 1 to $10 \mathrm{~cm}$ in diameter), are more uniform in size and distribution, and vary in infilling and rim thickness. The lithophysae in the Tptpll unit are highly variable (1 cm to 1.8 meters) in size, the shape is irregular (elliptical, spherical, cuspate, merged, and extension-crack lithophysae), and have infillings and rim thickness that vary greatly with vertical and horizontal spacing. With the large amount of the repository located in the lower lithophysal zone, a detailed study of the lithostratigraphic features in the Tptpll unit exposed in the ECRB Cross-Drift has recently been completed (DTN: GS021008314224.002 [DIRS 161910]). The data package documents the distribution of size, shape, and abundance of lithophysal cavities, rims, spots, and lithic clasts, and these data can be displayed and analyzed as local variations, along the tunnel (a 
critical type of variation), and as values for total zone. A detailed description of the lithophysal abundance and lithophysal characteristics is provided in Appendix O of BSC (2004 [DIRS 166107]).

\subsubsection{Implications for Seepage Analyses}

All repository units are situated in the Topopah Spring Welded tuff, with similar compositional and mineralogical rock characteristics, low matrix permeability, and relatively high fracture densities. Differences between the units are related to the fracture characteristics and the abundance of lithophysae, both of which are expected to be relevant for seepage as they influence the permeability and capillary-strength characteristics close to emplacement drifts. The following conclusions can be drawn from the above:

1. Lithophysal and nonlithophysal units have different fracture and lithopysal characteristics. It is thus important that underground testing regarding seepage-related parameters (i.e., liquid release and air permeability testing) is conducted in both lithophysal and nonlithophysal zones.

2. All repository units except for the upper lithophysal unit feature abundant fracturing with various fracture sets forming a well-connected fracture system on the scale of interest for seepage studies, i.e., the fractured rock in the immediate vicinity of emplacement drifts. Having a well-connected fracture system near the drifts is a prerequisite for the conceptual model used for the seepage predictions. Since the upper lithophysal rock misses the abundant small-scale fracturing typical for the Tptpll unit, the question of fracture connectivity on the relevant scale for seepage remains uncertain. However, air permeability studies indicate that the upper lithophysal rocks are as well connected and as permeable as the lower lithophysal rocks on a slightly larger (few-meter) scale.

3. The fracture characteristics are similar in the two nonlithophysal zones (Tptpmn and Tptpln units), with the fracture intensity slightly smaller in the Tptpln unit. This suggests that the Tptpmn unit and the less extensively tested Tptpln unit may be treated similarly with respect to seepage.

4. The fracture and lithophysal characteristics in the Tptpll unit differ from those in the Tptpul unit. The seepage characteristics in the less extensively tested Tptpul unit remain a source of uncertainty.

5. While the fracture and lithophysal characteristics are similar within repository units, there is spatial variability along ESF and the ECRB (e.g., Figures H-1 and H-2 in Appendix H for fracture characteristics, Figure 6-12 in BSC (2004 [DIRS 166107]) for lithophysal characteristics). One important along-the-tunnel variation is the intensely fractured zone in the Tptpmn unit, in which the overall fracture frequency is more than twice the frequency observed in other areas of the Tptpmn unit. It is important that the testing locations adequately cover this spatial variability. 


\subsubsection{Capillary-Strength Parameter}

The local capillary-strength parameter $1 / \alpha$ of the fractured rock is one of the key parameters affecting the capillary barrier behavior at the drift crown. The larger this parameter, the stronger the capillary force, which holds water in the fractures and prevents it from seeping into the drift. A value of zero is the lower limit for the capillary-strength parameter, corresponding to a fractured rock with zero capillary forces.

\subsubsection{Supporting Information}

As explained in Section 6.4.1, appropriate estimates of the fracture capillary-strength parameter are obtained by inverse modeling; this is the main purpose of the SCM (BSC 2004 [DIRS 171764]). The SCM was calibrated and validated against seepage-rate data from multiple liquid-release tests conducted in three niches along the ESF (Niches 3107, 3650, and 4788), one niche in the ECRB (Niche 1620), and in three systematic-testing boreholes (SYBT-ECRB-LA\#1-3) drilled into the ceiling of the ECRB. The test locations are in the two main repository units, the Tptpll and the Tptpmn units. No seepage tests have been conducted in the Tptpul and the Tptpln units, which was justified by the relatively small importance of these units (4.5 percent of the repository is in the Tptpul unit, 2.6 percent of the repository is in the Tptpln unit). The seepage tests were performed by sealing a short section of a borehole above the opening using an inflatable packer system, releasing water at a specified rate into the isolated test interval, and recording the amount of water dripping into the opening. For each interval tested, optimal values of a seepage-relevant capillary-strength parameter were calibrated. Seepage-rate data from multiple test events, using different liquid-release rates, were calibrated simultaneously in the inverse modeling approach. Inversions for the lower lithophysal zone were repeated for multiple realizations of the underlying stochastic permeability field to capture their influence on the calibrated results. Inversions for the middle nonlithophysal zone were conducted for only one realization of the underlying permeability field, which was justified by the smaller importance of this geologic unit for TSPA (12.4 percent of the repository is in the Tptpmn unit, compared to 80.5 percent in the Tptpll unit). The resulting capillary strength values for the Tptpmn unit may thus be affected by the specifics of the single realization of the permeability field, making them less robust compared to the Tptpll unit. This contribution to uncertainty is accounted for in Section 6.6.2.3.

A summary of calibrated capillary-strength values is provided in Table 6.6-1 (DTN: LB0302SCMREV02.002 [DIRS 162273], also given in BSC 2004 [DIRS 171764], Table 6-8). Data from six test intervals are available in the lower lithophysal zone: four intervals in boreholes located above the ECRB Cross-Drift, and two intervals in boreholes above Niche 1620. Four intervals in the middle nonlithophysal zone have been analyzed, one interval in a borehole above Niche 3107 and three intervals in boreholes above Niche 4788. Since multiple inversions with different realizations of the underlying heterogeneous permeability field were performed for test locations in the lower lithophysal zone, the capillary-strength parameter $1 / \alpha$ is calculated as the average of all inverse modeling results at that location. A standard deviation (SD) representing the related uncertainty of each inversion is computed. The standard error (SE) of the mean is calculated as $\mathrm{SE}=\mathrm{SD} /\left(i^{1 / 2}\right)$, where $i$ is the number of inversions performed (between 17 and 30 inversions). Note that the effect of lithophysal cavities on seepage is automatically included in the effective capillary-strength parameter by means of the 
inversion process. (The presence of lithophysal cavities is expected to increase the potential for seepage, because the openings (1) may promote flow channeling in the rock and (2) may create irregularities in the drift walls. The increased potential for seepage is reflected in the test results and thus in the calibrated parameters.) The estimates for the middle nonlithophysal zone are based on a single inversion, i.e., no estimation uncertainty as a result of uncertainty in small-scale heterogeneity can be given. Note that the values provided in Table 6.6-1 reflect characterization of $1 / \alpha$ that does not include the potential effects of mechanical and chemical rock alteration in response to heating the drifts. Effects of excavation, however, are implicitly accounted for in the calibrated values (Section 6.4.1).

The values given in Table 6.6-1 provide the basis for developing appropriate probability distributions that cover spatial variability and uncertainty of seepage-relevant fracture capillary strength for use in TSPA-LA. For that matter, it is important to understand the nature of the calibrated parameter $1 / \alpha$. From capillary theory, the capillary-strength parameter in a single fracture is governed by the aperture distribution. Aperture and capillary strength in a single fracture are negatively correlated; i.e., large apertures are typically associated with a smaller capillary-strength parameter. Since permeability in a single fracture increases with aperture (positive correlation), the fracture permeability and capillary-strength parameter are also negatively correlated. In a fracture continuum, with $1 / \alpha$ being a representative continuum parameter (as in the seepage process models), a change in continuum permeability can be related to (1) a change in fracture aperture or (2) a change in the fracture density (Birkholzer et al. 1999 [DIRS 105170], Section 2). In the first case, $1 / \alpha$ is approximately negatively correlated to the square root of fracture continuum permeability; in the second case, there is no change in $1 / \alpha$.

Most process models for unsaturated flow at Yucca Mountain use values for 1/ $\alpha$ that represent the physically based capillary-strength parameter of the fracture ensemble in the rock, as discussed above. Seepage process models like the SCM, however, consider $1 / \alpha$ as an effective process parameter for drift seepage that implicitly accounts for a number of additional factors affecting seepage, as listed in Section 6.4.1.1. Estimating 1/ $\alpha$ as an effective process parameter in the inversion makes the explicit inclusion of these factors into the seepage calibration model unnecessary (BSC 2004 [DIRS 171764], Section 6.3.4). The calibrated 1/ $\alpha$ value therefore represents a process-related parameter for estimating seepage with a specific conceptual model on a given spatial scale. Since some of the above-listed additional factors are not affected by intermediate-scale to large-scale rock type changes, the effective capillary strength may exhibit less significant variation between and within different geological units compared to other fracture properties such as, for example, the fracture permeability. For similar reasons, the calibrated capillary-strength parameter is not expected to be correlated to the mean fracture permeability used in the seepage process models (compare with Table 6.6-3). 
Table 6.6-1. Summary Statistics of Estimated Capillary-Strength Parameter for Lower Lithophysal Zone and Middle Nonlithophysal Zone

\begin{tabular}{|c|c|c|c|c|c|c|c|}
\hline \multicolumn{8}{|c|}{ Lower Lithophysal Zone (Tptpll Unit) } \\
\hline \multirow[b]{2}{*}{ Location } & \multirow[b]{2}{*}{ Interval } & \multirow[b]{2}{*}{$\begin{array}{c}\text { Number of } \\
\text { Inversions }^{(1)}\end{array}$} & \multicolumn{5}{|c|}{ Estimate $1 / \alpha[\mathrm{Pa}]$} \\
\hline & & & Mean & Std. Dev. ${ }^{(2)}$ & $\begin{array}{c}\text { Std. } \\
\text { Error }^{(3)}\end{array}$ & Min. & Max. \\
\hline SYBT-ECRB-LA\#1 & zone 2 & 17 & 534.3 & 56.8 & 13.8 & 447.7 & 674.1 \\
\hline SYBT-ECRB-LA\#2 & zone 2 & 21 & 557.1 & 56.4 & 12.3 & 457.1 & 676.1 \\
\hline SYBT-ECRB-LA\#2 & zone 3 & 19 & 534.8 & 57.8 & 13.3 & 443.1 & 645.7 \\
\hline SYBT-ECRB-LA\#3 & zone 1 & 23 & 452.0 & 54.7 & 11.4 & 382.8 & 616.6 \\
\hline Niche 1620 & $\mathrm{BH} \# 4$ & 30 & 671.2 & 223.2 & 40.8 & 356.0 & 1197.0 \\
\hline Niche 1620 & $\mathrm{BH} \# 5$ & 24 & 740.5 & 339.0 & 69.2 & 231.1 & 1840.8 \\
\hline \multicolumn{8}{|c|}{ Middle Nonlithophysal Zone (Tptpmn Unit) } \\
\hline Niche 3107 & UM & 1 & 741 & 一 & 一 & - & - \\
\hline Niche 4788 & UL & 1 & 646 & - & - & - & - \\
\hline Niche 4788 & UM & 1 & 603 & - & - & - & - \\
\hline Niche 4788 & UR & 1 & 427 & - & - & - & - \\
\hline
\end{tabular}

Source: DTN: LB0302SCMREV02.002 [DIRS 162273], also given in BSC (2004 [DIRS 171764], Table 6-8).

(1) Each inversion is based on a different realization of the heterogeneous permeability field.

(2) Represents estimation uncertainty on account of small-scale heterogeneity (not available for estimates for the middle nonlithophysal zone).

(3) Standard error of mean.

Note that this specific seepage-related definition of $1 / \alpha$ requires that downstream models using this parameter for seepage prediction must be fully compatible with the SCM. The process models used for predicting seepage during ambient and thermally perturbed conditions (the SMPA and the TH Seepage Model, respectively) are compatible in this sense (see Section 6.4).

\subsubsection{Spatial Variability}

The intermediate-scale variability of $1 / \alpha$ refers to the variation of this effective process parameter, provided on the spatial resolution similar to the SCM and SMPA model domain, within the repository rock units. Figure 6.6-1 shows a schematic illustration of the location of niches and drift sections where seepage tests have been conducted. The test sites are representative of the variability in fracture and lithophysal characteristics encountered along the ESF and the ECRB. The first three niche sites are located along the west side of the ESF in the Tptpmn unit and were selected for seepage testing based on their different fracture densities (BSC 2004 [DIRS 171764], Section 6.5.1). Niche 3107, at construction station (CS) 31+07 in the ESF, consists of a 6.3-meter long drift located in an area of relatively low fracture density. Niche 3650, at CS 36+50, consists of a 9-meter long drift located in a competent rock mass exhibiting relatively moderate fracture density. Niche 4788, at CS 47+88, consists of an 8.2-meter long drift located in the 950-meter long exposure of an intensely fractured zone in the Tptpmn unit (see Section 6.6.1.2). Fractures in this zone are not uniformly spaced, but instead occur in clusters of closely spaced fractures. The 15.0-meter long Niche 1620 is located on the south side of the ECRB Cross-Drift in the Tptpll unit. This unit comprises many small fractures 
(less than 1-meter long) interspersed with many lithophysal cavities, ranging in size from $1 \mathrm{~cm}$ to $180 \mathrm{~cm}$ (Section 6.6.1.3). Additional tests in the Tptpll unit were conducted in three systematic testing boreholes drilled into the ceiling of the ECRB Cross-Drift. Note that no calibrated capillary-strength values are available for Niche 3650. Though 27 liquid-release tests have been conducted (13 of which resulted in seepage), the testing methodology was considered less reliable because of the short test duration, making the test results very sensitive to storage effects (BSC 2004 [DIRS 171764], Section 7.3). All boreholes shown in Figure 6.6-1 are approximately parallel to the niche (drift) axis. Test intervals in the niches are approximately $1 \mathrm{ft}$ long $(0.3 \mathrm{~m})$; test intervals in the systematic testing boreholes are approximately 1.8-meter long.

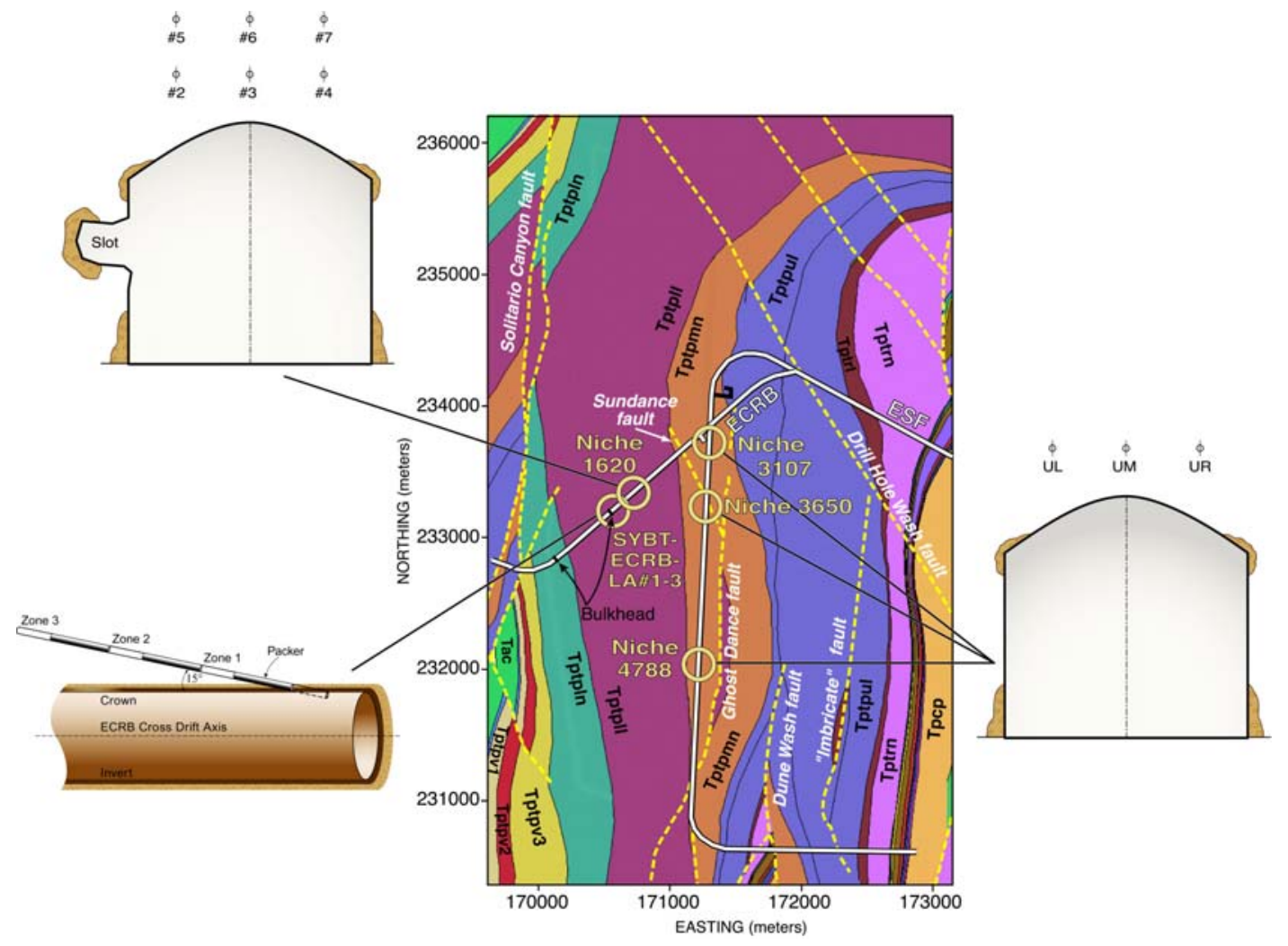

Source: BSC (2004 [DIRS 171764], Figure 6-4).

Figure 6.6-1. Schematic Geological Map Showing Approximate Location and Schematic Setup of Niches and Systematic Testing Boreholes SYBT-ECRB-LA\#1-3 (Formations Depicted at the Elevation of the ESF)

From Table 6.6-1 and Figure 6.6-1, calibrated 1/ $\alpha$ values are available from ten test intervals in four different niche or drift locations. The four locations provide broad spatial coverage of the primary repository units, with a north-south distance of about 1,700 meters between Niches 3107 and 4788, and an east-west distance of about 800 meters between the ESF niches and the location of the systematic testing boreholes. Considering the geological units separately, the Tptpmn unit test locations (Niches 3107 and 4788) are separated by a distance of about $1,700 \mathrm{~m}$, covering areas in the middle nonlithophysal zone with distinct fracture characteristics, while the Tptpll unit test locations (Niche 1620 and systematic testing boreholes) are in relatively close proximity within a 150-meter long section of the ECRB Cross-Drift. Where several 
boreholes were tested in one niche, the typical distance between test intervals was on the order of a few meters (boreholes are typically a few meters apart). A similar distance is measured between the two tested intervals in systematic testing borehole SYBT-ECRB-LA\#2 (BSC 2004 [DIRS 171764], Section 6.5.1). Thus, the ten available $1 / \alpha$ values are not randomly placed over the entire repository area; instead, sample points are clustered at four carefully selected test locations within two different rock types.

To develop appropriate probability distributions from these data, it is important to recall the nature of the parameter in question. If $1 / \alpha$ solely represented the capillary behavior of the fractured rock, one would expect this parameter to vary considerably between the two geological units, as a result of potential differences in fracture aperture and fracture wall roughness. Thus, the analysis would need to be conducted separately for the two geological units. Another consequence of $1 / \alpha$ solely representing capillary behavior would be that the $1 / \alpha$ values available in one niche location (or drift section) could not be used to constrain the intermediate-scale variation because of the close test proximity. Therefore, these values would need to be treated as statistically dependent; one would have to use the average of the available samples at each distinct niche location (or drift section) for further statistical analysis of intermediate-scale variability. This would leave a very small sample size at two distinct locations (Niches 3107 and 4788 in the Tptpmn unit; Niche 1620 and systematic testing boreholes in the Tptpll unit) as the basis for estimating intermediate-scale variability within the repository units, making the calculated statistical measures more uncertain.

On the other hand, as pointed out earlier, seepage models derive and apply $1 / \alpha$ as an effective process parameter that accounts for a number of additional factors affecting seepage. Some of these factors-drift-wall roughness, drop formation and detachment, artifacts of finite discretization - are largely independent of intermediate- and large-scale rock type variation. It is therefore possible that the $1 / \alpha$-variability is not significantly dependent on the geological unit. In this case, analysis of statistical measures could be conducted without distinguishing between geological units. It is also possible that the variation of effective fracture capillary strength is not closely tied to the location (or drift section). In this case, all ten samples could be considered as independent.

Table 6.6-2 provides statistical parameters defining spatial variability distributions-mean $\mu$ and standard deviation $\sigma$-calculated from the ten test samples provided in Table 6.6-1. (The mean of $1 / \alpha$ over multiple inversions is used for the Tptpll unit.) Also given is the standard error of the mean (SE), an estimate for the uncertainty in the mean value caused by a limited number of measurements. In light of the above discussion on the possible statistical independence of the ten test intervals, these statistical parameters have been derived using four different methods. These methods are as follows:

1. Derive mean and standard deviation from all ten samples in both units.

2. Calculate average values from multiple tests in one location, then derive mean and standard deviation from the resulting four samples in both units.

3. Derive mean and standard deviation separately for geological units, from six samples in the Tptpll unit and four samples in the Tptpmn unit. 
4. Calculate average values from multiple tests in one location, then derive mean and standard deviation separately for each geological unit.

Except for the standard error, the statistical values provided in Table 6.6-2 are consistent among the four calculation methods. The maximum differences in the mean (about $60 \mathrm{~Pa}$ ) and the standard deviation (about $20 \mathrm{~Pa}$ ) between methods A through $\mathrm{D}$ are significantly smaller than the variability in the calibrated $1 / \alpha$-values (or the range of results from multiple inversions, see Table 6.6-1). The two geological units do not show a significant difference in the effective capillary-strength parameter. In fact, the difference of $1 / \alpha$-values within a geological unit is on the same order as the difference of $1 / \alpha$ between geological units. However, the standard error of the mean varies between the different methods as a result of the varying sample size. The more statistically independent samples available, the more reliable the estimate of the mean.

Table 6.6-2. Intermediate-Scale Variability Statistics of Estimated Capillary-Strength Parameter over Repository Rock Block, Using Different Calculation Methods

\begin{tabular}{|c|c|c|c|c|c|}
\hline Method & $\begin{array}{c}\text { Number of } \\
\text { Samples }\end{array}$ & $\begin{array}{c}\text { Mean } \mu \\
(\mathbf{P a})\end{array}$ & $\begin{array}{c}\text { Std. Dev. } \sigma \\
(\mathbf{P a})\end{array}$ & $\begin{array}{c}\text { Std. Error of } \\
\text { Mean SE } \\
(\mathbf{P a})\end{array}$ & $\begin{array}{c}\text { Three Std. } \\
\text { Errors }^{2} \\
(\mathbf{P a})\end{array}$ \\
\hline $\begin{array}{c}\text { A } \\
\text { All Samples, Both Units }\end{array}$ & 10 & 591 & $109^{1}$ & 35 & 105 \\
\hline B & & & & & \\
All Locations, Both Units & 4 & 631 & 109 & 54 & 162 \\
\hline C & & & & & \\
All Samples in Tptpmn & 4 & 604 & 131 & 66 & 198 \\
All Samples in Tptpll & 6 & 582 & 105 & 43 & 129 \\
\hline D & & & & & \\
All Locations in Tptpmn & 2 & 650 & 129 & 91 & 273 \\
All Locations in Tptpll & 2 & 613 & 132 & 93 & 279 \\
\hline
\end{tabular}

Output DTN: LB0407AMRU0120.001

1 Due to rounding, the standard deviation of Method A was set to $109 \mathrm{~Pa}$ in this analysis instead of $110 \mathrm{~Pa}$, as suggested by the Excel spreadsheet results referred to in Appendix $\mathrm{B}$. This difference of less than 1 percent in the second moment is not relevant for the resulting parameter distributions.

2 Three standard errors are used to define the uncertainty distributions in Section 6.6.2.3.

Note that statistical tests are available to rigorously analyze the statistical independence of samples. However, because of the rather small sample size, such statistical tests have not provided clear indication about which one of the four methods is most appropriate for defining the spatial variability of the $1 / \alpha$-parameter. On the other hand, the sensitivity analysis conducted in Section 6.8.1 indicates that the overall seepage results are not significantly affected by the statistical evaluation method. It is therefore recommended that all four methods be included in TSPA as alternative representations of spatial variability and uncertainty in the $1 / \alpha$-parameter. The four methods should be uniformly sampled (i.e., equally weighted) in TSPA, incorporating the global epistemic uncertainty about these different statistical evaluation methods. The significance of this uncertainty in the seepage model can be evaluated as part of the TSPA linear regression analyses of individual dose. For further discussion of spatial variability and 
uncertainty treatment of $1 / \alpha$ in the remainder of this document, the resulting mean and standard deviation of Method A are used as an example.

The question of which parametric probability distribution should be best suited to represent the spatial variability of the ten samples deserves further attention. Since capillary strength in a single fracture is correlated to the aperture distribution, which is approximately lognormal in most fractured rocks, one would expect $1 / \alpha$ to be lognormally distributed as well. However, the histogram of the sample values in Figure 6.6-2 gives no clear indication of the parametric model, arguably because the calibrated capillary-strength parameter includes many additional factors affecting seepage (see Scientific Notebook, Birkholzer 2003 [DIRS 164526], p. 122, for definition of bins and calculation of probabilities). In light of this uncertainty about the relative likelihood of the data, the distribution of choice for the capillary-strength parameter is a simple uniform distribution, where all possible values between the specified minimum and maximum values are equally probable. The minimum and maximum values of this distribution can be easily calculated from the given mean and the standard deviation of the samples (Mishra 2002 [DIRS 163603], Section 3.2), as provided in Table 6.6-2. The minimum value is defined as $\mu-1.7321 \times \sigma$, giving $402 \mathrm{~Pa}$ using the respective values from Method $\mathrm{A}$. The maximum value is defined as $\mu+1.7321 \times \sigma$, which is $780 \mathrm{~Pa}$ for Method A (both units). The resulting probability distribution for spatial variability of $1 / \alpha$ using Method A is depicted in Figure 6.6-2. From similar considerations, the minimum and maximum values for Methods $\mathrm{B}, \mathrm{C}$, and $\mathrm{D}$ can be easily calculated. Method B arrives at a minim value of $442 \mathrm{~Pa}$ and a maximum value of $820 \mathrm{~Pa}$ (both units). Method $\mathrm{C}$ arrives at a minimum value of $377 \mathrm{~Pa}$ and a maximum value of $831 \mathrm{~Pa}$ for the Tptpmn unit, compared to a minimum value of $400 \mathrm{~Pa}$ and a maximum value of $764 \mathrm{~Pa}$ for the Tptpll unit. Method D arrives at a minimum value of $427 \mathrm{~Pa}$ and a maximum value of $873 \mathrm{~Pa}$ for the Tptpmn unit, compared to a minimum value of $384 \mathrm{~Pa}$ and a maximum value of $841 \mathrm{~Pa}$ for the Tptpll unit. (Note that the impact of choosing another parametric distribution, such as a normal distribution, is rather small, as shown in Section 6.8.2.) The uncertainty associated with the capillary-strength parameter will be discussed in the next section. 


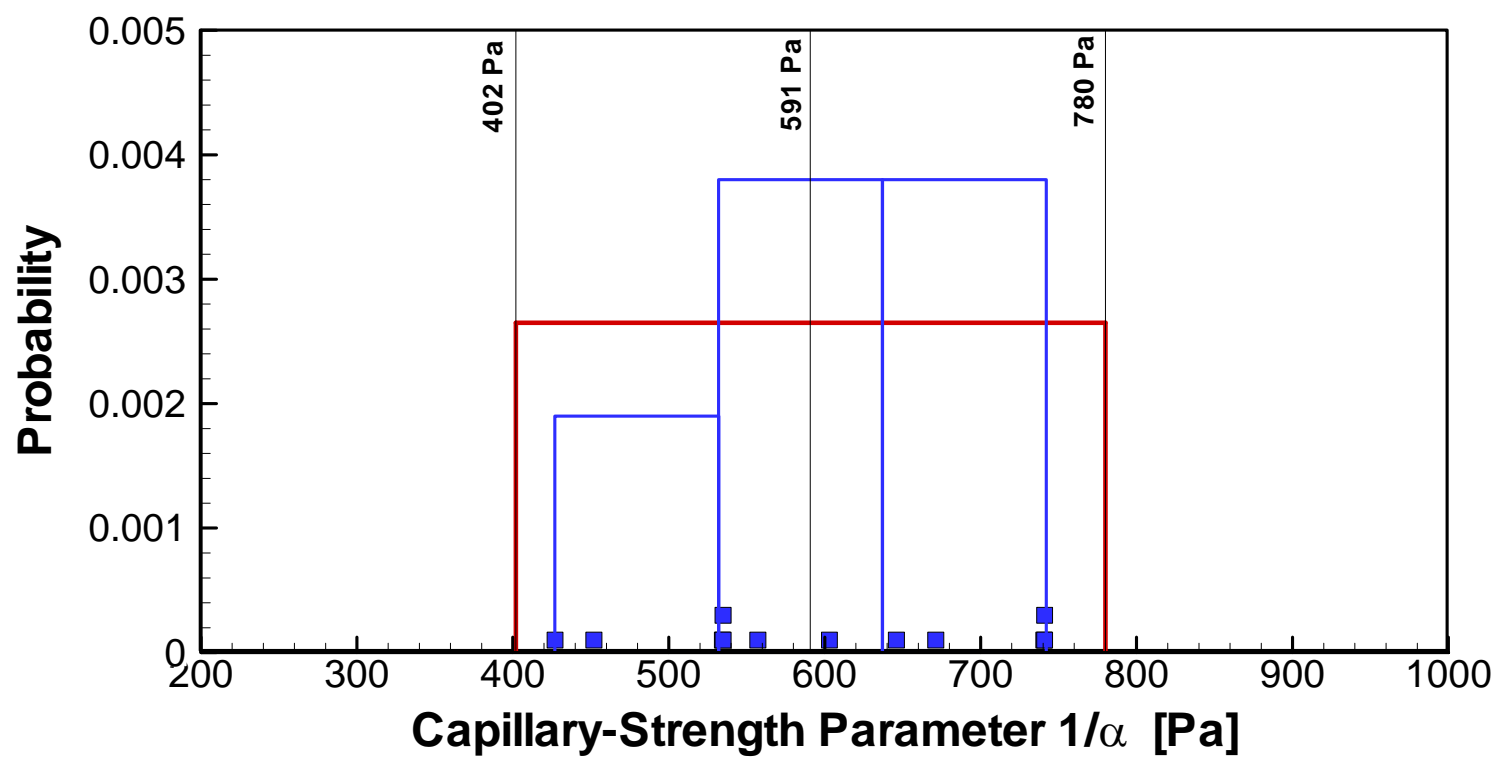

Source DTN: LB0302SCMREV02.002 [DIRS 162273].

NOTE: Vertical lines indicate mean and range of distribution. Blue symbols indicate calibrated sample values.

Figure 6.6-2. Histogram and Related Probability Distribution for Spatial Variability of Capillary-Strength Parameter $1 / \alpha$, Using Statistical Parameters Based on Method A

\subsubsection{Uncertainty}

The different sources of uncertainty related to the capillary-strength parameter are as follows:

\section{Measurement Uncertainty:}

The capillary-strength parameter is determined by calibrating the SCM against seepage-rate data from liquid-release tests (Section 6.4.1). As described in BSC (2004 [DIRS 170004], Sections 6.2, 6.11, 7.2.3), these tests have been carefully designed, and potential problems observed in early tests (i.e., memory effect, short test duration, ventilation) were fixed in subsequent testing phases, with tests conducted over longer periods, at various release rates, and under better control of ventilation regime and relative humidity conditions. Only these later tests were selected for calibration of the SCM, and evaporation effects were incorporated into the model (BSC 2004 [DIRS 171764], Section 6.5.4). The remaining uncertainty in the measured seepage rates is mainly caused by the possibility of unaccounted water losses, e.g., from evaporation in the seepage capture system or from unaccounted storage capacity in the rock. Thus, this contribution to uncertainty should be included in and propagated through the abstraction, using appropriate probability distribution functions.

\section{Conceptual Model Uncertainty:}

As explained in Section 6.4.1, the SCM is a sophisticated seepage process model for calibration of capillary-strength parameters on the scale and for the conditions of interest. The calibrated model with the appropriate effective parameters is capable of reproducing and predicting observed seepage data from liquid-release tests conducted above and 
below the seepage threshold; they are thus likely to yield reasonable seepage predictions into waste emplacement drifts. Alternative conceptual models corroborate the findings of the SCM. Altogether, the conceptual model uncertainty should be small compared to other sources of uncertainty inherent in the $1 / \alpha$-values. Therefore, inclusion of conceptual model uncertainty is not necessary in the abstraction.

\section{Estimation Uncertainty:}

The estimation uncertainty of $1 / \alpha$ in the Tptpll unit is mainly a result of uncertainty in the small-scale fracture permeability distribution used in the inversion model. Multiple realizations were performed with different realizations of conditioned random permeability fields. It was demonstrated in BSC (2004 [DIRS 171764], Section 6.6.4) that the estimation uncertainty on account of small-scale heterogeneity differences is on the order of 50 to about $300 \mathrm{~Pa}$. However, it is also pointed out in BSC (2004 [DIRS 171764], Section 8.2) that this source of estimation uncertainty should not be incorporated in the parameter distribution used for sampling in TSPA-LA. This is because the impact of undetermined details pertaining to small-scale heterogeneity is directly evaluated in the predictive seepage models, i.e., the SMPA and the TH Seepage Model. Using the range of results from these models in the TSPA calculations assures that the estimation uncertainty is intrinsically included in and propagated through the abstraction (see Section 6.5.1.3). In the Tptpmn unit, only one realization of permeability fields was analyzed, which makes the calibration results less robust than those for the Tptpll unit. This contribution to uncertainty should thus be accounted for in the abstraction. Another uncertainty factor may stem from the misfit between the results and the data; i.e., from the goodness of fit between calibration model and measurement. It is stated in BSC (2004 [DIRS 171764], Section 6.6.4) that uncertainty related to the misfit between the model and the data was significantly smaller than the uncertainty from small-scale heterogeneity. This contribution to the estimation uncertainty can be ignored in abstraction.

\section{Spatial Variability Uncertainty:}

Spatial variability uncertainty needs to account for uncertainty in the probability distribution chosen to represent spatial variability. This requirement stems from the fact that only a limited number of data points are available to derive the distribution parameters. The related uncertainty can be uncertainty both in the mean and in the standard deviation of $1 / \alpha$, defining the potential range of the data. In measurement theory, the standard error of the mean is often used to describe the potential error in the estimated mean resulting from a limited sample size. For the analysis based on all ten $1 / \alpha$ values (Method A, see Table 6.6-2), this error is comparably small at 35 Pa. Method $\mathrm{D}$, on the other hand, arrives at much higher standard errors of 91 and $93 \mathrm{~Pa}$ for the Tptmn and the Tptpll units. Thus, spatial variability uncertainty needs to be included in and propagated through the abstraction, using appropriate probability distribution functions.

With most of the above discussion being a qualitative assessment of uncertainty, the assignment of quantitative measures for uncertainty-i.e., the definition of appropriate probability distributions describing uncertainty—is necessarily subjective and somewhat arbitrary, and must 
be based on scientific judgment. The method chosen here is to account for uncertainty by varying the mean of the chosen probability distribution for spatial variability within appropriate ranges; i.e., by shifting the uniform distribution for spatial variability to smaller or larger $1 / \alpha$-values. The uncertainty distribution designated to provide this random adjustment of the mean is a symmetric triangular distribution, with a mean of zero, a maximum of three standard errors, and a minimum of minus three standard errors. For Method $\mathrm{A}$, this would give a range of $\pm 105 \mathrm{~Pa}$ (see Table 6.6-2). For Method $\mathrm{D}$, as an example, this range is much higher at $\pm 273 \mathrm{~Pa}$ for the Tptpmn unit and $\pm 279 \mathrm{~Pa}$ for the Tptpll unit (see Table 6.6-2). A range of approximately plus/minus two standard errors defines the 95 percent-confidence interval for the estimated mean value of the sample; i.e., this uncertainty range accounts for the fact that the estimated mean value of the limited sample may be different from the mean value of the entire population. As a consequence, the chosen uncertainty distribution covers sufficient uncertainty in the estimated mean values, while leaving room for additional uncertainty sources (e.g., measurement uncertainty, estimation uncertainty for the Tptpll unit stemming from a limited number of realizations). The parameter range is believed to cautiously but realistically represent the potential total uncertainty in $1 / \alpha$, comprising the respective contribution of measurement errors and spatial variability errors.

The triangular distribution is an appropriate model for uncertain quantities where a most likely value is known in addition to an estimated range of parameters. The triangular uncertainty distribution represents the key features desired, which are that a uniform spatial variability distribution with a mean value of $591 \mathrm{~Pa}$, a lower bound of $402 \mathrm{~Pa}$, and an upper bound of $780 \mathrm{~Pa}$ is the most likely case (see Section 6.6.2.2). Uniform spatial variability distributions with higher or lower mean are possible, but less likely. As mentioned above, values sampled from the uncertainty distribution are used to adjust the mean of the spatial variability distribution. No uncertainty is assigned to the specified minimum and maximum values of the uniform spatial variability distribution; i.e., the uniform spatial variability distribution is shifted to smaller or larger values without changing its range. Uncertainty about the range of the spatial variability distribution is believed to be small in light of the above discussion about the nature of this parameter; it should be fully accounted for in the triangular probability distribution for uncertainty of the mean.

A schematic of the spatial variability and uncertainty model is given in Figure 6.6-3, using the values derived from Method A as an example. The heavy blue line shows the triangular-shaped uncertainty distribution, assigning a probability to the mean of the uniform-shaped spatial variability distribution. The most likely spatial variability distribution is the one defined in Section 6.6.2.2, with a probability of $0.00951 / \mathrm{Pa}$ corresponding to the peak value of the triangular distribution. This spatial variability distribution has a mean of $591 \mathrm{~Pa}$, a minimum value of $402 \mathrm{~Pa}$, and a maximum value of $780 \mathrm{~Pa}$. Least likely are the two bounding cases, where the triangular distribution indicates a zero probability. The lower bounding case has a uniform spatial variability distribution with a mean of $486 \mathrm{~Pa}$, a minimum value of $297 \mathrm{~Pa}$, and a maximum value of $675 \mathrm{~Pa}$ (generated by subtracting three standard errors from the most likely distribution). The upper bounding case has a uniform spatial variability distribution with a mean of $696 \mathrm{~Pa}$, a minimum value of $507 \mathrm{~Pa}$, and a maximum value of $885 \mathrm{~Pa}$ (generated by adding three standard errors to the most likely distribution). Together, considering the combined effect of spatial variability and uncertainty, the range of $1 / \alpha$-values to be used in TSPA-LA is quite 
large, extending from $297 \mathrm{~Pa}$ to $885 \mathrm{~Pa}$. This range is significantly larger than the narrow distribution employed during validation of the Seepage Calibration Model (BSC 2004 [DIRS 171764], Section 7.2.2.1), which was based on a standard deviation for $\log (1 / \alpha)$ of 0.1 .

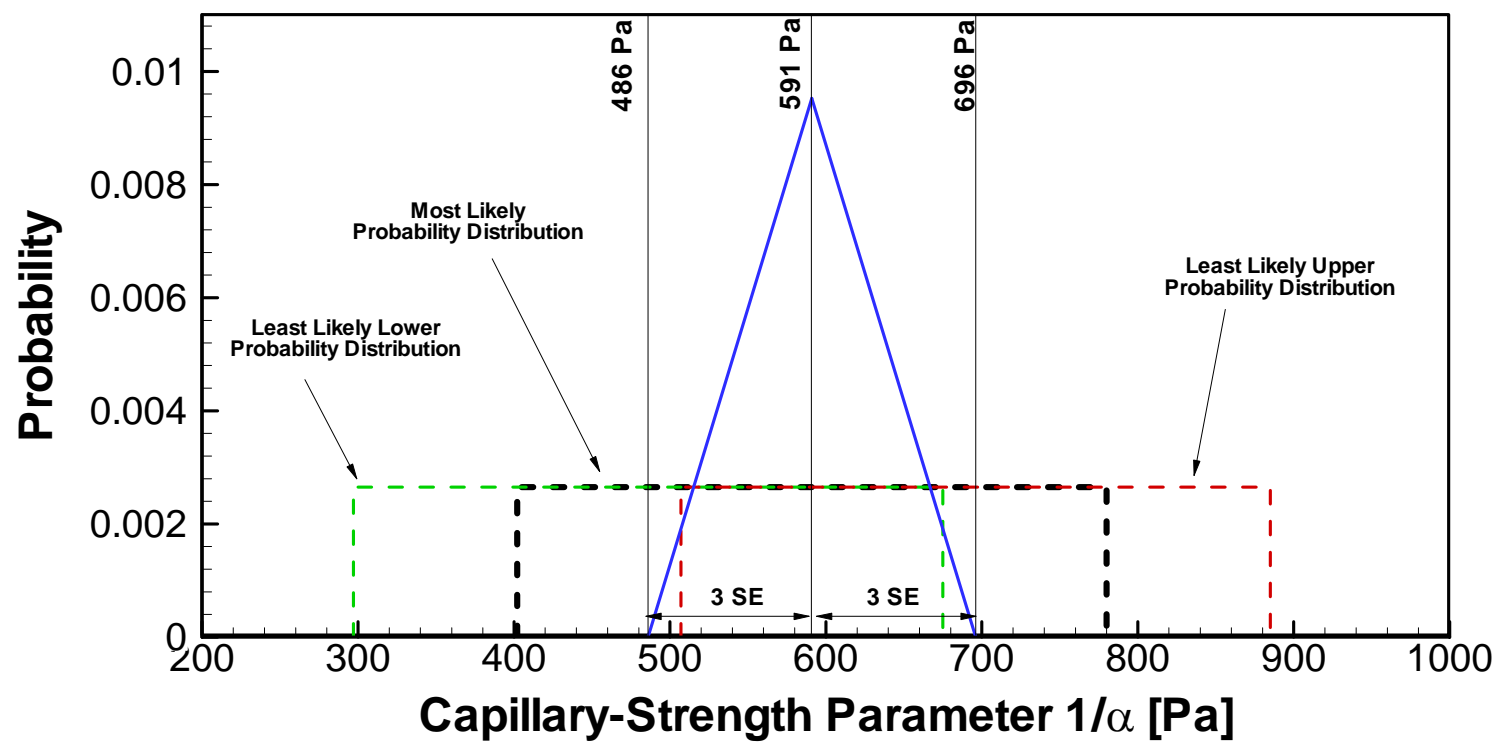

NOTE: The blue line assigns a probability to the mean of the uniform-shaped spatial variability distribution. The black dashed line shows the most likely spatial probability distribution (at the peak of the triangular distribution). The green and the red dashed lines show the least likely spatial probability distributions (at the minimum and the maximum of the triangular distribution); based on statistical parameters summarized in Table 6.6-2. SE denotes standard error.

Figure 6.6-3. Schematic Showing the Triangular Probability Distribution (Blue Line) for Covering Uncertainty of the Capillary-Strength Parameter by Varying the Mean of the Spatial Probability Distribution, Using Statistical Parameters Based on Method A

\subsubsection{Fracture Permeability}

The second key parameter affecting the diversion of water around drifts is the tangential fracture permeability in the boundary layer near the drift wall. The larger this parameter, the more likely is water-flow around the drift and the less likely is seepage (Birkholzer et al. 1999 [DIRS 105170], Sections 3 and 5). Similar to the SCM, the predictive models for seepage- the SMPA and the TH Seepage Model - apply a stochastic conceptualization of the permeability of the fracture continuum in the drift vicinity. The small-scale variability of the continuum permeability (resolution of about one foot or $0.3 \mathrm{~m}$ ) is implicitly accounted for in these models, using lognormal probability distributions based on air-injection measurements that were performed on the same scale. While the standard deviation of these small-scale permeability distributions, $\sigma_{S}$, can be treated as a constant for abstraction (see discussion in Section 6.4.2), their mean values, $\mu_{S}$, may vary significantly over the repository rock units. (For simplification, these mean values of small-scale permeability were simply referred to as $k$ in the previous sections.) For TSPA, distributions covering the intermediate-scale variability and the uncertainty of these mean values of small-scale permeability need to be developed (see Figure 6.6-4). The 
statistical parameters describing the distribution of intermediate-scale variability are the mean permeability $\mu$ and the standard deviation $\sigma$.

As discussed in Sections 6.4.1 and 6.4.2, the permeability values provided to the SMPA need to account for the effect of excavation. Typically, the excavation-disturbed permeabilities at the crown of an underground tunnel are larger than the permeabilities measured in undisturbed rock. It is therefore important to use permeability data for the seepage abstraction that reflect the impact of excavation (see Section 6.6.3.1 below). Excavation effects on permeability are (1) a result of stress redistribution during drift excavation, which leads to local opening of natural fractures above the tunnel and potentially the creation of new microfractures and (2) a result of the mechanical impact of the excavation devices, which depends on the method of excavation. (Tunnel-boring machines have been used for the excavation of the ESF and the ECRB, and will be used for the construction of the repository drifts. Alpine miners/roadheaders have been used for excavation of the niches, while drill/blast techniques have been employed in portions of Alcoves 2, 6, and in the plate-loading niche in Alcove 5 (Craig 2001 [DIRS 171411], "Observations")). Stress-redistribution effects are more prominent in the repository rocks at Yucca Mountain; they give rise to considerable increases in fracture permeability that extend to a distance of a few meter measured from the drift crown (see Figures 6.5.1-1 and 6.6.1-1 in BSC 2004 [DIRS 169864]). These effects are included in the permeability measurements from air injection tests conducted above the niches and the systematic testing boreholes (see Section 6.6.3.1 below). Typically, the injection boreholes are located at distances of about 0.75 to 1.5 meter above the tunnel crowns, thus representing the zone of stress-related permeability changes.

Mechanical effects related to the excavation method are less prominent and generally limited to small zones immediately at the drift walls, provided that no drill/blast methods are employed. Craig (2001 [DIRS 171411], “Conclusions”) reports that fractures generated by machine-excavated openings at Yucca Mountain are rare and small, and that the fracturing induced by alpine miner/roadheader techniques are similar in depth (measured from the drift wall) to those produced by tunnel boring machines. Fractures induced by alpine miner/roadheader techniques were observed to extend less than $10 \mathrm{~cm}$ from into the wall rock in zones with less natural fractures, and less than $20 \mathrm{~cm}$ into the wall rock in zones with lithophysae or more natural fractures. Fractures induced by tunnel-boring machines were determined to extend less than $5 \mathrm{~cm}$ into the wall rock, with the exception of intensely fractured zones (up to 0.5 meters into the wall rock). Thus, for both machine-excavated openings, the effect of fracturing is small and limited to local regions of wall rock. The air injection tests conducted in the niches and in the systematic testing boreholes are located outside of this local region; thus the measured permeabilities incorporate mostly stress-related permeability changes that are not or only marginally affected by the excavation method.

The following conclusions can be drawn from this discussion: (1) The measured permeabilities from niche tests include the prominent stress-related excavation effects on permeability, which is important for seepage evaluation. The local effects of fracturing induced by machine excavation are not included in these measurements; however, these effects are small and would, if included, increase the local permeability along the drift wall, which would lead to less seepage. Thus, the permeability estimates used in this abstraction model are conservative. (2) The fact that the niches were excavated by alpine miner/roadheader techniques while the repository drifts will be 
excavated by tunnel boring machines is not relevant for this abstraction model because (a) the permeability distributions developed for this abstraction model do not include the effects of machine excavation (see above), (b) the fractures generated by machine-excavated openings at Yucca Mountain were determined to be rare and small, and (c) the differences between induced fracturing from alpine miner/roadheader techniques and tunnel boring machines were determined to be small. Remaining uncertainties related to the effects of the excavation method are safely included in the uncertainty distributions developed in Section 6.6.3.3.

Additional effects potentially changing fracture permeability, stemming from THM or THC rock alteration during or after the heating phase of the repository, do not need to be included in the permeability distributions for TSPA, for the reasons presented in Section 6.5.1.4.

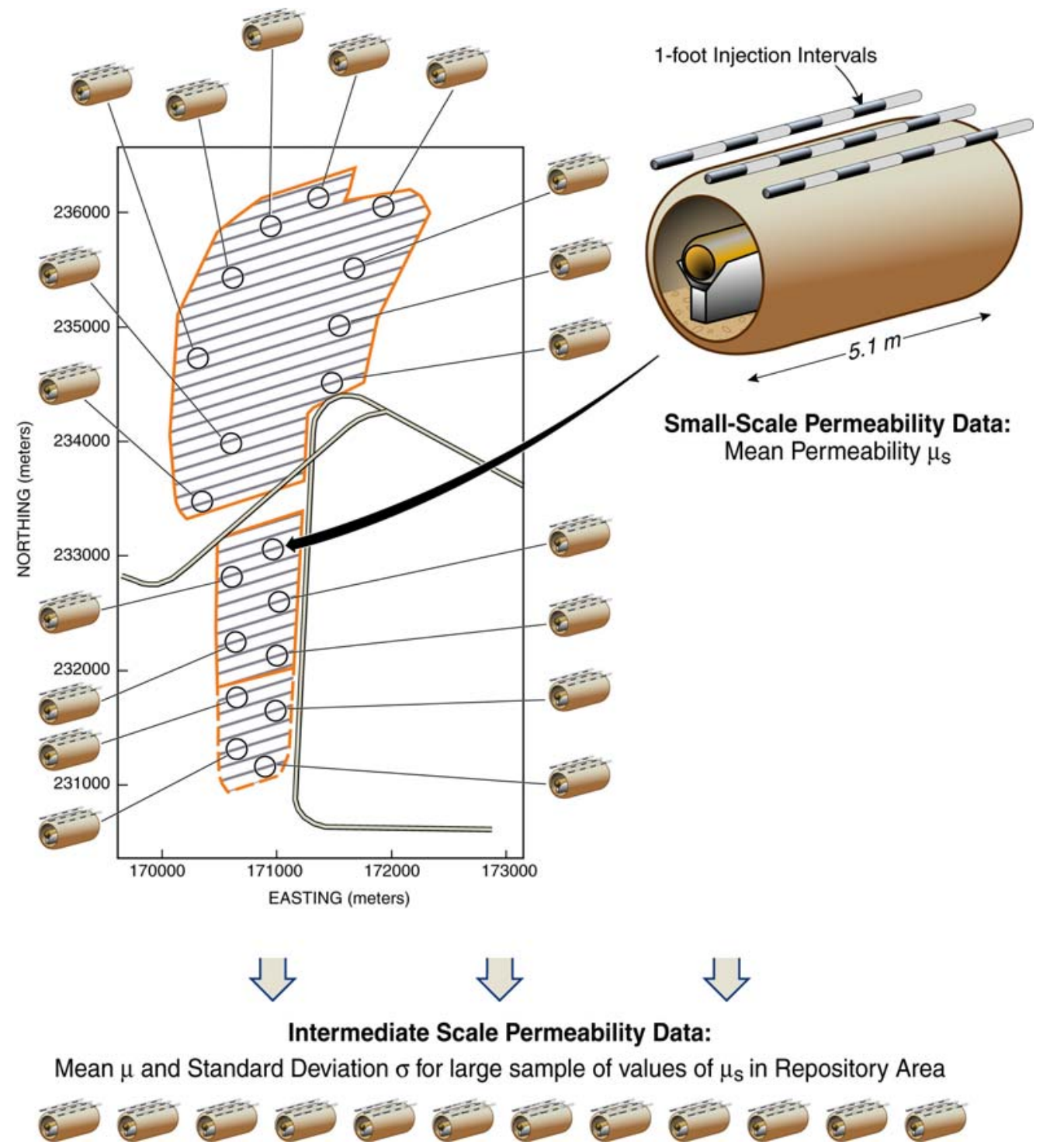

Figure 6.6-4. Schematic Showing the Relation between Statistics of Small-Scale Measurements (Mean Permeability $\mu_{S}$ ) and the Intermediate-Scale Variability Distribution of the Repository Units (Mean $\mu$ and Standard Deviation $\sigma$ ) 


\subsubsection{Supporting Information}

The most appropriate information on fracture permeability-measured on the scale of intereststems from the air-injection testing conducted in the boreholes and niches displayed in Figure 6.6-1. The tests were performed by isolating a short section of the boreholes (1 foot [about $0.3 \mathrm{~m}$ ] in niches, $6 \mathrm{ft}$ [about $1.8 \mathrm{~m}$ ] in systematic testing borehole SYBT-ECRB-LA\#2), using an inflatable packer system, and then injecting compressed air at a constant rate into the isolated injection interval. The pressure buildup in the injection interval and in nearby observation intervals was monitored with time until steady-state conditions were reached, which typically occurred within a few minutes. Air injection was terminated after reaching steady-state pressures, and the decline in air pressure was then monitored as it recovered to its initial pre-test condition. Using the pressure response as input, the air permeability value of the tested interval is calculated based on a commonly used analytical solution (BSC 2004 [DIRS 170004], Section 6.1.2.1; LeCain 1995 [DIRS 101700], p. 10, Equation 15). With the exception of the systematic testing boreholes, which were constructed after excavation of the drift, air permeability values are available both before and after excavation. The boreholes above Niches 3107, 3566, 3650, 4788, and 1620 had been drilled and tested prior to niche construction. Except for Niche 3566, testing was repeated using the same testing methodology and identical packer setup after excavation. Note that, as pointed out in Section 6.6.2.2, the test sites are representative of the variability in fracture and lithophysal characteristics encountered along the ESF and the ECRB. Sample points are clustered at carefully selected test locations within the Tptpmn and Tptpll units.

Analysis of pre-excavation measurements at Niches 3107, 3566, 3650, and 4788 is provided in BSC (2004 [DIRS 170004], Table 6.1.2-5), giving the mean and standard deviation of the small-scale permeabilities (DTN: LB990901233124.004 [DIRS 123273]). Statistical parameters for pre-excavation air permeability data from Niche 1620 were calculated in this model report from DTN: LB0012AIRKTEST.001 [DIRS 154586]; details are provided in Appendix C. Post-excavation data for Niches 3107, 3650, 4788, and 1620, as well as for systematic testing borehole SYBT-ECRB-LA\#2, were analyzed in BSC (2004 [DIRS 171764], Section 6.5 .2 and Table 6-4). The resulting statistics are provided in DTN: LB0302SCMREV02.002 [DIRS 162273]. Note that Niche 3566, located at CS 35+66, offers pre-excavation air permeability data, but was not tested after excavation, as the niche was sealed with a bulkhead to conduct long-term monitoring of in situ conditions. No air permeability data are available from boreholes SYBT-ECRB-LA\#1 and SYBT-ECRB-LA\#3 because of equipment problems during air-injection testing.

The mean values $\mu_{S}$ and the standard deviations $\sigma_{S}$ of all appropriate small-scale permeability data conducted at each of the test locations are summarized in Table 6.6-3, for both undisturbed and disturbed conditions, if available. Here, standard deviations reflect spatial variability within the test bed, on a 1-foot test interval scale. Statistical analyses are conducted with log-transformed values, because the niche permeabilities are approximately log-normally distributed (BSC 2004 [DIRS 171764], Section 6.6.2.1; note that log denotes base-10 logarithm in this report). All tests indicate the presence of a well-connected fracture system in the vicinity of the test boreholes. 
Table 6.6-3. Summary Statistics of Air Permeabilities Derived from Small-Scale Air-Injection Tests for Undisturbed and Excavation-Disturbed Conditions in the Middle Nonlithophysal Zone and the Lower Lithophysal Zone

\begin{tabular}{|c|c|c|c|c|c|c|}
\hline \multicolumn{7}{|c|}{ Middle Nonlithophysal Zone (Tptpmn Unit) } \\
\hline \multirow[b]{2}{*}{ Location } & \multicolumn{3}{|c|}{ Mean $\mu_{S}\left(\right.$ in $\left.\log k\left[\mathrm{~m}^{2}\right]\right)$} & \multicolumn{3}{|c|}{ Standard Deviation $\sigma_{S}\left(\right.$ in $\left.\log k\left[m^{2}\right]\right)$} \\
\hline & \multicolumn{3}{|c|}{ Dist./Undist. $^{3}$} & \multicolumn{3}{|c|}{$\begin{array}{l}\text { Dist./Undist. } \\
\text { Disturistured }\end{array}$} \\
\hline Niche 3107 & $-13.4^{1}$ & $-12.14^{2}$ & 18.2 & $0.70^{1}$ & $0.80^{2}$ & 1.14 \\
\hline Niche 3566 & $-13.0^{1}$ & - & - & $0.92^{1}$ & - & - \\
\hline Niche 3650 & $-13.4^{1}$ & $-11.66^{2}$ & 55.0 & $0.81^{1}$ & $0.72^{2}$ & 0.89 \\
\hline Niche 4788 & $-13.0^{1}$ & $-11.79^{2}$ & 16.2 & $0.85^{1}$ & $0.84^{2}$ & 0.99 \\
\hline \multicolumn{7}{|c|}{ Lower Lithophysal Zone (Tptpll Unit) } \\
\hline & \multicolumn{3}{|c|}{ Mean $\mu_{S}\left(\right.$ in $\left.\log k\left[m^{2}\right]\right)$} & \multicolumn{3}{|c|}{ Standard Deviation $\sigma_{S}\left(\right.$ in $\left.\log k\left[\mathrm{~m}^{2}\right]\right)$} \\
\hline Location & Undisturbed & $\begin{array}{r}\text { Disturbed } \\
\text { Dist./Undist. }\end{array}$ & Factor & Undisturbed & $\begin{array}{l}\text { Disturbed } \\
\text { Dist./Undist. }\end{array}$ & Factor \\
\hline Niche 1620 & $-11.5^{4}$ & $-10.95^{2}$ & 3.5 & $1.12^{4}$ & $1.31^{2}$ & 1.17 \\
\hline SYBT-ECRB-LA\#2 & - & $-10.73^{2}$ & - & - & $0.21^{2}$ & - \\
\hline
\end{tabular}

Output DTN: LB0407AMRU0120.001

NOTE: Computations documented in Appendix C.

1 Source: DTN: LB990901233124.004 [DIRS 123273], also given in BSC (2004 [DIRS 170004], Table 6.1.2-5).

2 Source: DTN: LB0302SCMREV02.002 [DIRS 162273], also given in BSC (2004 [DIRS 171764], Table 6-4).

${ }^{3}$ Ratio of disturbed and undisturbed permeability values, not in log space.

${ }^{4}$ Source: Statistics were calculated from individual measurements given in DTN: LB0012AIRKTEST.001 [DIRS 154586].

The small-scale mean permeabilities and their spatial variability as calculated for the niches located in the Tptpmn unit are consistent with one another, for both undisturbed and disturbed conditions. As expected from the discussion of fracture characteristics, the permeabilities in the Tptpll unit show distinct differences to values in the Tptpmn unit. Undisturbed permeability measured at one location in the lower lithophysal zone is approximately $1 \frac{1}{2}$ orders of magnitude larger than the respective Tptpmn unit value; disturbed-zone permeabilities differ by approximately one order of magnitude. While the post-excavation permeabilities in the Tptpmn unit are between 16 and 55 times larger than the pre-excavation values, the Tptpll unit permeability at Niche 1620 differs by a factor of only 3.5. Possibly, these differences are related to the initially higher permeability in the Tptpll unit (before excavation), if this higher permeability is a result of initially larger fracture apertures. The effect of excavation-related fracture dilation should be relatively small if the undisturbed fracture apertures are already large (Wang and Elsworth 1999 [DIRS 104366]).

Note that the standard deviations in all niches are similar for the undisturbed and the disturbed conditions. Changing the mechanical stress field does not give rise to substantial changes in the small-scale variability. For the lower lithophysal unit, the variability as measured in Niche 1620 $\left(\sigma_{S}=1.31\right)$ is significantly larger than that obtained in borehole SYBT-ECRB-LA\#2 $\left(\sigma_{S}=0.21\right)$. This is mainly a result of the injection intervals of borehole SYBT-ECRB-LA\#2 being six times longer than those in Niche 1620. From statistical theory, the standard deviation for the 
six-times-shorter measurement interval in the borehole can be estimated to be on the order of $0.21 \times 6^{1 / 2}=0.51$, which is still smaller than the standard deviation obtained Niche 1620 .

As mentioned earlier, the small-scale variability of permeability $\sigma_{S}$ is explicitly accounted for in the predictive seepage models. Most of the SMPA simulations were conducted using a base case standard deviation of 1.0 (see Section 6.4.2.1). It was demonstrated that a considerable increase in standard deviation $\left(\sigma_{S}=2.0\right)$ produced seepage rates only slightly larger than in the base case (BSC 2004 [DIRS 167652], Section 6.6.2). Therefore, variation of $\sigma_{S}$ can be neglected for seepage abstraction. On the other hand, the mean permeability $\mu_{S}$ and its potential intermediate-scale variation within the repository units are very important for seepage and need to be provided to the TSPA. In the discussion below, these mean values of small-scale permeability will be simply referred to as permeability, to avoid confusion with the statistical parameters (mean $\mu$ and standard deviation $\sigma$ ) developed for the intermediate-scale variation of this rock property.

Supporting information on the impact of excavation on permeability distributions in the drift vicinity is available from rock-mechanical model simulations (see Section 6.4.4.1.1). Analyses of excavation-related permeability changes were performed using a fully coupled THM continuum model, which was calibrated to available niche and drift air permeability data conducted at ambient conditions (BSC (2004 [DIRS 169864]). In theory, the excavation-related permeability increase at the crown of a circular-shaped drift should be slightly smaller than in niches where the ceiling has a flatter, approximately elliptic shape. Thus, the disturbed-zone permeabilities for niches may need adjustments to represent permeabilities of the excavation-disturbed zone around circular-shaped emplacement drifts. Modeling results also suggest anisotropic behavior; the horizontal permeability increase at the crown can be significant, while the vertical increase at the crown is almost negligible. Considering a circular drift in the Tptpmn unit, the permeability at the drift crown is predicted to increase by a factor of up to 19 in the tangential and by a factor of 1.5 in the radial direction (BSC 2004 [DIRS 169864], Section 6.5.1, Figure 6.5.1-1). The permeability increase in the Tptpll unit is smaller, with a factor of up to 8 tangentially and about 1.3 radially (BSC 2004 [DIRS 169864], Section 6.6.1, Figure 6.6.1-1). These values compare reasonably well with the measured changes at the crown of the niches, where the permeability increase is between 16 and 55 in the middle nonlithophysal unit (with a geometric mean of 25 over the three niches) and 3.5 in the lower lithophysal unit.

It was pointed out earlier in this model report that the diversion of water around drifts mainly depends on the tangential fracture permeability in the boundary layer near the drift wall. Thus, the increased tangential permeability component at the drift crown needs to be accounted for in seepage models. However, the process models developed for drift seepage predictions, like the SMPA and the TH Seepage Model, do not consider anisotropy in permeability. Therefore, the increased tangential permeability component is used in these models as an isotropic value. That the radial permeability component in the excavation-disturbed zone is overestimated as a result of such simplification results in higher predicted seepage values. As explained in BSC (2004 [DIRS 167652], Section 6.3.2), a higher tangential permeability in conjunction with a smaller vertical permeability will facilitate the flow of water laterally around the drift and hence reduce seepage probability. Note that the tangential permeability, as predicted by the THM model, not 
only increases at the crown of the drift, but also at the springline (BSC 2004 [DIRS 169864], Sections 6.5.1 and 6.6.1).

Section 6.6.3.2 points out the difficulty of evaluating the intermediate-scale permeability variation caused by the small sample size of the measured data. Post-excavation permeability data are available at three locations in the Tptpmn unit and two locations in the Tptpll unit. To improve the sample size, information from additional permeability measurements is used for the definition of spatial variability distributions, most of these additional measurements representing undisturbed fractured rock (see Section 6.6.3.2.1). These measurements need to be adjusted for the impact of excavation, since the final parameter distributions for the seepage calculation in TSPA-LA uses the permeability measured in the disturbed-zone close to the excavated drifts. The adjustment needs to represent the average difference between undisturbed and disturbed conditions, as the spatial variability of the resulting disturbed-zone permeability values is accounted for in a separate evaluation in Section 6.6.3.2.1. Since measured and predicted permeability differences between undisturbed and disturbed conditions show reasonable agreement, there are two possible methods of adjusting permeability measurements in undisturbed rock for the impact of excavation: (1) using the measured differences between preand post-excavation air permeability data, or (2) using the predicted permeability changes from the THM model described in Section 6.4.4.1.1.

In this model report, the selected method for adjusting undisturbed permeabilities is the one that gives rise to the higher seepage rates, in order to account for uncertainties in both the measured and the simulated results. Uncertainties in the measured data result mainly from the small sample size that is available to compare pre- and post-excavation data (three niche locations in the Tptpmn unit, only one niche location in the Tptpll unit). The measured values may be biased from the small sample size and not fully representative for the average excavation response of the entire host rock unit. The predictive THM model may be more reliable in predicting the average behavior. However, since the impact of excavation on rock properties was only a secondary output of the THM study (time-dependent thermally induced property changes were the main focus), the model was primarily calibrated in comparison with data measured during the heating phase of the DST (Section 6.4.4.1.1). Since smaller permeability values generally lead to more seepage (at given percolation fluxes and capillary-strength values), the chosen method for adjusting the undisturbed permeabilities is the one that provides the smaller increase in permeability from pre- to post-excavation. For the Tptpmn unit, where the measured permeability increase is larger than the predicted, the THM model results are applied. Based on BSC (2004 [DIRS 167652], Section 6.3.2), a factor of 10 is chosen as a representative average for the tangential permeability changes in the seepage-relevant boundary layer along the crown, which is smaller than the maximum predicted increase of 19 directly at the drift crown. (As explained earlier, the impact of excavation alterations decreases with distance from the drift wall.) For the Tptpll unit, where the measured change is smaller than the predicted, the measured factor of 3.5 is chosen as appropriate.

\subsubsection{Spatial Variability}

The intermediate-scale variability of permeability refers to the variation of this parameterprovided as the mean $\mu_{S}$ of small-scale permeability measurements-within the repository rock units. From Table 6.6-3, the two main host rock units have significantly different permeability 
ranges, as measured in Niches 3107, 3650, and 4788 for the Tptpmn unit, and in Niche 1620 and borehole SYBT-ECRB-LA\#2 for the Tptpll unit. Thus, analyses of intermediate-scale variability need to be conducted separately for the two units, which makes the sample size for developing appropriate probability distributions rather small. For the Tptpmn unit, pre-excavation permeability values are available at four niche locations, covering a stretch of about 1,700-meter length along the ESF (see Figure 6.6-1). Post-excavation data are available at three niches. Less information is available in the lower lithophysal unit. Pre-excavation data are available at one test location only (Niche 1620); post-excavation measurements are available at two locations that are relatively close (Niche 1620 and borehole SYBT-ECRB-LA\#2). Since this sample size is not sufficient to derive defensible probability distributions, information from other sources is needed to better constrain the parameter distributions. The following paragraphs describe the treatment of spatial variability separately for the Tptpmn and the Tptpll units.

\subsection{Middle Nonlithophysal Unit}

Table 6.6-4 summarizes the intermediate-scale statistical parameters (mean $\mu$ and standard deviation $\sigma$ ) calculated from the four niches located in the Tptpmn unit (see Table 6.6-3). Though covering a large distance along the ESF, and despite the fact that the niche locations have been carefully selected to represent rock zones with different fracture intensity (Section 6.6.2.2), the variability $\sigma$ of mean permeability observed among the four (three ${ }^{1}$ ) test locations is very small. This is consistent for both undisturbed- and disturbed-zone data, with standard deviations of 0.23 and 0.25 (in log10), respectively. Because standard deviation is small, the standard error of the mean is also small, although the number of samples is limited. This would lead to relatively narrow probability distributions for spatial variability and uncertainty.

The question arises whether these statistical values accurately represent the permeability distribution over the entire host rock unit. Additional air permeability data need to be evaluated to confirm or, if needed, to adjust the parameter distributions given in Table 6.6-3. Measurements of air permeability in the Tptpmn unit have been conducted in four vertical surface-based boreholes (NRG-7a, NRG-6, SD-12, and UZ\#16) and in numerous boreholes drilled into the Single Heater Test (SHT) and DST rock block (Alcove 5). Note that the full name of borehole UZ\#16 is "UE-25 UZ\#16". Out of convenience, the short name UZ\#16 is used throughout this model report.

The locations of these air permeability measurements are illustrated in Figure 6.6-5. Boreholes NRG-6 and UZ\#16 are located at some distance from the ESF; thus, they cover rock areas that have not been represented by niche measurements. The injection intervals used for air permeability measurements in the vertical boreholes were fairly consistent between 3.5 meters and 4.6 meters (more than one order of magnitude larger than in the niches), while the injection intervals in the heater test areas varied widely from approximately 2 to 11 meters for the SHT, and 3 to 39 meters in the DST.

\footnotetext{
${ }^{1}$ Numbers in parenthesis indicate excavation-disturbed measurement locations.
} 
Table 6.6-4. Intermediate-Scale Variability Statistics (Mean $\mu$ and Standard Deviation $\sigma$ ) of Permeability over Repository Rock Block, for Pre- and Post-Excavation Data in the Tptpmn Unit, Based on Air permeability Measurements in Niches

\begin{tabular}{|c|c|c|c|c|}
\hline Parameter & $\begin{array}{c}\text { Number of } \\
\text { Samples }\end{array}$ & $\begin{array}{c}\text { Mean } \mu \\
\text { (in log } \mathbf{~}\left[\mathrm{m}^{2}\right] \text { ) }\end{array}$ & $\begin{array}{c}\text { Std. Dev. } \\
\sigma\end{array}$ & $\begin{array}{c}\text { Std. Error } \\
\text { of Mean SE }\end{array}$ \\
\hline $\begin{array}{c}\text { Pre-excavation Permeability } \\
\text { (undisturbed) }\end{array}$ & 4 & -13.2 & 0.23 & 0.12 \\
\hline $\begin{array}{c}\text { Post-excavation } \\
\text { Permeability } \\
\text { (disturbed) }\end{array}$ & 3 & -11.9 & 0.25 & 0.14 \\
\hline
\end{tabular}

Output DTN: LB0407AMRU0120.001

NOTE: Computations documented in Appendix C.

Figure 6.6-6 compares the mean values (in log10 space) of data from the pre-excavation niche measurements (from Table 6.6-1), the surface-based boreholes, and the SHT/DST area, separately for each location (BSC 2004 [DIRS 170038], Section 6.1.1.1). The ranges of data, calculated as mean plus/minus one standard deviation, overlap, but generally the means of the small-scale niche data are lower than the other values. This is expected because the mean effective permeability increases as the scale of measurements increases (Neuman 1994 [DIRS 105731]). (Also, the observed range of data is larger for the niche measurements. This again is expected from scaling effects, because a larger measurement scale tends to neglect the impact of small-scale variability.) Thus, direct comparison of the mean permeability data observed at the niches with data from surface-based boreholes (or from the heater test block) is not appropriate; statistical analyses have to be conducted over locations with similar measurement scale. However, it can be beneficial to apply adequate scaling laws to adjust the mean permeability values obtained with different interval lengths. Also, the variability of mean permeability between surface boreholes should be similar to the variability of mean permeability between the niche locations. 


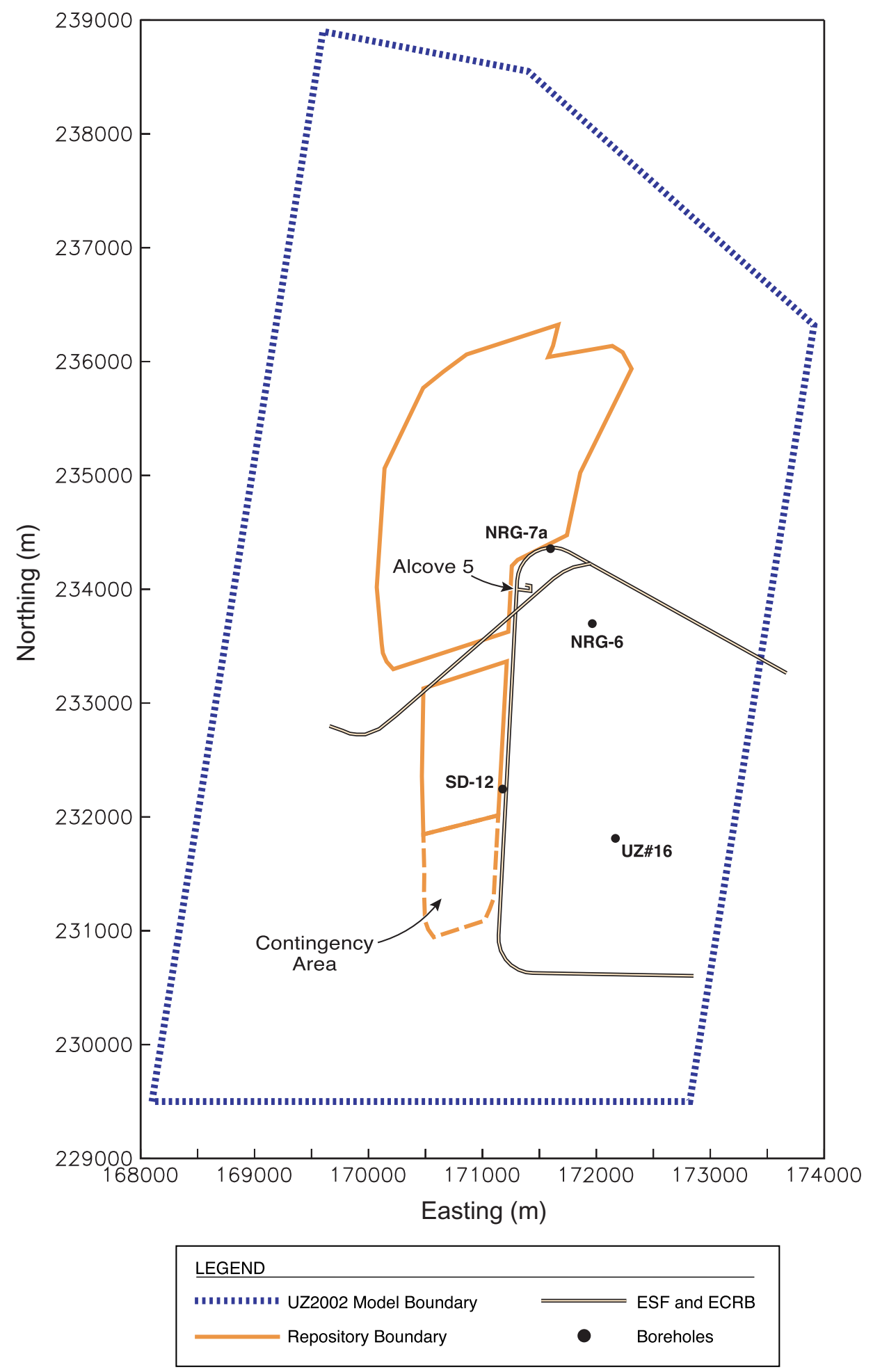

Source: Revised from BSC (2004 [DIRS 169855], Figure 6-1).

Figure 6.6-5. Map Showing Approximate Location of Surface-Based Boreholes NRG-7a, NRG-6, SD-12, and UZ\#16 and SHT/DST Heater Test Area (Alcove 5), together with the 2002 Repository Layout 


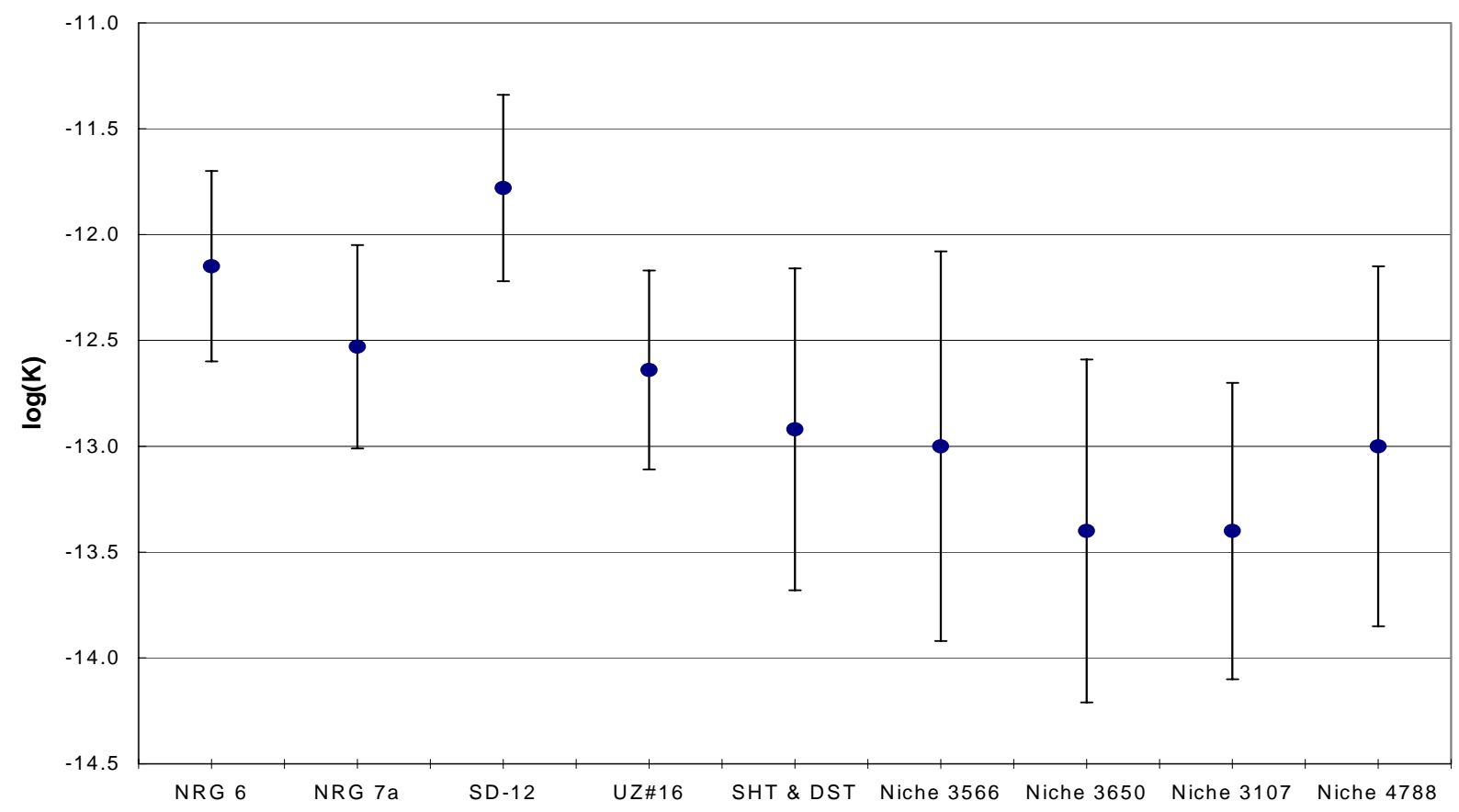

Source: BSC (2004 [DIRS 170038], Figure 6-2).

NOTE: $\quad$ Circles are the geometric means. Bars indicate mean plus/minus one standard deviation. Permeability values in $\log 10$ of unit $\mathrm{m}^{2}$.

Figure 6.6-6. Mean Fracture Permeabilities for Different Locations in the Tptpmn Unit

A more detailed analysis of intermediate-scale variation of permeability among the four vertical boreholes is presented in Table 6.6-5. Between 7 and 19 vertical intervals have been tested in the Tptpmn unit in each of these boreholes. The resulting air permeability data for each test interval are provided in DTN: GS960908312232.013 [DIRS 105574]. From these data, the mean permeability $\mu_{\text {sur }}$ was calculated for each location. In a second step, the statistics of the variation of this parameter over the repository unit were derived. Data from the SHT/DST heater test block have not been considered in this analysis, mainly because of the large, inconsistent measurement scale. Also, some of the tested boreholes in the heater test block are in close proximity to the alcoves or drifts, and thus they may not represent undisturbed rock. As shown in Table 6.6-5, the average of the mean log-permeability values at the four vertical boreholes is -12.2, which is one order of magnitude higher than the intermediate-scale mean $\mu$ estimated from the niche data. The standard deviation is 0.34 , about 50 percent larger than from the undisturbed niche data. It appears that the variability inferred from the niche experiments is on the low side when compared with additional information from vertical boreholes. To define a cautiously realistic variability for TSPA-LA, the larger $\sigma$ of 0.34 should be used. It will be discussed below whether the one-order-of-magnitude difference in the mean values can be fully explained by scale effects. (Note that there are minor differences in the mean permeabilities of boreholes NRG7a and UZ\#16 between Figure 6.6-6 and Table 6.6-5. These differences stem from a slightly different averaging procedure. For the analysis in Table 6.6-5, air-injection intervals that intersect two geological units have been assigned to both units.) 
Table 6.6-5. Mean Permeabilities of Undisturbed Rock from Tptpmn Unit Measured in Surface-Based Boreholes and Intermediate-Scale Variability Statistics over the Repository Rock Block

\begin{tabular}{|c|c|c|c|c|}
\hline Location & $\begin{array}{l}\text { Number of } \\
\text { Intervals }\end{array}$ & $\begin{array}{c}\text { Mean } \mu_{\text {sur }} \\
\left.\text { (in log }\left[\mathrm{m}^{2}\right]\right)\end{array}$ & $\begin{array}{c}\text { Interval } \\
\text { Length (m) }\end{array}$ & \\
\hline NRG-6 & 7 & -12.2 & $4.3^{1}$ & \\
\hline NRG-7a & 8 & -12.5 & 3.5 & \\
\hline SD-12 & 7 & -11.8 & 4.6 & \\
\hline UZ\#16 & 19 & -12.5 & 4 & \\
\hline $\begin{array}{l}\text { Statistics over All Four } \\
\text { Locations }\end{array}$ & $\begin{array}{l}\text { Number of } \\
\text { Locations }\end{array}$ & $\begin{array}{c}\text { Mean } \mu \\
\left.\text { (in } \log k\left[m^{2}\right]\right)\end{array}$ & Std. Dev. $\sigma$ & $\begin{array}{c}\text { Std. } \\
\text { Error of } \\
\text { Mean SE }\end{array}$ \\
\hline Tptpmn & 4 & -12.2 & 0.34 & 0.17 \\
\hline
\end{tabular}

Output DTN: LB0407AMRU0120.001

NOTE: Computations documented in Appendix C.

${ }^{1}$ One interval length is $11.3 \mathrm{~m}$ in NRG-6. All others are $4.3 \mathrm{~m}$.

While many theoretical upscaling approaches are available in the literature, an upscaling method for highly heterogeneous porous media is described by the following expression (Paleologos et al. 1996 [DIRS 105736], p. 1336, Equation 26):

$$
k_{e f f}=k_{S} \exp \left[\sigma_{S}\left(\ln k_{S}\right)^{2}(1 / 2-D)\right]
$$

where $k_{\text {eff }}$ is the effective permeability at a larger scale $L$ (about 3.5 to 4.6 meter scale), $k_{S}$ is the geometric mean of the small-scale permeability (about 1-foot scale), $\sigma_{S}\left(\ln k_{S}\right.$ ) is the standard deviation of the natural log-transformed small-scale permeability, and $D$ is a function of the spatial dimensions and the correlation scale. The exponential expression in Equation 1 is always larger than or equal to 1, indicating that the upscaled effective permeability is always larger than or equal to the small-scale geometric mean. Using an approximate value of 1 meter for the correlation scale $\lambda$ of permeability in the niches, estimated from BSC (2004 [DIRS 171764], Table 6-7), and with $L$ in the range between 3.5 and $4.6 \mathrm{~m}$, the domain integral $D$ can be evaluated from Figure 2 in Paleologos et al. (1996 [DIRS 105736]) as approximately 0.3. (Note: $2 \rho=2 L / \lambda$ as defined in Paleologos et al. (1996 [DIRS 105736], p. 1335) becomes 7 for $L=3.5$ and $\lambda=1)$. In this case, Equation 1 becomes

$$
\log \left(k_{e f f}\right)=\log \left(k_{S}\right)+0.46 \sigma_{S}^{2}
$$

where $\sigma_{S}$ is the standard deviation of the log-transformed small-scale permeability, as given in Table 6.6-3. Note that the logarithm of the geometric mean of a sample is equal to the arithmetic mean of the log-transformed data. This relationship can be used to derive the expected value of

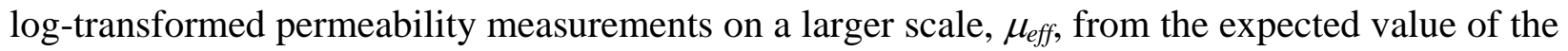
small-scale measurements, $\mu_{S}$, given in Table 6.6-3. The resulting equation is given as:

$$
\mu_{e f f}=\mu_{S}+0.46 \sigma_{S}^{2}
$$


If the differences between the niche measurements and the data from surface-based boreholes are merely a result of scale effects, these values for $\mu_{\text {eff }}$ should be consistent with the permeability values $\mu_{\text {sur }}$ from the surface-based boreholes.

Another approach for upscaling is to directly use the 1-foot permeability measurements of the niches. Estimates of effective permeabilities on a larger scale can be derived by calculating the arithmetic mean of these 1-foot values (not log-transformed) over appropriately long sections of the boreholes. It is presumed in this approach that the 1-foot data represent the exact spatial variability along the borehole, and that this exact variability is being measured using packed-off intervals of a larger interval length. It can be shown that the measured permeability over this larger interval would be the arithmetic mean of the 1-foot values within the interval. Since the arithmetic mean of heterogeneous data gives more weight to large values, the resulting effective permeability is higher than the geometric mean of the 1-foot data. The proposed upscaling approach was conducted for the four niches 3107, 3566, 3650, and 4788, using the permeability data given in the following DTNs: LB980901233124.101 [DIRS 136593] and LB0011AIRKTEST.001 [DIRS 153155]. A 3.6-meter interval length was chosen, comprising twelve 1-foot intervals. The available sample of undisturbed small-scale permeability at each niche location was divided into groups of twelve subsequent 1-foot measurements; i.e., one group represents the length covered by a 3.6-meter measurement interval. The arithmetic mean of permeability was calculated for each group. Then the means were log-transformed, and the mean of all groups belonging to one niche location was derived. The final result is the mean effective permeability $\mu_{e f f}$ measured at a 3.6-meter interval length, which can be compared with the mean of the small-scale measurements.

Table 6.6-6 summarizes results for both upscaling methods outlined above, giving the predicted increase of permeability as a result of scale effects, and listing the adjusted upscaled permeability values for measurements conducted on a 3.6-meter scale. While both methods are consistent in their trends, there are differences in magnitude. The average permeability increase as predicted by Equation 2 is 0.3 (in log10), while the average increase estimated from the arithmetic mean data analysis is 0.6 (in log10). Much of this larger increase, however, is provided by data from Niche 3566, where the fewest small-scale measurements are available. If data from Niche 3566 were disregarded, the respective average increases would be approximately 0.3 and 0.4 for the two approaches (in $\log 10$ ). 
Table 6.6-6. Upscaling Factors for Air Permeabilities in the Tptpmn Unit Derived Using Two Different Upscaling Approaches

\begin{tabular}{|c|c|c|c|c|c|c|}
\hline \multirow{3}{*}{$\begin{array}{c}\text { Location } \\
\text { Niche } 3107\end{array}$} & \multicolumn{2}{|c|}{ Small-Scale Measurements } & \multicolumn{4}{|c|}{ Upscaling Factor and Adjusted Mean $\mu_{\text {eff }}$} \\
\hline & \multirow{2}{*}{$\begin{array}{c}\begin{array}{c}\text { Mean } \mu_{\mathrm{s}} \\
\text { (in } \log \mathrm{k})\end{array} \\
-13.4^{1} \\
\end{array}$} & \multirow{2}{*}{$\begin{array}{c}\text { Std. Dev. } \\
\sigma_{S} \\
0.70^{1}\end{array}$} & \multicolumn{2}{|c|}{$\begin{array}{l}\text { Using Eq. (3) } \\
\text { (in log } \mathrm{k}\left[\mathrm{m}^{2}\right] \text { ) }\end{array}$} & \multicolumn{2}{|c|}{$\begin{array}{l}\text { Using Data Analysis } \\
\left.\text { (in } \log \mathrm{k}\left[\mathrm{m}^{2}\right]\right)\end{array}$} \\
\hline & & & 0.2 & -13.2 & 0.4 & -13.0 \\
\hline Niche 3566 & $-13.0^{1}$ & $0.92^{1}$ & 0.4 & -12.6 & 1.0 & -12.0 \\
\hline Niche 3650 & $-13.4^{1}$ & $0.81^{1}$ & 0.3 & -13.1 & 0.4 & -13.0 \\
\hline Niche 4788 & $-13.0^{1}$ & $0.85^{1}$ & 0.3 & -12.7 & 0.5 & -12.5 \\
\hline Mean All Niches & $-13.2^{2}$ & - & 0.3 & -12.9 & 0.6 & -12.6 \\
\hline
\end{tabular}

Output DTN: LB0407AMRU0120.001

NOTE: $\quad$ Computations documented in Appendix C.

1 Data from Table 6.6-3 (undisturbed)

2 Data from Table 6.6-4 (undisturbed)

The estimated scaling factors are significantly smaller than the one-order-of-magnitude difference between the mean permeability of the four niches $\left(-13.2 \mathrm{in} \log 10\left[\mathrm{~m}^{2}\right]\right)$ and the mean permeability from the four surface-based boreholes $\left(-12.2 \mathrm{in} \log 10\left[\mathrm{~m}^{2}\right]\right)$. Or, in other words, the effective permeability values $\mu_{\text {eff }}$ derived from upscaling the small-scale measurements are much smaller than the permeability values measured in surface-based boreholes. Thus, even though scale effects are considered to make both measurement scales comparable, the remaining difference is still half an order of magnitude. This may suggest that the four niche locations have relatively low permeability, compared to the average permeability of the Tptpmn unit, and that the scale-corrected data from surface-based boreholes could be used to adjust the mean of the niches to higher values for TSPA-LA, which would generally reduce seepage. On the other hand, one should keep in mind in this abstraction process that the four niche measurements represent the more reliable data source for the purpose of seepage modeling: they represent the scale of interest. The surface-based data, on the other hand, should be handled with care because of uncertainties related to the upscaling analysis. Therefore, the seepage abstraction model does not incorporate this possible adjustment of the niche permeabilities to larger values. The additional information available from the surface-based boreholes is used as corroborative evidence demonstrating that the niche data provide reasonably bounding parameter estimates for mean permeability in the Tptpmn unit.

Based on the discussion above, the parameter distributions for permeability variation within the middle nonlithophysal unit in TSPA-LA are defined as follows: The intermediate-scale mean log-permeability of the undisturbed measurements is -13.2 in $\log 10\left[\mathrm{~m}^{2}\right]$, derived from the mean over four niche locations (Table 6.6-4). Cautiously realistic, the intermediate-scale variability is described by a standard deviation of 0.34 , derived from the four surface-based borehole locations (Table 6.6-5). This standard deviation is larger than the one calculated from the niches (see Table 6.6-4). The permeability increase as a result of excavation is accounted for by increasing the mean permeability by one order of magnitude. This is consistent with modeling predictions, but smaller than the measured effect of excavation (see Section 6.6.3.1). The final probability distribution is given by a mean of $\mu=-12.2$ (in $\log 10\left[\mathrm{~m}^{2}\right]$ ) and a standard deviation of $\sigma=0.34$ (log-normal distribution); the 95 percent confidence interval of this distribution ranges 
approximately from -12.9 to -11.5 (in $\log 10\left[\mathrm{~m}^{2}\right]$ ). Uncertainty related to this distribution is discussed in Section 6.6.3.3.

\subsection{Lower Lithophysal Unit}

Table 6.6-7 summarizes statistical parameters for intermediate-scale variability within the Tptpll unit, based on the small-scale measurements conducted in Niche 1620 and borehole SYBT-ECRB-LA\#2 (see Table 6.6-3). It is recognized that the supporting sample size is very small: There is only one location where pre-excavation data have been measured (Niche 1620). Two locations are available for post-excavation data (Niche 1620 and borehole SYBT-ECRB-LA\#2, see Table 6.6-3), though the relatively close proximity limits the value of these data. Hence, the small standard deviation of 0.16 measured for the disturbed-zone permeabilities, relating to a small 95 percent confidence interval that covers about half an order of magnitude, is arguably not representative for the variability of Tptpll unit permeability values over the repository block. Additional air permeability data are therefore evaluated.

Table 6.6-7. Intermediate-Scale Variability Statistics (Mean $\mu$ and Standard Deviation $\sigma$ ) of Permeability over the Repository Rock Block, for Pre- and Post-Excavation Data in the Tptpll Unit, Based on Air Permeability Measurements in Niche 1620 and in ECRB

\begin{tabular}{|c|c|c|c|c|}
\hline Parameter & $\begin{array}{c}\text { Number of } \\
\text { Samples }\end{array}$ & $\begin{array}{c}\text { Mean } \mu \\
\text { (in log } \mathbf{~}\left[\mathbf{m}^{2}\right] \text { ) }\end{array}$ & Std. Dev. $\sigma$ & $\begin{array}{c}\text { Std. Error } \\
\text { of Mean SE }\end{array}$ \\
\hline $\begin{array}{c}\text { Pre-excavation Permeability } \\
\text { (undisturbed) }\end{array}$ & 1 & -11.5 & - & - \\
\hline $\begin{array}{c}\text { Post-excavation } \\
\text { Permeability } \\
\text { (disturbed) }\end{array}$ & 2 & -10.8 & 0.16 & 0.11 \\
\hline
\end{tabular}

Output DTN: LB0407AMRU0120.001

NOTE: $\quad$ Computations documented in Appendix C.

Surface-based boreholes NRG-7a and UZ\#16 offer undisturbed air permeability values for the Tptpll unit measured over interval lengths of 3.5 and $4 \mathrm{~m}$, respectively (see Figure 6.6-5 for the location of these boreholes). The measured data are given in DTN: GS960908312232.013 [DIRS 105574]. No measurements in the Tptpll unit are available at boreholes NRG-6 and SD-12, which leaves only two permeability values for analysis. In contrast, the upper lithophysal unit (Tptpul unit) has been tested at four locations, i.e., at NRG-7a, NRG-6, SD-12, and UZ\#16. While recognizing that there are differences in the small-scale fracturing and in the lithophysal characteristics, the analysis of the Tptpul unit has some value in providing additional information on the spatial variability of permeability in the lithophysal units. As pointed out in Section 6.6.1.3, the Tptpul unit has fracture statistics similar to the Tptpll unit for all fractures with trace lengths greater than $1 \mathrm{~m}$.

Table 6.6-8 below provides the calculated mean permeability $\mu_{\text {sur }}$ at each of the above listed borehole locations in the Tptpll and the Tptpul units, and gives summary statistics of the variation of this parameter within the repository. Note that despite the differences in small-scale fractures, both units have consistent mean permeability values. The measured permeability values at available locations are identical (NRG-7a) or differ by only 0.1 in log space (UZ\#16). Over all locations, the intermediate-scale mean $\mu$ is -12.1 (in $\log 10\left[\mathrm{~m}^{2}\right]$ ) in the Tptpll unit versus 
-11.8 (in $\log 10\left[\mathrm{~m}^{2}\right]$ ) in the Tptpul unit. Standard deviations are 0.58 versus 0.47 , respectively. The Tptpul unit values are considered the more reliable estimates for the lithophysal units (because the statistical analysis is based on a sample size of four) and shall be used below.

Comparison between the summary statistics over the surface-based boreholes, given in Table 6.6-8, and the Niche 1620/borehole SYBT-ECRB-LA\#2 data, given in Table 6.6-7, indicates significant differences. It appears that the standard deviation estimated from the smallscale measurements $(\sigma=0.16)$ is not representative of the intermediate-scale spatial variability within the Tptpll unit. Therefore, the larger value of 0.47 derived from surface-based boreholes (while using the Tptpul unit value as explained above) is recommended for use in the TSPA-LA.

Table 6.6-8. Mean Permeabilities of Undisturbed Rock from Tptpll and Tptpul Units Measured in Vertical Boreholes and Intermediate-Scale Variability Statistics over Repository Rock Block

\begin{tabular}{|c|c|c|c|c|c|c|}
\hline \multirow[b]{2}{*}{ Location } & \multicolumn{3}{|c|}{ Lower Lithophysal Unit (Tptpll Unit) } & \multicolumn{3}{|c|}{ Upper Lithophysal Unit (Tptpul Unit) } \\
\hline & $\begin{array}{l}\text { Number of } \\
\text { Intervals }\end{array}$ & $\begin{array}{c}\text { Mean } \mu_{\text {sur }} \\
\left(\text { in } \log k\left[\mathrm{~m}^{2}\right]\right)\end{array}$ & $\begin{array}{c}\text { Interval } \\
\text { Length (m) }\end{array}$ & $\begin{array}{l}\text { Number of } \\
\text { Intervals }\end{array}$ & $\begin{array}{c}\text { Mean } \mu_{\text {sur }} \\
\left(\text { in } \log k\left[\mathrm{~m}^{2}\right]\right)\end{array}$ & $\begin{array}{c}\text { Interval } \\
\text { Length (m) }\end{array}$ \\
\hline NRG- 6 & - & - & - & 5 & -11.7 & $4.3^{1}$ \\
\hline NRG-7a & 16 & -12.5 & 3.5 & 10 & -12.5 & 3.5 \\
\hline SD-12 & - & - & - & 6 & -11.4 & 4.6 \\
\hline UZ\#16 & 18 & -11.7 & 4 & 5 & -11.8 & 4 \\
\hline $\begin{array}{c}\text { Statistics over all } \\
\text { Locations }\end{array}$ & $\begin{array}{l}\text { Number of } \\
\text { Locations }\end{array}$ & $\begin{array}{c}\text { Mean } \mu \\
\left(\text { in } \log k\left[\mathrm{~m}^{2}\right]\right)\end{array}$ & $\begin{array}{c}\text { Std. Dev. } \\
\sigma\end{array}$ & $\begin{array}{l}\text { Std. Error } \\
\text { of Mean } \\
\text { SE }\end{array}$ & & \\
\hline Tptpll & 2 & -12.1 & 0.58 & 0.41 & & \\
\hline Tptpul & 4 & -11.8 & 0.47 & 0.23 & & \\
\hline
\end{tabular}

Output DTN: LB0407AMRU0120.001

NOTE: Computations documented in Appendix C.

${ }^{1}$ Two interval lengths are $11.3 \mathrm{~m}$ in NRG-6. All others are $4.3 \mathrm{~m}$.

As for the mean permeability, scaling effects need to be accounted for to make the different estimates from surface-based boreholes and from small-scale niche experiments comparable. Using the same two upscaling approaches as for the middle nonlithophysal unit, the upscaling factors for Niche 1620 are 0.6 from Equation 2 and 0.7 from the arithmetic-mean data analysis (Table 6.6-9). One can use these upscaling factors to adjust the mean permeability from the surface-based borehole data, making them representative of 1 -foot-interval measurements. With an upscaling factor of 0.7 from the arithmetic data analysis and using the more reliable Tptpul unit permeability value of $\mu_{\text {sur }}=-11.8$ in $\log 10\left[\mathrm{~m}^{2}\right]$ (Table 6.6-8), the resulting scale-adjusted mean permeability for the surface-based borehole data is $-12.5 \mathrm{in} \log 10\left[\mathrm{~m}^{2}\right]$. This permeability value is one order of magnitude smaller than the mean pre-excavation permeability of $\mu=-11.5$ (in $\log 10\left[\mathrm{~m}^{2}\right]$ ) from the small-scale niche measurements (Table 6.6-7). Quite possibly, Niche 1620 is located in a fairly permeable section of the lower lithophysal unit and may not be representative for other areas in the repository. For the purpose of seepage abstraction, the permeability value measured in Niche 1620 should be adjusted to smaller values to account for the possible existence of less permeable regions in the repository. It is therefore proposed to use adjusted permeability distributions for the Tptpll unit with a decreased mean permeability of 
-12.0 (in $\log 10\left[\mathrm{~m}^{2}\right]$ ), which is derived from simply averaging the respective values from the niche tests $\left(-11.5\right.$ in $\left.\log 10\left[\mathrm{~m}^{2}\right]\right)$ and the scale-adjusted surface-based data $\left(-12.5 \mathrm{in} \log 10\left[\mathrm{~m}^{2}\right]\right)$. This shift in the parameter distribution provides a reasonable bounding estimate for seepage, because smaller permeabilities generally lead to more seepage. One should keep in mind in this abstraction process that the measurements in Niche 1620 represent the more reliable data source for the purpose of seepage modeling: they represent the scale of interest. The surface-based data, on the other hand, should be handled with care because of uncertainties related to the upscaling analysis. In light of this, a permeability decrease by half an order of magnitude is a cautious, yet realistic parameter choice for the Tptpll unit.

Based on the above discussion, the parameter distributions for permeability variation within the lower lithophysal unit in TSPA-LA are defined as follows: The intermediate-scale mean log-permeability of the undisturbed measurements is -12.0 in $\log 10\left[\mathrm{~m}^{2}\right]$, derived from the averaging the scale-adjusted mean of surface-based boreholes with the mean permeability from the niche measurements. Cautiously realistic, the intermediate-scale variability can be described by a standard deviation of 0.47 , derived from the four surface-based borehole locations. This standard deviation is significantly larger than the one calculated from the niche/systematic testing data. The permeability increase as a result of excavation is accounted for by adjusting the mean permeability by a factor of 3.5 (Table 6.6-3). This is consistent with the measured effect of excavation, but less than predicted from the THM modeling studies (see Section 6.6.3.1). The final probability distribution for the Tptpll unit is given by a mean of $\mu=-11.5$ (in $\log 10\left[\mathrm{~m}^{2}\right]$ ) and a standard deviation of $\sigma=0.47$ (log-normal distribution); the 95 percent confidence interval of this distribution ranges approximately from -12.4 to -10.6 (in $\log 10\left[\mathrm{~m}^{2}\right]$ ). Compared to the middle nonlithophysal unit, the resulting distribution of disturbed-zone permeability in the Tptpll unit has a larger mean and a larger standard deviation. Uncertainty related to this distribution is discussed in Section 6.6.3.3.

Table 6.6-9. Upscaling Factors for Air permeability Measurements in the Tptpll Unit Derived Using Two Different Upscaling Approaches

\begin{tabular}{|c|c|c|c|c|c|c|}
\hline \multirow{3}{*}{$\begin{array}{l}\text { Location } \\
\text { Niche } 1620\end{array}$} & \multicolumn{2}{|c|}{ Small-Scale Measurements } & \multicolumn{4}{|c|}{ Upscaling Factor and Adjusted Mean $\mu_{\text {eff }}$} \\
\hline & $\begin{array}{l}\text { Mean } \mu_{S f} \\
(\text { in log } k)\end{array}$ & $\begin{array}{c}\text { Std. Dev. } \\
\sigma_{S}\end{array}$ & & & $\begin{array}{r}\text { Usin } \\
\text { (i }\end{array}$ & $\begin{array}{l}\text { alysis } \\
{ }^{2} \text { ]) }\end{array}$ \\
\hline & $-11.5^{1}$ & $1.12^{1}$ & 0.6 & -10.9 & 0.7 & -10.8 \\
\hline
\end{tabular}

Output DTN: LB0407AMRU0120.001

NOTE: Computations documented in Appendix C.

${ }^{1}$ Data from Table 6.6-3

\subsubsection{Uncertainty}

The different sources of uncertainty related to the intermediate-scale, disturbed-zone fracture permeability distribution are as follows:

\section{Measurement Uncertainty:}

Air-injection testing is the main method of estimating fracture permeability in the Yucca Mountain UZ. The measurement methodology for the niche test data-isolating borehole sections using an inflatable packer system, injecting compressed air, and monitoring the 
pressure response-is described in detail in Appendix A of BSC (2004 [DIRS 170004]). The flow rate of air is controlled by four different sizes of mass flow controllers from 1 to 500 standard liters per minute, ensuring that the anticipated flow rates can be prescribed with sufficient accuracy (BSC 2004 [DIRS 170004], Appendix A). Instrumentation error of the pressure sensors is about $300 \mathrm{~Pa}$ and thus negligible (BSC 2004 [DIRS 170004], Appendix A). Short circuiting of gas flow between adjacent boreholes (or borehole intervals), a potential error source of measurements conducted in the SHT (BSC 2004 [DIRS 169900], Section 6.2.2.4.2) is of no concern in the niche tests because all boreholes in one niche location are packed-off with multiple packer strings at one time. Some uncertainty arises because most of the permeability measurements have been conducted in niches excavated with alpine miner/roadheader techniques, while the repository drifts will be excavated with tunnel boring machines. Different machine excavation techniques may induce different degrees of local fracturing at the drift wall, which affects the local permeability. Though the impact of these differences is small (see discussion in Section 6.6.3), this type of measurement uncertainty is included in and propagated through the seepage abstraction model.

\section{Conceptual Model Uncertainty:}

The measured pressure response from the injection tests is converted into air permeability values using the modified Hvorslev's formula (LeCain 1995 [DIRS 101700], p. 10, Equation 15), derived for a steady-state ellipsoidal flow field around a finite line source. For post-excavation tests, where the niche opening acts as a constant pressure boundary, a cylindrical solution is adopted with an ambient constant pressure boundary at the external radius (BSC 2004 [DIRS 170004], Section 6.1.2.1). While the formulas used are based on a simplified geometric configuration, the derived permeability values are expected to adequately represent the fracture continuum permeability of the medium. Also, due to the consistency of the conceptual models for seepage calibration (SCM) and seepage prediction (SMPA), a possible bias in estimated air permeabilities would be removed from the predictive results because the calibrated capillary-strength parameter implicitly accounts for the impact of this bias. A final contribution to conceptual model uncertainty of fracture permeability may stem from the THM results used to constrain the choice of post-excavation parameters. However, the model results are compared (validated) with pre- and post-excavation measurements in the niches that give direct evidence of excavation effects. For abstraction, the smaller ones of the resulting disturbed-zone permeability values are used to acknowledge the remaining uncertainty (smaller permeability generally leads to more seepage).

\section{Estimation Uncertainty:}

There is no estimation uncertainty for permeability because the proposed parameter distributions covering intermediate-scale permeability differences, described by a log-normal distribution with mean $\mu$ and standard deviation $\sigma$, are directly based on the permeability data from air-injection testing. Estimation uncertainty would only arise if the parameter of interest was estimated from a random process (e.g., from a Monte-Carlo analysis). Note that the impact of random variations of small-scale heterogeneity is directly evaluated in the seepage models by using several realizations of random fields (Sections 6.4.1 through 6.4.3). 


\section{Spatial Variability Uncertainty:}

The main uncertainty source for permeability is related to the spatial variability assumed for this parameter, stemming from the limited number of data points available to derive the distribution parameters. Four (three ${ }^{1}$ ) niche locations are available in Tptpmn unit, compared to only one (two ${ }^{1}$ ) location(s) in the Tptpll unit. Therefore, additional information was used to better define appropriate probability distributions. For this purpose, data from surface-based boreholes were analyzed, adjusted to account for scale effects stemming from the longer measurement interval, and then compared to the niche data. In the case of the Tptpll unit, where the surface-based data indicated that the niche measurements might represent a rather permeable section, the mean permeability was adjusted to smaller values (which gives rise to more seepage). For standard deviation $\sigma$, the larger value was chosen, to make sure that the potential variability of permeability is adequately covered. While the use of additional permeability data and the choice of bounding parameters have provided confidence in the developed parameter distributions, the spatial variability uncertainty is still considered significant because of the limited number of data points. This uncertainty is included in and propagated through the abstraction, using appropriate probability distribution functions.

Similar to Section 6.6.2, uncertainty in the parameter of interest is quantitatively accounted for by varying the mean of the chosen probability distribution for spatial variability within appropriate ranges; i.e., by shifting the log-normal distribution for spatial variability to smaller or larger permeability values. Definition of these "appropriate ranges" is necessarily subjective, since it is based on scientific judgment. As pointed out above, the main contribution to uncertainty stems from the limited sample size constraining the spatial variability distribution. The method of choice in this abstraction is to apply a triangular uncertainty distribution with upper/lower bounds defined by plus or minus four standard errors. This adds a significant amount of additional parameter variability, believed to cover the uncertainty of the permeability estimates. As pointed out before, the standard error describes the potential uncertainty in the estimated mean of a sample of given size. A range of plus or minus two standard errors covers roughly the 95 percent confidence interval for the estimated mean. Thus, the defined range of the triangular distribution comprises sufficient uncertainty on account of the mean permeability and includes another two SE covering other sources of uncertainty (such as measurement uncertainty). In light of the supporting information used to corroborate niche data, and considering the bounding-case choices made in defining the spatial variability distributions, this uncertainty range can be considered cautious, yet realistic. Note the difference between the uncertainty range chosen for permeability (4 SE) and the uncertainty range chosen for the capillary-strength parameter in Section 6.6.2.3 (3 SE). The difference accounts for our assessment that the spatial variability distributions for permeability are more uncertain than the ones for capillary strength, because of (a) the smaller sample size for permeability values, and (b) the fact that $1 / \alpha$ is an effective calibrated parameter that may be less dependent on rock type variability.

\footnotetext{
${ }^{1}$ Numbers in parenthesis indicate excavation-disturbed measurement locations.
} 
A schematic of the spatial variability and uncertainty model for permeability in the middle nonlithophysal unit is given in Figure 6.6-7. The heavy blue line shows the triangular-shaped uncertainty distribution, assigning a probability to the mean of the normal-shaped spatial variability distribution. The most likely spatial variability distribution is the one defined in Section 6.6.3.2, with a probability of 1.47 corresponding to the peak value of the triangular distribution. This spatial variability distribution has a mean of -12.2 in $\log 10\left[\mathrm{~m}^{2}\right]$. The triangular distribution for shifting this mean has a range of about \pm 0.68 (using the standard error of 0.17 as given in Table 6.6-5). Thus, least likely are the two bounding cases with a mean of -12.9 in $\log 10\left[\mathrm{~m}^{2}\right]$ (minimum) and -11.5 in $\log 10\left[\mathrm{~m}^{2}\right]$ (maximum), respectively, where the triangular distribution indicates a zero probability. These two bounding probability distributions are generated by adding/subtracting four standard errors $(4 \mathrm{SE}=0.68)$ to the most likely distribution. Together, in consideration of spatial variability and uncertainty, the range of Tptpmn unit permeabilities to be used in TSPA-LA is quite large; using the approximate 95 percent confidence intervals of the minimum and the maximum spatial variability distribution as an estimate, this range extends from -13.6 to -10.8 in $\log 10\left[\mathrm{~m}^{2}\right]$ (almost three orders of magnitude, from about $4.0 \times 10^{-13} \mathrm{~m}^{2}$ to about $1.6 \times 10^{-11} \mathrm{~m}^{2}$ ).

The respective probability distributions for the lower lithophysal unit are illustrated in Figure 6.6-8. As a result of the larger standard deviation, both the spatial variability distribution and the uncertainty distribution are wider compared to the Tptpmn unit. The triangular distribution of uncertainty covers a range of about \pm 0.92 (using the standard error of 0.23 as given in Table 6.6-8). This shifts the mean of the spatial variability distribution (most likely value at $-11.5 \mathrm{in} \log 10\left[\mathrm{~m}^{2}\right]$ ) to bounding values of -12.4 in $\log 10\left[\mathrm{~m}^{2}\right]$ (minimum) and -10.6 in $\log 10\left[\mathrm{~m}^{2}\right]$ (maximum). The approximate 95 percent confidence interval of the possible spatial variability distributions ranges from -13.3 to -9.7 (almost four orders of magnitude; from about $5.0 \times 10^{-14} \mathrm{~m}^{2}$ to about $2.0 \times 10^{-10} \mathrm{~m}^{2}$ ). This range is significantly larger than the narrow distribution employed during validation of the Seepage Calibration Model (BSC 2004 [DIRS 171764], Section 7.2.2.1), which was based on a standard deviation for $\log (k)$ of 0.1 . 


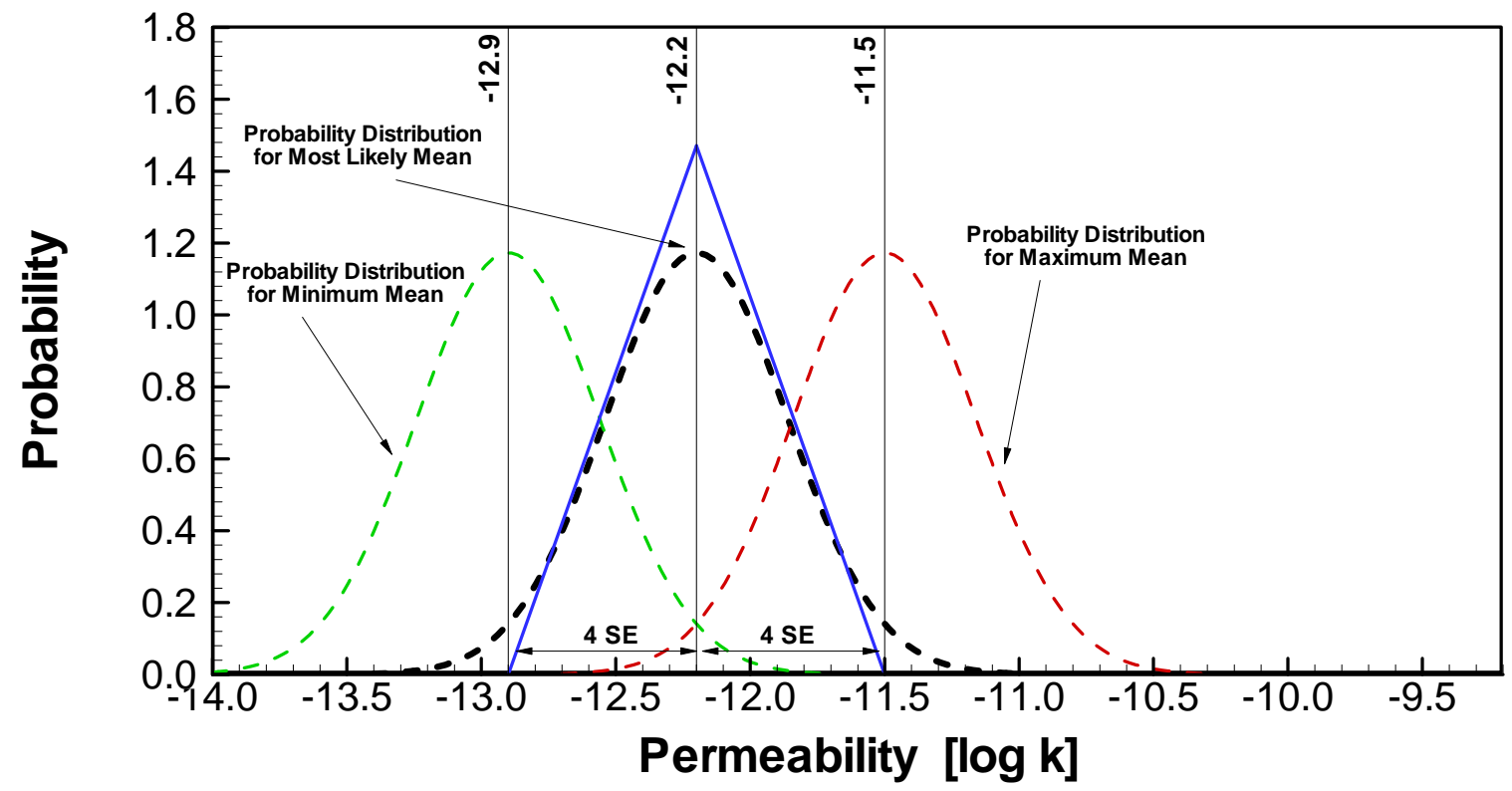

NOTE: The blue line assigns a probability to the mean of the normal-shaped spatial variability distribution. The black dashed line shows the most likely spatial probability distribution (at the peak of the triangular distribution). The green and the red dashed lines show the least likely spatial probability distributions (at the minimum and the maximum of the triangular distribution). Based on Tables 6.6-3, 6.6-4, 6.6-5 and 6.6-6 as well as discussion in Sections 6.6.3.2 and 6.6.3.3. Permeability values in $\log 10$ of unit $\mathrm{m}^{2}$. SE denotes standard error.

Figure 6.6-7. Schematic Showing Triangular Probability Distribution (Blue Line) for Covering Uncertainty of Permeability in the Tptpmn Unit by Varying the Mean of the Spatial Probability Distribution 


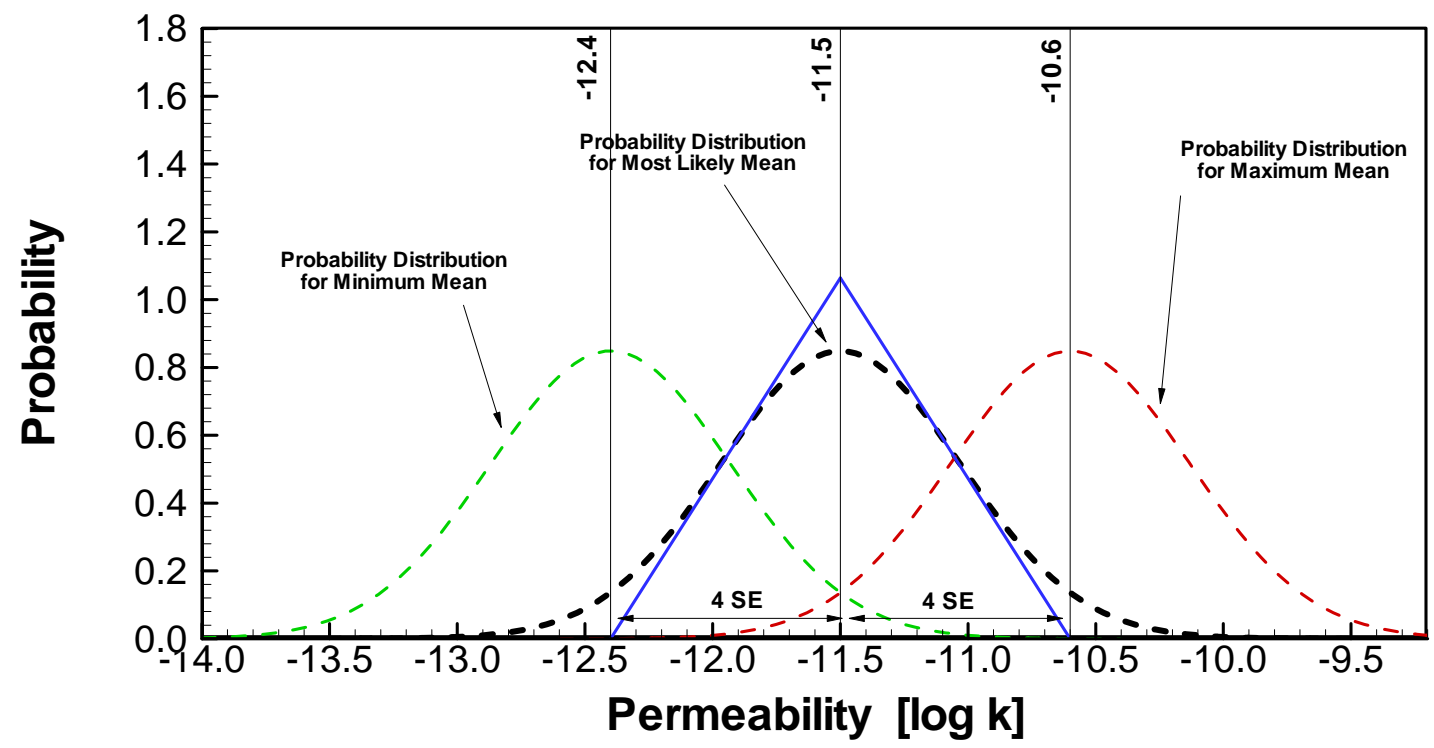

NOTE: The blue line assigns a probability to the mean of the normal-shaped spatial variability distribution. The black dashed line shows the most likely spatial probability distribution (at the peak of the triangular distribution). The green and the red dashed lines show the least likely spatial probability distributions (at the minimum and the maximum of the triangular distribution). Based on Tables 6.6-3, 6.6-7, 6.6-8, and 6.6-9 as well as discussion in Sections 6.6.3.2 and 6.6.3.3. Permeability values in log10 of unit $\mathrm{m}^{2}$. SE denotes standard error.

Figure 6.6-8. Schematic Showing Triangular Probability Distribution (Blue Line) for Covering Uncertainty of Permeability in the Tptpll Unit by Varying the Mean of the Spatial Probability Distribution

\subsubsection{Capillary Strength and Permeability Distributions for the Tptpul and Tptpln Units}

According to the current repository design, a small fraction of the emplacement drifts will be located in the Tptpul and the Tptpln units at Yucca Mountain. As pointed out in Section 6.3.1, the Tptpul unit comprises about 4.5 percent and the Tptpln unit about 2.6 percent of the repository area. Additional distributions are needed that cover the spatial variability and uncertainty of the seepage-relevant parameters (capillary strength and permeability) in these units. However, due to their limited importance for TSPA, results from seepage experiments and small-scale air-injection tests are not available for these units. Thus, these additional distributions need to be developed based on the seepage-relevant parameter distributions derived for the Tptpll and Tptpmn units, using the available hydrogeological information on the similarities and differences between the units. This approach introduces uncertainty due to (1) the capillary-strength parameters not being calibrated from measurements conducted in the unit considered, and (2) the small-scale permeability not being measured in the unit considered.

The analysis starts with the nonlithophysal units. It has been shown in Section 6.6.1 that the Tptpln unit is similar to the Tptpmn unit, with respect to fracturing, lithophysal characteristics, and mineralogy. There are some differences in the average fracture intensity of the two units, but these may be mostly caused by the prominent intensely fractured zone present along portions of Tptpmn unit exposed in the ESF (Section 6.6.1.2). Note also that, as was pointed out in Section 6.6.2.2, the calibrated capillary-strength values are effective parameters that may not be 
strongly affected by the rock type. Thus, the parameter distribution for the Tptpmn unit is expected to provide a reasonable estimate for the distributions of capillary-strength parameters in the Tptpln unit. Therefore, and in view of the limited importance of these additional units, the capillary-strength distribution in the Tptpln unit is based on the respective Tptpmn unit results discussed in Section 6.6.2.

While there are no small-scale permeability data in the Tptpln unit, information on the permeability in this unit can be derived from air injection tests conducted in surface-based boreholes. As pointed out in Section 6.6.3.1, permeability values from surface-based boreholes cannot be directly used for seepage evaluation purposes because (a) the measurement scale is different from the required 1-foot scale and (b) the measurements are conducted in undisturbed fractured rock. However, they are useful in comparison with available surface-based measurements conducted in the main repository units, in order to assess similarities between the respective units.

Permeability data for the Tptpln unit are available at surface-based boreholes SD-12 and UZ\#16 (DTN: GS960908312232.013 [DIRS 105574]). Table 6.6-10 below provides the mean permeability of the several test intervals at each of these locations, and also gives summary statistics of the variation of this parameter. The mean permeability value over both locations is -11.9 (in $\log 10\left[\mathrm{~m}^{2}\right]$ ); the standard deviation is 0.04 . These values need to be compared with those given for the Tptpmn unit (Table 6.6-5). The mean permeability of the Tptpln unit is slightly larger than the one measured for the Tptpmn unit; the spatial variability as indicated by the standard deviation is much smaller. These results would indicate that less seepage should be expected in the Tptpln unit, because both a larger mean and a smaller standard deviation would tend to reduce the overall seepage (see Section 6.8.2). However, the sample size of two surface-based boreholes is rather small, and the derived statistics may not be fully representative of the entire unit. Therefore, for seepage abstraction, the Tptpln unit has been assigned the same spatial variability and uncertainty distributions as the Tptpmn unit.

Table 6.6-10. Mean Permeabilities of Undisturbed Rock from Tptpln Unit Measured in Surface-Based Boreholes and Intermediate-Scale Variability Statistics over the Repository Rock Block

\begin{tabular}{|c|c|c|c|c|}
\hline Location & $\begin{array}{c}\text { Number of } \\
\text { Intervals }\end{array}$ & $\begin{array}{c}\text { Mean } \boldsymbol{\mu}_{\text {sur }} \\
\text { (in log } \mathbf{k})\end{array}$ & $\begin{array}{c}\text { Interval } \\
\text { Length }(\mathbf{m})\end{array}$ & \\
\cline { 1 - 4 } SD-12 & 6 & -11.9 & 4.6 & \\
\hline UZ\#16 & 14 & -11.9 & 4 & \multirow{2}{*}{$\begin{array}{c}\text { Std. Error of } \\
\text { Mean SE }\end{array}$} \\
\hline $\begin{array}{c}\text { Statistics over all two } \\
\text { Locations }\end{array}$ & $\begin{array}{c}\text { Number of } \\
\text { Locations }\end{array}$ & $\begin{array}{c}\text { Mean } \boldsymbol{\mu} \\
\text { (in log } \mathbf{k})\end{array}$ & Std. Dev. $\boldsymbol{1}$ & 0.03 \\
\hline Tptpln & 2 & -11.9 & 0.04 & \\
\hline
\end{tabular}

Output DTN: LB0407AMRU0120.001

NOTE: Computations documented in Appendix C.

Similarities and differences between the lithophysal units have also been discussed in Section 6.6.1. There are important differences with respect to seepage. The Tptpul unit lacks the intense small-scale fracturing abundant in the Tptpll unit and has somewhat different lithophysal characteristics (smaller, more uniform lithophysae compared to the Tptpul unit). It is thus 
questionable whether the parameter distributions of the Tptpul unit can be derived from those of the Tptpll unit. For example, the differences in the small-scale fracture characteristics between the Tptpll and the Tptpul units may result in differences in the effective capillary strength in these units. Also, while surface-based measurements have demonstrated similarity in fracture permeability between the two units (Table 6.6-8), these measurements have been conducted on a 3- to 4-meter scale and do not reveal the differences in small-scale fracturing (which are important for the flow diversion capacity of the fracture network close to the drift wall). However, for lack of better information on the seepage characteristics in the upper lithophysal unit, it is recommended to use the same parameter distributions for the Tptpul unit as derived for the Tptpll unit. This approach is justified because (1) the uncertainty related to this parameter choice should be covered by the many conservative choices for seepage and (2) because the upper lithophysal rock has only limited importance for the performance of the repository. Additional seepage testing in the Tptpul unit would provide a better data basis, but is not considered necessary.

\subsubsection{Percolation Flux and Flow Focusing}

The magnitude (and spatial distribution) of local percolation fluxes at the repository horizon is another key parameter affecting seepage into drifts. The larger the local percolation flux, the higher the potential for seepage to occur and the larger the amount of water that can seep into drifts. In the ambient seepage abstraction, the spatial and temporal distribution of percolation fluxes in the UZ is provided by the site-scale UZ Flow Model (BSC 2004 [DIRS 169861]). This model derives relevant information on the overall flow and transport fields at the Yucca Mountain, accounting for climate changes and related uncertainties, variability in net infiltration, and the effects of different stratigraphic units and faults. However, because of the large model area, the spatial resolution of the model is much larger than the extent of drift-scale seepage models, and layer-averaged properties are used within stratigraphic units. Thus, intermediate-scale heterogeneity is not represented in the UZ Flow Model. This heterogeneity may lead to focusing of flow on a scale smaller than the resolution of the site-scale model; i.e., it may increase the site-scale fluxes in some areas, while reducing them in other areas. The additional variability and uncertainty of percolation flux stemming from this effect is accounted for in the seepage abstraction model by appropriate flow focusing factors, to be multiplied with the percolation flux distribution from the site-scale model (see Section 6.6.5.2). The resulting flux distribution is expected to represent the local percolation flux distribution needed as input to the predictive drift-scale seepage models (e.g., the SMPA or the TH Seepage Model).

\subsubsection{Percolation Flux from the Site-Scale Model}

For ambient flow conditions, the 3-D spatial flux distributions in the UZ are provided by the site-scale UZ Flow Model, as documented in BSC (2004 [DIRS 169861]). The site-scale model incorporates the entire Yucca Mountain UZ; it accounts for the main stratigraphic units using layer-averaged rock properties and represents the major faults. Relevant rock properties of each hydrogeologic unit (for fractures, matrix, and fault zones) have been calibrated against saturation data, water-potential data, pneumatic-pressure data, perched-water data, temperature data, and geochemical data (BSC 2004 [DIRS 169857], Section 6.2 and BSC 2004 [DIRS 169861], Sections 6.2 through 6.5). The calibrated model is validated by comparison of model results with additional data that have not been used for calibration, as discussed in BSC (2004 
[DIRS 169861], Section 7). Model validation includes comparison with water-potential, pneumatic-pressure, perched-water, temperature, and geochemical data (carbon-14, chloride, and strontium in the pore water, calcite mineral abundance) as well as results from Alcove 8/Niche 3 seepage tests. Model predictions are conducted for three different climate conditions that are expected to occur during the 20,000-year time period considered in TSPA (BSC 2004 [DIRS 170002]). The first climate stage is a continuation of the current modern-day climate conditions from present day to 600 years into the future (present-day climate). The second climate stage begins at 600 years from present day and is characterized as a monsoon climate, with wetter summers than the modern climate. The third climate stage begins at approximately 2,000 years from present day and is characterized as a glacial transition climate, with (on average) higher infiltration. The glacial transition climate is predicted to last the remainder of the 20,000 years.

Uncertainty in climate predictions is accounted for by defining three alternative infiltration scenarios referred to as the mean, the upper-bound and the lower-bound scenarios (BSC 2004 [DIRS 170002]). Note that the occurrence probability of each infiltration scenario is provided in the Analysis Report Analysis of Infiltration Uncertainty (BSC 2003 [DIRS 165991]). This can be used in TSPA to assign the appropriate weight to the considered site-scale flow field. The mean infiltration scenario is the scenario that gives the best fit between the UZ model results and the available data (BSC 2004 [DIRS 169861], e.g., Section 8.4). Based on the precipitation rates and temperature predicted for the future climates, distributions of net infiltration have been simulated as documented in Simulation of Net Infiltration for Present-Day and Potential Future Climates (BSC 2004 [DIRS 170007]). Relatively high net infiltration rates occur generally in the northern portion of the site at high elevations and along the ridge where fractured bedrock is exposed.

The infiltration distributions, available for the three climate stages and the associated lower-bound, mean, and upper-bound scenarios, are used as direct input at the upper boundary of the site-scale UZ Flow Model (BSC 2004 [DIRS 169861], Section 6.1.3). Steady-state simulation runs are conducted with this model for each climate stage and infiltration scenario, resulting in a total of nine 3-D flow fields that give the spatial distribution of percolation flux (BSC 2004 [DIRS 169861], Section 6.1.4). TSPA uses the steady-state flow fields as being representative over the entire time period of the respective climate stage. Therefore, stepwise changes in percolation flux occur at 600 years (transition from present-day to monsoon climate) and at 2,000 years (transition from monsoon to glacial transition climate). Consequently, the ambient seepage rates - calculated as a function of percolation flux-also have a stepwise change at 600 years and at 2,000 years, corresponding to climate changes. The times required for the flow conditions in the UZ to adjust to the stepwise changes in net infiltration are expected to be shorter than the duration of the different climatic stages. Thus the steady-state conditions are representative over the TSPA time period, except for the durations following the stepwise changes at 600 and 2,000 years when the flow field equilibrates. Since the climate changes lead to an increase in average percolation for most infiltration scenarios, the steady-state representation gives rise to an overestimation of seepage rates during these equilibration periods. The one exception is the lower-bound infiltration scenario, where the glacial transition percolation is smaller than the monsoon percolation. However, because of the comparably small percolation fluxes, this lower-bound infiltration scenario gives small overall seepage rates compared to the other infiltration scenarios (see Section 6.8, Tables 6.8-1 and 6.8-2). 
In general, percolation flux through the Tiva Canyon welded tuff unit, the first fractured bedrock unit below alluvial deposits, is governed by the imposed distribution of net infiltration. Flow in this unit occurs mostly in the fractures before entering the underlying Paintbrush nonwelded hydrogeological unit (PTn). With its characteristics of high matrix porosity and low fracture frequency, and the existence of tilted layers of nonwelded vitric and bedded tuff, the PTn can divert a fraction of the percolating water to intercepting faults and fault zones (CRWMS M\&O 2000 [DIRS 141187], Section 6.1.2; Wu et al. 2002 [DIRS 161058]; BSC 2004 [DIRS 169861], Section 6.2.2). Also, the PTn unit dampens and homogenizes downward-moving transient pulses from surface infiltration events. Therefore, the percolation distribution below the PTn unit is considerably different from the distribution of net infiltration, both spatially and temporally. Note that this difference is substantiated by geochemical data obtained at Yucca Mountain, as discussed in BSC (2004 [DIRS 169861], Section 6.5). The geological unit below the PTn is the Topopah Spring welded tuff (TSw), a thick, densely fractured unit that hosts the repository. Results from the UZ Flow Model indicate that the flux in the TSw is mainly vertical without significant lateral diversion; as a result, the flux distribution at the PTn/TSw-interface should be similar to the flux distribution at the repository horizon.

The seepage abstraction model uses the percolation flux distributions across the PTn/TSw-boundary to provide input to the seepage look-up table. These fluxes incorporate the important effects of flow dampening and lateral flow diversion in the PTn, and they are fairly representative of the fluxes at the repository horizon. The rationale for using the PTn/TSw fluxes, instead of the flux distribution directly at the repository horizon, is mainly based on consistency considerations. The effect of flow focusing is estimated with a submodel that has the bottom of the PTn as its upper-boundary (see discussion in the following Section 6.6.5.2). Also the Multiscale Thermohydrologic Model, used for the simulation of in-drift TH conditions for feed into TSPA, has its upper boundary condition at the bottom of the PTn (BSC 2004 [DIRS 169565]).

The spatial percolation flux distributions across the PTn/TSw interface are given in DTN: LB0302PTNTSW9I.001 [DIRS 162277], for all three climate stages and scenarios. Flux values have been extracted from the 3-D model results for each vertical column of the model grid. Contours of these distributions are presented in Figure 6.6-9, using the glacial transition period of the mean infiltration scenario as an example. Note that the model domain is intersected by several major fault zones. The percolation fluxes in these fault zones are typically much larger than fluxes in nonfault zones. In fact, the extreme values of percolation occur in these zones. Relatively high fluxes are also found in the north of the model domain and at the mountain ridge. 


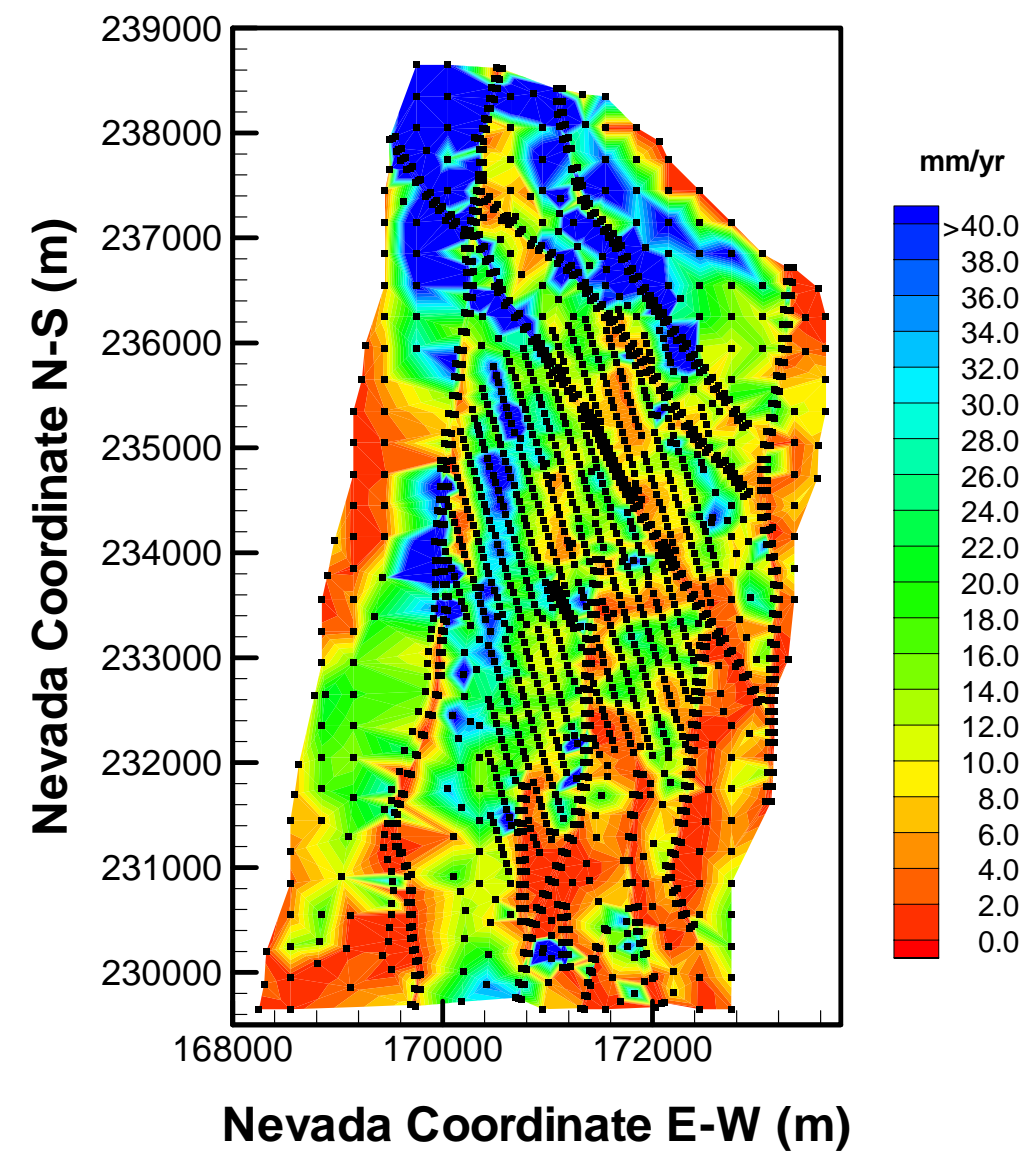

Source: LB0302PTNTSW9I.001 [DIRS 162277].

NOTE: Black symbols denote center nodes of UZ model grid.

Figure 6.6-9. Contour Map of Vertical Fluxes at the PTn/TSw Interface for the Glacial Transition Climate (Mean Infiltration scenario)

For use in TSPA, only those fluxes provided by the UZ Flow Model are needed that are representative of the repository area, because only these fluxes are relevant for seepage. Extracting the repository fluxes gives the distribution of percolation fluxes to be used in TSPA. Figure 6.6-10 shows the distribution of extracted PTn/TSw-fluxes for the repository columns of the UZ model grid. (Note that the so-called contingency area at the southern tip of the repository is not included.) Table 6.6-11 provides statistical measures-average percolation and maximum percolation-calculated for the flux distributions of the (a) entire UZ domain, and (b) the repository domain. Note that the statistical calculation is conducted without accounting for differences in the cross-sectional area of each vertical column. The impact of this simplification is small, however, and not relevant for the estimation of seepage, since the horizontal area of vertical columns is fairly uniform over the repository area. 


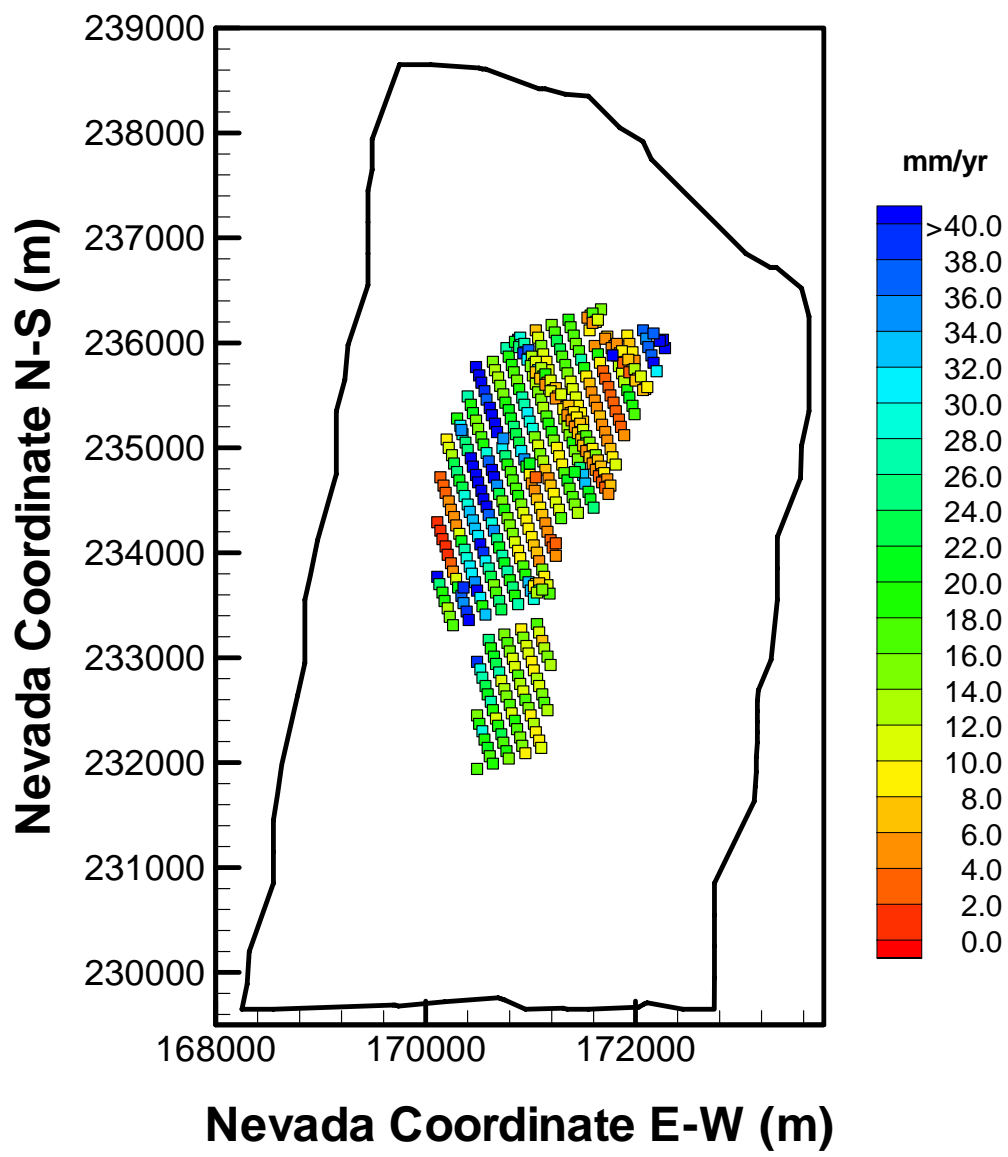

Source: LB0302PTNTSW9I.001 [DIRS 162277].

NOTE: Symbols denote center nodes of UZ model grid over the repository area, without contingency areas.

Figure 6.6-10. Extracted Vertical Fluxes at the PTn/TSw Interface for the Glacial Transition Climate (Mean Infiltration scenario)

For both the mean and the upper-bound scenario in Table 6.6-11, the percolation fluxes increase significantly as a result of the imposed climate changes at 600 and at 2,000 years. This is different for the lower-bound scenario. Here, at overall small percolation rates, the glacial transition climate has less percolation than the monsoon climate. The observed trends in percolation flux over the UZ model domain are consistent with the trends in net infiltration as reported in BSC (2004 [DIRS 170007], Tables 6-9, 6-13, and 6-18). In general, the fluxes extracted for the repository area are smaller than the fluxes over the entire UZ model domain, as indicated by the slightly smaller average values and the considerable differences in the maximum values. For comparison, Table 6.6-11 also gives statistics for repository fluxes without considering fault zones. While the average fluxes are hardly affected, the maximum percolation fluxes are significantly smaller without consideration of fault zones. In the seepage abstraction model, however, the large percolation fluxes in fault zone fluxes are included. It is not clear at this point if the emplacement of waste canisters in fault zones can be entirely avoided. 
Figure 6.6-11 shows histograms of the distribution of percolation flux over the repository area, for the present-day, monsoon, and glacial transition climate stages of the mean infiltration scenario. The histograms demonstrate that the maximum values observed in Table 6.6-11 are in fact extreme cases that are very sparsely distributed and not representative of the majority of locations in the repository area. Most of these extreme cases are associated with fault zones.

As already mentioned, the diversion capacity of the PTn unit is very important for the spatial distribution of percolation fluxes in the TSw. However, the characterization of groundwater flow within the PTn is critically dependent on detailed knowledge of the rock properties and the heterogeneity within the PTn unit. Related uncertainties have been studied in BSC (2004 [DIRS 169861], Section 6.6) by adjusting the PTn properties, allowing for considerably less lateral diversion. Based on this alternative property set, nine alternative flow fields have been simulated, and the related PTn/TSw fluxes have been provided in DTN: LB0305PTNTSW9I.001 [DIRS 163690]. Table 6.6-11 gives the average and the maximum percolation value for the alternative flow model, using the mean infiltration scenario as an example. While the average fluxes over the repository area are not affected by the different PTn flow conceptualization, the maximum flux values are considerably smaller compared to the normal scenario. Apparently, less water is diverted towards fault zones in the alternative conceptual model. (Note that the mean fluxes over the entire UZ are slightly different between the two PTn flow concepts. Because of mass conservation, they should be identical for the respective climate stages. The differences occur as a result of neglecting the respective cross-sectional area of each vertical column in the statistical evaluation, as explained above.) Figure 6.6-12 shows histograms of the percolation flux distribution over the repository area for the alternative flow model, using the same interval size as in Figure 6.6-11. In addition to the different maximum flux values, the histograms in Figures 6.6-11 and 6.6-12 reveal some qualitative differences in the distribution of the values. The impact of these differences is examined in Section 6.8.2, where seepage rates are calculated in a Monte Carlo analysis. It will be demonstrated that the resulting seepage rates are hardly affected, so that the alternative flow scenario does not need to be analyzed within the TSPA simulations. 
Table 6.6-11. Statistics of Percolation Flux Distributions at the PTn/TSw Interface

\begin{tabular}{|c|c|c|c|}
\hline \multicolumn{4}{|c|}{ Mean Infiltration scenario: Flux in mm/year } \\
\hline Climate stage & Entire UZ & $\begin{array}{c}\text { Repository Area } \\
\text { (used in TSPA) }\end{array}$ & $\begin{array}{c}\text { Repository Area } \\
\text { without Fault Zones }\end{array}$ \\
\hline Present Day Average & 4.8 & 3.8 & 3.8 \\
\hline Present Day Maximum & 111.1 & 39.9 & 20.6 \\
\hline Monsoon Average & 13.2 & 11.7 & 11.5 \\
\hline Monsoon Maximum & 211.6 & 127.9 & 61.3 \\
\hline Glacial Transition Average & 18.8 & 17.9 & 17.8 \\
\hline Glacial Transition Maximum & 276.5 & 192.4 & 90.9 \\
\hline \multicolumn{4}{|c|}{ Lower-Bound Infiltration scenario: Flux in mm/year } \\
\hline Climate stage & Entire UZ & $\begin{array}{c}\text { Repository Area } \\
\text { (used in TSPA) }\end{array}$ & $\begin{array}{c}\text { Repository Area } \\
\text { without Fault Zones }\end{array}$ \\
\hline Present Day Average & 1.1 & 0.4 & 0.4 \\
\hline Present Day Maximum & 83.5 & 3.2 & 3.2 \\
\hline Monsoon Average & 4.8 & 4.3 & 4.4 \\
\hline Monsoon Maximum & 103.3 & 22.8 & 16.3 \\
\hline Glacial Transition Average & 2.5 & 1.9 & 2.0 \\
\hline Glacial Transition Maximum & 77.5 & 11.6 & 10.5 \\
\hline \multicolumn{4}{|c|}{ Upper-Bound Infiltration scenario: Flux in mm/year } \\
\hline Climate stage & Entire UZ & $\begin{array}{c}\text { Repository Area } \\
\text { (used in TSPA) }\end{array}$ & $\begin{array}{c}\text { Repository Area } \\
\text { without Fault Zones }\end{array}$ \\
\hline Present Day Average & 12.0 & 11.1 & 11.2 \\
\hline Present Day Maximum & 197.5 & 80.3 & 44.0 \\
\hline Monsoon Average & 21.7 & 20.3 & 20.1 \\
\hline Monsoon Maximum & 358.7 & 161.1 & 97.9 \\
\hline Glacial Transition Average & 35.6 & 35.1 & 35.3 \\
\hline Glacial Transition Maximum & 530.2 & 282.2 & 164.1 \\
\hline \multicolumn{4}{|c|}{ Alternative Flow Model for PTn Unit } \\
\hline \multicolumn{4}{|c|}{ Mean Infiltration scenario: Flux in $\mathrm{mm} / \mathrm{year}$} \\
\hline Climate stage & Entire UZ & $\begin{array}{c}\text { Repository Area } \\
\text { (used in TSPA) }\end{array}$ & $\begin{array}{c}\text { Repository Area } \\
\text { without Fault Zones }\end{array}$ \\
\hline Present Day Average & 4.4 & 3.8 & 3.9 \\
\hline Present Day Maximum & 105.0 & 26.0 & 21.0 \\
\hline Monsoon Average & 12.6 & 11.8 & 11.7 \\
\hline Monsoon Maximum & 183.6 & 80.8 & 61.8 \\
\hline Glacial Transition Average & 18.2 & 17.9 & 18.0 \\
\hline Glacial Transition Maximum & 221.3 & 129.5 & 98.9 \\
\hline
\end{tabular}

Sources: DTNs: LB0302PTNTSW9I.001 [DIRS 162277]; LB0305PTNTSW9I.001 [DIRS 163690]; LB03033DSSFF9I.001 [DIRS 163047]. Output-DTN: LB0407AMRU0120.001.

NOTE: Computations documented in Appendix D. 


\section{(Present-day)}

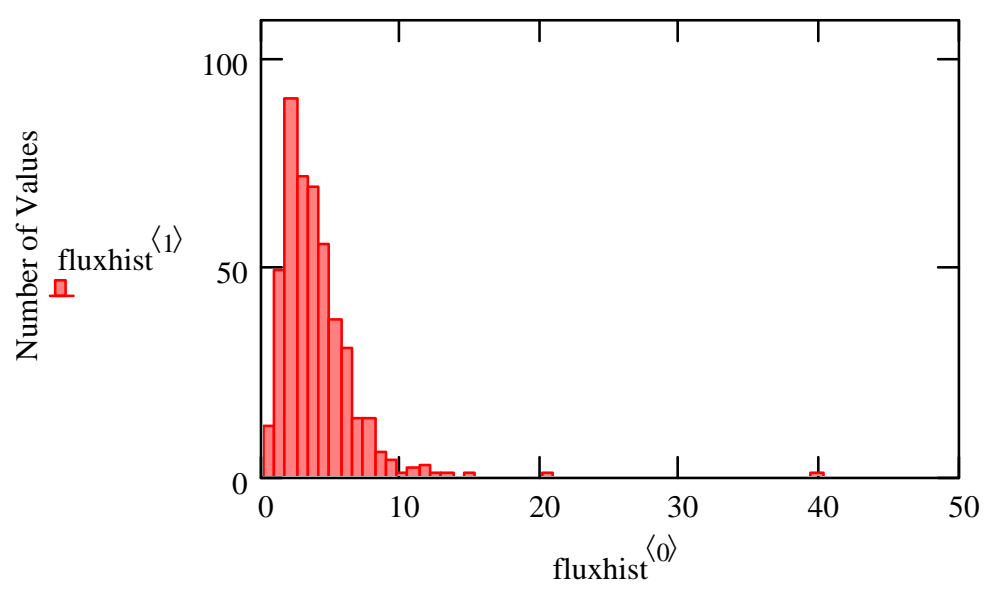

Percolation Flux in $\mathrm{mm} / \mathrm{yr}$

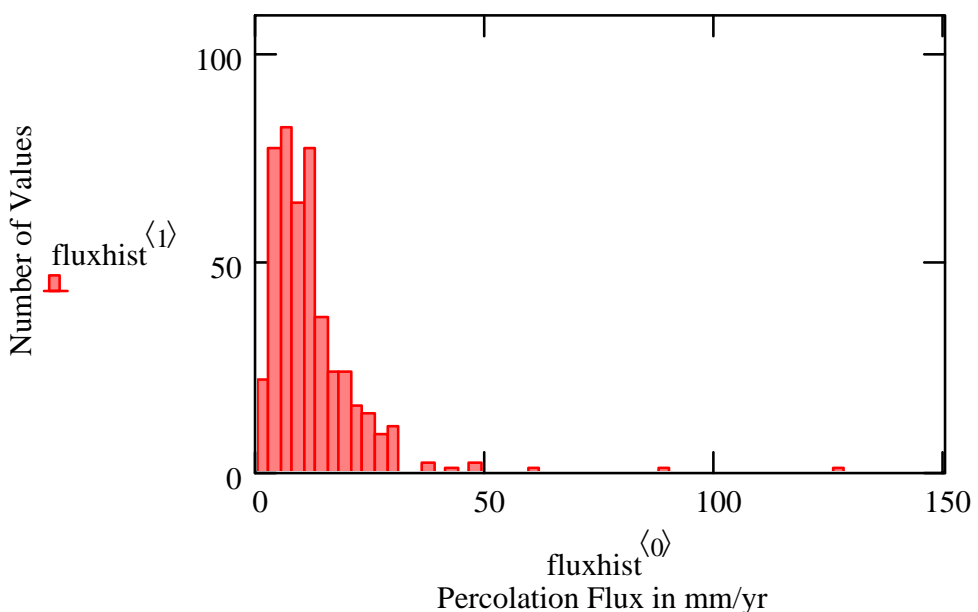

(Monsoon)

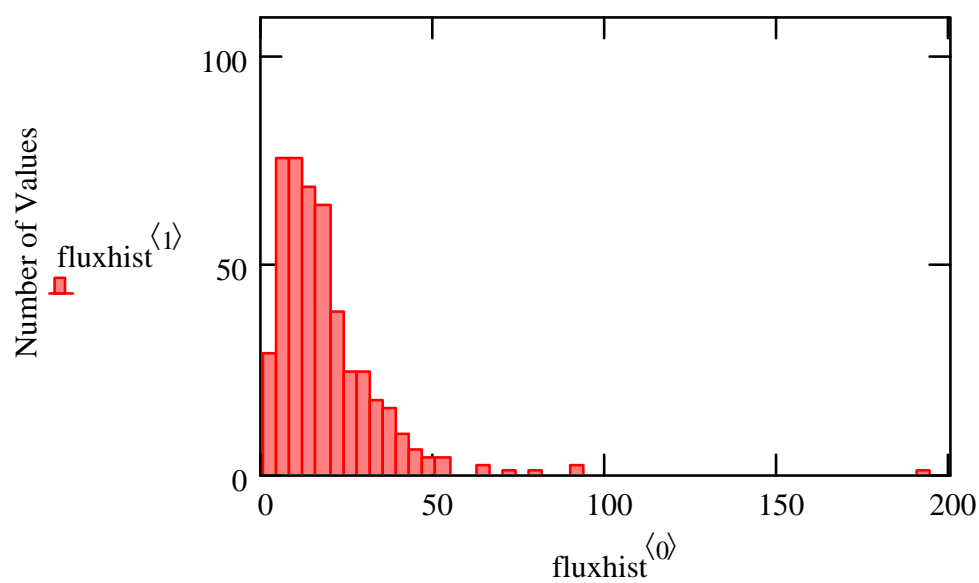

(Glacial Transition)

Percolation Flux in mm/yr

Sources: DTN: LB0302PTNTSW9I.001 [DIRS 162277] and DTN: LB03033DSSFF9I.001 [DIRS 163047].

NOTE: The symbols in the histograms (i.e., fluxhist ${ }^{\langle 0\rangle}$ and fluxhist ${ }^{\langle 1\rangle}$ ) denote the variable names given in the Mathcad 11 spreadsheet used for the calculation, see Appendix D. Fluxes are extracted for the repository area.

Figure 6.6-11. Histograms of Vertical Fluxes at the PTn/TSw Interface for the Mean Infiltration scenario 


\section{(Present-day)}

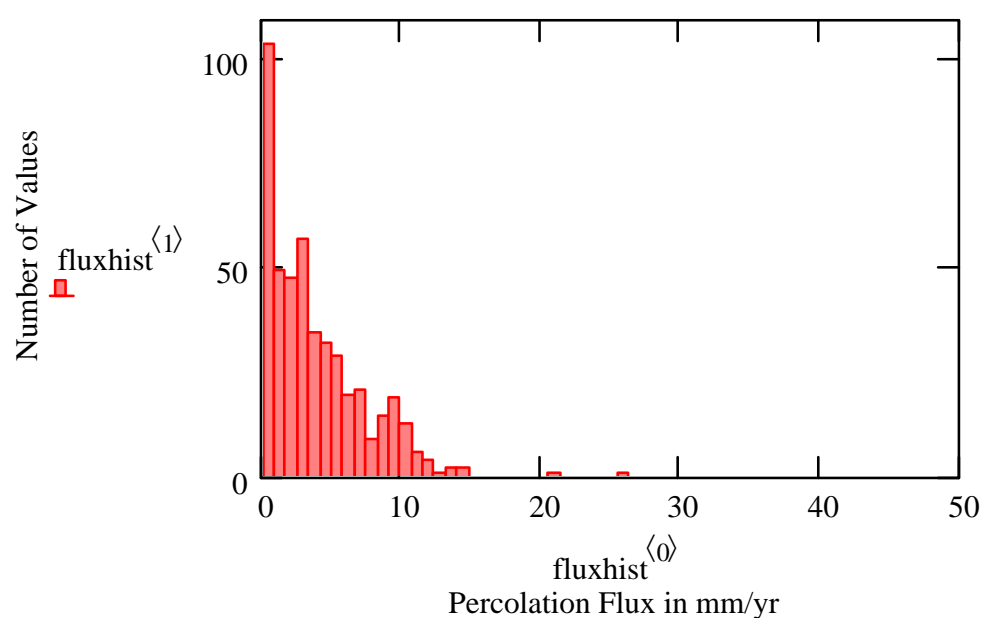

(Monsoon)
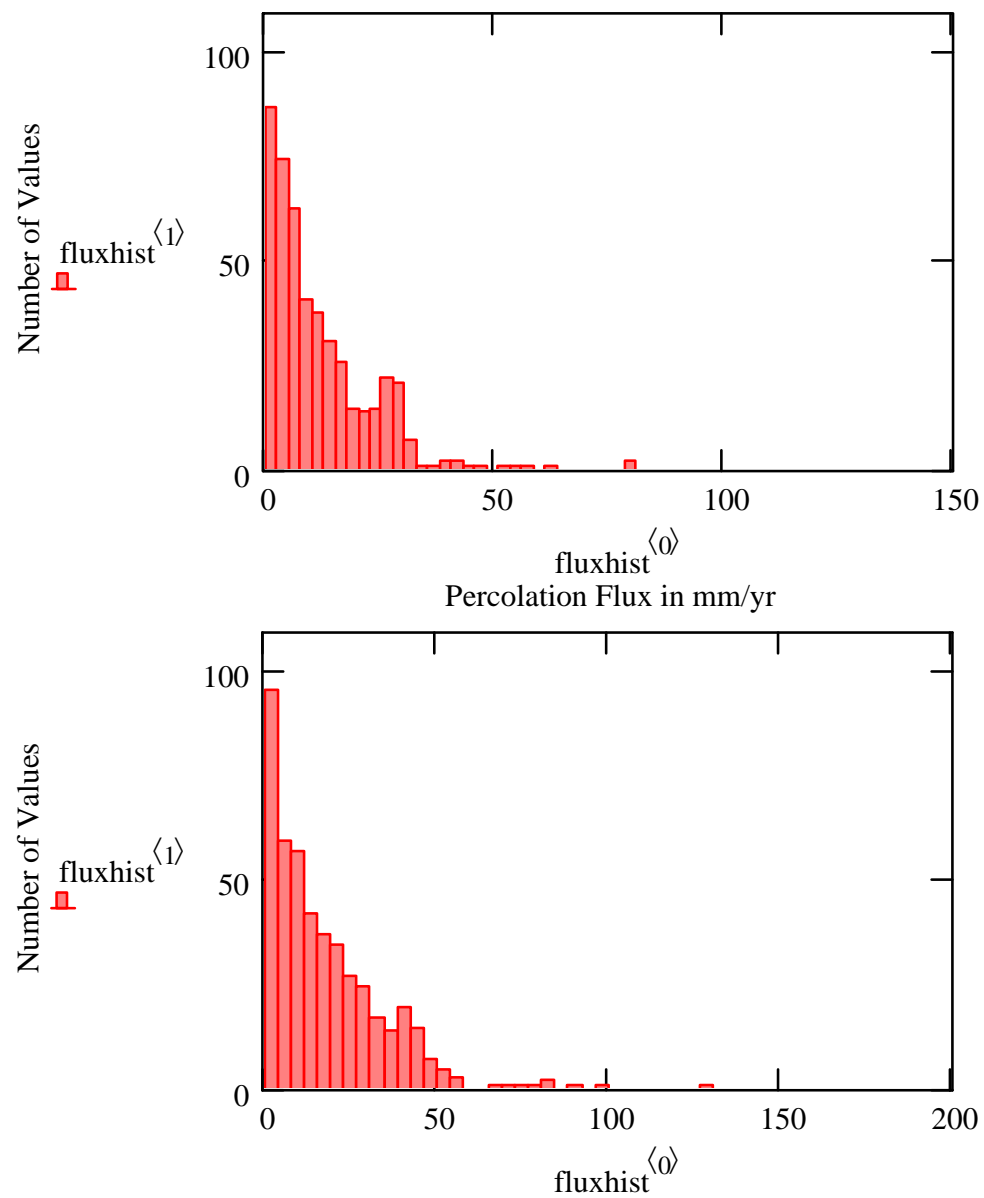

(Glacial Transition)

Percolation Flux in mm/yr

Sources: LB0305PTNTSW9I.001 [DIRS 163690] and LB03033DSSFF9I.001 [DIRS 163047].

NOTE: The symbols in the histograms (i.e., fluxhist ${ }^{\langle 0\rangle}$ and fluxhist ${ }^{<1>}$ ) denote the variable names given in the Mathcad 11 spreadsheet used for the calculation, see Appendix D. Fluxes are extracted for the repository area.

Figure 6.6-12. Histograms of Vertical Fluxes at the PTn/TSw Interface for the Mean Infiltration Scenario Using the Alternative Flow Concept in the PTn 


\subsubsection{Flow Focusing}

In the framework of seepage abstraction, flow focusing denotes the potential concentration of downward flow in the UZ from the base of the PTn onto a particular drift segment. This flow concentration could increase the local percolation flux in some locations, which would then increase the amount of seepage in those locations. The potential for flow focusing stems from the scale difference between the UZ Flow Model, which provides the 3-D distribution of percolation fluxes in the UZ, and the drift-scale seepage models, which use these percolation fluxes as inflow at the top model boundary. While the site-scale model accounts for variability in net infiltration and explicitly models the different stratigraphic units and faults, it cannot represent the intermediate-scale heterogeneity within geological units because of the layer-averaged rock properties and the relatively coarse gridding (on the order of about $100 \mathrm{~m}$ ). Drift-scale seepage models, on the other hand, have a lateral model extent on the order of a few drift diameters; the model domain typically includes the vicinity of one particular drift segment. Consequently, the distribution of percolation fluxes in the seepage abstraction model needs to describe the variability of this parameter on the spatial resolution of a few drift diameters. Since the site-scale model does not explicitly describe this spatial detail, the percolation flux distributions derived from this model need to be adjusted by multiplication with appropriately distributed flow focusing factors.

Note that flow focusing factors should not incorporate heterogeneity below the spatial resolution of a few drift diameters, since small-scale variability (on a scale of less than a meter) is explicitly accounted for in the drift-scale seepage models (the SMPA and the TH Seepage Model). It is shown in these models that small-scale heterogeneity is a key factor for seepage to occur; it gives rise to preferential-flow processes and increases the probability of local breaching of the capillary barrier at the rock-drift interface. These small-scale flow processes are referred to as "flow channeling" hereafter. In the framework of seepage abstraction, it is important to clearly distinguish between flow focusing and flow channeling. Flow focusing occurs on an intermediate scale and needs to be accounted for by appropriate factors. Flow channeling, on the other hand, occurs on a much smaller scale and is automatically included by using the seepage look-up tables of the SMPA.

\subsection{Flow Focusing Model and Results}

Flow focusing cannot be directly measured in the field. Therefore, flow focusing phenomena need to be addressed through models that are able to describe the intermediate-scale heterogeneity. An intermediate-scale simulation model was developed in BSC (2004 [DIRS 167652], Section 6.8) to specifically address the issue of spatial flow focusing, bridging the gap between the site scale and the drift scale. The modeling framework for the flow focusing study was based on earlier work described in Bodvarsson et al. (2003 [DIRS 163443]). The modeling study was conducted in a two-dimensional vertical cross section of the unsaturated zone 100 meters in horizontal extent and 150 meters in vertical extent. The top boundary was chosen at the bottom of the PTn unit, and the bottom boundary at the repository horizon. The 150-meter vertical extent of the model corresponds to an average distance between the PTn/TSw-interface and the repository. The model was validated by corroboration with qualitative evidence of preferential flow paths at Yucca Mountain, for example from observed 
fracture coatings. As mentioned above, direct measurements of flow focusing in the field are not available.

In contrast to the site-scale model, in which the rock properties within geological units are considered uniform, the intermediate-scale flow focusing model represents the heterogeneity of the fractured rock within the five stratigraphic layers residing in the model domain ${ }^{2}$ (BSC 2004 [DIRS 167652], Section 6.8) The fracture network is treated as a stochastic heterogeneous continuum with variable permeability, while flow through the matrix is neglected. Uniform and non-uniform percolation fluxes were introduced at the top boundary of the heterogeneous domain. Flow focusing phenomena were then studied by comparison of the flux distribution measured at the repository horizon (bottom boundary) with the original flux distribution introduced at the top boundary. The additional variability stemming from the downward flow in the heterogeneous model domain is the variability that cannot be described by the site-scale results, and that needs to be accounted for by appropriate distributions of flow focusing factors. Note that the grid resolution was on the order of less than a meter. Thus, the grid resolution of the flow focusing model was considerably finer than the typical model extent of drift-scale seepage models (which is on the order of a few drift diameters). Since flow variability is more pronounced in a fine-resolution grid, the maximum flow focusing factors derived in this study are arguably on the high end of possible values, providing cautiously realistic flux estimates. An alternative flow focusing study using a coarse grid resolution is discussed in Section 6.6.5.2.2.

Similar to the predictive seepage simulations conducted with the SMPA (see Section 6.4.2.1), the spatial distribution of fracture permeability was based on air permeability data (BSC 2004 [DIRS 167652], Section 6.8.1). A standard deviation of 1.0 in $\log 10$ and a fairly weak spatial correlation with correlation lengths of 1 meter and 3 meters, respectively, are consistent with the SMPA values. Based on these geostatistical data, realizations of spatially distributed fracture permeability values were generated and mapped to each gridblock of the 2-D model domain. To be consistent with the previous flow focusing analysis (e.g., Bodvarsson et al. 2003 [DIRS 163443]), other properties of the fracture continuum (mean permeability, layer-averaged porosity, capillary pressure, and relative permeability functions) were based on those reported in a previous version (Revision 00) of the Calibrated Properties Model (CRWMS M\&O 2000 [DIRS 144426], Section 6). There are differences between these properties and the most recent model calibrations in BSC (2004 [DIRS 169857], Section 6.3.2 and Table 6-8). The impact of these differences is evaluated in Section 6.6.5.2.2 below.

Simulation runs were conducted for several flow scenarios with varying infiltration rates imposed at the top boundary $(1,5,25,100$, and $500 \mathrm{~mm} /$ year $)$, different infiltration patterns (uniform, versus concentrated, and permeability-dependent), and different realizations as well as correlation lengths (BSC 2004 [DIRS 167652], Section 6.8.2). From the results, flow focusing factors in each gridblock were calculated by normalizing the flux values to the average infiltration rate imposed at the top boundary. Factors larger than one correspond to increased percolation fluxes, and factors smaller than one correspond to decreased percolation fluxes

\footnotetext{
2 These stratigraphic layers are the tsw31, tsw32, tsw33, tsw34, and tsw35, using the nomenclature of the UZ model reports. Note that the tsw34 corresponds to the Tptpmn unit when using the nomenclature of the Geological Framework Model (BSC 2004 [170029]). Similarly, the tsw35 corresponds to the Tptpll unit. The relationship between these different unit names are given in several model reports, e.g., in BSC (2004 [169855], Table 6-5).
} 
compared to the average percolation. As an example, Figure 6.6-13 shows the vertical distributions of flow focusing factors over the 2-D domain for two representative cases. The figure shows a number of high-flux, discrete flow paths. These flow paths are initialized within the TSw31 layer and vary somewhat with depth, as different stratigraphic layers with different properties are encountered.

Figure 6-14a shows the spatial variability of flow focusing factors at the bottom boundary of the model area. A significant variability in flow focusing is observed, with values ranging from almost zero to over 6. As shown in Figure 6-14b, a flow focusing factor of 1 has a cumulative frequency of approximately 60 percent, indicating that about 40 percent of the locations experience percolation fluxes that are higher than the average flux applied at the top of the model. However, only about 3 percent of the locations have local fluxes higher than three times the average percolation flux of $5 \mathrm{~mm} /$ year. The cumulative frequency curve of the flow focusing factor obtained at the bottom boundary is statistically similar to that for the whole model domain, as shown in Figure 6-14b, suggesting that the basic flow focusing characteristics remain similar over extended vertical distances. This statistical similarity indicates that the cumulative frequency curve at the bottom boundary can be used in the TSPA-LA to be representative for all repository locations.
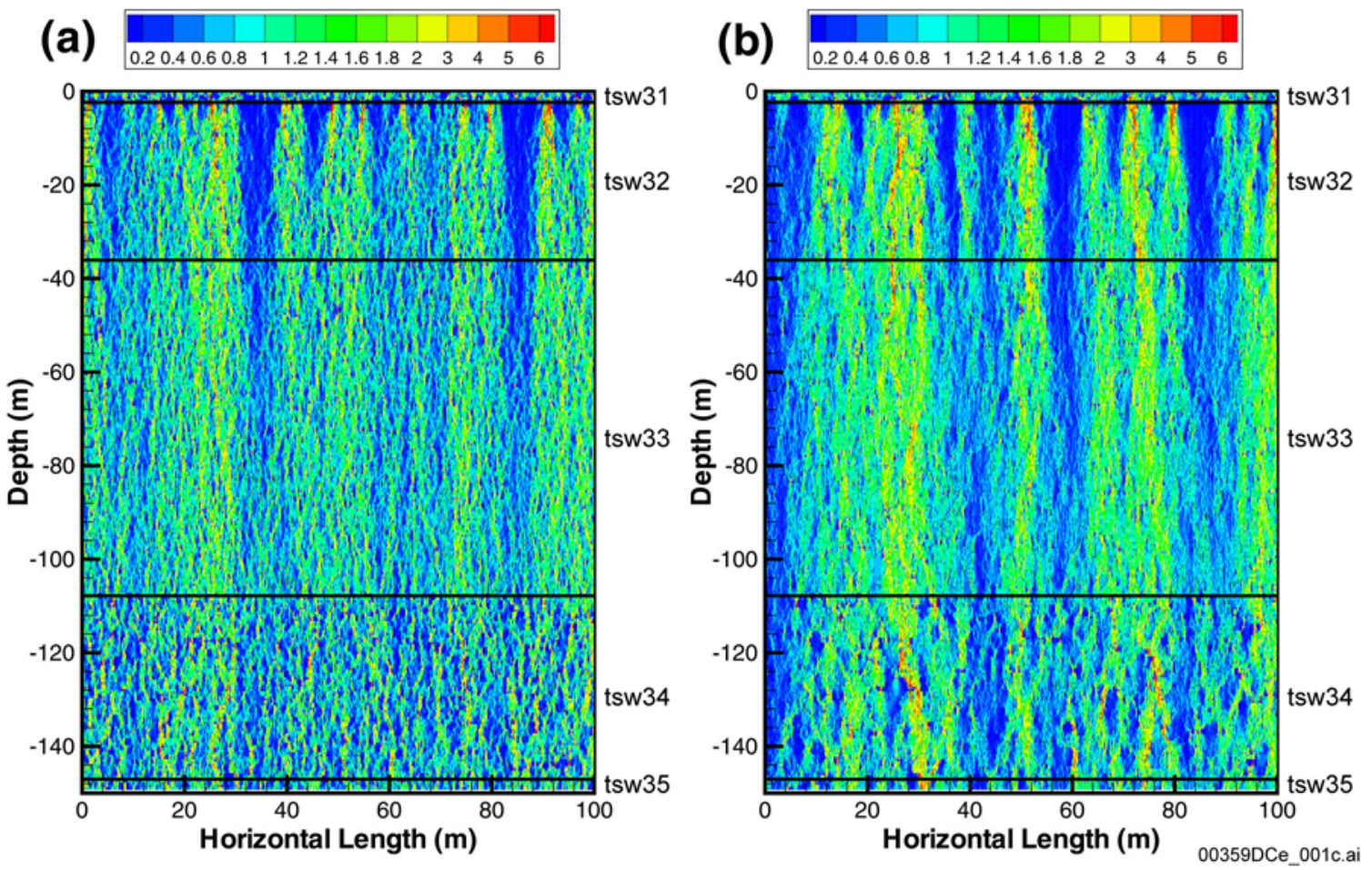

Source: Revised from BSC (2004 [DIRS 167652], Figure 6-24).

NOTE: Stratigraphic layers are based on File Mesh_K_1mR1.dat, given in DTN LB0406U0075FCS.001 [170711]

Figure 6.6-13. Distribution of Flow Focusing Factors within the 2-D Model Domain, for Two Different Realizations of Random Permeability Fields and a $5 \mathrm{~mm} / \mathrm{year}$ Uniform Infiltration on the Top Boundary 

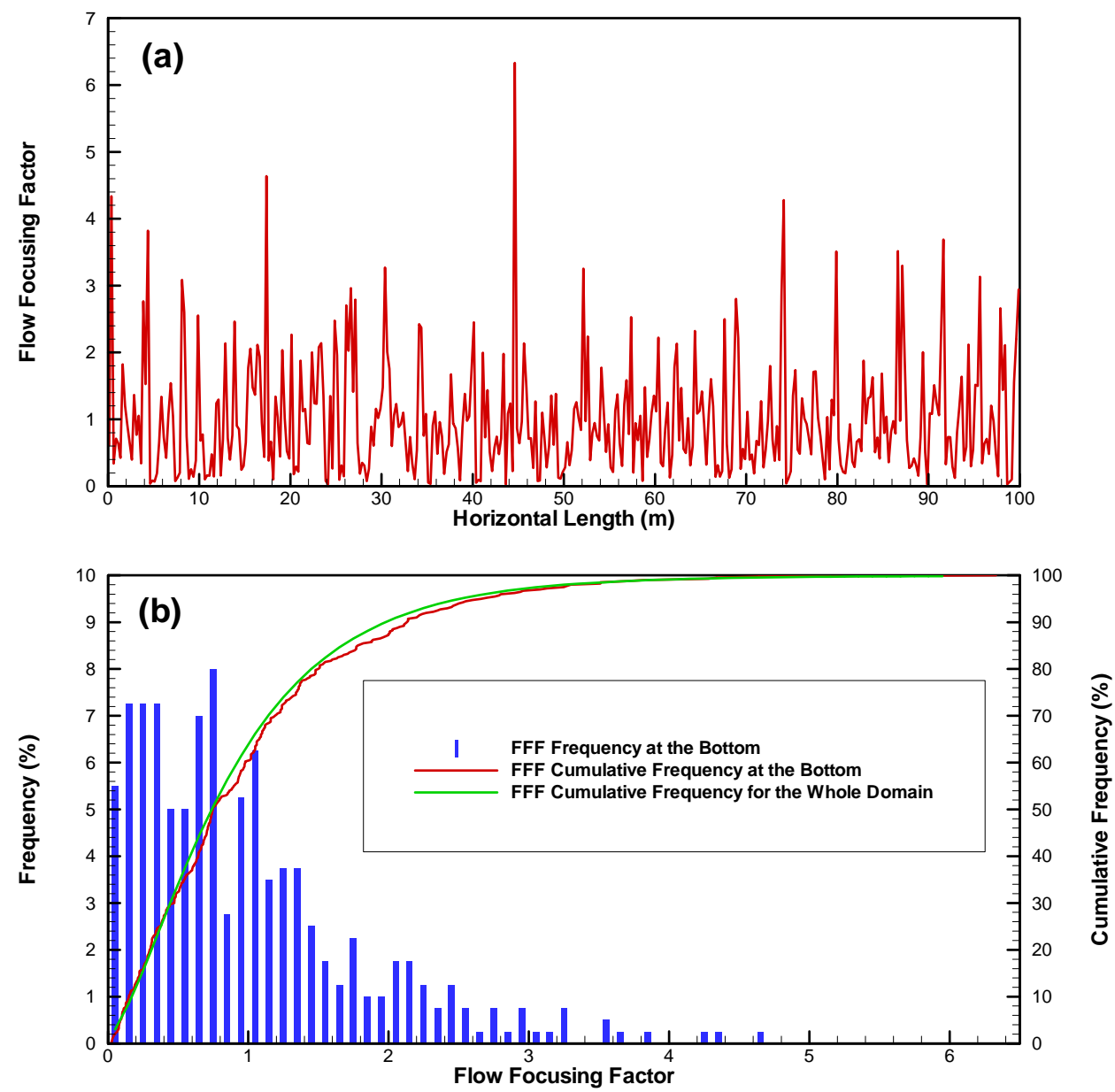

Source: BSC (2004 [DIRS 167652], Figure 6-25).

Figure 6.6-14. Flow Focusing Results for a Selected Simulation Case, Showing (a) Spatial Variability of Flow Focusing Factors (FFF) at the Bottom of the Model Domain, and (b) Frequency and Cumulative Frequency Distributions at the Bottom of the Model Domain and for the Entire Model Domain

To study the sensitivity of flow focusing factors, results from the various sensitivity analyses are plotted as cumulative frequency distributions in Figure 6.6-15. As mentioned above, the 15 sensitivity cases comprise varying infiltration rates, different infiltration patterns, and different permeability fields. It was concluded in BSC (2004 [DIRS 167652], Section 6.8) that all 15 cases in Figure 6.6-15 give similar statistical distributions, and that a single (generalized) cumulative frequency distribution of flow focusing factors could be developed for use in the seepage abstraction model. Based on the results from each sensitivity case, a generalized cumulative frequency distribution for flow focusing factors was created and described using a polynomial regression function. This curve is shown in Figure 6.6-15, together with the data points for all 15 sensitivity cases. The regression curve that was originally obtained by Bodvarsson et al. (2003 [DIRS 163443], Figure 13) is also shown in Figure 6.6-15. There are 
virtually no differences between the two regression curves, which are both given in DTN: LB0406U0075FCS.002 ([DIRS 170712]).

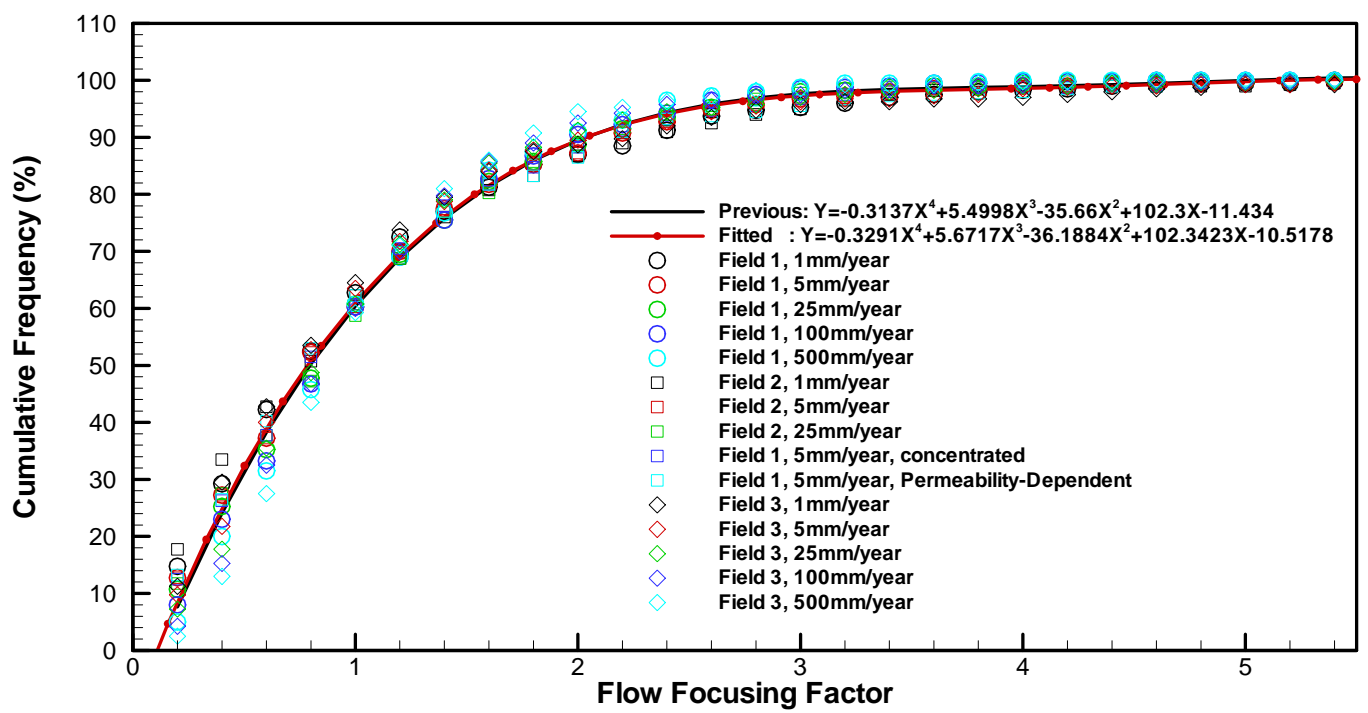

Source: BSC (2004 [DIRS 167652], Figure 6-26).

NOTE: There are two Cumulative Frequency Curves in this figure. One is the fitted curve for the data points, referred to as "Fitted"; the other is the curve previously obtained by Bodvarsson et al. (2003

[DIRS 163443], Figure 13), referred to as "Previous". (X: flow focusing factor; Y: cumulative frequency).

Figure 6.6-15. Data Points from 15 Different Sensitivity Cases (Symbols) and Generalized Cumulative Frequency Curves of Flow Focusing Factors

\subsection{Alternative Flow Focusing Model and Results}

As discussed in Section 6.6.5.2.1, the distribution of flow focusing factors was determined for a grid resolution of less than a meter, which is considerably finer than the typical model extent of a drift-scale seepage model. To evaluate the impact of grid resolution on the flow focusing results, an alternative study was conducted in Section 6.9.2 of BSC (2004 [DIRS 167652]). Fifteen flow fields were created analogous to those discussed in Section 6.6.5.2.1, but the resulting flow focusing factors were averaged over 5-meter long sections along the bottom boundary. (The 5-meter choice was based on the approximate drift diameter.) Also, instead of using the fracture properties of the base case study (BSC 2004 [DIRS 167652], Table 4-5), the revised fracture property set (BSC 2004 [DIRS 167652], Table 6-5) given in the most recent version of the Calibrated Properties Model (BSC 2004 [DIRS 169857], Section 6.3.2, Table 6-8) was applied. Using the most recent calibrated properties ensures that relevant parameter revisions are captured in the flow focusing analysis.

Figure 6.6-16 shows the cumulative frequency distributions of the flow focusing factor averaged over 5-meter wide sections at the bottom boundary, here based on 15 sensitivity cases using the most recent fracture property set. The 5-meter averaged flow focusing factors range from 0.2 to 2.4 over the 15 sensitivity cases, indicating that flow is less focused than in the fine-resolution study in Section 6.6.5.2.1, as expected. This difference is solely attributed to the averaging over 
5-meter sections; it is not related to the change in fracture properties, which has rather small impact. The cumulative frequency of flow focusing factors can be represented by a normal distribution with a mean of 1.0 and a standard deviation of 0.31 , with cut-off values at 0.2 and 2.4. The best-fit regression curve obtained from the fine-resolution study is also shown in Figure 6.6-16 for comparison. This curve shows more flow focusing than any of the 15 individual 5-meter averaged cases; it safely covers the variability of the sensitivity cases.

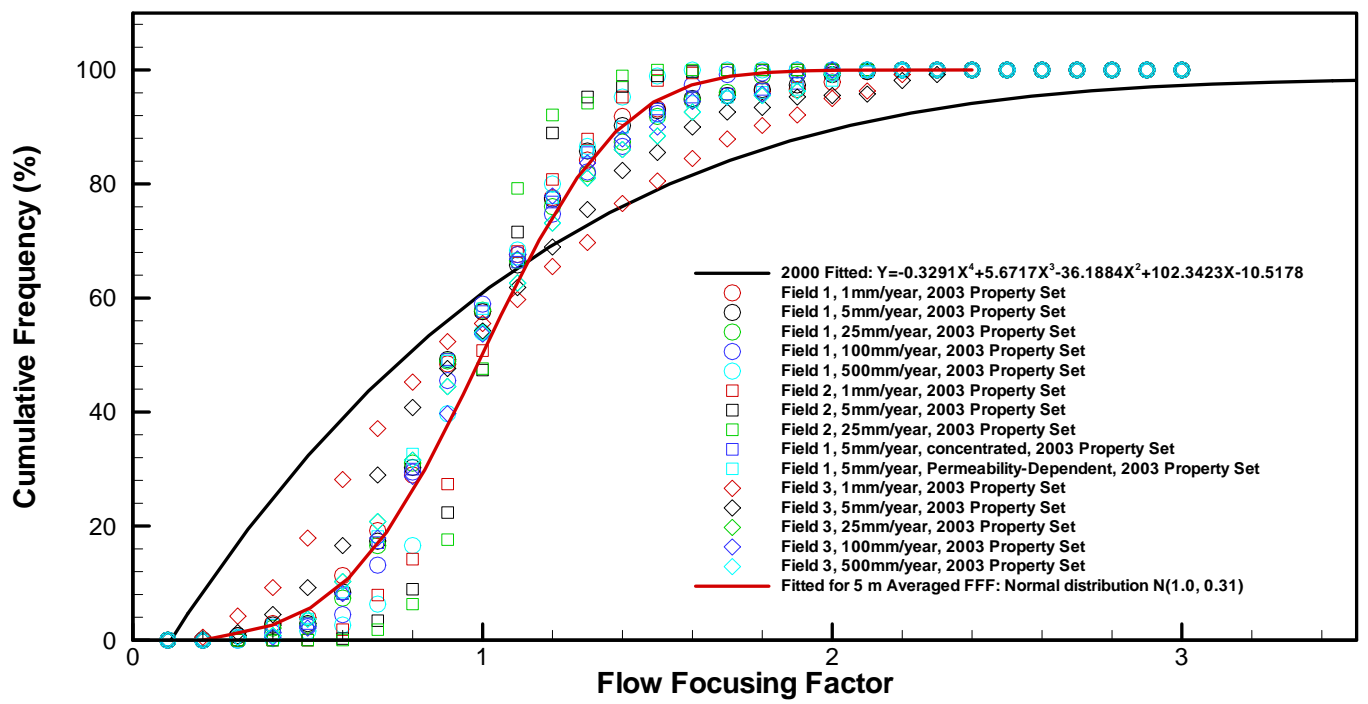

Source: BSC (2004 [DIRS 167652], Figure 6-28).

NOTE: $\quad$ Also Shown is the Generalized Cumulative Frequency Distribution Developed in Section 6.6.5.2.1 ("2000 Fitted").

Figure 6.6-16. Cumulative Frequency Distributions of Flow Focusing Factors, Averaged over 5-meter Horizontal Sections along the Bottom Boundary for 15 Sensitivity Cases Obtained for the Most Recent Calibrated Fracture Property Set

\subsection{Choice of Flow Focusing Distribution for Use in Seepage Abstraction}

Two alternative flow focusing distributions have been developed in BSC (2004 [DIRS 167652], Sections 6.8 and 6.9.2). The two distributions are the polynomial regression curve given in Figure 6.6-15, with maximum flow focusing factors of between five and six, and the normal distribution given in Figure 6.6-16, with a maximum factor of 2.4. Since flow focusing factors, per definition, are used to account for intermediate-scale heterogeneity of UZ flow, i.e., to bridge the gap between the large-scale heterogeneity of the mountain-scale models and the small-scale heterogeneity of the drift-scale models, the fine-resolution study in Section 6.6.5.2.1 may in fact overestimate the impact of flow focusing.

Seepage calculations have been conducted in Sections 6.8.1 and 6.8.2 of this model report to evaluate the impact of using the two different flow focusing concepts on seepage. The polynomial regression curve is used in the base-case seepage evaluation, while the alternative normal distribution is applied in Sensitivity Case 6b. It turns out that the alternative flow focusing distribution results in less average seepage compared to the base-case distribution (by about 40 percent). At the same time, the seepage fraction, a relative measure of the number of 
locations affected by seepage, increases slightly (by up to 10 percent). Overall, it can be expected that the polynomial curve (base case) is the more conservative case for performance assessment, caused by the considerable increase in average seepage compared to the small decrease in the relative number of seepage locations.

As pointed out in BSC (2004 [DIRS 167652], Section 7.4), no quantitative observation of flow focusing is available for a direct comparison with the simulated results. The concept of local flow redistribution can only be corroborated by indirect evidence of preferential flow paths occurring at Yucca Mountain. BSC (2004 [DIRS 167652], Section 7.4) uses observations of secondary minerals described in Whelan et al. (2002 [DIRS 160442], p. 738) as qualitative evidence for validation of the flow focusing model. According to this source, fewer than 6 percent of fractures longer than 1 meter are mineralized, suggesting that the majority of fractures may not contribute to downward flow. While this qualitatively supports the concept of flow focusing, BSC (2004 [DIRS 167652], Section 7.4) cautions that a quantitative comparison between the fraction of fractures with mineral coatings and flow focusing factors is difficult. This is because (1) the percentage of coated fractures is an areal measure that cannot be directly related to the amount of water flowing along these fractures, (2) mineralization is affected by many factors and processes, i.e., not all flow channels induce mineral precipitation, and (3) fracture coating data reflect small-scale flow channeling effects that are not (and do not need to be) included in the flow focusing factors to be used for the estimation of local percolation flux on the drift scale. Without a quantitative comparison, the simulated flow focusing factors are associated with considerable uncertainty. It is therefore appropriate to use the more conservative flow focusing distribution in the seepage abstraction model and in performance assessment, i.e., the polynomial regression curve developed in Section 6.6.5.2.1. This flow focusing distribution is expected to cover the intermediate-scale spatial variability of percolation flux plus the epistemic uncertainty associated with this spatial variability. From the two almost identical polynomial regression curves shown in Figure 6.6-15 the seepage abstraction model uses the one that was originally obtained by Bodvarsson et al. (2003 [DIRS 163443], Figure 13), to be consistent with previous seepage abstractions (BSC 2003 [DIRS 165564]).

The parameters of the chosen polynomial regression function for flow focusing are defined in DTN: LB0406U0075FCS.002 [DIRS 170712]. Note that the distribution of flow focusing factors defined by this function is mass conservative, as required, so that the total amount of downward water flow remains unchanged when using flow focusing factors as multipliers to the site-scale percolation fluxes (i.e., the arithmetic mean of all flow focusing factors of a large enough ensemble of random values is equal or close to 1$)^{3}$. Also note that the chosen regression curve is zero at a flow focusing factor of 0.116 and approaches 100 percent at a flow focusing factor of 5.016. Thus, sampling from the cumulative probability distribution will give a distribution of flow focusing factors ranging from 0.116 to 5.016. The regression curve is not defined outside of this range.

\footnotetext{
${ }^{3}$ The mean of the flow focusing factor distribution is calculated in the Mathcad spreadsheets in Appendix E, as provided in Output-DTN LB0407AMRU0120.002. The variable giving the mean of the flow focusing distribution is xfomean. For example, all spreadsheets in Appendix E that apply this flow focusing distribution have a mean flow focusing factor of $x$ fomean $=1.007$ over 10,000 random samples.
} 
While the use of fracture coating data has limited value in support of quantification of flow focusing, as discussed above, one may nevertheless attempt to use such data to derive estimates of flow focusing ranges. The observation that only 6 percent of all fractures show mineral coatings may indicate that the downward flux in the small fraction of "actively" flowing fractures should be about 17 times higher than the average percolation. The flux variability suggested by this value includes components of both flow focusing (intermediate-scale heterogeneity) and flow channeling (small-scale heterogeneity). As mentioned above, flow channeling is explicitly accounted for in seepage models by a stochastic representation of the small-scale variation in the drift vicinity. Let us assume that this small-scale variation may result in an additional flux variability that would lead to a maximum flow "channeling" factor of up to 5. (Note that the SMPA uses the same heterogeneity as the fine-resolution study in Section 6.6.5.2.1; thus a factor of 5 is a reasonable choice.) The combined flux variability from flow focusing (with a maximum factor of about 5) and flow channeling (with a maximum factor of about 5) would then lead to maximum fluxes up to 25 times higher than the average fluxes. This value is not inconsistent with the approximate flow elevation factor of 17 derived from the areal fracture coating data. It appears that the flux variability as defined in this model report cautiously overestimates the observed heterogeneity in mineral deposits on fracture walls as reported in Whelan et al. (2002 [DIRS 160442]). Note that there is additional evidence from measurements that the effect of flow focusing should not be much larger than described above. For example, distributions of water potential in the TSw are nearly uniform, indicating that there are many small flow paths instead of just a few large ones.

Note that an alternative conceptual model for estimating bounds on flow focusing factors was presented in CRWMS M\&O (2001 [DIRS 154291], Section 6.4.3.2), giving flow focusing distributions that were in general more widely distributed than the ones given above (BSC 2004 [DIRS 167652], Section 7.4). This alternative model derives flow focusing factors based on the spacing of actively flowing fractures and a simple weeps model, resulting in maximum flow focusing factors between 9.7 and 47. However, these values are believed to be unrealistically high. This is because (1) the evaluation of active fracture spacing addresses small-scale heterogeneity, which should not be included in the flow focusing distribution, and (2) the weeps model assumes that water is focused into fully saturated flow channels with completely dry fractures in between (BSC 2004 [DIRS 167652], Section 7.4).

\subsubsection{Resulting Distribution of Percolation Fluxes}

The resulting spatial distributions of percolation flux $q_{\text {perc,ff }}$ to be used in TSPA as input for seepage calculation-are generated as follows:

- The local PTn/TSw flux $q_{\text {perc }}$ is sampled for a large number of locations within the repository, using one of the nine site-scale flow fields, depending on the considered infiltration scenario and time period.

- Flow focusing factors $f_{f f}$ are randomly sampled for each location, using the cumulative flux distribution given in Figure 6.6-15 (referred to as "previous"). The flow focusing factors are not correlated to the local percolation flux. 
- The local flux values are multiplied with the local flow focusing factor to give the resulting local percolation flux $q_{\text {perc,ff }}$ for input into the seepage look-up table.

This procedure yields spatial flux distributions wider and more heterogeneous than the ones displayed in Figures 6.6-11 and 6.6-12. In theory, the maximum fluxes of each infiltration scenario/stage can be derived by multiplication of the values given in Table 6.6-11 with the maximum flow focusing factor of about five. (The mean values remain unchanged for a large enough sample, because of mass conservation.) This yields maximum values of about $200 \mathrm{~mm} /$ year for the present-day climate, about $640 \mathrm{~mm} /$ year for the monsoon climate, and about $960 \mathrm{~mm} /$ year for the glacial transition climate (using the mean infiltration scenario). For the upper-bound scenario, the theoretical maximum flux during the glacial transition climate is over $1,400 \mathrm{~mm} /$ year, which is beyond the flux range studied with the SMPA. One must note, however, that these maximum fluxes are extremely unlikely, caused by the extremely small probability that two independent events have extreme parameter values at the same time ${ }^{4}$.

There are several sources of uncertainty related to the percolation flux estimates. Uncertainty related to the future climate and net infiltration at Yucca Mountain is covered using three alternative infiltration scenarios. These scenarios, used as input to the UZ Flow Model, lead to alternative rock property calibrations and alternative percolation flux distributions that are accounted for in TSPA with their respective occurrence probability. Uncertainty related to simulation of flow processes in the UZ has been addressed by careful calibration and validation of the model to a wide variety and large amount of data from different sources (BSC 2004 [DIRS 169861], Sections 6 and 7). For the scope of evaluating seepage, the most important sources of uncertainty are the flow diversion capacity of the PTn and the impact of spatial variability within stratigraphic units. The impact of the PTn flow diversion is addressed in Section 6.8.2, where seepage rates are estimated using results of an alternative flow model for the PTn, one that does not allow for significant lateral flow. It is shown that the alternative flow model does not significantly impact the seepage estimates. The effect of intermediate-scale spatial variability, not accounted for in the UZ model results, is explicitly incorporated in the seepage abstraction model using the flow focusing concept. It is recognized that the flow focusing factors used in the seepage abstraction model may be overestimating the variability of percolation flux, because a fine grid resolution was used for the numerical study. Therefore, the resulting flux distributions used for seepage evaluation are expected to cautiously cover the spatial variability of this parameter and all related uncertainties. Thus, the flow focusing distribution comprises contributions from both aleatory and epistemic uncertainty.

\footnotetext{
${ }^{4}$ The small probability of extreme percolation flux events is evident from the probabilistic seepage calculation in Section 6.8.1. For the glacial transition climate and the mean infiltration scenario, the maximum sampled percolation flux (including spatial variability and flow focusing) from 10,000 random samples is 639 mm/year, compared to the theoretical maximum of about $960 \mathrm{~mm} /$ year. Using the upper bound infiltration scenario, the maximum sampled flux is $998 \mathrm{~mm} /$ year, compared to the theoretical maximum of 1,400 mm/year. (These values are given by variable xffomax in the Mathcad spreadsheets tptpll_glaq_ma.mcd and tptpll_glaq_ua.mcd, as explained in Appendix E and provided in Output-DTN LB0407AMRU0120.002.)
} 


\subsection{SUMMARY OF SEEPAGE ABSTRACTION}

\subsubsection{TSPA Seepage Calculation Methodology and Relevant Abstraction Results}

This section provides a roadmap of the proposed methodology for the TSPA seepage calculations (Output DTN: LB0407AMRU0120.001). The relevant calculation steps are briefly summarized together with the relevant parameter distributions and simplifications. The reader is referred to Sections 6.4, 6.5, and 6.6 of this model report for the rationale behind the abstraction methodology.

Seepage is treated as a probabilistic process in the TSPA-LA simulations (Figure 6.5-1). The TSPA seepage component conducts a stochastic evaluation of seepage over a large number of realizations $\mathrm{R}$, covering seepage uncertainty, and locations $\mathrm{r}$, covering seepage variability. The seepage evaluation has two main steps: (1) deriving ambient seepage rates from seepage look-up tables provided by the SMPA (for both nondegraded and collapsed drifts), and (2) adjusting the ambient seepage rates for other important factors such as thermal effects on seepage, drift degradation, and rock bolts, if necessary. Both steps are explained in detail in the previous sections. According to the definitions in Section 6.1.3, the seepage rates are given for a reference drift section of 5.1 meter length; as a result, they correspond to the amount of water that potentially drips on one waste package of average length.

\subsubsection{Step 1: Ambient Seepage}

Ambient seepage is a function of three key parameters: capillary strength $1 / \alpha$, permeability $k$, and percolation flux $q_{\text {perc,ff. }}$ Probability distributions have been developed within the abstraction process to represent the spatial variability and uncertainty inherent in these parameters. These distributions distinguish explicitly between spatial variability and uncertainty.

Four different methods have been identified in Section 6.6.2 to derive statistical parameters for describing the spatial variability and uncertainty in $1 / \alpha$. The four statistical methods provide four different probability distributions for spatial variability and uncertainty defined below (Table 6.6-2). Methods A and B arrive at similar distributions for all the geological units, Methods C and D have separate distributions for the nonlithophysal and lithophysal units. These four methods are to be used as four equally probable alternative representations of spatial variability and uncertainty in the capillary-strength parameter.

- Parameter Space for Capillary-Strength Parameter 1/ $\alpha$ using Methods A and B (Method B values in parentheses):

Spatial Variability Distribution (Section 6.6.2.2 and Table 6.6-2): Uniform Distribution with Mean $591 \mathrm{~Pa}$ (631 Pa). Lower Bound is $402 \mathrm{~Pa}$ (442 Pa). Upper Bound is $780 \mathrm{~Pa}(820 \mathrm{~Pa})$.

Uncertainty Distribution (Section 6.6.2.3 and Table 6.6-2): Triangular Distribution with Mean 0. Lower Bound is $-105 \mathrm{~Pa}(-162 \mathrm{~Pa})$. Upper Bound is +105 $\mathrm{Pa}$ (+162 Pa).

These distributions are identical for all units (Tptpll, Tptpul, Tptpmn, Tptpln), see Section 6.6.4. 
- Parameter Space for Capillary-Strength Parameter 1/ $\alpha$ using Methods C and D (Method $\mathrm{D}$ values in parentheses):

- Tptpmn Unit:

Spatial Variability Distribution (Section 6.6.2.2 and Table 6.6-2): Uniform Distribution with Mean $604 \mathrm{~Pa}(650 \mathrm{~Pa})$. Lower Bound is $377 \mathrm{~Pa}$ (427 Pa). Upper Bound is $831 \mathrm{~Pa}(873 \mathrm{~Pa})$.

Uncertainty Distribution (Section 6.6.2.3 and Table 6.6-2): Triangular Distribution with Mean 0. Lower Bound is $-198 \mathrm{~Pa}(-273 \mathrm{~Pa})$. Upper Bound is $+198 \mathrm{~Pa}$ (+273 Pa).

These distributions for the Tptpmn unit are also used for the Tptpln unit (Section 6.6.4).

- Tptpll Unit:

Spatial Variability Distribution (Section 6.6.2.2 and Table 6.6-2): Uniform Distribution with Mean $582 \mathrm{~Pa}(613 \mathrm{~Pa})$. Lower Bound is $400 \mathrm{~Pa}$ (384 Pa). Upper Bound is $764 \mathrm{~Pa}(841 \mathrm{~Pa})$.

Uncertainty Distribution (Section 6.6.2.3 and Table 6.6-2): Triangular Distribution with Mean 0. Lower Bound is $-129 \mathrm{~Pa}(-279 \mathrm{~Pa})$. Upper Bound is $+129 \mathrm{~Pa}$ (+279 Pa).

These distributions for the Tptpll unit are also used for the Tptpul unit (Section 6.6.4).

The spatial variability and uncertainty distributions for permeability are defined as follows (Section 6.6.3):

- Parameter Space for Permeability k (in $\log 10\left[\mathrm{~m}^{2}\right]$ )

- Tptpmn Unit:

Spatial Variability Distribution (Section 6.6.3.2.1): Lognormal Distribution with Mean -12.2 in $\log 10\left[\mathrm{~m}^{2}\right]$ and Standard Deviation 0.34 .

Uncertainty Distribution (Section 6.6.3.3): Triangular Distribution with Mean 0. Lower Bound is -0.68. Upper Bound is +0.68 .

The permeability distributions for the Tptpmn unit are also used for the Tptpln unit (Section 6.6.4).

- Tptpll Unit:

Spatial Variability Distribution (Section 6.6.3.2.2): Lognormal Distribution with Mean -11.5 in $\log 10\left[\mathrm{~m}^{2}\right]$ and Standard Deviation 0.47.

Uncertainty Distribution (Section 6.6.3.3): Triangular Distribution with Mean 0. Lower Bound is -0.92 . Upper Bound is +0.92 .

The permeability distributions for the Tptpll unit are also used for the Tptpul unit (Section 6.6.4). 
Values for $1 / \alpha$ and $k$ sampled from the spatial variability distributions are adjusted using values for $\Delta 1 / \alpha$ and $\Delta k$ sampled from the uncertainty distributions, to arrive at the final parameter distribution covering both spatial variability and uncertainty (Section 6.5.1.1).

The procedure for sampling percolation fluxes is slightly different (Section 6.5.1.1). The percolation flux distributions are provided by model results from the UZ Flow Model (DTN: LB0302PTNTSW9I.001 [DIRS 162277]). These spatial distributions are time dependent; they are given separately for three climate stages (present-day, monsoon, and glacial transition), during which the flow fields are considered steady state (Section 6.6.5.1). Uncertainty is expressed by three different scenarios of spatial flux distributions (mean, upper-bound, and lower-bound scenario), each of them associated with a certain occurrence probability (provided to TSPA in a separate model report). (Note that the nine flux distributions simulated using an alternative conceptual model for flow diversion in the PTn do not need to be considered in the TSPA.) The TSPA-LA seepage component samples from the spatial flux distribution at given locations $\mathrm{r}$ within the repository area, using the present-day, monsoon, or glacial transition flow field, depending on the considered time step. Over the R uncertainty realizations, the three flux scenarios are weighted according to their occurrence probability.

It should be pointed out for clarification that TSPA-LA will sample percolation flux at locations consistent with the numerous repository locations chosen for drift-scale TH simulations conducted with the Multiscale Thermohydrologic Model, which is described in BSC (2004 [DIRS 169565]). These simulations provide TSPA-LA with the future in-drift TH conditions, which are important, for example, to estimate corrosion of canisters. For each simulated location, the Multiscale Thermohydrologic Model imposes downward fluxes at its upper boundary that have been interpolated from percolation flux distributions at the PTn/TSw-boundary provided by the UZ Flow Model in DTN: LB0302PTNTSW9I.001 [DIRS 162277]. Rather than using the original data source, TSPA-LA uses the interpolated percolation flux values from the Multiscale Thermohydrologic Model in the TSPA seepage calculation. Thus, while technically extracted from the Multiscale Thermohydrologic Model, the percolation flux distributions used in TSPA-LA represent the flux values and their variability as predicted by the UZ Flow Model (DTN: LB0302PTNTSW9I.001 [DIRS 162277]).

These sampled percolation fluxes $q_{\text {perc }}$ need to be adjusted for intermediate-scale heterogeneity, which is not represented in the flux distributions from the UZ Flow Model. This is done using a spatial distribution of flow focusing factors $f_{f f}$ (Section 6.6.5.2) Multiplication of the sampled fluxes $q_{p e r c}$ from the site-scale model with the flow focusing factors $f_{f f}$ gives the local percolation flux $q_{\text {perc,ff }}$ to be used in the TSPA calculation. The spatial variability distribution for the flow focusing factor is defined as follows (DTN: LB0406U0075FCS.002 [DIRS 170712]):

- Flow Focusing Factor $f_{\text {ff }}$

- Spatial Variability Distribution (Section 6.6.5.2.1): Cumulative Probability Distribution given as $y=-0.3137 \mathrm{x}^{4}+5.4998 \mathrm{x}^{3}-35.66 \mathrm{x}^{2}+102.3 \mathrm{x}-11.434$ with $\mathrm{x}$ : flow focusing factor, $\mathrm{y}$ : cumulative frequency in $\%$

- Distribution is defined for $0.116<\mathrm{x}<5.016$ and $0 \leq \mathrm{y} \leq 1$

- Uncertainty Distribution: No Uncertainty. 
Note that the respective probability distributions for capillary strength, permeability, percolation flux, and flow focusing factor are not correlated (Section 6.5.1.1). This means that the random variables used to sample from the respective distributions should be generated independently in the TSPA.

For each set of seepage-relevant parameters $1 / \alpha, \mathrm{k}$, and $\mathrm{q}_{\mathrm{perc}, \mathrm{ff}}$ derived in the random sampling procedure over $\mathrm{R}$ realizations and $\mathrm{r}$ locations, seepage rates are calculated using the seepage look-up tables provided by the SMPA simulation results. These look-up tables are available for nondegraded drifts (DTN: LB0304SMDCREV2.002 [DIRS 163687]) as well as for collapsed drifts (DTN: LB0307SEEPDRCL.002 [DIRS 164337]). For both look-up tables, the SMPA simulation cases cover the parameter values given below. All possible combinations of these values were simulated in the systematic SMPA analysis, and a complete suite of results is provided in the seepage look-up tables (Section 6.4.2.3).

- SMPA Simulation Cases

- Capillary-Strength Parameter 1/ $\alpha$ : 100 to 1,000 Pa (intervals of $100 \mathrm{~Pa}$ )

- Permeability k: -14.0 to -10.0 (intervals of 0.25 )

- Local Percolation Flux qperc,ff: $1 ;$ 5; 10; 20; 50; 100; 200; 300; 400; 500; 600; 700; 800; 900; $1,000 \mathrm{~mm} /$ year

TSPA will select the appropriate look-up table, depending on the considered geologic unit and the considered nominal or disruptive scenario. This selection is based on categories of drift degradation that have been introduced in Section 6.5.1.5, based on results from BSC (2004 [DIRS 166107]). Category 1 comprises degraded drifts that may show local rock breakout but stay essentially intact. In this category, seepage is interpolated from the look-up table for nondegraded drifts. All drifts located in nonlithophysal rock are included in Category 1, regardless of the considered nominal or seismic scenario. For drifts located in lithophysal rock, all nominal cases (including thermal stress and rock strength degradation) and seismic events less severe than the $1 \times 10^{-4}$ seismic hazard level (peak ground motion velocity smaller than $0.384 \mathrm{~m} / \mathrm{s}$ ) are included in Category 1. Category 2 comprises the cases with complete drift collapse. These include all other seismic events occurring in lithophysal rock units, i.e., all seismic events with annual occurrence probability equal to or lower than $10^{-4}$ (peak ground motions equal or greater than $0.384 \mathrm{~m} / \mathrm{s}$ ). In this category, seepage is interpolated from the look-up table for collapsed drifts. If the time of a seismic event leading to drift collapse is not explicitly considered in TSPA, the collapsed drift scenario should be used for the entire postclosure period when one of the strength-induced collapsed drift scenarios is considered in TSPA. On the other hand, if the time of a seismic event leading to drift collapse is considered in TSPA, the collapsed drift scenario should be used, starting with the assumed time of the seismic event.

The seepage results for each sampled set of seepage-relevant parameters $1 / \alpha, k$, and $q_{p e r c, f f}$ derived in the random sampling procedure are calculated from a linear interpolation between the three independent seepage input parameters in the look-up tables (Section 6.5.1.2). It is possible (but unlikely) that the parameter range covered in the SMPA is exceeded for parameter values 
sampled from the probability distributions. The following recommendations are made in these cases:

- Truncation of Parameter Distributions

- If capillary strength is larger than 1,000 $\mathrm{Pa}$, set to 1,000 $\mathrm{Pa}$.

- If local percolation flux is less than $1 \mathrm{~mm} /$ year, set to $1 \mathrm{~mm} /$ year.

- If local percolation flux is more than $1,000 \mathrm{~mm} /$ year, set to $1,000 \mathrm{~mm} / \mathrm{year}$.

- If permeability is less than -14 , set to -14 (in log10).

- If permeability is larger than -10 , set to -10 (in log10).

The interpolated results from the seepage look-up tables are the mean seepage values $\bar{Q}_{\text {seep }}$ and the standard deviations $\sigma_{\text {seep }}$. The standard deviations represent the estimation uncertainty in the seepage results, which is different for each sampled set of parameters. Since this uncertainty must be included in the TSPA simulation, the interpolated mean seepage values $\bar{Q}_{\text {seep }}$ are adjusted using values for $\Delta \bar{Q}_{\text {seep }}$ sampled from appropriate uncertainty distributions (Section 6.5.1.3). These distributions are defined as follows:

- Uncertainty Distribution for Seepage Results

- Uniform distribution with Mean 0.

- $\quad$ Lower bound is $-1.7321 \times \sigma_{\text {seep }}$. Upper bound is $+1.7321 \times \sigma_{\text {seep }}$.

The mean seepage values $\bar{Q}_{\text {seep }}$ are adjusted by adding the sampled uncertainty value $\Delta \bar{Q}_{\text {seep }}$, which can be positive or negative, to the mean (i.e., the adjusted seepage rate can be higher or lower than the mean, depending on the sign of the sampled uncertainty value). After adjusting the seepage values to account for uncertainty, the results must be checked for consistency. If the resulting seepage rates are smaller than 0 , they are set to 0 . If the resulting seepage rates correspond to a seepage percentage larger than 100 percent, they are set to a rate corresponding to a seepage percentage of 100 percent. Another check of seepage results is conducted to identify sample cases with very small seepage rates that are mainly a result of the interpolation procedure. A seepage rate of $0.1 \mathrm{~kg} /$ year per waste package is suggested as a threshold for identifying such cases. This threshold is based on the observation that simulation cases with a seepage rate of less than $0.1 \mathrm{~kg} /$ year per waste package are extremely rare in the SMPA look-up table. In TSPA, locations with less than this threshold rate should be considered "no seepage," because such small values are mainly a result of the interpolation procedure. The final result of Step 1 of the TSPA seepage calculation is a probability distribution of ambient seepage rates (or seepage percentages) over $\mathrm{R}$ realizations and $\mathrm{r}$ locations, given for each time step studied in the TSPA simulation.

Three alternative abstraction methods are proposed for igneous events (see Section 6.5.1.7). The first method is to apply the seepage results obtained for nondegraded drifts, using the look-up table in DTN: LB0304SMDCREV2.002 [DIRS 163687]; the second method is to apply the 
seepage results for collapsed drifts, using the look-up table in DTN: LB0307SEEPDRCL.002 [DIRS 164337]; and the third method is to set the seepage percentage in intersected drifts to 100 percent (i.e., the seepage flux potentially contacting the waste is equal to the local percolation flux arriving at the drifts). In view of the significant uncertainty about the in-drift conditions after an igneous event, it is recommended that TSPA conduct sensitivity analyses with the three abstraction methods. The abstraction method that gives the highest seepage estimates should be chosen and propagated to the downstream TSPA modules. If the time of an igneous intrusion event is considered in TSPA, the selected abstraction method for igneous intrusion should be used, starting with the assumed time of the event.

\subsubsection{Step 2: Adjustments for Other Relevant Factors}

The ambient seepage distributions do not account for (1) alterations of seepage-relevant parameters as a result of heat-induced THM and THC effects, (2) alterations of seepage-relevant parameters as a result of drift degradation, (3) uncertainty related to seepage predictions for degraded drifts, and (4) thermal perturbations during the first several hundred years after emplacement when boiling occurs in the rock. The following adjustments are necessary to incorporate these additional factors into the seepage evaluation:

- THM and THC Alteration of $1 / \alpha$ and $\mathrm{k}$

The time-dependent alterations of these seepage-relevant parameters can (and should) be neglected in the seepage abstraction model (Section 6.5.1.4).

- Alteration of $1 / \alpha$ and $k$ as a Result of Drift Degradation

The degradation-induced alterations of these seepage-relevant parameters can be neglected in the seepage abstraction model (Section 6.5.1.5).

- Seepage Prediction Uncertainty for Degraded Drifts

For all collapsed drift cases, uncertainty is already accounted for in the interpolated seepage rates from the look-up table in DTN: LB0307SEEPDRCL.002 [DIRS 164337]. For noncollapsed cases, the ambient seepage rates, as interpolated from the look-up table in DTN: LB0304SMDCREV2.002 [DIRS 163687], are increased by 20 percent to account for additional uncertainty (Section 6.5.1.5). In this case, for large ambient seepage, the increased seepage rates may correspond to a seepage percentage larger than 100 percent. These are set to a rate corresponding to a seepage percentage of 100 percent. The reference area used to relate seepage rates and seepage percentages is $5.1 \mathrm{~m} \times 5.5 \mathrm{~m}$ in this case, i.e., the footprint of a 5.1-m long section of a nondegraded drift.

- Thermal Seepage

Two alternative abstraction approaches are used for the treatment of thermal seepage in the TSPA seepage calculation. The first abstraction model is very simple and provides upper-bounding estimates for thermal seepage; the second abstraction model is more 
realistic. The two abstraction approaches and their use in the TSPA seepage calculation are explained below:

Abstraction Model 1 is recommended for collapsed drifts (Sections 6.5.2.1 and 6.5.3). The model sets thermal seepage equal to the adjusted ambient seepage. In other words, the ambient seepage rates, giving the flow of liquid water from the formation into the rubble-filled drift, are not adjusted for thermal perturbation effects. The abstraction model is based on the model finding that in the case of drift collapse there is no vaporization barrier in the intact rock that prevents water flow from the formation into the rubble-filled drift. Note that for collapsed drifts, the ambient seepage rates used in the abstraction are determined using the look-up table for collapsed drifts (DTN: LB0307SEEPDRCL.002 [DIRS 164337]).

Abstraction Model 2 is recommended for nondegraded or moderately degraded drifts (Sections 6.5.2.1 and 6.5.2.2). The model sets thermal seepage to zero for the period of above-boiling temperatures in the drift vicinity. This approach takes credit for the vaporization barrier that prevents seepage during the period of above-boiling temperatures. The threshold temperature that defines the duration of the boiling period is conservatively set to $100^{\circ} \mathrm{C}$ because the boiling temeprature of water at the elevation of the emplacement drifts is about $96^{\circ} \mathrm{C}$. For the remaining time period (with belowboiling temperatures), thermal seepage is set equal to the adjusted ambient seepage rates. The abstraction is based on the model findings that thermal seepage never occurs at above-boiling temperatures and that the ambient seepage values provide an asymptotic upper limit for thermal seepage. For implementation of this model in the TSPA, detailed information is required about the duration of the boiling period for a large number of parameter cases. Note that for nondegraded or moderately degraded drifts, the ambient seepage rates are determined using the look-up table for nondegraded drifts (DTN: LB0304SMDCREV2.002 [DIRS 163687]), including the 20 percent uncertainty increase.

Seepage in ventilated drifts is highly unlikely. Therefore, in both thermal seepage abstraction models, seepage during the 50-year preclosure period can be neglected (Section 6.5.2.1).

\subsubsection{Step 3: Analysis of Seepage Results}

The final results of the TSPA seepage calculation are probability distributions of seepage rates appropriately incorporating all relevant factors, given for each time step. Statistical analyses can be conducted for a detailed evaluation of the seepage results in each time step. Such analyses can be conducted over all realizations and locations (uncertainty and spatial variability), or alternatively for one location over all realizations (uncertainty at one location) and one realization over all locations (spatial variability). Histograms reveal the shape of the respective distributions. Relating the mean seepage rate to the overall percolation flux demonstrates the barrier capability of the UZ, limiting the seepage of water into emplacement drifts. Dividing the total number of calculation cases (over realizations and locations) with a nonzero seepage rate by the total number of cases defines the seepage fraction $f_{\text {seep. }}$. This parameter is important because it reveals the fraction of waste packages potentially in contact with water. Other data processing 
of the seepage results (sorting, averaging, binning) may be needed for further use in downstream TSPA model components.

\subsubsection{Propagation of Uncertainty through the Abstraction}

Sources of uncertainty related to seepage-relevant parameters and seepage simulation results have been characterized in and propagated through the seepage abstraction for TSPA-LA. Uncertainty in the key parameters for ambient seepage (capillary strength, permeability, and percolation flux) has been explicitly represented through appropriate probability distributions (Section 6.6). The probabilities assigned to these key parameters distinguish between spatial variability (aleatory uncertainty) and uncertainty (epistemic uncertainty), using separate distributions. Spatial variability distributions for the capillary strength parameter and the local permeability have been derived in this model report by detailed statistical analysis of the sparsely distributed data (Sections 6.6.2 and 6.6.3). Spatial variability distributions for the local percolation flux are provided from site-scale simulations with the UZ Flow Model (Section 6.6.5.1). These fluxes are then adjusted to account for intermediate-scale heterogeneity, using a spatial distribution of flow focusing factors.

Uncertainty has been characterized by evaluation of potential sources for uncertaintyi.e., uncertainty in the measurements, the conceptual model, the estimation process, and the spatial variability. Information on uncertainty provided in upstream analyses or modeling has been included in this evaluation. Uncertainty inherent in the capillary strength parameter and the local permeability is described by triangular probability distributions (Sections 6.6.2 and 6.6.3). Alternative methods have been employed to derive statistical parameters describing the probability distributions for the capillary-strength parameter. It is recommended that the TSPA employs each method as an equally probable representation. Uncertainty in the percolation flux distributions is incorporated using three different flow scenarios (Section 6.6.5). In addition, an alternative flow scenario is evaluated in Section 6.8.2, but can be neglected in TSPA because of its limited impact.

Another contribution to uncertainty in the TSPA seepage calculations stems from the simulation results of drift-scale models that describe seepage-relevant processes. Drift-scale models are introduced in Section 6.4, including a detailed assessment of the respective model validation and corroboration with alternative conceptual models. As discussed in Section 6.5, the treatment of uncertainty in simulation results is based on this assessment and considers the respective use of the model in the abstraction. The estimation uncertainty of SMPA simulation results, used directly in TSPA-LA as a quantitative measure of seepage, is explicitly incorporated in the seepage abstraction model by uniform uncertainty distributions (Section 6.5.1.3). Other driftscale models provide quantitative and qualitative information used to adjust the SMPA seepage results for additional factors (THM and THC parameter alterations, drift degradation, rock bolts, and thermal seepage). These adjustments are generally based on simplifications of the more complex process model results. To incorporate uncertainty, these simplifications are chosen to be upper bounding cases for seepage. This means that the simplified abstractions tend to overestimate the seepage compared to the predicted process model results. THC parameter alterations, for example, were found to decrease the potential of seepage because of a precipitation umbrella forming a few meters above drifts. This process, however, is neglected in 
the abstraction because of considerable uncertainties in modeling the coupled THC processes (Section 6.5.1.4).

Two different approaches are chosen for ambient seepage estimates in degraded drifts. For noncollapsed drifts, the seepage rates are increased by 20 percent to account for uncertainty in the prediction (Section 6.5.1.5). For collapsed drifts, this increase is not necessary because this extreme degree of damage is related to a worst-case scenario that includes sufficient conservatism. Two alternative abstractions have been proposed for thermal seepage in nondegraded or moderately degraded drifts. The first approach is a simple bounding case; no incorporation of the vaporization barrier in superheated fractured rock takes place, so that the thermal seepage is not different from ambient seepage. The second approach is more realistic; it considers that there is no seepage during the period of above-boiling temperatures. To account for uncertainty, the threshold temperature used to define "above-boiling conditions" is chosen to be higher than the nominal boiling temperature of water (Section 6.5.2.2). For collapsed drifts, only the first approach is recommended (Section 6.5.3).

\subsection{SEEPAGE CALCULATION AND SENSITIVITIES}

In this section, a probabilistic calculation of seepage is conducted following the seepage abstraction method described in Sections 6.5 through 6.7. This calculation serves two purposes: (1) to demonstrate the barrier capabilities of the UZ and (2) to evaluate sensitivities in the abstraction process. As mentioned before, results from this calculation are not utilized in the performance assessment; they merely provide information on the expected seepage behavior for different test cases. However, they may be useful as corroborating information for validation of the seepage calculation procedure in the TSPA-LA. The TSPA-LA seepage component will perform a more comprehensive probabilistic seepage calculation within its Monte Carlo simulation procedure to provide the final seepage results used in the performance assessment.

The probabilistic analysis in this model report is conducted in a random procedure with sample size 10,000. For simplification, spatial variability and uncertainty distributions are simultaneously sampled in one calculational loop. In each random seepage case, noncorrelated random numbers are generated to sample from spatial variability distributions (for capillary strength, permeability, percolation flux, and flow focusing factor) and from uncertainty distributions (for capillary strength, permeability, and seepage uncertainty). In contrast, in the TSPA-LA calculation, uncertainty is sampled in an outer calculation loop over $\mathrm{R}$ realizations, while spatial variability is sampled in an inner calculation loop over $r$ spatial locations. These spatial locations will be selected in the TSPA-LA so that they are consistent with the numerous repository locations chosen for drift-scale $\mathrm{TH}$ simulations conducted with the Multiscale Thermohydrologic Model (BSC 2004 [DIRS 169565]) which feed into other abstractions (e.g., for the in-drift environment). In this model report, a simplified sampling procedure is utilized in the calculations below. The percolation flux values are randomly sampled using the probability distribution functions from the respective percolation flux fields (see histograms in Figures 6.6-11 and 6.6-12), without explicit consideration of the location in the repository area. Note that these differences may lead to minor differences in the predicted seepage results between the TSPA-LA calculation and the calculation conducted in this report. However, the main trends are not affected by these differences. 
The probabilistic seepage calculations are carried out using Mathcad 11, a standard technical calculation tool for solving mathematical problems of various kinds. The different Mathcad 11 spreadsheets developed for the several seepage calculation cases are provided in Appendix E. The mathematical calculation follows the seepage abstraction steps summarized in Section 6.7. Note that the base case seepage evaluation in Section 6.8.1 assumes noncollapsed drifts, using the appropriate look-up table from DTN: LB0304SMDCREV2.002 [DIRS 163687]. In Step 1 of the calculation, random numbers are generated to sample probabilistic parameter values from spatial variability distributions and to adjust them using respective uncertainty distributions. This is done for the three key parameters of ambient seepage, capillary strength, permeability, and percolation flux (the latter using site-scale fluxes and flow focusing factors). For each random parameter set, mean seepage rates and related standard deviations are interpolated from the look-up table, and the mean seepage rates are adjusted for seepage uncertainty. (The interpolation is conducted for the $k$-variable first, then for $1 / \alpha$, and finally for $q_{\text {perc,ff. }}$ ) Note that each seepage calculation case uses the same seed value for the random procedure. This ensures that the comparison of different sensitivity cases is not biased by artifacts of the random number procedure. Using a fixed random seed also ensures reproducibility of the results. In Step 2, the ambient seepage rates are corrected for the effect of drift degradation, increasing them by 20 percent (not done for collapsed drifts). The impact of thermal perturbation is not accounted for in this probabilistic seepage calculation; i.e., the proposed abstraction of thermal seepage (Abstraction Model 2 for intact drifts) is not explicitly applied. However, the benefit of using Abstraction Model 2 is briefly discussed below, assuming that the duration of the boiling period in all emplacement drifts corresponds to the duration of the present-day climate stage.

The following two sections give seepage calculation results for the base-case seepage evaluation (Section 6.8.1) and for selected sensitivity cases (Section 6.8.2). Histograms of the calculated seepage rates (in kg/year per waste package) and seepage percentages (relative to the percolation flux) are given for selected cases to demonstrate the variability of seepage over the 10,000 random cases. Summary results comprise the mean seepage rate and the mean seepage percentage, both of which are calculated over all 10,000 random cases with and without seepage, and the seepage fraction (fraction of cases with seepage). The mean seepage percentage is derived as the mean seepage rate (over all 10,000 random cases) related to the mean percolation flux (over the repository area). (This is different from simply averaging the 10,000 seepage percentage values). The seepage fraction is calculated using a threshold seepage rate of $0.1 \mathrm{~kg} /$ year per waste package. Locations with less than this threshold rate are considered "no seepage," because such small values are mainly a result of the interpolation procedure (simulation cases with a seepage rate of less than $0.1 \mathrm{~kg} /$ year per waste package are extremely rare in the SMPA look-up table).

\subsubsection{Base-Case Seepage Evaluation}

First, the probabilistic seepage analysis is presented for the Tptpll unit, the main repository unit according to the current repository design. Results of the seepage calculation are given separately for the three different infiltration scenarios (the mean, upper-bound, and lower-bound scenarios). In the TSPA-LA calculations, these separate results will be converted into one final distribution according to the respective occurrence probability of each scenario. These probabilities are given in the Analysis Report Analysis of Infiltration Uncertainty (BSC 2003 [DIRS 165991]). The seepage calculations in this section are conducted using the parameter 
distribution for capillary strength as derived from statistical Method A (see Table 6.6-2 and Section 6.6.2.2). The impact of applying the other distributions (from Methods B, C, and D) is evaluated in the sensitivity analysis in Section 6.8.2.

For illustration, Figures 6.8-1 and 6.8-2 present histograms of the calculated seepage rates and percentages for the mean infiltration scenario, showing only the random samples with nonzero seepage. (The great majority of the samples have zero seepage.) The seepage rates vary strongly, from small values below $0.1 \mathrm{~kg} /$ year per waste package up to almost $10,000 \mathrm{~kg} /$ year per waste package. (For comparison: A percolation flux of $500 \mathrm{~mm} /$ year that completely seeps into a 5.1-meter long drift section would give a seepage rate of more than $14,000 \mathrm{~kg} /$ year per waste package.) The seepage percentages also show considerable variability covering the entire range from 0 percent up to 100 percent. Most probable, however, are the small seepage percentages; only a few samples reach 80 percent seepage and more. In both figures, there is a clear trend of increasing seepage probability as a result of the climate changes from present-day to monsoon climate and from monsoon to glacial transition climate.

Table 6.8-1 gives summary results of the probabilistic analysis for the Tptpll unit, providing the mean seepage rate, the mean seepage percentage, and the seepage fraction, during the present-day, the monsoon, and the glacial transition climate. For the mean infiltration scenario, seepage is expected to occur at about 8 percent of all waste packages during the first 600 years after emplacement. This percentage rises to about 18 percent during the monsoon climate, and about 24 percent during the glacial transition climate. On average over all waste packages, the amount of seeping water is $1.7,17.5$, and $37.9 \mathrm{~kg} /$ year for the three climate stages, respectively. This translates to mean seepage percentages of 1.5 percent, 5.3 percent, and 7.5 percent. In other words, during the present-day climate, on average more than 98 percent of the percolation flux is diverted around drifts in the Tptpll unit. For the wetter climate stages of the monsoon and the glacial transition period, the mean percentage of diverted flux is smaller, but still at about 95 percent and 92 percent, respectively. This illustrates the barrier capability of the unsaturated flow processes in the fractured rock at and above the repository horizon.

As expected, the lower-bound infiltration scenario results in considerably less seepage. Here, the seepage fraction varies from about 1 percent for the present-day climate, to over 9 percent during the monsoon period, to 4 percent during the glacial transition climate. The respective mean seepage percentages are as low as 0.3 percent, 1.5 percent, and 0.9 percent. The opposite trend is seen for the upper-bound infiltration scenario, with the seepage fraction as high as 36 percent during the glacial transition climate. The mean seepage percentage during this climate stage is 11.8 percent. Thus, even for the upper-bound infiltration scenario with comparably strong downward percolation, the diversion capacity of the unsaturated rock is at least 88 percent.

The tabular values for mean seepage rate, mean seepage percentage, and seepage fraction are visualized in Figures 6.8-3 through 6.8-5, showing the evolution of seepage over time. Note that the time axis starts at 50 years after emplacement, i.e., of the beginning of the postclosure period. As a result of the forced ventilation with relatively dry air, seepage is not expected to occur during the 50-year preclosure period. For the mean and the upper-bound scenarios, the trend of seepage increase with changes in climate is clearly evident. The stepwise increases at 600 years and at 2,000 years are particularly strong for the mean seepage rates, which give the absolute 
amount of water seeping into drifts (Figure 6.8-3). Compared to the other two infiltration scenarios, the lower-bound infiltration scenario has much less seepage during all climate stages.

The seepage results displayed in Figures 6.8-3 through 6.8-5 can be used as a basis to discuss the benefit of using Abstraction Model 2 for thermal seepage into intact drifts. Abstraction Model 2 takes credit for a fully effective vaporization barrier during the time period that local rock temperatures in the drift vicinity are above boiling. For average percolation fluxes, this time period is expected to last for hundreds to more than one thousand years after waste emplacement (BSC (2004 [DIRS 169565]), Tables 6.3-6 and 6.3-7). For the discussion below, an average boiling period of 600 years is assumed in all emplacement drifts. The benefit of Abstraction Model 2 can be easily derived by setting the seepage flux, percentage, and fraction to zero during the present-day climate stage, in Figures 6.8-1 through 6.8-5 and in Table 6.8-1. It is obvious that the time period for a fully effective vaporization barrier coincides with the time period of relatively small ambient seepage compared to later climate stages. More benefit can be expected when the boiling period is longer than 600 years. In this case, the no-seepage period according to Abstraction Model 2 would extend into the monsoon climate stage, where the predicted ambient seepage is higher. 
(Present-day)

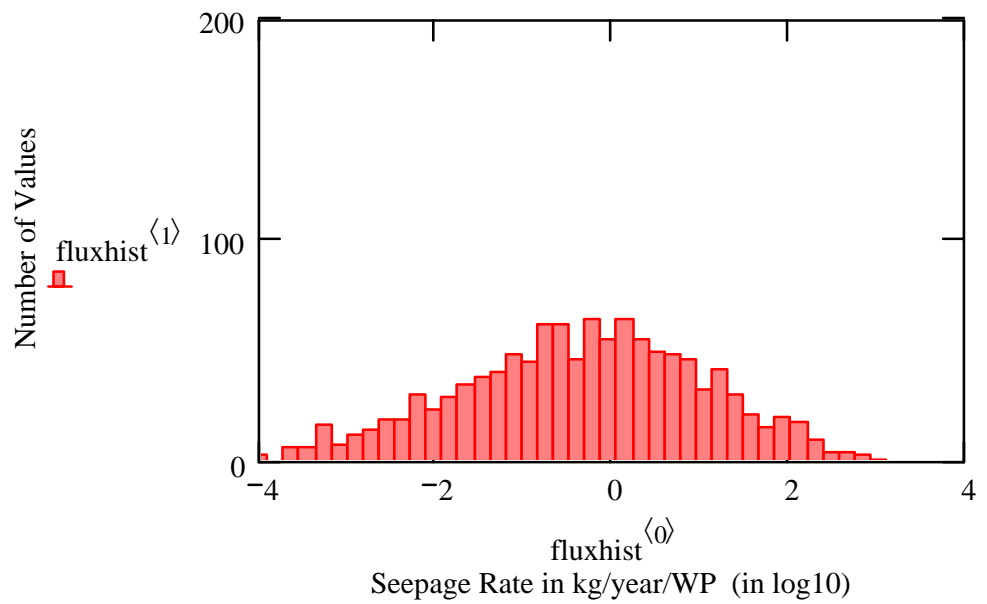

(Monsoon)

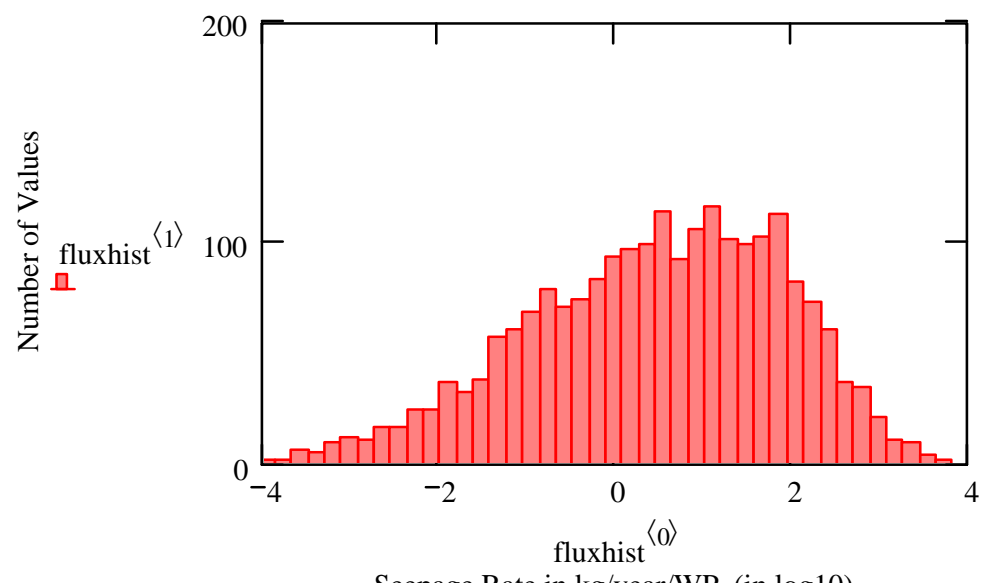

Seepage Rate in kg/year/WP (in log10)

(Glacial Transition)

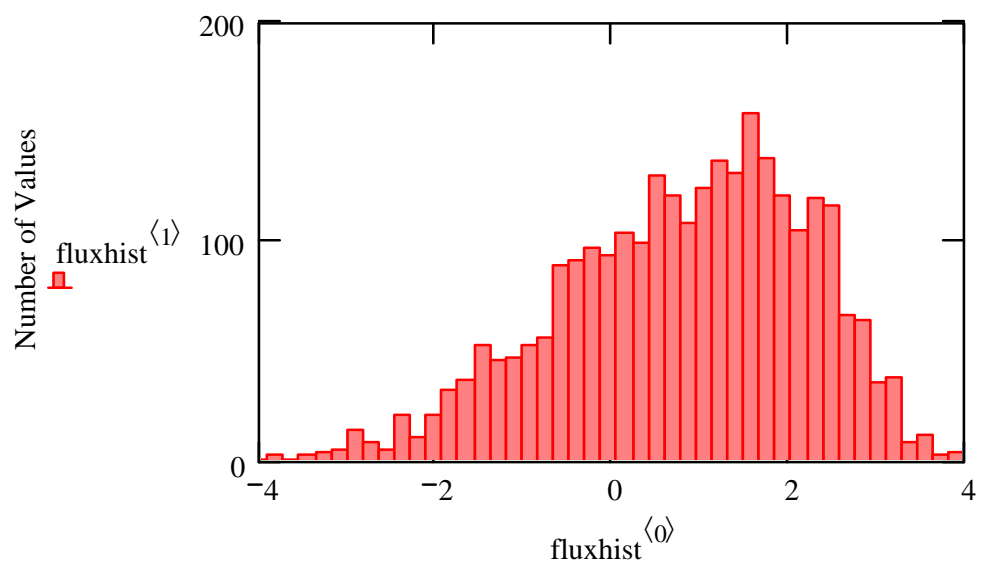

Seepage Rate in kg/year/WP (in log10)

Output DTN: LB0407AMRU0120.002

NOTE: The symbols in the histograms (i.e., fluxhist ${ }^{<>}$and fluxhist ${ }^{<1>}$ ) denote the variable names given in the Mathcad 11 spreadsheet used for the calculation, see Appendix E. Only the samples with non-zero seepage are depicted.

Figure 6.8-1. Histograms of Seepage Rates for Tptpll Unit 
(Present-day)

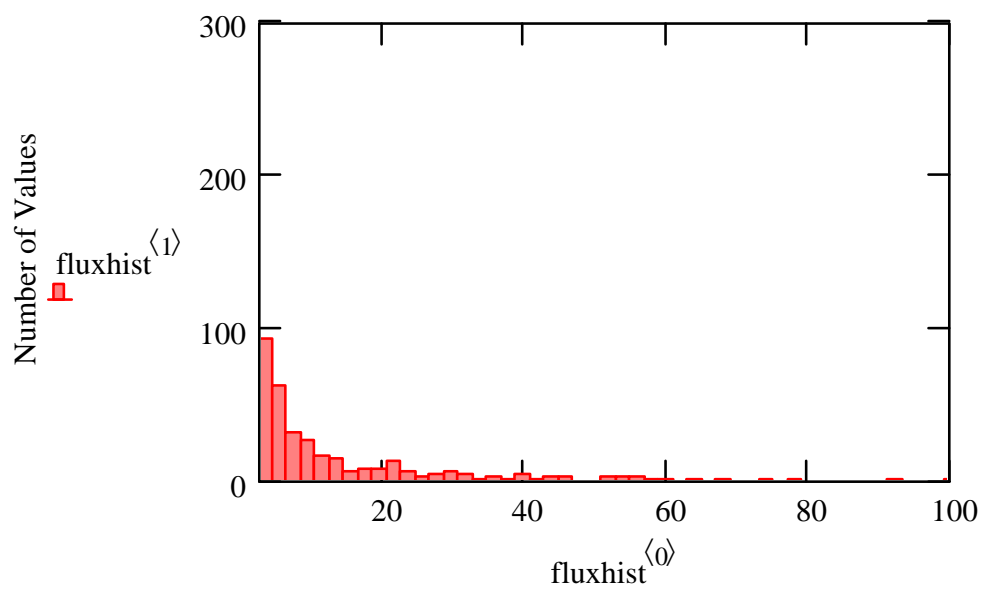

(Present-day)

(Monsoon)

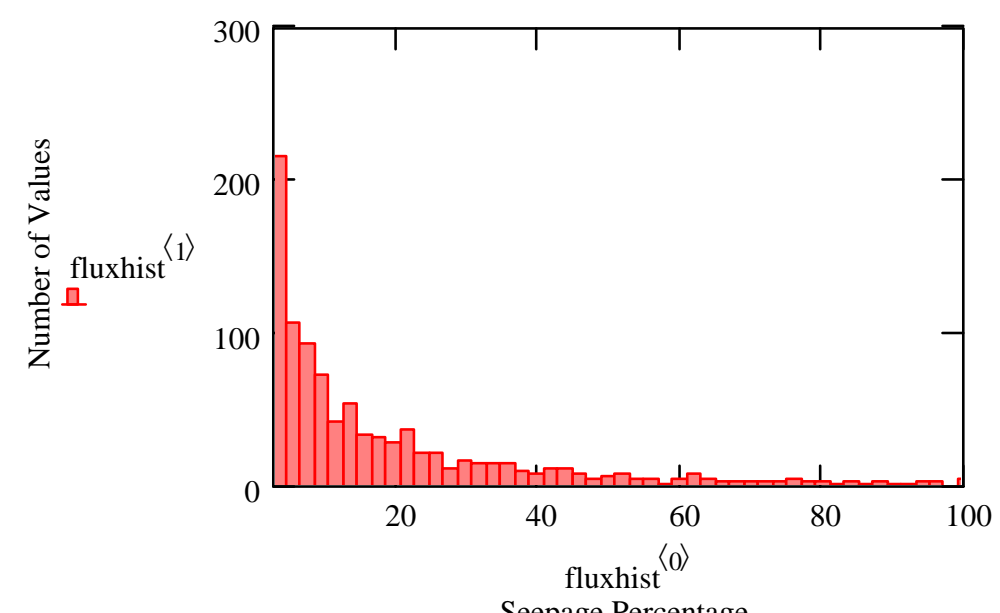

(Glacial Transition)

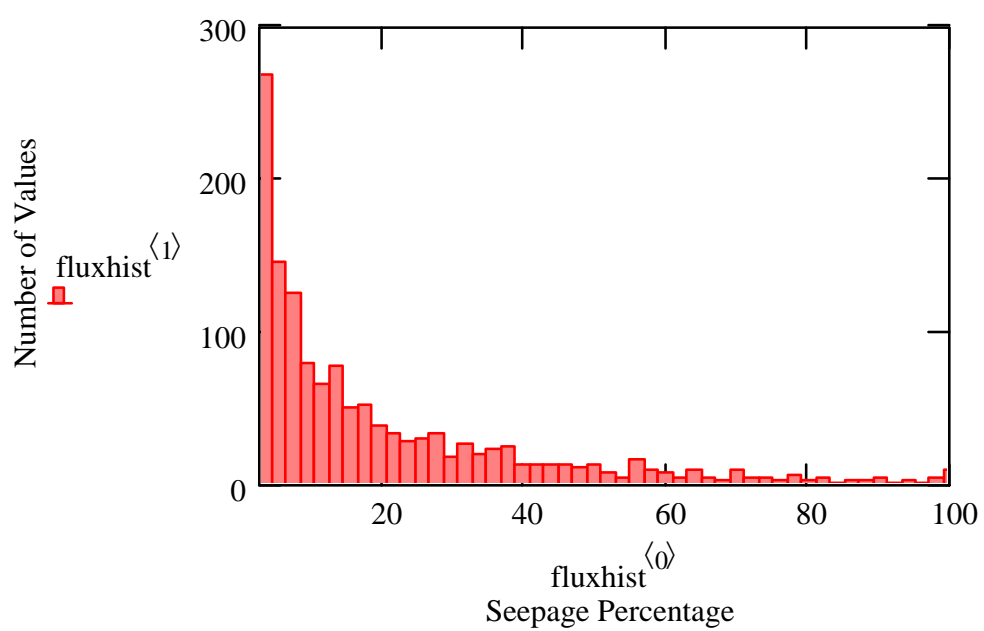

Output DTN: LB0407AMRU0120.002

NOTE: The symbols in the histograms (i.e., fluxhist ${ }^{<0>}$ and fluxhist ${ }^{<1>}$ ) denote the variable names given in the Mathcad 11 spreadsheet used for the calculation, see Appendix E. Only the samples with non-zero seepage are depicted.

Figure 6.8-2. Histograms of Seepage Percentages for Tptpll Unit 
Table 6.8-1. Summary Statistics for Probabilistic Seepage Evaluation (Tptpll Unit)

\begin{tabular}{|c|c|c|c|}
\hline \multicolumn{4}{|c|}{ Mean Infiltration scenario } \\
\hline Climate stage & $\begin{array}{c}\text { Mean Seepage Rate } \\
\text { (kg/year/WP) }\end{array}$ & $\begin{array}{l}\text { Mean Seepage } \\
\text { Percentage (\%) }\end{array}$ & Seepage Fraction (\%) \\
\hline Present Day & 1.7 & 1.5 & 7.9 \\
\hline Monsoon & 17.5 & 5.3 & 18.3 \\
\hline Glacial Transition & 37.9 & 7.5 & 24.2 \\
\hline \multicolumn{4}{|c|}{ Lower-Bound Infiltration scenario } \\
\hline Climate stage & $\begin{array}{c}\text { Mean Seepage Rate } \\
(\mathrm{kg} / \mathrm{year} / \mathrm{WP})\end{array}$ & $\begin{array}{l}\text { Mean Seepage } \\
\text { Percentage (\%) }\end{array}$ & Seepage Fraction (\%) \\
\hline Present Day & 0.0 & 0.3 & 0.8 \\
\hline Monsoon & 1.8 & 1.5 & 8.6 \\
\hline Glacial Transition & 0.5 & 0.9 & 3.9 \\
\hline \multicolumn{4}{|c|}{ Upper-Bound Infiltration scenario } \\
\hline Climate stage & $\begin{array}{c}\text { Mean Seepage Rate } \\
(\mathrm{kg} / \mathrm{year} / \mathrm{WP})\end{array}$ & $\begin{array}{l}\text { Mean Seepage } \\
\text { Percentage (\%) }\end{array}$ & Seepage Fraction (\%) \\
\hline Present Day & 13.1 & 4.2 & 18.3 \\
\hline Monsoon & 44.7 & 7.8 & 26.6 \\
\hline Glacial Transition & 117.5 & 11.8 & 36.0 \\
\hline
\end{tabular}

Output DTN: LB0407AMRU0120.002

NOTE: $\quad$ Computation documented in Appendix E.

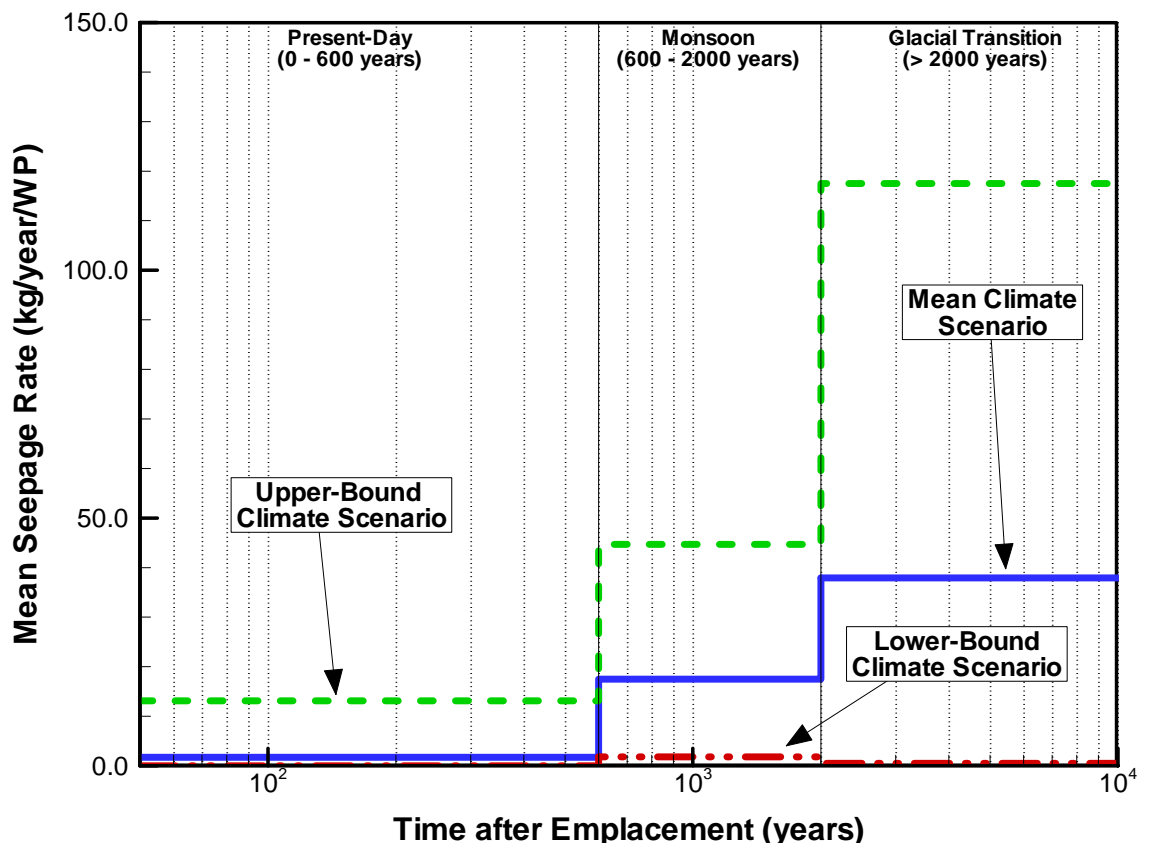

Source: Table 6.8-1; Output DTN: LB0407AMRU0120.002.

Figure 6.8-3. Mean Seepage Rate as a Function of Time after Emplacement for Tptpll Unit and Different Infiltration Scenarios 


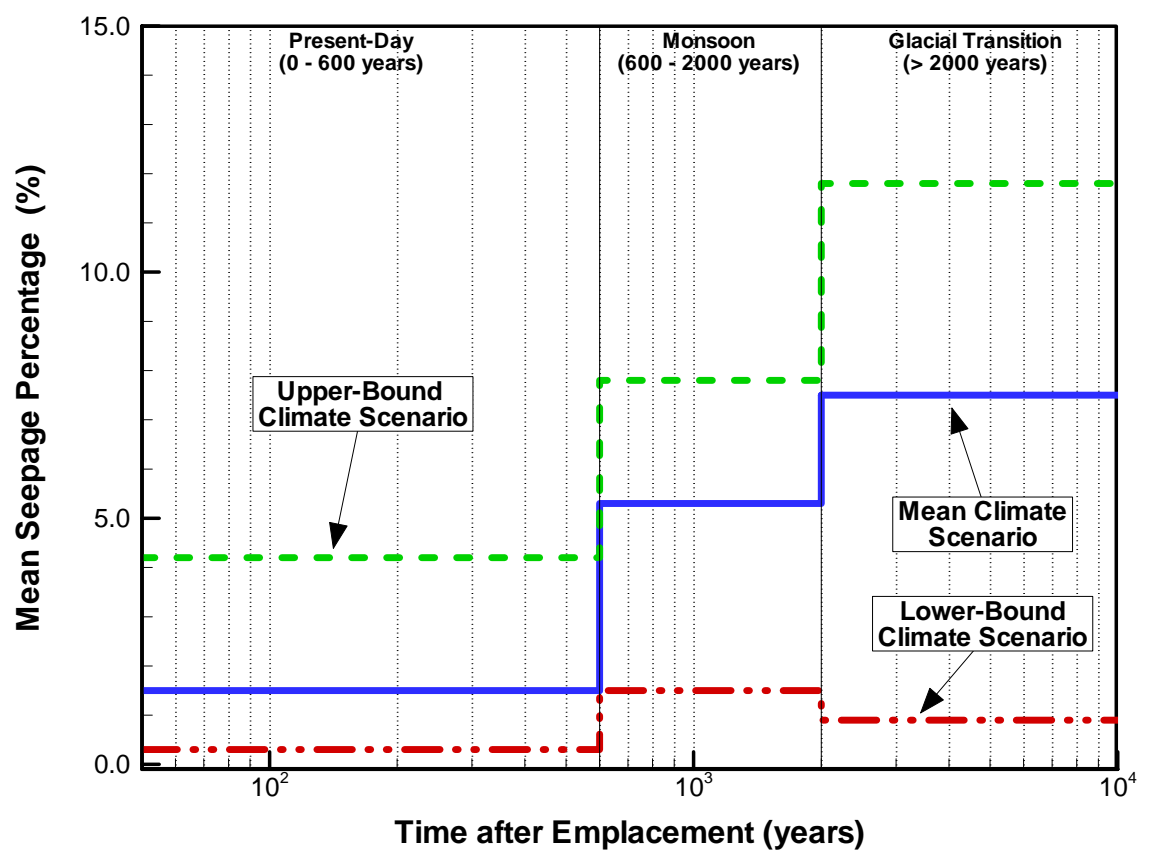

Source: Table 6.8-1; Output DTN: LB0407AMRU0120.002.

Figure 6.8-4. Mean Seepage Percentage as a Function of Time after Emplacement for Tptpll Unit and Different Infiltration Scenarios

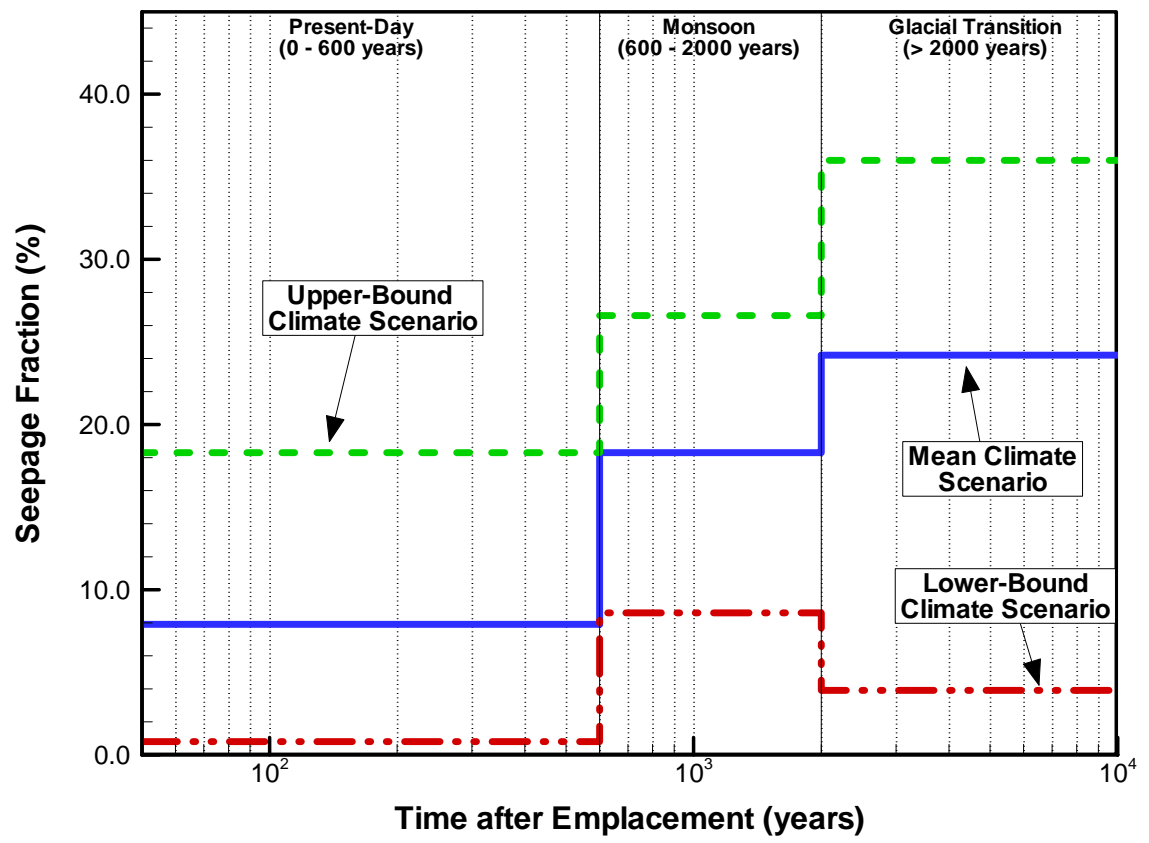

Source: Table 6.8-1; Output DTN: LB0407AMRU0120.002.

Figure 6.8-5. Seepage Fraction as a Function of Time after Emplacement for Tptpll Unit and Different Infiltration Scenarios 
Summary statistics for seepage in the Tptpmn unit are listed in Table 6.8-2, for the three climate stages and infiltration scenarios. Comparison with Table 6.8-1 indicates that considerably more seepage occurs at a larger number of locations in the Tptpmn unit compared to the Tptpll unit (i.e., higher mean seepage rate and percentage, higher seepage fraction). This is mainly a result of the smaller mean permeability assigned to the spatial variability distribution of the Tptpmn unit. Thus, with respect to seepage, the Tptpll unit is the better host rock unit compared to the Tptpmn unit. The trends in the seepage results-between the different climate stages and scenarios-are similar to the Tptpll unit.

Table 6.8-2. Summary Statistics for Probabilistic Seepage Evaluation (Tptpmn Unit)

\begin{tabular}{|c|c|c|c|}
\hline \multicolumn{4}{|c|}{ Mean Infiltration scenario } \\
\hline Climate stage & $\begin{array}{c}\text { Mean Seepage Rate } \\
\text { (kg/year/WP) }\end{array}$ & $\begin{array}{l}\text { Mean Seepage } \\
\text { Percentage (\%) }\end{array}$ & Seepage Fraction (\%) \\
\hline Present Day & 5.9 & 5.5 & 22.6 \\
\hline Monsoon & 50.6 & 15.3 & 41.6 \\
\hline Glacial Transition & 103.1 & 18.8 & 50.1 \\
\hline \multicolumn{4}{|c|}{ Lower-Bound Infiltration scenario } \\
\hline Climate stage & $\begin{array}{c}\text { Mean Seepage Rate } \\
\text { (kg/year/WP) }\end{array}$ & $\begin{array}{l}\text { Mean Seepage } \\
\text { Percentage (\%) }\end{array}$ & Seepage Fraction (\%) \\
\hline Present Day & 0.1 & 1.2 & 3.0 \\
\hline Monsoon & 6.6 & 5.5 & 24.6 \\
\hline Glacial Transition & 1.8 & 3.3 & 13.3 \\
\hline \multicolumn{4}{|c|}{ Upper-Bound Infiltration scenario } \\
\hline Climate stage & $\begin{array}{c}\text { Mean Seepage Rate } \\
(\mathrm{kg} / \text { year/WP) }\end{array}$ & $\begin{array}{l}\text { Mean Seepage } \\
\text { Percentage (\%) }\end{array}$ & Seepage Fraction (\%) \\
\hline Present Day & 41.0 & 13.0 & 42.3 \\
\hline Monsoon & 122.3 & 21.3 & 54.0 \\
\hline Glacial Transition & 294.6 & 29.6 & 65.4 \\
\hline
\end{tabular}

Output DTN: LB0407AMRU0120.002

NOTE: $\quad$ Computation documented in Appendix E.

As discussed in Section 6.5.1.2, sampled parameter values for capillary strength, permeability, and percolation flux are truncated if they fall outside of the parameter space covered by the SMPA look-up table. It is important for the validity of the seepage evaluation that the SMPA ranges are not exceeded in too many instances. Therefore, during the Mathcad calculation, the number of sampled values falling outside of the SMPA parameter space is counted and checked (see Appendix E for the parameter names in the Mathcad calculation). The results are as follows: The sampled capillary-strength parameter does not exceed the SMPA parameter range in this base-case seepage evaluation, where the parameter distribution is derived from Method A (see Table 6.6-2 and Section 6.6.2.2). In contrast, Method D may sporadically arrive at capillary-strength values larger than $1,000 \mathrm{~Pa}$, as demonstrated in Sensitivity Case 8 for Tptpll unit (Section 6.8.2). In the Tptpll unit and sampling from the probability distribution for Method D, a total number of 78 values is larger than 1,000 Pa. This number is sufficiently small compared to the total number of random cases. Similar results are obtained for permeability. In the Tptpll unit, none of the 10,000 permeability values is smaller than -14 (in log10) and a total of 72 values are higher than -10. Truncating at the upper permeability value, however, leads to 
higher overall seepage, because reducing permeability tends to increase the probability of seepage. Also, at this upper bound, seepage is only expected in extreme parameter cases. In the Tptpmn unit, with a narrower distribution for spatial variability and uncertainty, none of the sample values exceeds the parameter space. Considering the sampled percolation flux distributions, the number of flux values larger than $1,000 \mathrm{~mm} /$ year is zero for all climate stages and scenarios (see footnote in Section 6.6.5.3). Depending on the infiltration scenario, several sample values are smaller than $1 \mathrm{~mm} /$ year, the smallest percolation flux simulated with the SMPA. Truncating at this lower bound, however, is not significant because seepage hardly occurs at such small fluxes. The supporting seepage process models cover parameter spaces that safely include the vast majority of the sample cases in the random seepage evaluation. This ensures that the seepage evaluation results are not biased by sample truncation.

\subsubsection{Sensitivity Analysis}

Several sensitivity cases have been selected to identify how the overall amount of seepage and the seepage fraction in the repository may be affected by some choices made in the abstraction process. The sensitivity analysis is conducted only for the Tptpll unit using the mean infiltration scenario; the trends observed should be similar for the Tptpmn unit and should also be representative of other infiltration scenarios. Table 6.8-3 provides summary statistics for the respective sensitivity cases, giving the mean seepage rate, the mean seepage percentage, and the seepage fraction during the present-day, the monsoon, and the glacial transition climate. For comparison, the table not only provides the absolute seepage results for the considered case, but also the differences of these results from the base case (Table 6.8-1). A negative value indicates that the sensitivity case result is smaller than that of the base case (number in blue). A positive value indicates that the sensitivity case result is larger than that of the base case (number in red). Below, the sensitivity cases are discussed item by item.

\section{Normal Distribution for Spatial Variability of Capillary Strength Parameter}

As discussed in Section 6.6.2.2, the shape of the spatial variability distribution for the calibrated capillary strength parameter is not clearly indicated by the histogram of the data sample (Figure 6.6-2). Therefore, the distribution of choice for the TSPA-LA is a uniform distribution. For comparison, Sensitivity Case 1 utilizes a normal distribution instead of a uniform distribution. The seepage results using a normal distribution are almost identical to the base case, indicating a very small sensitivity to the shape of the distribution.

2. Normal Distribution for Uncertainty of Seepage Rate Predictions

Analysis of the SMPA results in Section 6.4.2.3 does not reveal a consistent trend for the uncertainty distribution describing the variability in seepage predictions from different realizations. Thus, a simple uniform distribution is selected in the abstraction for the TSPA-LA. In Sensitivity Case 2, a normal distribution is assumed as an alternative case. Again, the impact of choosing a different shape of the distribution is rather marginal, indicating a small sensitivity. 
3. No Spatial Variability in Permeability and Capillary Strength

Significant effort was devoted in Section 6.6 to define appropriate distributions describing the intermediate-scale variability of permeability and capillary strength over the repository area. Sensitivity Case 3 ignores the spatial variability of these seepage-relevant parameters. The seepage results in Table 6.8-3 indicates the considerable impact of using spatially uniform (but still uncertain) parameters. The overall amount of seepage (expressed in the mean seepage rate and the mean seepage percentage), as well as the seepage fraction, is considerably smaller than in the base case.

4. No Uncertainty in Permeability and Capillary Strength

Sensitivity Case 4 assumes that the uncertainty in the parameter distribution for the seepage-relevant parameters - permeability and capillary strength — can be neglected. (Spatial variability, however, is still considered, expressed by appropriate probability distributions.) Without uncertainty, the overall amount of seepage and the seepage fraction are smaller than in the base case. Comparison with Sensitivity Case 3 indicates that the impact of neglecting uncertainty is less significant than the impact of neglecting spatial variability.

5. Adjusted Mean Value of Spatial Variability Distribution for Permeability

In Sensitivity Case 5, the spatial variability distribution for fracture permeability is shifted to a larger mean value, from initially -11.5 to -11.0 (in $\log 10$ ). As discussed in Section 6.6.3.2, the small-scale permeability measurements conducted in Niche 1620 and in the ECRB suggest a mean permeability of about -11.0 in the excavation-disturbed zone around drifts. However, additional analysis of surface-based boreholes indicated that these permeability measurements might be on the high side, potentially representing a rather permeable region in the Tptpll unit. Therefore, the mean permeability value proposed for TSPA-LA seepage calculations was set half an order of magnitude smaller, to a value of -11.5. Sensitivity Case 5 uses the initial value of -11.0 to demonstrate the impact of this shift in the mean permeability. Having a higher permeability brings down the expected seepage in the Tptpll unit by a significant amount. During the glacial transition climate, for example, the mean seepage percentage decreases from 7.5 percent (base case) to 2.6 percent. Similarly, the seepage fraction changes from 24.2 percent (base case) to 11.3 percent during this climate stage. Thus, an increase in permeability reduces the overall amount of seepage as well as the number of waste packages contacted by water. The calculated numbers indicate that the proposed mean permeability of -11.5 clearly maximizes the seepage rate.

6. Adjusted Flow Focusing Factors

Flow focusing is described in the seepage abstraction model by a cumulative probability distribution giving maximum factors between 5 and 6 . Sensitivity Cases 6a, 6b, and 6c demonstrate the impact of flow focusing. Case 6a assumes 
that there is no flow focusing; i.e., the percolation flux distributions derived from the UZ Flow Model are directly applied for TSPA sampling (Section 6.6.5.1). Case $6 \mathrm{~b}$ uses the alternative flow focusing distribution introduced in Section 6.6.5.2.2. This alternative distribution has maximum flow focusing factors slightly above 2 . Thus, Cases $6 \mathrm{a}$ and $6 \mathrm{~b}$ provide seepage calculation results for no or less significant flow focusing. In contrast, Case $6 \mathrm{c}$ uses an extremely wide distribution of flow focusing factors, with a maximum factor of about 33. (The method of generating this wide distribution is described in Scientific Notebook Birkholzer 2003 [DIRS 164526], p. 137). Note that the considered distributions for flow focusing are all mass conservative; i.e., the mean of the distributions is always one. Thus, focusing of flow in one location (which tends to increase seepage) will reduce flow in other places (which tends to decrease seepage). The effect of this shift can be seen in the seepage calculation results. Having no flow focusing leads to a small increase in the seepage fraction (by as much as 10 percent compared to the base case), while the overall amount of seepage decreases considerably (by as much as 40 percent compared to the base case). During the glacial transition climate, for example, the mean seepage percentage decreases from 7.5 percent for the base case to 4.7 percent for the no-flow-focusing case. The sensitivity case with the alternative flow focusing distribution gives seepage results fairly similar to the no-flow-focusing case. The seepage rate and percentage are almost identical between Cases $6 \mathrm{a}$ and $6 \mathrm{~b}$, while the seepage fraction is slightly larger for the case with the alternative distribution. Compared to the base case, slightly more waste packages will have contact with water, but the average amount of water at these locations will be smaller for Cases 6a and 6b. In contrast, the wide distribution of flow focusing factors used in Case 6c leads to a strong increase in overall seepage (by a factor of three to five compared to the base case), combined with a significant decrease in the seepage fraction. As a result, fewer waste packages will have contact with water, but the amount of seepage at these locations will be very large.

7. Percolation Flux Distribution from Alternative PTn Flow Conceptualization

Alternative percolation flux distributions were introduced in Section 6.6.5.1, based on adjusted hydrological properties in the PTn unit. The impact of using these alternative distributions is analyzed in Sensitivity Case 7. The resulting differences in both the overall amount of seepage and the seepage fraction are small. Using the alternative flow fields leads to a minor increase in the mean seepage percentage combined with a small decrease in the seepage fraction. Because they have limited impact, alternative flow fields can be neglected in the TSPA-LA seepage evaluation.

\section{Alternative Methods for Definition of Capillary Strength Parameter Distribution}

As discussed in Section 6.6.2.2, four different methods have been employed to derive the mean and the standard deviation of sampled values of the capillary strength parameter $1 / \alpha$. The methods consider alternative statistical relationships between sample values measured in different geological units and at different 
locations, and they arrive at four alternative probability distributions for spatial variability and uncertainty of this parameter (see Section 6.7.1.1 for the definition of the four parameter distributions). Statistical tests have not provided a clear indication about the most appropriate method. It was recommended in Sections 6.6.2.2 and Section 6.7.1 that all four methods be included in TSPA as equally probable alternative representations of spatial variability and uncertainty in the 1/ $\alpha$-parameter. The base-case seepage results in Section 6.8.1 have been calculated using Method A. For comparison, Sensitivity Cases 8a, 8b, and 8c use parameter distributions for $1 / \alpha$ based on the statistical values derived using Methods B, C, and D, respectively. The resulting values of seepage percentage and fraction are slightly lower for Method B compared to Method A, whereas Methods C and D lead to slightly higher seepage estimates compared to Method A. Overall, the sensitivity of the seepage results to the evaluation method is rather small, providing confidence that the seepage calculation is not greatly affected by uncertainty about the statistical independence of the sample values.

9. Correlation between Sampled Values for Permeability and Capillary-Strength

The random sampling methodology described in Section 6.5.1.1 determines that the probability distributions for permeability and capillary strength are not correlated. This means that the random variables used to sample from the respective distributions should be generated independently in the TSPA. For comparison, this sensitivity case provides a probabilistic calculation of seepage assuming that the sampled values of permeability and capillary strength are negatively correlated. Instead of developing some constitutive relationship correlating the two parameters in question, the seepage calculation applies a simple correlation model that leaves the chosen probability distributions unchanged for the two parameters (i.e., a log-normal spatial variability for permeability and a uniform distribution for capillary-strength). In this model, the 10,000 sampled values for permeability and capillary strength (including spatial variability and uncertainty contributions) are sorted in ascending order. Then, for the seepage calculation, the smallest permeability value is used together with the largest capillary-strength value, the second-smallest permeability value with the secondlargest capillary-strength values, and so forth. Results of the calculation show clearly that this negative correlation can significantly decrease the seepage rates and the seepage fraction.

10. Correlation between Sampled Values for Permeability and Percolation Flux

The random sampling methodology described in Section 6.5.1.1 determines that the probability distributions for permeability and percolation flux are not correlated. This means that the random variables used to sample from the respective distributions should be generated independently in the TSPA. For comparison, Sensitivity Case 10 provides a probabilistic calculation of seepage assuming that the sampled values of permeability and percolation flux are positively correlated. Similar to Sensitivity Case 9, a simple correlation model is applied, where the 10,000 sampled values for permeability (including spatial 
variability and uncertainty contributions) and percolation flux (including spatial variability and flow focusing contributions) are first sorted in ascending order. Then, for the seepage calculation, the smallest permeability value is used together with the smallest percolation flux value, the second-smallest permeability value with the second-smallest percolation flux values, and so forth. Results of the calculation show clearly that this correlation significantly reduces the seepage rates and the seepage fraction.

\section{Collapsed Drift Scenarios}

Evaluation of seepage into collapsed drifts requires use of an alternative seepage look-up table given in DTN: LB0307SEEPDRCL.002 [DIRS 164337]. To demonstrate the impact of such extreme drift degradation on seepage, Sensitivity Case 11a provides probabilistic seepage estimates for collapsed drifts, using this alternative look-up table for seepage interpolation. As suggested in the proposed abstraction methodology for collapsed drifts in Section 6.5.1.5, the distributions of seepage-relevant parameters developed for the nondegraded drifts have not been adjusted for the impact of drift collapse; i.e., the seepage calculation uses the same probability distributions for permeability and capillary strength as in the nondegraded cases. The resulting values for seepage rates, percentages, and fractions have considerably increased compared to the base case values, indicating the importance of drift collapse. The strongest increase is in the seepage rates. As the footprint of the collapsed drifts has doubled in size, the amount of percolation flux arriving at the drift has also doubled. The seepage percentage for the collapsed case is calculated relative to the doubled percolation flux. Thus, the increase in this seepage parameter is not as strong as in the seepage rates.

Sensitivity Case 11b also utilizes the look-up table for collapsed drifts, and in addition accounts for the possible effect of drift collapse on seepage-relevant properties (i.e., permeability and capillary strength). As discussed in Section 6.4.4.1.2, estimated maximum values for these changes are a one-order-of-magnitude change in permeability and a 30 percent decrease in the capillary strength parameter. Thus, in Sensitivity Case 11b, the mean value of the spatial variability distribution of fracture permeability is decreased from -11.5 to -10.5 (in $\log 10$ ), whereas the mean value of the spatial variability distribution for the capillary strength parameter is reduced by 30 percent (from $591 \mathrm{~Pa}$ to $412 \mathrm{~Pa}$ ). Comparison between Sensitivity Cases 11a and 11b indicates that the impact of these parameter changes on the overall seepage results is small. Our conclusion is that the estimated effect of drift collapse on seepage-relevant properties can be safely neglected in the seepage calculations for collapsed drifts. 
Table 6.8-3. Summary Statistics for Seepage Sensitivity Cases (Tptpll Unit)

\begin{tabular}{|c|c|c|c|c|c|c|}
\hline \multicolumn{7}{|c|}{ 1. Normal Distribution for $1 / \alpha$ Instead of Uniform Distribution } \\
\hline Climate stage & \multicolumn{2}{|c|}{$\begin{array}{c}\text { Mean Seepage Rate } \\
(\mathrm{kg} / \text { /year/WP) }\end{array}$} & \multicolumn{2}{|c|}{$\begin{array}{l}\text { Mean Seepage } \\
\text { Percentage (\%) }\end{array}$} & \multicolumn{2}{|c|}{ Seepage Fraction (\%) } \\
\hline Present Day & 1.6 & -0.1 & 1.5 & 0.0 & 7.8 & -0.1 \\
\hline Monsoon & 17.2 & -0.3 & 5.2 & -0.1 & 18.2 & -0.1 \\
\hline Glacial Transition & 37.5 & -0.4 & 7.4 & -0.1 & 24.0 & -0.2 \\
\hline \multicolumn{7}{|c|}{ 2. Normal Distribution for Seepage Uncertainty Instead of Uniform Distribution } \\
\hline Climate stage & \multicolumn{2}{|c|}{$\begin{array}{l}\text { Mean Seepage Rate } \\
(\mathrm{kg} / \text { year/WP) }\end{array}$} & \multicolumn{2}{|c|}{$\begin{array}{l}\text { Mean Seepage } \\
\text { Percentage (\%) }\end{array}$} & \multicolumn{2}{|c|}{ Seepage Fraction $(\%$} \\
\hline Present Day & 1.4 & -0.3 & 1.3 & -0.2 & 7.6 & -0.3 \\
\hline Monsoon & 16.6 & -0.9 & 5.0 & -0.3 & 18.7 & +0.4 \\
\hline Glacial Transition & 36.6 & -1.3 & 7.3 & -0.2 & 24.8 & +0.6 \\
\hline \multicolumn{7}{|c|}{ 3. No Spatial Variability in Permeability and Capillary-Strength Parameter } \\
\hline Climate stage & \multicolumn{2}{|c|}{$\begin{array}{c}\text { Mean Seepage Rate } \\
(\mathrm{kg} / \text { year/WP })\end{array}$} & \multicolumn{2}{|c|}{$\begin{array}{l}\text { Mean Seepage } \\
\text { Percentage (\%) }\end{array}$} & \multicolumn{2}{|c|}{ Seepage Fraction (\%) } \\
\hline Present Day & 0.1 & -1.6 & 0.1 & -1.4 & 1.7 & -6.2 \\
\hline Monsoon & 5.6 & -11.9 & 1.7 & -3.6 & 10.3 & -8.0 \\
\hline Glacial Transition & 14.9 & -23.0 & 3.0 & -4.5 & 16.4 & -7.8 \\
\hline \multicolumn{7}{|c|}{ 4. No Uncertainty in Permeability and Capillary-Strength Parameter } \\
\hline Climate stage & \multicolumn{2}{|c|}{$\begin{array}{c}\text { Mean Seepage Rate } \\
(\mathrm{kg} / \text { year/WP) }\end{array}$} & \multicolumn{2}{|c|}{$\begin{array}{l}\text { Mean Seepage } \\
\text { Percentage (\%) }\end{array}$} & \multicolumn{2}{|c|}{ Seepage Fraction (\%) } \\
\hline Present Day & 0.9 & -0.8 & 0.8 & -0.7 & 4.8 & -3.1 \\
\hline Monsoon & 12.5 & -5.0 & 3.8 & -1.5 & 15.4 & -2.9 \\
\hline Glacial Transition & 28.6 & -9.3 & 5.7 & -1.8 & 21.0 & -3.2 \\
\hline \multicolumn{7}{|c|}{ 5. Adjusted Mean Permeability for Tptpll Unit: $k=-11.0$ instead of $k=-11.5$ (in log10) } \\
\hline Climate stage & \multicolumn{2}{|c|}{$\begin{array}{c}\text { Mean Seepage Rate } \\
(\mathrm{kg} / \text { year/WP) }\end{array}$} & \multicolumn{2}{|c|}{$\begin{array}{l}\text { Mean Seepage } \\
\text { Percentage (\%) }\end{array}$} & \multicolumn{2}{|c|}{ Seepage Fraction (\%) } \\
\hline Present Day & 0.4 & -1.3 & 0.4 & -1.1 & 2.4 & -5.5 \\
\hline Monsoon & 5.7 & -11.8 & 1.7 & -3.6 & 8.0 & -10.3 \\
\hline Glacial Transition & 13.3 & -24.6 & 2.6 & -4.9 & 11.3 & -12.9 \\
\hline \multicolumn{7}{|l|}{ 6a. No Flow Focusing } \\
\hline Climate stage & \multicolumn{2}{|c|}{$\begin{array}{c}\text { Mean Seepage Rate } \\
(\mathrm{kg} / \text { /year/WP) }\end{array}$} & \multicolumn{2}{|c|}{$\begin{array}{l}\text { Mean Seepage } \\
\text { Percentage (\%) }\end{array}$} & \multicolumn{2}{|c|}{ Seepage Fraction (\%) } \\
\hline Present Day & 0.9 & -0.8 & 0.9 & -0.6 & 8.1 & +0.2 \\
\hline Monsoon & 10.4 & -7.1 & 3.2 & -2.1 & 19.8 & +1.5 \\
\hline Glacial Transition & 23.6 & -14.3 & 4.7 & -2.8 & 26.6 & +2.4 \\
\hline \multicolumn{7}{|c|}{ 6b. Flow Focusing with Alternative Distribution (Maximum Flow Focusing Factor $f_{f f} \approx 2$ ) } \\
\hline Climate stage & \multicolumn{2}{|c|}{$\begin{array}{c}\text { Mean Seepage Rate } \\
(\mathrm{kg} / \text { year/WP) }\end{array}$} & \multicolumn{2}{|c|}{$\begin{array}{l}\text { Mean Seepage } \\
\text { Percentage (\%) }\end{array}$} & \multicolumn{2}{|c|}{ Seepage Fraction (\%) } \\
\hline Present Day & 0.9 & -0.8 & 0.8 & -0.7 & 8.1 & +0.2 \\
\hline Monsoon & 11.0 & -6.5 & 3.3 & -2.0 & 19.8 & +1.5 \\
\hline Glacial Transition & 25.0 & -12.9 & 5.0 & -2.5 & 26.3 & +2.1 \\
\hline
\end{tabular}


Table 6.8-3. Summary Statistics for Seepage Sensitivity Cases (Tptpll Unit) (Continued)

\begin{tabular}{|c|c|c|c|c|c|c|}
\hline \multirow{3}{*}{$\begin{array}{l}\text { 6c. Increased Flow } \\
\text { Climate stage } \\
\text { Present Day }\end{array}$} & \multirow{2}{*}{\multicolumn{2}{|c|}{$\begin{array}{c}\text { (Maximum Flow Focu } \\
\text { Mean Seepage Rate } \\
\text { (kg/year/WP) }\end{array}$}} & =actor & & \multirow{2}{*}{\multicolumn{2}{|c|}{ Seepage Fraction (\%) }} \\
\hline & & & \multicolumn{2}{|c|}{$\begin{array}{l}\text { Mean Seepage } \\
\text { Percentage (\%) }\end{array}$} & & \\
\hline & 10.6 & +8.9 & 9.5 & +8.0 & 5.3 & -2.6 \\
\hline Monsoon & 68.2 & +50.7 & 19.8 & +14.5 & 11.2 & -7.1 \\
\hline Glacial Transition & 127.2 & +89.3 & 24.1 & +16.6 & 14.1 & -10.1 \\
\hline \multicolumn{7}{|c|}{ 7. Percolation Flux Distribution From Alternative PTn Flow Conceptualization } \\
\hline Climate stage & \multicolumn{2}{|c|}{$\begin{array}{l}\text { Mean Seepage Rate } \\
\text { (kg/year/WP) }\end{array}$} & \multicolumn{2}{|c|}{$\begin{array}{l}\text { Mean Seepage } \\
\text { Percentage (\%) }\end{array}$} & \multicolumn{2}{|c|}{ Seepage Fraction (\%) } \\
\hline Present Day & 2.1 & +0.4 & 2.0 & +0.5 & 7.7 & -0.2 \\
\hline Monsoon & 20.1 & +2.6 & 6.0 & +0.7 & 17.2 & -1.1 \\
\hline Glacial Transition & 42.9 & +5.0 & 8.4 & +0.9 & 22.6 & -1.6 \\
\hline \multicolumn{7}{|c|}{ 8a. Spatial Variability and Uncertainty Distributions for $1 / \alpha$ Defined From Method B } \\
\hline Climate stage & \multicolumn{2}{|c|}{$\begin{array}{l}\text { Mean Seepage Rate } \\
\text { (kg/year/WP) }\end{array}$} & \multicolumn{2}{|c|}{$\begin{array}{l}\text { Mean Seepage } \\
\text { Percentage (\%) }\end{array}$} & \multicolumn{2}{|c|}{ Seepage Fraction (\%) } \\
\hline Present Day & 1.2 & -0.5 & 1.1 & -0.4 & 6.0 & -1.9 \\
\hline Monsoon & 14.0 & -3.5 & 4.2 & -1.1 & 15.0 & -3.3 \\
\hline Glacial Transition & 30.7 & -7.2 & 6.1 & -1.4 & 20.5 & -3.7 \\
\hline \multicolumn{7}{|c|}{ 8b. Spatial Variability and Uncertainty Distributions for $1 / \alpha$ Defined From Method C } \\
\hline Climate stage & \multicolumn{2}{|c|}{$\begin{array}{l}\text { Mean Seepage Rate } \\
\text { (kg/year/WP) }\end{array}$} & \multicolumn{2}{|c|}{$\begin{array}{l}\text { Mean Seepage } \\
\text { Percentage (\%) }\end{array}$} & \multicolumn{2}{|c|}{ Seepage Fraction (\%) } \\
\hline Present Day & 1.8 & +0.1 & 1.7 & +0.2 & 8.6 & +0.7 \\
\hline Monsoon & 18.8 & +1.3 & 5.7 & +0.4 & 19.4 & +1.1 \\
\hline Glacial Transition & 40.1 & +2.2 & 8.0 & +0.5 & 25.4 & +1.2 \\
\hline \multicolumn{7}{|c|}{ 8c. Spatial Variability and Uncertainty Distributions for $1 / \alpha$ Defined From Method D } \\
\hline Climate stage & \multicolumn{2}{|c|}{$\begin{array}{l}\text { Mean Seepage Rate } \\
\text { (kg/year/WP) }\end{array}$} & \multicolumn{2}{|c|}{$\begin{array}{l}\text { Mean Seepage } \\
\text { Percentage (\%) }\end{array}$} & \multicolumn{2}{|c|}{ Seepage Fraction (\%) } \\
\hline Present Day & 3.2 & +1.5 & 3.0 & +1.5 & 10.9 & +3.0 \\
\hline Monsoon & 24.1 & +6.6 & 7.3 & +2.0 & 20.4 & +2.1 \\
\hline Glacial Transition & 48.3 & +10.4 & 9.6 & +2.1 & 25.8 & +1.6 \\
\hline \multicolumn{7}{|c|}{ 9. Permeability Negatively Correlated to Capillary Strength } \\
\hline Climate stage & \multicolumn{2}{|c|}{$\begin{array}{l}\text { Mean Seepage Rate } \\
\text { (kg/year/WP) }\end{array}$} & \multicolumn{2}{|c|}{$\begin{array}{l}\text { Mean Seepage } \\
\text { Percentage (\%) }\end{array}$} & \multicolumn{2}{|c|}{ Seepage Fraction (\%) } \\
\hline Present Day & 0.2 & -1.5 & 0.2 & -1.3 & 1.2 & -6.7 \\
\hline Monsoon & 5.2 & -12.3 & 1.6 & -3.7 & 9.6 & -8.7 \\
\hline Glacial Transition & 13.5 & -24.4 & 2.7 & -4.8 & 16.6 & -7.6 \\
\hline \multicolumn{7}{|c|}{ 10. Permeability Correlated to Local Percolation Flux } \\
\hline Climate stage & \multicolumn{2}{|c|}{$\begin{array}{l}\text { Mean Seepage Rate } \\
\text { (kq/year/WP) }\end{array}$} & \multicolumn{2}{|c|}{$\begin{array}{c}\text { Mean Seepage } \\
\text { Percentage (\%) }\end{array}$} & \multicolumn{2}{|c|}{ Seepage Fraction (\%) } \\
\hline Present Day & $0.0^{1}$ & -1.7 & $0.0^{2}$ & -1.5 & 1.0 & -6.9 \\
\hline Monsoon & 0.1 & -17.4 & $0.0^{3}$ & -5.3 & 5.7 & -12.6 \\
\hline Glacial Transition & 0.4 & -37.5 & 0.1 & -7.4 & 12.4 & -11.8 \\
\hline
\end{tabular}


Table 6.8-3. Summary Statistics for Seepage Sensitivity Cases (Tptpll Unit) (Continued)

\begin{tabular}{|c|c|c|c|c|c|c|}
\hline \multirow{2}{*}{ Climate stage } & \multicolumn{2}{|c|}{$\begin{array}{c}\text { Mean Seepage Rate } \\
(\mathrm{kg} / \text { year/WP) }\end{array}$} & \multicolumn{2}{|c|}{$\begin{array}{l}\text { Mean Seepage } \\
\text { Percentage (\%) }\end{array}$} & \multicolumn{2}{|c|}{ Seepage Fraction (\%) } \\
\hline & 11.9 & +10.2 & 2.8 & +1.3 & 26.4 & +18.5 \\
\hline Monsoon & 89.5 & +72.0 & 6.8 & +1.5 & 42.3 & +24.0 \\
\hline Glacial Transition & 176.6 & +138.7 & 8.7 & +1.2 & 49.3 & +25.1 \\
\hline \multicolumn{7}{|c|}{$\begin{array}{l}\text { 11b. Seepage into Collapsed Drifts with Parameter Adjustment (Larger Permeability and Smaller } \\
\text { Capillary Strength) }\end{array}$} \\
\hline Climate stage & \multicolumn{2}{|c|}{$\begin{array}{l}\text { Mean Seepage Rate } \\
\text { (kg/year/WP) }\end{array}$} & \multicolumn{2}{|c|}{$\begin{array}{l}\text { Mean Seepage } \\
\text { Percentage (\%) }\end{array}$} & \multicolumn{2}{|c|}{ Seepage Fraction (\%) } \\
\hline Present Day & 14.0 & +12.3 & 3.2 & +1.7 & 26.7 & +18.8 \\
\hline Monsoon & 85.9 & +68.4 & 6.5 & +1.2 & 39.3 & +21.0 \\
\hline Glacial Transition & 161.8 & +123.9 & 8.0 & +0.5 & 44.9 & +20.7 \\
\hline
\end{tabular}

Output DTN: LB0407AMRU0120.002

NOTE: Left values in each column given seepage results for sensitivity case, right values give changes to base case. A negative value indicates that the sensitivity case result is smaller than that of the base case (number in blue). A positive value indicates that the sensitivity case result is larger than that of the base case (number in red). Computation documented in Appendix E.

1 Value is zero because of rounding; true value is $4.179 \times 10^{-3}$.

${ }^{2}$ Value is zero because of rounding; true value is $3.867 \times 10^{-3}$.

3 Value is zero because of rounding; true value is 0.03 .

The main results from the sensitivity analysis can be briefly summarized. The first two sensitivity cases prove that the chosen shape of the probability distributions for spatial variability of capillary strength and the uncertainty in seepage rates does not affect the seepage evaluation. As a consequence, the abstraction choice to use uniform distributions is supported. Sensitivity Cases 3 and 4 demonstrate that the consideration of spatial variability and uncertainty in seepage-relevant parameters $1 / \alpha$ and $k$ is important for seepage evaluation in TSPA-LA. Sensitivity Case 5 indicates the strong impact of the bounding-case parameter choice for permeability in the Tptpll unit. Additional air injection testing could be beneficial for this unit, to provide evidence that the mean permeability in the Tptpll unit should be higher than the one chosen in the abstraction (which would reduce the predicted seepage rates). As shown in Sensitivity Case 6, the distribution of flow focusing factors is also important for the seepage evaluation. In contrast to Sensitivity Cases 3, 4, and 5, where a consistent trend is seen in both the seepage percentage and the seepage fraction, a change in flow focusing factors results in opposite trends for these seepage parameters. An increase in the overall amount of seepage is associated with a decrease in the number of waste packages affected by seepage, and vice versa. Since it is not clear how such opposite trends affect the overall performance of the repository, the impact of using different distributions for flow focusing factors should be evaluated in further sensitivity testing, using the full TSPA model. Sensitivity Case 7 shows that the alternative flow conceptualization in the PTn unit is not important for the overall seepage evaluation. Sensitivity Cases 8a through 8c demonstrate that the seepage estimates are not strongly influenced by the evaluation method employed to define the spatial variability and uncertainty distribution for the capillary-strength parameter. Sensitivity Cases 9 and 10 investigate the impact of correlation between the probability distributions for permeability, capillary strength, and percolation flux. It is demonstrated that the suggested independent sampling of the three parameters tends to maximize the seepage rates and seepage fractions. The final sensitivity case shows the 
considerable impact of drift collapse on the seepage estimates compared to the nondegraded base case (Case 11a). Comparison between the two collapsed Sensitivity Cases 11a and 11b also demonstrates that excavation-disturbed properties for nondegraded drifts can be used to derive seepage estimates for collapsed drifts, because the net effect of degradation-induced alterations is small. 


\section{VALIDATION}

Water that seeps into drifts may contact waste packages and potentially mobilize radionuclides, and may result in advective transport of radionuclides through breached waste packages (BSC 2003 [DIRS 168796], Section 3.3.2). These processes can affect the performance of the repository. Therefore, a calculation of the amount and distribution of seepage is included in the TSPA-LA. The objective of this model report is to synthesize and simplify the relevant input from various upstream sources for the seepage calculations to be conducted in the TSPA-LA. The seepage abstraction model developed in this report is a model supporting seepage into emplacement drifts relevant to TSPA component model "Seepage into Emplacement Drifts." AP-2.27Q, Planning for Science Activities (Attachment 3, Table 1), requires Level I validation for models supporting seepage into emplacement drifts (models with less importance on annual dose).

The general validation criteria for Level I validation are listed in Attachment 3 of AP-2.27Q, Planning for Science Activities. Specifics to the validation criteria and activities for the seepage abstraction have been defined in the model validation plan of the original TWP Technical Work Plan for: Performance Assessment Unsaturated Zone, TWP-NBS-HS-000003 REV 02 (BSC 2004 [DIRS 167969], Attachment I, Section I-4-3-1). (Note that the recent TWP Technical Work Plan for: Unsaturated Zone Flow Analyses and Model Report Integration, TWP-MGR-HS-000001 REV 00 (BSC 2004 [DIRS 169654]) refers back to the original TWP for model validation of the seepage abstraction model). The model validation conducted in this model report is mostly consistent with the model validation plan. Model validation includes activities conducted during the model development process and activities for testing the model after development. There are minor differences between the following text sections and the model validation plan regarding model validation activities. These differences are related to minor changes between the current revision of AP-SIII.10Q and the revision that was in place when writing the model validation plan. These changes comprise, for example, minor modifications in the steps defined for confidence building during model development in Section 5.3.2(b) of AP-SIII.10Q. In case there are differences between the model validation plan and the definitions in the most current procedure, model validation was conducted according to the current procedure.

The seepage abstraction model developed in this model report is based on seepage predictions from detailed process models that have been validated in previous analyses, to ensure appropriate representation of the physical processes and relevant parameters (Section 6.4). As explained in Section 6.5, these results are either propagated to the TSPA-LA without changes (i.e., seepage look-up table) or have been simplified within the abstraction process (i.e., thermal seepage, THC and THM alterations, drift degradation, rock bolts). From the seepage look-up tables and the respective simplifications of additional model results, probabilistic seepage rates and uncertainties can be calculated as a function of seepage-relevant parameters. In the abstraction, appropriate spatial variability and uncertainty distributions have been developed for these parameters, based on either process model results (i.e., capillary strength, percolation flux) or in situ measurements (permeability).

Application of the developed abstraction model gives probabilistic seepage estimates for the future conditions in the entire repository, e.g., the expected probability distribution of seepage 
rates and the number of locations in the repository where seepage may occur. The validity of these final results depends on (1) the validity of the parameter distributions that feed into the seepage look-up tables, and (2) the validity of the seepage predictions that provide the look-up tables or serve as bases for certain simplifications. Thus, validation of the seepage abstraction model must demonstrate that (1) the input parameters for the seepage abstraction model are justified, (2) the seepage abstraction model captures the results provided by the process models in a qualitative and quantitative manner, and (3) uncertainties in the input parameters and the model results are appropriately incorporated.

The following Sections 7.1 and 7.2 describe the activities conducted for confidence building during and after model development, respectively. As mentioned above, these activities have been defined in the model validation plan of the TWP Technical Work Plan for: Performance Assessment Unsaturated Zone, TWP-NBS-HS-000003 REV 02 (BSC 2004 [DIRS 167969], Attachment I, Section I-4-3-1). In addition to these activities, Section 7.3 describes qualitative comparison of abstraction model results with auxiliary analyses including Yucca Mountain observations and natural analogues.

\subsection{CONFIDENCE BUILDING DURING MODEL DEVELOPMENT TO ESTABLISH SCIENTIFIC BASIS AND ACCURACY FOR INTENDED USE}

For confidence building during model development, Section 5.3.2(b) of AP-SIII.10Q specifies the following validation steps. Additional specifications are given in AP-2.27Q, Attachment 3. The development of the seepage abstraction model has been conducted according to these specifications, as follows:

1. Selection of input parameters and/or input data, and a discussion of how the selection process builds confidence in the model. [AP-SIII.10Q 5.3.2(b) (1) and AP-2.27Q Attachment 3 Level I (a)]

The input parameters used in the abstraction process have been carefully selected from appropriate seepage process models and from in situ testing; they are reasonable and consistent with the data. Process models that provide parameter input to the abstraction have been discussed and evaluated in Section 6.4. These process models have all been validated, typically in comparison with experimental data and through corroboration with alternative conceptual models. The seepage process models all have a consistent conceptual modeling framework similar to the SCM, an important requirement for predictive modeling of ambient and thermal seepage. The boundary conditions and parameter ranges applied to these process models are appropriate; they sufficiently cover the expected conditions and ranges at Yucca Mountain, including temporal changes and spatial variability of processes and properties. A significant effort was spent in the abstraction process to define appropriate probability distributions for the spatial variability and uncertainty of seepage-relevant parameters (Section 6.6). The spatial variability distributions for the capillary-strength parameter and permeability were developed from statistical calculations in Excel spreadsheets, using input from the SCM and from in situ air-injection tests. Both parameters have been derived on the appropriate scale representing the location of interest, i.e., the near-drift excavation-disturbed zone. The resulting distributions are significantly 
broader than those used for the stringent validation of the SCM. Percolation flux distributions were extracted from results of the UZ Flow Model, considering the additional impact of flow focusing. Uncertainty in these spatial variability distributions was identified and incorporated in the abstraction. This ensures validity of the input parameters that feed into the seepage abstraction model. The requirement is considered satisfied.

2. Description of calibration activities, and/or initial boundary condition runs, and/or run convergences, simulation conditions set up to span the range of intended use and avoid inconsistent outputs, and a discussion of how the activity or activities build confidence in the model. Inclusion of a discussion of impacts of any non-convergence runs. [(AP-SIII.10Q 5.3.2(b)(2) and AP-2.27Q Attachment 3 Level I (e)].

The seepage abstraction model is not a simulation model in the usual sense of a process model capturing physical processes. Therefore, since no numerical simulations are conducted, discussions of calibration activities and/or initial boundary condition runs, simulation conditions, and/or run convergences are not relevant for the seepage abstraction model developed in this model report. Process models that provide parameter input to the abstraction have been discussed and evaluated in Section 6.4. These process models have all been developed in compliance with the above requirements. Thus, this requirement can also be considered satisfied.

3. Discussion of the impacts of uncertainties to the model results including how the model results represent the range of possible outcomes consistent with important uncertainties. [(AP-SIII.10Q 5.3.2(b)(3) and AP-2.27Q Attachment 3 Level 1 (d) and $(f)]$

Relevant sources of uncertainty related to seepage-relevant parameters and seepage simulation results have been characterized in and propagated through the seepage abstraction (see summary discussion in Section 6.7.2). Uncertainty in spatial variability distributions, stemming from the limited number of intermediate-scale measurement locations, was identified and incorporated within the abstraction by use of triangular probability distributions. The spatial variability of percolation fluxes was provided by simulation results from the UZ Flow Model. To account for heterogeneity occurring below the resolution of this site-scale model, additional flux variability was incorporated using a spatial distribution of flow focusing factors. Furthermore, measurement and model uncertainty identified in the upstream sources feeding into this abstraction was accounted for. For example, seepage prediction uncertainty is explicitly included in the seepage abstraction by random sampling from a uniform uncertainty distribution, while uncertainty in the future climates and percolation fluxes is accounted for by three different infiltration scenarios. Other uncertainties are incorporated in the abstraction by means of using upper-bound seepage estimates. A sensitivity study was conducted in Section 6.8.2 to evaluate the sensitivity of the overall seepage in the repository to certain abstraction choices with regard to the treatment of spatial variability and uncertainty. This requirement can be considered satisfied. 
4. Formulation of defensible assumptions and simplifications. [AP-2.27Q Attachment 3 Level I (b)].

Discussion of assumptions and simplifications are provided in Section 5 and Section 6.5. There are no assumptions that pertain directly to the seepage abstraction model (Section 5). The simplifications made in Section 6.5 are consistent with the purpose of this model report, i.e., to develop an abstraction model that simplifies the complex process of seepage into drifts for incorporation into the TSPA-LA. These simplifications are adequate and defensible. Thus, this requirement can also be considered satisfied.

5. Consistency with physical principles, such as conservation of mass, energy, and momentum. [AP-2.27Q Attachment 3 Level I (c)]

The process models that provide parameter input to the abstraction have been discussed and evaluated in Section 6.4. Results from these upstream models are consistent with physical principles, such as conservation of mass, energy, and momentum. The simplifications made in the abstraction process are also consistent with physical principles (for example: the distribution of flow focusing factors for enhancing the variability of percolation flux is mass conservative). Thus, this requirement can also be considered satisfied.

\subsection{POST-DEVELOPMENT VALIDATION TO SUPPORT THE SCIENTIFIC BASIS OF THE MODEL}

For confidence building after model development, the model validation plan for seepage abstraction model imposes the following requirements for model validation (TWP-NBS-HS-000003 REV 02, BSC 2004 [DIRS 167969], Attachment I, Section I-4-3-1). The seepage abstraction model is to be validated by either one of two suggested methods. These are Method 6 in AP-SIII.10Q, Section 5.3.2(c), Corroboration of Abstraction Model Results with Results from the Validated Process Models, and Method 5 in AP-SIII.10Q, Section 5.3.2(d), Independent Technical Review. The validation method chosen for the seepage abstraction model is to demonstrate that the abstraction results are sufficiently close to the predictions of the supporting models (i.e., validation according to Method 6 in Section 5.3.2(c) of AP-SIII.10Q). Since the supporting models in turn are validated, the abstraction results can be considered validated, ensuring an appropriate representation of the relevant processes in the TSPA-LA. The validation criterion suggested in the TWP (BSC 2004 [DIRS 167969], Attachment I, Section I-4-3-1) calls for an agreement within 20 percent between the abstracted results and the process model results. A 20 percent threshold is sufficient considering a Level I validation, i.e., validation for a model with less importance on annual dose. This threshold is smaller than the sensitivity range of many of the sensitivity cases studied in Section 6.8. It should be added that this 20 percent threshold may be exceeded if the abstracted results lead to more seepage; i.e., if the abstraction method uses upper bounds for seepage. This ensures that the simplifications required in the seepage abstraction model do not lead to an underestimation of seepage. 
In seepage abstraction, the supporting models providing simulated seepage rates are the SMPA for ambient seepage and the Thermal Seepage Model for thermal seepage. In addition, the impact of THM and THC alterations is evaluated with the Drift-Scale THM Model and the THC Seepage Model, respectively. Percolation flux distributions feed into the seepage abstraction model using results from the UZ Flow Model, with additional modifications according to flow focusing distributions from the flow focusing model. The agreement between these models and the abstracted results can be summarized as follows:

1. SMPA Results

The seepage look-up tables for ambient seepage provided by the SMPA are propagated through the seepage abstraction without further simplification (Section 6.5.1). For given random parameter cases, the seepage results are directly interpolated from the predicted values in the look-up table. Thus, there is very good agreement between the process model results and the abstracted results. The seepage calculations in Appendix F demonstrate that the interpolation of seepage conducted within the seepage abstraction model is consistent with the values given in the seepage look-up tables.

2. TH Seepage Model Results

The temporal evolution of seepage at thermally perturbed conditions is abstracted using simplified time-dependent seepage estimates that provide an asymptotic upper limit to the process model results (Section 6.5.2). During early heating stages, these asymptotic estimates are more than 20 percent off from the process model results. However, the abstracted results are always upper bounds, as demonstrated in Figures 6.5-3 and 6.5-4.

\section{Drift-Scale THM Model Results}

The impact of THM parameter alterations is neglected in the seepage abstraction model. For nondegraded drifts, this assessment is based on THM model results that predict slightly smaller seepage for simulation runs including thermally induced property changes (Section 6.4.4.1.1). The differences between the abstracted results and the THM process model results are small, as demonstrated in Figure 6.4-33, with the abstraction results providing the higher seepage estimates. For collapsed drifts, this assessment is based on model results and related seepage calculations that show an increase in seepage when considering the collapse-induced property changes in the near-field rock (Section 6.4.4.1.2). The differences between a seepage calculation that includes collapse-induced property changes and a seepage calculation that neglects these changes are small, as demonstrated in Sensitivity Cases 11a and 11b in Table 6.8-3, with the abstraction results providing the higher seepage estimates for the monsoon and the glacial transition climate stages (Section 6.8.2).

4. THC Seepage Model Results

The impact of THC parameter alterations on seepage has been qualitatively evaluated with the THC Seepage Model (Section 6.4.4.2). The precipitation cap that may potentially form 7-8 meters above waste emplacement drifts after several hundred 
years of heating is expected to decrease seepage into drifts, since the percolating water is diverted sideways by the low-permeability cap before reaching the drift crown (Figure 6.4-35). This effect, however, is not accounted for in the seepage abstraction model because of significant uncertainties related to these estimates. While the resulting disagreement between the process model results and the seepage abstraction model cannot be exactly quantified because of the qualitative nature of the THC predictions with respect to seepage, the abstraction method provides upper bounds for seepage.

\section{UZ Flow Model Results}

The spatial distributions of percolation flux over the repository area provided by the UZ Flow Model are propagated through the seepage abstraction without further simplification (Section 6.6.5.1). In the seepage calculation in Section 6.8, random distributions of percolation flux are developed using the simulated flux values, by generating cumulative frequency distributions from these flux values and randomly sampling from the cumulative frequency distributions. Thus, for large enough samples, there is very good agreement between the process model results and the abstracted results. This can be demonstrated by comparing some statistical measures from the original flux distribution in Table 6.6-11 with the randomly sampled flux distribution used in the seepage calculations in Section 6.8. The statistical measures used are the mean flux and the maximum flux. A comparison of these statistical measures is given in Appendix $G$ for the three climate states. It is demonstrated that the flux distributions provided by the UZ Flow Model are accurately reproduced by the sampled flux distributions in the seepage calculations.

\section{Flow Focusing Model Results}

As pointed out in Section 6.6.5.2, the percolation flux distributions from the large-scale UZ model simulations need to be further modified for intermediate-scale flux heterogeneity. The percolation flux distributions are adjusted by multiplication with appropriately distributed flow focusing factors. The seepage abstraction model uses a polynomial frequency distribution of flow focusing factors, developed by the flow focusing model discussed in Section 6.6.5.2.1. The polynomial curve has a mean of 1 , a minimum value of 0.116 , and a maximum value of 5.016 (see Figure 6.6-15). In the seepage calculation in Section 6.8, distributions of flow focusing factors are developed by random sampling from the polynomial curve. Thus, for large enough samples, there is very good agreement between the polynomial curve and the abstracted results. This can be demonstrated by comparing the above cited mean and upper/lower bound values from the polynomial curve with the mean and upper/lower bound values from the sampled distributions. The sampled flow focusing factor distributions are generated in the Mathcad spreadsheets in Appendix E, as provided in Output DTN LB0407AMRU0120.002. The variable giving the mean of the sampled flow focusing distribution is xfomean. All spreadsheets in Appendix E that apply this flow focusing distribution have a mean flow focusing factor of $x$ fomean $=1.007$ over 10,000 random samples. The minimum value of the sampled distribution is xfomin $=0.117$. The maximum value is $x$ fomax $=5.016$. These values are almost identical to the theoretical values, 
demonstrating that the polynomial curve is accurately reproduced in the seepage abstraction model.

Items 1 through 6 above demonstrate that the seepage abstraction model is reasonably consistent with the respective process model results and provides upper bounds for seepage where they differ.

\subsection{MULTIPLE LINES OF EVIDENCE}

Sections 7.1 and 7.2 have demonstrated that the abstraction model has been developed following established scientific procedures and that the abstraction model results are sufficiently close to various validated process models. Comparison with these process models confirms the adequacy of sub-systems of the abstraction model, but does not necessarily demonstrate the validity of the overall system model for seepage abstraction. Therefore, in order to provide additional confidence in the overall system model, results from the seepage abstraction model are qualitatively tested against observation (or non-observation) of seepage in the ECRB and in natural analogues.

\subsubsection{ECRB Moisture Monitoring Study}

Except for the liquid-release tests (with forced release of water above drifts), seepage of liquid water has been never observed in ventilated sections of the ESF or the ECRB (BSC 2004 [DIRS 170004], Section 6.10). This lack of seepage can be explained by the capillary barrier mechanism, but can also be related to the ventilation effect, which can remove large amounts of moisture from the rock walls and suppress seepage. To determine if seepage can occur without ventilation, the last one-third of the ECRB was sealed with multiple bulkheads. Four different bulkheads were installed in a time period from June 1999 till November 2001, and the sealed-off sections have been monitored since. In-drift moisture conditions were evaluated using several different measurement devices (e.g., water potential measurements, relative humidities), but most importantly via visual inspections during periodic entries into the sealed-off sections. Results from these entries are summarized in Section 6.10.3.3 of BSC (2004 [DIRS 170004]). While various wet areas have been observed on several occasions, the visual observations suggested that the water originated from condensation. This finding was supported by chemical analysis of water collected from containers during a June 2000 entry into the sealed-off ECRB. The water was low in chloride and silicate contents, characteristic of condensate. None of the water samples indicated that the water could have seeped into the drift from the surrounding rocks. (Note that in-drift condensation is not a subject of this model report. Issues related to indrift condensation are analyzed in the In-Drift Natural Convection and Condensation Model report (BSC 2004 [DIRS 164327]).

The above studies do not prove that seepage has not occurred in the sealed-off section of the ECRB, because not all the wet spots have been chemically analyzed. Also, the visual inspections were conducted with long intervals between them; so it is possible that water could have seeped into the drift, but was not detected. However, the observations suggest that the probability of seepage into nonventilated drifts at Yucca Mountain is fairly small under present-day infiltration conditions. We can qualitatively compare these observations with the seepage calculations conducted with the seepage abstraction model in Section 6.8.1: On average, a seepage percentage 
of 1.5 percent and a seepage fraction of 7.9 percent are expected for the Tptpll (and the Tptpul) unit, using the mean infiltration scenario. In other words, about 1.5 percent of the percolation rate above the drift is expected to seep, while 7.9 percent of all 5.1-meter drift sections along the drift would be affected (Table 6.8-1). For the Tptpmn (and the Tptpln) unit, the calculated seepage percentage is 5.5 percent, and the calculated seepage fraction is 22.6 percent (Table 6.82). Note that the main geologic units encountered in the sealed-off section of the ECRB are the Tptpll, the Tptpln, and the Tptpul; the net infiltration rates and the percolation fluxes are relatively high in this area, considerably higher than average (BSC 2004 [DIRS 170004], Section 6.10.2). Thus, the seepage predictions for the sealed-off sections of the ECRB would be even higher than the seepage percentages given above if the specific percolation conditions in the ECRB were used for the calculation. The fact that seepage has not been detected suggests that the seepage abstraction model proposed for the TSPA-LA is certainly not underestimating the seepage potential. Providing upper bounds for seepage guarantees that the TSPA-LA calculations do not result in an under-representation of the risk estimate.

\subsubsection{Natural Analogues}

Natural analogues reported in TDR-NBS-GS-000027 REV 01, Natural Analogue Synthesis Report (BSC 2004 [DIRS 169218], Section 8) provide additional evidence that the concept of seepage exclusion describes a process that actually occurs in caves, lava tubes, rock shelters, and buildings. Section 8.2 in the Natural Analogue Synthesis Report refers to quantitative seepage measurements conducted in limestone caves in fractured karst terrains (i.e., Kartchner Caverns, Arizona; Altamira Cave, Spain). These measurements demonstrate that seepage is considerably smaller than the pertinent percolation flux at the cave sites. The seepage percentages estimated for these cave locations were less than 2 and less than 1 percent, respectively, while precipitation rates strongly exceeded the current rates measured at Yucca Mountain (BSC 2004 [DIRS 169218], Section 8.2). The fact that the seepage percentages are so small corroborate the overall system model results of the seepage abstraction model for the Yucca Mountain. In addition, various other natural analogue sites provide qualitative evidence that most of the infiltrating water is diverted around underground openings and does not become seepage (BSC 2004 [DIRS 169218], Section 8.5). Thus, natural analogues like the ones discussed above demonstrate that the overall findings of the seepage abstraction model-i.e., that seepage is much smaller than the local percolation flux in unsaturated rock-are reasonable.

\subsection{SUMMARY OF VALIDATION ACTIVITIES}

The validation activities conducted during and after development of the seepage abstraction model provide confidence in the suggested abstraction methodology. The validation criteria defined in the TWP (BSC 2004 [DIRS 167969], Attachment I, Section I-4-3-1) have been met. No further activities are needed to complete the validation of the seepage abstraction model. It has been demonstrated that the seepage abstraction model is sufficiently accurate and adequate for the intended purpose and to the level of confidence required by the model's relative importance to the potential performance of the repository system. 


\section{CONCLUSIONS}

\subsection{SUMMARY AND CONCLUSIONS}

Seepage into waste emplacement drifts affects the performance of the high-level nuclear waste repository at Yucca Mountain, Nevada. Theoretical analyses, numerical modeling studies, and field experiments have shown that seepage into underground openings excavated in unsaturated formations is smaller than the percolation flux at the given location. This is mainly a result of capillary pressures holding the water in the formation, diverting it around the cavity, and preventing it from entering the drifts. During the first several hundred to thousands of years after waste emplacement at Yucca Mountain, when above-boiling temperatures will develop in the formation as a result of heat generated by the decaying waste, seepage can also be prevented by the vaporization of percolating water.

In this model report, an abstraction model was developed for evaluating the future amount and distribution of seepage into the waste emplacement drifts at Yucca Mountain. The purpose of this abstraction is to provide the necessary methodology, parameters, and simplifications to the TSPA-LA, so that probabilistic seepage calculations can be conducted within the TSPA simulation loops. These probabilistic calculations provide estimates of seepage rates and the seepage fraction averaged over drift segments for given TSPA simulation time steps; they are not expected to predict individual seepage events or the precise spatial seepage distribution along the drifts and within the repository.

The seepage abstraction model is based on several input sources such as drift-scale and site-scale process models, as well as in situ testing in the UZ at Yucca Mountain. This model report evaluates the respective input sources, analyzes relevant results, and discusses the related uncertainties (Section 6.4). On this basis, the abstraction input is then synthesized, integrated, and simplified into a form that can be used in the TSPA-LA. Relevant uncertainties are characterized and propagated through the abstraction. A short summary of the treatment of natural variability and uncertainty in the abstraction is given in Section 6.7.2.

The proposed abstraction methodology is explained in detail in Section 6.5 of this model report. It is recognized that the amount of seepage is sensitive to key hydrological properties that are both spatially variable and uncertain. For ambient seepage, these key hydrological properties are the capillary-strength parameter, permeability, and local percolation flux. One of the main tasks of this seepage abstraction model is to define appropriate probability distributions that represent the spatial variability and uncertainty inherent in these parameters in a cautiously realistic manner. Section 6.6 explains the data evaluation methodology and provides the resulting parameter distributions separately for spatial variability and uncertainty. Relevant sources of data uncertainty have been identified, described, and accounted for, potentially stemming from measurement uncertainty, conceptual model uncertainty, estimation uncertainty, and spatial variability uncertainty. The resulting parameter distributions are significantly broader than those used for the stringent validation of the supporting process models.

Based on these parameter distributions, ambient seepage can be derived in a random process using predictive seepage simulations from the SMPA (Section 6.5.1). The SMPA results are given in the form of seepage look-up tables (DTNs: LB0304SMDCREV2.002 [DIRS 163687] 
and LB0307SEEPDRCL.002 [DIRS 164337]) that provide seepage results as a function of the seepage-relevant parameters. For a particular set of these parameters, randomly sampled from the respective distributions, the mean seepage rate and its inherent estimation uncertainty, expressed by the standard deviation over the 20 realizations conducted, are linearly interpolated between the table values. The standard deviation is used to define a uniform uncertainty distribution. A seepage uncertainty value is then randomly sampled from this distribution and used to adjust the mean seepage values, giving the final ambient seepage rate for the considered parameter set. Conducting this procedure over a large number of random parameter sets results in the final distribution of ambient seepage.

It is possible that the initially circular-shaped drifts will degrade with time as a result of rock fatigue or seismic events. Based on the SMPA modeling results, the impact of drift degradation is accounted for by using separate look-up tables for nondegraded and collapsed drifts. TSPA will select the appropriate look-up table depending on the considered geologic unit and the selected nominal or disruptive scenario. This selection is based on categories of drift degradation that have been introduced in Section 6.5.1.5, based on results from BSC (2004 [DIRS 166107]). Category 1 comprises degraded drifts that may show local rock breakout but stay essentially intact. In this category, seepage is defined as the flow of liquid water from the fractured formation into the open gas-filled drift. The magnitude of seepage is interpolated from the look-up table for nondegraded drifts. Drifts located in nonlithophysal rock are assigned to Category 1 for both the nominal and seismic scenarios. For drifts located in lithophysal rock, all nominal cases (including thermal stress and rock strength degradation) and seismic events less severe than the $1 \times 10^{-4}$ seismic hazard level (peak ground motion velocity smaller than $0.384 \mathrm{~m} / \mathrm{s}$ ) are included in Category 1 . The second category comprises the cases with partial and complete drift collapse. After drift collapse, the original drift opening has typically increased in size, but is filled with fragmented rubble with large voids. Cases with partial or complete drift collapse include all other seismic events occurring in lithophysal rock units, i.e., all seismic events with annual occurrence probability equal to or lower than $10^{-4}$ (peak ground motions equal or greater than $0.384 \mathrm{~m} / \mathrm{s}$ ). In this category, seepage is defined as the flow of liquid water from the fractured formation into the rubble-filled drift. The magnitude of seepage is interpolated from the look-up table for collapsed drifts.

Note that three alternative abstraction methods are proposed for igneous events (see Section 6.5.1.7). In view of the significant uncertainty about the in-drift conditions after an igneous event, it is recommended that TSPA conduct sensitivity analyses with the three abstraction methods. The highest seepage estimates should be chosen and propagated to the downstream TSPA modules.

Since the SMPA look-up tables account for seepage at idealized, ambient conditions, the impact of additional factors affecting seepage needs to be evaluated in a second step. These factors include the ground support with rock bolts, the expected transient changes in hydrological properties as a result of THM and THC effects as well as parameter changes stemming from drift degradation and drift collapse, and the thermal perturbation of the flow field as a result of boiling in the rock. The method proposed in this model report is to account for these factors in a simplified form, using the ambient seepage results as a basis and adjusting them as suggested by the relative importance of each factor. To incorporate uncertainty, the simplifications made in this process usually are "bounding," yet strive to be as realistic as possible. "Bounding” means 
that the simplified abstractions tend to overestimate seepage compared to the predicted process model results.

The impact of rock bolts as well as THM/THC and degradation-induced parameter alterations can be neglected in the abstraction, as demonstrated by the drift-scale process models simulating these processes. Two alternative abstraction models are proposed for seepage during the period of strong thermal perturbation at Yucca Mountain. Abstraction Model 1 is applied for thermal seepage into collapsed drifts, whereas Abstraction Model 2 is used for seepage into nondegraded or moderately degraded drifts. The first model is very simple; it sets thermal seepage equal to the respective ambient seepage rate throughout the TSPA period. The choice of this abstraction model is based on the model finding that in the case of drift collapse there is no (or just a small, short-lived) vaporization barrier in the intact rock that prevents water flow from the formation into the rubble-filled drift. The second model sets thermal seepage to zero for the period of above-boiling drift wall temperature, using a temperature threshold of $100^{\circ} \mathrm{C}$. Thus, this approach takes credit for the vaporization barrier that prevents seepage during the period of above-boiling rock temperatures. The abstraction is based on the model findings that thermal seepage in nondegraded or moderately degraded drifts never occurs at above-boiling temperatures and that the ambient seepage values provide an asymptotic upper limit for thermal seepage.

For illustration of the expected seepage behavior in the repository, a probabilistic seepage calculation was conducted within this model report following the proposed abstraction method (Section 6.8). Summary results indicate the importance of the natural barrier formed by the unsaturated rock at and above the repository horizon. For drifts located in the main geological unit in the repository (Tptpll unit) and assuming the mean infiltration scenario, the mean seepage percentage is about 8 percent during the "wet" glacial transition climate, when percolation flux is highest compared to other climate stages and the maximum seepage is expected. This means that on average, more than about 92 percent of the percolating water is diverted around the emplacement drifts. The calculation procedure was also applied to understand the impact of certain abstraction choices by analysis of various sensitivity cases. Note that the calculation results are not directly utilized in the performance assessment, because the seepage component in the TSPA simulations will conduct a similar seepage calculation embedded in the Monte Carlo simulation procedure.

The use of the results presented in this model report is restricted to a probabilistic TSPA simulation that follows the methodology outlined in Sections 6.5 and 6.6, summarized in Section 6.7, and demonstrated in Section 6.8. Specifically, the distributions of seepage-relevant parameters developed in this model report can only be used for seepage evaluations if combined with look-up tables that were generated from a consistent conceptual model (such as the SMPA). Furthermore, the use of the seepage abstraction model is limited to the conditions considered and described in the upstream process models (see Figure 1-1). 


\subsection{MODEL OUTPUT TO TSPA}

The model output developed in this model report is provided in DTNs LB0310AMRU0120.001, LB0310AMRU0120.002, LB0407AMRU0120.001, and LB0407AMRU0120.002. For the purposes of traceability and reproducibility, all files submitted to the TDMS are described in detail in Appendices A through E. All file dates and file sizes can be obtained from the TDMS.

DTN LB0407AMRU0120.001 is a revised version of DTN LB0310AMRU0120.001. Both DTNs contain the following subdirectories:

- Subdirectory seepage_uncertainty_evaluation: Mathcad 11 spreadsheet for analyzing seepage uncertainty histograms (see Appendix A).

- Subdirectory capillary_strength_analysis: Excel spreadsheet for analyzing the spatial variability of capillary strength (see Appendix B). Summary results are given in pdf-file.

- Subdirectory permeability_analysis: Excel spreadsheets for analyzing the spatial variability of permeability values (see Appendix C). Summary results are given in pdf-file.

- Subdirectory norm_flow_field_analysis: Mathcad spreadsheets for analyzing the site-scale percolation flux distributions for the base case (see Appendix D). Summary results are given in pdf-file.

- Subdirectory alternative_concept_flow_field_analysis: Mathcad spreadsheets for analyzing the site-scale percolation flux distributions for the alternative conceptual model of flow in the PTn (see Appendix D).

- Subdirectory summary_seepage_abstraction_method: Word document giving a brief roadmap of the proposed methodology of the TSPA seepage calculations (based on Section 6.7.1).

The first five subdirectories listed above-comprising statistical calculations needed for evaluating parameter distributions-are identical for DTNs LB0307AMRU0120.001 and LB0407AMRU0120.001. The only differences between these two DTNs are in the roadmap for seepage abstraction given in the last subdirectory summary_seepage_abstraction_method. These differences are mainly related to new results from the drift degradation analysis that feeds into the seepage abstraction (see Section 6.5.1.5). DTN LB0407AMRU0120.001 comprises the revised roadmap for seepage abstraction that must be used in the TSPA-LA instead of the other DTN LB0310AMRU0120.001. Except for this roadmap, either one of the two DTNs can be used.

DTN LB0407AMRU0120.002 is a revised version of DTN LB0310AMRU0120.002. Both DTNs contain various Mathcad 11 spreadsheets with seepage calculation results, comprising seepage histograms and summary statistics for seepage rate, seepage percentage, and seepage 
fraction (see Appendix E). Summary results are given in a word file. Supporting files needed for the seepage calculation are given in the following subdirectories:

- Subdirectory SMPA Input: Seepage lookup tables provided by the SMPA.

- Subdirectory UZ Flow Fields Norm: Percolation flux distributions developed by the UZ Flow Model, extracted for the repository area (base case flow fields).

- Subdirectory UZ Flow Fields Alternative: Percolation flux distributions developed by the UZ Flow Model, extracted for the repository area (alternative flow fields).

All the subdirectories listed above and most of the Mathcad 11 spreadsheets are identical for DTNs LB0307AMRU0120.001 and LB0407AMRU0120.001. The only differences are that the revised DTN LB0407AMRU0120.002 contains six revised spreadsheets and twelve additional spreadsheets. The corrected and additional spreadsheets are identified in the README file of DTN LB0407AMRU0120.002. For these revised and additional spreadsheets, DTN LB0407AMRU0120.002 must be used instead of DTN LB0310AMRU0120.002. Except for these corrected and additional spreadsheets, either one of the two DTNs can be used.

\subsection{SATISFACTION OF YMRP ACCEPTANCE CRITERIA}

The following information describes how this model report addresses the acceptance criteria in the Yucca Mountain Review Plan, Final Report (NRC 2003 [DIRS 163274], Sections 2.2.1.3.3.3 and 2.2.1.3.6.3). Only those acceptance criteria that are applicable to this report (see Section 4.2) are discussed. In most cases, the applicable acceptance criteria are not addressed solely by this report; rather, the acceptance criteria are fully addressed when this report is considered in conjunction with other analysis and model reports that describe other aspects of drift seepage and flow in the UZ.

Acceptance Criteria from Section 2.2.1.3.3.3, Quantity and Chemistry of Water Contacting Engineered Barriers and Waste Forms

Acceptance Criterion 1, System Description and Model Integration Are Adequate:

- Subcriterion (1): Physical phenomena and couplings are adequately incorporated in the seepage abstraction through the discussion and analysis of the important factors affecting seepage at both ambient and thermal conditions (Section 6.3), evaluation of process model results that predict relevant phenomena and couplings (Section 6.4), and use of parameters reflecting the variability and uncertainty of the hydrogeological conditions at Yucca Mountain (Section 6.6). Consistent and appropriate assumptions were made in the process of abstracting the process model results (Section 6.5) and defining parameter distributions (Section 6.6).

- Subcriterion (2): The assumptions, technical bases, data, and models used in the seepage abstraction are appropriate and consistent with the abstractions for UZ flow paths and for climate and infiltration (Section 6.6.5) as well as for drift degradation 
(Section 6.5.1.5). The descriptions and technical bases are transparent and traceable (Sections 4.1 and 6.4).

- Subcriterion (4): Spatial and temporal abstractions appropriately address physical couplings from thermal, hydrological, mechanical, and chemical processes (Sections 6.5.1.4, 6.5.1.5, 6.5.2, and 6.5.3). Flow perturbations resulting from these processes, which could potentially lead to increased flux of water towards drifts, have been analyzed by appropriate testing and modeling studies (Sections 6.4.3 and 6.4.4) and have been accounted for in the abstraction (Section 6.5.1.4, 6.5.1.5, 6.5.2, and 6.5.3).

- Subcriterion (5): Sufficient technical data and justification are provided for assumptions and approximations regarding the coupled effects on seepage and flow (Sections 6.4.3 and 6.4.4). The effects of flow distribution on the amount of water contacting waste packages are consistently addressed (Sections 6.4.1 through 6.4.3 for small-scale variability, Section 6.6 .5 for intermediate-scale variability).

- Subcriterion (8): Adequate technical bases are provided through independent modeling (TH model in Section 6.4.3 and combination of THM and THC models in Section 6.4.4), inclusion of the results of laboratory and field data (Sections 6.6.1 through 6.6.5), and sensitivity studies (Section 6.8.2) for inclusion of thermal-hydrological-mechanicalchemical couplings and features, events, and processes.

- Subcriterion (9): Performance-affecting processes observed in thermal-hydrological tests and experiments are included in the seepage abstraction by the use of model results from appropriate process models calibrated and validated against data from seepage and heater experiments (Sections 6.4.1, 6.4.3, 6.4.4, and 7). It has been demonstrated that refluxing water will not enhance seepage at Yucca Mountain (Sections 6.4.3 and 6.5.2).

- Subcriterion (12): This report was developed in accordance with the Quality Assurance Requirements and Description (DOE 2004 [DIRS 171539]), which commits to NUREG-1297 (Altman et al. 1988 [DIRS 103597]) and NUREG-1298 (Altman et al. 1988 [DIRS 103750]). Moreover, compliance with the DOE procedures, which are designed to ensure compliance with the Quality Assurance Requirements and Description (DOE 2004 [DIRS 171539]), is verified by audits by QA and other oversight activities. Accordingly, the guidance in NUREG-1297 (Altman et al. 1988 [DIRS 103597]) and NUREG-1298 (Altman et al. 1988 [DIRS 103750]) has been followed as appropriate.

\section{Acceptance Criterion 2, Data Are Sufficient for Model Justification:}

- Subcriteria (1): Geological, hydrological, and geochemical values are used in various process models that feed into the seepage abstraction model. Adequate descriptions of how these process models meet the several subcriteria are provided in detail in the respective model reports (as referenced in Section 6.4). It is demonstrated in those model reports that the geological, hydrological, and geochemical values used in these upstream process-level models are adequately justified. Parameter values developed in the seepage abstraction model were derived from appropriate site data (such as capillary 
strength and fracture permeability); their use and interpretation are described fully in Section 6.6.

- Subcriterion (2): The parameters used in the abstraction process have been carefully selected from appropriate upstream process models and from in situ testing; they are based on sufficient data and are consistent with the data (Sections 6.6.1 through 6.6.5). Development of the upstream process models is based on sufficient data, so that the characteristics of the natural system are adequately captured (Section 6.4). Reasonable initial and boundary conditions were used for the process models that feed into the seepage abstraction model.

- Subcriterion (3): TH tests have been designed and conducted with the explicit objectives of observing $\mathrm{TH}$ processes for the temperature ranges expected for the repository conditions and making measurements for process-level models (see references in Section 6.4.3). The data collected are sufficient to verify that the $\mathrm{TH}$ conceptual models capture the relevant phenomena (Section 6.4.3) such as the combined effect of the two barriers that may prevent seepage into drifts at elevated temperatures: (1) the capillary barrier, which is independent of the thermal conditions, and (2) the vaporization barrier, which is in effect only if boiling temperatures prevail.

Acceptance Criterion 3, Data Uncertainty Is Characterized and Propagated through the Model Abstraction:

- Subcriterion (1): Discussions in Sections 6.5 and 6.6 and information from upstream models discussed in Section 6.4 show that the seepage abstraction uses parameter values, ranges, probability distributions, and bounding assumptions that are technically defensible. These values reasonably account for uncertainties (Sections 6.5.1.3, 6.5.2.2, 6.6.2.3, 6.6.3.3, and 6.7.2) and variabilities. Abstraction simplifications are chosen to be upper bounding cases (Section 6.5) for seepage (i.e., the simplified abstractions tend to overestimate the seepage compared to the predicted process model results). Validation results show the seepage abstraction is reasonably consistent with the respective process model results and provides upper bounds for seepage where they differ (Section 7.2). Therefore, it is concluded that the seepage abstraction does not result in an underrepresentation of the risk estimate related to seepage into the drifts.

- Subcriterion (2): The parameter values, ranges, probability distributions, and bounding assumptions used in the seepage abstraction model are based on data from the Yucca Mountain region. These data include results from heater tests and niche liquid-release tests, from field measurements, and process-modeling studies, corroborated by natural analogue research on seepage exclusion in caves and other underground cavities (Sections 6.4, 6.5 and 7.3).

- Subcriterion (3): The input information used in the seepage abstraction model is derived from and consistent with measured data or parameters provided by process-level models (Section 6.4 and 7.2). Possible statistical correlations between input values have been evaluated in this abstraction (Sections 6.5.1.1 and 6.8.2). The impact of coupled processes is adequately represented in the seepage abstraction (Sections 6.5.1.4, 6.5.1.5, 
6.5.2, and 6.5.3), in the base case analysis of various infiltration scenarios (Section 6.8.1), and in the sensitivity analyses on important seepage parameters (Section 6.8.2). Reasonable ranges of parameters or functional relations are established (Section 6.6).

- Subcriterion (4): Uncertainties in the characteristics of the natural system are considered in the seepage abstraction (see summary in Section 6.7.2 and detailed discussions in Sections 6.5 and 6.6). Uncertainties are either explicitly described by appropriate probability distributions are constrained by upper limits or sensitivity analyses.

Acceptance Criterion 4, Model Uncertainty Is Characterized and Propagated through the Model Abstraction:

- Subcriterion (1): Alternative modeling approaches have been investigated in all upstream models that feed into the seepage abstraction model (Sections 6.4.1 through 6.4.4). The results and limitations are appropriately considered in this abstraction (Sections 6.5, 6.7.2, and 6.8.2).

- Subcriterion (2): The selected seepage abstraction model is consistent with available data and current scientific understanding (Section 6.5). The model is based on results from upstream process models that are also consistent with available data and current scientific understanding (Section 6.4). Alternative approaches not considered in the final analysis, and the limitations and uncertainties of the upstream models, are described in the individual model reports (Section 6.4) and are accounted for in the seepage abstraction model (Section 6.5).

- Subcriterion (3): Consideration of conceptual model uncertainty is consistent with available site characterization data, laboratory experiments, field measurements, natural analogue information, and process-level modeling studies as discussed in the validation of the model (Sections 7.2 and 7.3). The conceptual model adopts upper-bound approaches that estimate higher seepage than the more detailed process models. Therefore, the process model uncertainty does not result in an under-representation of risk (see Sections 6.5 and 6.6 and the summary in Section 6.7.2).

- Subcriterion (4): Adequate consideration is given to effects of thermal-hydrologicalmechanical-chemical processes in the assessment of alternative conceptual models (see Sections 6.4.3 and 6.4.4).

- Subcriterion (5): The process-level models feeding into the seepage abstraction are based on an equivalent continuum assumption for flow and transport in the fractured network and in the matrix blocks. As discussed in Section 6.4, these models have been validated by comparison with measured data and are appropriate for their use in seepage abstraction. Alternative models, such as the discrete fracture models or episodic finger-flow models, are briefly discussed in Sections 6.4.1.2 and 6.4.3.2, and references to a more in-depth discussion are given therein. It was demonstrated that seepage predictions with a continuum model were consistent with seepage predictions from a discrete or finger-flow model. 


\section{Acceptance Criterion 5, Model Abstraction Output Is Supported by Objective Comparisons:}

- Subcriterion (1): The abstraction results implemented in the TSPA-LA are based on and consistent with output from detailed process-level models, as demonstrated by comparison (Section 7.2) and empirical observations such as natural analogues (Section 7.3.1). For example, results from the process-level model for ambient seepage are incorporated in the seepage abstraction without any simplifications. Other abstractions of process-level models provide upper bounds to the process-level predictions (Section 6.4 and 6.5).

- Subcriterion (2): The abstraction model for thermal-hydrological-mechanical-chemical effects on seepage and flow is based on the same assumptions and approximations used for the process-level models (Sections 6.4.4). Note that results from the ambient seepage process-level models (estimating flow diversion of percolation flux around drifts) are incorporated in the seepage abstraction without any simplifications (Section 6.5.1). Other abstractions of process-level models provide upper bounds to the process-level predictions (e.g., abstraction of thermally induced parameter changes discussed in Section 6.5.1.4).

- Subcriterion (3): Accepted and well-documented procedures have been used to construct and test the numerical models that simulate coupled effects of seepage and flow, providing the basis for this abstraction (see references in Section 6.4). These numerical models are adequately supported in the model reports providing their basis. Abstracted model results are compared with more complex, upstream mathematical models, to judge robustness of results (Sections 6.6 and 6.7.2). Approved QA procedures identified in the TWP (BSC 2004 [DIRS 169654], Section 4) have been used to conduct and document the activities described in this model report.

\section{Acceptance Criteria from Section 2.2.1.3.6.3, Flow Paths in the UZ}

Acceptance Criterion 1, System Description and Model Integration Are Adequate:

- Subcriterion (1): Thermal-hydrologic-mechanical-chemical phenomena and couplings affecting processes in the fractured rock are incorporated in the abstraction as appropriate (Sections 6.4.3, 6.4.4, 6.5.1.4, 6.5.2, and 6.5.3).

- Subcriterion (2): All aspects of geology, hydrology, geochemistry, and physical phenomena affecting flow paths in the UZ are adequately considered in the seepage abstraction through adoption of results from upstream models or simplifications of upstream model approaches (Sections 6.3, 6.4, 6.5, and 6.7). Conditions and assumptions are readily identified and consistent with data (Sections 4.1, 6.3, 6.4, and $6.5)$.

- Subcriterion (3): The seepage abstraction model uses assumptions, technical bases, data, and models appropriate and consistent with abstractions of other analyses (UZ flow paths, climate, and infiltration, drift degradation and seismic consequence abstraction). Seepage abstraction utilizes results from UZ flow path simulations (which are based on 
climate and infiltration) without any additional simplifications (Section 6.6.5) and integrates them with seepage-relevant information from drift-scale models. The seepage abstraction model accounts for the impacts of drift degradation and seismic events in an adequate manner (6.5.1.5). The descriptions and technical bases are transparent and traceable to site and design data through the upstream model reports and data and parameters discussed in Sections 4.1 and 6.6.

- Subcriterion (5): Sufficient data and technical bases are provided in Section 6.2 to assess the degree to which FEPs have been included in this abstraction. Section 6.2 provides a complete table of FEPs with FEP descriptions, and reference to the section where the FEP is incorporated in this abstraction.

- Subcriterion (6): Several process-level models feed into the seepage abstraction model (Section 6.4). Adequate spatial variability of model parameters and boundary conditions are employed in these process-level models used to estimate flow paths in the unsaturated zone, percolation flux, and seepage flux. Temporal variability in boundary conditions incorporates thermal and climate-induced changes (Sections 6.1, 6.4, 6.5, and 6.7).

- Subcriterion (7): Average parameter estimates used in process-level models (Sections 6.4.1 through 6.4.4) are representative of the temporal and spatial discretizations considered in the abstraction model (see Sections 6.5, 6.6, and 6.7 for discussions of incorporation of upstream models and simplifications employed).

- Subcriterion (9): This report was developed in accordance with the Quality Assurance Requirements and Description (DOE 2004 [DIRS 171539]), which commits to NUREG-1297 (Altman et al. 1988 [DIRS 103597]) and NUREG-1298 (Altman et al. 1988 [DIRS 103750]). Moreover, compliance with the DOE procedures, which are designed to ensure compliance with the Quality Assurance Requirements and Description (DOE 2004 [DIRS 171539]), is verified by audits by QA and other oversight activities. Accordingly, the guidance in NUREG-1297 (Altman et al. 1988 [DIRS 103597]) and NUREG-1298 (Altman et al. 1988 [DIRS 103750]) has been followed as appropriate.

\section{Acceptance Criterion 2, Data Are Sufficient for Model Justification:}

- Subcriterion (1): Site and experimental data were adequately incorporated in upstream models that feed into the seepage abstraction model (Section 6.4). Adequate descriptions of how data were used in upstream models are provided in detail in the respective model reports (as referenced in Section 6.4). It is demonstrated in these reports that the input parameters used in the models are justified. Accepted and well-documented procedures have been used to construct and calibrate the numerical models. The models are technically defensible and based on data collected using acceptable techniques. Sensitivity analyses have been conducted to assess data sufficiency. Parameter distributions developed for the seepage abstraction model are adequately discussed in Section 6.6. 
- Subcriterion (2): The main hydrological properties (air permeability and the capillary-strength parameters) used in the seepage abstraction are based on adequately designed air injection (Section 6.6.3) and liquid release tests (Section 6.4.1 and 6.6.2). From the seepage rates measured in the liquid release tests, effective capillary-strength parameters have been calibrated with an appropriate inverse model (Section 6.4.1).

- Subcriterion (3): The percolation flux distributions used in the seepage abstraction model are based on a technically defensible UZ Flow Model that reasonably represents the physical system and is calibrated using site-specific hydrological, geological, and geochemical data (Section 6.6.5.1). These distributions provide the appropriate spatial and temporal variability of model parameters, including climate-induced changes in infiltration. Percolation fluxes are further adjusted using flow focusing factors to account for intermediate-scale heterogeneity (Section 6.6.5.2).

- Subcriterion (4): Appropriate thermal-hydrological tests have been designed and conducted to observe critical thermal-hydrological processes and properties. Values for relevant model parameters were estimated (see references in Sections 6.4.3 and 6.4.4) and employed in the upstream process models and in the abstraction model.

- Subcriterion (5): Sensitivity or uncertainty analyses were performed on data employed by the upstream process-level models as discussed in their respective reports (Section 6.4). Sensitivity analyses were also conducted with the seepage abstraction model (Section 6.8.2).

- Subcriterion (6): The process models used as the basis for the seepage abstraction model have been constructed and calibrated using accepted and well-documented procedures (Sections 6.4 and 6.5). Approved QA procedures identified in the TWP (BSC 2004 [DIRS 169654], Section 4) have been used to conduct and document the activities described in this model report.

- Subcriterion (7): The process models described in Section 6.4 are well developed and complete, use appropriate experimental and sampling data from Yucca Mountain, and reflect the UZ stratigraphy and properties. The mathematical models for these process models, as described in their individual model reports, are consistent with the conceptual model of unsaturated flow and with the site characteristics. Robustness of results is tested using alternative models. The seepage abstraction model directly incorporates the process model results (where possible) or uses upper-bound simplifications (Sections 6.5 through 6.8).

Acceptance Criterion 3, Data Uncertainty Is Characterized and Propagated through the Model Abstraction:

- Subcriterion (1): As discussed in Sections 6.5 and 6.7, the seepage abstraction model uses parameter values, ranges, probability distributions, and/or bounding assumptions that are technically defensible, reasonably account for uncertainties and variabilities, and do not result in an under-representation of risk. Validation results show that the seepage abstraction is reasonably consistent with the respective process model results and 
provides upper bounds for seepage where they differ (Section 7.2). Therefore, it is concluded that the seepage abstraction does not result in an under-representation of the risk estimate related to seepage into the drifts.

- Subcriterion (2): A full description of the technical bases for the parameter values used in this abstraction is provided (Section 6.6).

- Subcriterion (3): Possible statistical correlations between parameters have been evaluated in this abstraction. It was found that respective probability distributions for capillary strength, permeability, and percolation flux (i.e., the most important parameters relative to drift seepage) should not be correlated (Section 6.5.1.1). The impact of a possible correlation between these parameters is evaluated in Section 6.8.2, showing that the no-correlation assumption provides the higher seepage estimates.

- Subcriterion (4): The input information (boundary conditions and parameters) used in the seepage abstraction model is derived from and consistent with measured data and input from process-level models (Sections 6.4 and 7.2). Reasonable ranges of parameters or functional relations are established such that upper-bound results are obtained (Section 6.6).

- Subcriterion (5): The impact of coupled processes is adequately represented in the seepage abstraction (Sections 6.5.1.4, 6.5.1.5, 6.5.2, and 6.5.3).

- Subcriterion (6): Uncertainties in the characteristics of the natural system are explicitly considered in the seepage abstraction (see the summary in Section 6.7.2 and detailed discussions in Sections 6.5.1.3, 6.5.2.2, 6.6.2.3, and 6.6.3.3).

Acceptance Criterion 4, Model Uncertainty Is Characterized and Propagated through the Model Abstraction:

- Subcriterion (1): Alternative modeling approaches have been investigated in all upstream models that feed the seepage abstraction model (Sections 6.4.1 through 6.4.4). The results and limitations are appropriately considered in the seepage abstraction model (Sections 6.5, 6.7.2, and 6.8.2).

- Subcriterion (2): The bounds of uncertainty created by the process-level models are considered in the seepage abstraction model (Sections 6.4.1.3, 6.4.2, 6.4.3, 6.5.1.3, 6.5.2.2, 6.6.2.3, and 6.6.3.3).

- Subcriterion (3): Consideration of conceptual model uncertainty is consistent with available site characterization data, laboratory experiments, field measurements, natural analogue information, and process-level modeling studies as discussed in the validation of the model (Sections 7.2 and 7.3). The conceptual model adopts upper-bound approaches that estimate higher seepage than the more detailed process models. Therefore, the process model uncertainty does not result in an under-representation of risk (see Sections 6.5 and 6.6 and the summary in Section 6.7.2). 


\section{Acceptance Criterion 5, Model Abstraction Output Is Supported by Objective Comparisons:}

- Subcriterion (1): The abstraction results implemented in the TSPA-LA are based on and consistent with output from detailed process-level models, as demonstrated by comparison (Section 7.2) and empirical observations such as natural analogues (Section 7.3.2). For example, results from the process-level model for ambient seepage are incorporated in the seepage abstraction without any simplifications. Other abstractions of process-level models provide upper bounds to the process-level predictions (Section 6.4 and 6.5).

- Subcriterion (2): The validation process for the seepage abstraction model presented in Section 7.2 shows that the results of this model either closely reflect or conservatively bound predictions from the process models.

- Subcriterion (3): Sensitivity studies (Section 6.8.2), comparison to detailed process-level models (Section 7.2), and comparison to empirical observations and natural analogues (Section 7.3.1) are provided to verify the validity of the seepage abstraction model. 


\section{INTENTIONALLY LEFT BLANK}




\section{INPUTS AND REFERENCES}

The following is a list of the references cited in this document. The last column represents the unique six-digit numerical identifier (the Document Input Reference System [DIRS] number), which is placed in the text following the reference callout (e.g., BSC 2004 [DIRS 167969]). The purpose of these numbers is to assist the reader in locating a specific reference.

\subsection{DOCUMENTS CITED}

Albin, A.L.; Singleton, W.L.; Moyer, T.C.; Lee, A.C.; Lung, R.C.; Eatman, G.L.W.; 101367 and Barr, D.L. 1997. Geology of the Main Drift - Station 28+00 to 55+00, Exploratory Studies Facility, Yucca Mountain Project, Yucca Mountain, Nevada. Milestone SPG42AM3. Denver, Colorado: Bureau of Reclamation and U.S. Geological Survey. ACC: MOL.19970625.0096.

Altman, W.D.; Donnelly, J.P.; and Kennedy, J.E. 1988. Peer Review for High-Level 103597 Nuclear Waste Repositories: Generic Technical Position. NUREG-1297.

Washington, D.C.: U.S. Nuclear Regulatory Commission. TIC: 200651.

Altman, W.D.; Donnelly, J.P.; and Kennedy, J.E. 1988. Qualification of Existing

103750 Data for High-Level Nuclear Waste Repositories: Generic Technical Position.

NUREG-1298. Washington, D.C.: U.S. Nuclear Regulatory Commission.

TIC: 200652.

Birkholzer, J. 2003. "Penetration of Liquid Fingers into Superheated Fractured 163686 Rock.” Water Resources Research, 39, (4), 9-1 through 9-21. [Washington, D.C.]: American Geophysical Union. TIC: 254362.

Birkholzer, J.; Li, G.; Tsang, C-F.; and Tsang, Y. 1999. "Modeling Studies and 105170 Analysis of Seepage into Drifts at Yucca Mountain.” Journal of Contaminant Hydrology, 38, (1-3), 349-384. New York, New York: Elsevier. TIC: 244160.

Birkholzer, J.T. 2003. YMP-LBNL-JTB-2 Unsaturated Zone Synthesis \& Modeling - 164526 Abstraction of Drift Seepage. Scientific Notebook SN-LBNL-SCI-231-V1. ACC: MOL.20030728.0385.

Birkholzer, J.T. 2003. YMP-LBNL-JTB-3 Unsaturated Zone Synthesis \& Modeling 164525 Abstraction of Drift Seepage. Scientific Notebook SN-LBNL-SCI-231-V2. ACC: MOL.20030728.0383.

Birkholzer, J.T. and Tsang, Y.W. 2000. "Modeling the Thermal-Hydrologic 154608 Processes in a Large-Scale Underground Heater Test in Partially Saturated Fractured Tuff.” Water Resources Research, 36, (6), 1431-1447. Washington, D.C.: American Geophysical Union. TIC: 248278. 
Bodvarsson, G.S.; Boyle, W.; Patterson, R.; and Williams, D. 1999. “Overview of 120055 Scientific Investigations at Yucca Mountain-The Potential Repository for High-Level Nuclear Waste.” Journal of Contaminant Hydrology, 38, (1-3), 3-24.

New York, New York: Elsevier. TIC: 244160.

Bodvarsson, G.S.; Wu, Y-S.; and Zhang, K. 2003. "Development of Discrete Flow 163443 Paths in Unsaturated Fractures at Yucca Mountain.” Journal of Contaminant Hydrology, 62-63, 23-42. New York, New York: Elsevier. TIC: 254205.

BSC (Bechtel SAIC Company) 2001. Drift Degradation Analysis. ANL-EBS-MD156304 000027 REV 01 ICN 01. Las Vegas, Nevada: Bechtel SAIC Company. ACC: MOL.20011029.0311.

BSC 2001. Ground Control for Emplacement Drifts for SR. ANL-EBS-GE-000002 REV 00 ICN 01. Las Vegas, Nevada: Bechtel SAIC Company.

ACC: MOL.20010627.0028.

BSC 2002. Guidelines for Developing and Documenting Alternative Conceptual

158794 Models, Model Abstractions, and Parameter Uncertainty in the Total System Performance Assessment for the License Application. TDR-WIS-PA-000008 REV 00 ICN 01. Las Vegas, Nevada: Bechtel SAIC Company.

ACC: MOL.20020904.0002.

BSC 2003. Abstraction of Drift Seepage. MDL-NBS-HS-000019 REV 00 ICN 01.

165564 Las Vegas, Nevada: Bechtel SAIC Company. ACC: DOC.20031112.0002.

BSC 2003. Analysis of Infiltration Uncertainty. ANL-NBS-HS-000027 REV 01. Las Vegas, Nevada: Bechtel SAIC Company. ACC: DOC.20031030.0003.

BSC 2003. Risk Information to Support Prioritization of Performance Assessment Models. TDR-WIS-PA-000009 REV 01 ICN 01 [Errata 001]. Las Vegas, Nevada: Bechtel SAIC Company. ACC: MOL.20021017.0045; DOC.20031014.0003.

BSC 2004. Analysis of Hydrologic Properties Data. ANL-NBS-HS-000042 REV 00. 170038 Las Vegas, Nevada: Bechtel SAIC Company. ACC: DOC.20041005.0004.

BSC 2004. Calibrated Properties Model. MDL-NBS-HS-000003 REV 02. Las Vegas, Nevada: Bechtel SAIC Company. ACC: DOC.20041006.0004.

169857

BSC 2004. D\&E / PA/C IED Emplacement Drift Configuration and Environment. 168489 800-IED-MGR0-00201-000-00B. Las Vegas, Nevada: Bechtel SAIC Company. ACC: ENG.20040326.0001.

BSC 2004. D\&E / PA/C IED Subsurface Facilities Committed Materials. 800-IEDWIS0-00302-000-00B. Las Vegas, Nevada: Bechtel SAIC Company.

169058 ACC: ENG.20040318.0031. 
BSC 2004. D\&E/PA/C IED Typical Waste Package Components Assembly.

169472 800-IED-WIS0-00202-000-00C. Las Vegas, Nevada: Bechtel SAIC Company. ACC: ENG.20040517.0008.

BSC 2004. Development of Numerical Grids for UZ Flow and Transport Modeling.

169855 ANL-NBS-HS-000015 REV 02. Las Vegas, Nevada: Bechtel SAIC Company. ACC: DOC.20040901.0001.

BSC 2004. Dike/Drift Interactions. MDL-MGR-GS-000005, Rev. 01.

170028 Las Vegas, Nevada: Bechtel SAIC Company.

BSC 2004. Drift Degradation Analysis. ANL-EBS-MD-000027 REV 03.

166107

Las Vegas, Nevada: Bechtel SAIC Company. ACC: DOC.20040915.0010.

BSC 2004. Drift Scale THM Model. MDL-NBS-HS-000017 REV 01. Las Vegas, Nevada: Bechtel SAIC Company. ACC: DOC.20041012.0001.

BSC 2004. Drift-Scale Coupled Processes (DST and TH Seepage) Models. MDLNBS-HS-000015 REV 01. Las Vegas, Nevada: Bechtel SAIC Company. ACC: DOC.20040930.0003.

BSC 2004. Drift-Scale Radionuclide Transport. MDL-NBS-HS-000016 REV 01. Las 170040 Vegas, Nevada: Bechtel SAIC Company. ACC: DOC.20040927.0031.

BSC 2004. Drift-Scale THC Seepage Model. MDL-NBS-HS-000001, Rev. 03. 169856 Las Vegas, Nevada: Bechtel SAIC Company.

BSC 2004. Engineered Barrier System Features, Events, and Processes. ANL-WIS- 169898 PA-000002, Rev. 03. Las Vegas, Nevada: Bechtel SAIC Company.

BSC 2004. Features, Events, and Processes in UZ Flow and Transport. ANL-NBS- 170012 MD-000001, Rev. 03. Las Vegas, Nevada: Bechtel SAIC Company.

BSC 2004. Features, Events, and Processes: Disruptive Events. ANL-WIS-MD170017 000005, Rev. 02. Las Vegas, Nevada: Bechtel SAIC Company.

BSC 2004. Future Climate Analysis. ANL-NBS-GS-000008 REV 01. 170002 Las Vegas, Nevada: Bechtel SAIC Company. ACC: DOC.20040908.0005.

BSC 2004. Geologic Framework Model (GFM2000). MDL-NBS-GS-000002 170029 REV 02. Las Vegas, Nevada: Bechtel SAIC Company.

ACC: DOC.20040827.0008.

BSC 2004. In Situ Field Testing of Processes. ANL-NBS-HS-000005, Rev. 03. 170004 Las Vegas, Nevada: Bechtel SAIC Company. 
BSC 2004. In-Drift Natural Convection and Condensation. MDL-EBS-MD-000001

REV 00. Las Vegas, Nevada: Bechtel SAIC Company. ACC: DOC.20041025.0006.

BSC 2004. Multiscale Thermohydrologic Model. ANL-EBS-MD-000049 REV 02.

169565

Las Vegas, Nevada: Bechtel SAIC Company. ACC: DOC.20041014.0008.

BSC 2004. Natural Analogue Synthesis Report. TDR-NBS-GS-000027 REV 01. Las

169218

Vegas, Nevada: Bechtel SAIC Company. ACC: DOC.20040524.0008.

BSC 2004. Post-Processing Analysis for THC Seepage. ANL-NBS-HS-000045 REV

169858

00. Las Vegas, Nevada: Bechtel SAIC Company. ACC: DOC.20040929.0002.

BSC 2004. Q-List. 000-30R-MGR0-00500-000-000 REV 00. Las Vegas, Nevada:

168361

Bechtel SAIC Company. ACC: ENG.20040721.0007.

BSC 2004. Seepage Calibration Model and Seepage Testing Data. MDL-NBS-HS000004 REV 03. Las Vegas, Nevada: Bechtel SAIC Company.

ACC: DOC.20040922.0003.

BSC 2004. Seepage Model for PA Including Drift Collapse. MDL-NBS-HS-000002

REV 03. Las Vegas, Nevada: Bechtel SAIC Company. ACC: DOC.20040922.0008.

167652

BSC 2004. Seismic Consequence Abstraction. MDL-WIS-PA-000003 REV 01. Las

169183

Vegas, Nevada: Bechtel SAIC Company. ACC: DOC.20041025.0004.

BSC 2004. Simulation of Net Infiltration for Present-Day and Potential Future

170007

Climates. MDL-NBS-HS-000023, Rev. 00. Las Vegas, Nevada: Bechtel SAIC Company.

BSC 2004. Technical Work Plan for: Performance Assessment Unsaturated Zone.

167969

TWP-NBS-HS-000003 REV 02 [Errata 001]. Las Vegas, Nevada: Bechtel SAIC Company. ACC: MOL.20030102.0108; DOC.20040121.0001.

BSC 2004. Technical Work Plan for: Unsaturated Zone Flow Analysis and Model Report Integration. TWP-MGR-HS-000001 REV 00. Las Vegas, Nevada: Bechtel SAIC Company. ACC: DOC.20040701.0005.

BSC 2004. Thermal Conductivity of the Potential Repository Horizon. MDL-NBS169854 GS-000005 REV 01. Las Vegas, Nevada: Bechtel SAIC Company. ACC: DOC.20040928.0006.

BSC 2004. Thermal Testing Measurements Report. TDR-MGR-HS-000002 REV 00.169900 Las Vegas, Nevada: Bechtel SAIC Company. ACC: DOC.20040928.0005.

BSC 2004. Total System Performance Assessment (TSPA) Model/Analysis for the 168504 License Application. MDL-WIS-PA-000004, Rev. 00. Las Vegas, Nevada: Bechtel SAIC Company. 
BSC 2004. UZ Flow Models and Submodels. MDL-NBS-HS-000006, Rev. 02.

169861

Las Vegas, Nevada: Bechtel SAIC Company.

BSC 2004. Yucca Mountain Site Description. TDR-CRW-GS-000001 REV 02

169734

ICN 01. Two volumes. Las Vegas, Nevada: Bechtel SAIC Company.

ACC: DOC.20040504.0008.

Canori, G.F. and Leitner, M.M. 2003. Project Requirements Document. TER-MGR166275 MD-000001 REV 02. Las Vegas, Nevada: Bechtel SAIC Company.

ACC: DOC.20031222.0006.

Craig, R.W. 2001. "Transmittal of Level 5 Deliverable SPW205M5, 'Excavation-

171411

Induced Fracture Study'.” Letter from R.W. Craig (USGS) to T.C. Gunter

(DOE/YMSCO), September 26, 2001, with enclosure. ACC: MOL.20011114.0003.

CRWMS (Civilian Radioactive Waste Management System) M\&O (Management and

103731

Operating Contractor) 1998. Probabilistic Seismic Hazard Analyses for Fault

Displacement and Vibratory Ground Motion at Yucca Mountain, Nevada. Milestone

SP32IM3, September 23, 1998. Three volumes. Las Vegas, Nevada: CRWMS

M\&O. ACC: MOL.19981207.0393.

CRWMS M\&O 2000. Calibrated Properties Model. MDL-NBS-HS-000003

144426

REV 00. Las Vegas, Nevada: CRWMS M\&O. ACC: MOL.19990721.0520.

CRWMS M\&O 2000. Conceptual and Numerical Models for UZ Flow and

141187

Transport. MDL-NBS-HS-000005 REV 00. Las Vegas, Nevada: CRWMS M\&O.

ACC: MOL.19990721.0526.

CRWMS M\&O 2000. Fracture Geometry Analysis for the Stratigraphic Units of the

152286

Repository Host Horizon. ANL-EBS-GE-000006 REV 00. Las Vegas, Nevada:

CRWMS M\&O. ACC: MOL.20000918.0286.

CRWMS M\&O 2000. Yucca Mountain Site Description. TDR-CRW-GS-000001

151945

REV 01 ICN 01. Las Vegas, Nevada: CRWMS M\&O.

ACC: MOL.20001003.0111.

CRWMS M\&O 2001. Abstraction of Drift Seepage. ANL-NBS-MD-000005

154291

REV 01. Las Vegas, Nevada: CRWMS M\&O. ACC: MOL.20010309.0019.

DOE (U.S. Department of Energy) 2004. Quality Assurance Requirements and

171539

Description. DOE/RW-0333P, Rev. 16. Washington, D.C.: U.S. Department of Energy, Office of Civilian Radioactive Waste Management. ACC:

DOC.20040907.0002. 
Doughty, C. 1999. "Investigation of Conceptual and Numerical Approaches for

Evaluating Moisture, Gas, Chemical, and Heat Transport in Fractured Unsaturated Rock.” Journal of Contaminant Hydrology, 38, (1-3), 69-106. New York, New York: Elsevier. TIC: 244160.

Finsterle, S. 2000. "Using the Continuum Approach to Model Unsaturated Flow in Fractured Rock.” Water Resources Research, 36, (8), 2055-2066. [Washington, D.C.]: American Geophysical Union. TIC: 248769.

LeCain, G.D. 1995. Pneumatic Testing in 45-Degree-Inclined Boreholes in

101700 Ash-Flow Tuff Near Superior, Arizona. Water-Resources Investigations Report 95-4073. Denver, Colorado: U.S. Geological Survey. ACC: MOL.19960715.0083.

Liu, H.H.; Doughty, C.; and Bodvarsson, G.S. 1998. “An Active Fracture Model for 105729 Unsaturated Flow and Transport in Fractured Rocks." Water Resources Research, 34, (10), 2633-2646. Washington, D.C.: American Geophysical Union. TIC: 243012.

Mishra, S. 2002. Assigning Probability Distributions to Input Parameters of Performance Assessment Models. SKB TR-02-11. Stockholm, Sweden: Svensk Kärnbränsleförsörjning A.B. TIC: 252794.

Mongano, G.S.; Singleton, W.L.; Moyer, T.C.; Beason, S.C.; Eatman, G.L.W.; 149850 Albin, A.L.; and Lung, R.C. 1999. Geology of the ECRB Cross Drift - Exploratory Studies Facility, Yucca Mountain Project, Yucca Mountain, Nevada. [Deliverable SPG42GM3]. Denver, Colorado: U.S. Geological Survey. ACC: MOL.20000324.0614.

Mukhopadhyay, S. and Tsang, Y.W. 2003. "Uncertainties in Coupled Thermal-Hydrological Processes Associated with the Drift Scale Test at Yucca Mountain, Nevada.” Journal of Contaminant Hydrology, 62-63, 595-612. New York, New York: Elsevier. TIC: 254205.

Neuman, S.P. 1994. "Generalized Scaling of Permeabilities: Validation and Effect of 105731 Support Scale.” Geophysical Research Letters, 21, (5), 349-352. Washington, D.C.: American Geophysical Union. TIC: 240142.

NRC (U.S. Nuclear Regulatory Commission) 2003. Yucca Mountain Review Plan, Final Report. NUREG-1804, Rev. 2. Washington, D.C.: U.S. Nuclear Regulatory Commission, Office of Nuclear Material Safety and Safeguards. TIC: 254568.

Or, D. and Ghezzehei, T.A. 2000. "Dripping into Subterranean Cavities from 144773 Unsaturated Fractures under Evaporative Conditions.” Water Resources Research, 36, (2), 381-393. Washington, D.C.: American Geophysical Union. TIC: 246982. 
Paleologos, E.K.; Neuman, S.P.; and Tartakovsky, D. 1996. "Effective Hydraulic 105736 Conductivity of Bounded, Strongly Heterogeneous Porous Media.” Water Resources Research, 32, (5), 1333-1341. Washington, D.C.: American Geophysical Union. TIC: 245760.

Philip, J.R.; Knight, J.H.; and Waechter, R.T. 1989. "Unsaturated Seepage and 105743 Subterranean Holes: Conspectus, and Exclusion Problem for Circular Cylindrical Cavities.” Water Resources Research, 25, (1), 16-28. Washington, D.C.: American Geophysical Union. TIC: 239117.

Pruess, K.; Wang, J.S.Y.; and Tsang, Y.W. 1990. “On Thermohydrologic Conditions 100819 Near High-Level Nuclear Wastes Emplaced in Partially Saturated Fractured Tuff, 2. Effective Continuum Approximation.” Water Resources Research, 26, (6), 1249-1261. [Washington, D.C.]: American Geophysical Union. TIC: 224854.

Wang, J.S. 2003. "Scientific Notebooks Referenced in Model Report U0120 Abstraction of Drift Seepage, MDL-NBS-HS-000019 REV 00 ICN 01.” Interoffice correspondence from J.S. Wang (BSC) to File, November 4, 2003, with attachments. ACC: MOL.20031105.0451.

Wang, J.S. 2003. "Scientific Notebooks Referenced in Model Report U0120, Abstraction of Drift Seepage, MDL-NBS-HS-000019 REV 00.” Correspondence from J.S. Wang (BSC) to File, August 18, 2003, with attachments.

ACC: MOL.20030818.0371.

Wang, J.S. 2004. "Scientific Notebooks Referenced in Model Report U0120 170994 Abstraction of Drift Seepage, MDL-NBS-HS-000019 REV 01.” Interoffice correspondence from J.S. Wang (BSC) to File, July 26, 2004, with attachment. ACC: MOL.20040803.0090.

Wang, J.S.Y. and Elsworth, D. 1999. "Permeability Changes Induced by Excavation 104366 in Fractured Tuff." Rock Mechanics for Industry, Proceedings of the 37th U.S. Rock Mechanics Symposium, Vail, Colorado, USA, 6-9 June 1999. Amadei, B.; Kranz, R.L.; Scott, G.A.; and Smeallie, P.H., eds. 2, 751-757. Brookfield, Vermont: A.A. Balkema. TIC: 245246.

Wang, J.S.Y.; Flint, A.L.; Nitao, J.J.; Chesnut, D.A.; Cook, P.; Cook, N.G.W.; 101309 Birkholzer, J.; Freifeld, B.; Flint, L.E.; Ellet, K.; Mitchell, A.J.; Homuth, E.F.; Griego, G.J.; Cerny, J.A.; and Johnson, C.L. 1996. Evaluation of Moisture Evolution in the Exploratory Studies Facility. Milestone TR31K6M. Berkeley, California: Lawrence Berkeley National Laboratory. ACC: MOL.19961231.0089.

Whelan, J.F.; Paces, J.B.; and Peterman, Z.E. 2002. "Physical and Stable-Isotope 160442 Evidence for Formation of Secondary Calcite and Silica in the Unsaturated Zone, Yucca Mountain, Nevada.” Applied Geochemistry, 17, ([6]), 735-750. [New York, New York]: Elsevier. TIC: 253462. 
Williams, H. and McBirney, A.R. 1979. Volcanology. San Francisco, California:

Williams, N.H. 2001. "Contract \#: DE-AC08-01RW12101--Thermal Test Progress

160809

Report \#7.” Letter from N.H. Williams (BSC) to S.P. Mellington (DOE/YMSCO), November 9, 2001, NHW:TJV:bm-1025010261, with enclosure.

ACC: MOL.20011207.0060.

Wu, Y-S.; Zhang, W.; Pan, L.; Hinds, J.; and Bodvarsson, G.S. 2002. "Modeling Capillary Barriers in Unsaturated Fractured Rock.” Water Resources Research, 38, (11), 35-1 through 35-12. [Washington, D.C.]: American Geophysical Union.

TIC: 253854.

\subsection{CODES, STANDARDS, REGULATIONS, AND PROCEDURES}

10 CFR 63. Energy: Disposal of High-Level Radioactive Wastes in a Geologic

Repository at Yucca Mountain, Nevada. Readily available.

AP-2.22Q, Rev. 01, ICN 1. Classification Analayses and Maintenance of the Q-List. Washington, D.C.: U.S. Department of Energy, Office of Civilian Radioactive Waste Management. ACC: DOC.20040714.0002.

AP-2.27Q, Rev. 01, ICN 5. Planning for Science Activities. Washington, D.C.: U.S. Department of Energy, Office of Civilian Radioactive Waste Management. ACC: DOC.20041014.0001.

AP-SIII.10Q, Rev. 2, ICN 7. Models. Washington, D.C.: U.S. Department of Energy, Office of Civilian Radioactive Waste Management. ACC:

DOC.20040920.0002.

\subsection{SOURCE DATA, LISTED BY DATA TRACKING NUMBER}

GS021008314224.002. Lithophysal Data Study from the Tptpll in the ECRB from Stations $14+44$ to $23+26$. Submittal date: 01/28/2003.

GS960908312232.013. Air-Injection Testing in Vertical Boreholes in Welded and Non-Welded Tuff, Yucca Mountain, Nevada. Submittal date: 09/26/1996.

LB0011AIRKTEST.001. Air Permeability Testing in Niches 3566 and 3650. Submittal date: 11/08/2000.

LB0012AIRKTEST.001. Niche 5 Air K Testing 3/23/00-4/3/00. Submittal date: $12 / 21 / 2000$.

LB0301DSCPTHSM.002. Drift-Scale Coupled Process Model for

Thermohydrologic Seepage: Data Summary. Submittal date: 01/29/2003. 
LB0302PTNTSW9I.001. PTn/TSw Interface Percolation Flux Maps for 9 Infiltration

Scenarios. Submittal date: 02/28/2003.

LB0302SCMREV02.002. Seepage-Related Model Parameters K and 1/A: Data

Summary. Submittal date: 02/28/2003.

162273

LB03033DSSFF9I.001. 3-D Site Scale UZ Flow Fields for 9 Infiltration Scenarios:

Simulations Using Alternative Hydraulic Properties. Submittal date: 03/28/2003.

163047

LB0303DSCPTHSM.001. Drift-Scale Coupled Process Model for

Thermohydrologic Seepage: Simulation Files. Submittal date: 03/20/2003.

163688

LB0304SMDCREV2.002. Seepage Modeling for Performance Assessment, Including Drift Collapse: Summary Plot Files and Tables. Submittal

date: 04/11/2003.

LB0304SMDCREV2.004. Impact of Thermal-Hydrologic-Mechanical Effects on

Seepage: Summary Plot Files and Tables. Submittal date: 04/23/2003.

163691

LB0305PTNTSW9I.001. PTn/TSw Interface Percolation Flux Maps for 9

Alternative Infiltration Scenarios. Submittal date: 05/12/2003.

163690

LB0307SEEPDRCL.002. Seepage Into Collapsed Drift: Data Summary. Submittal date: 07/21/2003.

164337

LB0309DSCPTHSM.001. Drift-Scale Coupled Process Model For Thermohydrologic Seepage: Simulation Files for Additional Simulation Scenarios.

Submittal date: 09/19/2003.

LB0309DSCPTHSM.002. Drift-Scale Coupled Process Model for Thermohydrologic Seepage: Data Summary for Additional Simulation Scenarios.

Submittal date: 09/19/2003.

LB0310DSCPTHSM.001. Drift-Scale Coupled Process Model for Thermohydrologic 165943 Seepage: Simulation Files for Collapsed Drift Scenarios. Submittal date: 10/21/2003.

LB0310DSCPTHSM.002. Drift-Scale Coupled Process Model for Thermohydrologic Seepage: Data Summary for Collapsed Drift Scenarios.

Submittal date: 10/21/2003.

LB0406U0075FCS.001. Flow Focusing in Heterogeneous Fractured Rock: Simulations. Submittal date: 06/30/2004.

LB0406U0075FCS.002. Flow Focusing in Heterogeneous Fractured Rock: Summaries. Submittal date: 06/30/2004. 
LB980901233124.101. Pneumatic Pressure and Air Permeability Data from Niche 3107 and Niche 4788 in the ESF from Chapter 2 of Report SP33PBM4: Fracture

Flow and Seepage Testing in the ESF, FY98. Submittal date: 11/23/1999.

LB990901233124.004. Air Permeability Cross-Hole Connectivity in Alcove 6, Alcove 4, and Niche 4 of the ESF for AMR U0015, "In Situ Testing of Field

Processes.” Submittal date: 11/01/1999.

MO0306MWDDPPDR.000. Drift Profile Prediction and Degraded Rock Mass

Characteristics. Submittal date: 06/18/2003.

MO0407SEPFEPLA.000. LA FEP List. Submittal date: 07/20/2004.

\subsection{OUTPUT DATA, LISTED BY DATA TRACKING NUMBER}

LB0310AMRU0120.001. Supporting Calculations and Analysis for Seepage Abstraction and Summary of Abstraction Results. Submittal date: 10/23/2003.

LB0310AMRU0120.002. Mathcad 11 Spreadsheets for Probabilistic Seepage Evaluation. Submittal date: 10/23/2003.

LB0407AMRU0120.001. Supporting Calculations and Analysis for Seepage Abstraction and Summary of Abstraction Results. Revised from DTN LB0310AMRU0120.001. Submittal date: 09/20/2004.

LB0407AMRU0120.002. Mathcad 11 Spreadsheets for Probabilistic Seepage Evaluation. Revised from DTN LB0310AMRU0120.002. Submittal date: 09/20/2004. 
APPENDIX A

HISTOGRAMS OF SMPA REALIZATION RESULTS 


\section{HISTOGRAMS OF SMPA REALIZATION RESULTS}

Histograms of SMPA realization results were analyzed in Section 6.4.2.3 (Figure 6.4-7). A Mathcad 11 spreadsheet was used to read the SMPA look-up table results for the nondegraded drift and calculate the seepage histograms for selected cases. The following procedure was followed to conduct the analysis (see also Scientific Notebook, Birkholzer 2003 [DIRS 164525], pp. 20-25):

1. Copy file Fig6-3toFig6-8.xls from DTN: LB0304SMDCREV2.002 [DIRS 163687] into appropriate working directory.

2. Open a new Excel file named ResponseSurfaceSMPA_all_realizations_selected.xls, with three different Worksheets “-12 and 500”,“-12 and 100”,“-12 and 1000”.

3. Choose three parameter cases in $\mathrm{k}$ and $1 / \alpha$, representing SMPA results with average, large and small seepage (Case $1: \mathrm{k}=-12,1 / \alpha=500 \mathrm{~Pa}$, Case $2: \mathrm{k}=-12,1 / \alpha=1,00 \mathrm{~Pa}$, Case 3: $\mathrm{k}=-12,1 / \alpha=1,000 \mathrm{~Pa})$.

4. Copy SMPA results for each selected case from Fig6-3toFig6-8.xls into ResponseSurfaceSMPA_all_realizations_selected.xls. For each case, copy the full line of all percolation rates included in the look-up table. Copy all lines for Case 1 into Worksheet “-12 and 500”, all lines for Case 2 into Worksheet "-12 and 100”, and all lines for Case 3 into Worksheet “-12 and 1000”.

5. Delete the first seven columns in each Worksheet, so that only the 20 columns for each realization are left in the Excel file.

6. Use Mathcad 11 spreadsheet histogram_seepage_uncertainty.mcd to calculate and display the seepage histograms over the 20 realizations. The calculation reads the Excel file ResponseSurfaceSMPA_all_realizations_selected.xls. It then calculates and displays histograms for each case, choosing four percolation fluxes (50 mm/year, $200 \mathrm{~mm} /$ year, $500 \mathrm{~mm} /$ year, and 1,000 mm/year). The resulting histograms can be evaluated.

ResponseSurfaceSMPA_all_realizations_selected.xls and histogram_seepage_uncertainty.mcd are in Output-DTN: LB0407AMRU0120.001 (Directory: seepage_uncertainty_evaluation). Alternatively, DTN LB0310AMRU0120.001 can be used. 


\section{INTENTIONALLY LEFT BLANK}




\section{APPENDIX B}

STATISTICAL ANALYSIS OF CAPILLARY-STRENGTH PARAMETER VALUES 


\section{STATISTICAL ANALYSIS OF CAPILLARY-STRENGTH PARAMETER VALUES}

The calibrated capillary-strength parameters from the SCM were statistically analyzed in Section 6.6.2.2 (see also Scientific Notebook, Birkholzer 2003 [DIRS 164526], pp. 59-65, 118-127). The analysis was conducted with a Microsoft Excel 97 SR-2 calculation. The capillary-strength parameters are provided in DTN: LB0302SCMREV02.002 [DIRS 162273]. The DTN gives six calibrated capillary-strength parameter values in the Tptpll unit, available at two locations (Niche 1620 and systematic testing borehole in the ECRB), and four parameter values in the Tptpmn unit, available at two locations (Niche 3107 and Niche 4788). The statistical parameters calculated are the mean $\mu$, the standard deviation $\sigma$, and the mean error SE-an estimate for the uncertainty in the mean value caused by a limited number of measurements. Four different methods of deriving these statistical parameters are chosen to support the above approach. These methods are as follows:

A. Derive mean and standard deviation from all ten samples in both units.

B. Calculate average values from multiple tests in one location, then derive mean and standard deviation from the resulting four samples in both units.

C. Derive mean and standard deviation separately for geological units, from six samples in the Tptpll unit and four samples in the Tptpmn unit.

D. Calculate average values from multiple tests in one location, then derive mean and standard deviation separately for each geological unit.

Excel spreadsheet capillary_strength_variability_analysis.xls conducts the calculation. Methods A and B are included in Worksheet "both units." Methods C and D are included in Worksheets "tptpm" and "tptpl," separately for the two units. The Excel spreadsheet is provided in Output DTN: LB0407AMRU0120.001 (Directory: capillary_strength_analysis). Alternatively, DTN LB0310AMRU0120.001 can be used. The results support Table 6.6-2 of this model report. 


\section{INTENTIONALLY LEFT BLANK}




\section{APPENDIX C \\ STATISTICAL ANALYSIS OF PERMEABILITY VALUES}




\section{STATISTICAL ANALYSIS OF PERMEABILITY VALUES}

Permeability values measured in air-injection testing were statistically analyzed in Section 6.6.3.2 (see also Scientific Notebooks, Birkholzer 2003 [DIRS 164526], pp. 42-58, 128-132; Birkholzer 2003 [DIRS 164525], pp. 69-70). The analyses were conducted with Microsoft Excel 97 SR-2 calculations. The Excel spreadsheets used for the different calculations are provided in Output-DTN: LB0407AMRU0120.001 (Directory: permeability_analysis). Alternatively, they are also provided in DTN LB0310AMRU0120.001.

In a first step, permeability values from small-scale injection testing in close vicinity to niches or the ECRB tunnel were analyzed. Except for the systematic testing in the ECRB tunnel, permeability values are available for the conditions prior to and after niche construction (undisturbed versus disturbed). In most cases, summary statistics (mean and standard deviation) of these small-scale measurements had been provided prior to developing this seepage abstraction model and were available in the TDMS, in DTN: LB0302SCMREV02.002 [DIRS 162273] (disturbed measurements statistics) and DTN: LB990901233124.004 [DIRS 123273] (undisturbed measurements statistics). In the case of Niche 1620, summary statistics of the undisturbed small-scale measurements were not available. These were therefore calculated directly from DTN: LB0012AIRKTEST.001 [DIRS 154586], containing permeability values for all small-scale test intervals. The statistical calculation was conducted in Excel spreadsheet niche_1620_preexcavation.xls. The procedure is as follows:

1. Table 01048_001 from DTN: LB0012AIRKTEST.001 [DIRS 154586] was extracted from the TDMS. File zz_sep_278799.zip was copied to an appropriate working directory and unzipped. A text file named zz_sep_278799.txt opens.

2. A new Excel file named niche_1620_preexcavation.xls was generated. The text file zz_sep_278799.txt was opened into Excel, using space and tab delimited options. The last data column contains the permeability values in $\log 10$ space. This column was analyzed. From the 208 measurements in this column, stemming from different boreholes, the mean and standard deviation were calculated, and minimum and maximum values were derived.

3. Finally, editorial changes were conducted in Excel file niche_1620_preexcavation.xls. These include adding/changing headers and deleting columns that are not needed.

The statistics derived from niche_1620_preexcavation.xls support Table 6.6-3 of this model report. The mean permeability value derived in niche_1620_preexcavation.xls, as well as the other mean values from small-scale permeability measurements as provided in DTN: LB0302SCMREV02.002 [DIRS 162273] and DTN: LB990901233124.004 [DIRS 123273], are used then to calculate the intermediate-scale variability over the Yucca Mountain. This calculation is done in Excel spreadsheet permeability_variability_analysis_ small_scale.xls. Worksheet "undisturbed" comprises analysis of pre-excavation measurements, for four niches in the Tptpmn unit and one niche in the Tptpll unit. Worksheet "disturbed" comprises analyses of post-excavation measurements, from three niches in the Tptpmn unit and one niche plus and one systematic testing borehole. The statistical parameters calculated are the mean $\mu$, the standard deviation $\sigma$, and the mean error SE. Worksheet "comparison" analyzes 
undisturbed versus disturbed permeability values, looking at the changes in the mean values and changes in the standard deviation. The Excel spreadsheet is provided in Output DTN: LB0407AMRU0120.001 (Directory: Permeability_Analysis). The results of this support Tables 6.6-4 and 6.6-7 of this model report.

In a second step, permeability values from injection testing conducted in surface-based boreholes were analyzed. Measurements from surface-based boreholes, performed at four borehole locations in various units at the Yucca Mountain, are available in DTN: GS960908312232.013 [DIRS 105574]. The boreholes included in this DTN are NRG-6, NRG-7a, SD-12, and UZ\#16. The relevant units for this model report are the Tptpll, the Tptpmn, the Tptpul, and the Tptpln. A varying number of injection tests had been conducted in each unit and at each location, depending on the local thickness of the unit and the chosen injection interval length. For further analysis, the mean permeability value of all measurements at each location and each relevant unit was calculated in Excel spreadsheet vertical_boreholes.xls. The procedure was as follows:

1. Table S01163_001 from DTN: GS960908312232.013 [DIRS 105574] was extracted from the TDMS. File zz_sep_208683.zip was copied to an appropriate working directory and unzipped. A text file named zz_sep_208683.txt opens.

2. A new Excel file named vertical_boreholes.xls was generated. The text file zz_sep_208683.txt was opened into Excel, using space and tab delimited options. The last data column contains the permeability values in log10 space. This column was analyzed. Information on locations and units for each measurement is given in the second column (borehole) and the tenth column (unit). All data lines that do not represent the Tptpll, Tptpmn, Tptpul, and Tptpln units were deleted. This left two units for borehole NRG-6 (Tptpul and Tptpmn units), three units at NRG-7a (Tptpul, Tptpmn, and Tptpll units), three units at SD-12 (Tptpul, Tptpmn, and Tptpln units), and four units at UZ\#16 (Tptpul, Tptpmn, Tptpll, and Tptpln units). Some measurement intervals intersect two units. In such cases, the measured permeability value was applied to the statistical calculation of both units (i.e. the respective data line was copied and assigned to both units). Then, for each borehole and each unit, the mean and standard deviation was calculated, and minimum and maximum values were derived.

3. Finally, several editorial changes were conducted in Excel file vertical_boreholes.xls.

The mean permeability values derived from vertical_boreholes.xls support Tables 6.6-5, 6.6-8, and 6.6-10 of this model report. These values are then used to calculate the intermediate-scale variability over the Yucca Mountain. This calculation is done in Excel spreadsheet permeability_variability_analysis_vertical_boreholes.xls. The statistical parameters calculated are the mean $\mu$, the standard deviation $\sigma$, and the mean error SE, separately for the different units. The results of this calculation support Tables 6.6-5, 6.6-8, and 6.6-10 of this model report.

A final calculation analysis was performed in Section 6.6.3.2 to evaluate the effect of measurement interval differences between the niche air injection tests (1-foot-intervals) and those conducted in surface-based boreholes (interval lengths between 3.5 and $4.6 \mathrm{~m}$ ). The mean effective permeability increases with the interval length, so that upscaling laws have to be 
applied in order to make the permeability values comparable. One of the methods used in Section 6.6.3.2 was to use the 1-foot measurements in the niches and presume that these represent the exact spatial variability along the borehole. The individual permeability values were then divided into several groups of twelve consecutive 1-foot measurements; i.e., one group represents the length of a 3.6-meter interval. The arithmetic mean of the twelve 1-foot values in each group gives the permeability value that would have been measured in a 3.6-m-injection interval. The arithmetic mean values of all groups in one niche location can then be statistically analyzed to evaluate the scaling effects directly from the data.

The upscaling analysis was conducted using the pre-excavation measurements in Niches 1620, 3107, 3566, 3650, and 3566. These data are given in DTN: LB0012AIRKTEST.001 [DIRS 154586] (Niche 1620), DTN: LB980901233124.101 [DIRS 136593] (Niches 3107 and 4788), and DTN: LB0011AIRKTEST.001 [DIRS 153155] (Niches 3650 and 3566), containing permeability values for all small-scale test intervals. The statistical calculation was conducted with different Excel spreadsheets. The procedure was as follows:

Niche 1620:

1. Table S01048_001 from DTN: LB0012AIRKTEST.001 [DIRS 154586] was extracted from the TDMS. File zz_sep_278799.zip was copied to an appropriate working directory and unzipped. A text file named zz_sep_278799.txt opens.

2. A new Excel file named niche_1620_preexcavation_upscaling.xls was generated. The text file zz_sep_278799.txt was opened into Excel, using space and tab delimited options. The second last data column contains the permeability values in nonlogarithmic space. Starting with the first measurement interval, the arithmetic mean of groups of twelve consecutive values was calculated. Four measurement intervals at the end of the data set were disregarded in this analysis since they do not comprise a full group of twelve. The arithmetic mean values were transformed into $\log 10$ values. Finally, the arithmetic mean over all log10 values was calculated, giving the upscaled mean permeability value for the Niche 1620 measurements.

3. Finally, editorial changes were conducted in niche_1620_preexcavation_upscaling.xls. These include adding/changing headers and deleting columns that were not needed.

Niche 3107:

1. Table S99469_001 from DTN: LB980901233124.101 [DIRS 136593] was extracted from the TDMS. File zz_sep_208706.zip was copied to an appropriate working directory and unzipped. A text file named zz_sep_208706.txt opens.

2. A new Excel file named niche_3107_preexcavation_upscaling.xls was generated. The text file zz_sep_208706.txt was opened into Excel, using space and tab delimited options. The last data column contains the permeability values in nonlogarithmic space. Starting with the first measurement interval, the arithmetic mean of groups of twelve consecutive values was calculated. Three measurement intervals at the end of the data set were disregarded in this analysis since they do not comprise a full group of twelve. The arithmetic mean values were transformed into log10 values. Finally, the 
arithmetic mean over all $\log 10$ values was calculated, giving the upscaled mean permeability value for the Niche 3107 measurements.

3. Finally, editorial changes were conducted in niche_3107_preexcavation_upscaling.xls. These include adding/changing headers and deleting columns that are not needed.

Niche 4788:

1. Table S99469_002 from DTN: LB980901233124.101 [DIRS 136593] was extracted from the TDMS. File zz_sep_208707.zip was copied to an appropriate working directory and unzipped. A text file named zz_sep_208707.txt opens.

2. A new Excel file named niche_4788_preexcavation_upscaling.xls was generated. The text file zz_sep_208707.txt was opened into Excel, using space and tab delimited options. The last data column contains the permeability values in non-logarithmic space. Starting with the first measurement interval, the arithmetic mean of groups of twelve consecutive values was calculated. The last group contains only eleven permeability values. The arithmetic mean values were transformed into log10 values. Finally, the arithmetic mean over all $\log 10$ values was calculated, giving the upscaled mean permeability value for the Niche 4788 measurements.

3. Finally, editorial changes were conducted in niche_4788_preexcavation_upscaling.xls. These include adding/changing headers and deleting columns that are not needed.

Niche 3650:

1. Tables S00434_006 through S00434_009, S00434_011, S00434_013, and S00434_015 from DTN: LB0011AIRKTEST.001 [DIRS 153155] were extracted from the TDMS. Each table relates to a separate zip file for the boreholes tested in prior to construction of Niche 3107. The zip files were copied to an appropriate working directory and unzipped. Several text files containing the measurements of the different boreholes open.

2. A new Excel file named niche_3650_preexcavation_upscaling.xls was generated. All text files for the different boreholes were opened into Excel, using space- and tab-delimited options, and were then copied, one borehole after the other, into one spreadsheet. The second last data column contains the permeability values in non-logarithmic space. Starting with the first measurement interval, the arithmetic mean of groups of twelve consecutive values was calculated. Nine measurement intervals at the end of the data set were disregarded in this analysis since they do not comprise a full group of twelve. The arithmetic mean values were transformed into $\log 10$ values. Finally, the arithmetic mean over all $\log 10$ values was calculated, giving the upscaled mean permeability value for the Niche 3650 measurements.

3. Finally, editorial changes were conducted in niche_3650_preexcavation_upscaling.xls. These include adding/changing headers and deleting columns that are not needed. 
Niche 3566:

1. Tables S00434_001, S00434_002, and S00434_003 from DTN: LB0011AIRKTEST.001 [DIRS 153155] were extracted from the TDMS. Each table relates to a separate zip file for the boreholes tested prior to construction of Niche 3566. The zip files were copied to an appropriate working directory and unzipped. Several text files containing the measurements of the different boreholes open.

2. A new Excel file named niche_3566_preexcavation_upscaling.xls was generated. All text files for the different boreholes were opened into Excel, using space- and tab-delimited options, and were then copied, one borehole after the other, into one spreadsheet. The second last data column contains the permeability values in nonlogarithmic space. Starting with the first measurement interval, the arithmetic mean of groups of twelve consecutive values was calculated. Eight measurement intervals at the end of the data set were disregarded in this analysis, since they do not comprise a full group of twelve. The arithmetic mean values were transformed into $\log 10$ values. Finally, the arithmetic mean over all $\log 10$ values was calculated, giving the upscaled mean permeability value for the Niche 3566 measurements.

3. Finally, editorial changes were conducted in niche_3566_preexcavation_upscaling.xls. These include adding/changing headers and deleting columns that are not needed.

The statistics derived from the upscaling analysis for the five niches support Tables 6.6-6 and 6.6-9 of this model report. 


\section{INTENTIONALLY LEFT BLANK}


APPENDIX D

ANAL YSIS OF PERCOLATION FLUX FIELDS 


\section{ANALYSIS OF PERCOLATION FLUX FIELDS}

The percolation flux distributions predicted by the UZ Flow Model (BSC 2004 [DIRS 169861]) were statistically analyzed in Section 6.6.5.1 of this model report (see also Scientific Notebook, Birkholzer 2003 [DIRS 164526], pp. 97-117, 140-146). These fluxes were provided in DTN: LB0302PTNTSW9I.001 [DIRS 162277] (base case) and DTN: LB0305PTNTSW9I.001 [DIRS 163690] (alternative conceptual model for flow in the PTn). Several Mathcad 11 spreadsheets were used to calculate the mean, minimum, and maximum fluxes in these flow fields, and to analyze the distribution of fluxes using histograms. As pointed out in Section 6.6.5.1, the model domain of the UZ Flow Model is much larger than the repository area. Since only fluxes over the repository area are relevant for the seepage evaluation, the Mathcad calculation must extract the repository fluxes from the overall flux distribution for the entire UZ model domain. In addition, it is interesting to evaluate the potential impact of major fault zones that intersect the model domain. Therefore, fluxes that represent fault zones need to be identified in the Mathcad spreadsheets, and statistical parameters need to be calculated for flux distributions with and without fault zones.

The Mathcad calculation uses file REPO_ZONE.cell from DTN: LB03033DSSFF9I.001 [DIRS 163047] to identify the repository fluxes. This file lists the 469 repository elements in the UZ model grid by their 7-digit names. The last three digits denote the columns of the numerical grid; the first one of these three digits is a letter followed by a two-digit number. An upper-case letter indicates that the column represents a fault element, lower case letters stand for non-fault (fractured rock) elements. Based on the given list of repository element names, an Excel file REPO_ZONE_for_mathcad.xls was generated containing two worksheets. The first worksheet "Repository Columns" includes a list of the 469 repository elements with only the last three digits; the first four digits have been eliminated because they are not needed for identification of repository elements. The second worksheet "No Fault Repo Columns” includes a list of all non-fault 433 repository elements, again only giving the last three digits. This list was generated by eliminating all repository elements from Worksheet "Repository Columns" that have an upper case letter.

The nine flow fields from DTN: LB0302PTNTSW9I.001 [DIRS 162277] are given in separate data files; these are named as follows in the DTN:

$$
\begin{aligned}
& \text { preq_ma_ptn.q } \\
& \text { monq_ma_ptn.q } \\
& \text { glaq_ma_ptn.q } \\
& \text { preq_la_ptn.q } \\
& \text { monq_la_ptn.q } \\
& \text { glaq_la_ptn.q } \\
& \text { preq_ma_ptn.q } \\
& \text { monq_ma_ptn.q } \\
& \text { glaq_ma_ptn.q }
\end{aligned}
$$

mean infiltration scenario, present-day climate mean infiltration scenario, monsoon climate mean infiltration scenario, glacial transition climate lower-bound infiltration scenario, present-day climate lower-bound infiltration scenario, monsoon climate lower-bound infiltration scenario, glacial transition climate upper-bound infiltration scenario, present-day climate upper-bound infiltration scenario, monsoon climate upper-bound infiltration scenario, glacial transition climate 
The nine flow fields from DTN: LB0305PTNTSW9I.001 [DIRS 163690], for the alternative flow model in the PTn, are given in separate data files; these are named as follows in the DTN:

preq_mb_ptn.q
monq_mb_ptn.q
glaq_mb_ptn.q
preq_lb_ptn.q
monq_lb_ptn.q
glaq_lb_ptn.q
preq_mb_ptn.q
monq_mb_ptn.q
glaq_mb_ptn.q
mean infiltration scenario, present-day climate
mean infiltration scenario, monsoon climate
mean infiltration scenario, glacial transition climate lower-bound infiltration scenario, present-day climate lower-bound infiltration scenario, monsoon climate lower-bound infiltration scenario, glacial transition climate upper-bound infiltration scenario, present-day climate upper-bound infiltration scenario, monsoon climate upper-bound infiltration scenario, glacial transition climate

Each of these files contains the PTn/TSw-fluxes for all element columns of the UZ model grid. The first two variables in each line give the element coordinates, the third variable gives the vertical percolation flux at the PTn/TSw-interface in $\mathrm{mm} / \mathrm{year}$, and the fourth variable gives the element name (7-digits). For the Mathcad calculation, the list of element names was copied into an Excel file ptntsw_elements_for_mathcad.xls. The first four digits of each name were deleted, so that only the 3-digit column name remains in the Excel file.

The statistical analysis of these percolation flux fields is conducted with various Mathcad spreadsheets. Basically, the calculation procedure in these spreadsheets is identical; only the input and output file names are different. The Mathcad spreadsheets (1) read Excel files REPO_ZONE_for_mathcad.xls and ptntsw_elements_for_mathcad.xls, (2) read one of the 18 files for the percolation flux fields, (3) calculate over all fluxes (entire UZ domain), (4) identify and extract the repository fluxes, (5) write the extracted fluxes into an Excel file for further use in seepage evaluation, (6) calculate statistics for the extracted fluxes, and (7) plot a histogram of the distribution of extracted fluxes. The statistical analysis is conducted for all repository elements and for all non-fault repository elements, in separate spreadsheets. For the base case flow concept in the PTN, all nine flow fields are analyzed. For the alternative flow concept in the PTn, only the three climate stages of the mean infiltration scenario are analyzed.

The following list gives a selection of variable names that are used in the spreadsheets and provide output to further analysis. The steps in parenthesis refer to different calculation steps identified in the spreadsheets. More details on the procedure and variables can be found in the Scientific Notebook YMP-LBNL-JTB-2 (Birkholzer 2003 [DIRS 164526], pp. 112-117).

$\begin{array}{ll}\text { fluxv: } & \text { flux distribution over UZ domain (Step } 4 \text { in spreadsheet) } \\ \text { meanflux: } & \text { mean flux value over UZ domain (Step } 4 \text { in spreadsheet) } \\ \text { minflux: } & \text { minimum flux value over UZ domain (Step } 4 \text { in spreadsheet) } \\ \text { maxflux: } & \text { maximum flux value over UZ domain (Step } 4 \text { in spreadsheet) } \\ \text { fluxr: } & \text { flux distribution over repository area (Step } 6 \text { in spreadsheet) } \\ \text { meanflux: } & \text { mean flux value over repository area (Step } 6 \text { in spreadsheet) } \\ \text { minflux: } & \text { minimum flux value over repository area (Step } 6 \text { in spreadsheet) } \\ \text { maxflux: } & \text { maximum flux value over repository area (Step } 6 \text { in spreadsheet) } \\ \text { fluxhist: } & \text { histogram of flux distribution over repository area (Step } 7 \text { in } \\ & \text { spreadsheet) }\end{array}$


Table D-1 provides a list of the Mathcad spreadsheets for the percolation flux analysis using the base case flow fields, conducted for all repository elements. Table D-2 provides a list of the Mathcad spreadsheets for the same flow fields, but conducted for no-fault repository elements. Table D-3 gives a list of the Mathcad spreadsheets for the alternative flow fields analysis, conducted for the mean infiltration scenario for all repository elements. Table D-4 provides a list of the Mathcad spreadsheets for the same flow fields, but conducted for no-fault repository elements.

Table D-1. Mathcad Spreadsheets for Percolation Flux Analysis Using the Base Case Flow Fields from DTN: LB0302PTNTSW9I.001 [DIRS 162277]. Calculation is Conducted for All Repository Elements

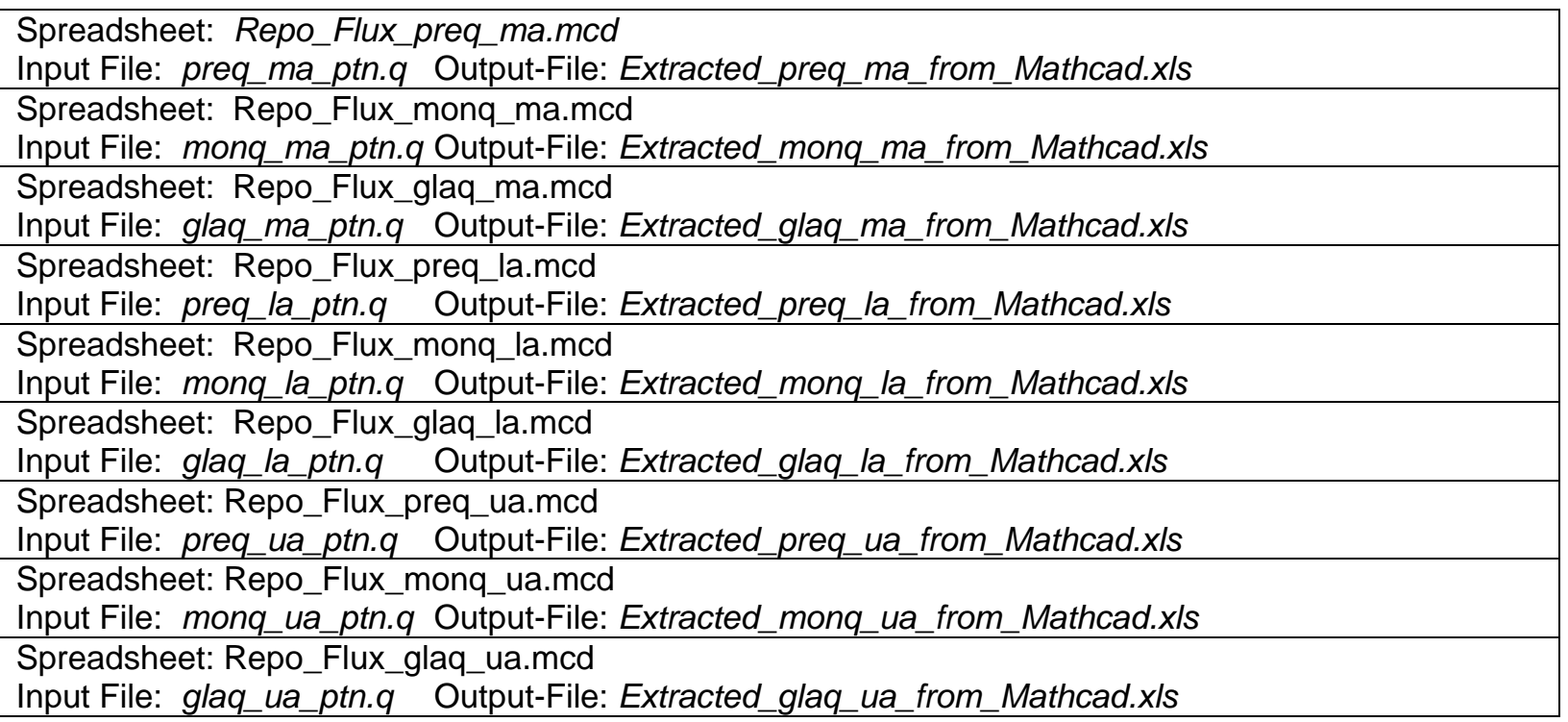

Table D-2. Mathcad Spreadsheets for Percolation Flux Analysis Using the Base Case Flow Fields from DTN: LB0302PTNTSW9I.001 [DIRS 162277]. Calculation is Conducted for No-Fault Repository Elements

\begin{tabular}{|l|}
\hline Spreadsheet: Repo_Flux_preq_ma_no_fault.mcd \\
Input File: preq_ma_ptn.q Output-File: NA \\
\hline Spreadsheet: Repo_Flux_monq_ma_no_fault.mcd \\
Input File: monq_ma_ptn.q Output-File: NA \\
\hline Spreadsheet: Repo_Flux_glaq_ma_no_fault.mcd \\
Input File: glaq_ma_ptn.q Output-File: NA \\
\hline $\begin{array}{l}\text { Spreadsheet: Repo_Flux_preq_la_no_fault.mcd } \\
\text { Input File: preq_la_ptn.q Output-File: NA }\end{array}$ \\
\hline Spreadsheet: Repo_Flux_monq_la_no_fault.mcd \\
Input File: monq_la_ptn.q Output-File: NA \\
\hline Spreadsheet: Repo_Flux_glaq_la_no_fault.mcd \\
Input File: glaq_la_ptn.q Output-File: NA \\
\hline $\begin{array}{l}\text { Spreadsheet: Repo_Flux_preq_ua_no_fault.mcd } \\
\text { Input File: preq_ua_ptn.q Output-File: NA }\end{array}$ \\
\hline Spreadsheet: Repo_Flux_monq_ua_no_fault.mcd \\
Input File: monq_ua_ptn.q Output-File: NA \\
\hline Spreadsheet: Repo_Flux_glaq_ua_no_fault.mcd \\
Input File: glaq_ua_ptn.q Output-File: NA
\end{tabular}


Table D-3. Mathcad Spreadsheets for Percolation Flux Analysis Using the Alternative Flow Fields from DTN: LB0305PTNTSW9I.001 [DIRS 163690]. Calculation is Conducted for All Repository Elements

Spreadsheet: Repo_Flux_preq_mb.mcd

Input File: preq_mb_ptn.q Output-File: Extracted_preq_mb_from_Mathcad.xls

Spreadsheet: Repo_Flux_monq_mb.mcd

Input File: monq_mb_ptn.q Output-File: Extracted_monq_mb_from_Mathcad.xls

Spreadsheet: Repo_Flux_glaq_mb.mcd

Input File: glaq_mb_ptn.q Output-File: Extracted_glaq_mb_from_Mathcad.xls

Table D-4. Mathcad Spreadsheets for Percolation Flux Analysis Using the Alternative Flow Fields from DTN: LB0305PTNTSW9I.001 [DIRS 163690]. Calculation is Conducted for No-Fault Repository Elements

Spreadsheet: Repo_Flux_preq_mb_no_fault.mcd

Input File: preq_mb_ptn.q Output-File: NA

Spreadsheet: Repo_Flux_monq_mb_no_fault.mcd

Input File: monq_mb_ptn.q Output-File: NA

Spreadsheet: Repo_Flux_glaq_mb_no_fault.mcd

Input File: glaq_mb_ptn.q Output-File: NA

The Mathcad spreadsheets and all input/output files are provided in Output DTN: LB0407AMRU0120.001. (Alternatively, they are also given in DTN LB0310AMRU0120.001.) The files listed in Tables IV-1 and IV-2 are provided in directory: Norm_Flow_Field_Analysis. The files listed in Tables IV-3 and IV-4 are provided in directory: Alternative_Concept_Flow_Field_Analysis. Summary statistics derived from these files are given in word document flow_field_summary_tables.doc in the DTN. Results from these files support Table 6.6-11 and Figure 6.6-12 of this model report. Summary statistics derived from all spreadsheets (base case and alternative flow fields) are given in word document flow_field_summary_tables.doc in the DTN in directory: Norm_Flow_Field_Analysis. 
APPENDIX E

PROBABILISTIC SEEPAGE CALCULATION 


\section{PROBABILISTIC SEEPAGE CALCULATION}

The results from probabilistic seepage calculations were described and discussed in Sections 6.8.1 and 6.8.2. Several Mathcad 11 spreadsheets were used to conduct these calculations for various evaluation cases. The Mathcad spreadsheets read the SMPA look-up table and the extracted repository percolation fluxes (see Appendix D), perform a random seepage calculation over 10,000 random samples, and derive seepage histograms as well as seepage summary statistics. The following procedure was followed to conduct the analysis (see also Scientific Notebook, Birkholzer 2003 [DIRS 164525], pp. 96-142):

1. Copy the seepage look-up table for nondegraded drifts in file Fig6-3toFig6-8.dat from DTN: LB0304SMDCREV2.002 [DIRS 163687] into appropriate working directory for Mathcad calculation, subdirectory SMPA Input. (For the collapsed drift cases in Sensitivity Case 11, a different look-up table is needed. In this case, the seepage look-up table for collapsed drifts as provided in file ResponseSurface SMPACollapsedDrift.dat from DTN: LB0307SEEPDRCL.002 [DIRS 164337] needs to be copied into the same working directory.)

2. Rename file Fig6-3toFig6-8.dat to ResponseSurfaceSMPA_for_Mathcad.dat. Delete first two lines. (For collapsed drifts: Rename file ResponseSurface SMPACollapsedDrift.dat to ResponseSurfaceSMPACollapseddrift_for_Mathcad.dat. Delete the first two lines.)

3. Copy the Excel files containing the extracted repository fluxes (see Appendix D, Table D-1 and D-3) into subdirectories UZ Flow Fields Norm (for base case flow fields) and UZ Flow Fields Alternative (for alternative flow fields).

4. Conduct Mathcad calculations using the various Mathcad spreadsheets listed in Tables V-1, V-2 and V-3. Tables E-1 and E-2 give the base case calculations described in Section 6.8.1, for the Tptpll and the Tptpmn units, respectively. Table E-3 lists the sensitivity case calculations described in Section 6.8.2. Table E-3 lists spreadsheets that are needed in Appendix $\mathrm{F}$ to demonstrate that the interpolation of seepage results is conducted correctly.

The following list gives a selection of variable names that are used in the spreadsheets. More details can be found in the Scientific Notebook YMP-LBNL-JTB-3 (Birkholzer 2003 [DIRS 164525], pp. 96-142).

nrand: $\quad$ number of random values

xkfield: $\quad$ random distribution of permeability

xkmean: $\quad$ mean of random distribution of permeability

xkstv: $\quad$ standard deviation of random distribution of permeability

xkmin: $\quad$ minimum value of random distribution of permeability

xkmax: $\quad$ maximum value of random distribution of permeability

ikmin: $\quad$ number of values smaller than parameter space covered by SMPA

ikmax: $\quad$ number of values larger than parameter space covered by SMPA

xafield: $\quad$ random distribution of capillary strength 


$\begin{array}{ll}\text { xamean: } & \text { mean of random distribution of capillary strength } \\ \text { xastv: } & \text { standard deviation of random distribution of capillary strength } \\ \text { xamin: } & \text { minimum value of random distribution of capillary strength } \\ \text { xamax: } & \text { maximum value of random distribution of capillary strength } \\ \text { iamin: } & \text { number of values smaller than parameter space covered by SMPA } \\ \text { iamax: } & \text { number of values larger than parameter space covered by SMPA } \\ \text { fluxfield: } & \text { random distribution of percolation flux (without flow focusing) } \\ \text { xfmean: } & \text { mean of random distribution of percolation flux } \\ \text { xfstv: } & \text { standard deviation of random distribution of percolation flux } \\ \text { xfmin: } & \text { minimum value of random distribution of percolation flux } \\ \text { xfmax: } & \text { maximum value of random distribution of percolation flux } \\ \text { focfield: } & \text { random distribution of flow focusing factors } \\ \text { xfomean: } & \text { mean of random distribution of flow focusing factors } \\ \text { xfostv: } & \text { standard deviation of random distribution of flow focusing factors } \\ \text { xfomin: } & \text { minimum value of random distribution of flow focusing factors } \\ \text { xfomax: } & \text { maximum value of random distribution of flow focusing factors } \\ \text { fluxfocfield: } & \text { final distribution of percolation flux (including flow focusing) } \\ \text { xffomean: } & \text { mean of final distribution of percolation flux } \\ \text { xffostv: } & \text { standard deviation of final distribution of percolation flux } \\ \text { xffomin: } & \text { minimum value of final distribution of percolation flux } \\ \text { xffomax: } & \text { maximum value of final distribution of percolation flux } \\ \text { ifmin: } & \text { number of values smaller than parameter space covered by SMPA } \\ \text { ifmax: } & \text { number of values larger than parameter space covered by SMPA } \\ \text { seepratefinal: } & \text { distribution of seepage rates } \\ \text { seepercfinal20: } & \text { distribution of seepage percentages } \\ \text { finalmean: } & \text { mean seepage rate } \\ \text { meanfinal: } & \text { mean seepage percentage } \\ \text { num0: } & \text { number of random samples without seepage }\end{array}$

Table E-1. Mathcad Spreadsheets for Probabilistic Seepage Calculation for the Tptpll Unit (Base Case Seepage Evaluation)

\begin{tabular}{|l|l|}
\hline tptpll_preq_ma.mcd & seepage calculation for present-day climate, mean infiltration scenario \\
\hline tptplI_monq_ma.mcd & seepage calculation for monsoon climate, mean infiltration scenario \\
\hline tptpll_glaq_ma.mcd & seepage calculation for glacial transition climate, mean infiltration scenario \\
\hline tptplI_preq_la.mcd & seepage calculation for present-day climate, lower-bound infiltration scenario \\
\hline tptpll_monq_la.mcd & seepage calculation for monsoon climate, lower-bound infiltration scenario \\
\hline tptpll_glaq_la.mcd & seepage calculation for glacial transition climate, lower-bound infiltration scenario \\
\hline tptpll_preq_ua.mcd & seepage calculation for present-day climate, upper-bound infiltration scenario \\
\hline tptpll_monq_ua.mcd & seepage calculation for monsoon climate, upper-bound infiltration scenario \\
\hline tptpll_glaq_ua.mcd & seepage calculation for glacial transition climate, upper-bound infiltration scenario \\
\hline
\end{tabular}

\footnotetext{
${ }^{1}$ The percentage of samples without seepage num0 can be converted to the seepage fraction (in percent) by the following calculation: $100 \times($ nrand - num0)/nrand.
} 
Table E-2. Mathcad Spreadsheets for Probabilistic Seepage Calculation for the Tptpmn Unit (Base Case Seepage Evaluation)

\begin{tabular}{|l|l|}
\hline tptpmn_preq_ma.mcd & seepage calculation for present-day climate, mean infiltration scenario \\
\hline tptpmn_monq_ma.mcd & seepage calculation for monsoon climate, mean infiltration scenario \\
\hline tptpmn_glaq_ma.mcd & seepage calculation for glacial transition climate, mean infiltration scenario \\
\hline tptpmn_preq_la.mcd & seepage calculation for present-day climate, lower-bound infiltration scenario \\
\hline tptpmn_monq_la.mcd & seepage calculation for monsoon climate, lower-bound infiltration scenario \\
\hline tptpmn_glaq_la.mcd & seepage calculation for glacial transition climate, lower-bound infiltration scenario \\
\hline tptpmn_preq_ua.mcd & seepage calculation for present-day climate, upper-bound infiltration scenario \\
\hline tptpmn_monq_ua.mcd & seepage calculation for monsoon climate, upper-bound infiltration scenario \\
\hline tptpmn_glaq_ua.mcd & seepage calculation for glacial transition climate, upper-bound infiltration scenario \\
\hline
\end{tabular}

Table E-3. Mathcad Spreadsheets for Probabilistic Seepage Calculation for the Tptpll Unit (Sensitivity Cases)

\begin{tabular}{|c|c|}
\hline $\begin{array}{l}\text { tptpll_preq_ma_normal_dist_alpha.mcd } \\
\text { tptpl__monq_ma_normal_dist_alpha.mcd } \\
\text { tptpll_glaq_ma_normal_dist_alpha.mcd }\end{array}$ & $\begin{array}{l}\text { sensitivity case } 1 \text { : normal distribution for spatial } \\
\text { variability of capillary strength, three climate } \\
\text { stages, mean infiltration scenario }\end{array}$ \\
\hline $\begin{array}{l}\text { tptpll_preq_ma_normal_dist_uncertainty_seep.mcd } \\
\text { tptpll_monq_ma_normal_dist_uncertainty_seep.mcd } \\
\text { tptpll_glaq_ma_normal_dist_uncertainty_seep.mcd }\end{array}$ & $\begin{array}{l}\text { sensitivity case } 2 \text { : normal distribution for } \\
\text { uncertainty of seepage rate predictions, three } \\
\text { climate stages, mean infiltration scenario }\end{array}$ \\
\hline $\begin{array}{l}\text { tptpll_preq_ma_mean_k_alpha.mcd } \\
\text { tptpll_monq_ma_mean_k_alpha.mcd } \\
\text { tptpll_glaq_ma_mean_k_alpha.mcd }\end{array}$ & $\begin{array}{l}\text { sensitivity case } 3 \text { : no spatial variability in } \\
\text { permeability and capillary strength, three climate } \\
\text { stages, mean infiltration scenario }\end{array}$ \\
\hline $\begin{array}{l}\text { tptpll_preq_ma_no_uncertainty_k_alpha.mcd } \\
\text { tptpll_monq_ma_no_uncertainty_k_alpha.mcd } \\
\text { tptplI_glaq_ma_no_uncertainty_k_alpha.mcd }\end{array}$ & $\begin{array}{l}\text { sensitivity case } 4 \text { : no uncertainty in permeability } \\
\text { and capillary strength, three climate stages, mean } \\
\text { infiltration scenario }\end{array}$ \\
\hline $\begin{array}{l}\text { tptpll_preq_ma_niche_1620.mcd } \\
\text { tptpll_monq_ma_niche_1620.mcd } \\
\text { tptplI_glaq_ma_niche_1620.mcd }\end{array}$ & $\begin{array}{l}\text { sensitivity case } 5 \text { : adjusted mean value for } \\
\text { permeability distribution, three climate stages, } \\
\text { mean infiltration scenario }\end{array}$ \\
\hline $\begin{array}{l}\text { tptpll_preq_ma_no_focus.mcd } \\
\text { tptpll_monq_ma_no_focus.mcd } \\
\text { tptpll_glaq_ma_no_focus.mcd } \\
\text { tptpll_preq_ma_alternative_focus.mcd } \\
\text { tptpll_monq_ma_alternative_focus.mcd } \\
\text { tptpll_glaq_ma_alternative_focus.mcd } \\
\text { tptpll_preq_ma_large_focus.mcd } \\
\text { tptpll_monq_ma_large_focus.mcd } \\
\text { tptpll_glaq_ma_large_focus.mcd }\end{array}$ & $\begin{array}{l}\text { sensitivity cases } 6 a, 6 b, 6 c \text { : adjusted flow focusing } \\
\text { factors (no flow focusing, alternative flow focusing, } \\
\text { and increased flow focusing), three climate stages, } \\
\text { mean infiltration scenario }\end{array}$ \\
\hline $\begin{array}{l}\text { tptpll_preq_mb_alternative_Ptn.mcd } \\
\text { tptpll_monq_mb_alternative_Ptn.mcd } \\
\text { tptpll_glaq_mb_alternative_Ptn.mcd }\end{array}$ & $\begin{array}{l}\text { sensitivity case 7: percolation flux distribution from } \\
\text { alternative Ptn flow concept, three climate stages, } \\
\text { mean infiltration scenario }\end{array}$ \\
\hline $\begin{array}{l}\text { tptpll_preq_ma_alphamethodB.mcd } \\
\text { tptplI_monq_ma_alphamethodB.mcd } \\
\text { tptpll_glaq_ma_alphamethodB.mcd } \\
\text { tptpll_preq_ma_alphamethodC.mcd } \\
\text { tptpll_monq_ma_alphamethodC.mcd } \\
\text { tptpll_glaq_ma_alphamethodC.mcd } \\
\text { tptpll_preq_ma_alphamethodD.mcd } \\
\text { tptpll_monq_ma_alphamethodD.mcd } \\
\text { tptpll_glaq_ma_alphamethodD.mcd }\end{array}$ & $\begin{array}{l}\text { sensitivity cases } 8 \mathrm{a}, 8 \mathrm{~b}, 8 \mathrm{c} \text { : alternative methods } \mathrm{B} \text {, } \\
\mathrm{C} \text {, and D for deriving statistical parameters for } \\
\text { capillary strength, three climate stages, mean } \\
\text { infiltration scenario }\end{array}$ \\
\hline
\end{tabular}


Table E-3. Mathcad Spreadsheets for Probabilistic Seepage Calculation for the Tptpll Unit (Sensitivity Cases) (Continued)

\begin{tabular}{|c|c|}
\hline $\begin{array}{l}\text { tptpll_preq_ma_perm_corr_alpha.mcd } \\
\text { tptpll_monq_ma_perm_corr_alpha.mcd } \\
\text { tptpll_glaq_ma_perm_corr_alpha.mcd }\end{array}$ & $\begin{array}{l}\text { sensitivity case 9: permeability correlated to } \\
\text { capillary-strength parameter, three climate stages, } \\
\text { mean infiltration scenario }\end{array}$ \\
\hline $\begin{array}{l}\text { tptpll_preq_ma_perm_corr_flux.mcd } \\
\text { tptpll_monq_ma_perm_corr_flux.mcd } \\
\text { tptpll_glaq_ma_perm_corr_flux.mcd }\end{array}$ & $\begin{array}{l}\text { sensitivity cases 10: permeability correlated to } \\
\text { capillary-strength parameter, three climate stages, } \\
\text { mean infiltration scenario }\end{array}$ \\
\hline $\begin{array}{l}\text { tptpll_preq_ma_collapsed_lookup.mcd } \\
\text { tptpll_monq_ma_collapsed_lookup.mcd } \\
\text { tptplI_glaq_ma_collapsed_lookup.mcd } \\
\text { tptpll_preq_ma_collapsed_lookup_properties.mcd } \\
\text { tptpll_monq_ma_collapsed_lookup_properties.mcd } \\
\text { tptpll_glaq_ma_collapsed_lookup_properties.mcd }\end{array}$ & $\begin{array}{l}\text { sensitivity cases } 11 \mathrm{a}, 11 \mathrm{~b} \text { : seepage evaluation } \\
\text { using the look-up table for collapsed drift in case } \\
11 \mathrm{a} \text {, in addition using adjusted parameter values of } \\
\text { mean permeability (increase by one order of } \\
\text { magnitude) and capillary strength (decrease by } \\
30 \% \text { ) in case } 11 \mathrm{~b} \text {, three climate stages, mean } \\
\text { infiltration scenario }\end{array}$ \\
\hline
\end{tabular}

Table E-4. Mathcad Spreadsheets for Seepage Interpolation Check in Appendix F

\begin{tabular}{|l|l|}
\hline tptpll_glaq_ma_interpol_alpha_check.mcd & $\begin{array}{l}\text { seepage calculation for glacial transition climate, } \\
\text { mean infiltration scenario, interpolation check for } \\
\text { capillary strength }\end{array}$ \\
\hline tptpll_qlaq_ma_interpol_k_check.mcd & $\begin{array}{l}\text { seepage calculation for glacial transition climate, } \\
\text { mean infiltration scenario, interpolation check for } \\
\text { permeability }\end{array}$ \\
\hline tptpll_glaq_ma_interpol_flux_check.mcd & $\begin{array}{l}\text { seepage calculation for glacial transition climate, } \\
\text { mean infiltration scenario, interpolation check for } \\
\text { local percolation flux }\end{array}$ \\
\hline
\end{tabular}

All Mathcad spreadsheets listed above are provided in Output DTN: LB0407AMRU0120.002. Results from these files support Figures 6.8-1 through 6.8-3, Tables 6.8-1 through 6.8-3, and Appendix F. For most spreadsheets, DTN LB0310AMRU0120.001 can be used as an alternative. The differences between the two DTNs are as follows. DTN LB0407AMRU0120.002 contains six revised and twelve additional spreadsheets. The revised spreadsheets are:

tptpll_preq_ma_collapsed_lookup.mcd
tptpll_monq_ma_collapsed_lookup.mcd
tptpll_glaq_ma_collapsed_lookup.mcd
tptpll_preq_ma_collapsed_lookup_properties.mcd
tptpll_monq_ma_collapsed_lookup_properties.mcd
tptpll_glaq_ma_collapsed_lookup_properties.mcd

The additional spreadsheets are:

$$
\begin{aligned}
& \text { tptpll_preq_ma_perm_corr_alpha.mcd } \\
& \text { tptpll_monq_ma_perm_corr_alpha.mcd } \\
& \text { tptpll_glaq_ma_perm_corr_alpha.mcd } \\
& \text { tptpll_preq_ma_perm_corr_flux.mcd } \\
& \text { tptpll_monq_ma_perm_corr_flux.mcd } \\
& \text { tptpll_glaq_ma_perm_corr_flux.mcd } \\
& \text { tptpll_glaq_ma_interpol_alpha_check.mcd }
\end{aligned}
$$


tptpll_qlaq_ma_interpol_k_check.mcd tptpll_glaq_ma_interpol_flux_check.mcd tptpll_preq_ma_alternative_focus.mcd tptpll_monq_ma_alternative_focus.mcd tptpll_glaq_ma_alternative_focus.mcd 


\section{INTENTIONALLY LEFT BLANK}


APPENDIX F

INTERPOLATION OF SMPA RESULTS IN SEEPAGE CALCULATIONS 


\section{INTERPOLATION OF SMPA RESULTS IN SEEPAGE CALCULATIONS}

As explained in Appendix E, several Mathcad 11 spreadsheets were used to conduct probabilistic seepage calculations for various evaluation cases. The Mathcad spreadsheets read the SMPA look-up tables and interpolate seepage values (seepage rate and uncertainty) for given random parameter cases. The randomly varied parameters are capillary strength, permeability, and local percolation flux. This appendix demonstrates that the interpolation of seepage is consistent with the values given in the seepage look-up tables. This demonstration is conducted using slightly modified Mathcad spreadsheets, where the random input parameters for the seepage interpolation have been replaced with fixed parameter values for all 10,000 random samples. For these fixed parameter values, the interpolation of the seepage results can be checked by hand calculations (see also Scientific Notebook YMP-LBNL-JTB-3, Birkholzer 2003 [DIRS 164525], pp. $123-126)$.

The interpolation check is done separately for the three seepage-relevant parameters. The following fixed parameter values are used for these checks:

1. Interpolation Check for Capillary Strength:

$$
\left.1 / \alpha=550.0 \mathrm{~Pa}, k=-12.0 \mathrm{~m}^{2} \text { (in } \log 10\right), q_{\text {perc }, f f}=100 \mathrm{~mm} / \text { year }
$$

2. Interpolation Check for Permeability:

$$
1 / \alpha=600.0 \mathrm{~Pa}, k=-12.125 \mathrm{~m}^{2} \text { (in log10), } q_{\text {perc }, f f}=100 \mathrm{~mm} / \text { year }
$$

3. Interpolation Check for Local Percolation Flux:

$$
\left.1 / \alpha=600.0 \mathrm{~Pa}, k=-12.0 \mathrm{~m}^{2} \text { (in } \log 10\right), q_{\text {perc }, f f}=150 \mathrm{~mm} / \text { year }
$$

For each check, one seepage-relevant parameter is set to a value different from the parameter values used for the various simulation cases in the seepage look-up tables (so that interpolation is necessary for this parameter) while the other two parameters are set equal to a parameter value from a simulation case in the look-up tables (so that interpolation is not needed for these two parameters).

The specific seepage interpolation for these three interpolation cases is done in three Mathcad Spreadsheets as follows (Output DTN: LB0407AMRU0120.002):

1. Interpolation Check for Capillary Strength: tptpll_glaq_ma_interpol_alpha_check.mcd

2. Interpolation Check for Permeability: tptpll_glaq_ma_interpol_k_check.mcd

3. Interpolation Check for Local Percolation Flux: tptpll_glaq_ma_interpol_flux_check.mcd

These are seepage calculations for the glacial transition climate, mean infiltration scenario, considering seepage into nondegraded drifts (i.e., using the seepage look-up table given in DTN: LB0304SMDCREV2.002 [DIRS 163687]). The interpolated seepage results are given in parameter fields seepperc (seepage percentage) and seeppercstv (seepage percentage uncertainty, 
expressed as standard deviation) in the spreadsheets. The seepage percentage values interpolated from the spreadsheet calculation are: (1) 22.195 percent, (2) 20.165 percent, and (3) 22.21 percent. The seepage standard deviation values interpolated from the spreadsheet calculation are: (1) 11.375 percent, (2) 11.14 percent, and (3) 11.395 percent.

The seepage hand calculations are conducted directly from the seepage look-up table given in DTN: LB0304SMDCREV2.002 [DIRS 163687], data file Fig6-3toFig6-8.dat). The data file gives seepage results (seepage percentage and uncertainty) for all simulation cases. The seepage results for simulation cases that bracket the chosen interpolation cases (1) through (3) above are extracted and a linear interpolation is conducted by hand. The extracted results are as follows:

1. Interpolation Check for Capillary Strength:

\begin{tabular}{|l|l|c|}
\hline \multicolumn{1}{|c|}{$\begin{array}{c}\text { Parameter Values in } \\
\text { Look-Up Table }\end{array}$} & $\begin{array}{c}\text { Seepage Percentage } \\
\text { from Look-Up Table }\end{array}$ & $\begin{array}{c}\text { Standard Deviation } \\
\text { from Look-Up Table }\end{array}$ \\
\hline $\begin{array}{l}1 / \alpha=500.0 \mathrm{~Pa} \\
k=-12.0 \mathrm{~m}^{2} \text { (in log10) } \\
q_{\text {perc,ff }}=100 \mathrm{~mm} / \text { year }\end{array}$ & $30.94 \%$ & $12.88 \%$ \\
$\begin{array}{l}1 / \alpha=600.0 \mathrm{~Pa} \\
k=-12.0 \mathrm{~m}^{2} \text { (in log10) } \\
q_{p e r c, f f}=100 \mathrm{~mm} / \text { year }\end{array}$ & $13.45 \%$ & $9.87 \%$ \\
\hline $\begin{array}{c}\text { Parameter Values for } \\
\text { Interpolation Check }\end{array}$ & Interpolated Values ${ }^{1}$ & 1 Interpolated Values ${ }^{1}$ \\
\hline $\begin{array}{l}1 / \alpha=550.0 \mathrm{~Pa} \\
k=-12.0 \mathrm{~m}^{2} \text { (in log10) } \\
q_{p e r c, f f}=100 \mathrm{~mm} / \text { year }\end{array}$ & $22.195 \%$ & $11.375 \%$ \\
\hline
\end{tabular}

${ }^{1}$ Arithmetic Mean of the two above values (linear interpolation)

2. Interpolation Check for Permeability:

\begin{tabular}{|c|c|c|}
\hline $\begin{array}{l}\text { Parameter Values in } \\
\text { Look-Up Table }\end{array}$ & $\begin{array}{l}\text { Seepage Percentage } \\
\text { from Look-Up Table }\end{array}$ & $\begin{array}{l}\text { Standard Deviation } \\
\text { from Look-Up Table }\end{array}$ \\
\hline $\begin{array}{l}1 / \alpha=600.0 \mathrm{~Pa} \\
\boldsymbol{k}=\mathbf{- 1 2 . 0} \mathbf{~ m}^{\mathbf{2}} \text { (in log10) } \\
q_{p e r c, f f}=100 \mathrm{~mm} / \text { year }\end{array}$ & $13.45 \%$ & $9.87 \%$ \\
\hline $\begin{array}{l}1 / \alpha=600.0 \mathrm{~Pa} \\
\boldsymbol{k}=\mathbf{- 1 2 . 2 5} \mathbf{~ m}^{\mathbf{2}} \text { (in log10) } \\
q_{p e r c, f f}=100 \mathrm{~mm} / \text { year }\end{array}$ & $27.78 \%$ & $12.41 \%$ \\
\hline $\begin{array}{l}\text { Parameter Values for } \\
\text { Interpolation Check }\end{array}$ & Interpolated Values ${ }^{1}$ & Interpolated Values ${ }^{1}$ \\
\hline $\begin{array}{l}1 / \alpha=600.0 \mathrm{~Pa} \\
\boldsymbol{k}=\mathbf{- 1 2 . 1 2 5} \mathbf{~ m}^{2}(\text { in log10) } \\
q_{\text {perc ff }}=100 \mathrm{~mm} / \text { year }\end{array}$ & $20.615 \%$ & $11.14 \%$ \\
\hline
\end{tabular}


3. Interpolation Check for Local Percolation Flux:

\begin{tabular}{|l|l|l|}
\hline \multicolumn{1}{|c|}{$\begin{array}{c}\text { Parameter Values in } \\
\text { Look-Up Table }\end{array}$} & $\begin{array}{c}\text { Seepage Percentage } \\
\text { from Look-Up Table }\end{array}$ & $\begin{array}{c}\text { Standard Deviation } \\
\text { from Look-Up Table }\end{array}$ \\
\hline $\begin{array}{l}1 / \alpha=600.0 \mathrm{~Pa} \\
k=-12.0 \mathrm{~m}^{2} \text { (in log10) } \\
\boldsymbol{q}_{\text {perc,ff }}=100 \mathrm{~mm} / \text { year }\end{array}$ & $13.45 \%$ & $9.87 \%$ \\
$\begin{array}{l}1 / \alpha=600.0 \mathrm{~Pa} \\
k=-12.0 \mathrm{~m}^{2} \text { (in log10) } \\
\boldsymbol{q}_{\text {perc,ff }}=\mathbf{2 0 0} \mathrm{mm} / \text { year }\end{array}$ & $30.97 \%$ & $12.92 \%$ \\
\hline $\begin{array}{c}\text { Parameter Values for } \\
\text { Interpolation Check }\end{array}$ & Interpolated Values & \\
\hline $\begin{array}{l}1 / \alpha=600.0 \mathrm{~Pa} \\
k=-12.0 \mathrm{~m}^{2} \text { (in log10) } \\
\boldsymbol{q}_{\text {perc,ff }}=150 \mathrm{~mm} / \mathrm{year}\end{array}$ & $22.21 \%$ & $11.395 \%$ \\
\hline
\end{tabular}

${ }^{1}$ Arithmetic Mean of the two above values (linear interpolation)

The hand-calculated seepage results in the above tables are identical to those calculated with the Mathcad spreadsheets, thus demonstrating that the interpolation of seepage in the probabilistic seepage calculation is consistent with the values given in the seepage look-up tables. 


\section{INTENTIONALLY LEFT BLANK}


APPENDIX G

COMPARISON OF FLUX DISTRIBUTIONS FROM UZ FLOW MODEL AND FROM SEEPAGE CALCULATIONS 


\section{COMPARISON OF FLUX DISTRIBUTIONS FROM UZ FLOW MODEL AND FROM SEEPAGE CALCULATIONS}

In the probabilistic seepage calculations in Section 6.8 (Appendix E), random distributions of percolation flux are developed using the simulated flux values from the UZ Flow Model. The Mathcad spreadsheets introduced in Appendix E generate cumulative frequency distributions from these flux values and perform random sampling from the cumulative frequency distributions over 10,000 sample points. There should be good agreement between the process model results and the abstracted results. This is demonstrated below by comparing some statistical measures from the original flux distribution in Table 6.6-11 with the randomly sampled flux distributions developed in the Mathcad spreadsheets. The statistical measures are the mean flux and the maximum flux. In the Mathcad spreadsheets, these statistical measures are named xfmean (mean flux) and xfmax (maximum flux). They can be extracted from the spreadsheets listed in, for example, Table E-1 in Appendix E. Table G-1 lists the percolation flux statistics for the UZ Flow Model results (from Table 6.6-11) in comparison with the flux statistics extracted from the Mathcad spreadsheets. As an example, the comparison is conducted for the mean infiltration scenario, using the three climate stages. The good agreement demonstrates that the flux distributions provided by the UZ Flow Model are accurately reproduced by the sampled flux distributions in the probabilistic seepage calculations (see also Scientific Notebook YMP-LBNL-JTB-3, Birkholzer 2003 [DIRS 164525], pp. 121-122).

Table G-1. Comparison of Flux Statistics between UZ Flow Model and Probabilistic Seepage Calculation

\begin{tabular}{|l|c|c|}
\hline \multicolumn{2}{|c|}{ Mean Infiltration scenario: Flux in mm/year } \\
\hline \multicolumn{1}{|c|}{ Climate stage } & $\begin{array}{c}\text { Fluxes From UZ Flow } \\
\text { Model (Table 6.6-11) }\end{array}$ & $\begin{array}{c}\text { Fluxes From } \\
\text { Probabilistic Seepage } \\
\text { Calculation }\end{array}$ \\
\hline Present Day Average & 3.8 & 3.8 \\
Present Day Maximum & 39.9 & 39.8 \\
\hline Monsoon Average & 11.7 & 11.6 \\
Monsoon Maximum & 127.9 & 127.7 \\
\hline Glacial Transition Average & 17.9 & 17.4 \\
Glacial Transition Maximum & 192.4 & 192.1 \\
\hline
\end{tabular}




\section{INTENTIONALLY LEFT BLANK}


APPENDIX H

TABLES AND FIGURES DESCRIBING FRACTURE

GEOMETRY CHARACTERISTICS 


\section{TABLES AND FIGURES DESCRIBING FRACTURE GEOMETRY CHARACTERISTICS}

The following tables and figures are compiled from different sources to provide a basis for the discussion of the geological characteristics of the repository units in Section 6.6.1 of this report.

Table H-1. Joint Set Spacing Summary Data from ESF and ECRB

\begin{tabular}{|c|c|c|c|c|}
\hline \multirow{4}{*}{ Lithostratigraphic Unit } & $\begin{array}{c}\text { Joint Set } \\
\text { Identification }\end{array}$ & $\begin{array}{c}\text { Strike/Dip } \\
\text { (degrees) }\end{array}$ & $\begin{array}{c}\text { Average Spacing } \\
\text { (meters) }\end{array}$ & $\begin{array}{c}\text { Median Spacing } \\
\text { (meters) }\end{array}$ \\
\hline \multirow{4}{*}{ Tptpul } & JS-1 & $186 / 82$ & 3.47 & 2.20 \\
\cline { 2 - 5 } & JS-2 & $121 / 83$ & 3.74 & 2.29 \\
\cline { 2 - 5 } & JS-3 & $156 / 81$ & 3.78 & 1.92 \\
\cline { 2 - 5 } & JS-4 & $210 / 82$ & 4.05 & 2.46 \\
\cline { 2 - 5 } & JS-Subhorizontal & $310 / 14$ & 3.21 & 1.54 \\
\cline { 2 - 5 } & JS-Medium Dip & $307 / 47$ & 4.58 & 2.68 \\
\hline \multirow{5}{*}{ Tptpmn } & JS-1 & $131 / 84$ & 0.60 & 0.22 \\
\cline { 2 - 5 } & JS-2 & $209 / 83$ & 1.92 & 1.01 \\
\cline { 2 - 5 } & JS-Subhorizontal & $329 / 09$ & 0.56 & 0.29 \\
\hline \multirow{3}{*}{ Tptpll } & JS-1 & $145 / 82$ & 3.47 & 1.57 \\
\cline { 2 - 5 } & JS-2 & $180 / 79$ & 4.05 & 3.18 \\
\cline { 2 - 5 } & JS-Subhorizontal & $315 / 05$ & 2.94 & 0.57 \\
\hline \multirow{3}{*}{ Tptpln } & JS-1 & $136 / 79$ & 1.44 & 0.74 \\
\cline { 2 - 5 } & JS-2 & $209 / 82$ & 2.51 & 1.36 \\
\cline { 2 - 5 } & JS-Subhorizontal & $330 / 13$ & 2.85 & 1.64 \\
\hline
\end{tabular}

Source: CRWMS M\&O (2000 [DIRS 152286], Table 12).

NOTE: Data are from detailed line survey for fractures 1 meter or longer. 
Table H-2. Joint Set Trace Length Summary Data from ESF and ECRB

\begin{tabular}{|c|c|c|c|c|}
\hline $\begin{array}{c}\text { Lithostratigraphic } \\
\text { Unit }\end{array}$ & $\begin{array}{c}\text { Joint Set } \\
\text { Identification } \\
\end{array}$ & $\begin{array}{l}\text { Strike/Dip } \\
\text { (degrees) }\end{array}$ & $\begin{array}{c}\text { Average Trace } \\
\text { Length } \\
\text { (meters) }\end{array}$ & $\begin{array}{c}\text { Median Trace } \\
\text { Length } \\
\text { (meters) } \\
\end{array}$ \\
\hline \multirow{7}{*}{ Tptpul } & JS-1 & $186 / 82$ & 3.50 & 2.13 \\
\hline & JS-2 & $121 / 83$ & 2.85 & 2.08 \\
\hline & JS-3 & $156 / 81$ & 2.91 & 2.20 \\
\hline & JS-4 & $210 / 82$ & 3.07 & 2.10 \\
\hline & JS-Subhorizontal & $310 / 14$ & 5.16 & 4.10 \\
\hline & JS-Med & $307 / 47$ & 8.29 & 6.90 \\
\hline & Random & Not Applicable & 3.85 & 2.10 \\
\hline \multirow{4}{*}{ Tptpmn } & JS-1 & $131 / 84$ & 2.54 & 2.03 \\
\hline & JS-2 & $209 / 83$ & 2.71 & 1.73 \\
\hline & JS-Subhorizontal & $329 / 09$ & 3.23 & 2.06 \\
\hline & Random & Not Applicable & 2.54 & 1.90 \\
\hline \multirow{4}{*}{ Tptpll } & JS-1 & $145 / 82$ & 4.56 & 2.11 \\
\hline & JS-2 & $180 / 79$ & 4.02 & 1.70 \\
\hline & JS-Subhorizontal & $315 / 05$ & 7.36 & 3.42 \\
\hline & Random & Not Applicable & 3.24 & 1.88 \\
\hline \multirow{4}{*}{ Tptpln } & JS-1 & $136 / 79$ & 4.07 & 2.30 \\
\hline & JS-2 & $209 / 82$ & 4.61 & 1.89 \\
\hline & JS-Subhorizontal & $330 / 13$ & 1.55 & 1.27 \\
\hline & Random & Not Applicable & 4.25 & 1.86 \\
\hline
\end{tabular}

Source: CRWMS M\&O (2000 [DIRS 152286], Table 13).

NOTE: Data are from detailed line survey for fractures 1 meter or longer. 
(a) North Ramp and Northern Portion of the Main Drift

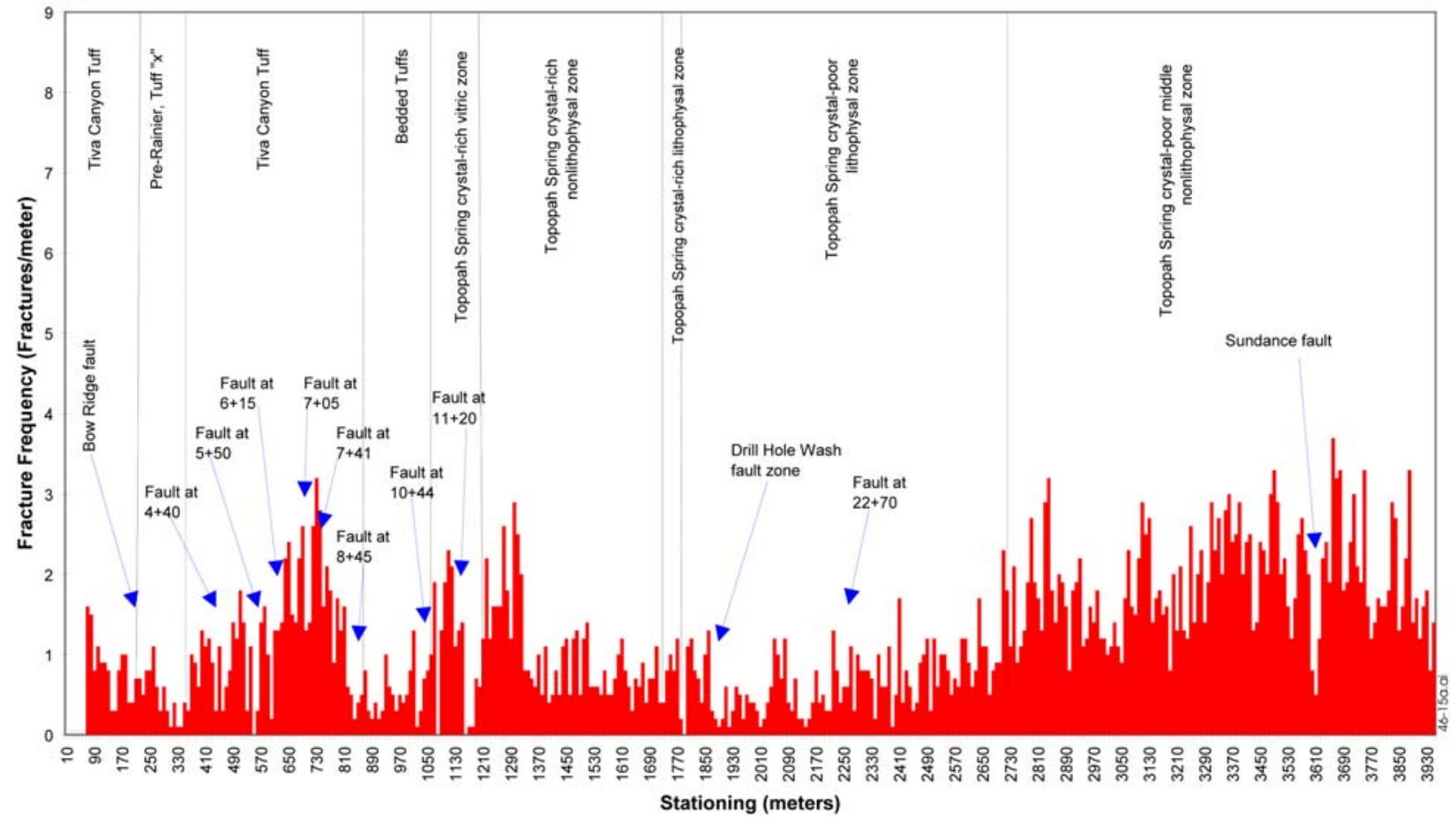

(b) Southern Portion of the Main Drift and Western Portion of the South Ramp

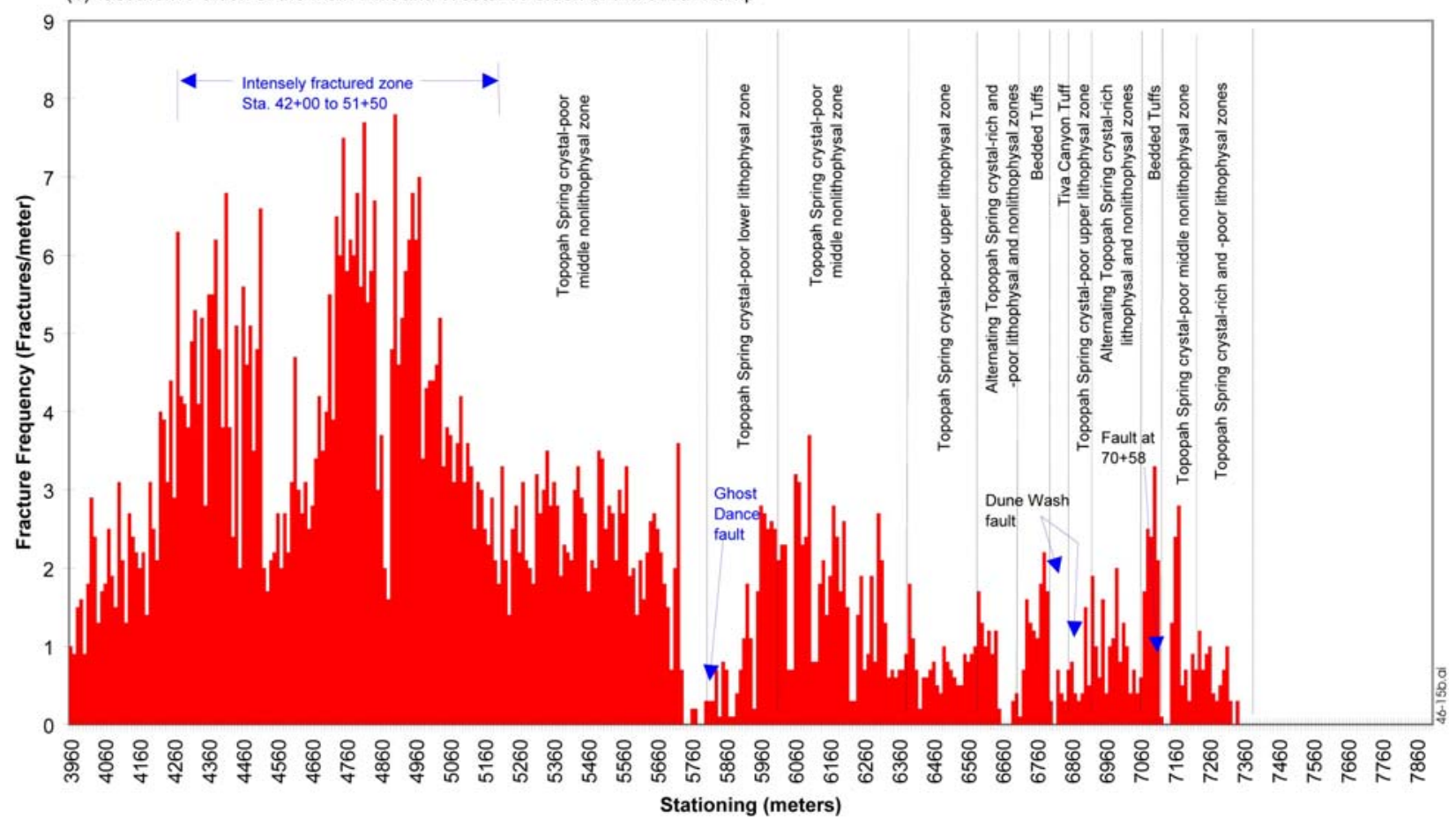

Source: CRWMS M\&O (2000 [DIRS 151945], Figure 4.6-15).

NOTE: Data are from detailed line survey for fractures 1 meter or longer.

Figure H-1. Fracture Frequency Measured in the ESF 


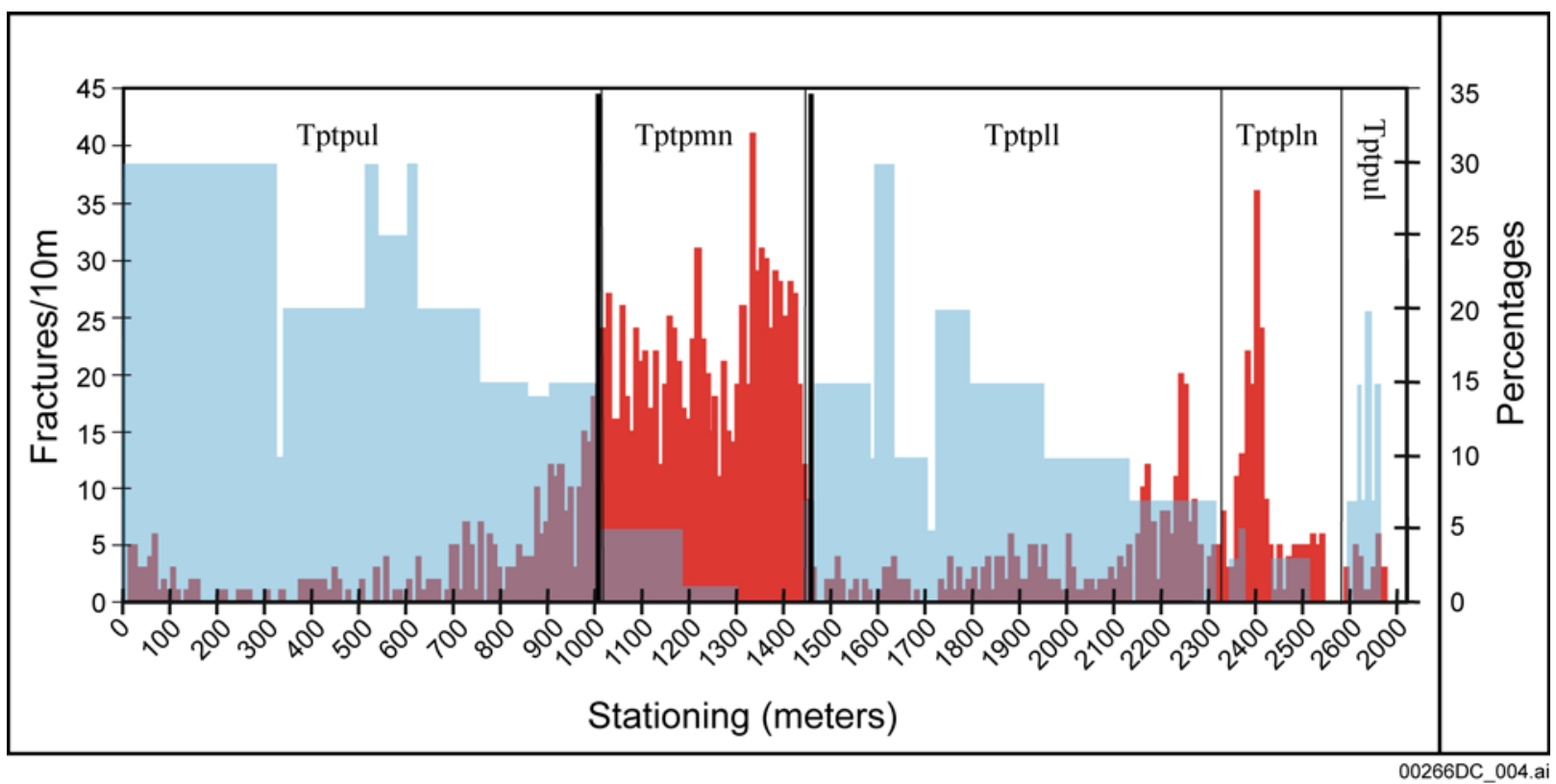

Fracture frequency/Lithophysal \%

Source: Mongano et al. (1999 [DIRS 149850], Figure 13).

NOTE: Data are from detailed line survey for fractures 1 meter or longer.

Figure H-2. Fracture Frequency and Lithophysal Abundance Measured in the ECRB Cross-Drift from Stations $0+00$ to $27+00$

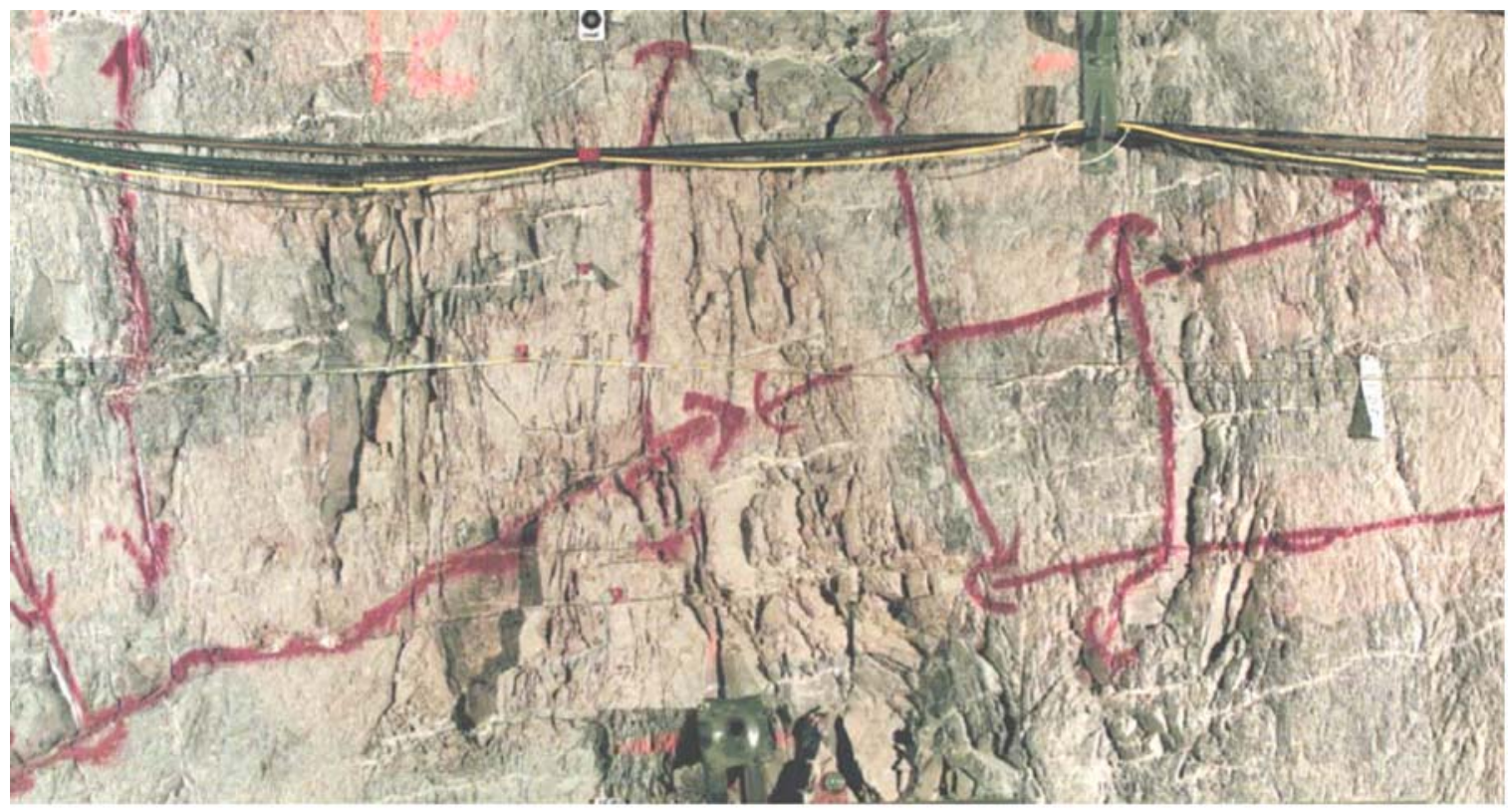

00266DC_007.ai

Source: BSC (2004 [DIRS 166107], Figure 6-8).

NOTE: T-junctions on fractures indicate terminations; arrowheads show continuous features.

Figure H-3. Fractures in the Wall of the ECRB Cross-Drift in the Tptpmn Unit 
(a)

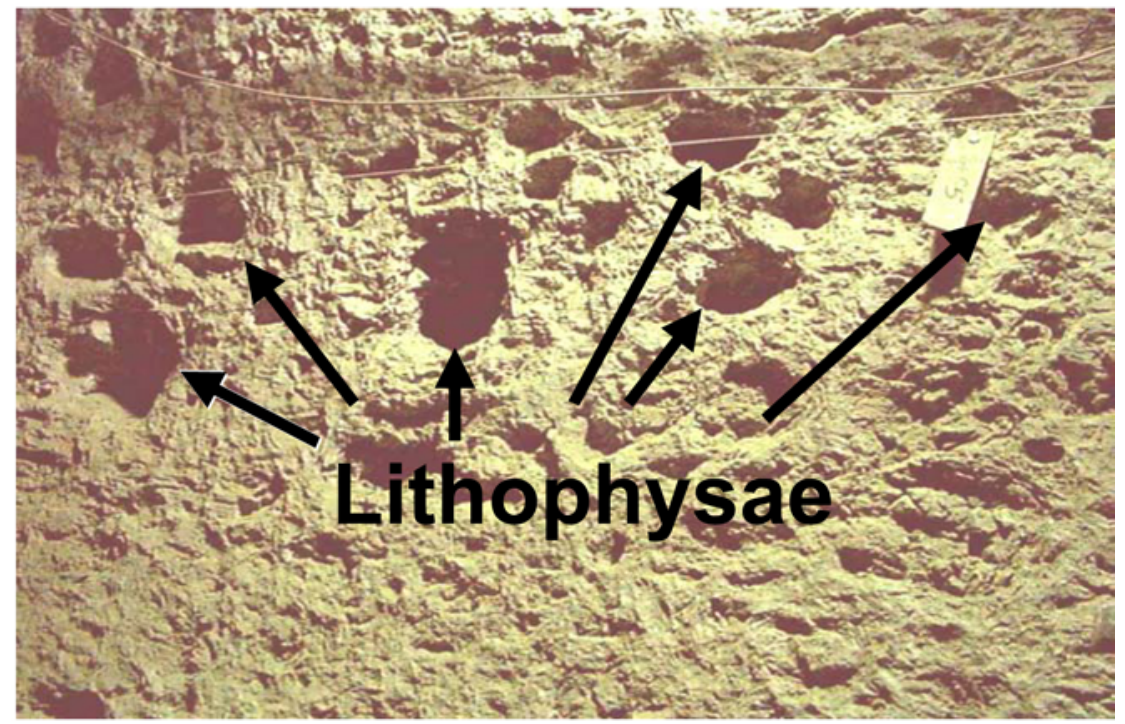

(b)

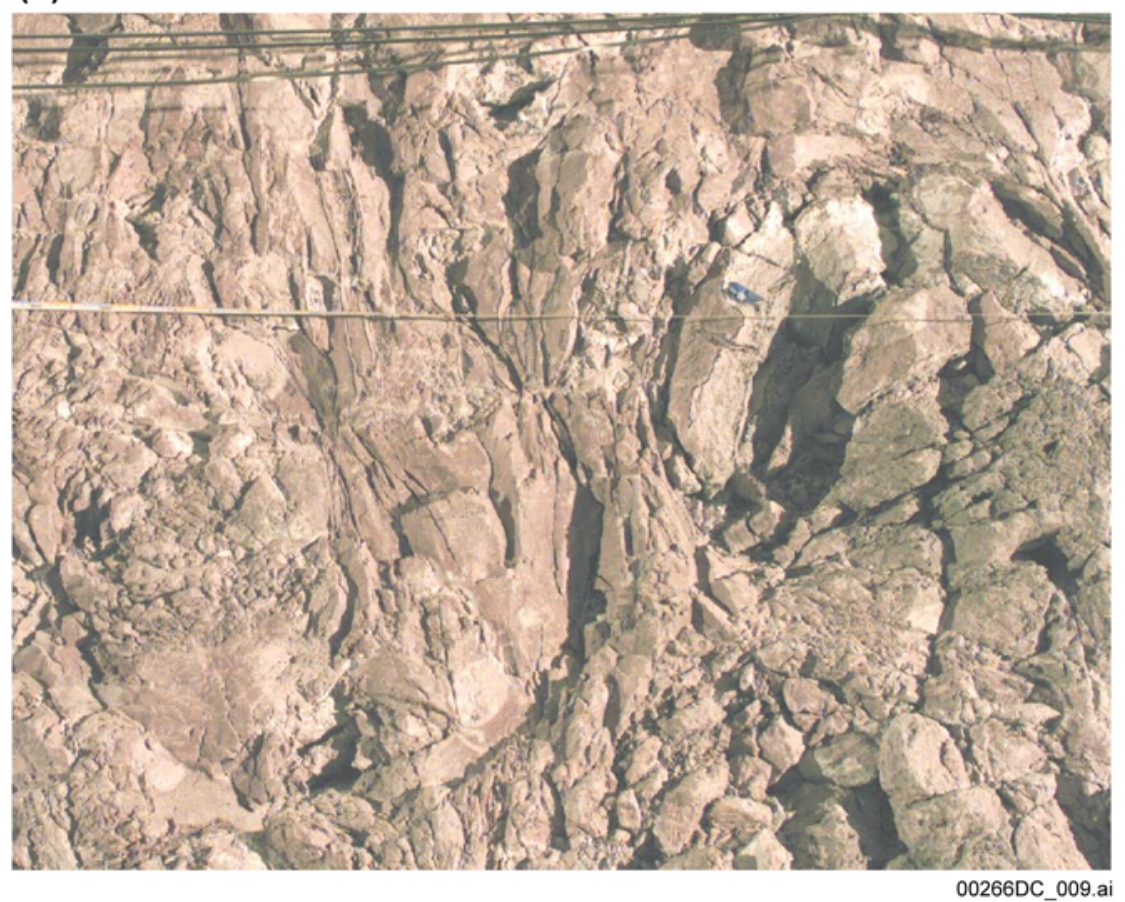

Source: BSC (2004 [DIRS 166107], Figure 6-10).

NOTE: The Tptpul unit (a) is characterized by a relatively few fractures in the matrix-groundmass between lithophysae whereas the Tptpll unit (b) has abundant, natural, short-length fractures in the matrixgroundmass between lithophysae and a few that intersect lithophysae. Spacing of the fractures in the Tptpll unit is generally less than $5 \mathrm{~cm}$.

Figure H-4. Comparison of Lithophysae and Fracturing in the Tptpul and Tptpll Units 


\section{INTENTIONALLY LEFT BLANK}

